
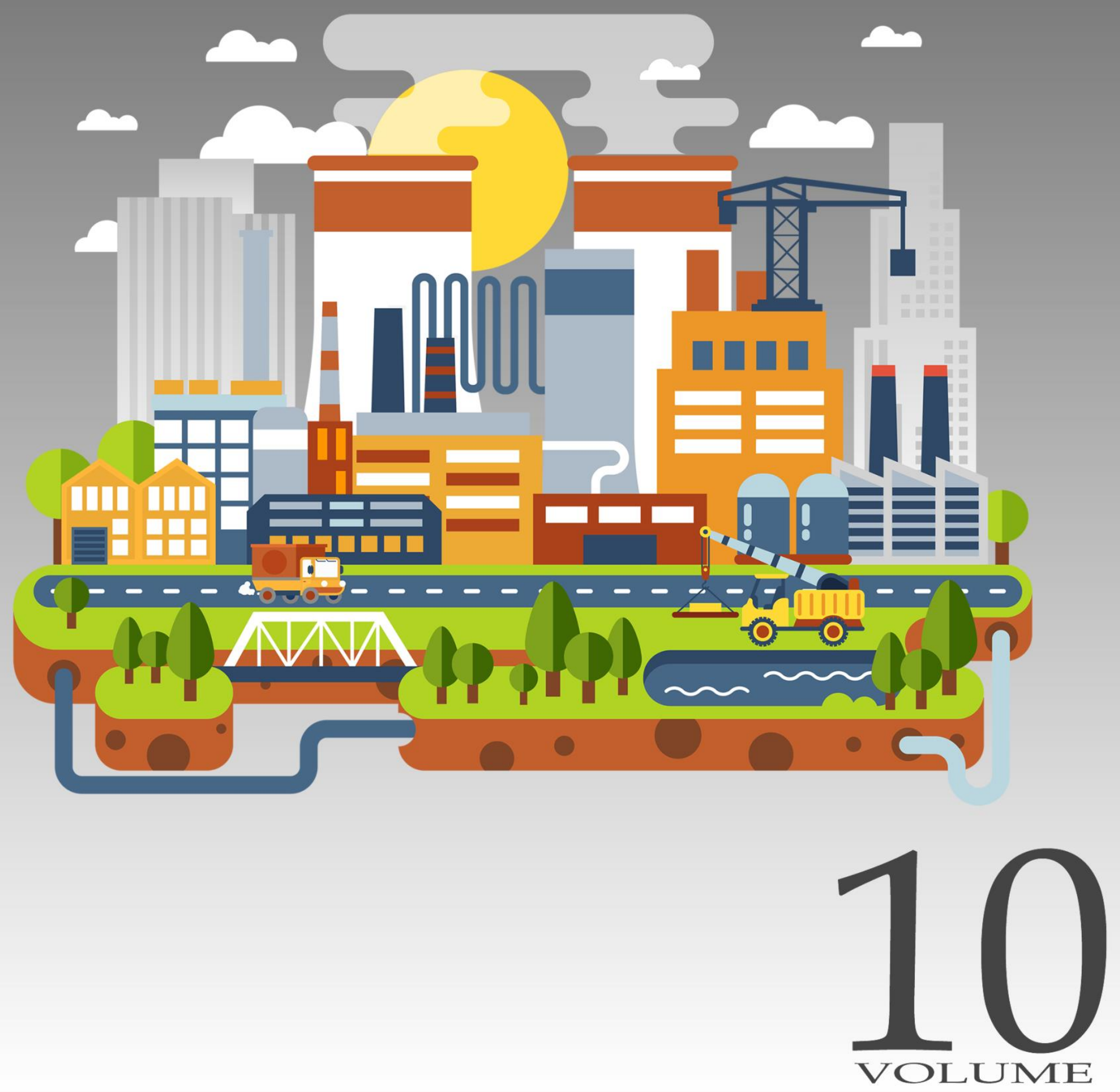

Editora Poisson 
Editora Poisson

\section{Gestão da produção em foco Volume 10}

1a Edição

Belo Horizonte

Poisson 


\section{Editor Chefe: Dr. Darly Fernando Andrade}

\section{Conselho Editorial}

Dr. Antônio Artur de Souza - Universidade Federal de Minas Gerais

Dra. Cacilda Nacur Lorentz - Universidade do Estado de Minas Gerais

Dr. José Eduardo Ferreira Lopes - Universidade Federal de Uberlândia

Dr. Otaviano Francisco Neves - Pontifícia Universidade Católica de Minas Gerais

Dr. Luiz Cláudio de Lima - Universidade FUMEC

Dr. Nelson Ferreira Filho - Faculdades Kennedy

Dados Internacionais de Catalogação na Publicação (CIP)

G393
Gestão da Produção em Foco- Volume 10/
Organização Editora Poisson - Belo
Horizonte - MG : Poisson, 2018
225p
Formato: PDF
ISBN: 978-85-93729-50-8
DOI: 10.5935/978-85-93729-50-8.2018B001
Modo de acesso: World Wide Web
Inclui bibliografia
1. Gestão da Produção 2. Engenharia de
Produção. I. Título
CDD-658.8

O conteúdo dos artigos e seus dados em sua forma, correção e confiabilidade são de responsabilidade exclusiva dos seus respectivos autores.

$\underline{\text { www.poisson.com.br }}$

contato@poisson.com.br 


\section{SUMÁRIO}

Capítulo 1: Análises de custos na gestão da manutenção e reparos em oficina de transformadores de potência

Bruno Cosse Pedroso, André Pereira Marques, Cacilda De Jesus Ribeiro, Leonardo Da Cunha Brito, José Antônio Martins Coury

Capítulo 2: Mapeamento como ferramenta de avaliação do processo produtivo de uma indústria sucroalcooleira

Larissa Carnaúba De Oliveira, Angela Carolina Laurindo De Mendonça, Laryssa Ramos De Holanda

Capítulo 3: Aplicação do método multicritério smarter na seleção de fornecedores de matéria prima: um estudo no setor avícola

Mirian Batista De Oliveira Bortoluzzi

Capítulo 4: A energia eólica no brasil e no mundo no contexto de fomento à renovabilidade de matrizes energéticas e de mitigação das mudanças climáticas

Rita De Cássia Lopes Moro, Jhonathan Fernandes Torres De Souza, André Felipe Simões

Capítulo 5: Método híbrido de previsão dos deslocamentos horizontais da crista da barragem da usina hidrelétrica de Itaipu.

Samuel Bellido Rodrigues, Tásia Hickmann, Jairo Marlon Corrêa, Levi Lopes Teixeira, Edgar

Manuel Carreño Franco

Capítulo 6: Integração das metodologias Balanced Scorecard (BSC) E 5S em uma empresa prestadora de serviços de informática

Juan Pablo Silva Moreira, Saulo Fonseca Soares, Adriel Augusto dos Santos Silva, Felipe

Augusto da Silva, Janser Queiroz Oliveira

Capítulo 7: Previsão de término de projetos pelo método do prazo agregado comparação entre a estimativa no término independente e a reprogramação bottom- up: estudo de caso em empreendimentos de construção civil

Orlando Poci Junior, Viviane Viana Sofiste De Abreu

Capítulo 8: Fatores críticos de sucesso do lean manufacturing, Seis Sigma, Lean-Seis Sigma e sustentabilidade: uma revisão sistemática da literatura

Fábio De Oliveira Neves, José Carlos De Toledo

Capítulo 9: Eficácia de programas com enfoque em treinamento de pessoal na área de segurança do trabalho: um estudo de caso em uma indústria de fabricação de painéis de madeira no estado do paraná 


\section{SUMÁRIO}

Capítulo 10: Perfil de acidentes típicos de trabalho em cidades de maior incidência no estado do ceará

Maria Alexsandra Pires Cavalcante, Maria Liduína Freitas Pinto, Euclídia Selênia Pereira Teixeira, Maxweel Veras Rodrigues, Sueli Maria De Araújo Cavalcante

Capítulo 11: A terceirização em uma instituição federal de ensino superior: uma breve análise de dados dos custos relacionados ao processo.

Maxweel Veras Rodrigues, Thaís Helena Cavalcante Lima, Ana Lúcia Da Silva, Margarida Maria De Souza

Capítulo 12: Atividades inovativas na indústria moveleira do vale do paranhana

Fabiano Barbieri, Paulo Roberto De Aguiar Von Mengden, Fladhimyr Castello

Capítulo 13: Influência das estratégias de manutenção na disponibilidade física de equipamentos de moagem de uma mineradora

Flávio Campos Pinheiro, Marcus Vinícius De Abreu Soeiro, Renato Ramos Coelho

Capítulo 14: Análise da eficácia de um programa de gestão de fadiga.

Renato Ramos Coelho, Marcus Vinícius De Abreu Soeiro, Diego Fernandes Silva

Capítulo 15: Um aplicativo gratuito de engenharia economica desenvolvida em $\mathrm{C}++$ para melhorar o processo de ensino em aprendizagem à distância

Ricardo Alexandre Deckmann Zanardini, Alessandra De Paula, Cristiane Adriana Ripka, Kellen Coelho Dos Santos, Luiz Antônio Forte

Capítulo 16: Mapeamento de fluxo de valor: um estudo de caso em uma empresa de ferramentaria.

Glauco Medeiros Borges, Fernanda Kempner-Moreira, Edson Manfioletti Gomes, Felipe Vicentin Moises

Capítulo 17: Aplicação combinada de mapa de fluxo de valor e simulação de eventos discretos na melhoria de linha produtiva.

Gabriel Cardinali, Emerson José De Paiva, Márcio Dimas Ramos, Carlos Henrique Oliveira, Tarcísio Gonçalves De Brito

Capítulo 18: O impacto do ranking de reputação merco na probabilidade de uma empresa ter investimento eficiente. 


\section{SUMÁRIO}

Capítulo 19: A participação da bicicleta no desenvolvimento de cidades sustentáveis. elaboração de modelo conceitual de malha cicloviária no campus universitário de Goiabeiras - UFES.

Miguel Macedo De Carvalho Filho, Antônio Luiz Caus, Marta Monteiro Da Costa Cruz

Capítulo 20: Análise de atributos da embalagem de pequi que influenciam a preferência de compra dos consumidores da cidade de tangará da serra - mt usando análise conjunta

Jéssica Ramos De Oliveira, Eduardo José Oenning Soares, Rodolfo Benedito Da Silva, Alexandre Gonçalves Porto, Rodrigo Carniel Sefstron

Capítulo 21: Integração da metodologia dmaic para o aumento das conformidades adquiridas na fabricação dos sidecars em uma empresa do setor automotivo.

Juan Pablo Silva Moreira, Saulo Fonseca Soares, Janser Queiroz Oliveira

Capítulo 22: A política nacional de resíduos sólidos e o gerenciamento de resíduos da construção civil

Monalyza Teles Teixeira, Adilson Silva De Almeida Júnior, Priscylla Jordânia Pereira De Mesquita 


\section{Gapítulo 1}

\section{ANÁLISES DE CUSTOS NA GESTÃO DA MANUTENCC̃̃O E REPAROS EM OFICINA DE TRANSFORMADORES DE POTENCIA}

\section{Bruno Cosse Pedroso}

André Pereira Marques

Cacilda de Jesus Ribeiro

Leonardo da Cunha Brito

José Antônio Martins Coury

Resumo: A manutenção e reparos com qualidade em transformadores de potência - equipamentos de custo elevado e estratégicos para o sistema elétrico - são de vital importância para restaurar suas condições de funcionamento, bem como na preservação e extensão de sua vida útil. Visando contribuir com a gestão da manutenção, com os estudos sobre a viabilidade econômica da manutenção e dos reparos em oficina destes equipamentos, este artigo tem como objetivo realizar uma análise quantitativa e qualitativa envolvendo os custos, apresentando dados estatísticos do período de 2007 a 2016 (dez anos), em função da tensão nominal, da potência, e da idade destes equipamentos. Os resultados deste trabalho, referente a transformadores de potência, são concernentes a análises dos custos médios de manutenção e reparos escalonados por subcategorias, tais como: reparos gerais, reparo principal, aplicação de vácuo, secagem da parte ativa, enchimento com óleo, ensaios elétricos e pintura. É apresentado estudo de viabilidade econômica por meio da comparação dos custos de manutenção e reparos - levando-se em conta a idade dos equipamentos - com o preço médio de aquisição dos mesmos.

Palavras-chave: custos, gestão da manutenção, reparos, transformadores de potência. 


\section{INTRODUÇÃO}

Ao longo da vida útil do transformador de potência se faz necessário o acompanhamento e, quando necessário, a realização de manutenções e reparos adequados para se manter a confiabilidade dos mesmos em níveis aceitáveis durante este período [1].

Na Oficina Eletromecânica do Departamento de Engenharia e Controle da Manutenção da Celg Distribuição são realizadas manutenções corretivas e preventivas em transformadores, autotransformadores, conjuntos de medição, transformadores de corrente, transformadores de potencial, disjuntores, chaves à óleo, religadores, reguladores de tensão e buchas, dentre outros equipamentos. Porém, este estudo concentra-se em uma análise financeira dos custos de manutenção referentes aos reparos em oficina dos transformadores e autotransformadores de potência da empresa, denominados ambos, neste trabalho, de transformadores de potência - ilustrados na Figura 1 -, apresentando dados estatísticos referentes ao período de 2007 a 2016 (dez anos).

Figura 1 - Transformador de potência: a) em operação na subestação de energia elétrica; e b) em manutenção na oficina eletromecânica da concessionária de energia elétrica.

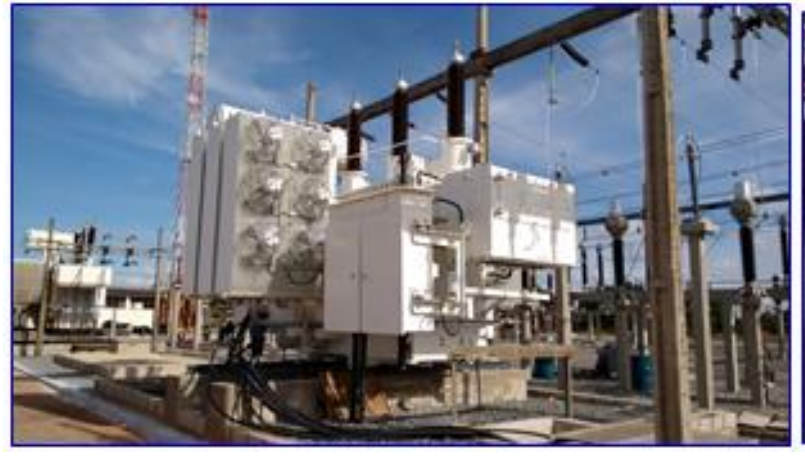

(a)

Nesse sentido, os objetivos deste artigo, referentes à gestão de manutenção e reparos de transformadores de potência, são:

a) análise da viabilidade econômica da manutenção comparando-se os custos de reparos com o preço médio de aquisição de equipamento novo, levando-se em conta a idade, a expectativa de vida útil média, estimada para estes equipamentos com base estatística, e, consequentemente, a vida remanescente estimada do equipamento a ser reparado; e

b) análise, por tensão nominal elétrica, dos custos médios de reparos dos equipamentos em função das subcategorias de manutenção.

Ressalta-se que as contribuições deste trabalho objetivam subsidiar as equipes de manutenção em tomadas de decisão, proporcionando estas análises destes importantes equipamentos para o setor elétrico.

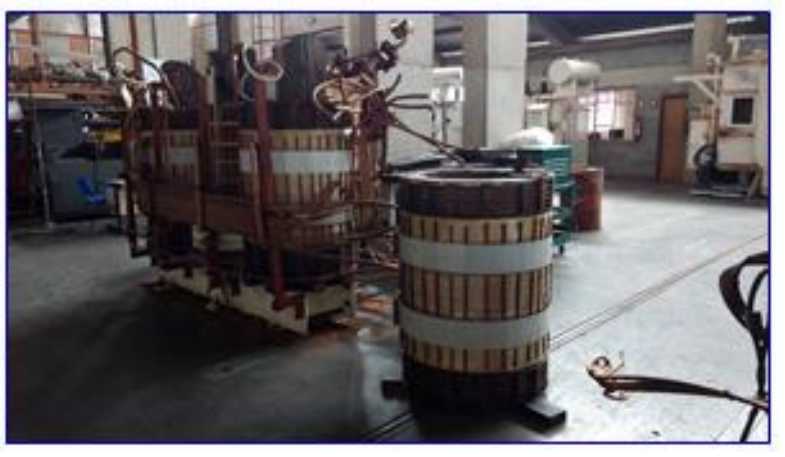

(b)
De uma forma geral, pode-se afirmar, com boa precisão, que a idade média atual do parque instalado no sistema elétrico brasileiro de equipamentos se aproxima dos 30 anos, e que, destes, aproximadamente $65 \%$ encontram-se com mais de 25 anos de uso e, além disso, que as condições operativas do sistema nacional estão cada vez mais severas [1]. Todos estes fatores indicam uma necessidade crescente de se manter o sistema elétrico em condições confiáveis - o que é hoje a questão principal -, e a um custo viável, devido a enormidade e complexidade do sistema. Portanto a opção de se fazer reparos em vez de se comprar um equipamento novo pode ser uma opção atraente e vantajosa - estratégica e economicamente falando - principalmente se feita com planejamento adequado [1].

Reparos em campo, ou seja, realizados no próprio local de instalação do equipamento como subestações de energia -, nem sempre 
são viáveis tecnicamente. Nestes casos, as opções são: fazer os reparos dos transformadores em uma fábrica ou em oficina do proprietário do equipamento, devendo ser levando em conta, no cômputo dos custos, as despesas com transporte.

Algumas empresas possuem oficina própria para reparos em equipamentos de médio e grande porte, normalmente localizada em um ponto estratégico para facilitar a logística de transporte e reduzir custos. Esta alternativa pode ser, muitas vezes, a mais viável, por apresentarem menores custos, tanto de transporte como de reparos, quando comparados a opção de se fazer em uma fábrica [1].

Segundo estudos realizados [2], muitos fatores devem ser levados em consideração na avaliação de custo da vida econômica do transformador, tais como a taxa de falhas, benefícios dos equipamentos e estratégias de manutenção.

De acordo com [3], a vida econômica de um transformador divide-se em três seções: operação, manutenção e retirada definitiva de operação. O fim da vida econômica ocorre quando os benefícios da retirada definitiva de operação do equipamento ultrapassam os ganhos com manutenção do mesmo.

$\mathrm{Na}$ literatura existente, por exemplo [1-11], são apresentadas algumas informações sobre metodologias para levantamento do perfil de custos de equipamentos, porém há lacunas referentes à precisão na coleta dos dados e escassez de informações sobre detalhes contábeis, o que dificulta a classificação final dos custos de manutenção. Sendo assim, tem-se como motivação o desenvolvimento deste trabalho, visando complementar estas abordagens e os estudos realizados, mostrando-se um método de análise eficiente para a gestão de manutenção destes ativos físicos, para as práticas de manutenção e ainda para dar suporte a decisões de aquisição de novos equipamentos, ao invés de repará-los, se for o caso.
2. ANÁLISE DE CUSTOS NA GESTÃO DA MANUTENÇÃO E REPAROS EM OFICINA DE TRANSFORMADORES DE POTENNCIA

\subsection{MANUTENÇÕES E REPAROS REALIZADOS EM UM PERÍODO DE DEZ ANOS (2007-2016) NA OFICINA}

As informações financeiras foram classificadas em duas categorias principais, que são os custos com mão de obra e os custos com materiais, que se dividem nas seguintes subcategorias: reparos gerais, reparo principal, aplicação de vácuo, enchimento com óleo e secagem da parte ativa, ensaios elétricos e pintura. O reparo principal caracteriza-se pelo motivo principal da retirada do equipamento de operação para manutenção, como, por exemplo, danos em enrolamentos por curto-circuito, disrupção dielétrica em buchas, danos em comutadores de derivação em carga etc, estando usualmente associado a falhas. Os reparos gerais caracteriza-se por correções de defeitos nos componentes (problemas de vedações ressecadas com vazamentos de óleo, válvulas emperradas corrosões etc) ou ainda tratamentos de óleo, que não impedem o funcionamento do equipamento, porém, em condições precárias. Outros dados foram coletados, como o tempo efetivo de reparo principal e relações de custos por potência para auxiliar na modelagem matemática desenvolvida.

É importante ressaltar que a análise de custos deste artigo baseou-se em estudos de casos de setenta e dois (72) procedimentos de manutenção e reparos de transformadores em oficina ocorridos durante um período de dez anos (2007-2016). Os transformadores de potência analisados tinham tensão nominal de $34,5 \mathrm{kV}, 69 \mathrm{kV}$ e $138 \mathrm{kV}$ e potência nominal de 1 a 33,25 MVA. Foi feita uma comparação normalizada, considerando a inflação média do dólar americano durante o período de coleta de dados, entre os custos e preços de aquisição dos transformadores de potência. $\mathrm{Na}$ Figura 2) é representado o número de manutenções e reparos de transformadores de potência, realizadas no período de dez anos. Verificou-se que ocorreram aproximadamente 15 manutenções e reparos de transformadores em oficina por ano (cálculo: 14,7/ano). 
Figura 2 - Número de manutenções e reparos em oficina em transformadores de potência, no período de dez anos (2007 e 2016).

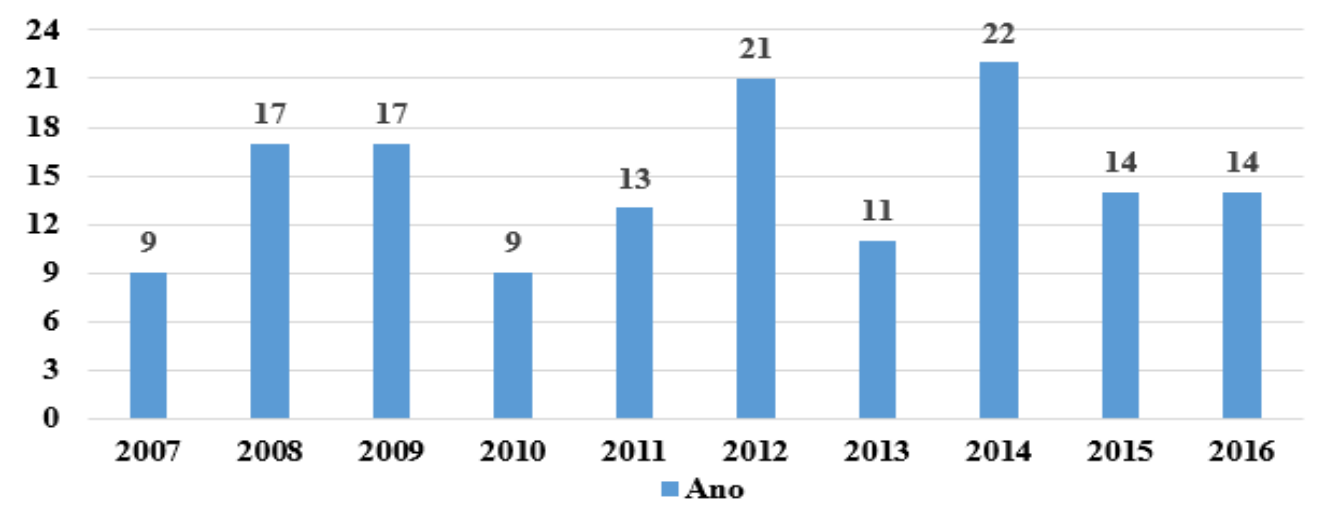

Fonte: próprio autor (2017).

\subsection{ANÁLISE DOS CUSTOS DE ACORDO COM A IDADE DOS TRANSFORMADORES}

A análise quantitativa dos custos de manutenção é realizada em função da tensão nominal, da potência e da idade do equipamento. Complementa a análise realizada neste estudo os resultados das porcentagens de custos de subcategorias da manutenção, dos gastos médios por tensão nominal, e comparativos entre o preço de aquisição e os custos com manutenção e reparos em oficina de acordo com a idade dos transformadores.

A análise dos procedimentos de manutenção e reparos dos 72 casos em oficina possibilitou

\begin{abstract}
fazer-se comparação entre os custos de manutenção e reparos e o preço de aquisição de novos transformadores de potência por tensão nominal, em dólares, considerando a cotação de 20 de dezembro de 2016 e a inflação da moeda durante o período de coleta de dados, os quais são representados na Figura 3. Constatou-se que os equipamentos de $69 \mathrm{kV}$ apresentaram custos $18,70 \%$ mais elevados em relação à equipamentos de $34,5 \mathrm{kV}$ e que os transformadores de $138 \mathrm{kV}$ apresentaram custos de 22,14 \% mais elevados em relação à transformadores de $69 \mathrm{kV}$.
\end{abstract}

FIGURA 3 - Comparativo não adequado entre as médias de custos totais por tensão nominal dos transformadores e o preço médio de aquisição.

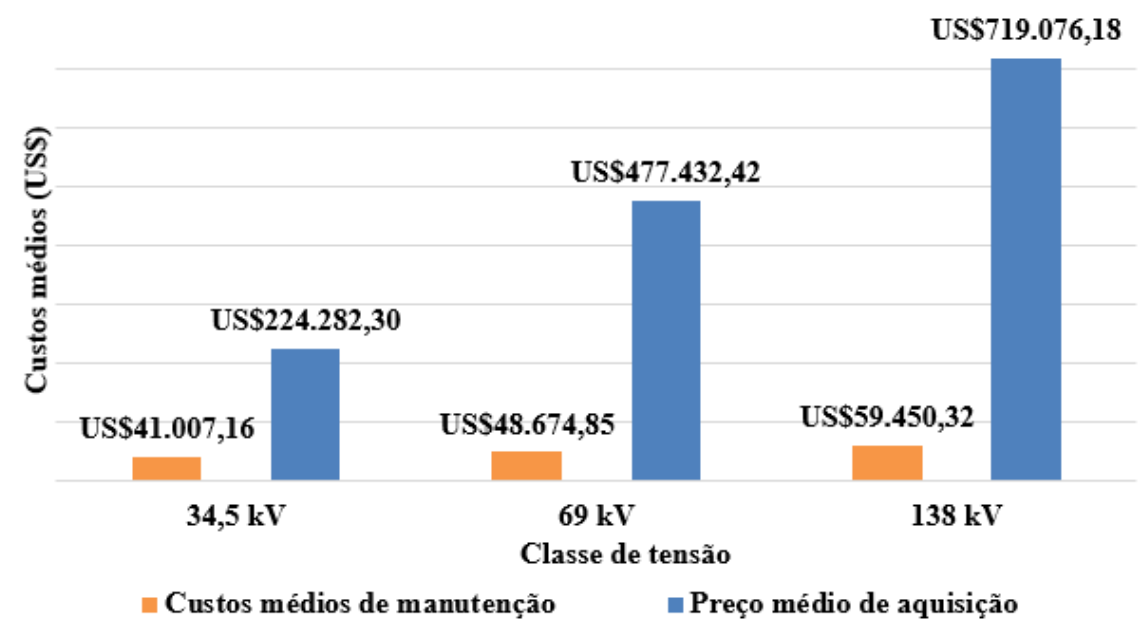

Fonte: Próprio autor (2017) 
Os custos de manutenção e reparos corresponderam a 18,28 \%, 10,19\% e 8,27 \% do preço médio de aquisição de um transformador novo (no mercado brasileiro) para equipamentos de $34,5 \mathrm{kV}, 69 \mathrm{kV}$ e $138 \mathrm{kV}$, respectivamente. Logo, em uma análise simplista, se poderia imaginar que os custos da manutenção e reparos equivaleriam, em média, a 12,25 \% do preço de aquisição de novos transformadores. Entretanto, não é condizente realizar esta análise comparativa entre preço de aquisição de transformadores novos e custos de manutenção e reparos de transformadores usados uma vez que a idade destes equipamentos não estaria sendo considerada na análise. Alguns fabricantes chegam até mesmo a afirmar que os reparos em um equipamento são viaveis se os custos forem inferiores a $60 \%$ do preço de aquisição de um novo, o que é muito impreciso [11].

$\mathrm{Na}$ sequencia, são apresentados resultados atinentes aos casos estudados. Para se ter uma visão global do estudo realizado, são apresentados valores médios (concernentes aos 72 casos), entretanto, nas tomadas de decisão diária, recomenda-se fazer a análise individual para cada transformador, caso a caso.

A expectativa de vida útil média e idade média, de acordo com [10, 11], e expectativa de vida útil média remanescente, em anos, dos transformadores analisados neste estudo são apresentadas na Tabela 1. A expectativa de vida remanescente consiste na diferença entre a expectativa de vida útil média e a idade do equipamento, ou seja, indica a quantidade de anos que o transformador provavelmente ainda poderia permanecer em operação continuamente. Constatando-se na Tabela 1 que a expectativa remanescente dos equipamentos de $69 \mathrm{kV}$ e $138 \mathrm{kV}$ indicam 8,5 e 9,9 anos restantes de operação, respectivamente. Enquanto que, os de $34,5 \mathrm{kV}$ apontam expectativa remanescente indeterminada, visto que a idade do equipamento ultrapassou a expectativa de vida útil média em 5,5 anos (sobrevida do transformador).

Tabela 1 - Expectativa de vida útil, idade e expectativa de vida útil remanescente médias dos equipamentos

\begin{tabular}{|c|c|c|c|}
\hline Tensão nominal & $34,5 \mathrm{kV}$ & $69 \mathrm{kV}$ & $138 \mathrm{kV}$ \\
\hline Expectativa de vida útil média de transformadores (anos) & 26,7 & 34,6 & 42,0 \\
\hline Idade média dos transformadores analisados (anos) & 32,2 & 26,1 & 32,1 \\
\hline $\begin{array}{l}\text { Expectativa de vida útil média remanescente dos transformadores } \\
\text { analisados (anos) }\end{array}$ & $-5,5^{\star}$ & 8,5 & 9,9 \\
\hline
\end{tabular}

*Nota: valor equivalente à sobrevida (ultrapassou a vida útil média esperada)

Fonte: Marques et al. (2004)

Por meio da expectativa de vida útil média e da vida remanescente estimada, realizou-se o comparativo de custo por ano entre o preço médio de aquisição e custos médios de manutenção e reparos em oficina com base na idade dos equipamentos, ou seja, comparando-se o custo de reparo para cada ano de vida remanescente do transformador usado com o custo de aquisição de cada ano de vida de um novo. Esta análise comparativa destaca-se por ser mais condizente com a realidade e condições de aquisição, operação e manutenção destes equipamentos por se estar comparando custos por ano de vida.

$\mathrm{Na}$ Figura 4 observa-se que os custos médios de manutenção por expectativa de vida útil média remanescente dos transformadores de $69 \mathrm{kV}$ e $138 \mathrm{kV}$ equivalem à 41,05 \% e $35,07 \%$ do preço médio de aquisição de um novo (com expectativa de vida útil média plena), respectivamente. Entretanto, para os equipamentos de $34,5 \mathrm{kV}$, os custos médios de manutenção por expectativa remanescente não fazem mais sentido, pois estes equipamentos ultrapassaram a expectativa de vida útil, ou seja, não há expectativa de vida remanescente. Para estes equipamentos, não seria viável, portanto, fazer-se a manutenção e reparos do ponto de vista econômico, conforme é ilustrado na figura. Entretanto, vale ressaltar que do ponto de vista estratégico e de necessidade e importância para o sistema, alguns equipamentos, dentre os de $34,5 \mathrm{kV}$, 
que foram considerados ainda íntegros, em

foram reparados.

uma análise de engenharia de manutenção,

Figura 4 - Comparativo entre o preço médio de aquisição por ano de expectativa de vida útil média e custos médios de manutenção por ano expectativa de vida útil média remanescente dos transformadores analisados.

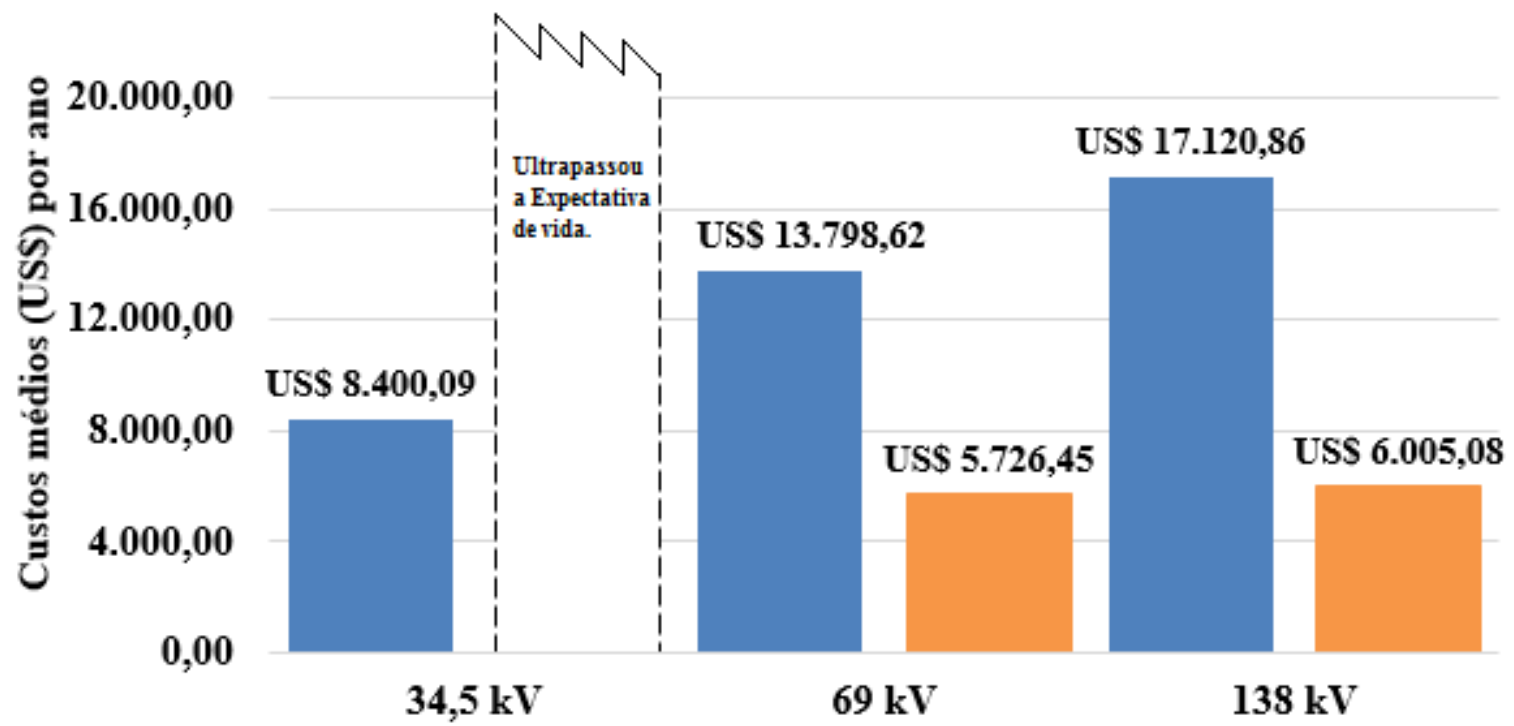

\section{Classe de tensão}

• Preço médio de aquisição (US\$) por ano de expectativa de vida útil média

\section{Custos médios de manutenção (US\$) por ano de expectativa de vida útil média remanescente}

Fonte: próprio autor (2017).

\subsection{ANÁLISE DOS CUSTOS DE ACORDO COM A TENSÃO NOMINAL ELÉTRICA DO TRANSFORMADOR}

As porcentagens de custos foram calculadas de acordo com o procedimento de manutenção ou reparos realizados, por tensão nominal: pintura, reparos gerais, reparo principal, ensaios elétricos, aplicação de vácuo, enchimento e secagem por meio do óleo.

Os transformadores de $34,5 \mathrm{kV}$ e $69 \mathrm{kV}$ apresentam $88,03 \%$ e $75,73 \%$ dos custos, concentrados em reparos principais e gerais, de acordo com a Figura 5a) e 5b), respectivamente. Além disso, constata-se que, estes equipamentos apresentam elevados gastos com reparo principal. Enquanto, os equipamentos de $138 \mathrm{kV}$, mostrados na Fig. $8 \mathrm{c}$ ), possuem elevados gastos com reparos gerais e aplicação de vácuo, enchimento e secagem por meio do óleo $(71,45 \%$ dos custos médios de manutenção). 
Figura 5 - Custos médios com manutenção e reparos em oficina de transformadores de: a) 34,5 kV; b) $69 \mathrm{kV}$; e c) $138 \mathrm{kV}$.

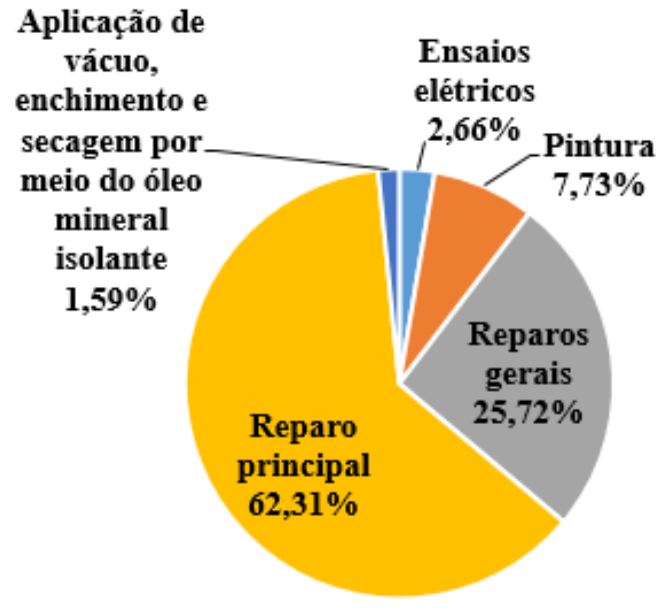

(a)

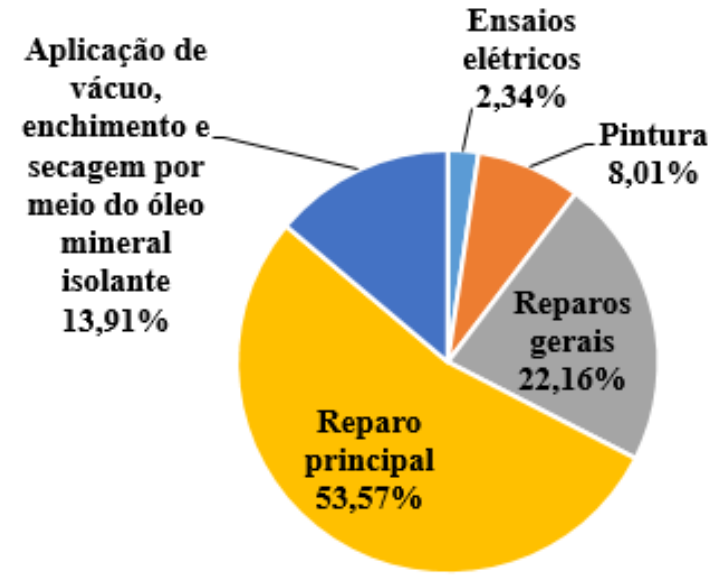

(b)

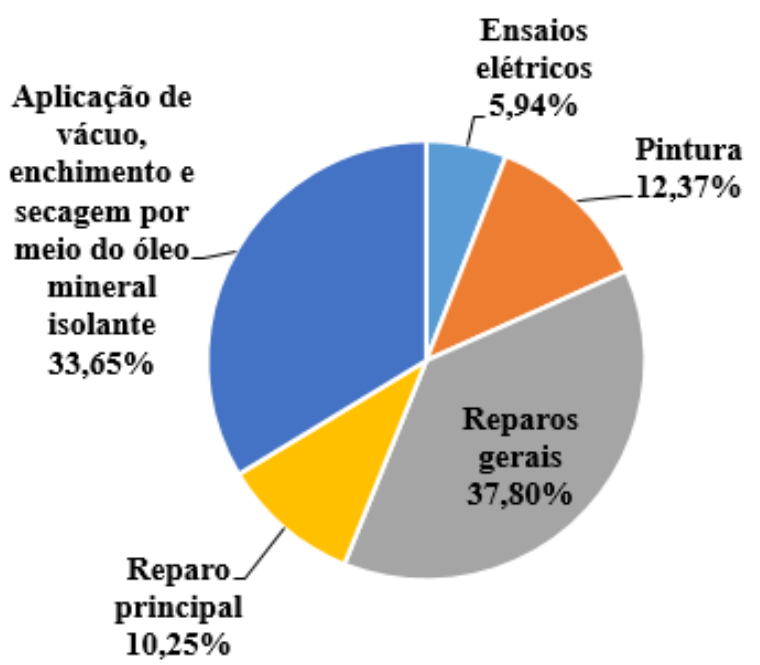

(c)

Fonte: próprio autor (2017).

\section{CONSIDERAÇÕES FINAIS}

Neste estudo são apresentados resultados significativos para se analisar a distribuição de recursos e das atividades da área de manutenção e reparos em oficina de transformadores de potência, com a análise dos custos de futuros procedimentos como reparos gerais, secagem por meio do óleo mineral isolante, aplicação de vácuo, enchimento e pintura destes equipamentos.

Como diferencial, destaca-se a análise comparativa entre os custos médios e os preços de aquisição de transformadores, por tensão nominal elétrica, onde se confirmou a viabilidade econômica dos reparos em oficina. Uma vez que os custos médios de manutenção por ano de expectativa de vida útil média remanescente dos transformadores de 69 kV e 138 kV equivalem à 41,05 \% e $35,07 \%$ do preço médio de aquisição por expectativa de vida útil média (por ano), respectivamente.

Entretanto, para os equipamentos de $34,5 \mathrm{kV}$, observou-se que, do ponto vista economico, não sereia viavel fazer-se reparos nos mesmos. Entretanto, em função de questão estratégica e necessidade e importânica para o sistema, forma reparados os que foram considerados integros em uma análise de engenharia de manutenção. 
Portanto, este trabalho auxilia nas tomadas de decisão no que diz respeito ao planejamento das atividades (mão de obra, tempo de serviço e materiais necessários versus custos), e à viabilidade econômica, verificando se compensa realizar a manutenção no transformador de potência.

\section{REFERÊNCIAS}

[1]. CIGRÉ WG A2.50, Guia de Manutenção para Transformadores de Potência, Brasil, 2013.

[2]. $Y U$, J. L.; WANG, C. F.; ZHANG, B. Economic life evaluation of power transformer in service. Proceedings of the CSU-EPSA, vol. 22, no. 3, pp. 86-90, 2010.

[3]. COSTA, L. A. N.; LIMA, G. A.; BOSSOLAN, R. P.; FREITAS, I.; DOTTO, F. Metodologia para resolver problemas na aquisição de custos na manutenção em programa de gestão econômica de ativos. Congresso Brasileiro de Manutenção, v. 141, Rio de Janeiro, 2012.

[4]. ZHOU, L.; WANG, Y.; LI, Y.; ZHU, M.; DU, $X$. A maintenance decision optimization method based on life cycle cost of converter transformer. 2016 IEEE Electrical Insulation Conference (EIC), pp. 288-291, Montreal, QC, 2016.

[5]. LIU, Z.; YAO, J.; YAN, G. Substation Project Life Cycle Cost Evaluation. China Electric Power Press, Beijing, 2012.

[6]. [6] JEROMIN, I.; BALZER, G.; BACKES, J.; HUBER, R. Life cycle cost analysis of transmission and distribution systems. IEEE Bucharest Power Tech Conference, Bucharest, Romania, 2009.
Concluindo-se assim, a importância de manter uma equipe especializada dentro das concessionárias de energia elétrica que contribuem com o rápido restabelecimento do equipamento e disponibilização para a operação no sistema.

[7]. GREENCE, L. E.; SHAW, B. L. The steps for successful life cycle cost analysis. IEEE 1990 National Aerospace and Electronics Conference NAECON, vol. 3, pp. 1209-1216, Dayton, Ohio, 1990.

[8]. DUCHARME, C.; DA SILVA, A. P. A. Modelagem e Otimização do Programa de Manutenção de Transformadores de Potência. Seminário Nacional de Produção e Transmissão de Energia Elétrica - SNPTEE, Brasília, vol. 1, pp. 1-7, 2013.

[9]. ZHANG, Y. Y. Study on life cycle cost based maintenance decision making for power transformers considering condition assessment and insulation life assessment. Ph. D. dissertation, School of Electrical Engineering, Chongqing University, Chongqing, China, 2014.

[10]. MARQUES, A. P.; MARQUES, F. P. Software CTransf $\AA$ - Carregamento de Transformadores, modelagem térmica. Versão 2.5, Goiânia, 2001.

[11]. MARQUES, A. P. Eficiência energética e vida útil de transformadores de distribuição imersos em óleo mineral isolante. Dissertação de Mestrado - Escola de Engenharia Elétrica, Mecânica e de Computação, Universidade Federal de Goiás. Goiânia, Brasil, 2004. 


\section{Papítulo 2}

\section{MAPEAMENTO COMO FERRAMENTA DE AVALIAÇÃO DO PROCESSO PRODUTIVO DE UMA INDÚSTRIA SUCROALCOOLEIRA}

\section{Larissa Carnaúba de Oliveira}

Angela Carolina Laurindo de Mendonça

\section{Laryssa Ramos de Holanda}

Resumo: O presente trabalho mostra a importância do uso do mapeamento, no caso em questão o fluxograma, para a verificação das falhas existentes no processo de estocagem do açúcar em uma indústria sucroalcooleira no estado de alagoas, bem como a aplicação da matriz gut, com o intuito de reconhecer, priorizar e mitigar ao máximo as falhas operacionais e garantir um maior lucro na produção. Por tratar de uma empresa de grande porte, algumas falhas passam despercebidas por serem consideradas geradoras de um desperdício muito pequeno diante de todo faturamento bruto da produção. Este trabalho visa trazer melhorias que auxiliem nos problemas operacionais da estocagem do açúcar no armazém. 


\section{INTRODUÇÃO}

A competitividade no mercado industrial ocasionou grandes transformações nas organizações, principalmente na indústria brasileira. Com a globalização, as empresas necessitam avançar constantemente suas tecnologias, aperfeiçoar seus processos e eliminar desperdícios, para assim conseguir sobreviver em um ambiente global tão intenso e competitivo, onde o produto se destaca pelo menor preço e maior qualidade.

Dessa forma, para firmarem-se nesse novo mercado, empresas de pequeno e grande porte buscam caminhos para potencializar a rapidez e dinamismo de sua evolução, tal crescimento se fundamenta na otimização do sistema produtivo, redução de custos e melhoria do padrão de qualidade da produção. Para tanto, é necessário total conhecimento da empresa, principalmente do processo de desenvolvimento dos produtos, que a partir de análises é possível compreender com clareza os procedimentos existentes na fábrica, identificando falhas, podendo trazer grande vantagem competitiva para a indústria.

Uma recente análise que abrangeu 68 grupos, no setor sucroalcooleiro, responsáveis por mais de $70 \%$ da capacidade de moagem, concluiu que 42 deles eram financeiramente saudáveis enquanto os 26 restantes foram considerados em estado sofrível. Esse levantamento confirma a profundidade da crise que assola o setor, em virtude que algumas usinas paralisaram por completo suas operações (ÚNICA DATA, 2015).

O mapeamento de processos é uma ferramenta que ajuda na observação do sistema produtivo, fazendo com que sejam eficientemente analisado, buscando uma melhor identificação de falhas e um maior funcionamento da produção. Nesse trabalho destacam-se falhas operacionais e retrabalhos, que quando gerenciados eficientemente proporcionam uma melhoria importante no desempenho industrial, com isso deve-se aplicar uma ferramenta de auxílio na priorização dos problemas identificados, solucionando de maneira mais rápida os mais críticos e importantes, que podem gerar maiores danos na empresa.

O trabalho tem por objetivo propor um conhecimento maior sobre os procedimentos que ocorrem na indústria, através do mapeamento de processo, além disso, propor reparações em alguns mecanismos com a utilização da ferramenta GUT (Gravidade, Urgência, Tendência), analisando os problemas encontrados e buscando uma melhor forma para resolvê-los.

\section{REFERENCIAL TEÓRICO}

De acordo com Campos (1992), a análise de um processo é uma sequência de procedimentos lógicos, embasada em dados e fatos, que tem por objetivo localizar a causa principal dos problemas. E para que haja a melhoria na qualidade e produtividade de seus processos, Villela (2000) enfatiza que as organizações precisam conhecer profundamente as atividades que constituem seus processos principais. Uma vez identificados os processos principais, o próximo passo é mapeá-los e representá-los graficamente, para que se possa identificar qualquer falha na operação.

Segundo Soliman (1998), o mapeamento de processo é uma técnica usada para detalhar o processo enfatizando os elementos mais importantes que influenciam diretamente $\mathrm{o}$ seu comportamento atual.

O mapeamento de processos está ligado à qualidade do processo, e existem quatro enfoques que devem ser considerados no desenvolvimento de possíveis melhorias de processos segundo Barnes (1982), são eles: Eliminar todo o trabalho desnecessário; Combinar operações ou elementos; Modificar a sequência das operações; Simplificar as operações essenciais.

Além disso, ferramentas da qualidade quando aplicadas, auxiliam nas tomadas de decisões e possibilitam maior controle dos processos. São empregadas para o aperfeiçoamento, observação, avaliação e otimização na qualidade das empresas/indústrias, com a finalidade de identificar e solucionar problemas encontrados (BAMFORD; GREATBANKS, 2005).

De acordo com Pestana et al (2016), as dificuldades em eleger quais os problemas prioritários dentro das empresas, faz com que gestores tenham incertezas nas suas análises, então é necessário que haja uma discriminação das atividades e suas falhas para assim organizar e planejar a resolução das adversidades constatadas. A matriz GUT é uma ferramenta muito usada para priorizar 
os problemas que devem ser resolvidos, tornando possível verificar as atividades que devem ser realizadas inicialmente.

\section{METODOLOGIA}

De acordo com Gil (2002), o método de pesquisa utilizado consiste em um estudo de caso, pois permite um estudo detalhado, obtendo assim um conhecimento mais amplo, onde é possível reunir informações e propor intervenções. Quanto ao seu objetivo o artigo caracteriza-se como exploratório e descritivo, com a finalidade de oferecer mais informações sobre o objeto em estudo a fim de elaborar hipóteses, descrevendo detalhadamente os procedimentos que ocorrem na empresa e os problemas encontrados.
Para identificar as falhas no processo de armazenagem, área de carregamento e descarregamento do açúcar na usina, a técnica usada foi o fluxograma, pois com ele pode-se identificar o caminho real e ideal do açúcar após sua saída da indústria. O fluxograma nada mais é do que uma demonstração sequencial de todas as etapas de um processo, isto é, como é realizado cada etapa e os materiais que entram/saem do processo.

Utilizando este método, o entendimento do processo torna-se mais compreensível a todos os envolvidos, pois visualizando o processo por partes fica mais fácil identificar os gargalos existentes dentro do setor. O fluxograma utiliza um conjunto de símbolos para representar as etapas do processo, como indica a figura 1.

Figura 1 - Símbolos utilizados na elaboração de fluxogramas.

\begin{tabular}{|c|c|}
\hline Simbolo & Descricăo \\
\hline & $\begin{array}{l}\text { Rotangulo: descriçao de atividade de qualquer natureza. A atividade deve ser } \\
\text { escrita dentro do espaço do simbolo. }\end{array}$ \\
\hline & Seta Grossa: movimento de saida de uma localidade. \\
\hline & $\begin{array}{l}\text { Losango: tomada de decisaso, As atividades apos essa etapa dependerâo da } \\
\text { decisto tomada. A pergunta que levard a decosio deve ser escrita dentro do } \\
\text { simbolo. }\end{array}$ \\
\hline & $\begin{array}{l}\text { Circulo Grando: indica ponto do processo em que de é interrompido para que } \\
\text { a qualidade da saida seja avaliada ou ponto } \mathrm{em} \text { que uma assinatura ê } \\
\text { necesssária. }\end{array}$ \\
\hline & $\begin{array}{l}\text { Rotingulo com fundo ondulado: representa um documento impresso } \\
\text { Significa que a saida de uma atividade inclui registro de informaçoes em papel. }\end{array}$ \\
\hline & $\begin{array}{l}\text { Retingulo de lados arredondados: representa espera, Indica que of } \\
\text { processo necessita espera ate que a proxima atividade scja executada. }\end{array}$ \\
\hline & $\begin{array}{l}\text { Triangulo: utízado para indicar que existe armazenagem sob controle e uma } \\
\text { ordem ou requisiçso necessâria para prosseguir à atividade seguinte. }\end{array}$ \\
\hline & Sota: indica o sentido e a sequência em que as atividades acontecem. \\
\hline & $\begin{array}{l}\text { Sota interrompida: indica existencia de transmisssaso instantånea de } \\
\text { informaçăo como transmissâo eletronica, chamada telefonica, fax, etc. }\end{array}$ \\
\hline 0 & $\begin{array}{l}\text { Circulo Poquono: utilizado, nocmalmente, com uma latra inserida para indicar } \\
\text { que a saida daquela parte do fluxograma servira de entrada em outro } \\
\text { fuxograma. }\end{array}$ \\
\hline & $\begin{array}{l}\text { Círculo Alongado: utlizado para identificar o inicio e o firn do processo. As } \\
\text { palavras inicio e fim sto escritas dentro do simbolo. }\end{array}$ \\
\hline
\end{tabular}

Fonte: Heberle (2010)

Após a visualização dos fluxogramas, é possível analisar algumas falhas existentes durante o processo, podendo ser utilizada a ferramenta da qualidade Matriz GUT para definir quais os problemas com maior prioridade de resolução. 
Matriz GUT é uma ferramenta utilizada para priorizar problemas e logo após resolvê-los, atribuindo valores de 1 a 5 para cada item, levando em consideração a Gravidade (G), Urgência $(U)$ e Tendência $(T)$ das falhas, como mostra na tabela 1. Segundo Gomes (2006), a gravidade está relacionada com o impacto do problema sobre processos, resultados, organizações. Urgência é o tempo necessário para solucionar o problema, e tendência é a capacidade do avanço, redução ou desaparição do problema. A Figura 2 mostra os fatores e valores considerados na Matriz GUT.

Figura 2 - Fatores e valores consideráveis na Matriz GUT

\begin{tabular}{|c|c|c|c|}
\hline Gravidade & Urgência & Tendência & Nota \\
\hline Extrema mente grave & Ação imediata & Piorar rapidamente & 5 \\
\hline Muito grave & Alguma urgência & Piorar em pouco tempo & 4 \\
\hline Grave & 0 mais cedo possível & Piorar em médio prazo & 3 \\
\hline Pouco grave & Pode esperar um pouco & Piorar em longo prazo & 2 \\
\hline Sem gravidade & Não tem pressa & Não vai piorar & 1 \\
\hline
\end{tabular}

Fonte: Autores.

\section{RESULTADOS}

\subsection{DESCRIÇÃO DA EMPRESA}

A usina estudada nesse artigo é localizada em Alagoas, sendo a matriz de um grupo grande que possui mais quatro unidades industriais em Minas Gerais: Iturama, Campo Florido, Limeira do Oeste e Carneirinho, além de uma empresa energética.

Seus três pólos de produção fabricam 19 milhões de sacos de açúcar e 460 milhões de litros de álcool. Possuem infraestrutura para estocar 9,2 milhões de sacos de açúcar e 203 milhões de litros de álcool. Na safra de 2014/2015, alcançou um recorde histórico com 13,5 milhões de cana-de-açúcar moído. A usina possui diversas áreas são elas: administrativo, área agrícola, garagem, indústria e armazém (USINA CORURIPE, 2016)

De forma resumida o processo de fabricação do açúcar contempla a extração do caldo da cana de açúcar e seu preparo para consumo, etapa realizada na indústria. No mercado são encontrados vários tipos de açúcar tanto na forma sólida como na forma líquida como: açúcar cristal, açúcar refinado, demerara, mascavo e o VHP ( "Very Hight Polarization") e orgânico. A usina em estudo produz três tipos: o açúcar cristal, VHP e açúcar demerara, esse último em menor quantidade.

\subsection{AÇÚCAR VHP}

O açúcar bruto produzido para exportação é utilizado como matéria prima para outros processos devido a sua alta polarização, grande parte da massa total do açúcar mais de $90 \%$ é sacarose por esse fato depois que é exportado ele passa por um reprocessamento permitindo ao cliente transformá-lo em vários tipos de açúcar para consumo.

Este açúcar é semelhante ao demerara, porém possui menos mel e sua umidade é menor, na safra de 14/15 foram produzidos no total 191.240,20 toneladas de açúcar e foi constatado um desperdício de 242 toneladas. A seguir será apresentado o processo de estocagem, identificando e ilustrando o carregamento e descarregamento do açúcar VHP.

\subsubsection{PROCESSO DE ESTOCAGEM}

A Figura 3 apresenta o fluxograma desenvolvido para 0 processo de descarregamento para estocagem do VHP. Abaixo segue a explicação do fluxo.

a) O açúcar vem da indústria diretamente para o armazém, transportado através de caminhões chamados de graneleiros. Existem seis graneleiros que fazem esse transporte, quatro com capacidade de 60 toneladas e dois com capacidade de 50 toneladas.

b) O graneleiro passa pela balança, onde ocorre a pesagem do caminhão em uma balança rodoviária com capacidade de 60ton/50ton. O peso líquido do produto é obtido pela diferença dos pesos, isto é, o produto inicialmente é pesado, e depois de 
descarregado, executa-se a pesagem do veículo vazio (tara);

c) Se houver demanda, o açúcar não é estocado nos galpões dentro do armazém, após a pesagem do graneleiro ele segue para descarregar o açúcar no porto de Maceió, onde se encaminha para exportação.

d) No entanto, se não houver demanda imediata, o graneleiro segue para estocagem, para descarregamento do açúcar nos galpões 6 e 7 (existem 7 galpões na usina, porém para esse processo são utilizados apenas os galpões 6 e 7).

e) O graneleiro se dirige para moega, que é uma área coberta que possui uma abertura no piso para o descarregamento do açúcar, então o caminhão é aberto quando encaixado. A moega possui três válvulas responsáveis pela liberação do açúcar que cai diretamente nas esteiras, existem três esteiras que determinam se o açúcar será estocado no galpão 6 ou no 7. A decisão de qual esteira o açúcar irá percorrer o caminho, fica a cargo do operador que observa a quantidade de açúcar em cada esteira para que não haja transbordamento causando desperdício. Duas causas de desperdício nesta etapa foram detectadas, se o açúcar estiver muito úmido ao ser aberta a válvula do caminhão o açúcar pode esborrar para fora da moega ou então na própria esteira, se o operador passar do tempo de mudar de esteira o açúcar também é esborrado dentro da moega, causando um retrabalho aos funcionários que tem que recolocar o açúcar na esteira novamente.

f) A escolha de qual armazém será estocado - açúcar fica a cargo do coordenador do armazém, normalmente primeiro estoca todo o açúcar no galpão 6 que possui capacidade para 1.000 .000 de sacos de 50 kg, e o galpão 7 possui capacidade para 1.600 .000 sacos de $50 \mathrm{~kg}$;

g) A dispersão do açúcar dentro dos armazéns é feita com a ajuda de um carrinho de distribuidor-tripler que auxilia no processo de arrumação do açúcar VHP no armazém;

h) Por fim, o graneleiro volta vazio para a balança para fazer a diferença de pesagem. 
Figura 3 - Fluxograma descarregamento no armazém açúcar VHP.

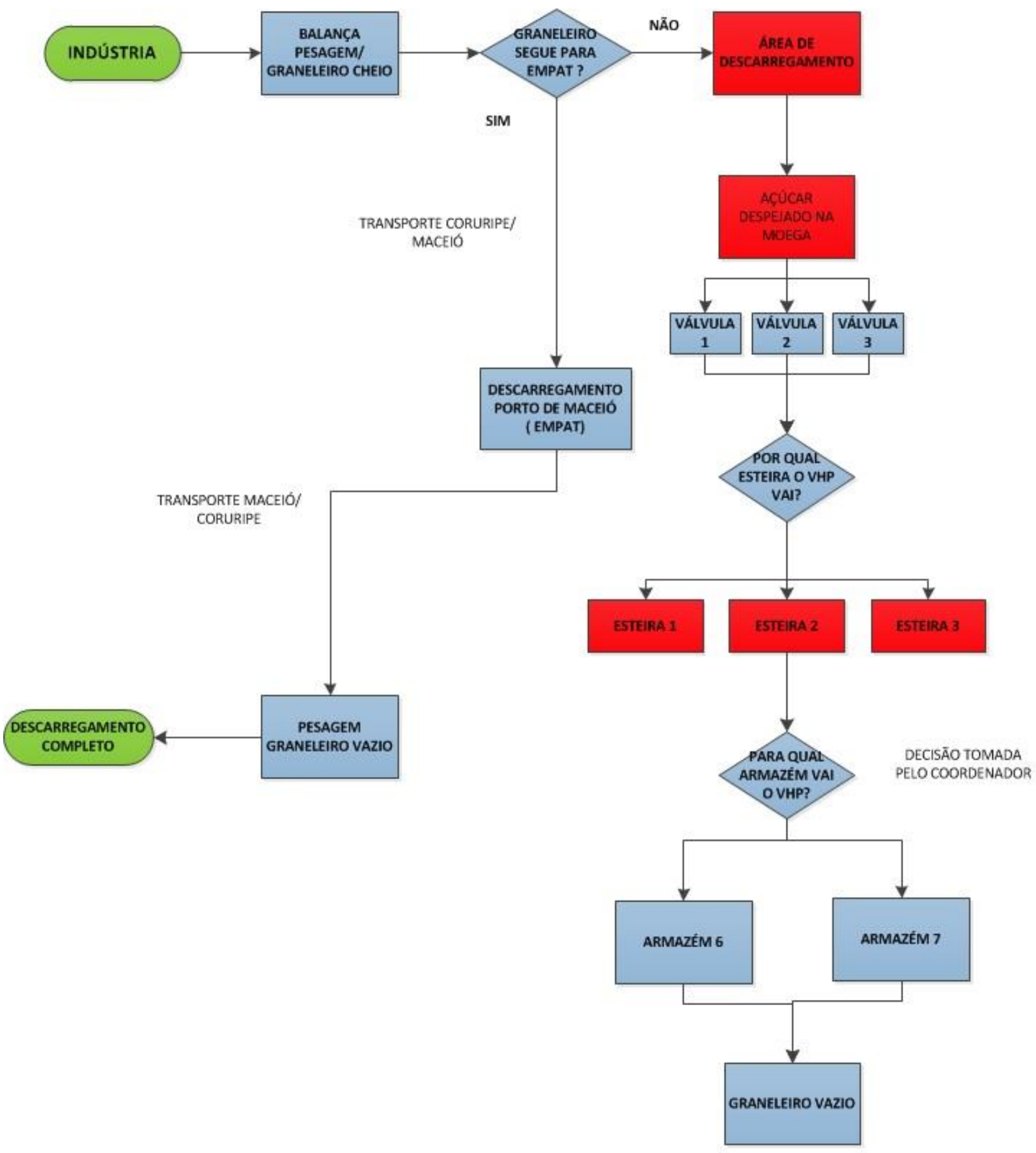

* áreas marcadas em Vermelho são pontos críticos ( PCC'S)

Fonte: Autores.

Já o processo de carregamento do açúcar estocado nos armazéns para saída direta ao porto de Maceió, é bem parecido com o processo de descarregamento do açúcar vindo da indústria para o armazém. A figura 4 apresenta o fluxograma e abaixo segue descrição do fluxo:

a) O graneleiro entra vazio no armazém e é pesado; b) Em seguida o caminhão entra na área de carregamento e é auxiliado a alinhar rentes as bocas da moega para que haja o carregamento do caminhão através das esteiras;

c) O galpão onde o açúcar está estocado possui "bocas" no chão, 22 bocas no galpão 6 e 28 bocas no galpão 7, quando abertas o açúcar cai por gravidade diretamente nas 
esteiras, localizadas embaixo das bocas, o controle para que o açúcar não transborde nas esteiras fica a cargo do operador que fiscaliza a operação por meio do tempo que o açúcar leva para encher a esteira, eles trabalham com uma média de tempo; d) O caminhão cheio segue em direção a pesagem, para que seja feita a verificação do peso líquido de açúcar que está sendo levado para o porto.

Figura 4 - Fluxograma carregamento no armazém açúcar VHP.

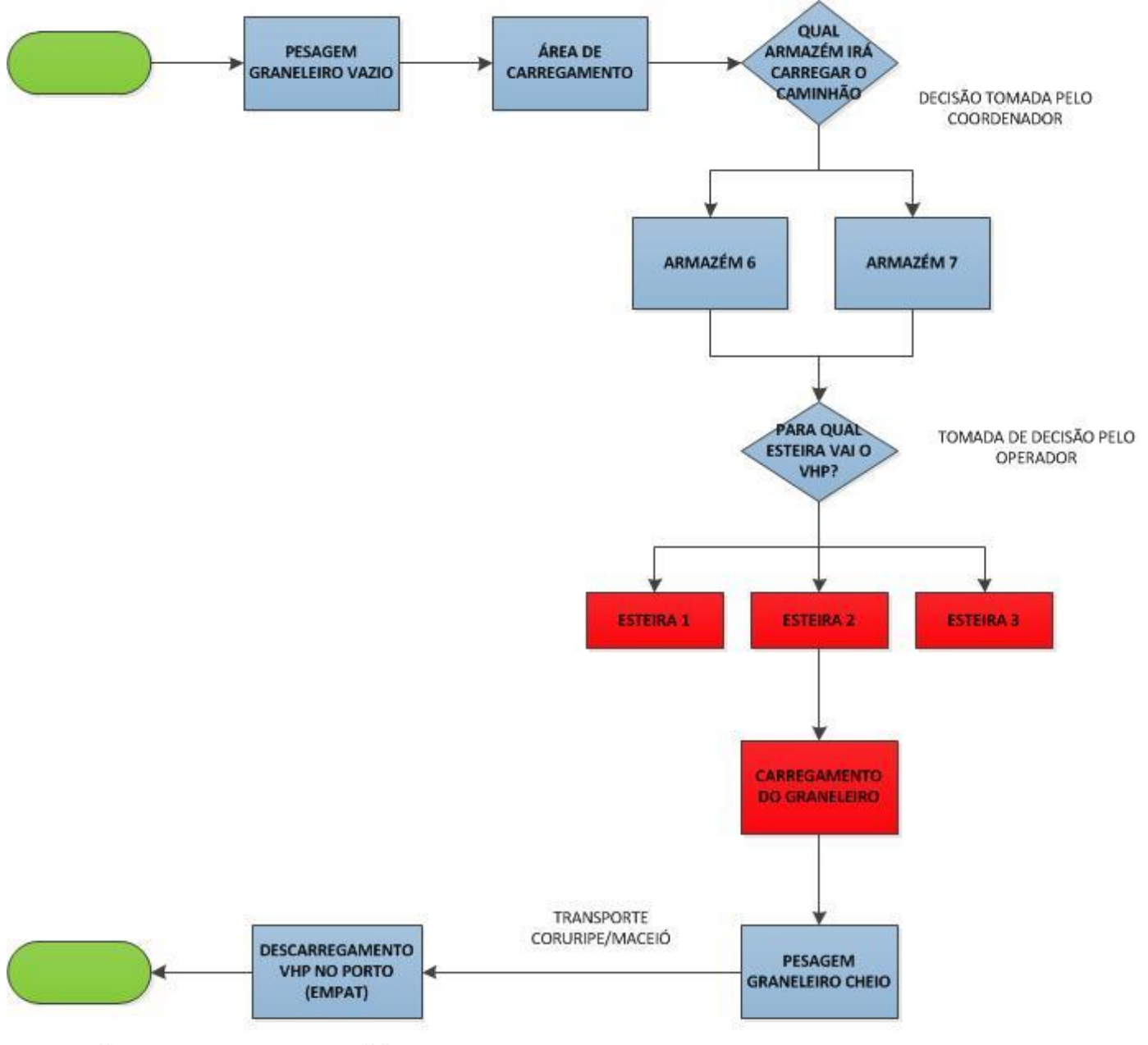

- áreas marcadas em vermelho são pontos criticos (PCC's)

. Fonte: Autores.

Foram identificados pequenos gargalos no processo que causam algum desperdício de açúcar ao longo do processo de estocagem. As esteiras quando transbordam causam desperdício, o açúcar que fica no chão no canto dos armazéns vira mel devido à temperatura do ambiente, a umidade do açúcar dentro do caminhão faz com que fixe um pouco de açúcar nas bordas do caminhão. O valor do desperdício é muito, porém muito pequeno comparado ao valor total da produção. Na última safra foram produzidas 191.240.200 toneladas de açúcar VHP e o desperdício total de açúcar ficou em torno de 242 toneladas, o que representa menos de $1 \%$ de desperdício de açúcar produzido.

\subsection{AÇÚCAR CRISTAL E DEMERARA}

O açúcar cristal branco é caracterizado por ser um açúcar de alta polarização. Polarização é a porcentagem em massa de sacarose contida em uma solução açucarada, o processo de clarificação utilizado no açúcar cristal é mais eficiente do que o utilizado no açúcar demerara, seu aspecto branco o torna 
mais sofisticado, ele é comercializado no mercado interno e externo.

A diferença entre o açúcar cristal branco e o demerara se dá basicamente pela fase de clarificação do caldo, pois o demerara apresenta cristais envoltos por uma fina camada aderente de mel, por este motivo possui um menor grau de polarização.

\subsubsection{PROCESSO DE ESTOCAGEM}

O açúcar vem direto da indústria para o armazém através dos graneleiros, diferente do açúcar VHP ele passa por um processo de empacotamento antes de ser estocado ou vendido diretamente por demanda ao cliente. $O$ processo de estocagem segue o seguinte fluxo:

a) Assim que o graneleiro entra no armazém ele passa pela balança, onde ocorre a pesagem do caminhão, na mesma balança utilizada no processo descrito do VHP;

b) O graneleiro após a pesagem segue para o silo, local onde é descarregado todo o açúcar, e é acoplado um tubo diretamente no caminhão para que o açúcar seja todo descarregado sem nenhum contato manual com os operadores; c) Dentro do silo o açúcar passa por uma "peneira" e direciona-se diretamente através da tubulação para a área de empacotamento, caindo nas máquinas;

d) A área de empacotamento é uma área totalmente higienizada onde todos os funcionários utilizam os EPI'S e o contato manual com o produto só ocorre após o empacotamento do açúcar em sacos de $1 \mathrm{~kg}$ ou $50 \mathrm{~kg}$. Na área de empacotamento de $1 \mathrm{~kg}$ possuem oito máquinas produzindo sacos de açúcar cristal e duas máquinas produzindo sacos de açúcar demerara, cada máquina produz em média 26.000 sacos por dia.

e) O empacotamento é totalmente automático, assim que o açúcar cai nas máquinas ele é empacotado e pesado, existe um padrão de qualidade onde os pacotes que pesam menos de $1 \mathrm{~kg}$ e os que pesam mais de $1.050 \mathrm{~kg}$ (existe uma tolerância de $50 \mathrm{~g}$ ) são descartados pela própria máquina. Quando é acumulado uma quantidade considerável de descartes, o operador pega essas embalagens descartadas e rasga o açúcar dentro de um bag (chamado "caramba"), ilustrado na Figura 5, e posteriormente esse açúcar é colocado junto ao açúcar de exportação, sendo vendido por um menor preço.

Figura 5 - Embalagens descartadas dentro da caramba.

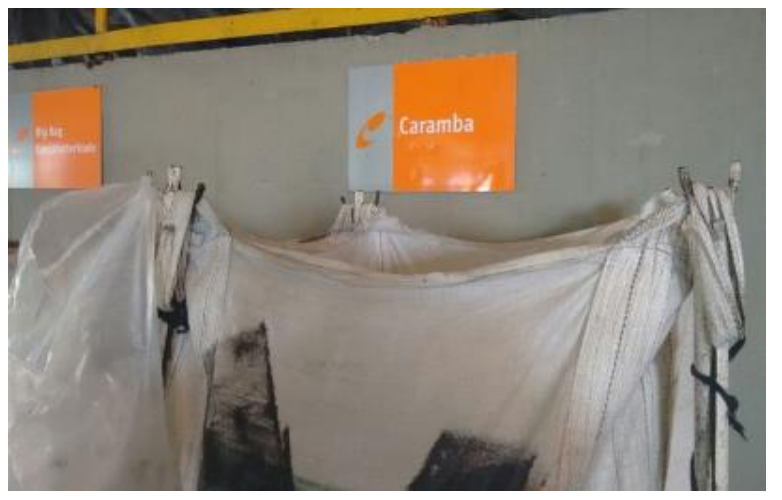

Fonte: Autores.

f) Os pacotes que seguem as especificações e os padrões de qualidade seguem sem nenhum contato manual através das esteiras para formar fardos. Um fardo possui 30 sacos de um kg, só então depois de formar um fardo é que o açúcar sai da área de empacotamento coberta e segue para área de carregamento do caminhão. A área de carregamento possui uma esteira e os operários fazem uma segunda inspeção para ter certeza que não possui nenhum saco rasgado ou fora dos padrões visuais de qualidade.

g) O açúcar empacotado pode ter dois destinos ir direto para o cliente ou ir para o estoque, se o destino do açúcar for o cliente os operários carregam o caminhão, que segue para a balança e depois para o cliente. Mas se o destino for o estoque há mais uma 
fase no processo, pois o açúcar não é estocado em fardos, e sim em "magicons". Um magicon completo contém 30 fardos embalados, ou seja, se um fardo possui 30 pacotes então um magicon contém 900 pacotes de $1 \mathrm{~kg}$ de açúcar. O transporte para o estoque se dá através das empilhadeiras. A empilhadeira pega um magicon que passa na balança e segue direto para o estoque (armazém).

A figura 6 contém o fluxograma que explica esse processo de estocagem, os pontos marcados em vermelho são os pontos críticos que chamamos de PC'S.

FIGURA 6 - Fluxograma Açúcar cristal.

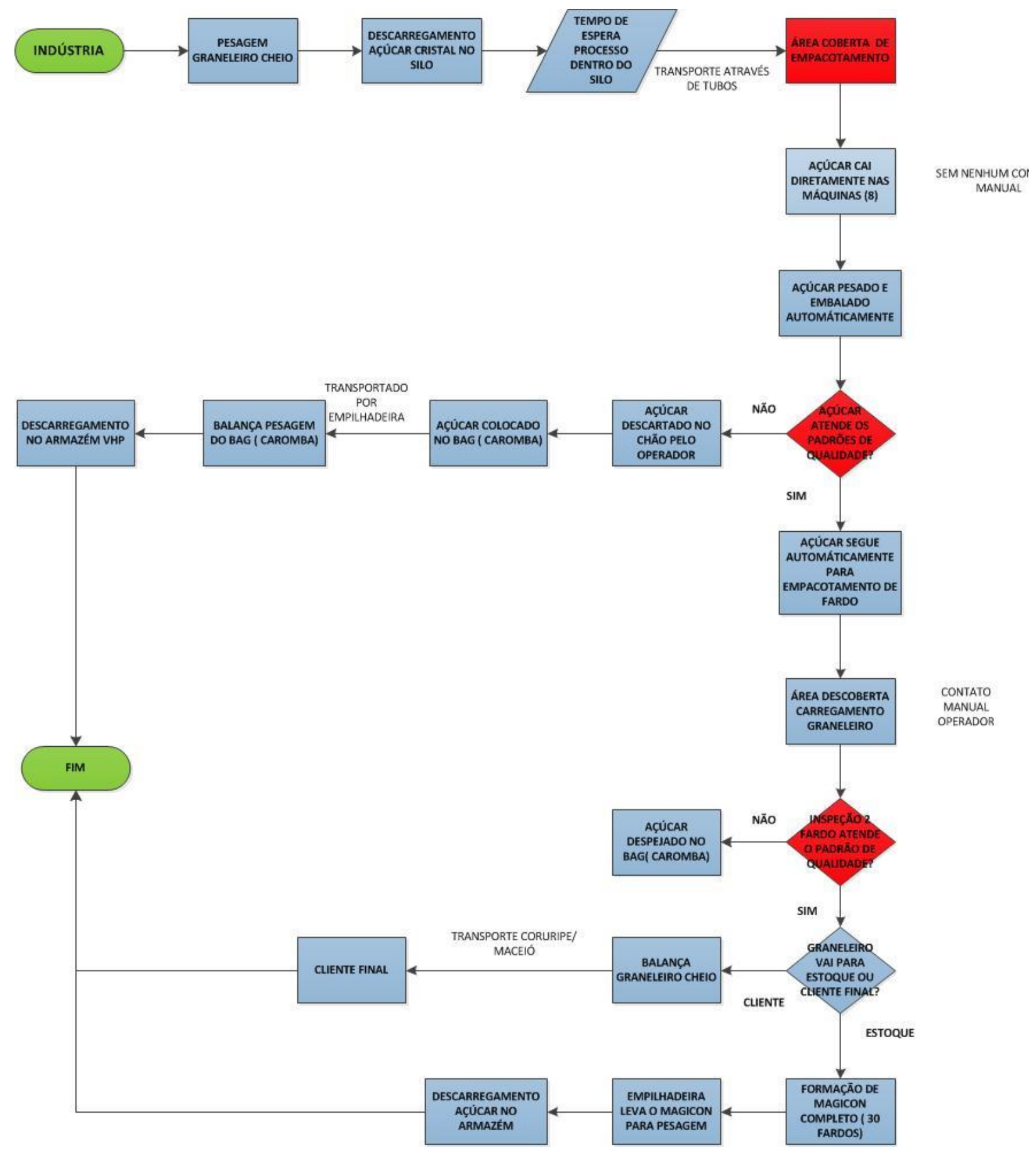


Existem alguns pontos críticos identificados no fluxograma em que há algumas falhas no processo de empacotamento e consequente desperdício de açúcar cristal, isso ocorre porque todo o açúcar que não atende aos padrões de qualidade da empresa é descartado, mesmo sem ainda ter havido contato manual do produto com os operários, em bag's que vão diretamente para o armazém de VHP, ou seja, o açúcar que é produzido como cristal, que possui um valor de produção superior ao VHP, pois passa por um processo de clarificação encarecendo sua fabricação, que o açúcar de exportação não passa, é despejado no armazém de exportação e vendido mais barato, diante disso o açúcar sem contato manual, apenas por ter sido embalado com peso inferior a $1 \mathrm{~kg}$ ou superior a $1.050 \mathrm{~kg}$ é descartado e vira açúcar de exportação.

\subsection{ELABORAÇÃO DA MATRIZ GUT}

Foi aplicada uma matriz GUT com o objetivo de destacar e priorizar os problemas observados ao verificar os fluxogramas elaborados para mapear os processos existentes na empresa. Com os dados obtidos foi possível chegar às causas e a ordem de priorização da resolução das mesmas, indicado na figura 7.

Figura 7 - Matriz GUT. Fonte: Autores.

\begin{tabular}{|c|c|c|c|c|c|}
\hline Causas & \multicolumn{2}{|c|}{ Gravidade Urgência Tendência } & GUT & Priorização \\
\hline $\begin{array}{c}\text { Desperdício } \\
\text { Retrabalho }\end{array}$ & 5 & 4 & 4 & 80 & 25 \\
\hline Falhas no empacotamento & 3 & 3 & 3 & 27 & 35 \\
\hline
\end{tabular}

Após aplicação da matriz GUT, propõe-se solucionar primeiramente a falha no empacotamento do açúcar, onde ocorre o descarte do mesmo devido ao erro de pesagem da máquina. $O$ correto seria que houvesse um reprocessamento do empacotamento do açúcar descartado, no entanto, existe a problemática de transporte do açúcar de volta para o silo, para que haja esse reprocessamento. Isso pode ser resolvido com a construção de um maquinário que fure automaticamente os sacos descartados dentro de um bag, que deve possuir uma válvula para que possa ser acoplada à válvula do silo, e assim, transportando o açúcar de volta ao silo onde começaria todo o processo de empacotamento.

Em seguida sugere-se resolver o desperdício do produto durante alguns processos, principalmente no carregamento e descarregamento, e por fim, o retrabalho dos funcionários em recolocar o açúcar quando transborda para fora da moega ou da esteira.

\section{CONCLUSÃO}

No cenário atual da economia as empresas buscam cada vez mais maximizar o lucro e minimizar os prejuízos de sua produção para que se sobressaiam no mercado que está cada vez mais competitivo.

Foram feitos três fluxogramas mapeando toda área do armazém, onde ocorre o carregamento e descarregamento do açúcar, sendo possível visualizar quais as áreas dentro do armazém geram alguns desperdícios. Para finalizar aplicou-se a ferramenta da qualidade Matriz GUT, permitindo assim, fazer um melhor reconhecimento dos gargalos identificados, para que cada problema seja resolvido de forma preferencial, levando em conta os índices da ferramenta.

A empresa possui uma dificuldade de reaproveitamento correto do açúcar descartado por erro automático da máquina de empacotamento. A partir da elaboração desse artigo foi possível mostrar que há soluções para este problema evitando assim que haja um prejuízo no lucro da empresa.

Ainda existem ajustes a serem feitos na forma com que deve ser elaborado esse novo maquinário, porém a ideia já está lançada com o objetivo de evitar que o açúcar produzido mais caro seja vendido mais barato. 


\section{REFERÊNCIAS}

[1]. BAMFORD, David R.; GREATBANKS, Richard W. The use of quality management tools and techniques: a study of application in everyday situations. International Journal of Quality \& Reliability Management, Vol. 22, n. 4, p. 376-392, 2005.

[2]. BARNES, R.M., Estudo de movimentos e tempos. Edgard Blucher, São Paulo, 1982.

[3]. CAMPOS, Vicente Falconi. TQC Controle da qualidade total (no estilo japonês). Belo Horizonte: Fundação Christiano Ottoni: Bloch Editores, 1992.

[4]. GIL, A. C.. Como Elaborar Projetos de pesquisa. 4. ed. São Paulo: Atlas S.a, 2002. $175 \mathrm{p}$.

[5]. GOMES, Luis Gustavo dos Santos. Reavaliação e melhoria dos processos de beneficiamento de não tecidos com base em reclamações de clientes. Revista FAE, Curitiba, v. 6. n. 2, p. 1-26, 2006.

[6]. HEBERLE, Déborah Schirmer. Gestão de processos na Heberle \& Roman Arquitetura LTDA. Universidade Federal do Rio Grande do Sul. Escola de Administração. Porto Alegre, 2010.
[7]. PESTANA, Marcelo Diniz; VERAS, Gabriela Pinheiro; FERREIRA, Maria Teresa Matos; SILVA, Abraao Ramos. Aplicação integrada da matriz gut e da matriz da qualidade em uma empresa de consultoria ambiental. Um estudo de caso para elaboração de propostas de melhorias. XXXVI ENEGEP, João Pessoa, PB: ABEPRO, 2016.

[8]. SOLIMAN, Optimum level of process mapping and least cost business processesengineering International Journal of Operations \& Production Management, Vol.18, no 9/10, 1998, pp.810-816.

[9]. ÚNICA DATA. União da indústria de Cana-de-açúcar. São Paulo - Brasil. Disponível em: <http://www.unicadata.com.br>. Acesso em 10 nov. 2016.

[10]. USINA CORURIPE. Disponível em: $<$ http://www.usinacoruripe.com.br/index.php/c onteudo/produtos>Acessp em 20 Out. 2016.

[11]. VILLELA, C. S. S. Mapeamento de processos como ferramenta de reestruturação e aprendizado organizacional. Dissertação de Mestrado (Mestrado em Engenharia de Produção), Universidade Federal de Santa Catarina, Florianópolis, 2000. 


\section{Capítulo 3}

APLICAÇÃO DO MÉTODO MULTICRITERIO SMARTER
NA SELECÃO DE FORNECEDORES DE MATERIA PRIMA:
UM ESTUDO NO SETOR AVICOLA

\section{Mirian Batista de Oliveira Bortoluzzi}

Resumo: No contexto competitivo em que as empresas se encontram, faz-se necessário o desenvolvimento de diferenciais para sobrevivência em um mercado em constante mudança. Nesse cenário, os critérios de avaliação e seleção de fornecedores podem ser utilizados no contexto do gerenciamento da cadeia de suprimentos. Nesse sentido, este artigo buscou estruturar o processo decisório para seleção de fornecedores de matéria prima (soja/milho) em uma empresa do setor avícola utilizando o método de apoio multicritério à decisão SMARTER. O resultado apontou como melhor alternativa para a empresa o Fornecedor de embalagem (F7), no qual apresenta a maior utilidade multiatributo.

Palavras-chave: Seleção de Fornecedores; Setor Avícola; Decisão Multicritério; SMARTER. 


\section{INTRODUÇÃO}

A atual globalização econômica do mercado, aliada com ao desenvolvimento das tecnologias, tem levado empresas a buscarem menores custos, menores tempos de atendimento aos clientes, menor tempo de desenvolvimento de novos produtos e imediata disponibilidade de produtos para atender o consumidor. Neste cenário, o ambiente de negocio cada vez mais dinâmico e competitivo, faz com que o sucesso organizacional dependa da gestão efetiva da empresa em se integrar à sua rede de fornecedores (LAMBERT, 2008).

O processo de seleção de fornecedores tem sido estudado em diversos tipos de negócios e sob diferentes óticas. Atualmente, várias metodologias pertinentes à seleção de fornecedores têm sido desenvolvidas, o que mostra a seriedade do tema (CHEUNG et al., 2002; PESÄMAA et al., 2008). Sendo este, um peculiar problema de decisão com um alto grau de complexidade, pois requer que os indivíduos façam avaliações e trade-offs entre escopos conflitantes e recursos restritos (WATT et al., 2009).

Segundo Lambert e Cooper (2000) abordam que empresas individuais não concorrem como instituição independentes, mas como cadeias de suprimentos. Assim, com as mudanças nos mercados, principalmente no que tange a diminuição do número de pessoas no núcleo familiar, e a nova estrutura por produtos embalados em porções individuais ou embalagens menores, e a busca pela rapidez e praticidade, e estas mudanças faz com que as empresas busquem ser mais competitivo em custos e de desenvolver relacionamentos mais próximos com fornecedores.

Diante deste cenário, o desenvolvimento desse relacionamento entre empresa e fornecedor, é uma questão que faz parte da estratégia de compras, uma vez que a empresa necessita definir quantos e quais fornecedores pretende desenvolver uma parceria, além do mais o tipo de relacionamento que a empresa pretende manter com os mesmos será também uma condição para a seleção dos fornecedores (SLACK et al., 1999).

Dessa forma as empresas do setor avícola, busca sempre uma parceria com fornecedores qualificados, comprometidos com os objetivos do cliente e que sejam capazes de empreendê-los. Portanto, o processo de avaliação e seleção de fornecedores torna-se um elemento chave para as empresas da atualidade, principalmente nos setores de carnes.

Assim, nas organizações decisões são tomadas diariamente de forma auxiliada ou não por métodos formais de apoio à decisão. Qualquer decisão escolhida impacta na organização e há uma preocupação com a consequência desta. Assim, é importante a construção de modelos de decisão e a escolha de métodos que fundamentam tais decisões (ALMEIDA, 2013).

Devido a esta complexidade, o objetivo deste trabalho é apresentar a aplicação de modelos de decisão na seleção de fornecedores de matéria-prima (soja/milho) em uma empresa do setor avícola, dado que a seleção deste, é uma atividade necessária para garantir a competitividade e sucesso das empresas desse setor.

Para tanto, este artigo compõe-se de 4 seções, sendo que nesta $1^{\text {a }}$ seção é apresentada a introdução; na $2^{\text {a }}$ discutem-se problema de apoio a decisão multicritério, além de uma breve apresentação sobre modelo de agregação aditivo e método SMARTER; na $3^{\text {a }}$ seção apresenta-se a aplicação do método SMARTER, mediante a apresentação dos resultados obtidos a partir da pesquisa desenvolvida em uma empresa do setor avícola no estado de Mato Grosso, e, por fim, na $4^{a}$ seção tem-se as conclusões do estudo.

\section{REFERENCIAL BIBLIOGRÁFICO}

Nesta seção faz-se uma breve revisão bibliográfica sobre o problema de Apoio a decisão multicritério e o modelo de agregação aditivo deterministico apresentando os métodos SMARTS e SMARTER.

\subsection{APOIO À DECISÃO MULTICRITÉRIO}

Um problema multicritério consiste em uma situação em que há pelo menos duas opções alternativas para escolher, e esta escolha é conduzida pelo desejo de atender a múltiplos objetivos, que estão associados com as conseqüências da escolha para cada alternativa a ser seguida (ALMEIDA, 2013).

A modelagem de problemas de decisão envolvendo múltiplos critérios e diferentes 
preocupações de decisão sobre alternativas como escolha, ordenação ou classificação. E são usados multicritérios decisão apoio métodos (MCDA), que abrangem uma ampla gama de métodos disponíveis na literatura, e opiniões sobre eles podem ser encontrados em KEENEY; RAIFFA (1976), ROY (1996), BELTON; STEWART (2002), ALMEIDA (2013).

Para elaboração de um problema de decisão multicritério tem-se o conjunto das alternativas de ação, o conjunto das consequências e o conjunto dos critérios, esse último atende as propriedades de exaustividade e não redundância. Um critério é um padrão de julgamento, no contexto de tomada de decisão que indica um meio ou forma de julgar, no qual uma alternativa de ação pode ser julgada como mais ou menos desejável que outra. Logo, o critério é definido como uma função sobre o conjunto de alternativas de ação e representa a preferência do decisor de acordo com um ponto de vista. Um problema de decisão com alternativas discretas e consequências determinísticas pode ser apresentado por uma matriz de consequências, como na Tabela 1 ou por uma matriz de decisão (ALMEIDA, 2013; BELTON \& STEWART, 2002).

Tabela 1 - Matriz de decisão

\begin{tabular}{|c|c|c|c|}
\hline \multicolumn{4}{|c|}{ Critérios } \\
\hline Alternativas & $\mathrm{Ci}$ & $\mathrm{C} 2$ & $\mathrm{Cm}$ \\
\hline $\mathrm{Ai}$ & $\mathrm{vi}(\mathrm{Ai})$ & V2(Al) & $\operatorname{Vm}(A \quad 1)$ \\
\hline A2 & v 1(A2) & V2(A2) & $\mathrm{Vm}(\mathrm{A} 2)$ \\
\hline An & VI (An) & V2(An) & $\mathrm{Vm}(\mathrm{An})$ \\
\hline
\end{tabular}

Fonte: Almeida, (2013).

Existem dois tipos de avaliações para resolver um problema de decisão multicritérios: (i) a avaliação intracritério ocorre através da avaliação de cada alternativa i para cada critério j, o que leva a uma função valor vj(ai), baseada na avaliação das consequências e (ii) a avaliação intercritério considera a associação entre os diferentes critérios por meio de um método de agregação desses critérios, que possibilitam a comparação entre as alternativas, por meio de uma pontuação global para cada alternativa ou por um procedimento que compare as alternativas sem atribuir um valor global (ALMEIDA, 2013). Para tal deve-se escolher um método de agregação destes critérios, isto é, um método MCDA.

Os principais métodos de apoio à decisão multicritério são classificados em três grandes grupos: Critério Unico de Sintese, Metodos de Sobreclassificação eos Interativos (ROY, 1996; BELTON, STEWART, 2002). Outra classificação amplamente utilizada é a divisão entre métodos compensatórios e não compensatórios (ALMEIDA, 2013).

\subsubsection{MODELO DE AGREGAÇÃO ADITIVO DETERMINÍSTICO}

Segundo Almeida (2013), o modelo aditivo determinístico consiste em agregar os desempenhos das alternativas segundo cada critério. Está relacionada à suposição de situação de certeza em um contexto determinístico na obtenção das consequências para cada alternativa. $\mathrm{Na}$ equação (1), kj representa a constante de escala para cada critério j e vj (a) é o desempenho da alternativa (a) do critério j, segundo as preferências do avaliador. Essa formulação considera a captação das preferências de um único indivíduo (ou de vários indivíduos através do consenso).

$$
V(a)=\sum_{j=1}^{n} K_{j} V_{j}(a) \quad, \sum_{j=1}^{n} K_{j}=1
$$


É importante ressaltar que a obtenção das constantes de escala não pode ser baseada apenas no grau de importância dos critérios. Dado que o modelo aditivo representa a

$$
\mathrm{V}(\mathrm{x})=\sum_{\mathrm{j}=1}^{\mathrm{n}} \mathrm{K}_{\mathrm{j}} \mathrm{V}_{\mathrm{j}}(\mathrm{xj})
$$

Os procedimentos para se obter os valores de kj: (i) avaliação intra-criterio (ii) ordenação dos critérios; (iii) explorando mais o espaço das consequências (iv) obtenção da relação entre as constantes de escalas ( $v$ ) avaliação das outras constantes de escalas e por fim (vi) finalização: efetuar testes de consistência.

As constantes de escalas estão associadas com a taxa de substituição, que traz a noção de trade-offs entre os critérios, ou seja, a ideia de compensação de ganhos em um critério quando se perde em outro. O valor da constante de escala depende dos limites do espaço de consequência. Já os pesos podem traduzir apenas a noção de importância dos critérios, não havendo a noção de trade-offs e compensação entre os critérios (ALMEIDA, 2013). Por apresentar um método simples e bem intuitivo, esse procedimento de agregação é o mais utilizado.

\subsubsection{MÉTODOS SMARTS E SMARTER}

Os métodos SMARTS (Simple Multi-Attribute Rating Technique using Swings) e o SMARTER (Simple Multi-Attribute Rating Technique using Exploiting Rankings) foram propostos por Edwards \& Barron em 1994 para obtenção da utilidade multiatributo. Essas duas abordagens foram elaboradas busca corrigir um erro intelectual do método SMART (Simple Multiattribute Rate Technique), proposto por Edwards em 1977. ALMEIDA (2013).

De acordo com Almeida (2013), para corrigir esse erro foi desenvolvido um procedimento função valor definida sobre as consequências ao invés de ser definidas sobre às alternativas, onde $x$ é o vetor consequência, conforme equação 2 , temos:

chamado de "swing weights" (peso das trocas), que incluem a questão da amplitude dos valores das alternativas nos critérios à noção de importância e compensação intercritérios. Admite que a função utilidade unidimensional seja linear e que função de agregação multiobjectivo é aditiva. Esse processo de elicitação de preferências produz erros maiores do que àqueles resultantes das simplificações do modelo; o que justifica a adoção de técnicas mais simples para mensurar a utilidade multiatributo (ALMEIDA, 2013).

Outra inovação proposta foi o método SMARTER que tem que consiste na exploração da ordenação dos critérios, ou seja, é um método que definir os pesos de cada critério de acordo com as suas importâncias relativas.

Diante deste contexto, o método SMARTER foi recomendado para determinar a utilidade multiatributo das alternativas constantes no problema abordado neste artigo, devido a facilidade dos procedimentos para a definição dos pesos dos critérios serem mais simples para os decisores.

Para a utilização dos métodos SMARTS e SMATER, duas séries de nove passos são utilizados, sendo propostos por Edwards \& Barron (1994) que têm como propósito mensurar a utilidade multiatributo das alternativas envolvidas num determinado processo de tomada de decisão. A Figura 1 apresenta os nove passos do SMARTER; para maiores detalhes destas etapas, consultar Edwards \& Barron (1994). 
Figura 1 - Etapas do método SMARTER. Fonte: Adaptado de Almeida, (2013).

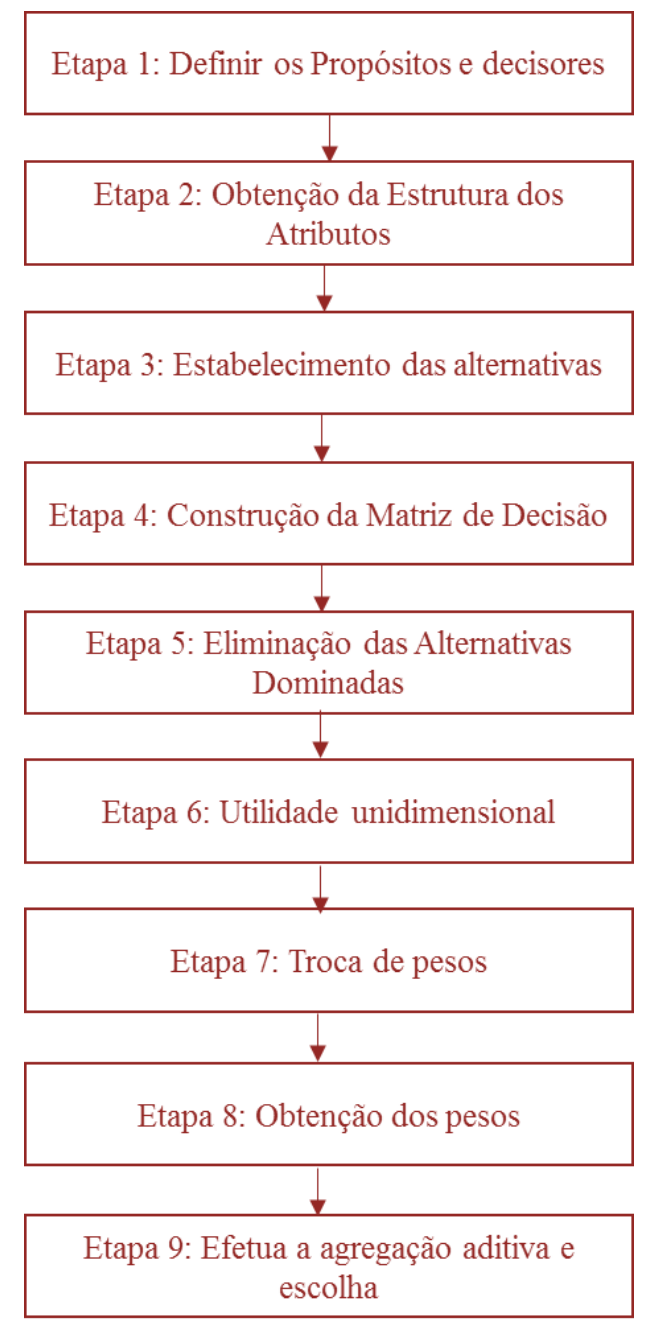

A seguir será explicado as etapas da utilização do método SMARTER, (ALMEIDA, 2013):

Etapa 1: Definir os propósitos e decisores: Nessa etapa busca-se identificar os decisores e os objetivos do problema de decisão.

Etapa 2: Obtenção da estrutura dos Atributos. São estabelecido nessa etapa os critérios com base no proposto do modelo e as informações fornecida pelo decisor.

Etapa 3: Estabelecimento das Alternativas. São definidos o conjunto de alternativa que serão avaliados no modelo de apoio a decisão.
Etapa 4: Construção Matriz de Decisão: A etapa 4 consiste em formular uma matriz com a consequência de cada alternativa em função de cada critério.

Etapa 5: Eliminação das Alternativas dominadas: Nessa etapa consiste em eliminar as alternativas dominadas.

Etapa 6: Utilidades unidimensionais. Devemse reformular as entradas da matriz de alternativas por critério considerando as utilidades unidimensionais. Edwards \& Barron (1994) propõem, quatro formas diferentes para determinar a função utilidade unidimensional $\mathrm{u}(\mathrm{a}) \mathrm{j}$, conforme Figura 2. 
Figura 2 - As quatro classes das funções utilidades unidimensionais. Fonte: Edwards \& Barron (1994).

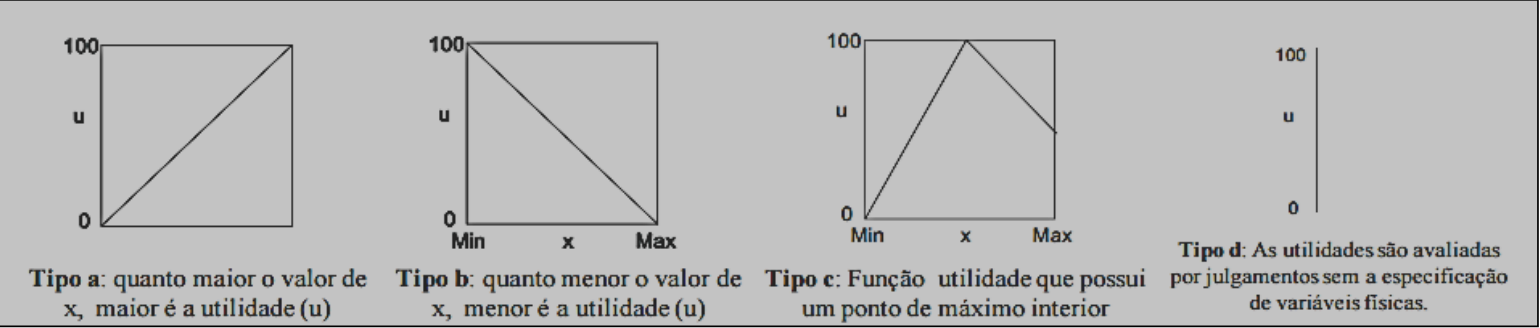

Etapa 7: Troca de pesos. Essa etapa consiste na parte 1 do Swing para ordenação dos pesos. Essa etapa faz à operação de troca das pontuações de algumas alternativas levando-se em consideração a importância os critérios disponíveis.

Etapa 8: Obtenção dos Pesos: Esta etapa consiste em um procedimento de elicitação dos pesos dos critérios. Para a obtenção dos pesos usa-se da abordagem chamada de
ROC - Rank Order Centroid ou simplesmente de pesos ROC, conforme as equações abaixo:

Então, se, W1 $\geq$ W2 $\geq \ldots \geq W k$

$$
\begin{aligned}
& W_{1}=(1+1 / 2+1 / 3+\ldots+1 / K) / K \\
& W_{2}=(0+1 / 2+\ldots+1 / K) / K \\
& W_{3}=(0+0+1 / 3+\ldots+1 / K) / K \\
& W_{k}=(0+\ldots+0+1 / K) / K
\end{aligned}
$$

De maneira geral, se K é o número de critérios, então o peso do k-ésimo critério será:

$$
\mathrm{Wi}=1 / n \sum_{\mathrm{j}=\mathrm{i}}^{\mathrm{n}} 1 / \mathrm{j}
$$

Etapa 9: Nesta etapa, decide sobre a alternativa que apresentar a melhor utilidade multiatributo.

O SMARTER em diversas situações pode ser útil, principalmente quando o decisor não deseja efetuar a elicitação de magnitude dos pesos.

\section{CARACTERIZAÇÃO DA EMPRESA}

O estudo de caso foi realizado em uma empresa do setor avícola do estado de Mato Grosso, a qual será chamada de empresa "A".

A empresa $A$, tem hoje um número de colaboradores que gira em torno 2000 funcionários, tem um sistema integrado com aproximadamente 765 aviários, de tamanho médio de $1500 \mathrm{~m}^{2}$ cada, com esse sistema integrado a empresa auxilia na abastecimento desses aviario, sendo asssim a mesma possui armazéns (soja/milho) para o estoque da matéria prima. Sendo que o destino da produção da empresa $A$, tem-se que grande parte é destinada ao mercado externo (90\%), o principal destino desse volume de exportação é para o Oriente Médio, no qual exporta apenas frango inteiro - 50\% e cortes $50 \%$. , enquanto somente $10 \%$ da produção são voltadas para o mercado nacional.

No que se refere a compra de matéria prima (soja/milho) a empresa estabelece critérios para escolha, porém, considera somente o preço baixo, a garantia nos prazos de entrega e qualidade, bem como a busca de relações de longo prazo com fornecedores importante. Já a busca por condições vantajosas momentâneas é totalmente sem importância para a empresa; e a facilidade nas negociações de pagamentos e cumprimento das especificações técnicas do produtor é considerada pouco importante.

\subsection{APLICAÇÃO DO MÉTODO SMARTES NA SELEÇÃO DE FORNECEDOR MATÉRIA PRIMA DE UMA EMPRESA DO SETOR AVÍCOLA}

A aplicação numérica do método proposto foi realizada com um profissional do 
departamento de compras empresa A do segmento de carne de frango localizado no estado de Mato Grosso. Sendo o departamento de compras responsavel pelas compras e seleção de fornecedores de Matéria Prima (soja/milho) para a empresa.

A empresa realiza a homologação dos fornecedores por meio de analise documental, assim os fornecedores analisados já se encotram devidamente cadastrados, e portanto, já haviam sido aprovados quanto aos critérios qualificadores, o decisor listou e definiu quatro critérios ganhadores de pedidos considerados os mais relevantes no processo de seleção dos fornecedores de matéria prima (soja/milho), são eles:

- Qualidade - Envolve aspectos relacionados com a qualidade do produto requisitado da melhor forma possível. As informações e documentações fornecidas a respeito da empresa são importantes para avaliar esse critério.

- Prazo de entrega - Consiste em uma das maiores preocupação da empresa, pois existe no estado um gargalo que consiste na logistica e infraestrutura. Sendo é o principal fator que dificulta a parceria entre 0 contratante e o contratado.
- Preço - Nesse critério a empresa avalia o fornecedor na sua capacidade de oferecer preços competitivos, não significando necessariamente o menor preço.

- Prestação de Serviço Pós-venda - Se o produto tem natureza técnica ou provavelmente necessitará de peças de reposição ou apoio técnico, o fornecedor deve ter um bom serviço de atendimento pós venda.

Os valores de qualidade e conceito da empresa foram determinados subjetivamente, de acordo com a opinião do decisor e sua experiência na área, sendo, portanto, qualitativos. Para isso, utilizou-se uma escala de 1 (equivalente a péssimo) a 5 (equivalente a excelente). Os valores para preço e entrega, foram determinados quantitativamente, baseando-se em informações existentes no banco de dados da empresa.

A Tabela 2 identifica os valores de cada alternativa nos respectivos critérios foi determinado pelo decisor, apresenta as informações de um dos produtos considerado como crítico no processo de seleção de fornecedores, nesse caso a matéria prima (soja/milho).

Tabela 2 - Matriz de Decisão

\begin{tabular}{|c|c|c|c|c|}
\hline \multicolumn{5}{|c|}{} \\
\hline Alternativas & Qualidade & Entrega & Preço & Serviço pós-venda \\
\hline F1 & 3 & 2 meses & $R \$ 18.000,00$ & 4 \\
\hline F2 & 5 & 3 meses & $R \$ 19.000,00$ & 3 \\
\hline F3 & 2 & 4 meses & $R \$ 15.000,00$ & 2 \\
\hline F4 & 3 & 2 meses & $R \$ 17.500,00$ & 5 \\
\hline F5 & 4 & 1 mes & $R \$ 16.000,00$ & 5 \\
\hline F6 & 3 & 3 meses & $R \$ 15.500,00$ & 2 \\
\hline F7 & 4 & 5 meses & $R \$ 15.800,00$ & 3 \\
\hline F8 & 5 & 2 meses & $R \$ 18.500,00$ & 0,0625 \\
\hline Pesos & 0,5208 & 0,2708 & 0,1458 & 5 \\
\hline
\end{tabular}

Fonte: Esta pesquisa (2017)

A Tabela 3 apresenta a matriz de decisão normalizada, no qual os valores normalizados são obtidos no intervalo $0 \leq v^{\prime} j$ (ai) $\leq 1$, onde pode ser interpretado como sendo um percentual do total., nesse procedimento utiliza a divisão pelo soma. E tambem são identificadas as constantes de escalas de cada critério, obtido pelo o procedimento de SMARTERS. 
Tabela 3 - Matriz de Decisão normalizada e a ponderação

\begin{tabular}{|c|c|c|c|c|c|}
\hline \multicolumn{6}{|c|}{ Critérios } \\
\hline Alternativas & Qualidade & Entrega & Preço & Serviço pós-venda & Ponderação \\
\hline $\mathrm{F} 1$ & 0,1034 & 0,0909 & 0,1330 & 0,1429 & 0,10682 \\
\hline F2 & 0,1724 & 0,1364 & 0,1404 & 0,1071 & 0,15389 \\
\hline F3 & 0,0690 & 0,1818 & 0,1109 & 0,0714 & 0,10578 \\
\hline F4 & 0,1034 & 0,0909 & 0,1293 & 0,1786 & 0,10851 \\
\hline F5 & 0,1379 & 0,0455 & 0,1183 & 0,1429 & 0,11031 \\
\hline F6 & 0,1034 & 0,1364 & 0,1146 & 0,1786 & 0,11867 \\
\hline F7 & 0,1379 & 0,2273 & 0,1168 & 0,0714 & 0,15487 \\
\hline F8 & 0,1724 & 0,0909 & 0,1367 & 0,1071 & 0,14104 \\
\hline Pesos & 0,5208 & 0,2708 & 0,1458 & 0,0625 & \\
\hline
\end{tabular}

Fonte: Esta Pesquisa (2017)

Por fim, a Tabela 4 mostra a ranking dos fornecedores de matéria prima (soja/milho).

Portanto, diante desse resultado a alternativa que o decisor deve de fato escolher é o fornecedor (F7), pois é a que possui a melhor utilidade multiatributo.

Tabela 4 - Ranking dos Fornecedores de matéria prima (soja/milho)

\begin{tabular}{|c|c|}
\hline Rank & Ponderação \\
\hline F7 & 0,1549 \\
\hline F2 & 0,1539 \\
\hline F8 & 0,1410 \\
F6 & 0,1187 \\
\hline F5 & 0,1103 \\
\hline F4 & 0,1085 \\
\hline F1 & 0,1068 \\
\hline F3 & 0,1058 \\
\hline
\end{tabular}

\section{CONSIDERAÇÕES FINAIS}

A proposta deste artigo foi apresentar um modelo multicritério para apoiar a seleção de fornecedores de matéria prima de uma empresa do setor avícola. O modelo proposto baseia-se em um modelo de agregação aditivo determinístico considerando quatro fatores fundamentais na seleção de fornecedores. O método SMATER foi utilizado para definir os pesos dos critérios. Este tipo de abordagem é especialmente útil quando o decisor tem dificuldades para estimar os valores precisos dos pesos dos critérios.

Com uma aplicação numérica, foi possível entender o processo de avaliação e seleção de fornecedores de matéria prima (soja/milho), através da aplicação de um método multicritério de apoio à decisão. Sendo, possível selecionar os fornecedores que apresentam maior compromisso com os objetivos do cliente. Além disso, com o estudo realizado, foi possível confirmar que nem 
sempre o preço é o critério de seleção mais importante e que, portanto, a estratégia baseada no menor preço, em muitos casos, é inadequada.

Concluindo, o processo de seleção e avaliação de fornecedores matéria prima (soja/milho), é de extrema importância para que os objetivos da empresa sejam alcançados. A seleção e avaliação de fornecedores precisam ser realizadas de

\section{REFERÊNCIAS}

[1]. AlMEIDA, A.T.: Processo de Decisão nas Organizações: Construindo Modelos de Decisão Multicritério. São Paulo: Editora Atlas (2013)

[2]. BELTON, V.; STEWART, T. J. Multiple Criteria Decision Analysis. Kluwer Academic Publisher, (2002).

[3]. CHEUNG, F.K.T.; KUEN, J.L.F. \& SKITMORE, M. Multi-criteria evaluation model for the selection of architectural consultants. Construction Management and Economics. Vol. 20, n.7, p.569-80,(2002).

[4]. LAMBERT, D.M.; COOPER, M.C.; PAGH, J.D.; Supply Chain Management: implementation issues and research opportunities. The International Journal of Logistics Management. Vol.09, No.2, 1998, pp.1-19.

[5]. LAMBERT, D. M. Supply Chain Management: processes, partnerships, performance. $\quad 3^{\circ}$ ed, Supply Chain maneira correta, pois a qualidade do produto (matéria prima (soja/milho)) interfere de forma direta na qualidade e segurança do produto final. Assim, o método utilizado mostrou-se bastante eficaz na resolução do problema, pois se apresenta de forma simples e metodologicamente estruturada no que concerne ao tratamento multicritério ao problema.

Management Institute, Sarasota, Florida,. 431 p. (2008).

[6]. PESÄMAA, O.; ERIKSSON, P.E. \& HAIR, J.F. Validating a model of cooperative procurement in the construction industry. International Journal of Project Management. doi:10.1016/j.jproman.2008.10.007. 2008)

[7]. ROY B.: Multicriteria Methodology for Decision Aid. Kluwer, Academic Publishers (1996).

[8]. SLACK, N. et al. Administração da produção : São Paulo: Atlas (1999).

[9]. VINCKE P.: Multiciteria decision-aid. JohnWiley \& Sons (1992).

[10]. KEENEY, R. L.; RAIFFA, H.; Decision with Multiple Objectives: Preferences and Value Trade-offs. John wiley \& Sons. (1976).

[11]. WATT, D.J.; KAYIS, B. \& WILLEY, K. Identifying key factors in the evaluation of tenders for projects and services. International Journal of Project Management. Vol. 27, n.3, p.250-260, (2009). 


\section{Bapítulo 4}

\section{A ENERGIA EÓLICA NO BRASIL E NO MUNDO NO CONTEXTO DE FOMENTO À RENOVABILIDADE DE MATRIZES ENERGÉTICAS E DE MITIGAÇÃO DAS MUDANÇAS CLIMÁTICAS}

Rita de Cássia Lopes Moro

Jhonathan Fernandes Torres de Souza

André Felipe Simões

Resumo: A energia eólica é uma fonte energética de baixo carbono em crescimento mundial, e tem sido considerada promissora para substituição de combustíveis fósseis. Entretanto, ainda existem barreiras para o desenvolvimento e ampliação desta fonte, sobretudo no Brasil. Desta forma, este artigo tem por objetivo apresentar o cenário energético e o estado-da-arte das tecnologias na área de energia eólica, suas características e condicionantes. A pesquisa tem caráter exploratório e se apoia na revisão da literatura. Foi possível identificar que a energia eólica possui grande relevância no setor mundial e brasileiro, se comportando estrategicamente como uma forma de diversificação da matriz, aumentando a segurança energética e contribuindo para a redução dos GEE e na meta determinada pelo Brasil no Acordo de París. Todavia, existem entraves por falta de incentivos políticos e de investimento em P\&D, que faz com que o Brasil dependa de tecnologia externa, prejudicando assim a ampliação desta fonte e a eficiência de redução das emissões de GEE.

Palavras-chave: Energia Eólica; Mudança Climática; Ciclo de Vida; Matriz Elétrica. 


\section{INTRODUÇÃO}

A produção de energia é diretamente proporcional à atividade industrial de um país, e por isso, influi decisivamente no cálculo do seu Produto Interno Bruto (PIB), um indicador que reflete a riqueza de uma nação. Por sua vez, o aumento do PIB depende de uma matriz energética robusta, e se possível diversificada e independente do provimento de matéria-prima internacional. Portanto, é estratégico para cada nação fazer uso máximo do seu potencial energético e desenvolver tecnologias próprias (SILVA, 2009; YERGIN, 2014).

Os combustíveis fósseis ainda são os mais utilizados dentro da matriz energética global, cujo uso resulta em grande emissão de gases de efeito estufa (GEE), e também apresentam alta volatilidade de preço, que é um fator estratégico para cada país (YERGIN, 2014).

O quinto relatório de avaliação do Painel Internacional sobre Mudanças Climáticas (IPCC - International Panel on Climate Change) afirma que as atuais emissões antrópicas de GEE são as maiores da história, com o aquecimento inequívoco da temperatura média global e diversas mudanças climáticas sem precedentes foram observadas desde a década de 1950 (IPCC, 2014). Ainda segundo o relatório, é imprescindível, caso desejemos evitar que a temperatura global aumente acima de $2^{\circ} \mathrm{C}$ em relação ao período pré-industrial, a adoção de medidas urgentes para a redução das emissões de GEE.

Por isso a utilização de fontes renováveis, como a eólica, se constitui de uma medida de baixo carbono para diversificação da matriz energética, contribuindo para a mitigação das mudanças climáticas e ainda para uma possível estabilização dos custos da geração de eletricidade a longo prazo, possibilitando um desenvolvimento sustentável (AQUILA et al. 2017, IEA, 2017).
A energia está em grande expansão, ganhando importância no cenário político global (IRENA, 2016). Dados da International Energy Agency (IEA, 2017) prevê que a energia eólica pode gerar até $18 \%$ da eletricidade mundial até 2050, aumentando de oito a dez vezes a capacidade instalada atualmente, o que evitará emissões da ordem de 4,8 giga toneladas (Gt) de dióxido de carbono $\left(\mathrm{CO}_{2}\right)$ por ano.

Outro fator que merece grande atenção é o fato da energia eólica ser uma forma democrática e descentralizada de produção de energia elétrica. Segundo Farrell (2011), este novo paradigma é chamado de geração distribuída e está mudando as formas de geração de energia. Esta contribui também para o desenvolvimento de localidades, muitas vezes remotas. No entanto, pode encontrar barreiras em países onde há forte centralização e impasses na interligação.

Em um cenário mundial, a evolução dos líderes em produção de energia elétrica compreende tanto países em desenvolvimento quanto os desenvolvidos, o que pode inferir na democratização dessa fonte de energia. Entre os 10 maiores produtores eólicos do mundo em 2016, pelo relatório do Global Wind Energy Council (GWEC, 2017), há a presença de dois países em desenvolvimento: a China, liderando com a maior capacidade instalada acumulada de 168.732 mega watts (MW), e a Índia em quarto lugar, com $28.700 \mathrm{MW}$. Entre os países desenvolvidos, os EUA lideram com 82.184 MW, sucedido pela Alemanha com 50.018 MW, que mantém sua posição número um na Europa. O Brasil também é destaque nesse seleto grupo, ficando na nona posição em capacidade instalada acumulada em 10.740 MW, em quinto lugar no crescimento da capacidade de 2016, com instalação nesse último ano de 2.014 MW (GWEC, 2017), como mostra a Figura 1. 
Figura 1- Os dez maiores países em capacidade instaladada e acumulada.

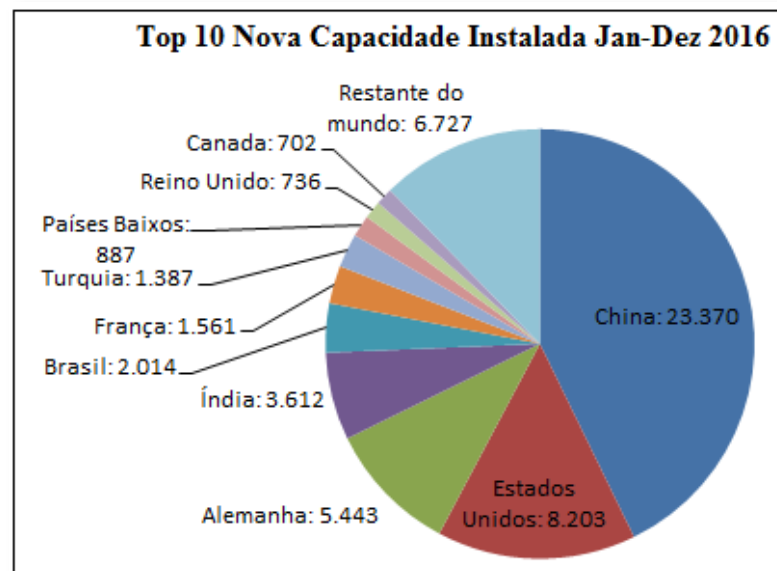

Total: $\mathbf{5 4 . 6 4 2} \mathrm{MW}$

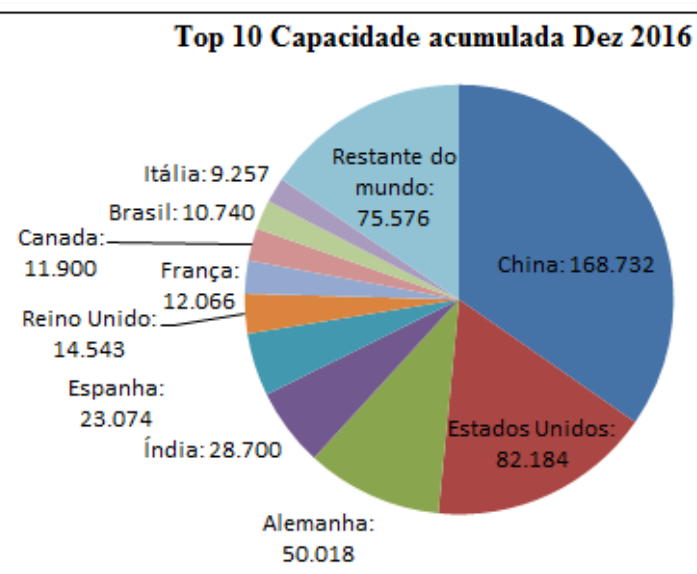

Total: $486.790 \mathrm{MW}$

Fonte: Elaborado pelos autores com base em GWEC (2017, p.16)

Um dos estimuladores desse crescimento da energia eólica na matriz elétrica brasileira foi a meta estabelecida em sua contribuição nacional voluntária (NDC - Nationally Determined Contribution) em 2015, no âmbito do Acordo de París, que colocou o objetivo de reduzir em 37\% das emissões de GEE até 2025 e 43\% até 2030, em relação ao ano base de 2005. Em relação a matriz energética, aumentar para 33\% o uso de fontes renováveis, além da energia hídrica, na matriz total de energia até 2030, acrescentando a parcela de energias renováveis (além da energia hídrica) no fornecimento de energia elétrica para ao menos 23\% até 2030, com a participação de eólica, biomassa e solar (UNFCCC, 2015; BRASIL, 2015).

Esses países se tornaram líderes mundiais por investimentos em criação de mercado, desenvolvimento tecnológico e industrial, criados através de políticas governamentais destinadas especificamente ao setor eólico (CAMILLO, 2013). Dentre esses, o desenvolvimento tecnológico se destaca como grande potencializador para o aumento da contribuição da energia eólica, além de possibilitar o domínio sobre Pesquisa e Desenvolvimento (P\&D), se tornando estratégico ao país investir em tecnologia.

Dessa forma, o presente artigo tem como objetivo apresentar o estado-da-arte da energia eólica, analisando sob a perspectiva das mudanças climáticas, elucidando a presença da cadeia produtiva local e seus desafios, de forma exploratória, buscando também apresentar a presença desse tipo de recurso energético nacionalmente e mundialmente. Para tanto, utilizou-se como procedimentos metodológicos pesquisa documental, revisão bibliográfica e análise descritivas dos dados obtidos, resultando em um estudo exploratório, o qual permite que o pesquisador maximize seu conhecimento em relação ao problema de pesquisa (GIL, 2002).

\section{ENERGIA EÓLICA NA MATRIZ ELÉTRICA BRASILEIRA}

No Brasil, a matriz elétrica tem como maior fonte de geração as usinas hidrelétricas, isso se deve em função das características que o país possui, rico em recursos hídricos, topografia favorável a quedas d'água, como também em relação ao menor custo de produção em comparação com as outras fontes (SANTIAGO; CAMPELLO DE SOUZA; DE CARVALHO BEZERRA, 2014).

Segundo os dados da ABEEólica (2017), a matriz elétrica brasileira é composta basicamente por hidrelétricas que representam por: $61,2 \%$ de grande porte e $3,3 \%$ de pequenas centrais hidrelétricas (PCHs). Mas essa grande dependência pode ter impacto negativo no fornecimento de energia elétrica com a mudança brusca do clima, como ocorreu no período de seca nos anos 2001 e 2002, que resultou em crises energéticas.

Ao passo que gera prejuízos econômicos, estas crises também privilegiam o uso da 
eólica, como mostra a Figura 2, a qual apresenta outro momento de crise hídrica, ocorrido mais recentemente entre nos anos 2011 e 2013 (AQUILA, et al., 2017). Nessa perspectiva o quinto relatório do IPCC, o 5AR (IPCC, 2014) sobre as mudanças climáticas, coteja 4 possíveis cenários associáveis aos efeitos das mudanças climáticas até o ano de 2100. Destes, resumidamente, pode-se considerar que 2 são considerados mais otimistas e 2 mais pessimistas, denominados, respectivamente, de A1, B1, A2 e B2. Neste contexto, trabalho capitaneado por Schaeffer et al (2008) projetou o comportamento da velocidade média e a frequência dos ventos para os anos 2071, 2080, 2090 e 2100 considerando apenas os cenários mais pessimistas (A2 e B2). Observou-se, no contexto dos resultados deste trabalho e sob a égide dos supracitados 4 cenários, que, no caso do Cenário $A 2$, a velocidade média dos ventos é maior para as regiões Nordeste, Sul e Sudeste do Brasil, este prevê o aumento da temperatura, o que provavelmente implicará na diminuição da precipitação e consequente menos disponibilidade hídrica. Em contrapartida, neste mesmo cenário, há um aumento da velocidade média dos ventos.

Dessa forma, frente ao cenário de crise hídrica, a busca pela diversificação da matriz energética deve ser constante e com planejamentos bem definidos, e a energia eólica se mostra como boa alternativa à hidrelétrica (ABEEOLICA, 2017).

Figura 2- Fornecimento total de eletricidade em 2011 (a) e 2013 (b).

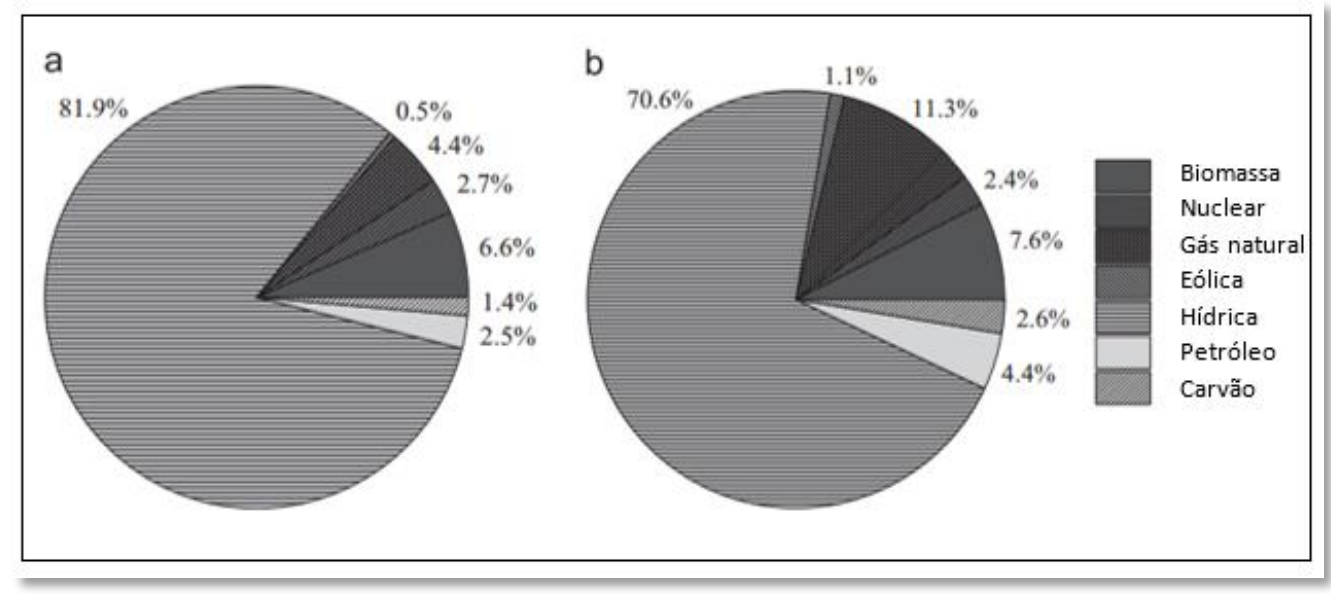

Fonte: Correa, Marchi Neto e Silva (2016).

A capacidade instalada de energia eólica no ano de 2016 representou $7,1 \%$ da matriz elétrica (ABEEOLICA, 2017), tendo como exemplo de sucesso os parques eólicos de Osório-RS, que juntos formam o segundo maior complexo gerador de energia a partir dos ventos da América Latina. Com diferentes tipos de aerogeradores, o parque está em franca expansão, porém tem como limitante atual sua subestação (ENERFIN, 2017).
O crescimento e investimento nesse tipo de energia tem impulsionado o cenário brasileiro com um forte crescimento nos últimos anos, como mostra o gráfico ilustrado na Figura 3, , e ainda porque segundo GWEC (2017), o Brasil tem alguns dos melhores recursos eólicos do mundo. 
Figura 3 - Capacidade instalada no Brasil.

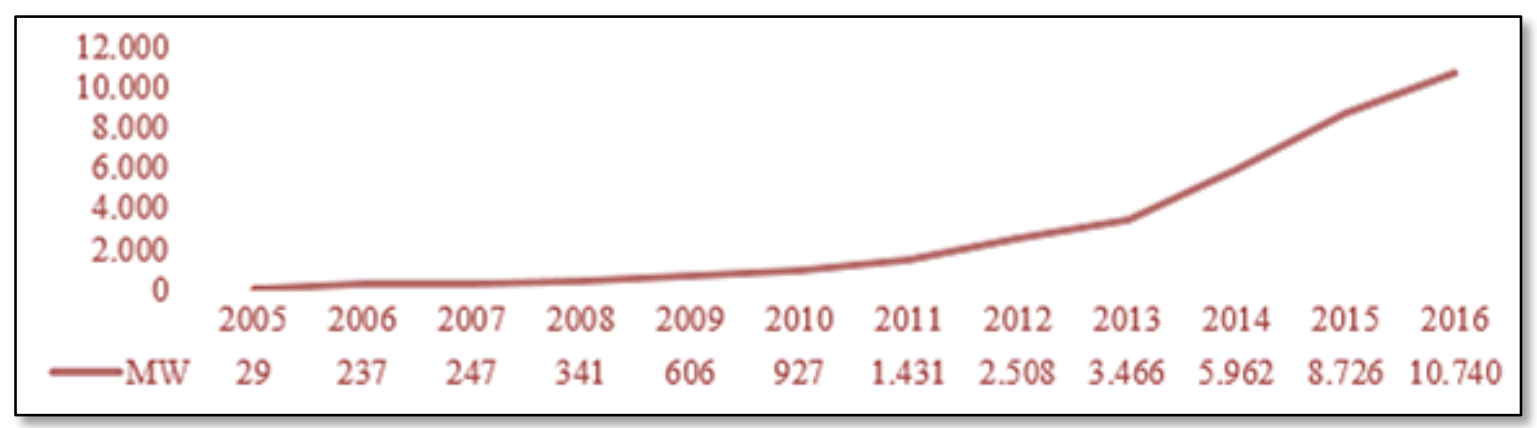

Fonte: GWEC (2017, p.31).

Segundo a perspectiva do GWEC (2017), o Brasil continuará sendo o mercado onshore mais promissor para energia eólica na região até 2020, apesar das recentes preocupações com os próximos leilões em decorrência do cancelamento dos leilões reserva em 2016, em função das crises políticas e econômicas.

\section{ENERGIA EÓLICA: TECNOLOGIA}

O processo de produção de energia eólica tem início na transformação da energia solar em energia cinética dos ventos, devido ao aquecimento desigual da Terra e geração de áreas de alta e baixa pressão atmosférica. A energia cinética "por sua vez, é transformada em energia mecânica pelo rotor do aerogerador e, posteriormente, em energia elétrica, no gerador" (VEIGA; OLIVEIRA; PEREIRA, 2012, p.95).

Os tipos de captação do vento se diferenciam em função da tecnologia empregada, sendo a captação na terra (onshore) a mais utilizada mundialmente, no mar (offshore), e mais recentemente, começou a ser introduzida a minigeração eólica, dentro de cidades (VEIGA; OLIVEIRA; PEREIRA, 2012; EPE, 2014).
A implantação offshore em larga escala começou, mais lentamente do que o esperado inicialmente, principalmente na Europa. Até o final de 2012, foram instalados 5,4 giga watts (GW), acima de 1,5 GW em 2008, principalmente no Reino Unido (3 GW) e Dinamarca (1 GW), com grandes usinas eólicas offshore instaladas na Bélgica, China, Alemanha, Holanda e Suécia (IEA, 2017). No entanto, o custo de investimento nessa tecnologia pode ser até três vezes maior que a onshore (IEA, 2013).

As turbinas onshore tem um tempo de vida médio de 20 anos, sendo necessário ser substituída depois, para não comprometer a eficiência de geração de energia elétrica. Assim, essa repotenciação, ou seja, a substituição de turbinas eólicas "antigas" por equipamentos mais modernos e produtivos está em ascensão, o que permite gerar mais energia na mesma área com modelos mais avançados em tecnologia. Uma turbina eólica de $2 \mathrm{MW}$ com um rotor de 80 metros $(\mathrm{m})$ de diâmetro agora gera quatro a seis vezes mais eletricidade do que um rotor de 500 quilowatts (kW) de 40 m de diâmetro construído em 1995 
Figura 4). Elas ainda podem gerar um novo nicho de negócio. Após o final do ciclo de vida para a geração de energia em larga escala, esses aerogeradores podem ser revendidos a produtores independentes, como exemplo, para a geração de energia de subsistência (ENERFIN, 2017). 
Figura 4- Crescimento no tamanho das turbinas eólicas desde 1980 e projeções.

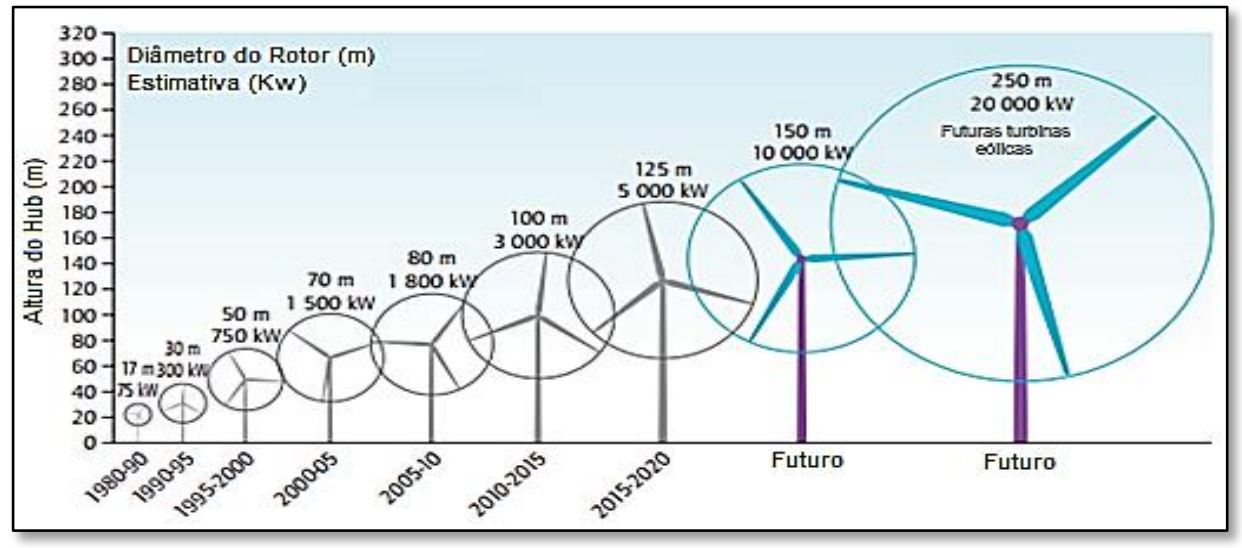

Fonte: IEA (2013).

Em relação aos avanços, atualmente, as turbinas possuem diâmetros de rotor variando de $50 \mathrm{~m}$ a $125 \mathrm{~m}$, geradores de 1,5 MW a 3,5 MW e alturas de $90 \mathrm{~m}$ a $150 \mathrm{~m}$ (IEA, 2017). Dessa forma, o domínio da tecnologia se torna importante para o aumento da produção, e nesse sentido houve uma reorientação do mercado. Atualmente, das 10 maiores empresas produtoras mundial de aerogeradores, as chinesas correspondem a 50\% (LAGE; PROCESSI, 2013). Esse especial crescimento da China, tanto ao nível de desenvolvimento da tecnologia quanto à capacidade instalada, se deve aos incentivos do governo, além da sua própria necessidade de diversificação de sua matriz energética (IEA, 2014). Para o funcionamento dos aerogeradores, há controladores de velocidade atuando como um dispositivo de segurança do sistema. Após atingir a velocidade mínima (cut-in) o aerogerador começa o processo de produção de energia, iniciando a conversão de energia cinética em mecânica e depois em elétrica. E ao ultrapassar a velocidade máxima (cut-out), o aerogerador é travado pelos mecanismos de frenagem para que não ocorrer danos a estrutura (VEIGA, 2012; EPE, 2014).

A geração eólica pode ser interligada na rede ou não. O sistema sem interligação (off-grid) é utilizado para suprir a demanda individual sem o compartilhamento da energia remanescente na rede, já no sistema interligado (on-grid) existe compartilhamento, que no Brasil, é realizado pelo Sistema Interligado Nacional (SIN). Este distribui a energia hidro-termo-eólico de grande porte por uma malha de transmissão que congrega estados do Sul, Sudeste, Centro-Oeste, Nordeste e parte do Norte do Brasil. As operações e controles são centralizados pelo Operador Nacional do Sistema (ONS), responsável por equalizar a energia de modo que evite o mau funcionamento da rede (SILVA; VIEIRA, 2016).

A turbina eólica está estruturada em três macro componentes: a torre, o rotor de pás e a nacele, podendo ser de eixo horizontal (HAWT - Horizontal Axis Wind Turbine), que é o tipo mais usual, ou com eixo vertical (VAWT - Vertical Axis Wind Turbine) como mostra a

A VAWT, mesmo não sendo a mais comum, tem experimentado um crescimento maior nos últimos anos, especialmente porque possui a lâmina reta e vantagens como baixo custo, fácil instalação e manutenção (ISLAM; MEKHILEF; SAIDUR, 2013). As principais diferenças entre estas duas tecnologias estão dispostas no Quadro 1. 
Figura 5- Tipos de eixos da turbina (a) horizontal e o (b) vertical.

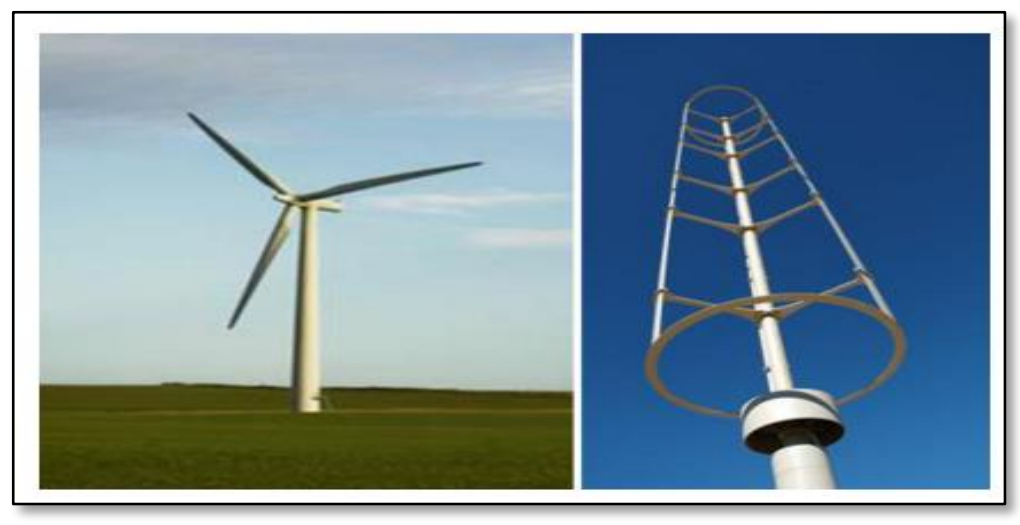

Fonte: Islam; Mekhilef; Saidur (2013)

Conforme Dutra e Szklo (2008), em 2001, o CEPEL contratou empresas para analisar o potencial de eólico brasileiro e identificar qual a melhor opção de turbina a ser utilizada. Este relatório concluiu que a turbina da Enercon E70 (2,3 MW e altura de 100m) seria a mais recomendável e os melhores locais em termos de velocidade do vento é a região nordeste $(7,5$ a 8,0 metros por segundo $(\mathrm{m} / \mathrm{s}))$, seguida pelas regiões sul e sudeste $(7,0$ e $7,5 \mathrm{~m} / \mathrm{s})$. Entretanto, atualmente já se utiliza outros modelos como Enercon 82 e 92 (ENERFIN, 2017).

Os custos ao longo dos anos foram diminuindo, tanto em função da aprendizagem quanto em função do avanço tecnológico. Segundo dados do IEA (2017), estima-se que os custos de investimento em turbinas eólicas, entre os anos 2014-2015, diminuíram 3-5\% para cerca de US\$1.050/kW para turbinas de alta velocidade e US\$175/kW para turbinas de baixa a média velocidade. Caso se adote como fonte elétrica principal, a energia eólica, por possuir natureza intermitente, necessita de outra fonte energética interligada para suprir a carência em condições desfavoráveis de geração, quando não há ventos (JONG; KIPERSTOK; TORRES, 2015; YERGIN, 2014), sendo este um dos motivos de seu encarecimento.

Quadro 1 - Diferenças entre as tecnologias HAWT e VAWT

\begin{tabular}{|c|c|c|}
\hline Diferenças & HAWT & VAWT \\
\hline Tipo de eixo & Horizontal ou paralelo com o chão & Vertical ou perpendicular ao solo \\
\hline $\begin{array}{l}\text { Produção e } \\
\text { condições } \\
\text { do vento }\end{array}$ & $\begin{array}{c}\text { Menor produção e não é adequada } \\
\text { para gerar eletricidade com } \\
\text { velocidade do vento inferior a } 6 \mathrm{~m} / \mathrm{s} \text { e } \\
\text { velocidade superior a } 25 \mathrm{~m} / \mathrm{s}\end{array}$ & $\begin{array}{c}\text { Produz até } 50 \% \text { mais eletricidade numa base } \\
\text { anual, gerando eletricidade com ventos de até } 2 \\
\text { m/s e continua a gerar energia em velocidade do } \\
\text { vento de até } 65 \mathrm{~m} / \mathrm{s} \text {, e com base no modelo e } \\
\text { produção } 10 \text { vezes maior em uma mesma área. }\end{array}$ \\
\hline Aplicação & $\begin{array}{l}\text { Mais apropriado em produção em } \\
\text { parques eólicos e fazendas. }\end{array}$ & $\begin{array}{l}\text { É apropriado para projetos grandes e pequenos, } \\
\text { com possibilidade de aplicação residencial }\end{array}$ \\
\hline $\begin{array}{l}\text { Peso da } \\
\text { Turbina }\end{array}$ & Pesado & Mais leve comparativamente \\
\hline $\begin{array}{l}\text { Direção do } \\
\text { vento }\end{array}$ & Unidirecional & Multidirecional \\
\hline $\begin{array}{l}\text { Condições } \\
\text { climáticas }\end{array}$ & $\begin{array}{l}\text { Eles não podem suportar condições } \\
\text { climáticas extremas como geada, } \\
\text { chuva de granizo, neve pesada e } \\
\text { ventos fortes acima de } 50 \mathrm{~m} / \mathrm{s}\end{array}$ & $\begin{array}{c}\text { Boa resistência a condições climáticas extremas } \\
\text { como neve, granizo, areia, sal, umidade e } \\
\text { condições de vento acima de } 60 \mathrm{~m} / \mathrm{s} \text {. }\end{array}$ \\
\hline Partida & A maioria é auto partida & $\begin{array}{c}\text { Baixo torque de partida e pode exigir energia para } \\
\text { começar a girar }\end{array}$ \\
\hline $\begin{array}{l}\text { Transporte e } \\
\text { instalação }\end{array}$ & $\begin{array}{l}\text { Difícil de transportar e instalar e ocupa } \\
\text { maior espaço em função do tamanho } \\
\text { da hélice e da disposição necessária }\end{array}$ & $\begin{array}{l}\text { Menor custo de construção e transporte e menor } \\
\text { espaço de área e espaçamento }\end{array}$ \\
\hline Tecnologia & Mais difundida & Menos difundida \\
\hline
\end{tabular}

Fonte: elaborado pelos autores com base em Islam, Mekhilef e Saidur (2013) 


\section{CADEIA DE VALOR DA INDÚSTRIA EÓLICA BRASILEIRA}

O Brasil conta com 449 usinas, com capacidade instalada de 11,17 GW, o que contribui para a não emissão de aproximadamente $19.300 \quad \mathrm{tCO}_{2} / \mathrm{ano}, \mathrm{e}$ emprega 160 mil pessoas (GWEC, 2017; ABEEOLICA, 2017). Até 2007, havia apenas uma empresa fabricante de aerogeradores com fábrica em operação no país, tendo sido ampliada ao longo dos anos. No entanto, a cadeia produtiva nacional ainda não detém a tecnologia, esta continua sendo dominada pelas empresas estrangeiras, e apresentam gargalos na produção. Alguns desses gargalos são importantes componentes da torre, pás, nacele e cubo. Esses itens impactam na competitividade dos projetos, nos leilões de contratação e/ou na sua operação (ABDI, 2014).

As principais montadoras de aerogeradores no território nacional são: Impsa, GE, Wobben/Enercon, Gamesa, Suzlon, Alstom, Vestas, Siemens e Fuhrlander (EPE, 2014). Esse aumento do número de empresas é o resultado de um conjunto de políticas públicas voltadas para esse setor, buscando o fortalecimento da cadeia de suprimento local como também atrair investidores (GWEC, 2017).
O Programa de Incentivo às Fontes Alternativas de Energia Elétrica (Proinfa), criado pela LEI № 10.438/2002, foi o principal impulsionador para o uso de tecnologias renováveis para a geração de eletricidade. Conta com incentivos e subsídios em perspectivas de curto e longo prazo, bem como a interconexão da energia na rede pelo SIN. Em conjunto a esse programa, o Banco Nacional de Desenvolvimento Econômico Social (BNDES) incentivou com redução da taxa de juros, ampliação da concessão de crédito para financiamento de parques eólicos, entre outros, com a especificação de que tenham empresas locais produzindo a tecnologia, ou seja, os aerogeradores e seus componentes (KISSEL; KRAUTER, 2006; JUÁREZ et al., 2014; IRENA, 2016).

Esse comportamento segundo O GWEC (2017), se deve tanto por se tratar de uma diversificação da matriz elétrica, aproveitando o recurso natural abundante, como também estrategicamente, visando manter a contratação de um volume de 2 GW de energia eólica por ano tanto para manter ativa a cadeia produtiva local quanto para alcançar os objetivos climáticos que o Brasil se comprometeu com a assinatura do Acordo de Paris. A Figura 6, apresenta a cadeia de valor de bens e serviços para produção da energia eólica.

Figura 6 - Cadeia de Valor de bens e serviços.

\begin{tabular}{|c|c|c|c|c|c|}
\hline Materiais & Componentes & Manulatura & $\begin{array}{l}\text { Logistica e } \\
\text { operaçōes }\end{array}$ & $\begin{array}{l}\text { Produtores } \\
\text { de Energia }\end{array}$ & Uso Final \\
\hline $\begin{array}{l}\text { Aço laminado } \\
\text { Concreto } \\
\text { Aço forjado } \\
\text { Alumínio } \\
\text { Ferro Fundido } \\
\text { GFRP } \\
\text { Fibra de vidro } \\
\text { Fibra de carbono } \\
\text { Resina } \\
\text { Madeira balsa } \\
\text { Adesivos } \\
\text { Imäs permanentes } \\
\text { Aço Silício } \\
\text { Cobre }\end{array}$ & $\begin{array}{l}\text { Torre } \\
\text { Pá } \\
\text { Cubo } \\
\text { Nacele }\end{array}$ & $\begin{array}{l}\text { OEMs- } \\
\text { Montadoras }\end{array}$ & $\begin{array}{l}\text { Promotores } \\
\text { de projeto } \\
\text { Consultores } \\
\text { Gerenciadores } \\
\text { de Projeto } \\
\text { Transporte, } \\
\text { movimentação } \\
\text { montagem } \\
\text { Operação \& } \\
\text { Montagem }\end{array}$ & $\begin{array}{l}\text { Empresas } \\
\text { do setor } \\
\text { elétrico } \\
\text { Bancos } \\
\text { Eletro- } \\
\text { intensivos } \\
\text { Construtoras } \\
\text { Fundos de } \\
\text { Pensão }\end{array}$ & $\begin{array}{l}\text { Empresas } \\
\text { privadas } \\
\text { Empresas } \\
\text { públicas } \\
\text { municipais } \\
\text { Empresas } \\
\text { públicas } \\
\text { estaduais } \\
\text { Empresas } \\
\text { públicas } \\
\text { federais }\end{array}$ \\
\hline$P \& D$ & $\begin{array}{l}\text { Universida } \\
\text { laboratório }\end{array}$ & $\begin{array}{l}\text { laboratóric } \\
\text { s e empres }\end{array}$ & $\begin{array}{l}\text { lações e ins } \\
\text { viduais }\end{array}$ & pesquisa, & \\
\hline
\end{tabular}

Fonte: ABDI (2014)

A cadeia de valor mostra que há empresa produtoras, montadoras e de serviços subsidiários, no entanto, o P\&D ainda é o setor de menor expressão. Segundo a 
Agêngia Brasilera de Desenvolvimento Industrial (ABDI, 2014), os valores investidos em $P \& D$, no Brasil, em energia eólica, são baixos quando comparados às reais necessidades e ao desenvolvimento que essa fonte vem apresentando no país. No entanto, existem grupos de pesquisa em distintas instituições, espalhadas por todo o país, o que permite inferir que há interesse da academia nas diferentes temáticas do assunto, mas estes grupos são compostos por um pequeno número de participantes, sinalizando a carência de pesquisadores existente neste setor.

Essa defasagem tecnológica ainda é um dos obstáculos para o avanço da energia eólica no cenário nacional, dando espaço para empresas estrangeiras se instalarem no país. De acordo com De Oliveira Neto e Lima (2016, p. 319), depois dessas empresas "terem desenvolvido os mercados nos seus países de origem, esses fabricantes agora investem estrategicamente para além de suas fronteiras para ganhar mercado em outros países, pois apresentam maturação e domínio da tecnologia", dessa forma, o investimento em tecnologia nacional torna-se estratégico para que o Brasil avance, gere empregos e reforce a participação da energia eólica dentro da matriz energética, o que permitirá desenvolver de forma sustentável e sem depender de empresas estrangeiras.

\section{CONSIDERAÇÕES FINAIS}

A energia eólica está em grande expansão a nível mundial e nacional, e vem sendo incorporada com grande presença na composição da matriz elétrica de países desenvolvidos e em desenvolvimento. Esta tem sido considerada por muitos uma forma democrática e descentralizada de geração de eletricidade, o que traz benefícios locais e diminui a dependência de fontes fósseis de energia, reduzindo os impactos ambientais como a poluição por substâncias nocivas à saúde e a geração de GEE.

Em um cenário de mudanças climáticas tende a implicar, no caso do Brasil, numa maior possibilidade de emprego da energia eólica para fins de geração de energia elétrica configurando, assim, numa potencial externalidade positiva (de viés econômico e social, em particular) positiva decorrente das mudanças climáticas.

A expansão da participação da energia eólica, dentro da gama de fontes renováveis para geração de eletricidade, está em consonância com a NDC brasileira, portanto, se constituindo em uma das chaves para que o país atinja suas metas para 2025 e 2030.

Em âmbito mundial, as tecnologias e produção de energia eólica estão em grande avanço, os países dominantes compreendem tanto os desenvolvidos como Alemanha, EUA, Espanha quanto os em desenvolvimento como a China, Índia e Brasil.

O Brasil também está em grande expansão, encontrando-se em nono lugar em capacidade instalada e ainda com promissores recursos eólicos. No entanto, os avanços em P\&D ainda são irrisórios, se constituindo uma das mais importantes barreiras a ser superada, que segundo Veiga (2010) a ausência de inovação tecnológica e conhecimento cientifico, impede grandes avanços dentro de um cenário competitivo. A dependência do país por tecnologia externa se torna um fator limitante para a sua expansão. Aliás, o fator da importação de tecnologia é determinante no balanço de emissões de GEE. Uma vez que a maior parte da emissão provém da fase de produção das turbinas, é provável que não haja compensação se estas forem produzidas em países com alto fator de emissão de geração elétrica, como a China, para reduzir as emissões no Brasil, que já possui uma matriz elétrica relativamente limpa. Daí a importância da análise do ciclo de vida na avaliação da eficiência destas tecnologias de baixo carbono, onde está situada a energia eólica, o que poderá ser analisado por pesquisas futuras.

Esse artigo se limitou em concentrar no estado-da-arte em partes das variáveis importantes para a constituição de um conhecimento mais aprofundado, se fazendo necessário mais pesquisas referentes aos gargalos da cadeia produtiva, quais serão os impactos da não realização do leilão de energia reserva em 2016, em termos de emissões de GEE, se houver uma demanda maior de energia em função da expansão da economia, e se isso impactará no valor da energia eólica nos próximos leilões. 


\section{REFERÊNCIAS}

[1]. ABDI- Agência Brasileira de Desenvolvimento Industrial. MAPEAMENTO DA CADEIA PRODUTIVA DA INDÚSTRIA EÓLICA NO BRASIL. 2014. Disponível em: <http://www.abdi.com.br/Estudo_Backup/Mapeame nto\%20da\%20Cadeia\%20Produtiva\%20da\%20Ind \%C3\%BAstria\%20E\%C3\%B3lica\%20no\%20Brasil. pdf>, acesso em: jun 2017.

[2]. ABEEÓLICA - ASSOCIAÇÃO BRASILEIRA DE ENERGIA EÓLICA. Boletim anual de geração, $2017 . \quad$ Disponível em: <http://www.abeeolica.org.br/wpcontent/uploads/2017/05/424_Boletim_Anual_de_G eracao_Eolica_2016_Alta.pdf>. Acesso em: 10 jun. 2017.

[3]. AQUILA, G., PAMPLONA, E.O., QUEIROZ, A.R., ROTELA Jr, P., FONSECA, M.N., (2017). An Overview of Incentive Policies for the Expansion of Renewable Energy Generation in Electricity Power Systems and the Brazilian Experience, Renewable and Sustainable Energy Reviews, 70: 1090-1098 (IF 6.798).

[4]. BRASIL. Federative Republic of Brazil INDC. Submetido à UNFCCC em 28 de setembro de 2015. Disponível em: $<$ http://www4.unfccc.int/Submissions/INDC/Publish ed\%20Documents/Brazil/1/BRAZIL\%20iNDC\%20en glish\%20FINAL.pdf> Acesso em: abr. 2017.

[5]. CAMILLO, E. V. As políticas de inovação da indústria de energia eólica: uma análise do caso brasileiro com base no estudo de experiências internacionais. 192 f. Tese (Doutorado em Política Científica e Tecnológica). Instituto de Geociências da UNICAMP, Universidade Estadual de Campinas, Campinas, 2013.

[6]. CORREA, R. S; MARCHI NETO, I.; SILVA, S. Electricity supply security and the future role of renewable energy sources in Brazil. Renewable \& Sustainable Energy Reviews, v. 59, p. 328-341, 2016.

[7]. DE OLIVEIRA NETO, Calisto Rocha; LIMA, Elaine Carvalho. Novas perspectivas de desenvolvimento: uma análise da energia eólica no Brasil. Revista Grifos, v. 25, n. 41, p. 304-324, 2017.

[8]. DUTRA, R.M., SZKLO A.S. Assessing longterm Incentive Programs for Implementing wind power in Brazil using Gis Rule-based methods. Renewable Energy, 33 (2008), pp. 65-76.

[9]. ENERFIN. Complexo eólico de Osório. Disponível em: <http://complexoeolicodeosorio.com.br/br/coplexo_ eolico_de_osorio.php>, acesso em: mai 2017.

[10]. EPE - Empresa de Pesquisa Energética. Plano Decenal de Expansão de Energia 2023. Ministério de Minas e Energia. Empresa de Pesquisa Energética (EPE). Brasília: MME/EPE, 2014.
FARREL,John. Democratizing the Electricity System. A Vision for the 21 st Century Grid. The New Rules Project, junho 2011. Disponível em: <http://atcscam.homestead.com/democratizingelectricity-system.pdf>. Acesso em: jun de 2017.

[12]. GIL, A. C. Como elaborar projetos de pesquisa. 4. ed. São Paulo: Atlas, 2002.

[13]. GWEC. Global Wind Report: Annual Market Update. 8th National Renewable Energy Forum Ulaanbaatar, Mongolia 5 May 2017. Disponível http://files.gwec.net/files/GWR2016.pdf, acesso em: jun 2017.

[14]. IEA, International Energy Agency. https://www.iea.org/topics/renewables/subtopics/wi $\mathrm{nd} /(2017)$

[15]. IEA, International Energy Agency. Technology Roadmap. Diponível em: http://www.iea.org/publications/freepublications/pu blication/Wind_2013_Roadmap.pdf acesso em: jun 2017.

[16]. IPCC. Climate Change 2014: Synthesis Report. Contribution of Working Groups I, II and III to the Fifth Assessment Report of thelntergovernmental Panel on Climate Change [Core Writing Team, R.K. Pachauri and L.A. Meyer (eds.)]. Geneva (Suíça): IPCC, 2014. 169 p. Disponível $<$ https://www.ipcc.ch/pdf/assessmentreport/ar5/syr/SYR_AR5_FINAL_full_wcover.pdf> Acesso em: jul. 2017

[17]. IRENA - International Renewable Energy Agency. REMap 2030: RENEWABLE ENERGY AUCTIONS ANALYSING 2016. Disponível em: $<$ http://www.irena.org/DocumentDownloads/Publica tions/IRENA_Renewable_Energy_Auctions_2017.pd $\mathrm{f}>$. Acesso em: junho 2017.

[18]. ISLAM, M.R., MEKHILEF, S; SAIDUR, R. Progress and recent trends of wind energy technology. Renewable Sustainable Energy Rev, 21 (2013), pp. 456-468

[19]. JONG, P; KIPERSTOK, A.; TORRES, E. A. Economic and environmental analysis of electricity generation technologies in Brazil. Renew Sustain Energy Rev 2015; 52:725-39.

[20]. SANTIAGO, K. T. M.; CAMPELLO DE SOUZA, F. M. ; DE CARVALHO BEZERRA, D. A strong argument for using non-commodities to generate electricity. Energy Economics JCR, v. 43, p. 34-40, 2014.

[21]. SCHAEFFER, R. et al. Mudanças Climáticas e Segurança energética no Brasil, jun. 2008.

Disponível em: http://mudancasclimaticas.cptec.inpe.br/ rmcli ma/pdfs/destaques/CLIMA_E_SEGURANCA-

EnERGETICA_FINAL.pdf. Acesso em: junho de 2017. 
[22]. SILVA, Darly Henriques da. Protocolos de Montreal e Kyoto: pontos em comum e diferenças fundamentais. Rev. bras. polít. int., Brasília, v. 52, n. 2, p. 155-172, Dec. 2009.

[23]. VEIGA, José Eli da; OLIVEIRA, A.; PEREIRA, S. ENERGIA EÓLICA. 1. ed. São Paulo: Senac São Paulo, 2012. 213p.
[24]. VEIGA, J. Eli. A emergência socioambiental. 2. ed. São Paulo: Senac, 2010. 138 p.

[25]. YERGIN, Daniel. A busca: energia, segurança e reconstrução do mundo moderno. Trad. Ana Beatriz Rodrigues. 1 ed. Rio de Janeiro: Intrínseca. 2014 


\section{Bapítulo 5}

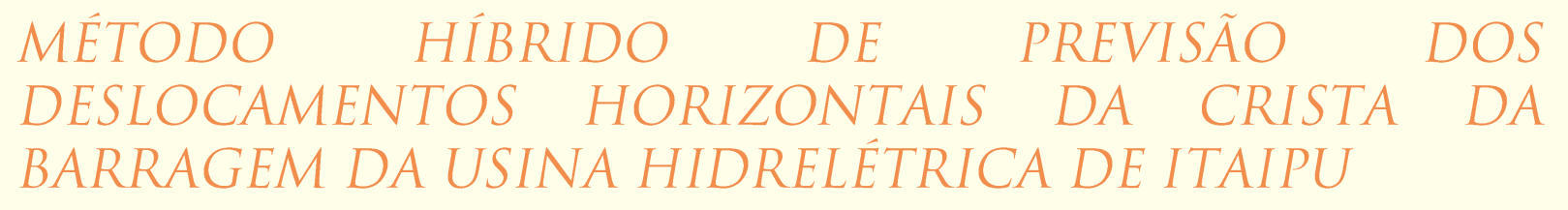

Samuel Bellido Rodrigues

Tásia Hickmann

Jairo Marlon Corrêa

Levi Lopes Teixeira

Edgar Manuel Carreño Franco

Resumo: Este artigo apresenta a metodologia híbrida para previsões de séries temporais chamada SARIMA Support Vector Regression Wavelet de Múltiplos Núcleos (SSVRWMN) para a projeção dos deslocamentos horizontais de um bloco da barragem da usina hidrelétrica de Itaipu.

Todos os resultados estatísticos alcançados por SSVRWMN são mais acurados que outras técnicas tradicionais (usadas aqui como benchmark), encorajando a sua adoção para tal finalidade.

Palavras-chave: deslocamentos horizontais; decomposição wavelet; modelos SARIMA; support vector regression; previsões. 


\section{INTRODUÇÃO}

As barragens de concreto de usinas hidrelétricas são, em geral, monitoradas com - auxílio de instrumentos que realizam aferições de diferentes grandezas, como temperatura, subpressão, deslocamentos, tensões, deformações, entre outras. Os dados aferidos ao longo do tempo podem ser do ponto de vista estatístico interpretados como séries temporais estocásticas que exibem estruturas de autodependência (visto que o valor de leitura corrente de um instrumento é afetado pelos seus valores passados). Com efeito, tais séries obedecem a um determinado regime estocástico de comportamento, o qual pode ser mapeado de forma aproximada, por meio de um método preditivo com a finalidade de se produzir previsões.

As técnicas estatísticas em conjunto com o avanço tecnológico estão propiciando cada vez mais o uso de previsões para auxiliar os tomadores de decisão em análises e planejamento de necessidades operacionais futuras em áreas diversificadas. Pesquisadores buscam constantemente estudar e desenvolver modelos estatísticos confiáveis e que apresentem boa precisão e, neste contexto muitos métodos híbridos são apresentados, como pode ser visto em: (HICKMANN et al., 2016), (CORRÊA et al., 2016), (TEIXEIRA et al., 2015), (WALLIS, 2011),. Morettin e Toloi (2006) e (DE GOOIJER; HYNDMAN, 2006). Estes ressaltam que independentemente da metodologia utilizada na previsão o objetivo é minimizar erros provenientes dos processos utilizados na obtenção de previsões (BOX; JENKINS; REINSEL, 2008).

No estudo de séries de tempo, três etapas são imprescindíveis: a análise, a modelagem e a previsão. Dentre as diversas técnicas usadas na análise, modelagem e previsão de séries temporais é possível citar: a teoria Wavelet, a metodologia de Box e Jenkins, o método Support Vector Regression e a combinação de previsões. Maiores detalhes sobre estas aplicações são encontrados nos seguintes trabalhos: (HAAR, 1911), (MALLAT, 2009), (BOX; JENKINS; REINSEL, 2008), (VAPNIK, 2005), (SMOLA; SCHÖLKOPF, 1998), (BATES; GRANGER, 2001).

Dentre as diversas variáveis que afetam a saúde estrutural de uma barragem de concreto estão os movimentos entre blocos, e entre estes e suas fundações, assunto de extremo interesse e relevância. Nesse estudo é considerada as aferições do instrumento denominado pêndulo. Na Barragem da Usina de Itaipu, um deles está localizado no bloco chave 110, o qual mede os deslocamentos horizontais da crista deste bloco. O monitoramento do comportamento do bloco 110, em termos de deslocamento, pode ser monitorado por meio de previsões obtidas por meio do método híbrido SARIMA Support Vector Regression Wavelet de Múltiplos Núcleos (SSVRWMN) proposto em (RODRIGUES, 2015).

\section{MATERIAIS E MÉTODOS}

$\mathrm{Na}$ presente seção é apresentada a série temporal proveniente das aferições do pêndulo direto e o método empregado nas previsões destas séries.

\subsection{MATERIAIS}

A Itaipu Binacional é uma das maiores usinas hidrelétricas do mundo e tem a sua localização no rio Paraná a $14 \mathrm{~km}$ à montante da ponte internacional que liga a cidade de Foz do Iguaçu, no Brasil, a Ciudad del Este, no Paraguai, (ITAIPU: USINA HIDRELÉTRICA, 2009). A barragem principal de Itaipu é de concreto, do tipo gravidade aliviada, sendo composta por 20 blocos, cada um dotado de uma unidade geradora. No total são 2792 instrumentos instalados no concreto e na fundação, fornecendo dados temporais que auxiliam na análise do comportamento dos blocos e por consequência da barragem como um todo. Alguns blocos são designados blocos-chave (como é o caso do Bloco 110, objeto de nosso estudo), os quais são dotados de maior quantidade de instrumentos. Os blocos estão sujeitos, principalmente à ação do nível do lago devido à maior força que recebem da água no sentido montante-jusante, ou seja, no sentido do leito do rio. Esse volume de água também exerce, nas partes inferiores dos blocos, uma pressão (denominada de subpressão) que cria um efeito contrário ao que a sua própria massa exerce sobre a fundação, e das variações de temperatura, como no caso do verão em que ocorrem dilatações no concreto que provocam uma tendência de deformação do bloco para a direção montante, que por sua vez pode fazer com que aumentem as tensões de compressão no pé de montante dos blocos. No inverno o concreto se contrai, 
e provoca uma tendência de deformação do bloco à jusante. Pode-se então identificar um comportamento cíclico da estrutura, intimamente condicionado às condições ambientais da região, (OSAKO, 2002). Por esse motivo, as informações futuras, obtidas pelas previsões, se tornam valiosas no auxílio às tomadas de decisões.

Neste estudo são realizadas previsões da série temporal pêndulo direto localizado no bloco chave (110) situado no trecho I da barragem hidrelétrica de Itaipu (ver Figura 1a), que contribuem no monitoramento do comportamento dos deslocamentos da crista da barragem em relação ao um ponto considerado fixo na fundação.

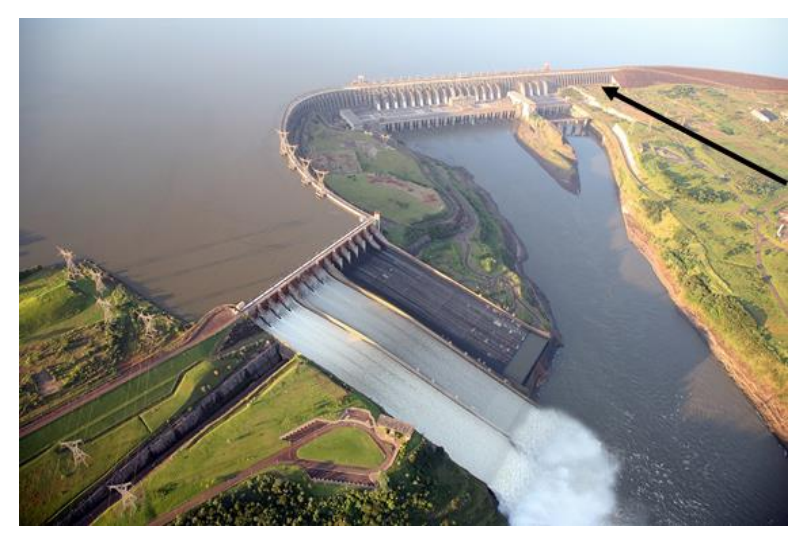

Figura 1a - localização do bloco I10

Inicialmente foi realizado o tratamento das informações, para serem estruturadas de acordo com a metodologia de previsão e optou-se por trabalhar com o período de 1994-2014 com valores mensais. Dos 252 valores que cada série temporal possui, os 228 primeiros dados foram utilizados no ajuste dos modelos base (SARIMA e SVR, SSVRWMN), os 12 valores seguintes foram reservados para validação e os 12 últimos
Dentre os diversos instrumentos, o pêndulo direto é um instrumento fixo à crista da barragem indo até o contato concreto-rocha, ou seja, é instalado na estrutura e é responsável em monitorar os deslocamentos da crista da barragem em relação ao ponto considerado fixo na fundação, do pêndulo direto se obtêm duas aferições uma no sentido montante-jusante (CO-I-2/X) e outra no sentido margem direita-esquerda (CO-I-2/Y). Nesta aplicação será considerada a série COI-2/X, que dá os deslocamentos horizontais da crista da barragem no sentido montantejusante. Para a série temporal proveniente da aferição do instrumento pêndulo direto CO-I2/X os valores são dados em milímetros, e são apresentados na Figura 1b.

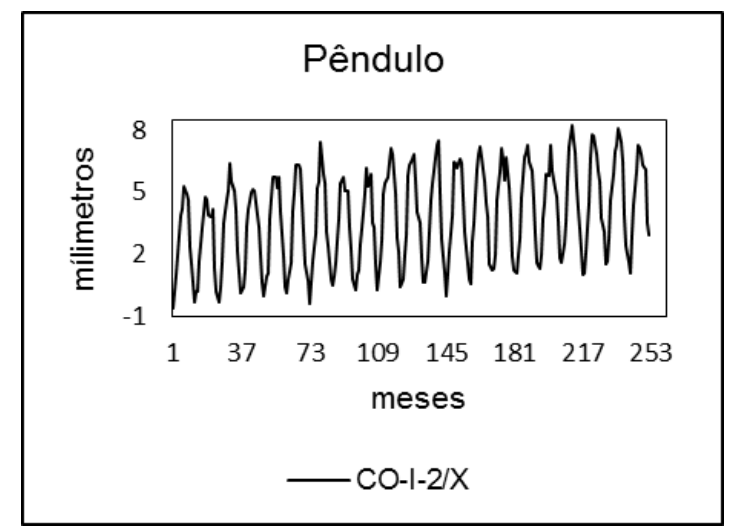

Figura 1b - série do pêndulo direto CO-I-2/X

valores referentes ao ano de 2014 para teste. A metodologia usada é de previsões multi step ahead, ou seja, $h$ passos à frente, nesta aplicação $h=12$, portanto 0 horizonte de previsão coincide com o total de passos. Para a avaliação dos métodos, foram utilizados os erros MAPE (mean absolute percent error), MSE (mean square error) e MAE (mean absolute error), (HAMILTON, 1994) representados na Equação.

$$
M A P E=\frac{1}{T} \sum_{t=1}^{T}\left|\frac{y(t)-\hat{y}(t)}{y(t)}\right|, M S E=\frac{1}{T} \sum_{t=1}^{T}(y(t)-\hat{y}(t))^{2}, M A E=\frac{1}{T} \sum_{t=1}^{T}|y(t)-\hat{y}(t)|
$$




\subsection{MÉTODO}

O método SARIMA Support Vector Regression Wavelet de Múltiplos Núcleos considera uma série temporal $(y(t))_{t=1}^{T}$ que será projetada pela média das previsões obtidas por um modelo linear (SARIMA) e um não linear (Support Vector Regression Wavelet de Múltiplos Núcleos). A Figura 2 apresenta um fluxograma com as etapas do método híbrido proposto.

Figura 2 - Fluxograma do método SSVRWMN. Fonte: (RODRIGUES, 2015).

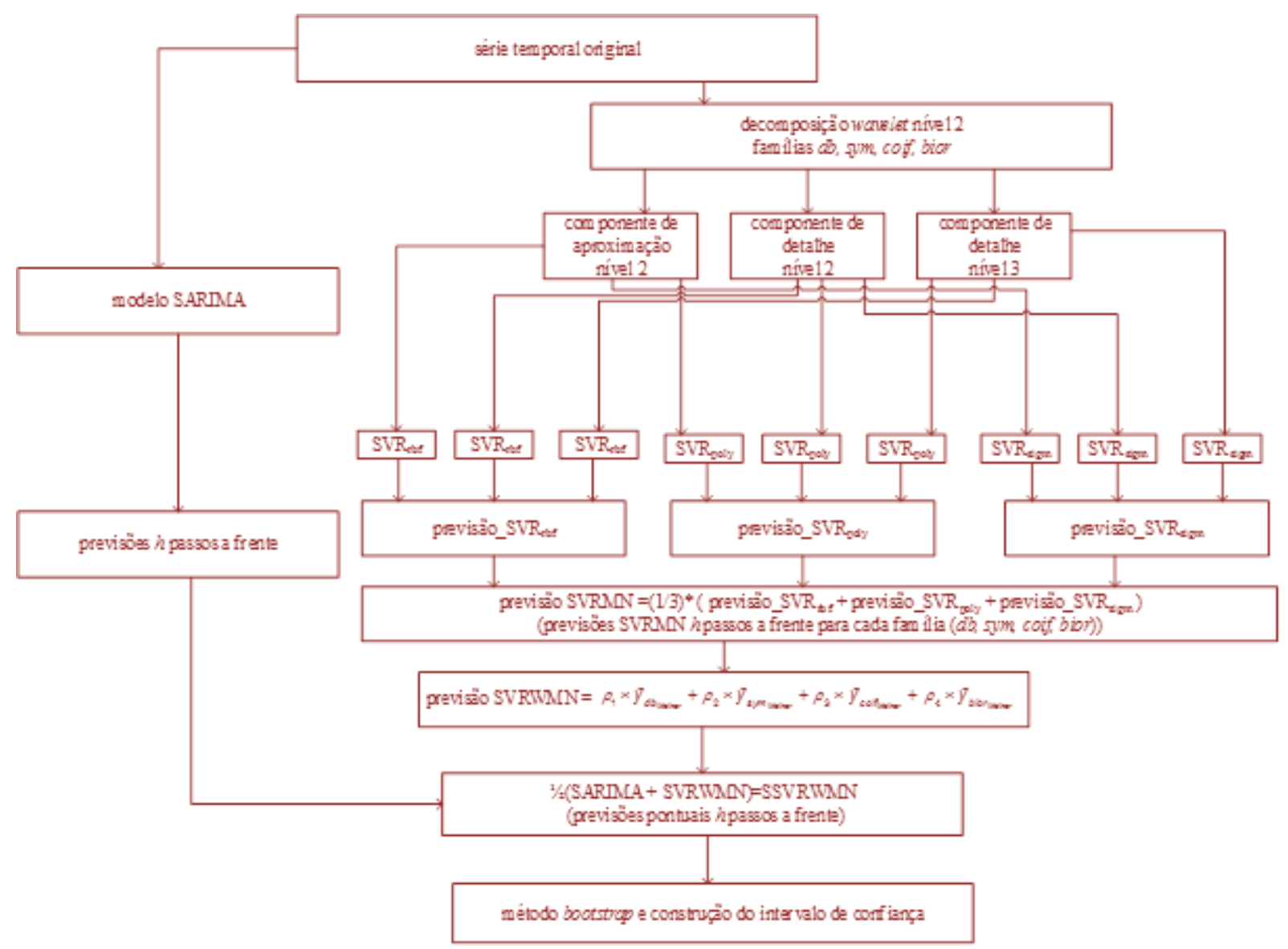

$\mathrm{Na}$ etapa 1 é realizada a modelagem via SARIMA, na série temporal original $(y(t))_{t=1}^{T}$, obtendo-se assim a previsão da componente linear $(L(t))_{t=1}^{T+h}$.

Na etapa 2 é realizada a decomposição ortogonal Wavelet de nível $r$ na série temporal original, $(y(t))_{t=1}^{T}$, gerando $r+1$ CWs, (DAUBECHIES, 1992) e (DONOHO e JOHNSTONE, 1994).

$\mathrm{Na}$ etapa 3, é realizada a modelagem das Componentes Wavelet via SVR Múltiplos Núcleos. O método denominado SVR Múltiplos Núcleos considera uma série temporal na qual são realizadas as modelagens através do SVR núcleo RBF, SVR núcleo Polynomial e SVR núcleo Sigmoidal, separadamente. As previsões obtidas através da combinação das previsões advindas das modelagens SVR núcleo RBF, SVR núcleo Polynomial e SVR núcleo Sigmoidal é que se denomina de Support Vector Regression de Múltiplos Núcleos (SVRMN). Da etapa 2, temse que para cada base Wavelet foram obtidos três componentes Wavelet que nesta etapa são modeladas pelo método SVRMN.

$\mathrm{Na}$ etapa 4 são selecionadas as modelagens que apresentaram o menor erro quadrático médio (MSE) com base nos dados de validação, para cada família Wavelet, na etapa anterior, para em seguida ser realizada a combinação linear, obtendo-se assim a 
previsão da componente não linear
$(N(t))_{t=1}^{T}$.

$\mathrm{Na}$ etapa 5, combinam-se as previsões obtidas na etapa 1 e obtidas na etapa 4, para a obtenção das previsões pontuais para cada instante $t$, gerando desta forma previsões dentro e fora da amostra (previsões multi step), que consiste nos resultados do método SARIMA Support Vector Regression Wavelet de Múltiplos Núcleos (SSVRWMN).

Na etapa 6, após obter a série dos resíduos, utilizou-se o processo Bootstrap residual, para obtenção do intervalo de confiança (IC) no nível de 95\%.

Mais detalhes consultar (RODRIGUES, 2015).

\section{RESULTADOS}

Nesta seção são apresentados os resultados obtidos da modelagem da série temporal provenientes das aferições do pêndulo direto, pelo método híbrido SSVRWMN que foram comparadas com outras abordagens já consagradas na literatura, tais como a modelagem Box e Jenkins, Support Vector Regression e o composto SARIMA-SVR. Onde se verificou que o método proposto SSVRWMN obteve nas previsões das séries temporais testadas redução nas estatísticas de aderência MSE, MAPE e MAE. Denotaremos a série temporal do pêndulo direto, por

$$
\left(y_{c o}(t)\right)_{t=1}^{252}
$$

Na etapa 1 foi realizada para a série temporal a modelagem através de um modelo SARIMA, gerando previsões dentro da amostra de treino e previsões na amostra de teste num horizonte de 12 passos à frente, estas previsões são consideradas pelo método híbrido como as previsão da componente linear. Para modelagem SARIMA foi utilizado o software Eviews sendo feita a análise gráfica da série temporal e identificado o modelo apropriado. A definição das ordens dos modelos ocorreu com a análise dos gráficos das funções de autocorrelação FAC, autocorrelação parcial FACP, resíduos e testes com diversas opções de ordens $p, d, q$. As estatísticas encontradas com a análise das séries temporais do pêndulo direto estão representada na Tabela 1.

$\mathrm{Na}$ etapa 2 para a série temporal $y_{c o}(t)$ foi realizada a decomposição ortogonal Wavelet de nível $r=2$, considerando as bases daubechies ( $\mathrm{db} 1,2, \ldots, 45)$, coiflets (coif $1,2, \ldots, 5)$, symlets (sym 1,2, .,30) e biorthogonal (1.1, 1.3, .., 6.8), num total de 95 decomposições. Foi gerada uma componente de aproximação que é a representação da série original em baixa frequência, e duas componentes de detalhe que são séries de altas frequências (séries mais ruidosas) em cada decomposição realizada, obtendo assim para a série $y_{c o}(t) 285$ subséries. As CWs de aproximação e detalhe são obtidas a partir do aplicativo computacional Matlab 8.0, que oferece várias opções de bases wavelet, tais como: as famílias Daubechies (db), coiflets (coif) e symlets (sym), desenvolvidas por Ingrid Daubechies (DAUBECHIES, 1992).

Tabela 1 - Modelagem SARIMA para a série temporal $y_{c o}$.

\begin{tabular}{|c|c|c|c|c|}
\hline Variável & Coeficiente & Erro padrão & Estatística-t & Probabilidade \\
\hline $\mathrm{AR}(12)$ & 1.001462 & 0.006894 & 145.2634 & 0.0000 \\
\hline $\mathrm{MA}(1)$ & -0.632463 & 0.049493 & -12.77889 & 0.0000 \\
\hline $\mathrm{MA}(3)$ & -0.416386 & 0.054726 & -7.608606 & 0.0000 \\
\hline $\mathrm{MA}(9)$ & 0.085333 & 0.036069 & 2.365816 & 0.0189 \\
\hline SMA(12) & -0.843251 & 0.038201 & -22.07423 & 0.0000 \\
\hline R-quadrado & 0.832369 & \multicolumn{2}{|c|}{ Média da variável dependente } & 0.009692 \\
\hline R-quadrado ajustado & 0.829348 & Desvio padrão da variável dependente & 1.260694 \\
\hline Erro padrão da regressão & 0.520793 & Akaike & 1.554850 \\
\hline Soma dos resíduos ao quadrados & 60.21192 & Schwarz & 1.630290 \\
\hline Log likelihood & -171.4755 & Hannan-Quinn & 1.585291 \\
\hline Durbin-Watson & 1.901669 & \multicolumn{3}{|c|}{} \\
\hline
\end{tabular}


Na etapa 3 para cada umas das 285 subsérie provenientes da decomposição Wavelet da séries $y_{c o}(t)$, foram realizadas as previsões via Support Vector Regression de Múltiplos
Núcleos. Foram considerados para compor o método os três principais núcleos, que são o RBF, o polinomial, e o Sigmoidal, (SMOLA e SCHÖLKOPF, 2004).

Por exemplo, para a série $\left(y_{d b 1_{\_} c o}(t)\right)_{t=1}^{240}$, foram geradas as previsões,

$$
\begin{aligned}
& \left(\hat{y}_{d b 1_{-} c o_{-} R B F}(t)\right)_{t=12}^{240+12}=\left(\hat{y}_{d b 1_{-} c o_{-} R B F A_{2}}(t)\right)_{t=12}^{240+12}+\left(\hat{y}_{d b 1_{-} c o_{-} R B F D_{2}}(t)\right)_{t=12}^{240+12}+\left(\hat{y}_{d b 1_{-} c o_{-} R B F D_{3}}(t)\right)_{t=12}^{240+12}, \\
& \left(\hat{y}_{d b 1_{\_} c o_{-} P o l y}(t)\right)_{t=12}^{240+12}=\left(\hat{y}_{d b 1_{-} c o_{-} P o l y A_{2}}(t)\right)_{t=12}^{240+12}+\left(\hat{y}_{d b 1_{\_} c o_{-} P o l y D_{2}}(t)\right)_{t=12}^{240+12}+\left(\hat{y}_{d b 1 \_c o \_P o l y D_{3}}(t)\right)_{t=12}^{240+12} \mathrm{e} \\
& \left(\hat{y}_{d b 1_{\_} c c_{-} S i g m}(t)\right)_{t=12}^{240+12}=\left(\hat{y}_{d b 1_{-} c o_{-} S i g m A_{2}}(t)\right)_{t=12}^{240+12}+\left(\hat{y}_{d b 1_{-} c c_{-} S i g m D_{2}}(t)\right)_{t=12}^{240+12}+\left(\hat{y}_{d b 1_{-} c o_{-} S i g m D_{3}}(t)\right)_{t=12}^{240+12} .
\end{aligned}
$$

Sendo a previsão da série $\left(y_{d b 1_{\_} c o}(t)\right)_{t=1}^{240}$, a média das previsões, ou seja,

$$
\left(\hat{y}_{d b 1_{-} c o}(t)\right)_{t=12}^{240+12}=\frac{1}{3}\left(\hat{y}_{d b 1_{-} c o_{-} R B F}(t)\right)_{t=12}^{240+12}+\frac{1}{3}\left(\hat{y}_{d b 1_{-} c o_{-} P o l y}(t)\right)_{t=12}^{240+12}+\frac{1}{3}\left(\hat{y}_{d b 1_{-} c o_{-} S i g m}(t)\right)_{t=12}^{240+12} \text {. }
$$

Este processo foi repetido para todas as 95 decomposições Wavelet.

Para obtenção dos parâmetros ótimos do modelo SVR, os dados da série temporal reservado para o ajuste foram subdivididos em treino e validação, sendo escolhido o modelo que apresentou um menor MSE no conjunto de validação, sendo a cardinalidade do conjunto de validação igual a 12. Foi utilizada uma biblioteca para SVR para Matlab denominada de LIBSVM, proposta por (CHANG, C. C. ; LIN, 2011), bem como outras rotinas aqui requeridas (RODRIGUES, 2015).

Segue na Tabela 2, os dois melhores resultados obtidos para cada família Wavelet e a estatísticas MSE da amostra de validação, para a série temporal do pêndulo $y_{c o}$.

Tabela 2 - dois melhores resultados para cada família wavelet para a série $y_{c o}$

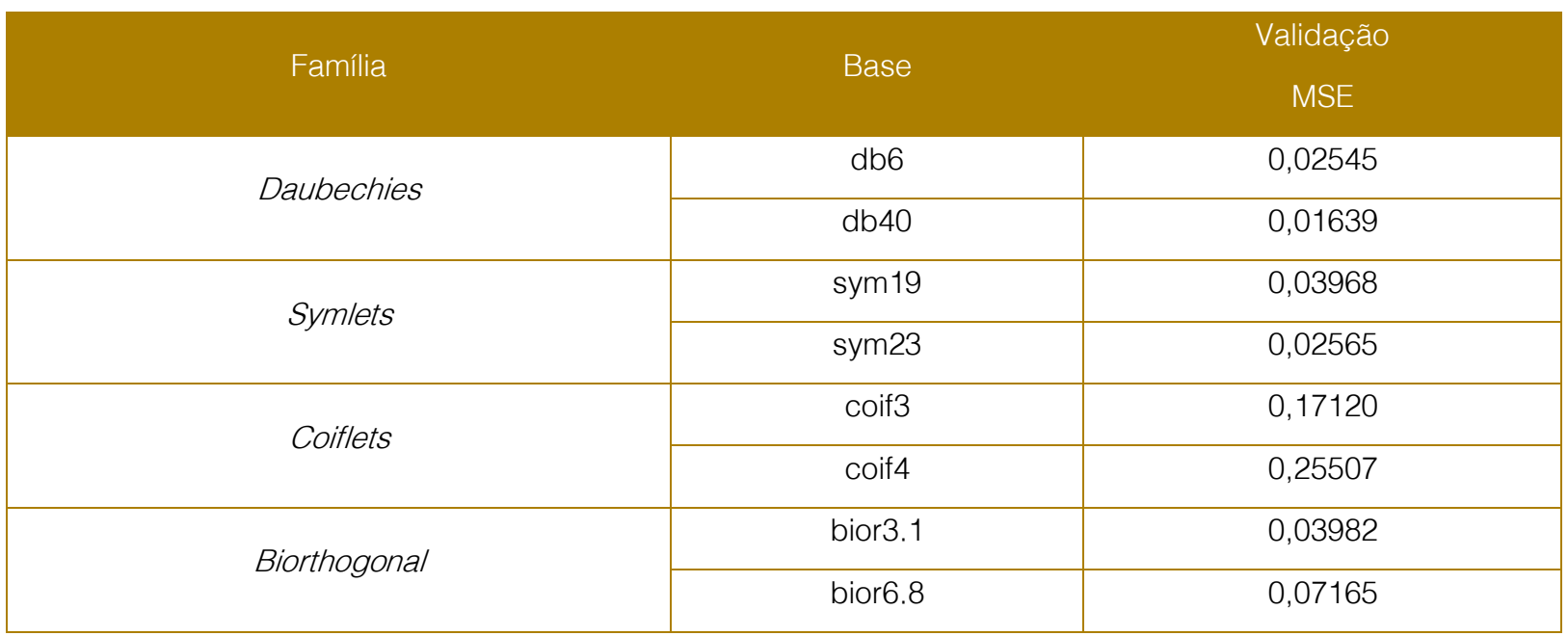


Da Tabela 2, observa-se que as modelagens selecionadas são aquelas que apresentaram a menor estatística de aderência MSE, e são elas para a série CO-I-2/X as bases db40, sym23, coif3 e bior3.1.
$\mathrm{Na}$ etapa 4 foram combinadas as previsões das melhores modelagens obtidas quando comparada a estatística MSE no conjunto de validação referente a cada família Wavelet.

Para a série temporal do pêndulo $y_{c o}$ a combinação é representada por:

$$
\left(\hat{y}_{c o}(t)\right)_{t=12}^{240}=\left[\rho_{1} \times\left(\hat{y}_{\text {db } 40_{-} c o}(t)\right)+\rho_{2} \times\left(\hat{y}_{s y m 23_{-} c o}(t)\right)+\rho_{3} \times\left(\hat{y}_{\text {coif } 3_{-} c o}(t)\right)+\rho_{4} \times\left(\hat{y}_{\text {biar 3.1 } 1_{c} c o}(t)\right)\right]_{t=12}^{240}
$$

onde as constantes adaptativas assumem os seguintes valores $\rho_{1}=0,458526$, $\rho_{2}=0,085159, \quad \rho_{3}=0,251612 \quad \mathrm{e}$ $\rho_{4}=0,221247$, após a minimização do erro quadrático médio (MSE).

Nesta etapa, foram obtidas as previsões do modelo SVR Wavelet múltiplos núcleos, ou seja, da componente não linear para cada uma das séries temporais modeladas e que são representadas respectivamente por:

$$
\left(\hat{N}_{\infty}(t)\right)_{t=12}^{240}
$$

$\mathrm{Na}$ etapa 5 tomam-se as previsões obtidas pelo modelo linear (SARIMA) e pelo modelo não linear (SVRWMN) e calcula-se a média, para a obtenção das previsões pontuais para cada $t$, para cada uma das séries temporais modeladas.

O método híbrido SSVRWMN apresenta em sua estrutura de autodependência informações lineares e não lineares e é considerada como uma versão filtrada da série temporal $y(t)$, tanto por um filtro linear (etapa 1) quanto por um filtro não linear (etapas 3 e 4). Logo a lista de previsões para a série temporal do pêndulo direto é

$$
\left(\hat{y}_{c o}(t)\right)_{t=12}^{240+12}=\frac{1}{2}\left(\hat{L}_{c o}(t)+\hat{N}_{c o}(t)\right)_{t=12}^{240+12}
$$

Nesta etapa, é possível fazer a comparação das previsões do método proposto com as previsões obtidas pelo método SARIMA, SVR e combinação SARIMA-SVR. As estatísticas de aderência comparadas são: MSE, MAPE e MAE.

Na Tabela 3 é apresentada a comparação para a série temporal do pêndulo. $y_{c o}$

Tabela 3 - comparativo mse, mape e mae para série $y_{c o}$ multi step $\mathrm{h}=12$

\begin{tabular}{|c|c|c|c|}
\hline Método & MSE & MAPE & MAE \\
\hline SARIMA & 0,3615 & $12,7 \%$ & 0,4581 \\
\hline SVR & 0,8398 & $19,8 \%$ & 0,8419 \\
\hline SARIMA-SVR & 0,7146 & $18,6 \%$ & 0,7801 \\
\hline SSVRWMN & 0,2157 & $11,8 \%$ & 0,4149 \\
\hline
\end{tabular}


Da Tabela 3, verifica-se que o método proposto SSVRWMN obteve nas previsões da série temporal do instrumento CO-I-2/X uma redução nas três estatísticas de aderência MSE, MAPE e MAE, em relação a todos os demais métodos preditivos listados. Comparando-o ao segundo melhor resultado (a saber, o método SARIMA), a redução relativa foi de, aproximadamente, 40,3\% na medida MSE, de 9,4\% na medida MAE e 7,1\% na medida MAPE.

Na etapa 6, após obter a série dos resíduos, utilizou-se o processo Bootstrap residual, para obtenção do intervalo de confiança (IC) no nível de 95\%, que pode ser visto na Figura 3.

Figura 3 - gráfico do ic e previsões pelo método ssvrwmn da série do pêndulo CO-I-2/X

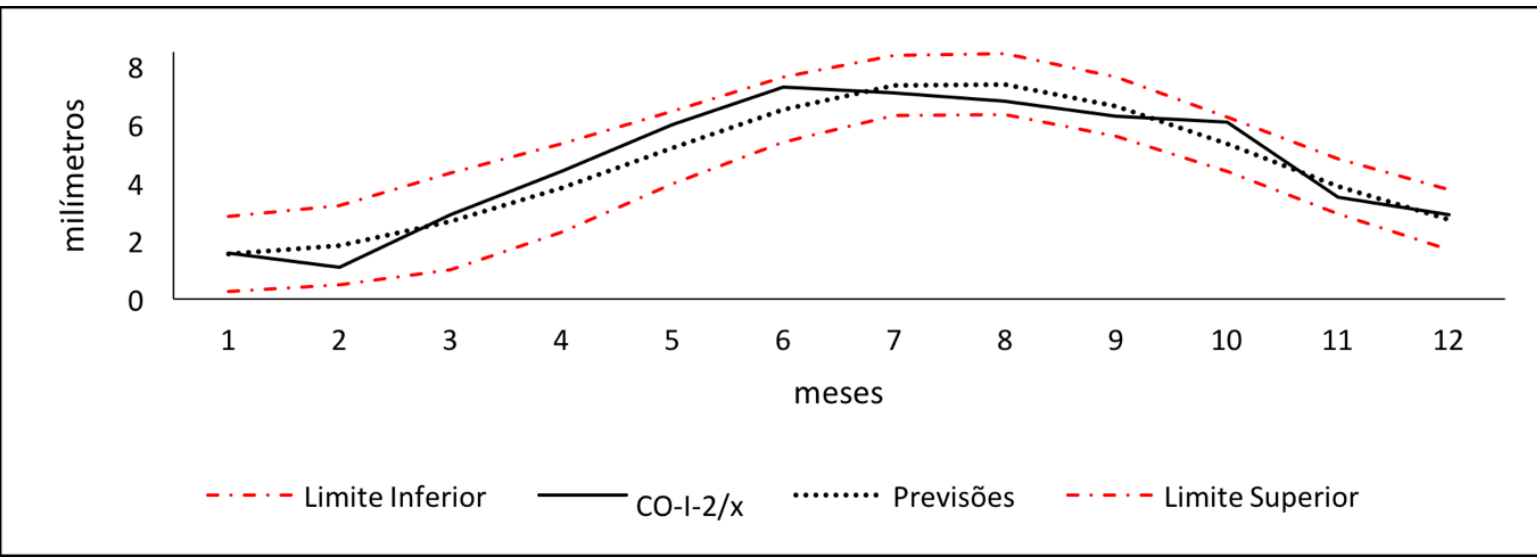

\section{CONSIDERAÇÕES FINAIS}

O presente artigo apresentou um método de previsão da série temporal proveniente da aferição do instrumento pêndulo direto CO-I2/X localizado no bloco I10 da barragem da usina hidrelétrica de Itaipu, que monitoram o deslocamento do referido bloco sentido montante jusante.

Em síntese, no processo de geração de previsões, o método SSVRWMN gerou previsões substancialmente melhores que os obtidos pelos métodos preditivos SARIMA e SVR individualmente, e o composto SARIMASVR, em todas as estatísticas de aderência consideradas. Portanto, as previsões provenientes do método SSVRWMN veem agregar informações, contribuindo desta forma com a tomada de decisão, no que se refere ao problema estudado.

O método SSVRWMN se mostrou uma alternativa factível e eficiente à modelagem de séries temporais (advindas de acontecimentos reais), dadas a sua abrangência e a sua eficiência mostrada nas pesquisas. Tais resultados são motivadores da aplicação do método para séries temporais de outras áreas, mesmo que a base teórica do método híbrido proposto é matematicamente complexo, o uso dos softwares e rotinas computacionais referenciados no texto permite a sua utilização.

\section{AGRADECIMENTOS}

Os autores externam seus agradecimentos às instituições UTFPR - Medianeira, ao programa de pós-graduação em engenharia elétrica e computação - UNIOESTE - Foz do Iguaçu, a UFPR, ao CEASB e a equipe de superintendência de engenharia da Itaipu Binacional pelo apoio e contribuição das discussões. 
[2]. BOX, G. E. P.; JENKINS, G. M.; REINSEL, G. C. Time series analysis: forecasting and control. [s.I.] J. Wiley \& Sons, 2008.

[3]. CHANG, C. C. ; LIN, C. J. \{LIBSVM\}: A library for support vector machines. ACM Transactions on Intelligent Systems and Technology, v. 2, n. 3, p. 27:1--27:27, 2011.

[4]. CORREAA, J. M. et al. Time series forecasting with the WARIMAX-GARCH method. Neurocomputing, 2016.

[5]. DAUBECHIES, I. Ten Lectures on Wavelets. [s.l: s.n.].

[6]. DE GOOIJER, J. G.; HYNDMAN, R. J. 25 years of time series forecasting. International Journal of Forecasting, v. 22, n. 3, p. 443-473, jan. 2006.

[7]. DONOHO, D. L.; JOHNSTONE, J. M. Ideal spatial adaptation by wavelet shrinkage. Biometrika, v. 81, n. 3, p. 425-455, 1994.

[8]. HAAR, A. Zur Theorie der orthogonalen Funktionensysteme. Mathematische Annalen, v. 71, n. 1, p. 38-53, 1911.

[9]. HAMILTON, J. D. Time Series Analysis. [s.I.] Princeton University Press, 1994. v. 39

[10]. HICKMANN, T. et al. Wavelet - SVR hybrid methodology for the projection of relative displacements in block 111 of the Itaipu hydroelectric plant dam. Revista Gestão da Produção Operações e Sistemas, v. 11, n. 2, p. 103-120, jun. 2016.

[11]. ITAIPU: USINA HIDRELÉTRICA. Projeto: Aspectos de Engenharia". 1. ed. Foz do Iguaçu - Pr: ITAIPU, 2009.
[12]. MALLAT, S. A Wavelet Tour of Signal Processing: The Sparse Way. Third Edit ed. [s.l: s.n.].

[13]. MORETTIN, P. A.; TOLOI, C. M. DE C. Análise de séries temporais. [s.I.] Edgard Blucher, 2006.

[14]. OSAKO, C. I. A manutenção dos drenos nas Fundações de Barragens o caso da Usina Hidrelétrica de Itaipu. [s.l.] Dissertação Curso de Pós-Graduação em Construção Civil, Universidade Federal do Paraná, 2002.

[15]. RODRIGUES, S. B. Método híbrido interativo sarima support vector regression wavelet de múltiplos núcleos na previsão de séries temporais de instrumentos de barragens. [s.l.] Tese de Doutorado Univerisdade Federal do Paraná, 2015.

[16]. SMOLA, A. J.; SCHÖLKOPF, B. A tutorial on support vector regressionStatistics and Computing, 1998.

[17]. SMOLA, A. J.; SCHÖLKOPF, B. A tutorial on support vector regression. Statistics and Computing, p. 199-222, 2004.

[18]. TEIXEIRA, L. L. et al. Forecasts for the Canadian Lynx time series using method that bombine neural networks, wavelet shrinkage and decomposition. Revista Gestão da Produção Operações e Sistemas, v. 10, n. 4, p. 159-172, 3 dez. 2015.

[19]. VAPNIK, V. Universal learning technology: Support vector machines. Nec Journal Of Advanced Technology, v. 2, n. 2, p. 137-144, 2005.

[20]. WALLIS, K. F. Combining forecasts: forty years later. Applied Financial Economics, p. 33-41, 2011. 


\section{Bapítulo 6}

\section{INTEGRAÇÃO DAS METODOLOGIAS BALANCED SCORECARD (BSC) E SS EM UMA EMPRESA PRESTADORA DE SERVICOS DE INFORMÁTICA}

\section{Juan Pablo Silva Moreira \\ Saulo Fonseca Soares \\ Adriel Augusto dos Santos Silva \\ Felipe Augusto da Silva \\ Janser Queiroz Oliveira}

Resumo: Com o crescente aumento da competitividade e o dinamismo do cenário organizacional, tornou-se comum a elaboração de um planejamento estratégico que auxiliasse as organizações na obtenção de vantagens competitivas e de valor agregado para os seus serviços. Assim, o objetivo deste trabalho é realizar um estudo sobre a utilização da metodologia BSC em conjunto com a filosofia 5S denominada pelos autores como 5BSC'S - em uma pequena empresa prestadora de serviços de informática, localizada na cidade de Guimarânia/mg, que para fins de confidencialidade, designar-se-á, na presente pesquisa como Empresa Gama, analisando a contribuição que a união destas duas metodologias fornece na gestão do empreendimento, apresentando soluções estratégicas ligadas aos fatores considerados importantes para a tomada de decisão da empresa. Por isso, a fim de tornar a concretização visível aos colaboradores da empresa, nessa análise foi utilizado formulários de maneira descritiva e qualitativa, pois essas formas pesquisa permitem maior interação com o cotidiano da linha de produção organizacional. Através desta pesquisa, foi possível destacar que a modelagem 5BSC'S se mostra eficiente, pois proporcionou a elaboração de um plano de ação eficiente que forneça maior confiabilidade e satisfação para com os clientes, além de permitir um controle mais efetivo dos equipamentos. 


\section{INTRODUÇÃO}

Com o crescente aumento da competitividade e o dinamismo do cenário organizacional, tornou-se comum a elaboração de um planejamento estratégico que auxiliasse as organizações na obtenção de vantagens competitivas e de valor agregado para os seus serviços. Segundo Porter (2004) o planejamento estratégico está diretamente ligado ao empreendimento e ao contexto organizacional no qual ele está inserido, pois através da união destes fatores é possível direcionar esforços que maximizem os resultados previamente estabelecidos.

Com processo de inovações da tecnologia, se tornou muito importante que os empreendimentos desenvolvam periodicamente melhorias para que seus produtos não entrem em decadência. Para Tidd et al. (2008) a era da tecnologia consiste em formular novas de planejar, organizar e coordenar os parâmetros julgados essenciais para desenvolver instrumentos mais rentáveis e, como isso obter um aumento da lucratividade almejada pelos gestores.

Neste contexto, para tornar o processo de produção da empresa uniforme e eficiente, torna-se necessário a obtenção um planejamento que forneça pleno acesso as informações relevantes para a empresa. Oliveira (2003) explana que os "serviços de informações excelentes são uma exigência para que os funcionários consigam melhorar os processos, através de iniciativas diversas, como: controle de qualidade redesenha de fluxos de trabalho, ou mesmo reengenharia".

Em 1992 foi criado por Kaplan e Norton, o Balanced Scorecard (BSC), uma metodologia que tem a finalidade de organizar o planejamento estratégico dos empreendimentos em objetivos e medidas, dispostos em quatro perspectivas: financeira; do cliente; de processos internos e de aprendizado e crescimento. De acordo com Kaplan e Norton (2010), o BSC é um instrumento desenvolvido para mensurar os indicadores de gestão, planejamento e controle de pequenas, médias e grandes empresas.

No entanto, para que haja uma melhor adoção do BSC nas organizações, é necessário que o ambiente de trabalho esteja organizado, pois todos os envolvidos no processo de implantação devem ser conscientizados da importância desta ferramenta. Deste modo, uma filosofia que pode ser usada para dar auxílio na implantação do BSC é a metodologia 5S. A metodologia $5 S$ é uma ferramenta relevante para as empresas, já que busca por melhorias de desempenho e qualidade, além de auxiliar significativamente na redução de custos, ao deixar o ambiente propício para a realização das atividades operacionais de produção (MOREIRA, et. al 2015).

A utilização da metodologia BSC em conjunto com a filosofia $5 S$ permite que a organização obtenha um melhor controle quanto à medição de desempenho dos serviços prestados, além de apresentar uma visão mais clara das estratégicas que devem ser seguidas. Assim, o objetivo deste trabalho é realizar um estudo sobre a utilização da metodologia BSC em conjunto com a filosofia $5 S$ - denominada pelo autor como 5BSC'S em uma pequena empresa prestadora de serviços de informática, localizada na cidade de Guimarânia/MG, que para fins de confidencialidade, designar-se-á, na presente pesquisa como Empresa Gama, analisando a contribuição que a união destas duas metodologias fornece na gestão do empreendimento, apresentando soluções estratégicas ligadas aos fatores considerados importantes para a tomada de decisão da empresa.

Para tanto, a fim de melhor evidenciar as informações com um maior grau de eficiência, desenvolveu-se um estudo mediante o estudo sistemático dos conteúdos disponíveis em métodos, técnicas e/ou procedimentos de caráter técnico-cientifico. Assim, quanto aos objetivos, esta pesquisa foi caracterizada como descritiva, pois para Gil (2002) a pesquisa descritiva pode ser definida como "a descrição das características de determinada população ou fenômeno, ou, então, o estabelecimento de relação entre as variáveis".

Além disso, para se analisar melhor os indicadores desenvolvidos na Empresa Gama, os autores deste trabalho fazem uso de uma abordagem de caráter qualitativo. Essa abordagem possibilita aos pesquisadores desenvolver uma comparação direta entre o meio real e o assunto pesquisado, ao permitir a possibilidade de evidenciar, observar e interpretar determinado fenômeno sem o auxílio de recursos numéricos ou quantitativos (SILVA; MENEZES, 2005). Ainda segundo as mesmas autoras 
esta abordagem permite a percepção de um fato relacionado às pessoas: atitudes, hábitos ou comportamentos.

\section{PLANEJAMENTO ESTRATÉGICO EM PEQUENAS E MÉDIAS EMPRESAS - PMES}

O Planejamento Estratégico é um processo em que serão criadas e desenvolvidas as principais estratégias dos empreendimentos, nesse tipo de planejamento pretende-se realizar um norteamento para as empresas, deixando-as em conformidade com a missão e o meio no qual elas estão inseridas. Assim, Almeida (2001) informa que o "Planejamento Estratégico é uma técnica administrativa que procura ordenar as ideias das pessoas, de forma que se possa criar uma visão do caminho que se deve seguir".

Desta maneira, a utilização de um planejamento estratégico para as Pequenas e Médias Empresas (PMEs) está diretamente ligado ao fato de que esses empreendimentos ainda estão imaturos no mercado e, por isso, é necessário que os gestores sempre planejem e analisem suas atividades futuras, para que com isso seja possível competir em um patamar de competitividade para com as empresas de grande porte. De acordo com Almeida (2001), a aquisição de um planejamento estratégico para uma PME pode ser considerado um processo menos complexo, já que por haver uma quantidade menor de funcionários, é possível estabelecer um plano de ação com maior poder de flexibilidade, garantindo assim, que a organizações se adaptem a um cenário cheio de incertezas.

Contudo, o mesmo autor informa ainda que em pequenos empreendimentos, é comum encontrar empresas familiares, e nestes casos, estas são gerenciadas por um ou mais proprietários, e em algumas vezes, por um proprietário e seus filhos. Desta forma, por ocorrer uma centralização das atividades exercidas por cada um dos diretores, em que grande parte do tempo é voltada à parte operacional, e pouco deste tempo é destinado ao gerenciamento e planejamento estratégico e organizacional, torna-se muito desgastante persuadir e quebrar o paradigma de que é necessário estimular ações que visam o planejamento futuro da empresa, mesmo que atualmente esteja se obtendo lucro com a venda de seus produtos.
Neste sentido, Porter (2004) relata que planejamento estratégico em PMEs tem a finalidade de proporcionar benefícios significativos, ao demostrar de maneira explícita, os procedimentos estratégicos necessários para alinhar, coordenar e dirigir os coordenadores às metas previamente estipuladas pelos empreendimentos. Uma metodologia bastante utilizada para organizar o planejamento estratégico das organizações é o Balanced Scorecard.

\subsection{BALANCED SCORECARD (BSC)}

O BSC traduzido para a língua portuguesa pode ser analisada como "Indicadores balanceados de desempenho". Esta metodologia tem contribuído para a composição e a visualização das medidas de desempenho que refletem na estratégia de negócios das empresas (KAPLAN e NORTON, 2010).

Castro e Tavares (2016) salientam que o BSC serve como uma bússola, orientando os objetivos organizacionais futuros, ao fornecer a cada colaborador informações essenciais para auxiliar na tomada de decisão do dia a dia, além disso, essa metodologia serve também para melhorar o desempenho de todos os processos da organização. Segundo Kaplan e Norton (2010) ainda são escassos os estudos que podem comprovar a verdadeira eficiência do uso do BSC no sucesso das PMEs, entretanto, é possível comprovar que o aumento na competitividade desses empreendimentos no mercado. Os mesmos autores afirmam ainda que para iniciar a implantação do BSC, é necessário considerar as suas quatro perspectivas básicas:

1- Perspectiva Financeira: Monitora como a estratégia da organização está contribuindo para intensificar os resultados financeiros. As metas financeiras devem estar correlacionadas com os indicadores de rentabilidade, crescimento;

2- Perspectiva do Cliente: é formulada através de definições quanto ao mercado e segmentos que a organização deseja atuar. $\mathrm{O}$ empreendimento organizar em medidas específicas, os indicadores importantes para os consumidores. A proposta é acompanhar como está sendo prestado o serviço ao cliente; 
3- Perspectiva dos Processos Internos: Os indicadores referentes à perspectiva dos clientes e dos acionistas devem ser apoiados por processos internos. As empresas devem identificar os processos críticos necessários para a realização dos objetivos propostos para as duas perspectivas anteriores;
4- Perspectiva do Aprendizado e do Crescimento: organizações com condição de se tornarem melhores são empresas que possuem capacidade de aprender. A capacitação da organização ocorre por meio dos investimentos em equipamentos, treinamento, pesquisa ou em sistemas e procedimentos da empresa.

A figura 1 demonstra a relação existente entre as perspectivas do BSC.

Figura 1 - Gestão estratégica e BSC.

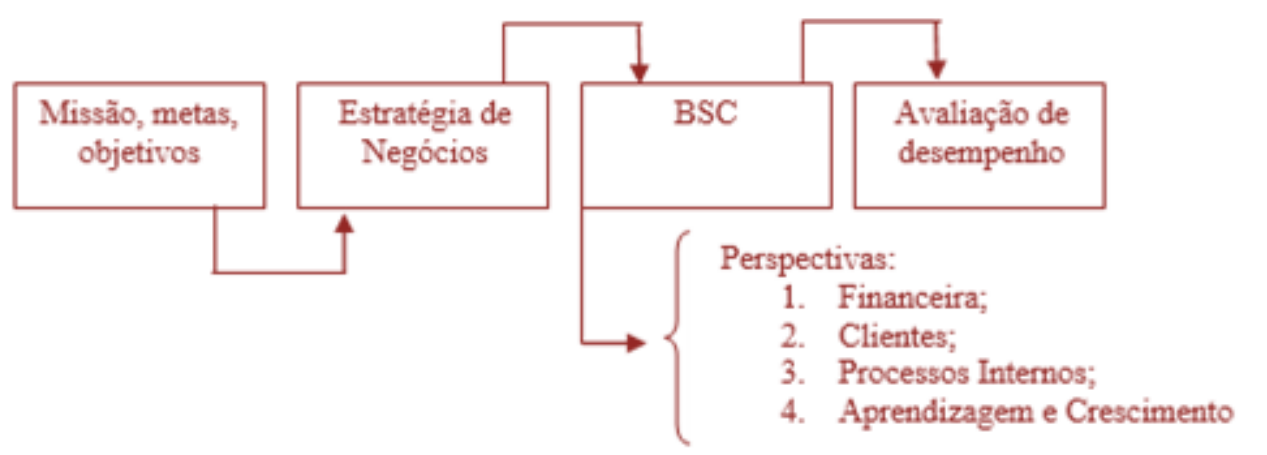

Fonte: Adaptado de Naro e Travaillé (2011)

O BSC possui uma percepção sistemática, pois, de acordo com Kaplan e Norton (2010), este instrumento tem o objetivo de interligar as metas, indicadores de desempenho e ações de forma a englobar o desenvolvimento da aprendizagem organizacional às perspectivas do mercado.

\section{$2.25 S$}

Wekerma (2006) conceitua o 5S como um método que tem a finalidade de "promover e manter a limpeza e a organização das áreas de trabalho - tanto administrativas quanto de manufatura". Campos (2004) acrescenta que implantar o programa 5S é uma boa maneira de iniciar uma melhoria eficiente no gerenciamento operacional da organização, já que esta filosofia promove o aculturamento dos colaboradores, tornando o ambiente organizado, disciplinado, produtivo e com um índice menor de retrabalhos.

A metodologia $5 S$ é uma ferramenta fundamental para a empresa, pois auxilia no desenvolvimento de melhorias de desempenho e qualidade, além de influenciar de forma satisfatória na redução de custos e na criação de um ambiente de trabalho que garanta a realização dos processos produtivos da linha de produção (MOREIRA et al., 2015). O $5 S$ é fundamento em cinco passos sequenciais, cíclicos e contínuos, formado a partir de 5 palavras japonesas (Seiri, Seiton, Seiso, Shitsuke, Seiketsu). A figura 2 demonstra o processo contínuo da filosofia 5S. 
Figura 2 - Estrutura da ferramenta 5S. Fonte: Adaptado de Silva (1994)

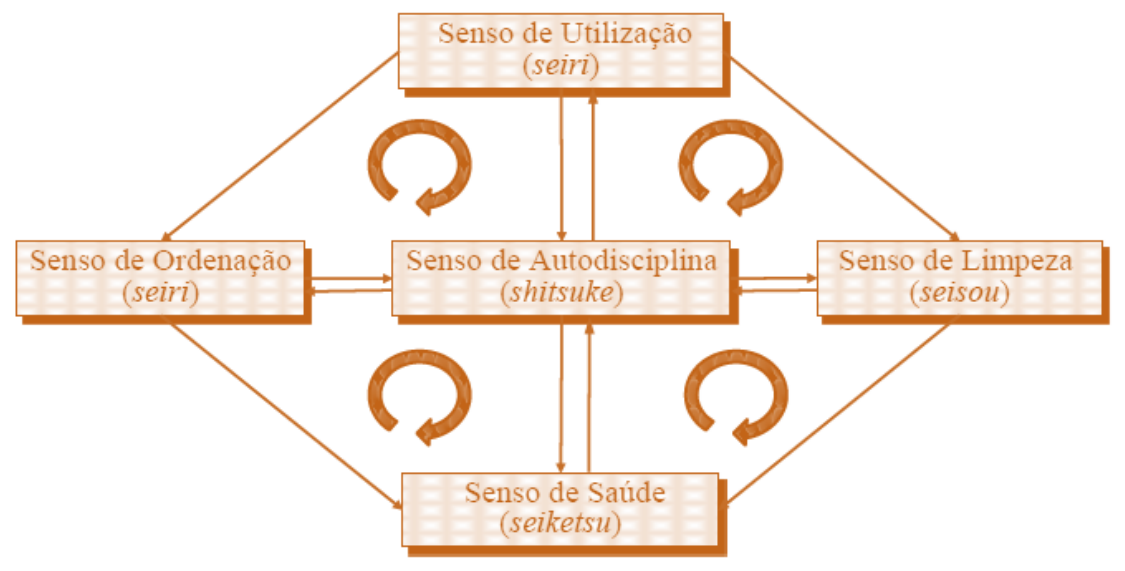

Para Silva (1994), primeiro senso, Seiri (senso de utilização) se baseia na organização, ou classificação dos materiais são necessários para o ambiente de trabalho. Este senso está relacionado com a necessidade de reduzir o hábito natural do ser humano de manter em posse objetos que não lhes tem utilidade, ou seja, é preciso identificar os motivos dos excessos de materiais, adotando ações preventivas de forma a evitar o que é desnecessário para 0 ambiente de trabalho do empreendimento (NAKATA, 2000).

A etapa seguinte, Seiton (senso de organização) consiste em classificar os equipamentos necessários e definir o local adequado para que eles deixem o ambiente mais produtivo. Desta forma é possível otimizar o manuseio dos mesmos, facilitando a execução dos processos.

A etapa do Seiso (senso de limpeza) tem o objetivo de eliminar a sujeira, verificando as causas de sua origem. Nakata (2000) relata que "Remover a sujeira torna tudo mais visível. Removendo o pó e as manchas, a parte oculta pela sujeira fica exposta à inspeção".

Em relação ao quarto senso, o Seiketsu (senso de saúde) está diretamente relacionado ao conceito de higiene do ambiente de trabalho que, segundo Ribeiro (1994) se basicamente de padronizar todos os procedimentos, hábitos e normas, de modo que os três primeiros sensos sejam mantidos. Entretanto, esta etapa só será concluída após a execução dos 3Ss anteriores (Seiri, Seiton, Seiso)

E por fim o quinto senso, o Shitsuke (senso de autodisciplina), almeja incentivar o desenvolvimento de uma disciplina capaz de manter todas as etapas anteriores. Ribeiro (1994) coloca que ser disciplinado é cumprir rigorosamente as normas e tudo o que for estabelecido pela organização. Quando se atinge $05^{\circ}$ senso, já é possível se pode considerar que uma cultura de manutenção e de bons hábitos foi criada no local em que foram implantados. Porém, Moreira et al. (2015) alertam que em alguns casos se torna difícil sustentar o hábito de manter os procedimentos corretos, já que pelo fato desses comportamentos estarem arraigados, é comum o retorno ao status quo, isto é, à zona de conforto do "velho modo" de executar as atividades operacionais da empresa.

A implantação do 5 S deve ser elaborada com base em um planejamento estratégico fornecido a partir das informações fornecidas dos empresários ou gestores de uma determinada área, pois só assim será possível para elevar as chances de sucesso na implantação dessa metodologia (MOREIRA et al., 2015). Para que ocorra uma implantação eficiente do $5 S$ é necessário que todos os colaboradores participem desde os níveis de gerência aos funcionários de mais baixo cargo na escala hierárquica.

\section{METODOLOGIA}

Foi realizado um estudo para a utilização da metodologia Balanced Scorecard em conjunto com a metodologia 5S, denominada pelo autor como 5BSC'S, em uma empresa prestadora de serviços de informática nomeada como Empresa Gama. Para tanto, os dados primários da pesquisa foram coletados através de um questionário 
semiestruturado, composto por questões fechadas, aplicadas aos proprietários da empresa e aos demais funcionários. Todos os funcionários responderam ao questionário aplicado, num total de cinco (5) colaboradores, pois a mudança na gestão estratégica e organização da empresa afeta todos os colaboradores. Os dados secundários da pesquisa foram obtidos a partir de consulta a artigos científicos, monografias teses e dissertações.

As questões contidas no questionário tinham o objetivo de realizar um levantamento quanto à organização do ambiente de trabalho, o planejamento estratégico, os indicadores, a missão e a visão e os objetivos da organização. Além disso, o questionário serviu também para identificar as razões da implantação do 5BSC'S, avaliar a opinião das pessoas envolvidas no processo mencionado e também para identificar as contribuições que podem ser trazidas após a implantação do 5BSC'S, bem como analisar as principais dificuldades que podem ser encontradas durante sua implantação.

\section{ANÁLISE DOS RESULTADOS}

Com base nos dados coletados foi realizada a proposta para a implantação da metodologia
5BSC'S na Empresa Gama. O primeiro passo para a proposta foi a modelagem da metodologia 5S para a empresa. Após esse passo foi feita a definição dos objetivos estratégicos a partir do BSC, analisados sob as perspectivas do cliente, dos processos internos e do aprendizado e crescimento, finalizando com a criação de indicadores, metas e ações para cada objetivo estratégico criado.

De acordo com Naro e Travaillé (2011) o primeiro passo para a implantação do BSC é escolha de um líder para o projeto. A escolha de uma pessoa para liderar toda a equipe durante um projeto de implantação da metodologia $5 S$ também é importante, conforme Oliveira (2003). Como o 5BSC'S tem como base a união de conceitos dessas duas metodologias, o primeiro passo é escolher um líder. O líder do projeto será responsável pela organização das informações sobre a integração de toda equipe do projeto, dentre outros.

Para a proposta de implantação da primeira parte do 5BSC'S, que corresponde à implantação do 5S na empresa, foram seguidos os passos citados por Canto et al., (2006), adaptados à situação da Empresa Gama (Figura 3).

Figura 3 - Proposta de implementação do 5BSC'S.

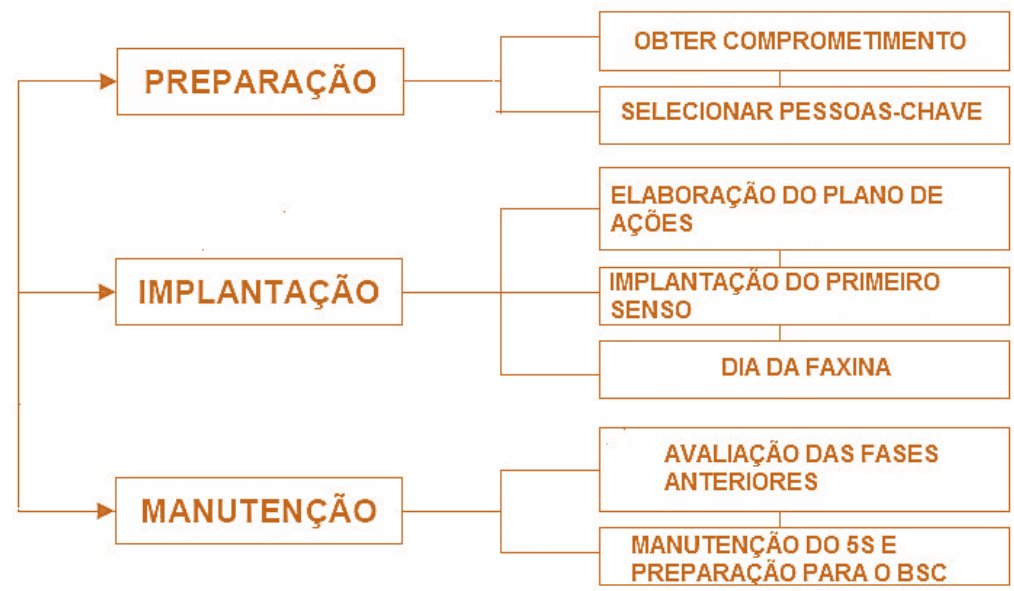

Fonte: Adaptado de Canto et al., (2006)

A etapa de implantação do $5 S$ começa com a elaboração do plano de ações, nesta atividade são listados os propósitos e metas do programa $5 \mathrm{~S}$ e as ações necessárias para que esses propósitos e metas sejam alcançados. Os propósitos para a implantação da metodologia 5S são organizar - ambiente de trabalho e preparar os colaboradores para a aplicação de estratégias baseadas na metodologia BSC. 
Com o plano de ações pronto, deverá ser feito um trabalho coletivo para a implantação do senso de utilização. Após o encerramento da etapa de implantação do programa $5 \mathrm{~S}$ na empresa, os três primeiros sensos, de utilização, de ordenação e de limpeza, já estarão implantados, restando assim, a etapa de manutenção do programa 5S, que corresponde aos dois últimos sensos. A avaliação das fases anteriores deve ser feita pela equipe de pessoas chave selecionada na etapa de preparação, juntamente com o líder do projeto, identificando problemas de organização que ainda precisam ser solucionados e propondo ações de melhoria. Novas modificações deverão continuar sendo realizadas na empresa e os funcionários deverão ser incentivados à participação e envolvimento no programa, para que possam buscar melhorar continuamente o ambiente e atividades de trabalho, contribuindo assim para a manutenção do programa $5 S$ na empresa.

A segunda parte da proposta de implantação do 5BSC'S na Empresa Gama corresponde à proposta de implantação de estratégias na empresa sob a ótica do BSC.

A proposta apresentada levou em consideração a missão e a visão da instituição, as informações do ambiente, os temas estratégicos e os objetivos estratégicos. Os temas estratégicos foram formulados de acordo com a missão e a visão, e os objetivos estratégicos derivam dos temas estratégicos.

Para que cada um dos objetivos criados fosse alcançado, foram definidos indicadores, metas e ações para cada uma das perspectivas do BSC utilizados no trabalho (tabela 1).

Tabela 1 - Indicadores propostos para a Empresa Gama

\begin{tabular}{|c|c|c|c|}
\hline Perspectiva & Indicador & Cálculo & Mensuracâo \\
\hline \multirow{3}{*}{ Financeira } & Lucratividade (L) & $L=$ Receita - Custos & $\mathrm{RS}$ \\
\hline & índice de Investimento (II) & $I I=($ Investimento Receita total $) \times 100$ & $\%$ \\
\hline & $\begin{array}{c}\text { índice de Serviços Prestados } \\
\text { (ISP) }\end{array}$ & $\begin{array}{c}\text { ISP }=\text { Número de Serviços Prestados. } \\
\text { Número Total Mensal }\end{array}$ & uni. \\
\hline \multirow[t]{3}{*}{ Clientes } & índice de Novos Clientes (INC) & $\begin{array}{c}\text { INC = (Número de Novos Clientes } \\
\text { Número de Visitas }) \times 100\end{array}$ & $\%$ \\
\hline & índice de Inadimplência (IN) & $\begin{array}{l}\text { IN }=\text { (Número de clientes inadimplentes } \\
\text { Número de clientes fidelizados }) \times 100\end{array}$ & $\%$ \\
\hline & índice de Ocupação (TO) & $\begin{array}{c}\text { TO = (Número total de funcionários } \\
\text { disponíveis Número total de clientes) } \mathrm{x}\end{array}$ & $\%$ \\
\hline \multirow{2}{*}{$\begin{array}{l}\text { Processos } \\
\text { Internos }\end{array}$} & $\begin{array}{c}\text { índice de Satisfação pelo } \\
\text { Serviço (ISS) }\end{array}$ & $\begin{array}{l}\text { ISS = (Número de clientes satisfeitos } \\
\text { com o serviço Número total de clientes }\end{array}$ & $\%$ \\
\hline & $\begin{array}{l}\text { índice de Frequência de } \\
\text { Reuniões (IFR) }\end{array}$ & $\begin{array}{c}\text { IFR = Número de reuniões realizadas } \\
\text { Total de dias de funcionamento da } \\
\text { empresa no mês }\end{array}$ & (Adimensional) \\
\hline $\begin{array}{l}\text { Aprendizage } \\
\quad \text { m e } \\
\text { Crescimento }\end{array}$ & $\begin{array}{c}\text { índice de Frequência de } \\
\text { Treinamentos (1FT) }\end{array}$ & $\begin{array}{l}\text { IFT = Número de treinamentos } \\
\text { realizados. Total de dias de } \\
\text { funcionamento da empresano mês }\end{array}$ & (Adimensional) \\
\hline
\end{tabular}

Fonte: Adaptado de Castro e Tavares (2016)

Em relação aos indicadores financeiros, além do lucro obtido pela Empresa Gama, que continua a ser, o principal indicador da organização, houve o desenvolvimento de um indicador que auxiliasse a mensurar o índice de investimento utilizado no próprio empreendimento.
Os objetivos da perspectiva dos clientes têm o propósito de mensurar o nível de fidelidade dos consumidores atuais, o índice de contratação de serviços pelas pessoas que visitam a empresa, bem como verificar o percentual de clientes que estão em débito.

Em relação aos processos internos, o índice de ocupação tem o intuito de melhorar a 
alocação dos materiais utilizados pelos funcionários. Já o índice de satisfação pelo serviço mensura, por meio de uma pesquisa de satisfação, os aspectos relativos sobre o desempenho dos funcionários e os serviços prestados pela Empresa Gama.

$\mathrm{Na}$ perspectiva de aprendizagem e crescimento, $\mathrm{o}$ indicador de frequência de reuniões mensura o índice de reuniões com funcionários para a troca de conhecimentos e experiências relacionadas à organização. Por outro lado, o indicador de frequência de treinamentos avalia o desenvolvimento profissional de cada um dos funcionários.
Após definir as estratégias e os indicadores para a Empresa Gama, fez-se o levantamento das iniciativas, a fim de adquirir um elevado nível dos indicadores propostos, seja de maneira preventiva ou corretiva.

Esta etapa consistiu em organizar iniciativas de modo a adquirir melhorias de forma contínua na organização, pois os indicadores, apesar de realizarem a mensuração do desempenho, não resultam em melhorias concretas nos resultados sem que haja ações atreladas a eles. A tabela 2 demonstra tais iniciativas.

Tabela 2 - Iniciativas para a melhoria contínua da Empresa Gama

\begin{tabular}{|c|c|c|}
\hline \multirow[t]{2}{*}{ Perspectiva } & Indicador & Iniciativas \\
\hline & Lucratividade (L) & Minimizar per das com Inadimplência \\
\hline Financeira & índice de Investimento (II) & $\begin{array}{l}\text { Analisar as fontes de receitas, custos e } \\
\text { lucros }\end{array}$ \\
\hline \multirow[t]{3}{*}{ Clientes } & índice de Serviços Prestados (ISP) & - Realizar promoções \\
\hline & índice de Novos Clientes (INC) & Oferecer descontos \\
\hline & índice de Inadimolência (IN) & - Realizar um cadastro para os clientes \\
\hline $\begin{array}{l}\text { Processos } \\
\text { Internos }\end{array}$ & índice de Ocupação (TO) & $\begin{array}{c}\text { Realizar um controle dos equipamentos mais } \\
\text { utilizados pelos colaboradores }\end{array}$ \\
\hline \multirow{3}{*}{$\begin{array}{l}\text { Aprendizagem e } \\
\text { Crescimento }\end{array}$} & índice de Satisfação pelo Serviço (ISS) & - Realizar pesquisas de satisfação \\
\hline & índice de Frequência de Reuniões (IFR) & $\begin{array}{l}\text { Fixar datas para a realização de reuniões } \\
\text { ordinárias }\end{array}$ \\
\hline & $\begin{array}{l}\text { índice de Frequência de Treinamentos } \\
\text { (IFT) }\end{array}$ & $\begin{array}{l}\text { - Realizar planejamento anual para } \\
\text { treinamento dos colaboradores }\end{array}$ \\
\hline
\end{tabular}

$\mathrm{Na}$ perspectiva financeira, deve-se erradicar os casos de inadimplência, bem como compreender as fontes geradoras de receitas e de custos e qual a destinação do lucro obtido com as vendas e prestações de serviços.

Já em relação aos indicadores da perspectiva dos clientes, salienta-se a importância das promoções e descontos com o objetivo de atrair novos consumidores e para fidelizar os atuais. Outra medida interessante seria treinar os colaboradores, de modo que eles possam atender os clientes de maneira mais apropriada.

No que concerne aos processos internos, recomenda-se identificar a frequência de uso dos objetos e de equipamentos utilizados pelos colaboradores da organização, visando melhorar uma melhoria no ambiente organizacional. Outro fator observado é a realização periódica de uma pesquisa de satisfação, fornecendo ações para melhorias.

Em relação à perspectiva de aprendizagem e crescimento, sugere-se o desenvolvimento de um planejamento quanto à realização das reuniões mensais e de treinamentos.

Após ter se concluído todos os procedimentos necessários para a execução do BSC, passando-se algumas semanas do processo em andamento, foi realizada uma comparação entre o antes e o depois da implantação da metodologia, no qual pode-se perceber uma redução satisfatória quanto a incidência de falhas na Empresa Gama no setor, os dados obtidos foram evidenciados no gráfico, representados como figura 4. A média de aproximadamente 10 falhas semanais (representado de azul) foi substituída por uma 
média de aproximadamente 02 falhas (representado de laranja), ou seja, houve uma redução de $75 \%$ das falhas existentes no setor, acarretando um aumento na produtividade e uma melhoria significativa do atendimento aos clientes.

Figura 4 - Comparativo das falhas presentes na Empresa Gama

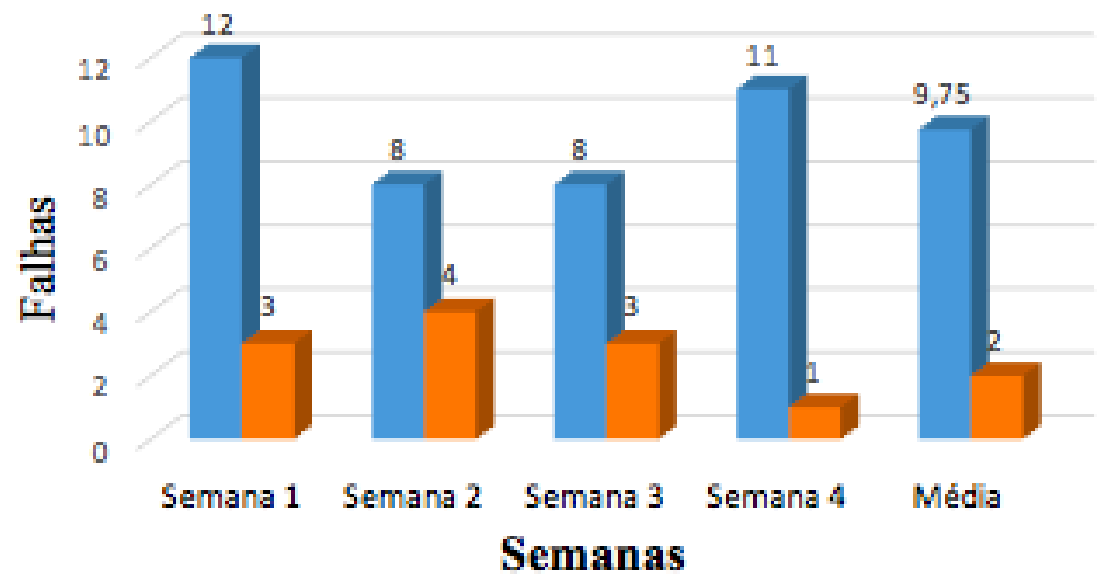

Antes Depois

Deste modo, foi possível perceber que após a implantação da melhoria os colaboradores teriam um controle maior sobre o local de trabalho, já que com o ambiente mais organizado a incidência de falhas se torna menor. Além disso, os colaboradores acabaram possuindo um respaldo maior sobre quais atitudes tomar caso ocorresse algum problema Esse fator fez com que se elevasse a motivação dos funcionários, já que com o treinamento adquirido, se torna possível a execução de escolhas que auxiliem no aumento da qualidade do serviço oferecido pela empresa.

\section{CONCLUSÃO}

Através desta pesquisa foi possível evidenciar que a união das metodologias BSC e 5S trazem para empresa em que ela foi implantada. A filosofia 5S é considerada

\section{REFERÊNCIAS}

[1]. ALMEIDA, M. I. R. Manual de Planejamento Estratégico. São Paulo, Atlas. 2001.

[2]. CANTO, Líliam Caroline Cardoso et al. Implantação do sistema 5S no setor de armazenagem de uma empresa de pequeno porte do sul de Santa Catarina. Fortaleza: XXVI ENEGEP, 2006. essencial para garantir a organização do ambiente e dos materiais que são utilizados diariamente pela Empresa Gama. Já a metodologia BSC é importante para realizar a mensuração de indicadores, bem como verificar os processos internos que apresentam algum tipo de deficiência.

Assim, foi possível destacar que a modelagem 5BSC'S se mostra eficiente, pois proporcionou a elaboração de um plano de ação eficiente que forneça maior confiabilidade e satisfação para com os clientes, além de permitir um controle mais efetivo dos equipamentos. Foi possível relatar também que com esta nova metodologia os funcionários estão mais preparados para a inserção de estratégias que favoreçam uma melhoria no ambiente de trabalho e um aumento na qualidade dos serviços oferecidos aos seus consumidores.

http://www.abepro.org.br/biblioteca/ENEGEP2006_ TR470319_7396.pdf. Acesso em: 23 nov. 2016.

[3]. CASTRO, B. D.; TAVARES M. N. R. Proposta de indicadores de desempenho utilizando o Balanced Scorecard: o caso de uma academia de ginástica. In: XXVI Encontro Nacional de 
Engenharia de Produção - ENEGEP. João Pessoa/PB. 2016.

[4]. GIL, Antônio Carlos. Técnicas de pesquisa em economia e elaboração de monografias. 4ํㅡㄹ São Paulo: Atlas, 2002.

[5]. KAPLAN, R. S.; NORTON, D. P. Conceptual foundations of the Balanced Scorecard. Harvard Business School, Working Paper, p:10-74. 2010.

[6]. MOREIRA, J. P. S. et al. Implantação das metodologias Método de Análise e Solução de Problemas (MASP) e 5S no almoxarifado de uma indústria de sidecar. In: XXV Encontro Nacional de Engenharia de Produção - ENEGEP. Fortaleza/CE. 2015.

[7]. NAKATA, Kenji. Acerto 100\%, desperdício zero: um novo conceito dos 5S.São Paulo: Editora Infinito, 2000.

[8]. NARO, G. TRAVAILLÉ, D. The role of the balanced scorecard in the formulation and control of strategic processes, Journal of Applied Accounting Research, Vol. 12 Iss: 3, pp.212 233. 2011.

[9]. OLIVEIRA, L. C. Balanced Scorecard: uma ferramenta de análise estratégica. Marketing Place, 2003.

[10]. PORTER, M. E. Estratégia competitiva: técnicas para análise de indústrias e da concorrência. 2.ed. Rio de Janeiro: Elsevier, 2004.

[11]. RIBEIRO, Haroldo. 5S: A Base para a Qualidade Total. Salvador, BA: Casa da Qualidade, 1994.

[12]. SILVA, E. L.; MENEZES, E. M. Metodologia da pesquisa e elaboração de dissertação. 4. ed. rev. atual. Florianópolis/SC: Laboratório de Ensino a Distância da UFSC, 2005.

[13]. TIDD, Joe et al. Gestão da Inovação. Porto Alegre: Bookman, 2008. 


\section{Capítulo 7}

\section{PREVISÃO DE TERMINO DE PROJETOS PELO MÉTODO DO PRAZO AGREGADO - COMPARAÇÃO ENTRE A ESTIMATIVA NO TERMINO INDEPENDENTE E A REPROGRAMACÃO BOTTOM-UP: ESTUDO DE CASO EM EMPREENDIMENTOS DE CONSTRUÇÃO CIVIL}

\section{Orlando Poci Junior}

Viviane Viana Sofiste de Abreu

Resumo: Desenvolver um cronograma não é um processo trivial, pois envolve uma série de técnicas de programações, logo, são relevantes métodos e técnicas de controle de cronograma. O conceito de prazo agregado é uma técnica de controle de prazo que permite estimar quando o projeto vai terminar, através da equação da Estimativa Independente no Término em função do tempo, sem a necessidade de realizar uma estimativa bottom-up detalhada do trabalho faltante. O objetivo deste trabalho é testar a capacidade da fórmula de previsão da estimativa independente no término (EINT) comparando o seu resultado com a estimativa bottom-up. Foram utilizados três empreendimentos onde foi aplicada a técnica de controle do prazo agregado durante a sua fase de construção. Em todos os empreendimentos foram realizados reagendamentos (um em cada) através da estimativa bottom-up detalhada. Os resultados desta reprogramação foram comparados com as previsões da estimativa independente no término em cada empreendimento, consideradas na mesma data base. Os resultados variaram em uma margem de mais ou menos cinco por cento. Conclui-se que foi possível verificar a poder da fórmula, porém esse valor não pode ser considerado aceitável para qualquer projeto, é preciso levar em conta a tolerância ao risco da empresa e as características de cada empreendimento. 


\section{INTRODUÇÃO}

O cronograma é a concretização do melhor entendimento de como conduzir o projeto um documento realmente importante. Possivelmente o cronograma é, por si só, o mais importante documento do projeto. (LIPKE, 2016)

Desenvolver um cronograma não é um processo trivial, pois envolve uma série de técnicas de programação. De acordo com o PMI® (2013), "desenvolver o cronograma é um processo de análise das sequências das atividades, suas durações, recursos necessários e restrições do cronograma visando criar o modelo do cronograma do projeto. "

No entanto, conforme explica KERZENER (2011), existem alguns problemas que podem impactar todas as técnicas de programação. Esses problemas incluem:

I. Uso de estimativas irrealistas para
o esforço e a duração;
II. Incapacidade de lidar com
desequilíbrios de carga de trabalho do
empregado;
III. Ter de compartilhar recursos
críticos em vários projetos;
IV. Recursos superalocados;
V. Reajustes contínuos na Estrutura
Analítica do Projeto, principalmente a
partir de mudanças no escopo;
VI. Gargalos não previstos.

Esses problemas ganham potencialidade quando em razão de que, conforme discutido por GREY (1997) apud KERZENER (2011), há uma tendência comum, especialmente entre as pessoas que foram convencidas que devem "pensar positivo", de não estarem dispostas a aceitar que uma atitude pode levar mais tempo do que o planejado. Para a pergunta "Qual o tempo máximo que a atividade pode ser realizada? ", elas respondem com: "Ela será finalizada no tempo previsto, pois não permitiremos que leve mais tempo."

O evento da copa do mundo de 2014 sediada no Brasil trouxe evidências do comportamento do parágrafo anterior. Conforme destaca FILHO (2016), muitos estádios foram entregues inacabados, em condições inadequadas, porém havia um deadline, que era de junho de 2014, que não podia ser postergado, afinal a tabela e os locais dos jogos já haviam sidos divulgados pela FIFA desde setembro de 2012.

Nesse panorama são relevantes métodos e técnicas de controle de cronograma. Segundo o PMI® (2013), "controlar o cronograma é o processo de monitoramento das atividades do projeto para atualização no seu progresso e gerenciamento das mudanças feitas na linha de base do cronograma para realizar o planejado". Esse processo fornece meios de reconhecer o desvio do planejado e tomar ações corretivas e preventivas, que podem incluir uma atualização ou reprogramação do plano vigente.

No universo do Gerenciamento de Projetos a metodologia do gerenciamento do valor agregado (GVA) é a de maior utilização. O PMI® (2013) traz a seguinte definição para este método:

Gerenciamento do valor agregado (GVA) é uma metodologia que combina escopo, cronograma, e medições de recursos para avaliar o desempenho e progresso do projeto. É um método comumente usado para medição do desempenho dos projetos. Ele integra a linha de base de custos e à linha de base do cronograma para formar a linha de base de medição de desempenho, que ajuda a equipe de gerenciamento do projeto a avaliar e medir o desempenho e progresso do projeto. (PMI®, 2013)

LIPKE (2013) ressalva que os profissionais aplicam o GVA no gerenciamento de custo e pouco utilizam as informações disponíveis sobre desempenho de prazo. O autor destaca três razões para este comportamento:

(1) Os especialistas em GVA acreditam que os indicadores de prazo não representam com precisão o desempenho real em prazo;

(2) Os indicadores de prazo do GVA são falhos em projetos atrasados;

(3) De modo contra intuitivo, os indicadores de prazo não são associados com o tempo, mas baseados em custo.

Ainda segundo LIPKE (2013), desde os primórdios do GVA, havia o desejo permanente por indicadores confiáveis de prazo que pudessem ser derivados das medidas do GVA, de preferência em unidades de tempo. 
O conceito de prazo agregado (PA) satisfaz as condições de melhoria do GVA descritas no parágrafo anterior. LIPKE (2013) afirma que o PA permite responder à pergunta mais frequente feita em revisões de status de projeto: "Quando você estima que esse projeto vai terminar? " Com a prática atual do GVA, os profissionais não conseguem responder à esta pergunta sem realizar uma estimativa bottom-up detalhada do trabalho faltante. Esse processo é extremamente entediante devido à complexidade e interdependências inerentes ao cronograma do projeto, especialmente quando subcontratados estão envolvidos. O PA oferece esse recurso na equação da Estimativa Independente no Término em função do tempo (EINT(t)).

LIPKE (2012) destaca que a capacidade de previsão desta equação mostrou-se razoavelmente boa em simulação e aplicação a dados de projetos reais; entretanto esta pesquisa propõe testar a capacidade da fórmula de previsão da estimativa independente no término (EINT) comparando o seu resultado com a estimativa bottom-up.

\section{FUNDAMENTAÇÃO TEÓRICA}

Segundo VIANA VARGAS (2013) a Análise (ou Gerenciamento) do Valor Agregado é a responsável pelo acompanhamento do desempenho geral do projeto através de uma perspectiva financeira. Ainda segundo o autor os três elementos básicos da análise são os seguintes:

(1) Valor Planejado (VP): Valor que indica a parcela que deveria ser gasta, considerandose o custo da linha de base da atividade. O VP é o custo proveniente do orçamento.

(2) Valor Agregado (VA): Valor que indica a parcela do orçamento que deveria ser gasta, considerando-se o trabalho realizado até 0 momento e o custo de linha de base para a atividade, atribuição ou o recurso. O VA é calculado como o percentual da atividade realizada, multiplicado pelo seu orçamento.

(3) Custo Real (CR): Valor que indica os custos reais decorrestes do trabalho já realizado por um recurso ou atividade, até a data de referência ou data atual do projeto, provenientes de dados financeiros.

No âmago do GVA encontra-se a Linha de Base da Medição de Desempenho (LBMD) que é a base para a análise de desempenho. A LBMD é desenvolvida no processo de planejamento e estimativa. O projeto é detalhado numa representação arquitetônica denominada Estrutura Analítica de Projeto (EAP). As estimativas de custo e duração são elaboradas no nível de detalhe mais baixo, ou seja, tarefas ou pacotes de trabalho. As tarefas são interligadas, para identificar dependências, e a alocação de recursos é ajustada e otimizada. O resultado é o cronograma do projeto a partir do qual a LBMD pode ser derivada: ou seja, a soma acumulada do custo ou valor planejado (VP) ao longo do tempo desde o início do projeto até a sua conclusão esperada, a duração prevista e o orçamento no término. (LIPKE, 2013)

LIPKE (2013) define o conceito de prazo agregado como, determinar o instante em que o VA acumulado deveria ter ocorrido segundo a LBMD. No gráfico da figura 1, no instante de tempo 7, que é o Tempo Real (TR), o valor agregado é dado por VA. Agora, segundo o plano, quando o valor de VA deveria ser atingido? A resposta é: no momento em que um valor planejado (VP) igual ocorrer na LBMD. Graficamente esse valor é determinado pela projeção do VA na curva LBMD (seta A), e, em seguida, traçando uma linha vertical para o eixo do tempo (seta B). O tempo desde o início do projeto até essa linha vertical $B$ é o valor de PA. 
Figura 7: Conceito de Prazo Agregado.

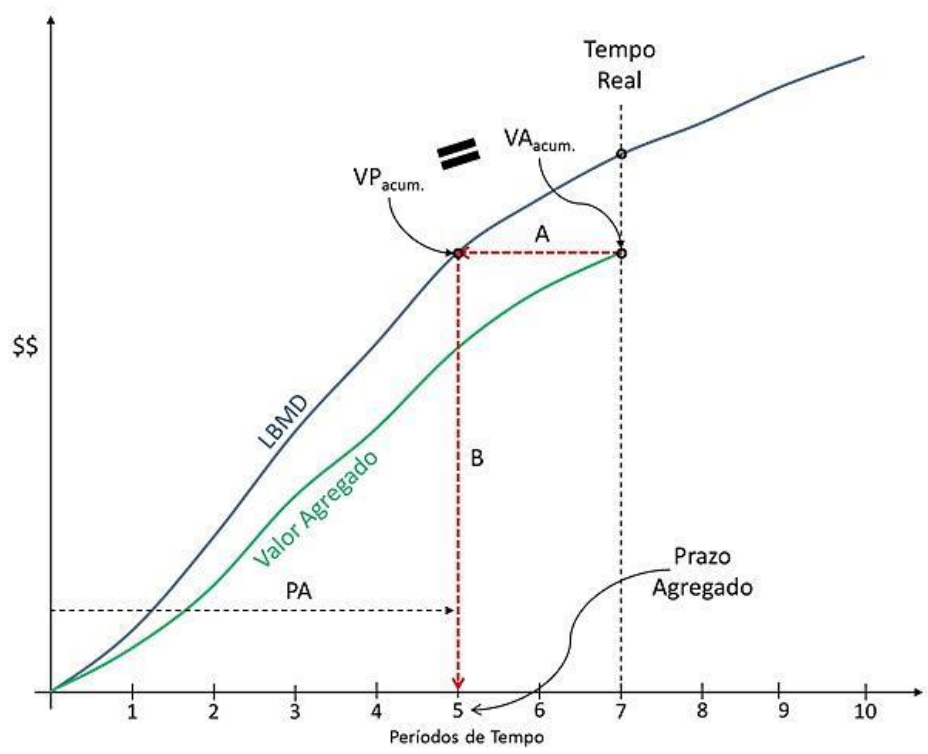

Fonte: Adaptado de Lipke (2013).

LIPKE (2013) alerta que o Prazo Agregado normalmente não é um número inteiro. A seta $\mathrm{B}$, geralmente estaria situada entre dois períodos. No entanto, na figura 1 é facilmente determinado que o PA é igual a cinco períodos de tempo. Quando a seta B situa-se entre dois períodos, o PA é determinado inicialmente pela contagem do número de períodos inteiros concluídos para, em seguida, adicionar a fração agregada do período incompleto. O Prazo Agregado desse período é determinado por interpolação linear dos custos conhecidos (VA \& VP), conforme mostrado na figura 2 abaixo.

Figura 8: Interpolação Fracionária de PA.

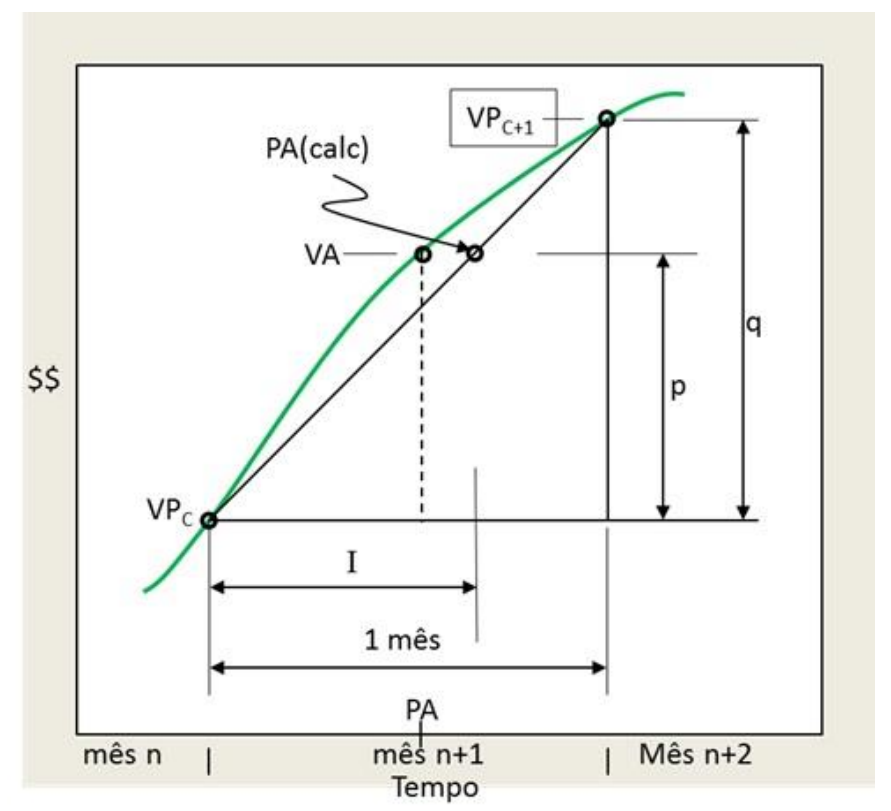

Fonte: Adaptado de Lipke (2013). 
No gráfico da figura 2, apenas o período incompleto é mostrado. Também são exibidos os três valores orçamentários de interesse: VA, VPC e VPC+1. LIPKE (2013) define que os subscritos $\mathrm{C}$ e $\mathrm{C}+1$ são os números dos períodos em ambos os lados da inserção da curva da LBMD em que VA $=$ VP. Neste exemplo utilizaram-se meses para o período de tempo. Mas, o período pode ser escolhido como semanas ou qualquer outra unidade de tempo desejada.

Do Triângulo no diagrama da figura 2 por semelhança de triângulos, sabe-se que:

$$
\frac{I}{1 \text { mês }}=\frac{p}{q} \rightarrow I=(p / q) \times 1 \text { mềs }
$$

Os valores de $\mathrm{p}$ e q são determinados por (ver figura 2):

$$
P=V A-V P_{C} \quad e \quad q=V P_{C+1}-V P_{C}
$$

Após a substituição algébrica chega-se a equação para calcular a parte fracionária medida do PA:

$$
I=\left(V A-V P_{C} / V P_{C+1}-V P_{C}\right) \times 1 m \hat{e} s
$$

Também mostrado na figura 2 estão PA e o prazo agregado calculado $\left(\mathrm{PA}_{\text {(calc.) }}\right)$. Segundo LIPKE (2013) PA representa a verdadeira intersecção da curva da LBMD, enquanto $\mathrm{PA}_{\text {(calc.) }}$ é o valor determinado por interpolação. Esses dois valores de PA ilustram que existe um erro inerente na interpolação ao substituir por uma linha reta um período de tempo da curva. De acordo com o autor o erro, ou seja, a diferença entre PA e PA(calc.), é extremamente pequeno, insignificante.

Com essa medida, através do índice de desempenho em prazo (IDP(t)), é possível calcular a eficiência de desempenho de cronograma. O IDP(t) é igual ao PA divido pelo tempo real (TR) que é a duração desde o início do projeto até o ponto de status. O $\operatorname{IDP}(\mathrm{t})$ é utilizado para fazer a previsão da duração do projeto através da fórmula: EINT(t) $=\mathrm{DP} / \mathrm{IDP}(\mathrm{t}) ;$ Onde: EINT = Estimativa Independente no Término; e DP = Duração Prevista. (LIPKE, 2012)

\section{METODOLOGIA}

Para atestar a testar a capacidade da fórmula de previsão da estimativa independente no término (EINT), serão utilizados a LBMD de três empreendimentos imobiliários:

Empreendimento A: Edificação residencial multifamiliar composta de um subsolo, um pavto térreo, um pavimento de uso comum, cinco pavimentos tipo e um telhado.

Empreendimento B: Edificação comercial com um pavimento de acesso/lojas/estacionamento, um pavimento de jirau, um pavimento de usos comum/2o garagem e cinco pavimentos de salas comerciais.

Empreendimento C: Edificação comercial dividida em shopping e hotel a parte correspondente ao shopping é composta de dois pavimentos de subsolo para estacionamento de veículos e serviços comuns e dois pavimentos de lojas. A parte correspondente ao hotel é composta de dois pavimentos de subsolo (excluídas as áreas destinadas a uso exclusivo do shopping), dois pavimentos de serviços e quatro pavimentos de quartos.

Todos esses empreendimentos foram acompanhados segundo a metodologia do prazo agregado. Todos tem em comum que, em algum momento da sua execução, foi feito uma reprogramação utilizando a técnica de estimativa bottom-up detalhada do trabalho faltante. Essa reprogramação foi feita através de um reagendamento da rede de precedência existente, nenhum serviço foi eliminado ou acrescido.

Então a pesquisa comparou a duração obtida após a reprogramação aplicada em cada empreendimento, com a duração resultante da Estimativa Independente no Término $(E I N T(t))$ resultante do método do prazo agregado.

\section{ESTUDO DE CASO}

\subsection{EMPREENDIMENTO A}

O plano do empreendimento tinha como intenção o início em 01/09/12 e término em 15/08/14, ou seja, uma duração de 713 dias. O valor total do custo previsto para esse empreendimento foi de $\mathrm{R} \$ 11.184 .644,93$. Esse valor distribuído no tempo, de acordo com o cronograma, tem como resultado a 
Gráfico 1: Gráfico LBMD do empreendimento A.

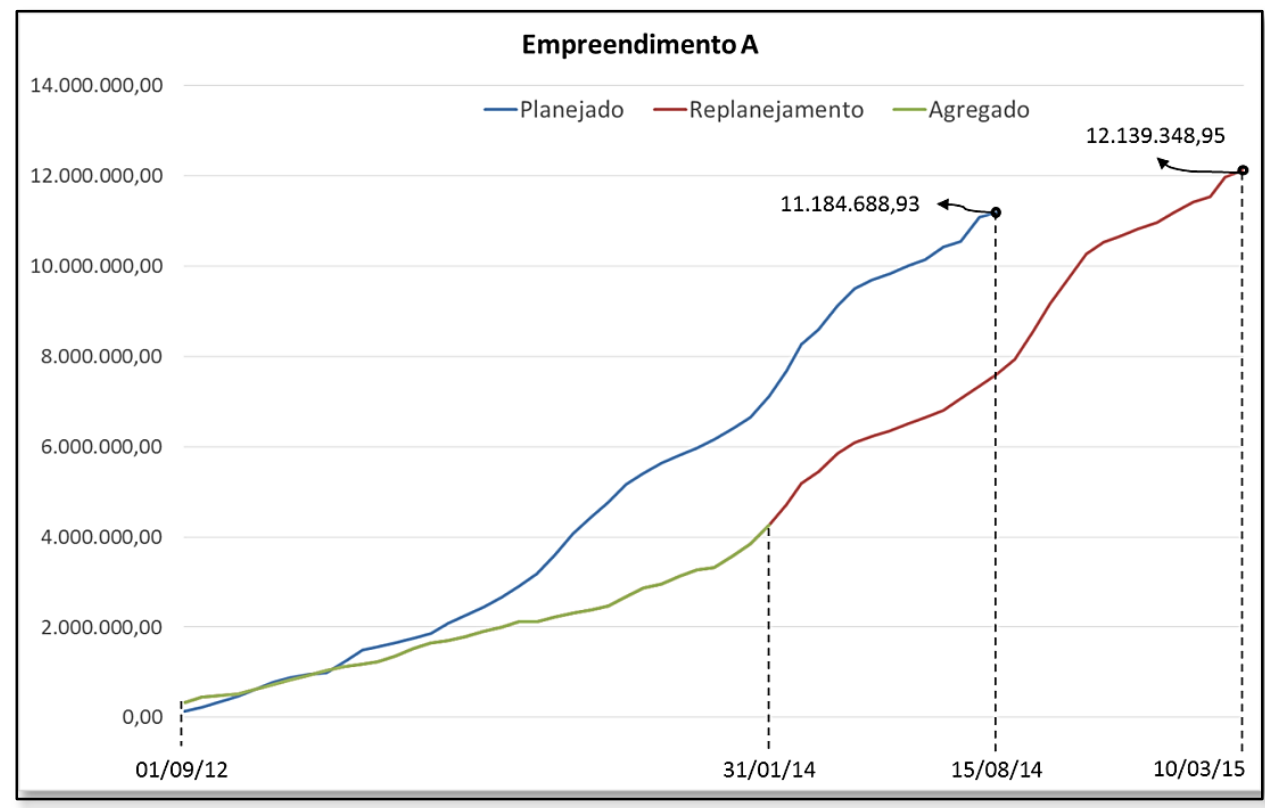

Fonte: Autores (2017)

Após o início do empreendimento foram registrados os valores agregados quinzenalmente, em função desses valores foram calculados o prazo agregado (PA) e o indicadore de desempenho de prazo $\left(\mathrm{IDP}_{\mathrm{t}}\right) \mathrm{de}$ acordo com a tabela 1 a seguir.

Tabela 2: Indicadores de prazo agregado do empreendimento A.

\begin{tabular}{ccccccccc}
\hline Data & Planejado & Agregado & TR & C & I & PA & IDP(t) & EINT(t) \\
\hline $15 / 09 / 12$ & $136.544,69$ & $326.621,08$ & 14,00 & 44,00 & 2,47 & 46,47 & 3,32 & 680,53 \\
$30 / 09 / 12$ & $230.925,73$ & $447.977,81$ & 29,00 & 44,00 & 12,69 & 56,69 & 1,95 & 685,31 \\
$15 / 10 / 12$ & $297.250,33$ & $481.461,42$ & 44,00 & 60,00 & 0,58 & 60,58 & 1,38 & 696,42 \\
$\vdots$ & $\vdots$ & $\vdots$ & $\vdots$ & $\vdots$ & $\vdots$ & $\vdots$ & $\vdots$ & $\vdots$ \\
$31 / 12 / 13$ & $6.411 .113,64$ & $3.583 .023,97$ & 486,00 & 317,00 & 14,19 & 331,19 & 0,68 & 867,81 \\
$15 / 01 / 14$ & $6.655 .767,78$ & $3.836 .789,33$ & 501,00 & 333,00 & 7,42 & 340,42 & 0,68 & 873,58 \\
$31 / 01 / 14$ & $7.113 .155,75$ & $4.254 .593,88$ & 517,00 & 348,00 & 7,59 & 355,59 & 0,69 & 874,41 \\
\hline
\end{tabular}

Fonte: Autores (2017).

Em 31/01/14 verificou-se que, em função do atraso verificado, seria impossível terminar o empreendimento no prazo original (15/08/14). Nesse período foi feito uma reprogramação, através do reagendamento da rede de precedencia em função dos dados apurados até a data de referência.

Com a reprogramação, o cronograma passou a indicar o término da obra para a data de 10/03/15, conforme mostra a curva vermelha do gráfico 1. Com esse reagendamento a duração total do empreendimento passou a ser de 920 dias, passando a custar $\mathrm{R} \$ 12.139 .348,95$.

\subsection{EMPREENDIMENTO B}

No empreendimento $B$ a previsão foi de iniciar em 01/12/13 e terminar em 31/03/16, o que corresponde a uma duração de 851 dias, totalizando $R \$ 19.944 .234,04$, conforme a LBMD (linha azul) do gráfico 2 a seguir. 
Gráfico 2: Gráfico LBMD do empreendimento B.

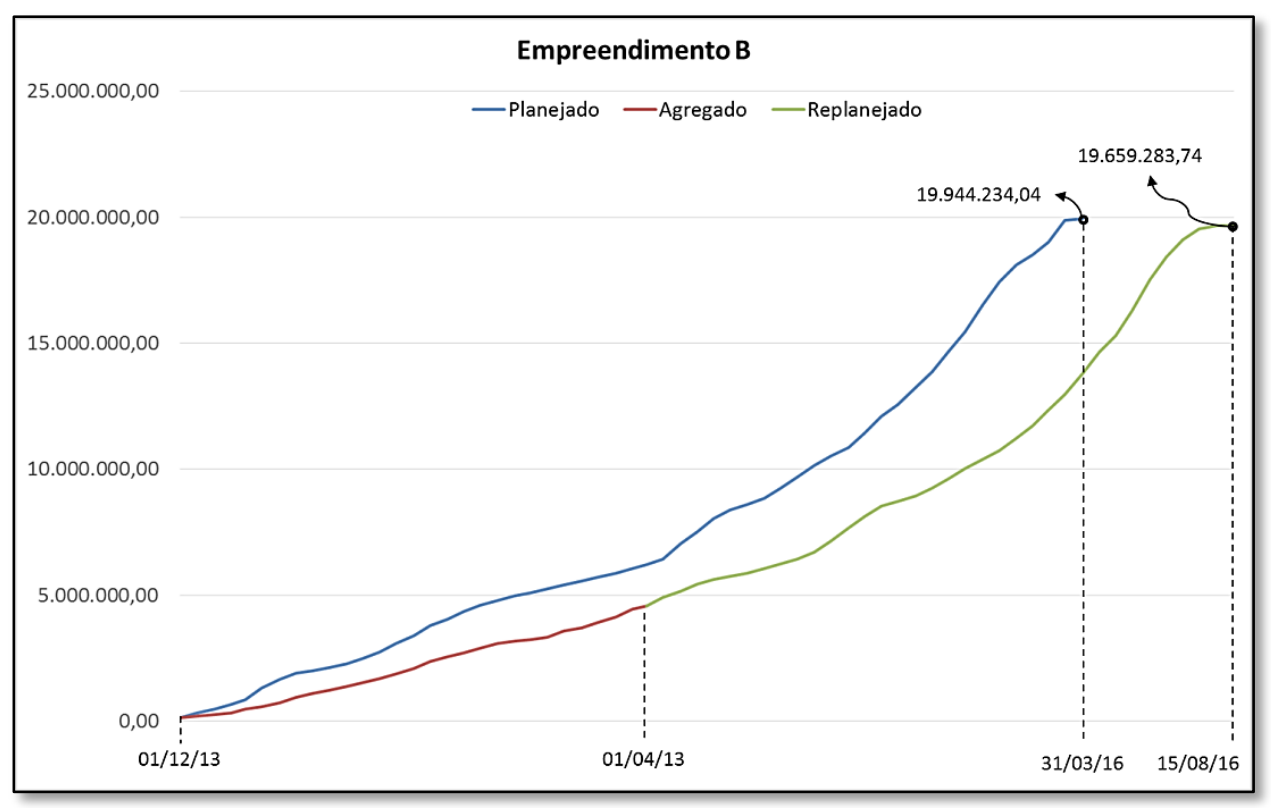

Fonte: Autores (2017).

Com o controle através da metologia do prazo agregado, chegou-se aos valores da tabela 2.

Em função dos atrasos verificados foi feito uma reprogramação a apartir de 28/02/15, através de um reagendamento da rede de precedências do cronograma. Como resultado a previsão de término passou para o dia 15/08/16, aumentando a duração total para 988 dias e passando a custar 19.659.283,74.

Tabela 3: Indicadores de prazo agregado do empreendimento B.

\begin{tabular}{ccccccccc}
\hline Data & Planejado & Agregado & TR & C & I & PA & IDP(t) & EINT(t) \\
\hline $31 / 12 / 13$ & $140.084,10$ & $134.137,51$ & 30,00 & 0,00 & 28,73 & 28,73 & 0,96 & 852,27 \\
\hline $15 / 01 / 14$ & $338.150,35$ & $198.640,46$ & 45,00 & 30,00 & 4,43 & 34,43 & 0,77 & 861,57 \\
$31 / 01 / 14$ & $477.311,85$ & $269.593,71$ & 61,00 & 30,00 & 9,81 & 39,81 & 0,65 & 872,19 \\
\hline$\vdots$ & $\vdots$ & $\vdots$ & $\vdots$ & $\vdots$ & $\vdots$ & $\vdots$ & $\vdots$ & $\vdots$ \\
$31 / 01 / 15$ & $5.873 .866,10$ & $4.142 .155,39$ & 426,00 & 257,00 & 4,78 & 261,78 & 0,61 & $1.015,22$ \\
$15 / 02 / 15$ & $6.064 .521,13$ & $4.433 .827,12$ & 441,00 & 288,00 & 4,80 & 292,80 & 0,66 & 999,20 \\
$28 / 02 / 15$ & $6.200 .877,95$ & $4.571 .776,11$ & 454,00 & 288,00 & 13,16 & 301,16 & 0,66 & $1.003,84$ \\
\hline
\end{tabular}

Fonte: Autores (2017).

\subsection{EMPREENDIMENTO C}

O útimo empreendimento do estudo tinha a previsão de iniciar em 01/04/13 e terminar em
15/04/16, o que corresponde a uma duração de 1.110 dias, totalizando $R \$ 137.123 .652,57$, conforme a LBMD (linha azul) do gráfico 3 a seguir. 


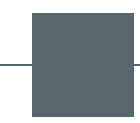

Gráfico 3: Gráfico LBMD do empreendimento C.

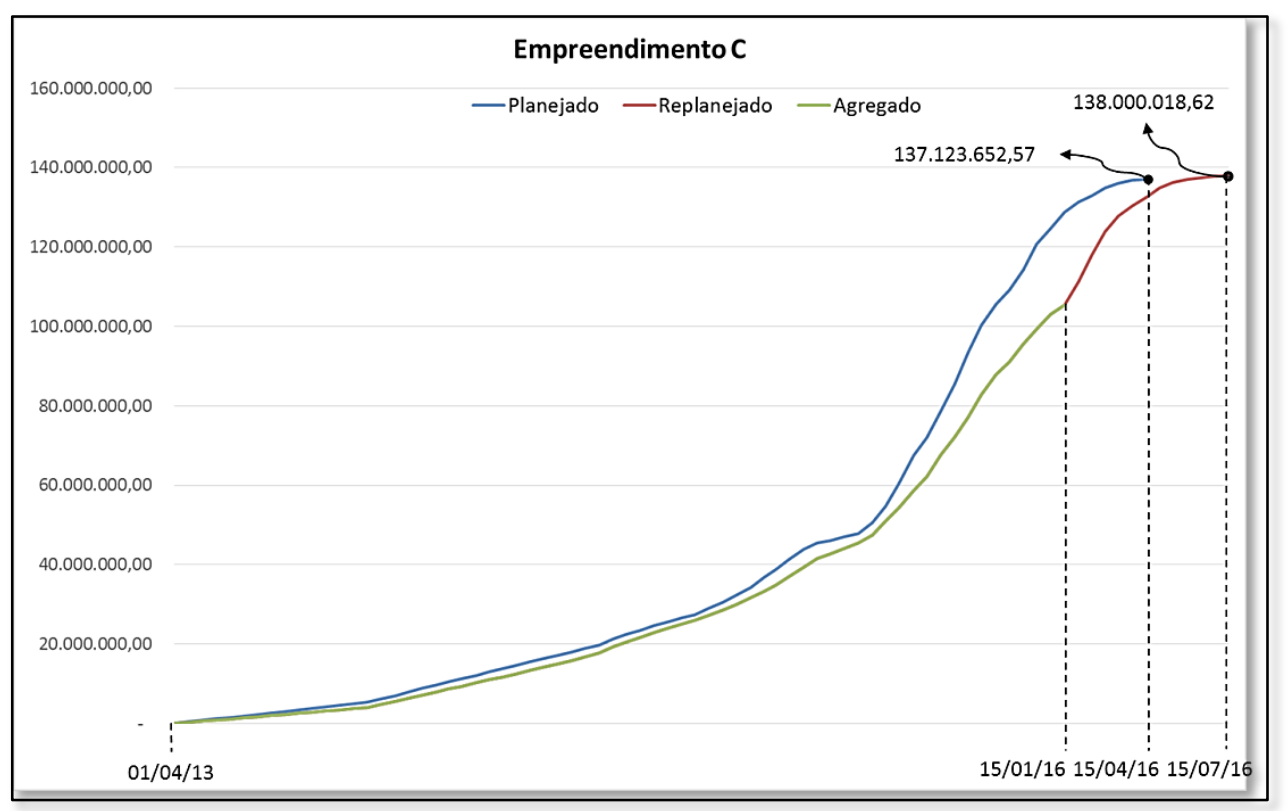

Fonte: Autores (2017).

Através da aplicação do método do prazo agregado (linha verde do gráfico 3) chegouse aos valores da tabela 3 .

Em função dos atrasos verificados foi feito uma reprogramação a apartir de 15/01/16, através de um reagendamento da rede de precedências do cronograma. Como resultado a previsão de término passou para o dia 15/07/16, que correspondeu a uma nova duração de 1.201 dias e passando a custar 138.000.018,62.

Tabela 4: Indicadores de prazo agregado do empreendimento $\mathrm{C}$

\begin{tabular}{ccccccccc}
\hline Data & Planejado & Agregado & TR & C & I & PA & IDP(t) & EINT(t) \\
\hline $30 / 04 / 13$ & $36.586,07$ & $27.286,82$ & 29,00 & 0,00 & 22,37 & 22,37 & 0,77 & $1.116,63$ \\
$15 / 05 / 13$ & $402.446,73$ & $300.154,99$ & 44,00 & 29,00 & 10,81 & 39,81 & 0,90 & $1.114,19$ \\
$31 / 05 / 13$ & $804.893,46$ & $600.309,98$ & 60,00 & 44,00 & 7,37 & 51,37 & 0,86 & $1.118,63$ \\
$\vdots$ & $\vdots$ & $\vdots$ & $\vdots$ & $\vdots$ & $\vdots$ & $\vdots$ & $\vdots$ & $\vdots$ \\
$15 / 12 / 15$ & $120.829 .708,90$ & $99.301 .809,05$ & 988,00 & 912,00 & 12,82 & 924,82 & 0,94 & $1.173,18$ \\
$31 / 12 / 15$ & $124.602 .339,20$ & $103.021 .900,73$ & $1.004,00$ & 927,00 & 7,81 & 934,81 & 0,93 & $1.179,19$ \\
$15 / 01 / 16$ & $128.759 .203,75$ & $105.345 .396,60$ & $1.019,00$ & 927,00 & 14,46 & 941,46 & 0,92 & $1.187,54$ \\
\hline
\end{tabular}

Fonte: Autores (2017).

\section{RESULTADOS}

O gráfico 4 abaixo apresenta as diferenças entre as durações (em dias) resultantes da reaprogramação do cronograma e as durações calculadas através da fórmula EINT(t) do método do prazo agregado. Ambas com as mesmas datas de referência nos respectivos empreendimentos. 
Gráfico 4: Gráfico comparativo entre duração do cronograma reagendado x EINT $(t)$.

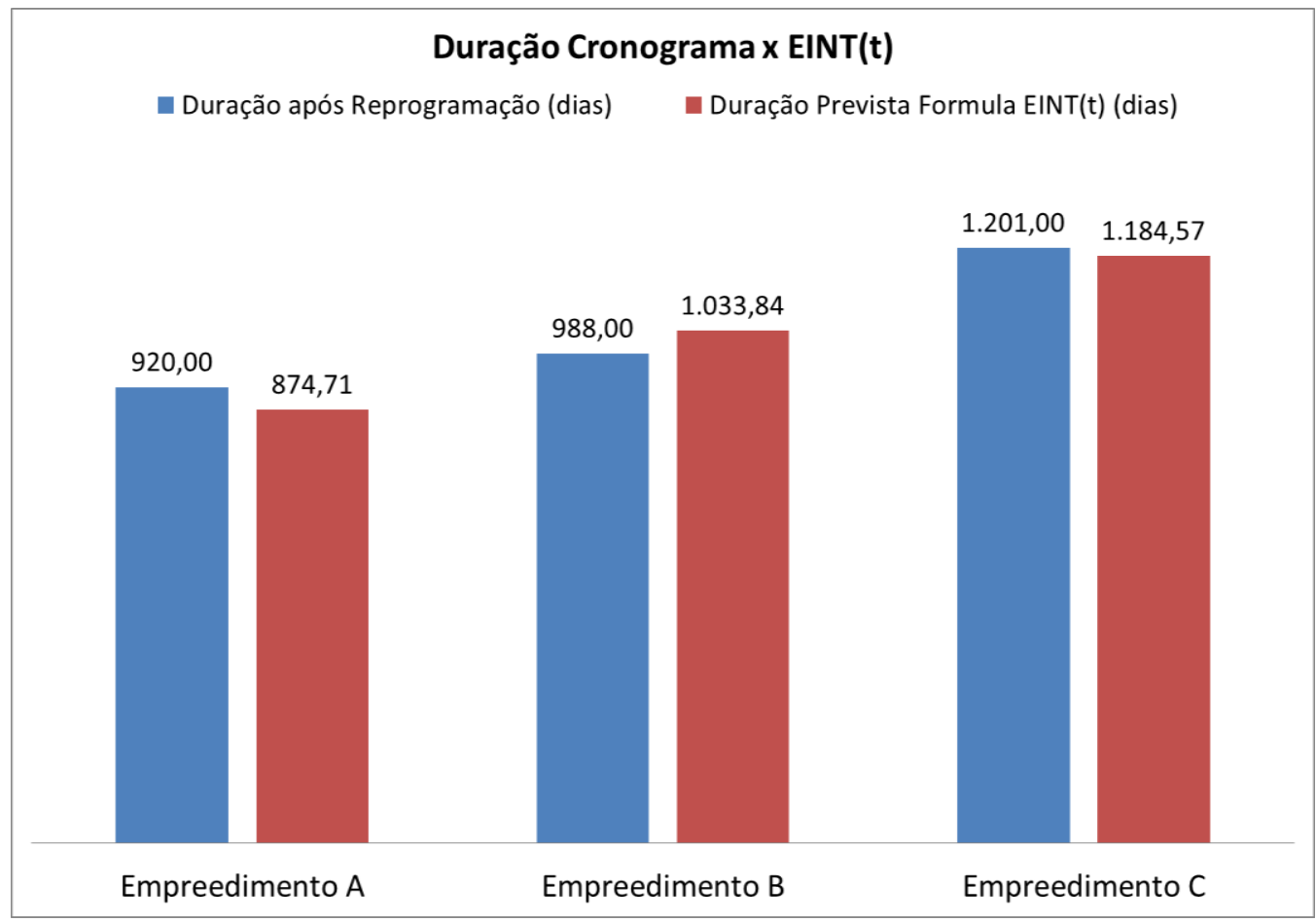

Fonte: Autores (2017)

A tabela 4 abaixo apresenta as diferenças em dias e o percentual entre as durações após a reprogramação e as durações calculadas pela fórmula EINT(t).

Tabela 5: Diferença entre duração reprogramada x EINT (t)

\begin{tabular}{lrr}
\hline Empreendimento & $\begin{array}{c}\text { Diferença } \\
\text { (dias) }\end{array}$ & $\begin{array}{c}\text { \% em relação a duração } \\
\text { prevista }\end{array}$ \\
\hline Empreedimento A & $-45,29$ & $-4,92 \%$ \\
Empreedimento B & 45,84 & $4,64 \%$ \\
Empreedimento C & $-16,43$ & $-1,37 \%$ \\
\hline
\end{tabular}

Fonte: Autores (2017).

\section{CONCLUSÕES}

Os dados apresentados permitem uma análise do poder da fórmula de previsão EINT(t), pois comparou o valor obtido com a fórmula e a duração resultante da reprogramação detalhada bottom up de cada empreendimento, na mesma data de referência.

Como o objetivo da previsão EINT(t) é simular a duração que seria prevista se na data de referência fosse feita uma reprogramação bottom up, esses valores são passíveis de comparação.
As diferenças ficaram em uma faixa de mais ou menos $5 \%$ em relação a data prevista, porém não se pode concluir que essa margem é aceitável ou não, pois isso depende de fatores ambientais, ou seja, características da empresa que realiza o empreendimento. Logo pode ser que derminada empresa consiga assimilar essa margem ou não.

Depende também das caracteristicas do empreendimento que, em função de uma análise de riscos, tenha uma margem aceitável de desvio na faixa de mais ou menos 5\%. Porém o trabalho atingiu o objetivo 
de testar a capacidade da fórmula do EINT(t), na medida em que transfou em números a sua comparação em relação a um plano

\section{REFERENNCIAS}

[1]. FILHO, Armando Terribili. Prazo Agregado: Uma abordagem prática para gestão de prazos em projetos., Mundo Project Management, Curitiba, $\mathrm{n}^{\circ}$ 67, p. 62-69, Fev. /Mar., 2016.

[2]. KERZNER, Harold. Gerenciamento de Projetos: uma abordagem prática. Traduzido por João Gama e Joyce Parado. 10ª ed., São Paulo: Blucher, 2011.

[3]. LIPKE, Walter T. Speculations of Project Duration Forecasting., PM World Today, Oklahoma, Vol. XIV, Issue III, Mar., 2012.

[4]. LIPKE, Walter T. Prazo Agregado: Uma extensão ao Gerenciamento do Valor Agregado... para a gerência do cronograma de execução. Traduzido por Paulo André. Publicação eletrônica. Rio de Janeiro: 2013. detalhado. Cabe avaliar especificamente em cada empreendimento se essa diferença é aceitável.

[5]. LIPKE, Walter T. Aderência ao cronograma: Um indicador útil na gestão de projetos. Traduzido por Paulo André de Andrade, Mundo Project Management, Curitiba, n 71, p. 60-67, Out. /Nov., 2016.

[6]. PMI $\quad$. Um guia do conhecimento em gerenciamento de projetos. Guia PMBOK@ $5^{a}$. ed. -Pennsylvania: Project Management Institute, 2013.

[7]. VIANA VARGAS, Ricardo. Análise de valor agregado: Revolucionando 0 gerenciamento de prazos e custos. $6^{\underline{a}}$ ed. Rio de Janeiro: Bransoft, 2013. 


\section{Capítulo 8}

\section{FATORES CRITTICOS DE SUCESSO DO LEAN MANUFACTURING, SEIS SIGMA, LEAN-SEIS SIGMA E SUSTENTABILIDADE: UMA REVISÃO SISTEMÁTICA DA LITERATURA}

\section{Fábio de Oliveira Neves; José Carlos de Toledo;}

Resumo: Os modelos de gestão da operação foram desenvolvidos em consonância com as mudanças das demandas pela sociedade civil, tais como, melhores condições de trabalho, sistema de produção limpa, produtos recicláveis e reutilizáveis além das condições sociais. Assim, surgem novos desafios de modelos de gestão sustentável para os processos de fabricação. Dessa forma, esse trabalho traz como instigação verificar quais os fatores críticos de sucesso (FCS) na adoção do Lean Manufacturing, Seis sigma e Lean-Seis sigma estão alinhados com o conceito de sustentabilidade. Foi realizado uma revisão sistemática da literatura analisando um total de trinta e nove (39) periódicos no período de 2000 a 2017. Foram identificados dez (10) FCS, sendo eles, técnicas de medição, cultura organizacional, liderança, técnicas de gestão, apoio da alta gerência, desempenho ambiental e organizacional, gestão de recursos humanos, parceria com fornecedores, envolvimento de pessoas e gerenciamento de tecnologias. Estes 10 fatores críticos de sucesso são divididos em dois elementos principais: os elementos fortes e os elementos moderados. Ainda, para a implementação da sustentabilidade no interior das empresas necessita-se do apoio da alta gerência por intermédio de atitudes pró-ativas.

Palavras-chave: Fatores críticos de sucesso, sustentabilidade, Lean Manufacturing, Seis-Sigma, Lean Seis Sigma. 


\section{INTRODUÇÃO}

No cenário global da atualidade, os principais desafios enfrentados por nossas sociedades são a mudança climática, a pobreza, a desigualdade, o crescimento populacional, a poluição e o aumentos dos custos de recursos. Empresas de todo o mundo encontram-se sob pressão de clientes, reguladores sócio ambientais e outras partes interessadas (sociedade civil) para gerenciar suas ações de uma maneira responsável no ambiente social, ambiental e econômico. Assim, melhorar o desempenho reduzindo o impacto dos processos industriais deixou de ser um papel imperativo empresarial. Emergindo a sustentabilidade como um novo modelo competitivo (WONG e WONG, 2014).

Um dos problemas mais complexos que as organizações enfrentam hoje é alcançar sucesso compatível com sustentabilidade. Esforços para melhorar a sustentabilidade ambiental e social em conjunto com a sustentabilidade econômica nos processos industriais têm, tradicionalmente, constituído barreiras às organizações (LONGONI e CAGLIANO, 2014, JOHANSSON e SUNDIN, 2014, SAGNAGe KAZANCOGLU, 2016).

Nos últimos anos, a utilização de sistemas de gestão que contempla a perspectiva de sustentabilidade tem sido explorada (CHERRAFI et al., 2016). Nesse contexto, o Lean Manufacturing e Seis Sigma surgem como importante resposta à adoção da sustentabilidade nas organizações. A possível integração de Lean Manufacturing, Seis Sigma e Sustentabilidade tiveram surgimento recente na academia, sendo que, neste trabalho, verificou-se um total de 39 publicações, em contraste com outros trabalhos publicados. Há poucos relatos de revisões de literatura, principalmente aqueles direcionados para a identificação dos fatores críticos de sucesso (FCS) que levam as empresas com leanmanufacturing, Seis Sigma e Lean Seis Sigma a adotarem conceitos de sustentabilidade (COMM e MATHAISEL, 2005; TAYYAB e SARKAR, 2016).

Assim, partindo da ausência de estudos sobre o tema, realizou-se uma revisão sistemática da literatura para identificar os FCS na adoção do Lean Manufacturing, Seis Sigma e Lean Seis Sigma nos princípios de sustentabilidade.

Estruturou-se o trabalho em cinco seções: a primeira faz uma breve introdução ao assunto estudado; a segunda apresenta uma breve revisão bibliográfica relativa ao tema; a metodologia é tratada na terceira seção e a apresentação dos resultados e sua discussão encontra-se na quarta. A quinta seção constitui a conclusão do trabalho.

\section{REVISÃO DA LITERATURA}

Na revisão da literatura são discutidos quatro (4) pontos que dão suporte a uma melhor compreensão do contexto de elaboração deste trabalho. Primeiramente, descreve-se o Lean Manufacturing, em seguida, o Seis Sigma e o Lean Seis Sigma. Finalmente, a última parte, ocupa-se de sustentabilidade.

\subsection{LEAN}

O conceito Lean tornou-se popular por meio do livro de Womack e Jones (1990),"The Machine. That Changed the World". A produção Lean foi definida de diversas formas, e uma das razões para a falta de uma única definição concreta está na evolução do conceito (HINES, et al. 2004). Todavia, seu objetivo principal é bem definido: produzir produtos e ou serviços de maior qualidade ao menor custo e tempo, eliminando os resíduos (HAJMOHAMMAD et al., 2013). No contexto do conceito Lean, resíduos são definidos como:

"Qualquer coisa que seja a quantidade mínima de equipamentos, materiais, peças, espaço e tempo, que sejam absolutamente essenciais para adicionar valor aos produtos" (RUSSEL e TAYLOR, 2000).

Cherrafiet al. (2016) identificou sete (7) formas de resíduos que possuem um impacto direto no desempenho e custos: transporte, inventário, movimento, espera, superprocessamento, sobre-produção e defeitos. Essas operações não transferem valor em forma de pagamentos para os clientes.

Além disso, com a ascensão da consciência ambiental e social, a definição lean foi expandida para que incorporasse os conceitos de sustentabilidade econômica, social e ambiental. Assim, não foi à toa que a Agência de Proteção Ambiental dos EUA definiu os objetivos lean como:

"Desenvolver produtos de alta qualidade, ao menor custo, com o menor tempo de espera. E eliminando continuamente o desperdício, 
respeitando as pessoas e o meio ambiente"(EPA, 2003).

As aplicações lean baseiam-se no envolvimento máximo das pessoas por meio de ferramentas e técnicas como, por exemplo, o 5S, Single- Minute- Exchange -de -Die (SMED), manutenção produtiva total (TPM) e Kanban. Alguns autores, como MartinezJurado (2014) e Sarkiset al. (2016) discutiram essas ferramentas como formas de aplicação prática, e o modo como podem afetar a sustentabilidade ambiental.

\subsection{SEIS SIGMA}

Para Schoroederet al. (2008),

"Seis Sigma é uma estrutura organizada, paralela intermediária, com o intuito de reduzir a variação na organização por meio de especialistas de melhoria. Um método estruturado e com métricas de desempenho, cuja finalidade é alcançar objetivos estratégicos" (SCHOROEDER et al. 2008)

O Seis Sigma é utilizado e implementado com sucesso em muitos contextos nos processos de produção (CHERRAFI et al., 2016). No entanto, de acordo com Dayna e Damien (2005),o Seis Sigma carece de um fundamento teórico e de uma base para pesquisas que não seja a de "melhores práticas". Os objetivos do Seis Sigma são melhorar o desempenho do processo e alcançar altos níveis de qualidade, investigando e eliminando as causas raízes de defeitos e minimizando processos e a variabilidade do produto ( $\mathrm{ZU}$ et al., 2008).O algoritmo Seis Sigma de resolução de problemas, denominado ciclo DMAIC, inclui cinco etapas: Definir, Medir, Analisar, Melhorar e Controlar (TAYYAB E SARKAR, 2016; GOSLING et al, 2016). É rotineiramente utilizado para orientar a implementação do Seis Sigma e para que consecução dos objetivos da empresa.

De um ponto de vista prático, os profissionais Black e Green Belts realizam projetos de resolução de problemas usando ferramentas derivadas da Gestão da Qualidade Total (TQM) (CHERRAFI et al., 2016). Tipicamente, depois de declarado o tipo de problema na fase Definir, ferramentas específicas são empregadas para Medir o estado atual do problema Em seguida, é tempo de Analisar e encontrar as causas raízes, para que sejam removidas e, assim, Melhorar o processo com planos de ação específicos. Finalmente, na fase de Controlar, as economias são alcançadas no nível sigma da Qualidade Crítica (CTQ). Características são medidas e certificadas para o gerente sênior que patrocina o projeto.

Do ponto de vista da pesquisa, o estudo realizado por Johansson e Sundin (2014), indica que o domínio da abordagem tradicional do Seis Sigma deve ser expandido e estendido para segurança ambiental, integridade e responsabilidade social que são mutuamente dependentes e críticos para o alcance do Seis Sigma. Nesse cenário, Marsh (2009) tem proposto um procedimento para integrar considerações ambientais na técnica Seis Sigma, como forma de aumentar o nível de eco-eficiência das empresas. Em geral, os estudos na área de Seis Sigma e sustentabilidade parecem sugerir que sua adoção tem um efeito benéfico no desempenho da sustentabilidade. Isso está de acordo com Caliaet al. (2009), que conduziram uma análise de 2096 projetos de prevenção da poluição, entre 1995 e 2007, e concluíram que o desempenho do programa de Prevenção da Poluição aumentou após a implementação do Seis Sigma. Além disso, as análises de 1906 projetos de poluição por meio do Seis Sigma, para redução de custos em 27 países, indicam que, nos países onde a implementação do Seis Sigma é mais expressiva, a poluição é evitada mais do que em países menos expressivos na implementação.

De fato, a implementação do Seis Sigma melhora a capacidade organizacional para o gerenciamento de projetos baseado em dados. Da mesma forma, Verrieret al. (2013) sugerem que o Seis Sigma também pode melhorar as características relacionadas à sustentabilidade, especialmente a sustentabilidade ambiental. A esse respeito, em recente estudo, Sarkiset al. (2016) afirmam que o modelo DMAIC, com os princípios e ferramentas do Seis Sigma, pode ajudar as organizações a implementar, gerenciar, sustentar e melhorar seu desempenho.

\subsection{LEAN SEIS SIGMA}

O termo Lean Six Sigma foi utilizado no período entre o final dos anos 90 e início dos anos 2000 (Wong e Wong, 2014; Sarkiset al., 2016), para descrever a combinação de filosofias Lean e Seis Sigma (FERGN e PRICE, 2005). Essa combinação visava superar as deficiências de cada um. A fusão de duas 
metodologias de melhoria contínua foi uma forma de as organizações aumentarem seu potencial (FERGN e PRICE, 2005). O Lean Seis Sigma é definido como um negócio estratégico em uma metodologia que aumenta o desempenho do processo e desenvolve a satisfação, liderança e resultados financeiros, melhorando a qualidade, a rapidez e os custos (PAMPANELLI et al., 2014). Conseguido através de aplicação de ferramentas e técnicas de Lean e Seis Sigma, o sucesso do Lean Seis Sigma é conhecido como um dos melhores híbridos de melhoria contínua. Muitas organizações, em todo o mundo, têm adotado a metodologia em suas operações para tornarem-se mais competitivas.

\section{SUSTENTABILIDADE}

O conceito de desenvolvimento sustentável foi aplicado pela primeira vez em 1972, na Conferência do Meio Ambiente Humano, realizada em Estocolmo (ROGERS et al., 2008). Existem várias definições de desenvolvimento sustentável, e a mais conhecida é a da Comissão Mundial sobre Meio Ambiente e Desenvolvimento (1987): "desenvolvimento econômico é o desenvolvimento que satisfaz as necessidades da geração atual sem comprometer as capacidades das futuras gerações, com o intuito de atender às suas próprias necessidades".

Uma definição similar que incide sobre o lucro, o planeta e as pessoas foi proposta pelo EPA (2003): "A sustentabilidade cria e mantém as condições sob as quais os seres humanos e a natureza podem existir em harmonia, que permitam satisfazer os requisitos sociais, econômicos e outros às gerações futuras. E para o desenvolvimento sustentável que reflete sobre o sistema produtivo "Nos setores manufatureiros, a sustentabilidade de produtos que utilizam processos e práticas que maximizam os lucros, minimizam os aspectos ambientais, conservam recursos naturais e energia, e são seguros para os funcionários, consumidores e comunidades (NACFAM, 2012). Os produtos devem igualmente assegurar as necessidades de uma população (ZHOU et al., 2000). Consequentemente, a fabricação exige uma visão completa que abranja não só o produto e os processos envolvidos na sua produção, mas também toda a cadeia de suprimento e o sistema de manufatura (FAULKNER e BADURDEEN, 2014).

Ao longo do tempo, a sustentabilidade tem sido implementada através de vários sistemas de gestão ambiental, gestão de saúde e de segurança, bem como responsabilidade social (Ql et al., 2013). Para tanto, muitos padrões e diretrizes foram emitidos tanto por organizações privadas, como por instituições públicas, a fim de orientar empresas para uma responsabilidade social corporativa adequada.

\section{METODOLOGIA}

Este trabalho é do tipo teórico-conceitual e realiza uma revisão bibliográfica sistemática de estudos que tratam dos fatores críticos de sucesso de Lean Manufacturing, Seis Sigma e Sustentabilidade. As publicações de interesse foram localizadas por meio de consultas nas bases de dados dos periódicos da CAPES (Coordenação de Aperfeiçoamento de Pessoal de Nível Superior). A utilização dessa base de dados é justificada por sua grande abrangência e facilidade de acesso para a maioria dos pesquisadores no Brasil. Inicialmente, é importante destacar que, para identificar, localizar e adquirir as publicações de interesse, foram consultadas as bases de dados disponíveis no portal periódicos da CAPES, na área de conhecimento Engenharia. Inicialmente buscou-se, em todo o texto de cada periódico, o termo "criticalf actors". Posteriormente, foram focados os termos "sustentability", "lean manufacturing", "six sigma", "lean six sigma" e, finalmente, "lean sustentability manufacturing".

Esta revisão inclui trabalhos de revisão publicados em revistas por pares, abrangendo publicações do período de 2000 a 2017.

\section{RESULTADOS E DISCUSSÕES}

A análise da Tabela 1 revela que os fatores críticos de sucesso encontrados nos 39 artigos estudados encontram-se divididos em dois tipos de elementos. Os moderados (cultura organizacional, liderança, técnicas de gestão, apoio da alta gerência, desempenho ambiental e organizacional, gestão de recursos humanos, envolvimento de pessoas e parcerias com fornecedores) e os fortes (técnicas de medição e métricas e gerenciamento de tecnologias). Os elementos moderados são difíceis de serem copiados, 
são vantajosos e regenerativos. Enquanto os elementos considerados fortes são os mais fáceis de serem copiados e não possuem, comparativamente, uma regeneração e vantagem ao ser comparado com os elementos moderados, já que estão mais relacionados a aspectos técnicos e de alta tecnologia (CHERRAFI et al., 2016 e SARKS et al., 2016).

Verifica-se que Hineset al. (2004), Bhasin (2008), Hines et al. (2004) Johansson e Sundin, (2014) e Wong e Wong, (2014) destacam a necessidade de os elementos fortes e moderados se contraporem. Não é suficiente centrar-se unicamente em algumas práticas (técnicas de medição e métricas) do Seis Sigma e Lean Manufacturing, faz-se necessário atender a aspectos como mudanças culturais e de pensamento organizacional, sendo importante abordar, conjuntamente, a estratégia e o apoio da alta gerência, o comportamento e compromisso de todos os membros da empresa, gerenciamento de tecnologias e ferramentas e técnicas.
Para Seuring e Muller, (2014) e Longoni e Cagliano (2015), lições devem ser tiradas de falhas passadas e o compromisso interno deve ser resolvido principalmente por meio da participação e comprometimento para os FCS, desempenho ambiental e organizacional, gestão de recursos humanos, envolvimento de pessoas e técnicas de gestão. Sendo necessária uma visão clara da liderança de gestão, uma comunicação estratégica eficaz, com consultas frequentes a interesses de grupos intervenientes, por meio de uma metodologia de gestão de projetos estruturada.

Ainda, para Sarkiset al (2016) e Verrier et al. (2014) a implementação da sustentabilidade no interior das organizações necessitam de ajuda da alta gerência, por meio das atitudes pró-ativas para liderar com mudanças e o compromisso da cultura organizacional. No envolvimento das pessoas, na gestão de recursos humanos e com os fornecedores.

Tabela 1: Fatores Críticos de Sucesso levantados na literatura

\begin{tabular}{|c|c|}
\hline Fatores Críticos de Sucesso & Autores \\
\hline Técnicas de Medição e Métricas & $\begin{array}{l}\text { Hineset al. (2004), Jha e Saini, (2011); Sagnag e Kazancoglu, (2016); } \\
\text { Faulkner e Badurdeen, (2014);Tayyab e Sarkar, (2016); } \\
\text { Hajmohammad, (2013), Bhasin (2008); Martinez e Jurado (2014); } \\
\text { Johansson e Sundin, (2014); Kováčová, (2013); Kurdve et al. (2014); } \\
\text { Vinodh et al. (2011);Wong e Wong, (2014); Thomas et al. (2010) e } \\
\text { Verrier et al.(2014);Freitas et al. (2017) e Freitas e Costa (2017) }\end{array}$ \\
\hline Cultura Organizacional & $\begin{array}{l}\text { Comm e Mathaisael, (2005); Hines et al. (2004); Tayyab e Sarkar, } \\
\text { (2016); Gosling et al, (2016); Thomas, (2008); Kurdve, (2014); } \\
\text { Seuring e Muller, (2008); Sarkis et al. (2016); Bhasin (2008), Martinez } \\
\text { e Jurado (2014), Freitas e Costa (2017); Freitas et al. (2017); } \\
\text { Zackrisson et al (2017) e Alhuraish et al. (2017) }\end{array}$ \\
\hline Liderança & $\begin{array}{c}\text { Calia, et al (2009); Comm e Mathaisael, (2005); Thomas, } \\
\text { (2008); Turesky e Connell (2010); Seuring e Muller, (2008); Tayyab e } \\
\text { Sarkar, (2016); Zackrisson et al (2017); Freitas et al. (2017) e Freitas e } \\
\text { Costa (2017) }\end{array}$ \\
\hline Técnicas de Gestão & $\begin{array}{l}\text { Hajmohammad, (2013); Fergn e Price, (2005), Abdul-Rashid et al. } \\
\text { (2017) e Helleno et al. (2017) }\end{array}$ \\
\hline Apoio da alta gerência & $\begin{array}{l}\text { Calia, et al. (2009); Johansson e Sundin, (2014); Kurdve, (2014); } \\
\text { Jørgensen et al., (2007); Sarkis et al (2016); Verrier et al. (2014); } \\
\text { Powell et al. (2017) e Alhuraish et al. (2017) }\end{array}$ \\
\hline $\begin{array}{l}\text { Desempenho ambiental e } \\
\quad \text { organizacional }\end{array}$ & $\begin{array}{l}\text { Hajmohammad, (2013); Bateman (2005); Johansson e Sudin, (2014); } \\
\text { Jørgensen, (2007); Sarkis et al. (2016); Seuring e Muller, (2008); } \\
\text { Freitas et al. (2017) e Yang et al. (2011) }\end{array}$ \\
\hline
\end{tabular}


Tabela 1: Fatores Críticos de Sucesso levantados na literatura (continuação)

\begin{tabular}{|c|c|}
\hline $\begin{array}{c}\text { Fatores Críticos de Sucesso } \\
\text { Gestão de Recursos Humanos }\end{array}$ & $\begin{array}{c}\text { Autores } \\
\text { Langenwalter (2006); Bateman (2005); Pampanelli et al. (2014); Wong } \\
\text { e Wong (2014); Cherrafi et al. (2016); Powell et al. (2017); Zackrisson } \\
\text { et al (2017) e Alhuraish et al. (2017) }\end{array}$ \\
\hline Parceria com Fornecedores & $\begin{array}{r}\text { Dayna e Damien (2005); Helper et al. (1997); Galeazzo et al. (2013); } \\
\text { Marsh (2009); Pampanelli et al. (2014); Vachon e Klassen (2006); } \\
\text { Vachon (2007); Helleno et al. (2017); Freitas e Costa (2017); Cherrafi } \\
\text { et al. (2016); Zackrisson et al (2017) e Abdul-Rashid et al. (2017) }\end{array}$ \\
\hline Envolvimento de Pessoas & $\begin{array}{c}\text { Alves e Alves (2015); Longoni e Cagliano (2015); Longoni et al. } \\
\text { (2014); Pampanelli et al. (2014); Cherrafi et al. (2016); Powell et al. } \\
\text { (2017); Zackrisson et al (2017) e Alhuraish et al. (2017) }\end{array}$ \\
\hline Gerenciamento de Tecnologias & $\begin{array}{c}\text { Martinez-Jurado (2014); Hineset al. (2004); Helleno et al. (2017); } \\
\text { Sarkis et al. (2016); Zackrisson et al (2017) e Powell et al. (2017) }\end{array}$ \\
\hline
\end{tabular}

Dessa forma,o conceito de sustentabilidade seria incorporado na fase de resultados no controle sobre as melhorias alcançadas, no sentido de propriedade e monitorização e controle.

Em suma, os elementos moderados têm papel decisivo na implementação do Lean

\section{CONSIDERAÇÕES FINAIS}

Neste estudo, foi realizada uma revisão da literatura sobre os fatores críticos de sucesso da integração de Lean, Seis Sigma e Sustentabilidade, analisando 39 artigos publicados até julho de 2017, considerados relevantes para o estudo.

Identificaram-se dez principais fatores críticos de sucesso: técnicas de medição, cultura organizacional, liderança, técnicas de gestão, apoio da alta gerência, desempenho ambiental e organizacional, gestão de recursos humanos, parceria com fornecedores, envolvimento de pessoas e gerenciamento de tecnologias.

Esses fatores críticos são divididos em dois tipos de elementos principais: os moderados (cultura organizacional, liderança, técnicas de gestão, apoio da alta gerência, desempenho ambiental e organizacional, gestão de manufacturing, Seis Sigma ou Lean-seis sigma com os conceitos de sustentabilidade e, em confronto com os elementos considerados fortes, tenderão a ter maior facilidade na sua concepção e consecução e maior dificuldade de serem imitados.

recursos humanos, envolvimento de pessoas e parcerias com fornecedores) e os fortes (técnicas de medição e métricas e gerenciamento de tecnologias). Os fatores moderados, em comparação com os fortes, são os que têm maiores dificuldades de serem copiados, sendo mais vantajosos e regenerativos.

Ainda, a implementação da sustentabilidade no interior das empresas necessita de ajuda da alta gerência através das atitudes próativas para liderar com mudanças e o compromisso da cultura organizacional

Como sugestão para futuros trabalhos, recomenda-se verificar a motivação, os benefícios e dificuldades da integração do Lean, Seis Sigma e sustentabilidade, além dos efeitos negativos dessa integração. 


\section{REFERÊNCIAS}

[1]. ABDUL-RASHID, S.H., SAKUNDARINI, N., GHAZILLA, R.A.R., THURASAMY, R. The impact of sustainable manufacturing practices on sustainability performance: empirical evidence from Malaysia. International Journal of Operations \& Production Management, n. 2, p.182-204, 2017.

[2]. AlHURAISH, I., ROBLEDO, C., KOBI, A. A Comparative Exploration of Lean Manufacturing and Six Sigma in terms of their Critical Success Factors. Journal of Cleaner Production, n.15, p.325337, 2017.

[3]. ALVES, J.R.X., ALVES, J.M. Production management model integrating the principles of lean manufacturing and sustainability supported by the cultural transformation of a company. International Journal Production Research, n. 11, p.1-1, 2015.

[4]. BATEMAN, N., 2005. Sustainability: the elusive element of process improvement. International Journal Operations Production Management, n.3, p.261-276, 2005.

[5]. BHASIN, S. Lean and performance measurement.Journal of Manufacturing Technology Management, n. 5, p. 670-684, 2008.

[6]. CALIA, R.C., MÜLLER-GUERRINI, F., DE CASTRO, M.The impact of Six Sigma in the performance of a Pollution Prevention program.Journal of Cleaner Production, n 17, p.1303-1310, 2009.

[7]. CHERRAFI, A., ELFEZAZI, S., CHIARINI, A., MOKHLIS, A., BENHIDA, K.The integration of lean manufacturing, Six Sigma and sustainability: a literature review and future research directions for developing a specific model. Journal of Cleaner Production, n.15, p.828-846, 2016.

[8]. COMM, C.L., MATHAISEL, D.F.X. A case study in applying lean sustainability concepts to universities. International Journal of Sustentabilty Higher Education, n.2, p.134-146, 2005.

[9]. DAYNA, F.S., DAMIEN, J.P., Use the supply relationship to develop lean and green suppliers. Supply Chain Management An International Journal, n. 1, p.60 - 68, 2005.

[10]. EPA, Lean Manufacturing and the Environment: Research on Advanced ManufacturingSystems and the Environment and Recommendations for Leveraging Better Environmental Performance, 2003. http://www.epa.gov/lean/environment/pdf/leanrepor t.pdf (acessado 8 de Dezembro 2016).

[11]. FAULKNER, W., BADURDEEN, F. sustainable value stream mapping (Sus-VSM): methodology to visualize and assess manufacturing sustainability performance. Journal of Cleaner Production, n.15, p.8-18, 2014.

[12]. FERNG, J., PRICE, A.D.F. An exploration of the synergies between Six Sigma, total quality management, lean construction and sustainable construction. International Journal Sigma and Competitive Advantage, n.2, p.167-187, 2005.

[13]. FREITAS, J.G., COSTA, H.G. Impacts of Lean Six Sigma over organizational sustainability: a systematic literature review on Scopus base. International Journal of Lean Six Sigma, n.1, p.89108, 2017.

[14]. FREITAS, J.G., COSTA, H.C., FERRAZ, F.T. Impacts of Lean Six Sigma over organizational sustainability: A survey study. Journal of Cleaner Production, n.10, p.262-275, 2017.

[15]. GALEAZZO, A., FURLAN, A., VINELLI, A. Lean and green in action: interdependencies and performance of pollution prevention projects. Journal of Cleaner Production, n.15, p.191-200, 2013.

[16]. GOSLING, J., JIA, F., GONG, Y., BROWN, $S$.The role of supply chain leadership in the learning of sustainable practice: Toward an integrated framework. Journal of Cleaner Production, n.20, 1458-1469, 2016.

[17]. HAJMOHAMMAD, S., VACHON, S., KLASSEN, R. D., GAVRONSKI, I. Reprint of Lean management and supply management: their role in green practices and performance. Journal of Cleaner Production, n. 56, p.86-93, 2013.

[18]. HELLENO, A.L., MORAES, A.J.I., SIMON, A.T. Integrating sustainability indicators and Lean Manufacturing to assess manufacturing processes: Application case studies in Brazilian industry. Journal of Cleaner Production, n.1, p.405-416, 2017.

[19]. HELPER, S., CLIFFORD, P.G., ROZWADOWSKI, H. Can Green Be Lean? Academy of Management Annual Meeting, n. 1, p. 8-13, 1997.

[20]. HINES, P., HOLWEG, M., RICH, N. Learning to evolve: a review of contemporary lean thinking. International Journal Operations Production Management, n. 10, p.994-1011, 2004.

[21]. JHA, R., SAINI, A. K. Process Benchmarking through Lean Six Sigma for ERP Sustainability in Small \& Medium Enterprises. International Journal of Information Technology, n.2, p.382-390, 2011.

[22]. JOHANSSON, G., SUNDIN, E. Lean and green product development: two sides of the same coin? Journal of Cleaner Production, n.15, p.104121, 2014

[23]. JØRGENSEN, F., MATTHIESEN, R., NIELSEN, J., JOHANSEN, J. Lean maturity, lean sustainability. Advances in Production Management Systems, n. 246, p. 371-378, 2007.

[24]. KOVÁčOVÁ, L. The integration of lean management and sustainability.Transfer inováci, n.26, p. 195-199, 2013. 
[25]. KURDVE, M., ZACKRISSON, M., WIKTORSSON, M., HARLIN, U. Lean and green integration into production system models e experiences from Swedish industry. Journal of Cleaner Production, n. 15, p.180-190, 2014.

[26]. LANGENWALTER, G. Life is Our Ultimate Customer: From Lean to Sustainability. Target, n.1, p. 5-15, 2006.

[27]. LONGONI, A.; CAGLIANO, R. Environmental and social sustainability priorities. International Journal of Operations \& Production Management, n.2, p. 216-245, 2015.

[28]. LONGONI, A.; GOLINI, R., CAGLIANO, C. The role of new forms of work organization in developing sustainability strategies in operations, International Journal of Production Economics , Parte A, p. 147-160, 2014.

[29]. MARSH, J. Exploration of the Impact of Business Improvement approach Lean Six Sigma on the Environment. International Journal Environmental Cultural Economic Society Sustainability, n. 1, p.357-366, 2009.

[30]. MARTÍNEZ-JURADO, P., J., MOYANOFUENTES, J. Lean Management, Supply Chain Management and Sustainability: A Literature Review.Journal of Cleaner Production, n.15, 134, 150, 2014.

[31]. NACFAM (National Council for Advanced Manufacturing),

2012.http://www.nacfam.org/PolicyInitiatives/Sustai nableManufacturing/tabid/64/Default.aspx

(acessado 7 Dezembro 2016).

[32]. PAMPANELLI, A.B., FOUND, P., BERNARDES, A.M. A lean \& green model for a production cell.Journal of Cleaner Production, $\mathrm{n}$. 15, p.19-35, 2014. POWELL, D., LUNDEBY,S., CHABADA, L., DREYER, $H$. Lean Six Sigma and environmental sustainability: the case of a Norwegian dairy producer. International Journal of Lean Six Sigma, n. 1, p.53-64, 2017

[33]. QI, G., ZENG, S., YIN, H., LIN, H. ISO and OHSAS certifications: how stakeholders affect corporate decisions on sustainability. Management Decision, n.10, p.1983-2005, 2013.

[34]. ROGERS, P.P., JALAL, K.F., BOYD, J.A. An introduction to sustainable development.Glen Educational Foundation, Inc., London, 2008.

[35]. RUSSELL, R.S., TAYLOR, B.W. Operations Management. Prentice-Hall, Englewood Cliffs, 2000.

[36]. SAGNAG, M., KAZANCOGLU, Y. Integration of green lean approach with six sigma: an application for flue gas emissions. Journal of Cleaner Production, n. 20, p.112-118, 2016.

[37]. SARKIS, J., BAI, C. JABBOUR, A.B.L.S., JABBOUR, C.J.C.,SOBREIRO, A.V. Connecting the pieces of the puzzle toward sustainable organizations: A framework integrating OM principles with GSCM. Benchmarking: An International Journal, n.6, p. 2-27, 2016.

[38]. SEURING, S., MÜLLER, M., From a literature review to a conceptual framework for sustainable supply chain management. Journal of Cleaner Production, n.15, p.1699-1710, 2008.

[39]. Schroeder, R.G., Linderman, K., Liedtke, C., Choo, A.S. Six Sigma: Definition and underlying theory. Journal of Operations Management, n.4, p.536-554, 2008.

[40]. TAYYAB, M., SARKAR, B. Optimal batch quantity in a cleaner multi-stage lean production system with random defective rate. Journal of Cleaner Production, n. 15, p.922-934, 2016.

[41]. THOMAS, A. J., ROWLANDS, H., BYARD, P., ROWLAND-JONES, R. Lean Six Sigma: an integrated strategy for manufacturing sustainability, International Journal Six Sigma and Competitive Advantage, n. 4, p. 333-354, 2008.

[42]. TURESKY, E.F., CONNELL, P., Off the rails: understanding the derailment of a lean manufacturing initiative. Organization Management Journal, n 2, p.110-132, 2010.

[43]. VACHON, S. Green supply chain practices and the selection of environmental technologies.International Journal of Production Research, n.18, p.4357-4379, 2007.

[44]. VACHON, S., KLASSEN, R.D. Extending green practices across the supply chain: The impact of upstream and downstream integration. International Journal of Operations \& Production Management, n. 7, p.795 - 821, 2006.

[45]. VERRIER, B., ROSE, B., CAILLAUD, E.,REMITA, H. Combining organizational performance with sustainable development issues: the Lean and Green project benchmarking repository. Journal of Cleaner Production, n. 15, p. 83-93, 2014.

[46]. VINODH, S., ARVIND, K.R., SOMANAATHAN, M. Tools and techniques for enabling sustainability through lean initiatives. Clean Technologies and Environmental Policy, n.3, p.469479, 2011.

[47]. Womack, J.P., Jones, D.T., Ross, D., 1990. The Machine that Changed the World. Rawson

[48]. Associates, New York.

[49]. WONG, W. P., WONG, K.Y. Synergizing an ecosphere of lean for sustainable operations. Journal of Cleaner Production, n.15, p.51-66, 2014.

[50]. YANG, M.G. M., HONG, P., MODI, S.B. Impact of lean manufacturing and environmental management on business performance: An empirical study of manufacturing firms. International Journal Production Economics, n.129, p.251-261, 2011. 
[51]. ZACKRISSON, M., KURDVE, M., SHAHBAZI, S., WIKTORSSON, M., WINROTH, M., LANDSTRÖM, A., ALMSTRÖM, P., ANDERSSON, C., WINDMARK, C., ÖBERG, A.E., MYRELID, A. Sustainability performance indicators at shop floor level in large manufacturing companies. Procedia CIRP, n. 1, 457-462, 2017.

[52]. ZHOU, Z., CHENG, S., HUA, B. Supply chain optimization of continuous process industries with sustainability considerations.Computer \& Chemical Engineering, n.1, p.1151-1158, 2000.

[53]. ZU, X., FREDENDALL, L.D., DOUGLAS, T.J. The evolving theory of quality management: the role of Six Sigma. Journal of Operations Management, n.5, p. 630-650, 2008. 


\section{Bapítulo 9}

EFICÁCIA DE PROGRAMAS COM ENFOQUE EM TREINAMENTO DE PESSOAL NA ÁREA DE SEGURANÇA DO TRABALHO: UM ESTUDO DE CASO EM UMA INDÚSTRIA DE FABRICAÇÃO DE PAINÉIS DE MADEIRA NO ESTADO DO PARANÁ

\section{Maria Eleonor Litaiff}

Ana Caroline Dzulinski

\section{Oscar Regis Junior}

Resumo: Este capítulo relata uma pesquisa que teve como objetivo demonstrar a evolução do desempenho de segurança do setor de painéis de madeiras em uma empresa da região dos campos gerais no paraná. Mais especificamente analisar a aplicação de uma ferramenta de prevenção da área de segurança do trabalho e apresentar seus resultados. A ferramenta adotada para o estudo foi o stop, que consiste em sete módulos de aplicação, onde se realizou treinamento sobre uma ferramenta para um grupo de gestores. Para completar o estudo de caso foram aplicadas avaliações individuais para obtenção de dados quanto à aprendizagem dos módulos da ferramenta. Observou-se não início do trabalho que a taxa de gravidade dos acidentes estava maior e ou quase não havia registro de quase acidentes. Após a aplicação da ferramenta comprovou-se que a ferramenta é eficiente, pois houve uma redução na gravidade dos acidentes e um aumento nos registros dos quase acidentes, demonstrando o trabalho preventivo que a ferramenta proporciona. 


\section{INTRODUÇÃO}

Grande parte das indústrias trabalha para reduzir, ao máximo, o número de acidentes e principalmente fatalidades em seus ambientes de trabalho, para isso buscam no mercado várias ferramentas e formas de fazer gestão, que juntas, colaboram para que sejam alcançados os objetivos dentro da área de segurança e saúde do trabalhador.

Toda essa preocupação dá-se devido ao impacto das perdas, não somente financeiras, dos acidentes e doenças ocupacionais tanto nas empresas como na sociedade como um todo. Não pode ser tolerável que pessoas percam suas vidas, membros ou fiquem inválidas devido à falta de segurança dentro dos locais de trabalho. Devido ao alto impacto, o governo também tem uma forte frente de trabalho, criando normas e instruções, realizando fiscalizações e aplicando multas às empresas que não cumprem as legislações existentes. O papel do Ministério do Trabalho é de fundamental importância para que as empresas saiam da inércia que se encontram quanto ao tema de prevenção e busquem alternativas de sucesso para que não seja somente uma idealização o conceito de "zero acidente".

Como uma forma de colaborar na redução dos acidentes foi desenvolvido um programa baseado na observação do trabalhador, que trabalha na transformação do comportamento inseguro para o comportamento seguro, denominado STOP $尺$ (Programa de Treinamento de Segurança por Observação). Esta ferramenta de supervisão é um programa de treinamento de segurança abrangente, projetado para ensinar desde a alta gerência até os supervisores de primeira linha, a como eliminar atos inseguros que são a principal causa de todos os acidentes.

A mudança de comportamento é uma atitude muito difícil de ser alcançada, pois se trata, na maioria das vezes, de crenças, valores pessoais e costumes de cada ser humano, que muitas vezes não entende ou não aceita determinadas movimentações do seu eu próprio. Visando este aspecto, o programa STOP® é uma ferramenta que auxilia na mudança de comportamento, proporcionando tudo que é necessário para alcançar excelência em segurança, enfatizando aos envolvidos os principais motivos de se trabalhar com segurança: vida, família, profissão, sucesso, valores.
Direcionando, portanto, os aspectos comportamentais da segurança do trabalho e a gestão envolvida por parte das indústrias, o presente artigo apresenta o estudo realizado em torno da seguinte pergunta de partida: "Como uma ferramenta destinada ao treinamento de pessoal pode reduzir a ocorrência de acidentes de trabalho na indústria?"

O objetivo da pesquisa realizada em torno da questão de partida teve como foco a determinação, através de um estudo de caso em uma indústria de painéis de madeira situada no Paraná, a eficácia da aplicação da ferramenta STOP® direcionada a treinamentos para redução da frequência e gravidade dos acidentes de trabalho.

Nos próximos tópicos, através de embasamento teórico, serão abordados os principais temas relacionados com o objetivo da pesquisa, a metodologia utilizada, os resultados e discussões, e por fim a conclusão do estudo.

\section{SEGURANÇA E SAÚDE DO TRABALHADOR}

Segurança e saúde são imprescindíveis quando o propósito é manter um ambiente de trabalho seguro e produtivo. Tais questões estão diretamente ligadas à valorização do elemento humano como primordial para o sucesso de qualquer organização.

Práticas de trabalho deveriam ser consideradas parte integral de um programa de controle sendo elas documentadas, todos os empregadores comunicados, sendo ainda parte de um programa de treinamento para novos empregados. Práticas de trabalho podem ser desenvolvidas na fábrica ao longo de um período de anos ou podem ser introduzidas como parte dos padrões estabelecidos pela Occupational Safety and Health Adminitration (OSHA). Os trabalhadores podem ser fontes valiosas de desenvolvimento de procedimentos para a minimização da exposição.

Quando se avalia a eficácia de práticas de trabalho publicadas, devem-se observar os trabalhadores para determinar se todos eles usam os mesmos procedimentos para completar o trabalho. Se cada trabalhador faz "do seu jeito" os padrões de exposição serão bastante variados. 
Uma das formas de alcançar bons resultados em segurança e saúde do trabalho é focar na melhoria da qualidade de vida dos trabalhadores. Os efeitos negativos podem provocar efeitos negativos e a não qualidade de vida pode refletir diretamente na postura do colaborador frente as suas atividades contratuais dentro de uma instituição, impactando diretamente nos seus indicadores de segurança e saúde.

Considerando sua grande responsabilidade social, é indispensável que a indústria brasileira se preocupe com a promoção de iniciativas que possibilitem a redução de problemas tão graves. O comportamento seguro das pessoas pode proporcionar um ambiente de trabalho seguro e saudável. Mas é muito difícil criar e manter uma mudança de comportamento. As pessoas têm dificuldade de mudar seus comportamentos. A partir do momento que as pessoas entendem a importância de se comportarem de forma segura, concretizamos a cultura de segurança como um valor para a empresa. A mudança de comportamento é fomentada nas empresas e, de uma forma automática, ela é extravasada para além dos limites dos muros da indústria.

Essa é a segurança moderna. Antigamente falava-se em atos inseguros, condições inseguras e hoje em dia é falado também sobre comportamento seguro. Se o funcionário tem um comportamento seguro, automaticamente não cometerá atos inseguros e tratará todas as condições inseguras. Desta forma, as principais causas dos acidentes serão neutralizadas.

A Lei $n^{\circ}$ 8213, de 24 de julho de 1991, da Previdência Social define em seu artigo 19 que "Acidente do Trabalho é o que ocorre pelo exercício do trabalho, a serviço da empresa, provocando lesão corporal ou perturbação funcional que cause a morte, ou perda, ou redução permanente ou temporária, da capacidade para o trabalho. "

De acordo com Xavier (2002) o conceito técnico de acidente do trabalho se refere a todas as circunstâncias não previstas ao andamento normal da atividade do trabalho, que poderão resultar danos físicos e/ou funcionais, ou morte e perdas materiais e econômicas. Um acidente gera alteração no andamento da rotina de trabalho, causando atrasos (ETCHALUS et al., 2006).

Segundo Pinheiro e Arruda (2001), dos 343.996 acidentes de trabalho registrados no Brasil em 2000, 83,6\% corresponde a acidentes típicos, o que demonstra que a grande concentração dos acidentes no Brasil ocorre dentro da própria empresa, durante o desenvolvimento de suas atividades laborais.

Neste contexto, observa-se que nos últimos 20 anos o cliente de segurança tem sido um dos principais temas de interesse no âmbito teórico da Psicologia da Segurança no Trabalho. As pesquisas realizadas com este fenômeno auxiliaram na compreensão de certos aspectos psicossociais e da relevância e impacto destes na prevenção dos acidentes de trabalho (TURBAY, 2007).

A ferramenta STOP $尺$, portanto, tem como objetivo fomentar a abordagem comportamental, estimulando um ambiente onde todos possam abordar uns aos outros sem receios, proporcionando um ambiente de trabalho mais seguro, distribuindo a responsabilidade da segurança para todos os colaboradores da empresa.

\section{A FERRAMENTA STOP®}

O programa STOP $\AA$ foi desenvolvido pela empresa DuPont Sustainable Solutions. Há mais de 30 anos esta ferramenta tem ajudado as empresas a evitar ferimentos aumentando a consciencialização de segurança e ajudando as pessoas a falarem sobre segurança entre elas. Milhares de empresas e organizações governamentais em todo o mundo perceberam não apenas os benefícios humanos deste programa, mas também o impacto financeiro, assim como a proposta de um local de trabalho mais seguro às pessoas.

O programa STOP® está baseado nos princípios ilustrados na Figura 1 a seguir, sendo estes testados e comprovados para ajudar a reduzir acidentes e lesões. 
Figura 9 - Princípios do programa STOP.

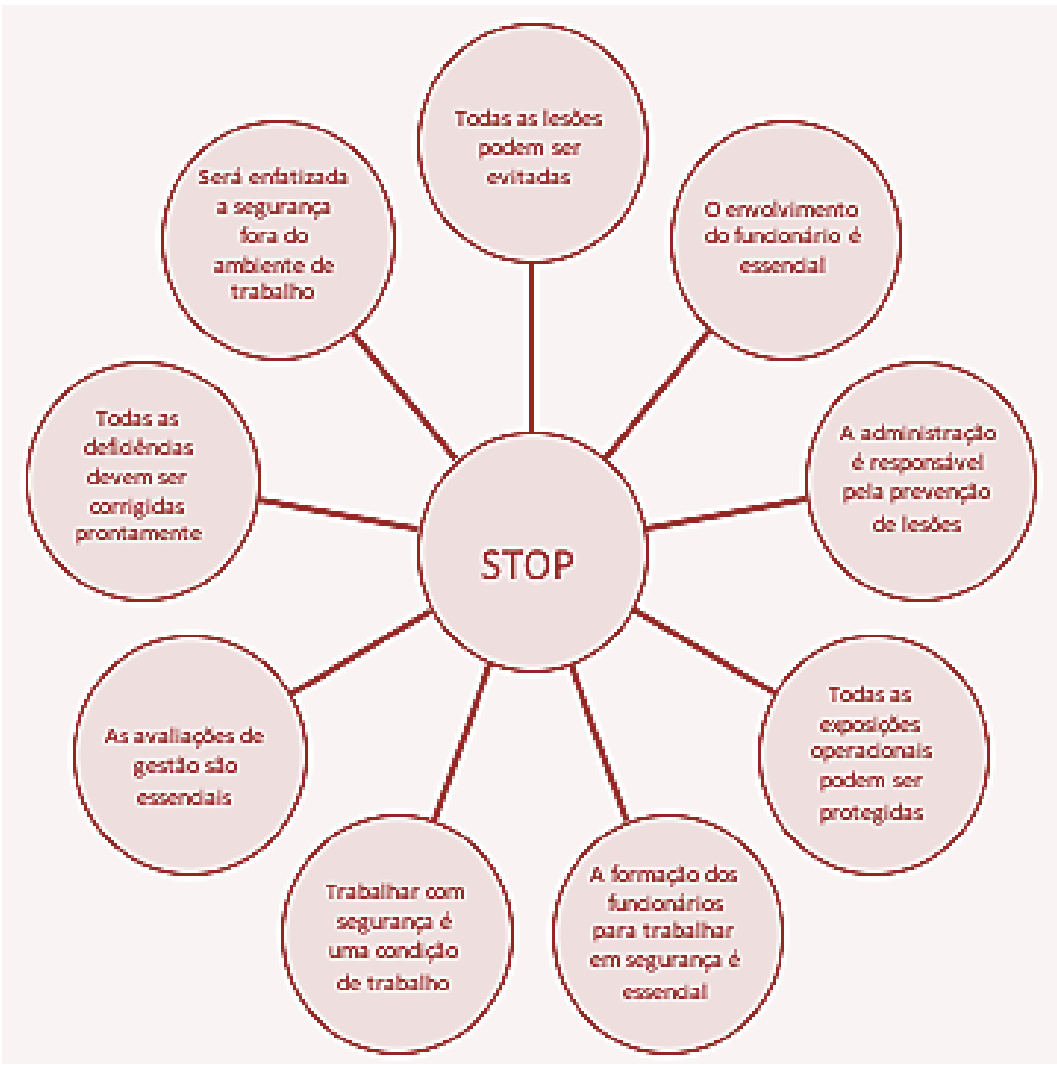

Fonte: Material didático da Dupont (1986)

No programa é utilizada uma combinação de métodos para proporcionar às pessoas informação, habilidades e disposição para trabalhar com mais segurança, maximizando a aprendizagem e aplicando o que se aprende no mundo real. Os programas representam uma abordagem em três partes:

Estudo individual: são usados livros para introduzir conceitos básicos e dar início ao desenvolvimento de habilidades de segurança.

Aplicação de atividades em campo: Os participantes do programa STOP $\AA$ colocam em prática o que aprenderam nas suas próprias áreas de trabalho.

Reuniões de grupo: depois de assistir a um DVD, os participantes discutem o que aprenderam e pensam em como tal conteúdo pode ser aplicado.

O programa STOP® para supervisão baseiase na ideia de que os líderes são responsáveis pela segurança dos seus funcionários. Este gera habilidades de comunicação e observação da segurança, possibilitando discussões construtivas com os funcionários sobre práticas de trabalho seguras e inseguras.

Os conceitos e o foco do programa STOP $\AA$ para supervisão são listados no Quadro 1. As definições e conceitos são de grande importância para esclarecer e direcionar, os profissionais e lideranças, dentro de uma estrutura organizacional. 


\section{Quadro 1 - Conceitos importantes e foco do programa STOP®}

\section{Conceitos importantes}

\section{Foco}

Todas as lesões e doenças ocupacionais podem ser prevenidas. Este é um modo de pensar, uma forma de abordar a segurança, que significa que há sempre algo que pode ser feito para evitar lesões.

Os supervisores e líderes de equipe são responsáveis e respondem pela segurança dos seus funcionários. A segurança é tão importante quanto à produção, os custos e outras questões relacionadas ao negócio pelas quais os líderes de equipe são responsáveis.

Perceber a segurança. Significa ficar tão sintonizado na segurança que a pessoa percebe a segurança, automaticamente, aonde quer que ela esteja. "Tornar a segurança um hábito" reflete a forma como os funcionários se sentem em relação à segurança.

Observações de segurança formais e informais regulares para perceber ações e condições seguras e inseguras. O programa possibilita discussões com pessoas sobre práticas de trabalho seguras e inseguras. Os participantes aplicam as suas novas habilidades formais no final do programa.

Segurança diária bem como a realização de observações. Os participantes trabalham no desenvolvimento das suas habilidades de comunicação e observação durante todo o programa STOP $®$ para supervisão para tornar a segurança uma parte das operações regulares, não um evento especial.

Condições bem como ações das pessoas - seguras e inseguras. Comunicação sobre segurança diária, não apenas quando estão a ser realizadas observações.

\section{Fonte: Material didático da Dupont}

No treinamento foram abordados os sete módulos do programa STOP®. Cada um deles será apresentado de maneira sintetizada a seguir.

\subsection{MÓDULO 1 - INTRODUÇÃO AO SISTEMA STOP®}

A apostila do módulo 1, "Introdução ao Sistema STOP®", desenvolve as habilidades necessárias para que o líder seja um campeão de segurança, focando na observação de segurança, comunicação, trabalho em equipe e compreensão. Faz parte do programa STOP® fazer observações de segurança diariamente, como rotina de trabalho, desenvolvendo um hábito da observação experiente, correção e de prevenção da reincidência de atos inseguros. Uma ferramenta para organizar a forma de abordar a segurança é o ciclo de observação. Os cinco passos básicos do Ciclo de Observação estão representados na Figura 2 a seguir.

Figura 10 - Ciclo de observação de segurança

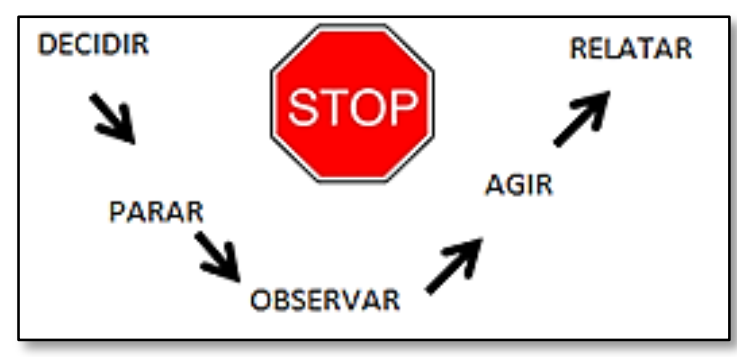

Fonte: Material didático da Dupont (1986) 


\subsection{MÓDULO 2 - EQUIPAMENTO DE PROTEÇÃO INDIVIDUAL}

No estudo de causas de acidentes a falha em utilizar equipamentos de proteção individual causa aproximadamente $12 \%$ de todos os acidentes com afastamento e acidentes com restrição de trabalho, conforme informação do manual do programa STOP $®$ da DuPont. Deve-se pensar nos benefícios ao prevenir estes tipos de atos inseguros e acidentes.

Ao observar o uso do equipamento de proteção individual, deve-se desenvolver o hábito de checar cada pessoa da cabeça aos pés. Comece verificando se a cabeça está protegida e depois desça corpo abaixo até chegar aos pés, tendo certeza que cada parte genérica do corpo está protegida.

\subsection{MÓDULO 3 - POSIÇÃO DAS PESSOAS}

Os atos inseguros, às vezes, desaparecem ou se evaporam muito rapidamente. Atos inseguros evaporativos são atos inseguros que desaparecem muito rapidamente. Por exemplo, muitas vezes um funcionário pode colocar ou ajustar o equipamento de proteção individual em apenas 10 a 30 segundos.

A chave para observar posições de pessoas no trabalho é a lista das causas de acidentes. Esta lista ajudará a esperar o inesperado. Usando-a pode-se prever e corrigir situações que possam resultar em acidente, caso aconteça o inesperado. Será que os funcionários do setor levantam, puxam, empurram ou alcançam objetos? Sobem em escadas? Lidam com substâncias perigosas? Andam de um lugar para outro? Em cada uma destas atividades ou posições há um potencial para acidentes. O objetivo é reconhecer este potencial e treinar os funcionários para que também o reconheçam.

\subsection{MÓDULO 4 - REAÇÃO DAS PESSOAS}

Este módulo orienta quanto à importância da atenção do observador quanto à mudança ou não do comportamento do observado durante a abordagem de segurança. Este comportamento pode indicar que o colaborador encara a aplicação de práticas seguras simplesmente como algo que a supervisão quer que seja seguido e não como algo para seu próprio benefício. Portanto, podem achar que os atos inseguros devem ser escondidos e que não são perigosos para eles. Se tiverem esta atitude, os colaboradores provavelmente reagirão à presença do observador e evitarão os atos inseguros apenas quando estiver por perto. $\mathrm{O}$ observador é responsável por estar alerta para as reações das pessoas, pois estas são indícios possíveis atos inseguros.

As reações das pessoas são importantes por serem indícios que atos inseguros talvez tenham sido cometidos. Caso não seja investigado e não tomada nenhuma ação para evitar reincidência, a pessoa provavelmente cometerá novamente o mesmo ato inseguro e poderá se ferir.

\subsection{MÓDULO 5 - FERRAMENTAS E EQUIPAMENTOS}

A maioria dos trabalhos requer o uso de ferramentas e equipamentos. Independentemente de estarem usando um computador, um trator ou uma chave de fenda, as pessoas devem seguir práticas seguras ou correr o risco de se acidentar.

Muitos dos atos inseguros das pessoas, envolvendo o uso de ferramentas e equipamentos, não são evaporativos. Isso quer dizer que o observador terá mais de 30 segundos para fazer a observação. Por outro lado, muitas vezes o observador tem menos que 30 segundos para observar reações, equipamentos de proteção individual e posições. Portanto, a observação sobre o uso de ferramentas e equipamentos vem depois da observação das reações, equipamento de proteção individual e posição das pessoas.

A técnica de observação total ajudará o observador a chegar mais perto do objetivo de zero acidente. Para ser um observador experiente o observador deve se treinar a estar atendo com tudo a sua volta. Ao usar a técnica de observação total o observador seguirá quatro sentidos: Olhar atrás, para baixo, para cima e dentro; Escutar vibrações e sons incomuns; Cheira odores incomuns e Sente temperaturas e vibrações incomuns.

\subsection{MÓDULO 6 - PROCEDIMENTOS E ORGANIZAÇÃO}

Nos setores existem procedimentos tanto para trabalhos de rotina como para trabalhos não rotineiros. Seguindo estes procedimentos, os funcionários podem executar estes trabalhos, geralmente da maneira mais eficiente. É 
importante analisar os procedimentos e o padrão de organização do ponto de vista da segurança. Acidentes podem resultar de qualquer um dos três problemas: Procedimentos Inadequados para o trabalho; Procedimentos Desconhecidos e não entendidos pelos envolvidos; Procedimentos Conhecidos e entendidos, mas não seguidos.

Se a causa originadora for um procedimento inadequado, por exemplo, o observador não deve apenas conversar com a pessoa envolvida sobre os perigos de seus atos inseguros, mas também tomar ações para tornar o procedimento adequado.

\subsection{MÓDULO 7 - USANDO O SISTEMA}

Este é o último módulo de treinamento. Ao terminar este módulo o colaborador terá aprendido os princípios e técnicas do sistema STOP®. Com esta mudança de comportamento sabe-se que o desempenho de segurança aumentará. Por outro lado, se o colaborador não usar sua experiência e conhecimento STOP $®$, seu desempenho de segurança não melhorará.

Neste módulo espera-se recuperar alguns pontos básicos dos módulos 1 até 6; explorar algumas formas de incentivar um desempenho com segurança; aprender quando é necessário tomar ações de alcance maior visando evitar a reincidência de atos inseguros; lembrar-se da importância de um forte comprometimento com a segurança; estudar o resumo; revisar detalhadamente $O$ que foi aprendido no treinamento STOP®; avaliar o desempenho pessoal de segurança no trabalho e se preparar para as discussões futuras em grupo. Neste módulo são apresentados vários exemplos de situações com atos inseguros para ajudar na orientação aos colaboradores quanto à forma correta de abordagem e cultivar a análise crítica dos comportamentos inseguros.

Após passar por todos os passos da observação comportamental, para finalizar o ciclo, o observador deve preencher o "gabarito de observação" e registrar os desvios encontrados durante a sua caminhada de segurança. Cada registro é tabulado e avaliado para posterior proposta de ações sistêmicas e/ou pontuais que possam reduzir os desvios apontados durante as observações comportamentais.

\section{METODOLOGIA}

Para que o objetivo da pesquisa fosse alcançado a ferramenta STOP $尺$ foi aplicada realizando-se o treinamento dos níveis de gestão da empresa considerada no estudo de caso, pois o foco da empresa é desenvolver líderes capacitados em observação em segurança e saúde do colaborador. O treinamento inicial ocorreu a 70 líderes onde todos receberam a capacitação teórica e prática do programa de observação de segurança.

Durante a reunião mensal de segurança, com a participação de todos os gerentes da fábrica, foi apresentada a proposta com cronograma da aplicação da ferramenta do Programa de Observação de Segurança. Houve a necessidade de definir um setor específico para a aplicação da ferramenta com possibilidade posterior de proceder com a abrangência a todos os demais setores.

O treinamento foi realizado em duas fases: a fase teórica, onde todo o conteúdo programático foi aplicado e a fase prática, onde os líderes colocaram em prática o conhecimento adquirido em sala de aula. Após o primeiro mês de aplicação prática da ferramenta de observação comportamental, os líderes foram acompanhados, aleatoriamente, durante as abordagens com o objetivo de identificar se as técnicas recebidas durante o treinamento estavam sendo aplicadas. Outra análise realizada foi quanto à qualidade dos registros das observações comportamentais. Essa análise foi importante para alinhar conceitos e também padronizar a forma de registro das observações comportamentais.

\section{RESULTADOS E DISCUSSÕES}

Primeiramente foi realizado um levantamento de dados referentes aos eventos de segurança, para que fossem visíveis as informações que seriam utilizadas para comparação, e por fim avaliar à eficiência do programa. Os dados do Gráfico 1 são referentes a todo o ano de 2014, classificados de acordo com a sua ocorrência. Os critérios de classificação são definidos conforme procedimento corporativo da empresa analisada.

No total houveram 117 ocorrências em todo o ano de 2014, dos quais não se constata nenhum registro de desvios comportamentais. 
Este tipo de gestão em segurança demonstra que não há trabalho com prevenção e que a qualquer momento podem ocorrer acidentes graves e até mesmo fatais.

Gráfico 1 - Classificação dos acidentes por área

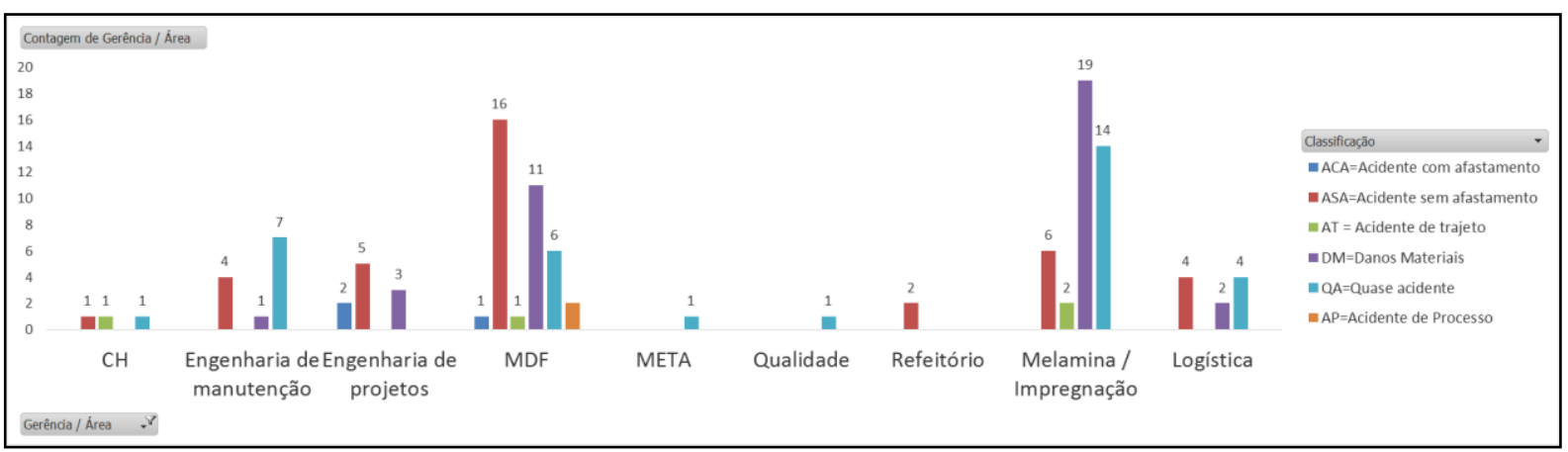

Fonte: Indústria de painéis de madeira (2014)

Segundo Frank E. Bird (PIRÂMIDE DE SEGURANÇA, 2015), existe uma proporção das ocorrências dos eventos de segurança. Esta proporção foi estudada através de dados estatísticos de eventos que ocorreram em 297 empresas de diferentes seguimentos, envolvendo 1.750.000 empregados e mais de 3 bilhões de homens-horas trabalhadas. Esta proporção, 1:10:30:600, significa que há uma lesão incapacitante ou grave, para 10 lesões leves, para 30 acidentes com danos a propriedade, para 600 incidentes. As

Figura 11 - Pirâmide de Frank Bird com os dados de 2014 - Antes da aplicação da ferramenta

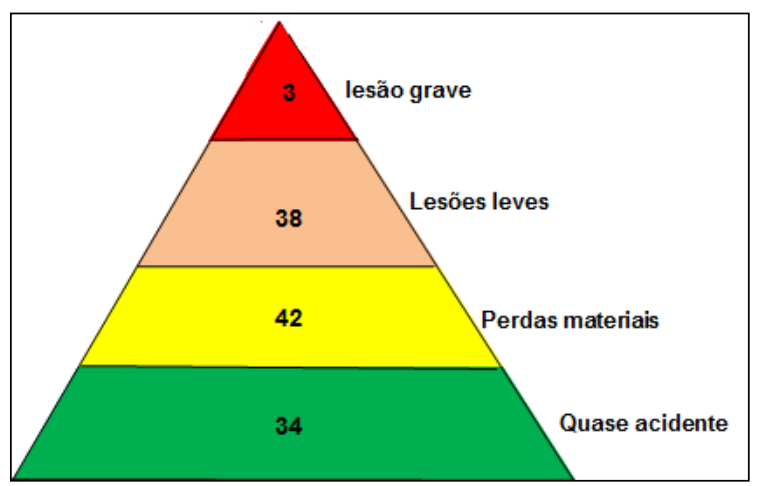

Após a aplicação da ferramenta, os resultados de acidentes graves reduziram em mais de $60 \%$, os acidentes menores ou sem afastamento reduziram $37 \%$ e as ocorrências com danos materiais reduziram em $66 \%$. Houve um aumento de $333 \%$ quanto ao empresas que querem buscar a excelência em segurança e saúde devem comparar seus dados à pirâmide de Frank Bird, onde podem traçar ações preventivas antecipadamente na base da pirâmide antes que os acidentes mais graves aconteçam.

$\mathrm{Na}$ Figura 3 ilustra-se a Pirâmide de Segurança construída com os dados antes da aplicação da ferramenta STOP $®$, e na Figura 4 a Pirâmide de Segurança elaborada após a aplicação da referida ferramenta.

Figura 12 - Pirâmide de Frank Bird com os dados de 2016 - Após aplicação da ferramenta

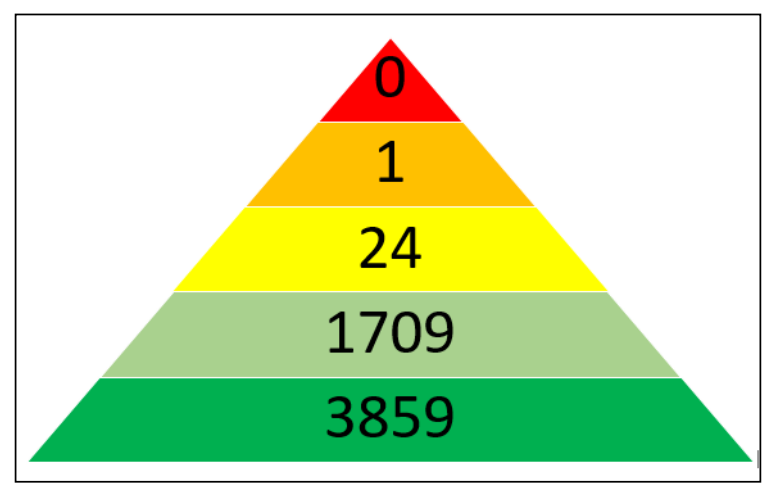

registro dos incidentes. Mas este aumento foi provocado de forma proposital, pois a cultura do registro dos incidentes é uma forma do colaborador passar do modelo corretivo e dependente para o modelo preventivo e independente onde o tratamento correto do 
incidente elimina o risco do acidente antes que ele se torne realidade.

Observa-se também o número de desvios ao longo do projeto. O número reduziu em 17\% em 2016 comparado com 2014. Este é um ponto importante, pois demonstra que a quantidade dos atos inseguros está reduzindo em função das abordagens do programa STOP $®$. Em contra partida observa-se que houve um aumento expressivo dos comportamentos considerados seguros e que impactam diretamente na eliminação das ocorrências por esta causa. À medida que a observação ocorre, percebe-se aumento do número de comportamentos seguros, o que significa que os observadores estão atuando realmente conforme a metodologia define, e que os abordados estão colaborando, através da conscientização, praticando atos seguros e percebendo os riscos envolvidos em suas atividades.

\section{CONCLUSÕES}

As indústrias são responsáveis pelas maiores taxas de acidentes e requerem atenção especial. Alto turn over, automatização, baixa escolaridade, são alguns fatores que contribuem para o aumento das taxas de acidentabilidade. Com a chegada das normas mais voltadas a gestão de segurança, as empresas percebem que precisam avançar na descoberta de novas ferramentas que ajudem a reduzir a ocorrência dos acidentes.

Entretanto é válido destacar que a aplicação das ferramentas de segurança por vezes é comprometida, pois a partir do momento que você está com um profissional qualificado, o mercado pode vir e movimentá-lo para outra empresa e todo o trabalho de conscientização já iniciado, acaba perdendo-se no meio deste processo. Um programa de auditorias, com enfoque no comportamento humano evidencia que sua atitude é o fator primordial na prevenção de acidentes de trabalho, pois se sabe que as condições inseguras se somam aos atos inseguros, que juntos, causam a ocorrência de acidentes. Sendo assim, quando consegue-se atuar no comportamento das pessoas, as condições inseguras, por consequência, também serão corrigidas.

É neste momento que surgem as ferramentas de segurança que juntamente com o direcionamento da empresa, colaboram para alcançar seus objetivos. Na pesquisa exposta neste artigo foi aplicada a ferramenta STOP $®$ que procura desenvolver uma forma de abordagem segura e assertiva dos comportamentos inadequados. Ao implantar esta ferramenta, a empresa inicia o processo de cultura em segurança dentro de sua empresa, senod este o primeiro passo para mudar o estilo de comportamento de seus colaboradores. A partir das abordagens do programa STOP $尺$, a empresa pode implantar outras diversas ferramentas de segurança, porque esta prepara a base da empresa para o processo de mudança.

A aplicação da ferramenta na indústria resultou na redução da gravidade dos acidentes, atuando na implantação da cultura de segurança. Nota-se que as definições claras das normas e procedimentos de segurança da empresa impactam diretamente no comportamento dos colaboradores. Durante os treinamentos observa-se o comprometimento de todo o corpo de liderança da empresa em fazer de forma correta a observação de segurança. Concluise que a segurança na empresa, hoje, não tem como dificuldade principal a redução dos custos ou também o volume de produção, mas sim a falta de cultura de segurança entre todas as pessoas envolvidas.

Cabe ao corpo de gestores uma melhor conscientização por parte dos colaboradores, com treinamentos mais eficazes e acompanhamentos mais frequentes no chão de fábrica. Estas considerações permitem afirmar que o objetivo da pesquisa foi alcançado, onde demonstra-se que com a implantação do programa de auditorias comportamentais, aplicado pelos gestores, reduz-se o número de acidentes, assim como suas gravidades. 


\section{REFERÊNCIAS}

[1]. DUPONT SUSTAINABLE SOLUTIONS. Stop $\circledast$ para todos. Manual de Treinamento. 2014.

[2]. ETCHALUS, J. M.; PEREIRA FILHO, J. I.; XAVIER, A.A.de P., PILATTI, L. A. Relação entre acidente do trabalho e a produtividade da mão de obra na construção civil. SIMPEP, 13, 2006.

[3]. PINHEIRO, V. C. ARRUDA, G. A. Segurança no trabalho no Brasil. Informe de Previdência Social, Brasília, v.13, n.10, out. 2001. Disponível em <www.previdenciasocial.gov.br>.
[4]. PIRÂMIDE DE SEGURANÇA. Disponível em < http://www.btseguranca.com/piramides-deseguranca/>. Acesso: dezembro de 2016.

[5]. TURBAY, Júlio Cezar Ferri. Uma revisão teórica acerca do conceito de clima de segurança. Porto Alegre, 2007.

[6]. XAVIER, A.A. de P. Introdução à engenharia do trabalho. Apostila do Curso de Especialização de Engenharia de Segurança do Trabalho. Pato Branco: UTFPR, 2002. 


\section{Gapítulo 10}

\section{PERFIL DE ACIDENTES TIPICOS DE TRABALHO EM CIDADES DE MAIOR INCIDÊNCIA NO ESTADO DO CEARÁ}

\section{Maria Alexsandra Pires Cavalcante \\ Maria Liduína Freitas Pinto \\ Euclídia Selênia Pereira Teixeira \\ Maxweel Veras Rodrigues \\ Sueli Maria de Araújo Cavalcante}

RESUMO: Objetivo: o presente estudo tem como objetivo analisar o perfil do acidentado de trabalho através de dados da previdência social, do anuário estatístico de acidente de trabalho, dados do Instituto Brasileiro de Geografia e Estatística - IBGE e propor ações de política pública para minimizar esse impacto social. Método: a pesquisa caracteriza-se como descritiva, utilizou como fonte de coleta de dados o Anuário Estatístico de Acidente de Trabalho-AEAT (2015) e para corroborar com esses dados, foi realizado uma pesquisa documental, onde os dados foram coletas dos portais eletrônicos do IBGE, IPECE, Anuário Estatístico da Previdência Social - AEPS (2015) e também das Normas Regulamentadoras - NR's do Ministério do Trabalho e Emprego. Resultados: pode-se perceber que na maioria dos municípios estudados houve aumento nos casos de acidente de trabalho, em destaque a cidade de São Gonçalo do Amarante houve um aumento de $(7,12 \%)$, acredita-se que este fato deve-se ao complexo portuário. Considerações finais: $O$ primeiro passo para minimizar os acidentes típicos de trabalho seria realmente um diagnóstico preciso do perfil profissiográfico, tendo como base os bancos de dados abertos disponíveis, de forma consolidada, em seguida ações pontuais e a nível municipal, de forma a mitigar esses riscos, pois sabe-se que a cada profissional acidentário tem um custos direto e indireto para a sociedade como um todo. 


\section{INTRODUÇÃO}

Os acidentes de trabalho são um grande problema de saúde pública com consequências para além dos envolvidos diretamente, visto que causam impacto econômico pela diminuição de produção assim como despesas com benefícios previdenciários, de modo que sua prevenção se mostra importante tanto em termos humanos quanto materiais(GONÇALVES FILHO, RAMOS; 2015).

Por outro lado, com o processo de globalização, o incremento tecnológico vem, a passos largos, modernizando máquinas, equipamentos, instalações e nem sempre capacitando trabalhadores e trabalhadoras com conhecimentos específicos que evitem a ocorrência de acidentes do trabalho ou doenças profissionais, o que influenciado pela crescente industrialização, no país, está acontecendo o aumento no número de casos de acidentes de trabalho (RODRIGUES; DE MELO; GUEDES, 2015).

O resultado é a potencialização de acidentes de trabalho que podem resultar na incapacidade temporária ou mesmo na morte da pessoa. Isto tudo diante de um cenário de desregulação de direitos trabalhistas em nome de uma maior competitividade econômica por parte da indústria brasileira(RODRIGUES; DE MELO; GUEDES, 2015).

Segundo Cortez, Jasmim e Silva (2017) quando ocorre um acidente de trabalho que gera danos morais ou materiais ao empregado acidentado, resta à Justiça, na maioria das vezes, solucionar a questão pelo entendimento jurisprudencial, onde os responsáveis competentes tomam suas decisões mediante as provas apresentadas no processo, no qual se deve, muitas vezes, comprovar se houve culpa do empregador ou do empregado, como, por exemplo, por inobservância das normas de segurança e uso dos Equipamentos de Proteção Individual por parte do empregado ou pelo fato de o empregador obrigar o empregado a trabalhar frequentemente executando horas extras que possam ter causado um desgaste físico e mental resultando no acidente, por exemplo.

Com a Constituição Federal de 1988, aumentou a preocupação com a saúde do trabalhador e consequentemente com os acidentes de trabalho, de forma que em seu Art. 200, inciso II "Ao sistema único de saúde compete, além de outras atribuições, nos termosda lei:[...] executar as ações de vigilância sanitária e epidemiológica, bem como as desaúde do trabalhador". (BRASIL, 1988)

Em 2012, o então ministro da saúde de uso de suas atribuições através da portaria $\mathrm{n}^{\circ}$ 1.823, de 23 de agosto de 2012, institui a Política Nacional de Saúde do Trabalhador e da Trabalhadora, que já havia sido prevista na lei 8.080/90 referente ao Sistema Único de Saúde - SUS, onde em seu Art. 16, define que compete ao SUS, formular ações relativas as condições e aos ambientes de trabalho, bem como participar da definição de normas, critérios e padrões para o controle das condições e dosambientes de trabalho e coordenar a política desaúde do trabalhador. (BRASIL, 1990)

Diante desta perspectiva o presente estudo tem como objetivo analisar o perfil do acidentado de trabalho através de dados da previdência social, do anuário estatístico de acidente de trabalho, dados do Instituto Brasileiro de Geografia e Estatística - IBGE e propor ações de política pública para minimizar esse impacto social. Para isso foi necessário identificar os municípios que mais ocorreram acidentes típicos de trabalho e qual o seu ramo de negócio preponderante.

\section{ACIDENTES DE TRABALHO}

O artigo 19 da lei no 8.213/91 diz que:

acidente de trabalho é o que ocorre pelo exercício do trabalho a serviço da empresa ou pelo exercício do trabalho dos segurados referidos no inciso VII do art. 11 desta lei, provocando lesão corporal ou perturbação funcional que cause a morte ou a perda ou redução, permanente ou temporária, da capacidade para o trabalho"(BRASIL, 1991)

As doenças profissionais e/ou ocupacionais são equiparadas a acidentes de trabalho. $O$ artigo 20 da mesma lei determina que doença profissional é aquela produzida ou desencadeada pelo exercício do trabalho peculiar a determinada atividade e constante da respectiva relação elaborada pelo Ministério do Trabalho e da Previdência Social - MTPS. Doença do trabalho é aquela adquirida ou desencadeada em função de condições especiais em que o trabalho é realizado e a ele diretamente relacionada. 
O artigo 21 da lei ำ 8.213/91 equipara também ao acidente de trabalho (BRASIL, 1991):

I. I - O acidente ligado ao trabalho que, embora não tenha sido a causa única, haja contribuído diretamente para a morte do segurado, para redução ou perda da sua capacidade para o trabalho, ou produzido lesão que exija atenção médica para a sua recuperação;

II. II - O acidente sofrido pelo segurado no local e no horário do trabalho, em conseqüência de: a) Ato de agressão, sabotagem ou terrorismo praticado por terceiro ou companheiro de trabalho; b) Ofensa física intencional, inclusive de terceiro, por motivo de disputa relacionada ao trabalho; c) Ato de imprudência, de negligência ou de imperícia de terceiro ou de companheiro de trabalho; d) Ato de pessoa privada do uso da razão; e) Desabamento, inundação, incêndio e outros casos fortuitos ou decorrentes de força maior.

III. III - A doença proveniente de contaminação acidental do empregado no exercício de sua atividade;

IV. IV - Acidente sofrido pelo segurado ainda que fora do local e horário de trabalho: Na execução de ordem ou na realização de serviço sob a autoridade da empresa; $\mathrm{Na}$ prestação espontânea de qualquer serviço à empresa para lhe evitar prejuízo ou proporcionar proveito; Em viagem a serviço da empresa, inclusive para estudo quando financiada por esta, dentro de seus planos para melhor capacitação da mão de obra,independentemente do meio de locomoção utilizado, inclusive veículo de propriedade do segurado; no percurso da residência para o local de trabalho ou deste para aquela, qualquer que seja 0 meio de locomoção, inclusive veículo de propriedade do segurado.

(BRASIL, 1991)

No Brasil os acidentes de trabalho típicos acontecem com maior frequência na indústria. No Ceará, as empresas que mais registram acidentes são as da construção civil e na indústria calçadista, de acordo com os dados do Anuário Estatístico de Acidentes de Trabalho/2015.

\section{POLÍTICA PÚBLICA DE ATENÇÃO AO TRABALHADOR}

Contemplando uma camada de 1,32 milhões de trabalhadores formais segundo dados CAGED (2017), a política pública de saúde do trabalhador tem como princípios: "I universalidade; II - integralidade; III participação da comunidade, dos trabalhadores e do controle social; IV descentralização; V - hierarquização; VI equidade; e VII - precaução" (BRASIL, 2012).

Diante destes princípios percebe-se que esta política deve ser para todos de forma integral sem distinção de cor, raça ou orientação sexual. Servindo de fortalecimento para a participação da comunidade em busca de melhoria, pois ninguém melhor do que o próprio usuário para gerir suas preferências.

Essa atitude serve de veículo de inclusão social, uma vez o trabalhador acidentado gera um custo para a sociedade, devido ao seu afastamento, gerando estigmas de "peso para a sociedade", "inútil", entre outros, em relação a família esse estigma é inevitável, pois os familiares são os mais atingidos quando um ente sofre um acidente de trabalho.

Esse atendimento ao acidentado deve ser de amplo acesso, gratuito, eficaz, e equitativo, a fim de otimizar o atendimento e minimizar sequelas tanto físicas quanto psíquicas e por fim, mas não menos importante, a precaução.

A Organização Mundial da Saúde -OMS (2015) alerta que os maiores desafios para a saúde do trabalhador são os problemas de saúde ocupacional ligados as novas tecnologias de informação e automação; a novas substâncias químicas e energias físicas, problemas relacionados com a crescente mobilidades dos trabalhadores e ocorrência de novas doenças ocupacionais de várias origens.

Cavalcante, et al (2015) afirma que no Brasil é evidente que uma das principais dificuldades na atenção à saúde do trabalhador, se dá pela limitação dos sistemas de informação (SI) que não permitem estimar e acompanhar o real impacto do trabalho sobre a saúde da população brasileira.

Os sistemas de informação disponíveis são: Comunicações de Acidentes de Trabalho CAT, que é informado para o Instituto Nacional de Seguridade Social (INSS), ao Ministério da Previdência Social - MPS através do DATAPREV; Sistema de 
Informações sobre Mortalidade - SIM e registros das Declarações de Óbito (DO); Sistema de Informações Hospitalares -SIH, registros de Autorização de Internação Hospitalar - AlH são gerenciados pelo Ministério da Saúde; o Sistema de Informação de Agravos de Notificação - SINAN, este é relativo a acidentes de trabalho, implantado em 2015 é também gerenciado pelo Ministério da Saúde; então a Relação Anual das Informações Sociais - RAIS, gerenciada pelo Ministério do Trabalho e Emprego, com dados sobre movimentação dos empregados com contrato formal de trabalho.

O Instituto de Pesquisa Econômica Aplicada IPEA utiliza-se de um sistema chamado de Linkage, onde faz uma síntese dos dados dos outros sistemas, descritos acima, de forma muito útil, mas ainda incipiente pois os dados são compilados e informados muitas vezes um ano após a síntese dos outros sistemas.

Diante desta realidade o que resta são políticas públicas mais efetivas, acerca da promoção da saúde destes trabalhadores, adequadas conforme o perfil profissiográfico.

Construir estratégias de abrangência multiprofissional, lúdicas, de fácil compreensão, equitativas e dinâmicas, e otimizar os sistemas de informação.

\section{METODOLOGIA}

A pesquisa caracteriza-se como descritiva, uma vez que busca descrever a realidade em relação às características de acidentes típicos de trabalho com maior representatividade nas cidades do estado do Ceará e, segundo GIL
(2002), a pesquisa do tipo descritiva tem por objetivo descrever uma determinada população estudada.

Para isso, utilizou como fonte de coleta de dados o Anuário Estatístico de Acidente de Trabalho-AEAT (2015) e para corroborar com esses dados, foi realizado uma pesquisa documental, onde os dados foram coletas dos portais eletrônicos do IBGE, IPECE, Anuário Estatístico da Previdência Social - AEPS (2015) e também das Normas Regulamentadoras - NR's do Ministério do Trabalho e Emprego. Além disso, fez uso de pesquisa bibliográfica, onde foram verificados artigos científicos, livros e demais referências pertinentes ao tema.

Ressalto ainda que a pesquisa é expost facto, pois os dados analisados são oriundos de fatos ocorridos entre os anos de 2014 e 2015. Esses dados foram tratados de tal forma que possam nortear a aplicabilidade da política pública de saúde do trabalhador.

\section{RESULTADOS E DISCUSSÃO}

Essa sessão apresenta os resultados alcançados mediante os dados coletados através de fontes disponíveis em portais e anuários. Sendo eles demonstrados na sequência.

A Tabela 1 apresenta a quantidade de acidentes ocorridos nos municípios de Fortaleza, Caucaia, Limoeiro do Norte, Maracanaú, Sobral, Horizonte, Eusébio e São Gonçalo do Amarante, nos anos de 2014 e 2015 
Tabela 1: Acidentes de trabalho típico por municípios em relação a população, 2014-2015

\begin{tabular}{|c|c|c|c|c|c|}
\hline \multirow{3}{*}{ Município } & \multirow{3}{*}{ População } & \multicolumn{4}{|c|}{ Acidentes } \\
\hline & & \multicolumn{2}{|c|}{2014} & \multicolumn{2}{|c|}{2015} \\
\hline & & $\begin{array}{c}\text { № DE } \\
\text { ACIDENTES }\end{array}$ & $\%$ & $\begin{array}{l}\text { № DE } \\
\text { IDENTES }\end{array}$ & $\%$ \\
\hline Fortaleza & 2.609 .716 & 2818 & $10,798 \%$ & 2922 & $11,197 \%$ \\
\hline Caucaia & 358.164 & 317 & $8,851 \%$ & 329 & $9,186 \%$ \\
\hline Limoeiro do norte & 268.248 & 172 & $6,412 \%$ & 136 & $5,070 \%$ \\
\hline Maracanaú & 223.188 & 622 & $27,869 \%$ & 538 & $24,105 \%$ \\
\hline Sobral & 203.682 & 206 & $10,114 \%$ & 240 & $11,783 \%$ \\
\hline Horizonte & 64.673 & 220 & $34,017 \%$ & 185 & $28,605 \%$ \\
\hline Eusébio & 51.913 & 199 & $38,333 \%$ & 177 & $34,096 \%$ \\
\hline São Gonçalo do Amarante & 47.791 & 206 & $43,10 \%$ & 240 & $50,22 \%$ \\
\hline TOTAL & 3.827 .375 & 4760 & $12,437 \%$ & 4767 & $12,455 \%$ \\
\hline
\end{tabular}

Fonte: Elaborada pelos autores, dados extraídos do Anuário Estatístico de Acidente de Trabalho 2015, e estimativa da população em 2016.

Analisando a Tabela 1, pode-se perceber que apesar de Fortaleza em 2014 deter (75,19\%) do valor adicionado da indústria cearense, a sua representatividade em relação ao acidente típico de trabalho, teve um leve incremento de $(3,57 \%)$ entre os anos de 2014 e 2015. Já em São Gonçalo do Amarante, região metropolitana de Fortaleza, esse percentual é bem expressivo, o que se se pode vir a crer que deve ser devido a expansão do Pecém distrito deste município. De acordo com o portal da Associação das empresas do Complexo Industrial e Portuário do Pecém - AECIPP, são exatamente 13.330 mil hectares na área industrial, faturando em média 11,9 bilhões de reais.

Gráfico 1: Comparativo dos acidentes de trabalho típico no municípios estudados, 2014-2015

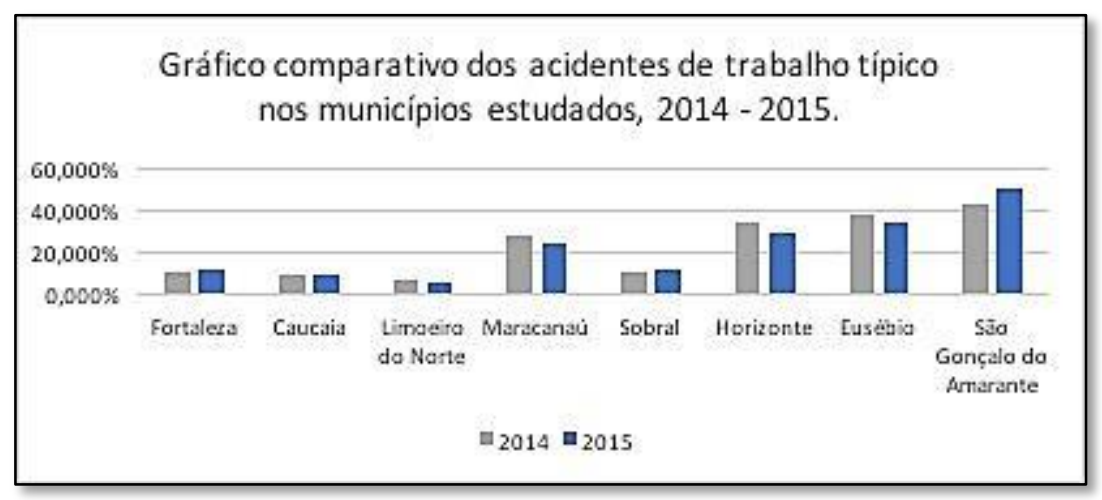

Analisando o gráfico 1, pode-se perceber que na maioria dos municípios estudados houve aumento nos casos de acidente de trabalho, exceto na cidade de Limoeiro do Norte, o fato deve-se provavelmente a intensificação da vigilância da saúde do trabalhador naquela cidade com a implantação de uma Organização Não Governamental - ONG, e a participação da sociedade para minimizar os efeitos nocivos e agravos a saúde dos trabalhadores daquela região.

Porém em São Gonçalo do Amarante houve um aumento de $(7,12 \%)$ no casos de acidente entre os anos de 2014 - 2015, acredita-se que este fato deve-se ao complexo portuário que 
teve início no ano de 2002, das 11.2 milhões de toneladas de cargas movimentadas em 2016, 5.6 milhões foram provenientes da siderúrgica (Portal de notícias G1, 2017).

A Companhia Siderúrgica do Pecém - CSP teve sua construção iniciada em 2011, começando a operar com a produção de placas de aço em 2016 as quais foram exportadas para quatro continentes (Ásia, Europa, Américas e Ásia) e mais de 12 países, como Alemanha, Coreia do Sul,
Estados Unidos, Indonésia, Itália, Marrocos, México, Reino Unido, República Tcheca, Tailândia, Taiwan e Turquia, a mesma tem previsão para 2017 de operar (60,0\%) da capacidade de exportação do porto do Pecém. Então, levando-se em conta este potencial econômico do estado do Ceará, acredita-se que o aumento nos acidentes de trabalho típicosnesta região, coincide com o início das operações de fabricação das placas de aço na siderúrgica.

Gráfico 2: comparativo dos contribuintes previdenciários no Ceará, 2014-2015.

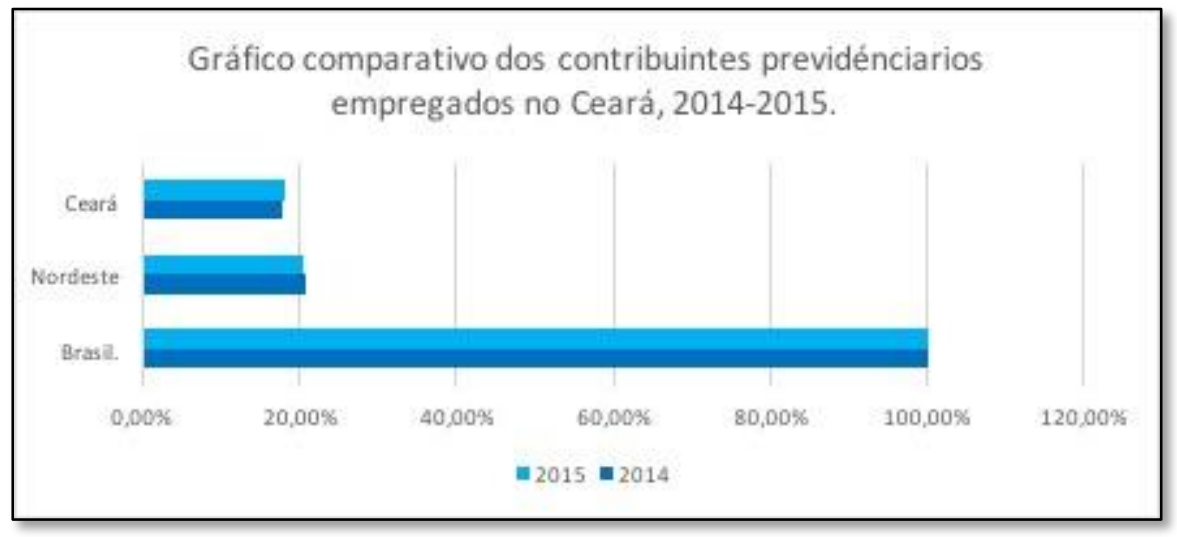

Segundos dados da Previdência, segue analise do gráfico 2, onde o total de contribuintes empregados no Brasil, nos anos estudados foi de 56.576.291 e 54.775.531 respectivamente. Sendo que a região nordeste ficou com (20,73\%) destes contribuintes em 2014, já em 2015 ficou com o percentual de $(20,48 \%)$ representando uma leve defasagem. No Ceará, o quadro se inverte, em 2014, o estado registrou (17,72\%) de contribuintes da previdência empregados, e, no ano de 2015, houve um acréscimo de $(0,35 \%)$ do ano anterior, totalizando $(18,07 \%)$, esses dados são comprovados mediante 0 incremento na oferta de emprego, devido ao incentivo fiscal disponibilizado as empresas oriundas da Coreia do Sul.

Segundo dados do anuário estatístico de acidente de trabalho (2015) afirma que segundo dados de acidentes por Classificação Nacional de Atividades Econômicas - CNAE, o setor mais propício a acidente típico de trabalho é a indústria, e no Ceará não é diferente.Os setores mais atingidos são: construção civil, 914 (36,6\%), fabricação de calçados em geral e de couro, 1453 (51,9\%), e fabricação de fogões e refrigeradores, 434 (15,4\%).
De acordo com as estatísticas de contribuintes empregados, segundo o Setor de Atividade Econômica, neste caso a indústria no Brasil em 2014 foi de 18.882.914 e em 2015, foi de 17.174.807. Segundo o portal da indústria (2014)(74,2\%) dos empregos no Ceará são nesta área, o que faz com que corrobore com as informações coletadas acerca dos acidentes de trabalho típicos.

O Ceará ainda é um estado de pouca expressão industrial no contexto do Brasil. Seu PIB industrial foi de 21,2 bilhões de reais em 2014, equivalente a $19,2 \%$ do PIB total do estado e $1,8 \%$ do PIB industrial do país. Sua participação no total nacional subiu apenas 0,2\% entre 2004 e 2014, e nesse mesmo período a participação da indústria no PIB do estado diminuiu 4\%. Os principais setores da indústria no Ceará são de construção, com $37,1 \%$ do PIB industrial; serviços industriais de utilidade pública, relacionados a abastecimento de água e energia, com 12\%; couros e calçados, com 10,6\%; alimentos, com 8,6\%; e vestuário, com 5,9\%. Desses, o setor de vestuário foi que apresentou maior aumento, crescendo 1,5\% entre 2004 e 2014 (LEAL, 2014) 
Em 2014, a região metropolitana de Fortaleza concentrava $75,19 \%$ do valor adicionado da indústria cearense. (IPECE, 2017)

Em 2015, havia 15.415 empresas industriais no Ceará, correspondendo a 3\% do total do Brasil. Dessas, 6,9\% eram microempresas, empregando $10,1 \%$ da força de trabalho; $24,1 \%$ eram pequenas empresas, empregando 22,1\%; $5,9 \%$ eram médias empresas, empregando 25,6\%; e 1,2\% eram grandes empresas de mais de 250 funcionários, responsáveis por 42,1\% dos empregos da indústria (ARAÚJO, 2016).

Em 2016, o valor das exportações industriais cearenses foi de 999 milhões de reais, colocando-o na décima quarta colocação entre os estados brasileiros com $1 \%$ da participação total. $O$ setor de couros e calçados foi 0 mais representado nas exportações, responsável por 39\% do total. A indústria foi responsável por $77,2 \%$ das exportações cearenses (Portal de notícias G1 Ceará, 2017).

Quanto ao emprego, a indústria representa $22,6 \%$ dos empregos formais no estado, com 348.200 vagas. Isso representa $3,3 \%$ da força de trabalho industrial do Brasil. O salário médio industrial em 2015 foi de $R \$ 1.525,60$, ou seja $37,6 \%$ abaixo da média nacional. Em relação à educação dos trabalhadores, 57,8\% têm pelo menos o ensino médio completo, enquanto a média nacional é de 59,1\% (Portal da Indústria Ceará, 2016).

Então, segundo os dados analisados, tem-se um quadro típico de acidente de trabalho devido à atividade laboral na área industrial, que pode ser acarretado pelo aumento de mão de obra, escassez de mão de obra

\section{REFERÊNCIAS}

[1]. ARAÚJO, Alana. Ceará tem mais de 1,5 mil vagas de emprego disponíveis. G1 Ceará. http://g1.globo.com/ceara/noticia/2016/12/cearatem-mais-de-15-mil-vagas-de-empregodisponiveis-confira-lista.html. 27 de dezembro de 2016. Acessado em: 14 de junho de 2017.

[2]. BRASIL. Constituição da República Federativa do Brasil. Brasília, 1988.

[3]. Instituto Brasileiro de Geografia e Estatística - IBGE. Censo estatístico. 2010.

[4]. LEI № 8.213, DE 24 DE JULHO DE 1991. Dispõe sobre os Planos de Benefícios da qualificada, baixa escolaridade e falta de acesso a equipamentos de proteção individual e ou coletivas (SEBRAE, 2015).

\section{CONCLUSÃO}

Diante da análise dos resultados, ficou comprovado que o Ceará em relação à região Nordeste, foi o estado que liderou o ranking dos contribuintes da previdência empregados. Isso se deu pelo fato do incentivo fiscal que o estado proporcionou aos investidores estrangeiros em troca de emprego e renda, consequentemente, o aumento com acidentes de trabalho típicos foi inevitável. Porém, acredita-se que esta realidade pode ser modificada com implementação de estratégias de política pública de acidente de trabalho.

O primeiro passo para minimizar os acidentes típicos de trabalho seria realmente um diagnóstico preciso do perfil profissiográfico, tendo como base os bancos de dados abertos disponíveis, de forma consolidada, em seguida ações pontuais e a nível municipal, de forma a mitigar esses riscos, pois sabe-se que a cada profissional acidentário tem um custos direto e indireto para a sociedade como um todo.

Diante do exposto neste estudo, fica a recomendação de atividades lúdicas em treinamentos específicos para a área da indústria, além de desenvolver uma cartilha de informação para conscientizar, vistorias dos órgãos de controle para verificar a efetividade do uso da proteção coletiva e individual como também realizar estudo aprofundado acerca da consolidação das informações para efetivar as demais ações.

Previdência Social e dá outras providências. Brasília,

1991.<http://www. planalto.gov.br/ccivil_03/leis//821 3cons.htm>. Acesso em 01/06/2017.

[5]. Ministério da Previdência Social. Anuário estatístico da previdência social. Brasília: Instituto Nacional do Seguro Social, 2015.

[6]. PORTARIA № 1.823, DE 23 DE AGOSTO DE 2012. Institui a Política Nacional de Saúde doTrabalhador e da Trabalhadora.Brasília, 2012.

[7]. Ministério da Previdência Social. Anuário estatístico dos acidentes de trabalho. Disponível em http://www.previdencia.gov.br/wp- 
content/uploads/2015/08/AEPS-2015-FINAL. pdf. Acesso em 01/04/2017.

[8]. CAVALCANTE, Cleonice Andréa Alves. COSSI, Marcelly Santos. COSTA, Raphael Raniere de Oliveira. MEDEIROS, Soraya Maria de. MENEZES, Rejane Maria Paiva de.CriticalAnalysisOfAccidents At Work In Brazil. Rev. de Atenção à Saúde, v. 13, no 44, abr./jun. 2015, p. 100-109.

[9]. CORTEZ. EA, JASMIM. JS, SILVA. LM da. Análise da mortalidade por acidentes de trabalho no Brasil: revisão integrativa.Revenferm UFPE online., Recife, 11(Supl. 1):429-37, jan, 2017.

[10]. GONÇALVES FILHO, A.P. RAMOS, M.F. Acidentes de trabalho em sistemas de produção: abordagem e prevenção. Gestão \& Produção, vol.22, São Carlos - SP, 2015.

[11]. LEAL, Jocélio. Indústria cearense perde peso no PIB. Jornal de Hoje em o povo online (Fortaleza, Ce). 07 de novembro de 2014. http://www20.opovo.com.br/app/opovo/economia/2 014/11/07/noticiasjornaleconomia,3344086/industri a-cearense-perde-peso-no-pib.shtml. Acessado em: 16 de junho de 2017.

[12]. MEDEIROS, Cleyber Nascimento de. SOUSA, Fátima Juvenal de. LIMA, Kathiuscia Alves de. LIMA, Jader Ribeiro de. Panorama socioeconômico das regiões de planejamento do estado do Ceará. Instituto de Pesquisa e Estratégia Econômica do Ceará (IPECE)2017. Acesso em: 05 de junho de 2017. Disponível:http://www.ipece.ce.gov.br/publicacoes/
Livro_Panorama_Regioes_Planejamento_Ceara_20 17.pdf.

[13]. PORTAL DA INDÚSTRIA. A Participação do Ceará no PIB industrial nacional. 2016. http://perfilestados.portaldaindustria.com.br/estado /ce. Acessado em: 16 de junho de 2017.

[14]. PORTAL DE NOTÍCIAS G1 CEARÁ. CSP bate recorde de embarques de placas no Porto do Pecém, no Ceará. 2017. Acesso em: 17 de junho de 2017. Disponível em: http://g1.globo.com/ceara/noticia/2017/02/cspbate-recorde-de-embarques-de-placas-no-portodo-pecem-no-ceara.html

[15]. RODRIGUES, D.F., DE MELO, S.L.W., GUEDES, P.M.S.: Avaliação do impacto da industrialização no aumento de acidentes de trabalho no Brasil (2002-2012). Cadernos de Pesquisa Interdisciplinar em Ciências Humanas Vol. 16 N. 108, jan./jun. 2015

[16]. SEBRAE. Gestão de pessoas: A importância da mão de obra qualificada. 01 de dezembro de 2015. Acessado em: 01 de junho de $2017 . \quad$ Disponível: https://www.sebrae.com.br/sites/PortalSebrae/artig os/a-importancia-da-mao-de-obraqualificada,3b03438af1c92410VgnVCM100000b27 2010aRCRD.

[17]. TRIBUNAL SUPERIOR DO TRABALHO (BR). Estatísticas. Dados Nacionais. Dados oficiais sobre benefícios por incapacidade - MPS [Internet]. Brasília: Tribunal Superior do Trabalho; 2011 [cited 2014 Oct 15]. 


\section{Bapítulo 11}

\section{A TERCEIRIZAÇÃO EM UMA INSTITUIÇÃO FEDERAL DE ENSINO SUPERIOR: UMA BREVE ANÁLISE DE DADOS DOS CUSTOS RELACIONADOS AO PROCESSO}

\section{Maxweel Veras Rodrigues}

Thaís Helena Cavalcante Lima

Ana Lúcia da Silva

\section{Margarida Maria De Souza}

Resumo: Este estudo tem por objetivo analisar os custos relacionados ao processo de terceirização no serviço público, especificamente no caso de uma Instituição Federal de Ensino Superior (IFES). Inicialmente, partiu-se de dados empíricos os quais predispunham que a terceirização era adotada em razão da redução de custos dela decorrente. Partindo-se desse pressuposto, realizou-se, após uma abordagem conceitual e normativa do instituto, um estudo comparativo e quantitativo dos custos assumidos pela IFES relativamente ao cargo de auxiliar administrativo efetivo e de auxiliar administrativo terceirizado. O estudo concluiu que, a despeito da economia advinda da terceirização, esta vem acompanhada de fatores nocivos ao interesse público, tais como a precarização do trabalho e a redução da qualidade do serviço prestado.

Palavras-chave: Terceirização; Custos; IFES. 


\section{INTRODUÇÃO}

Com o propósito de adequar-se às constantes mudanças organizacionais, as empresas buscam técnicas para se manterem em um sistema de alta competividade, imposto pelo processo de Globalização.

Essa também é a realidade das Instituições de Ensino Superior (IES), que procuram mecanismos para suprirem as exigências do mercado globalizado. Para muitas, a saída foi investir em novas tecnologias, inovação e mão de obra especializada. Tal ação, entretanto, contava com um grande desafio: inovar sem gerar mais despesas públicas. No intuito de reduzir os custos da máquina administrativa, as instituições passaram a buscar ações estratégicas, sendo uma delas a parceria com as empresas privadas através da terceirização.

$\mathrm{Na}$ concepção de Giosa (2003), a terceirização é um processo no qual uma organização deixa de realizar determinada atividade, passando a responsabilidade de executá-la a empresas especializadas nesta prestação de serviços. Analisando a temática, o autor destaca algumas dificuldades enfrentadas pelas empresas contratantes no processo de terceirização: algumas empresas, mesmo logrando êxito no processo de licitação, não têm suporte para atender as atividades pré-fixadas no contrato; aponta-se, ainda, a precarização decorrente do processo.

O presente estudo analisa uma faceta específica do instituto trabalhado por Giosa (op.cit): a redução de custos relacionada ao processo e a precarização de mão de obra dela decorrente no âmbito da Universidade Federal do Ceará (UFC).

Autores como Delgado (2012), Martins (2014), Bezerra Filho (2008), Streck (1995), contribuíram para a realização de uma abordagem conceitual e legal do instituto da terceirização. O dossiê preparado pela Central Única dos Trabalhadores - CUTacerca da terceirização também auxiliou no embasamento teórico da presente pesquisa.

Partindo para a análise em números da terceirização na UFC, o estudo foi embasado nos levantamentos de Diógenes (2013) e em dados disponíveis no site de compras on line do governo federal. Foram utilizados, por fim, contracheques de trabalhadores terceirizados e efetivos.
Nesse contexto, propõe-se a apreciação de dados relativos à terceirização na UFC, destacando a diferença salarial entre o cargo de auxiliar administrativo efetivo e de auxiliar administrativo terceirizado. Por tratar-se de um processo em franca ascensão na gestão pública e pela complexidade da temática a ser estudada, acredita-se na relevância dos dados trazidos na presente pesquisa, a despeito do caráter embrionário das análises suscitadas.

\section{TERCEIRIZAÇÃO}

\subsection{CONSIDERAÇÕES GERAIS}

Neste tópico, propõe-se a realização de sumária abordagem conceitual e normativa relativa ao instituto da terceirização. Superada esta análise inicial, a pesquisa poderá seguir para a verificação casuística que a justifica.

O doutrinador Delgado (2012), oportunamente, lembra que terceirizar é neologismo proveniente da área de administração de empresas, derivado do vernáculo "terceiro", aqui compreendido como intermediário, interveniente. Conceituando o instituto analisado no presente trabalho, o autor aduz que:

[...] terceirização é o fenômeno pelo qual se dissocia a relação econômica de trabalho da relação justrabalhista que the seria correspondente. Por tal fenômeno insere-se o trabalhador no processo produtivo do tomador de serviços sem que se estendam a este os laços justrabalhistas, que se preservam fixados com uma entidade interveniente. A terceirização provoca uma relação trilateral em face da contratação de força de trabalho no mercado capitalista: o obreiro, prestador de serviços, que realiza suas atividades materiais e intelectuais junto à empresa tomadora de serviços; a empresa terceirizante, que contrata este obreiro, firmando com ele os vínculos jurídicos trabalhistas pertinentes; a empresa tomadora de serviços, que recebe a prestação de labor, mas não assume a posição clássica de empregadora desse trabalhador envolvido. (DELGADO, 2012, p.435, grifo nosso)

$\mathrm{Na}$ esteira das palavras do autor, tem-se que terceirizar é estabelecer, na relação laboral, uma conexão trilateral, na medida em que o trabalhador, aqui denominado "obreiro", desempenha suas atividades em determinada empresa, a "tomadora de serviços", 
perfazendo seu vínculo justrabalhista perante outra, a empresa terceirizante.

O professor Martins (2014), trabalhando esta temática, aferiu que a terceirização consiste, essencialmente, em contratar terceiros para desempenhar as atividades-meio da empresa, ou seja, para executar tarefas não compreendidas em seu objeto principal.

A criação do instituto está intrinsecamente relacionada ao advento da globalização, mormente a partir do final de sua segunda fase, adotando-se aqui a classificação trabalhada por estudiosos da área da geografia. Esse processo intensificou as disputas entre empresas pelos mais diversos "quinhões de mercado", inflando-se, no cerne das organizações, a premente necessidade de se fazerem cada dia mais eficientes $e$ competitivas.

A eficiência, tomando de empréstimo as palavras de Bezerra Filho (2008, p. 12), significa "operacionalizar ao mínimo custo possivel, administrar corretamente os bens, com boa distribuição do tempo, economia de trabalho e dinheiro." No contexto acima apresentado, este passou a ser o apelo das organizações: fazer mais com menos recursos. É nesse cenário que surge o instituto da terceirização. Em essência, depreende-se que, se uma empresa delega suas atividades-meio a estabelecimentos que seriam especializados em tais práticas, restaria para ela maior tempo e mais recursos para investimento em sua atividade fim. Tal processo teria o condão de conferir maior eficiência ao processo produtivo das organizações.

No Brasil, o instituto ganha espaço já na segunda metade do século XX. É a lição que Delgado (2012, p.436) apresenta: " $A$ terceirização é fenômeno relativamente novo no Direito do trabalho do país, assumindo clareza estrutura e amplitude de dimensão apenas nas últimas três décadas do segundo milênio no Brasil."

Conceituado o instituto e realizada a sumária digressão histórica relativa ao tema trabalhado na presente pesquisa, propõe-se breve incursão na normatização que atualmente regulamenta a terceirização.

Antes, entretanto, é oportuno registrar que a abordagem até aqui edificada não põe em relevo uma importante faceta do processo de terceirização: a precarização da mão de obra empregada no seio das organizações. Este aspecto, entretanto, será melhor analisado no tópico subsequente, onde será abordada a terceirização na Universidade Federal do Ceará e os custos de folha de pagamentos relacionados ao processo.

Retomando a análise normativa acima proposta, convém pontuar, desde já, que a Constituição Federal de 1988 possui forte inclinação à proteção trabalhista. Já em seu artigo inaugural, indica que "os valores sociais do trabalho" constituem fundamentos da República Federativa do Brasil. Adiante, o texto constitucional dedica seu sétimo artigo à enumeração de vários direitos que visam à melhoria da condição social de trabalhadores urbanos e rurais.

No texto constitucional, entretanto, não há expressa menção ao instituto da terceirização. Há, sim, a formação de uma base principiológica que deve guiar toda e qualquer relação trabalhista.

Passa-se, pois, a uma abordagem legal relativa ao instituto estudado. A Consolidação das Leis do Trabalho - CLT- principal diploma de regulamentação trabalhista, também não disciplina a temática da terceirização. Em seu texto, a CLT trata apenas dos institutos da empreitada e da subempreitada, que, apesar de constituírem relação laboral onde há interveniência de um terceiro, inicialmente estranho à relação originalmente estabelecida, não se configuram como a terceirização nos moldes acima delineados. Isto porque, conforme mencionado acima, em 1943, ano de publicação da CLT, não existia o instituto da terceirização no Brasil, logo, não havia a necessidade jurídica de regulamentação do processo.

As primeiras referências normativas que indicavam a necessidade de se terceirizar atividades-meio vieram com a edição do Decreto-Lei $n^{\circ}$ 200/1967, que disciplinava acerca da organização da Administração Federal, e com a Lei 5645/70, que estabelecia diretrizes para a classificação de cargos do Serviço Civil da União e das autarquias federais.

O Decreto-Lei n² 200/1967, em seu artigo 10, estipula:

Art. 10. A execução das atividades da Administração Federal deverá ser amplamente descentralizada.

$[\ldots]$ 
$\S 7$ ㅇ Para melhor desincumbir-se das tarefas de planejamento, coordenação, supervisão e contrôle e com o objetivo de impedir o crescimento desmesurado da máquina administrativa, a Administração procurará desobrigar-se da realização material de tarefas executivas, recorrendo, sempre que possível, à execução indireta, mediante contrato, desde que exista, na área, iniciativa privada suficientemente desenvolvida e capacitada a desempenhar os encargos de execução.(grifo nosso)

A inteligência do dispositivo legal supra mencionado conduz à ideia de que a Administração, para melhor desempenhar suas "atividades fim" de planejar, coordenar, supervisionar e controlar a máquina administrativa, deveria se desincumbir da realização material de tarefas meramente executivas. Alguns anos mais tarde, a Lei 5645/70 exemplificou as mencionadas tarefas executivas indicadas no Decreto 200/67. O parágrafo único do art. $3^{\circ}$ da referida lei assim disciplinada:

\section{Art. $3^{\circ}-[\ldots]$}

Parágrafo único - As atividades relacionadas com transporte, conservação, custódia, operação de elevadores, limpeza e outras assemelhadas serão, de preferência, objeto de execução indireta, mediante contrato, de acordo com o artigo 10, § 7을 do Decreto-lei no 200, de 25 de fevereiro de 1967.

Em âmbito privado, pode-se indicar como referências normativas a leis 6.019/74, que dispõe sobre o Trabalho Temporário nas Empresas Urbanas, recentemente alterada pela lei 13.429/2017, e a lei 7.102/83, alterada pela lei 8863/1994, que dispõe sobre segurança para estabelecimentos financeiros, estabelece normas para constituição e funcionamento das empresas particulares que exploram serviços de vigilância e de transporte de valores.

Com a nova redação dada pela lei 13.429/2017, 0 art. $4^{\circ}$ e $9^{\circ}, \$ 3^{\circ}$, da lei 6.019/74 passaram a dispor:

Art. 4ํ-A. Empresa prestadora de serviços a terceiros é a pessoa jurídica de direito privado destinada a prestar à contratante serviços determinados e específicos. (Incluído pela Lei no 13.429, de 2017)

$\S 1^{\circ} \mathrm{A}$ empresa prestadora de serviços contrata, remunera e dirige 0 trabalho realizado por seus trabalhadores, ou subcontrata outras empresas para realização desses serviços. (Incluído pela Lei $\mathrm{n}^{\circ}$ 13.429, de 2017)

$\S 2^{\circ}$ Não se configura vínculo empregatício entre os trabalhadores, ou sócios das empresas prestadoras de serviços, qualquer que seja o seu ramo, e a empresa contratante. (Incluído pela Lei $n^{\circ}$ 13.429, de 2017)

[...]

Art. $9^{\circ}-\S 3^{\circ} \mathrm{O}$ contrato de trabalho temporário pode versar sobre o desenvolvimento de atividades-meio e atividades-fim a serem executadas na empresa tomadora de serviços.

Embora ainda não se tenha aí o vocábulo "terceirização", já se pode identificar o fenômeno tal como descrito no início deste tópico. Da mesma forma, a lei 7.102/83, em seu art. $3^{\circ}$, admite a ocorrência da terceirização nos estabelecimentos financeiros, em atividades de transporte de valores e de vigilância, embora não utilize a nomenclatura "terceirização" para designar o fenômeno trabalhista de contratação de empresas "especializadas" para desempenhar tais atividades.

Finalizando a breve digressão normativa proposta, cabe pontuar que, a partir do ano de 2011, a principal referência normativa disciplinadora do processo da terceirização foi a Súmula $n^{\circ} 331$ editada pelo Tribunal Superior do Trabalho - TST. Para Streck (1995, p. 127) "[...] as Súmulas são o resultado da jurisprudência predominante de um tribunal superior brasileiro, autorizado pelo Código de Processo Civil a emiti-la toda vez que existir um incidente de uniformização de jurisprudência [...]". Ou seja, o conjunto de decisões exaradas por um tribunal em um mesmo sentido, podem originar enunciados, as súmulas, que resumem postura daquele tribunal sobre determinada temática.

$\mathrm{Na}$ ausência de uma legislação específica que disciplinasse de forma plena o instituto da terceirização, desde o ano de 2011, a súmula 331/TST tem sido uma importante referência em julgamentos nesta temática.

Por fim, cabe pontuar que as recentes alterações trazidas ao ordenamento jurídico com a edição da lei 13.429/2017 polarizaram os debates relativos à temática. A mídia veicula a ideia de que o permissivo legal de terceirização nas atividades fim, em contratos 
temporários, representa um retrocesso para o Direito do Trabalho. Toledo Filho, por outro lado, analisando a temática, no texto intitulado "Nova lei impede terceirização permanente da atividade-fim", entende que a terceirização nas atividades fim em contratos temporários não é novidade. Nessa esteira de raciocínio, o permissivo legal finda por vedar a terceirização no âmbito de qualquer outra modalidade de relação laboral.

Por ser muito recente, não se pode aferir o real impacto social que a lei 13.429/2017, de 31 de março de 2017, alcançará na regulamentação da temática ora discutida. $\mathrm{O}$ atual cenário político edificado no Brasil, entretanto, não permite inferir que a alteração legal venha a fortalecer a proteção social trabalhista constitucionalmente assegurada.

Realizada a breve incursão conceitual e normativa proposta, passa-se à segunda parte do presente estudo, cuja finalidade volta-se para uma breve incursão nos dados de terceirização na Universidade Federal do Ceará.

\section{A TERCEIRIZAÇÃO EM NÚMEROS NA UFC}

A par do que se discutiu, tem-se que o uso da terceirização na UFC não difere dos pressupostos admitidos pela a Administração Pública em geral. Estes, por sua vez, estão ligados ao paradigma neoliberal da necessidade de modernização gerencial do
Estado visando à redução das despesas da máquina administrativa do Estado, bem como desburocratizá-la permitindo mais flexibilidade gerencial.

No rol das justificativas para o uso da terceirização, encontram-se geralmente aspectos ligados aos fatores econômicos, seja em circunstância do agravamento da crise econômica, seja buscando a desoneração das obrigações trabalhistas.

$\mathrm{Na}$ pesquisa de Diógenes (2013), são encontrados os primeiros aos dados referentes aos contratos na área da terceirização na UFC. Os mesmos estão ligados à vigilância e à limpeza na década de 80, com vigência a partir de 1987. Seu estudo traz os primeiros dados da terceirização na UFC relativos ao ano de 2012.

Como elemento novo, traz-se uma comparação simples entre os valores desembolsados pela UFC para o cargo de auxiliar administrativo terceirizado e o valor desembolsado para remunerar o mesmo cargo de natureza efetiva, ou seja, auxiliar administrativo efetivo.

Por ausência de uma planilha técnica de custos que demonstrem todos os encargos sociais que compõem os custos do cargo efetivo, apresenta-se, inicialmente, sumária figura comparativa (figura 1) dos benefícios e encargos presentes nos contracheques de ambos.

Figura 1 Comparativo de Custos/Referência Abril /2017.

\begin{tabular}{|c|c|c|c|c|c|c|}
\hline & Salário Base & Vale Transporte & Alimentação & Previdência & $\begin{array}{c}\text { 13 Salário/ } \\
\text { proporcional } \\
\text { /mês }\end{array}$ & $\begin{array}{l}\text { 1/3 de férias } \\
\text { proporcional }\end{array}$ \\
\hline \multirow{2}{*}{ CRIART } & \multirow{2}{*}{$1.032,75$} & $\begin{array}{l}\text { Desconto } \\
\text { de } 61,97\end{array}$ & $\begin{array}{l}\text { Desconto } \\
\text { de } 3.26\end{array}$ & $\begin{array}{l}\text { Servidor } \\
82,62\end{array}$ & \multirow[t]{2}{*}{86,06} & \multirow{2}{*}{28,68} \\
\hline & & $\begin{array}{l}\text { Crédito } \\
\text { de } 140,80\end{array}$ & $\begin{array}{l}\text { Crédito de } \\
400,00\end{array}$ & $\begin{array}{c}\text { Patronal } \\
206,55\end{array}$ & & \\
\hline \multirow{2}{*}{ UFC } & \multirow{2}{*}{1.945 .07} & $\begin{array}{c}\text { Não há } \\
\text { descontos }\end{array}$ & $\begin{array}{c}\text { Não há } \\
\text { descontos }\end{array}$ & $\begin{array}{l}\text { Servidor } \\
213,95\end{array}$ & \multirow{2}{*}{162,08} & \multirow{2}{*}{54,02} \\
\hline & & $\begin{array}{l}\text { Crédito } \\
\text { de } 24,09\end{array}$ & $\begin{array}{c}\text { Crédito } \\
\text { de } 458,00\end{array}$ & $\begin{array}{c}\text { Patronal } \\
427,91\end{array}$ & & \\
\hline
\end{tabular}

Fonte: contra cheques cedidos por servidor da CRIART e UFC. 
Mesmo em sumária análise à figura acima colacionada, será patente a disparidade existente entre a contrapartida financeira efetuada, pela UFC, frente ao auxiliar administrativo terceirizado e $\mathrm{O}$ auxiliar administrativo efetivo.

Destaque-se, por oportuno, que se escolheu como parâmetro ao "terceirizado auxiliar administrativo" um "auxiliar administrativo efetivo" em início de carreira, sem se considerar possíveis progressões, gratificações por desempenho de funções, ou mesmo o "incentivo à qualificação", pago a todos os servidores que possuem qualificação superior à exigida pelo cargo ocupado. Nessa esteira, vislumbra-se que mesmo o menor salário pago pela universidade ao seu "auxiliar administrativo efetivo" é bem superior ao valor desembolsado com o terceirizado.

Retoma-se, nesta etapa, a ideia de que o fenômeno da terceirização revela a precarização do trabalho, apesar de a legislação assegurar o instituto da isonomia salarial para coibir a violação da redução de salários entre os pares que trabalham na mesma empresa ou órgão. Entretanto, na Administração Pública não há equivalência, haja vista a disparidade entre o salário de um servidor terceirizado e o efetivo. Fato constatado na figura 1.

A figura 1 registra uma diferença de salário base de $\mathrm{R} \$$ 922,32, o que significa, percentualmente, que o terceirizado recebe, relativamente a esta parcela, aproximadamente $53 \%$ de um servidor efetivo ingressante para desempenhar as mesmas funções. Tal diferença reflete diretamente nas demais parcelas salariais, tais como 13은 salário e 1/3 de férias.

Nessa temática, convém destacar um importante ponto da Lei no 6.019/74, cujo disciplinamento encontra-se no caput do art. 12, alínea "a":

Art.12 - Ficam assegurados ao trabalhador temporário os seguintes direitos:

a) Remuneração equivalente à percebida pelos empregados da mesma categoria da empresa tomadora ou cliente calculados à base horária, garantida, em qualquer hipótese, a percepção do salário-mínimo regional. (Brasil, 1974)
A Central Única dos Trabalhadores (CUT) traz um estudo de 2014 em que ressalta o contexto da precarização do trabalho terceirizado não apenas pela desigualdade salarial, mas pelas condições de trabalho. Da pesquisa realizada pela CUT, depreende-se que há expressiva diferenciação na concessão de benefícios e garantias para terceirizados e efetivos. No referido contexto de precarização, é prudente destacar, ainda, a ausência de garantias de que as obrigações sociais e trabalhistas serão honradas nas rescisões contratuais dos terceirizados.

O estudo da CUT (2014) registra também relatos de discriminação dos trabalhadores terceirizados, com maior incidência nas áreas de asseio, conservação e vigilância. Há, no ambiente laboral, um preconceito silencioso e velado que abrange, não somente o setor de lotação dos trabalhadores terceirizados, mas também tem relação direta com outros fatores como: salários, ausência de formação acadêmica, jornadas e horas trabalhadas.

Condições "diferentes", no sentido de serem de pior qualidade e precárias.

$[\ldots]$

Segundo relatos de dirigentes sindicais do setor de vigilância, que atuam nos bancos, o local de vestuário, descanso e refeição desses trabalhadores é nos porões. "É só perguntar onde fica o porão que você encontra o local onde ficam os vigilantes. São lugares escuros e pouco ventilados" (Relato de dirigente sindical do setor). No setor de saúde, os dirigentes relataram que, em muitos casos, o local de descanso dos trabalhadores terceirizados fica ao lado dos necrotérios. É o "lugar" do terceirizado na sociedade, física e simbolicamente. (CUT, 2014, p.29)

Partindo da pesquisa da CUT (2014), infere-se que os fatores acima elencados promovem uma alta rotatividade da mão de obra terceirizada no seio da empresa terceirizante e das próprias empresas prestadoras de serviço. Este cenário é ratificado no âmbito da UFC, conforme verificado pelos dados abaixo colacionados, relativos às empresas que prestaram serviços nesta autarquia nos anos de 2012 e 2017. 
Figura 2 Demonstrativo Contrato/Vigência 2012.

\begin{tabular}{|c|c|c|}
\hline Campus & XYZ - Limpeza & ZRT - Apoio Administrativo \\
\hline Fortaleza & $581.275,16$ & $163.649,77$ \\
\hline Cariri & $24.984,93$ & $3.963,63$ \\
\hline Quixadá & $6.623,08$ & $4.429,24$ \\
\hline Pentecoste & $1.842,68$ & $11.549,51$ \\
\hline Sobral & $23.702,54$ & $183.592,15$ \\
\hline TOTAL & $638.428,39$ & \\
\hline
\end{tabular}

Fonte: DIOGENES (2013)

Faz-se necessário pontuar que as 2 (duas) empresas indicadas como prestadoras de serviços em 2012 não integralizam o rol de empresas que, neste ano, possuíam contratos vigentes com a UFC. O recorte foi feito em razão dos dados financeiros disponíveis para a presente pesquisa.

Sublinhe-se, dessa forma, que em 2012 a UFC, além da XYZ serviços de limpeza e zeladoria e da ZRT atuando nos serviços de apoio administrativo, havia, segundo Diógenes (2013) a ZARF, a qual atuava na área de segurança e vigilância, e a TAK, que trabalhava com serviços de portaria e recepção.
Uma análise comparativa da figura 2 e da figura 3, adiante colacionada, evidencia que não há similitude de nenhuma das empresas que prestavam serviços na UFC em 2012, e as que desempenham tais atividades no ano em curso, o que evidencia a alta rotatividade das empresas terceirizadas com contratos vigentes junto ao setor público. Há de se destacar também, um aumento da abrangência de atuação das empresas terceirizadas na esfera pública, o que retrata a consolidação desta modalidade contratual.

Ratificando a ideia esposada, verificamos, em 2017, as seguintes empresas com atuação a Universidade Federal do Ceará:

Figura 3 Demonstrativo Contrato/Vigência 2017.

\begin{tabular}{|c|c|c|c|}
\hline Empresas & Objeto do Contrato & Valor Mensal & Valor Anual \\
\hline CRIART & Apoio administrativo & $704.061,59$ & $8.448 .739,08$ \\
\hline CRIART & Limpeza & $779.959,24$ & $9.359 .510,88$ \\
\hline $\begin{array}{c}\text { FAZ EMPRESA } \\
\text { E SERVIÇOS EIRELI }\end{array}$ & $\begin{array}{l}\text { Contínuo/ Operador de } \\
\text { Microcomputador }\end{array}$ & $36.984,12$ & $443.809,42$ \\
\hline GARDEN & Motoristas & $285.736,52$ & $3.428 .838,29$ \\
\hline SERVAL & $\begin{array}{c}\text { Serviço de limpeza/Áreas } \\
\text { verdes }\end{array}$ & $305.716,38$ & $3.668 .596,51$ \\
\hline SERVAL & Portaria/Recepção & $431.489,70$ & $5.177 .876,36$ \\
\hline SERVIARM & Vigilância armada & $713.808,01$ & $8.565 .696,13$ \\
\hline Total & & $1.806 .741,47$ & $21.680 .897,67$ \\
\hline
\end{tabular}

Fonte: BRASIL, Compras Governamentais, 2017.

Partindo para a análise dos custos trabalhistas, é notório a complexidade e o excesso de encargos que são computados para o cálculo do custo do trabalhador. O custo do processo de terceirização na UFC, naturalmente, não é diferente, de modo que a empresa disponibilizadora de mão de obra repassa todos os custos e encargos à tomadora.

Em observância à planilha de custo de formação de preços para o cargo de auxiliar administrativo da empresa CRIART, ganhadora do pregão eletrônico 118/2015 (contrato em vigência, disponível no site de 
compras do governo federal), cujo objeto é o fornecimento de serviços de apoio administrativo, é possível aferir que a empresa terceirizante repassa à tomadora dos serviços todos os custos com encargos sociais e todos os gastos que poderá eventualmente ter com o trabalhador terceirizado (licença maternidade, auxílio funeral, ausência por doença, auxílio creche, dentre outros) minimizando os "riscos" assumidos pela empresa terceirizante e maximizando os lucros por ela auferidos. Em contrapartida, vislumbra-se a patente precarização da mão de obra terceirizada, que finda por "arcar" com todas essas eventualidades, visto que considerável parcela do valor repassado à prestadora de serviços deixa de ser convertido em remuneração ao trabalhador.

A planilha demonstra que a proposta vencedora do pregão eletrônico 118/2015, apresenta como custos gerais para o cargo de auxiliar administrativo 0 valor de $\mathrm{R} \$$ 2.421,77, enquanto um auxiliar administrativo aufere, em 2017, salário-base de 1032,75, conforme apresentado na figura 1.

\section{CONCLUSÃO}

A administração pública, ao delegar partes de suas atividades a terceiros, o faz em nome do enxugamento da máquina estatal e a bem da qualidade dos serviços. No entanto, verificouse ser paradoxal falar em redução de custos e aumento da qualidade de serviços, quando se constatou a alta rotatividade dos trabalhadores terceirizados e mesmo das empresas terceirizantes. Tal fenômeno provoca, por vezes, a interrupção abrupta das atividades prestadas e contribui para a queda na qualidade dos serviços ofertados aos cidadãos.

\section{REFERÊNCIAS}

[1]. BEZERRA FILHO, João Eudes. Contabilidade Pública: teoria, técnica de elaboração de balanços e questões. $3^{\circ}$ Edição. Rio de Janeiro: Elsevier, 2008.

[2]. BRASIL, Constituição Federal de 1988. Disponível el em: <http://www.planalto.gov.br/ccivil_03/constituicao/c onstituicao.htm>. Acesso em: 08 maio 2017.

[3]. Decreto-Lei $n^{\circ} 5452$, de 01 de maio de 1943. Dispõe sobre a Consolidação das Leis do Trabalho. Disponível em: <http://www.planalto.gov.br/ccivil_03/decretolei/Del5452.htm>. Acesso em: 08 maio 2017.
Acerca da terceirização na UFC, cabe enfatizar que a diferença remuneratória do cargo de auxiliar administrativo terceirizado e efetivo revela uma economia de aproximadamente 53\% no pagamento do "salário base", mesmo tendo como parâmetro o salário inicial da carreira do servidor efetivo, desconsiderando-se qualquer outro benefício por ele auferido. Portanto, a pesquisa evidenciou que, do ponto de vista financeiro, a terceirização é uma atividade viável dentro da administração pública, face à redução de custos atrelada ao processo.

Importante ressaltar, contudo, outra faceta do mesmo instituto: a precarização advinda do processo de terceirização. Evidenciou-se, durante a pesquisa, que o empregado terceirizado suporta grande parte do ônus dos custos da atividade terceirizante, visto que não se converte em remuneração ao trabalhador a maior parte do valor repassado pela tomadora à prestadora de serviços. O trabalhador terceirizado, portanto, encontra-se numa situação de vulnerabilidade econômicosocial.

A guisa de conclusão cabe pontuar que, a despeito da economia advinda da terceirização, esta vem acompanhada de fatores nocivos ao interesse público. Como visto, premissas neoliberais, oriundas única e exclusivamente da ótica mercadológica do lucro, dão sustentação a este processo. A Administração Pública, entretanto, enquanto guardiã do interesse público, não pode se guiar por interesses meramente econômicos. Toda e qualquer atividade incorporada à rotina administrativa deve estar atrelada ao seu princípio finalístico: a promoção de serviços de qualidade à sociedade.

[4]. Decreto-Lei $n$ ㅇ 200, de 25 de fevereiro de 1967. Dispõe sobre a organização da Administração Federal, estabelece diretrizes para a Reforma Administrativa e dá outras providências. Brasília: Presidência da República, 1967. Disponível em: <http://www.planalto.gov.br/ccivil_03/decretolei/Del0200.htm>. Acesso em: 08 maio 2017.

[5]. Lei 5645/70, de 10 de dezembro de 1970. Estabelece diretrizes para a classificação de cargos do Serviço Civil da União e das autarquias federais, e dá outras providências. Disponível em: <http://www.planalto.gov.br/ccivil_03/leis/L5645.ht m>. Acesso em: 08 maio 2017. 
[6]. Lei n. 6.019 de 03 de janeiro de 1974: dispõe sobre o trabalho temporário nas empresas urbanas e dá outras providências. Brasília, DF, 03 jan. 1974. Disponível em:

[7]. <http://www. planalto.gov.br/ccivil_03/leis/L 6019.htm>. Acesso em: 08 maio 2017.

[8]. Lei no 7.102, de 20 de junho de 1983. Dispõe sobre segurança para estabelecimentos financeiros, estabelece normas para constituição e funcionamento das empresas particulares que exploram serviços de vigilância e de transporte de valores, e dá outras providências. Brasília: Presidência da República, 1983. Disponível em: <http://www. planalto.gov.br/ccivil_03/leis/L7102.ht m>. Acesso em: 08 maio 2017

[9]. Lei 8863/1994, de 28 de março de 1994: Altera a Lei 7.102, de 20 de junho de 1983.Disponível em: <http://www. planalto.gov.br/ccivil_03/leis/L8863.ht m>. Acesso em: 08 maio 2017.

[10]. Lei n. 13.429, de 31 de março de 2017: Altera dispositivos da Lei № 6.019, de 3 de janeiro de 1974, que dispõe sobre o trabalho temporário nas empresas urbanas e dá outras providências; e dispõe sobre as relações de trabalho na empresa de prestação de serviços a terceiros. Brasília, DF, mar. $2017 . \quad$ Disponível em: <http://www.planalto.gov.br/ccivil_03/_ato20152018/2017/lei/L13429.htm>. Acesso em: 08 maio 2017.

[11]. Portal de Compras do Governo Federal Compras Governamentais. Ministério do Planejamento. Disponível em: <http://comprasnet.gov.br/acesso.asp?url=/livre/Pr egao/ata0.asp $\geq$. Acesso em: 08 maio 2017

[12]. Tribunal Superior do Trabalho. Súmula TST no 331, 31 de maio de 2011. Disponível em
$<$ <ww.tst.jus.br/jurisprudencia>. Acesso em: 08 maio 2017.

$\begin{array}{lcr}\text { [13]. CENTRAL } & \text { ÚNICA } & \text { DOS } \\ \text { TRABALHADORES. } & \text { Terceirização } & \text { e }\end{array}$ desenvolvimento: uma conta que não fecha: / dossiê acerca do impacto da terceirização sobre os trabalhadores e propostas para garantir a igualdade de direitos. Secretaria Nacional de Relações de Trabalho e Departamento Intersindical de Estatística e Estudos Socioeconômicos. - São Paulo: Central Única dos Trabalhadores, 2014. Disponível em: <https://www.cut.org.br/system/uploads/ck/files/Do ssie-Terceirizacao-e-Desenvolvimento.pdf, 56 p>. Acesso em: 08 maio 2017.

[14]. DELGADO, Mauricio Godinho. Curso de Direito do Trabalho. $11^{\circ}$ Edição. São Paulo: LTr, 2012.

[15]. DIÓGENES, S. H. do A. B. Estudo do comprometimento de funcionários terceirizados como processo de melhoria na gestão institucional na UFC. Dissertação, p.138. Disponível em: <http://www.repositorio.ufc.br/handle/riufc/8036 2 . Acesso em: 08 maio 2017.

[16]. GIOSA, Lívio Antonio. Terceirização: uma abordagem estratégica. São Paulo: Pioneira, 1993.

[17]. MARTINS, Sérgio Pinto. A terceirização e o direito do trabalho. São Paulo: Atlas, 2014.

[18]. STRECK, Lenio Luiz. Súmulas no Direito Brasileiro: eficácia, poder e função. Porto Alegre: Livraria do Advogado, 1995.

[19]. TOLEDO FILHO, Manoel Carlos. Nova lei impede terceirização permanente da atividade-fim. Disponivel em: http://justificando.cartacapital.com.br/2017/04/05/n ova-lei-impede-terceirizacao-permanente-daatividade-fim/>. Acesso em: 08 maio 2017. 


\section{Capítulo 12}

ATIVIDADES INOVATIVAS NA INDÚSTRIA MOVELEIRA DO VALE DO PARANHANA

\section{Fabiano Barbieri}

\section{Paulo Roberto de Aguiar Von Mengden}

\section{Fladhimyr Castello}

Resumo: Este estudo apresenta os resultados de uma pesquisa exploratória de abordagem qualitativa que teve como objetivo o diagnóstico da indústria moveleira do Vale do Paranhana no que concerne à inovação. Foi adaptado e aplicado em dezoito empresas o Diagnóstico de Inovação, que é parte do Projeto de Extensão Produtiva e Inovação, o qual foi elaborado pelo Governo do Estado do Rio Grande do Sul. A partir dos resultados obtidos, algumas sugestões foram feitas com o intuito de que se reduzam ou se eliminem os fatores que prejudicam a inovação e a implementação das atividades inovativas, bem como para que a taxa de inovação na indústria moveleira seja alavancada.

Palavras-chave: Diagnóstico de Inovação. Inovação. Atividades de inovação. 


\section{INTRODUÇÃO}

O desenvolvimento de tecnologias e as inovações são importantes para que as empresas se desenvolvam e continuem competitivas no mercado, principalmente devido ao processo de globalização. A capacidade de determinar as atividades inovadoras, as características das empresas que inovam, bem como os fatores internos e sistêmicos que influenciam a inovação é um pré-requisito para o desenvolvimento e análise das políticas que visam a incentivar a inovação tecnológica (MANUAL DE OSLO, 2005).

A inovação se tornou, ao longo dos anos, um fator determinante para as empresas e para o desenvolvimento e crescimento do país. O Estado do Rio Grande do Sul detém 14,1\% das empresas em atividade no país, $18,6 \%$ da produção nacional, $13,5 \%$ em volume de pessoal ocupado, $16,3 \%$ do faturamento e $29 \%$ das exportações brasileiras, ocupando a primeira posição como o estado que mais exporta móveis (MOVERGS, 2014).

De acordo com a MOVERGS/IEMI, 2014, a Região Sul do Brasil concentra o maior número de empresas moveleiras se comparado com as demais regiões do país. A região sul possui aproximadamente $40 \%$ das empresas, seguida pela região sudeste com $38 \%$, nordeste com $12 \%$, centro-oeste com $7 \%$ e região norte com $2 \%$.

Tendo como objetivo a elaboração de indicadores nacionais e regionais das atividades de inovação tecnológica nas empresas industriais brasileiras, compatíveis com as recomendações internacionais em termos conceituais e metodológicos, foi iniciada, no ano de 2000, a Pesquisa Industrial de Inovação Tecnológica - PINTEC. O Brasil, com a implementação desta pesquisa, iniciou um marco importante no país, permitindo o entendimento de, eventualmente, interferir no desenvolvimento econômico com o intuito de que se avalie o processo de geração, difusão e incorporação do processo tecnológico. Nesta pesquisa fica evidente o potencial do mercado relacionado com "fabricação de produtos de madeira".

\section{FUNDAMENTAÇÃO TEÓRICA}

\subsection{INOVAÇÃO}

Uma empresa pode alterar seus métodos de produção, suas técnicas e ferramentas, seus fatores de produção, visando ao aumento da produtividade, consequentemente, gerando um maior desempenho comercial. De acordo com o Manual de Oslo (2005), inovação tecnológica é a implementação de produtos (bens ou serviços) ou processos tecnologicamente novos ou substancialmente aprimorados, ocorrendo quando o produto é introduzido no mercado, bem como quando o processo começa a ser operado na empresa. Inovações de produto envolvem mudanças significativas nos produtos ou serviços, incluindo-se bens e serviços totalmente novos ou aprimorados para produtos já existentes. Inovações de processo caracterizam-se por mudanças significativas nos métodos de produção e de distribuição, conforme o Manual de Oslo (2005).

As inovações são um meio para que se obtenham vantagens competitivas sustentáveis para as empresas em que a capacidade de inovar é vista como um dos fatores mais importantes no desempenho dos negócios (BARBIERI, 2003).

As inovações são classificadas em quatro tipos: inovações de produto, inovações de processo, inovações organizacionais e inovações de marketing (MANUAL DE OSLO, 2005). A inovação é um processo que se inicia a partir da percepção de novos mercados, de oportunidades que conduzam ao desenvolvimento, produção e desenvolvimento comercial (CARVALHO, 2009).

De acordo com Cavalcanti (2007), as principais barreiras contra o investimento em pesquisa, desenvolvimento e inovação por parte, principalmente, das pequenas e médias empresas podem ser agrupadas em quatro áreas: (i) Falta de recursos financeiros; (ii) Falta de conhecimento; (iii) Falta de capital humano e (iiii) Falta de governança.

Quando as organizações se deparam com necessidades ou identificam desejos dos clientes, por vezes pode ser difícil criar ou aperfeiçoar um produto ou processo, no entanto essas inovações podem proporcionar um diferencial competitivo muito importante. Conforme Motta (1999), inovação é a introdução de uma novidade no produto, serviço ou modelo de negócio. Robbins (2001) complementa, afirmando que a inovação incentiva o surgimento de oportunidades e o crescimento da organização. 
De Negri, Salerno e Castro (2005) afirmam que as empresas inovadoras obtêm uma significativa melhora na qualidade do produto, permitindo que se amplie ou se mantenha a participação no mercado, que se reduzam custos e impactos ao meio ambiente, além de ajudar na adequação às normas dos mercados internos e externos. Porter (1998) reforça que a inovação é a única maneira de se desenvolver e manter uma vantagem estratégica sobre a concorrência.

As empresas que mais inovam no mundo sabem o quanto é necessário ter um processo sistêmico, deliberado e contínuo a fim de identificar as grandes oportunidades para que se inove e se diferencie no mercado (TERRA, 2011).

A inovação ocorre ao nível de produtos, processos e tecnologias, iniciando-se sempre a partir de uma busca incessante pela vantagem competitiva (BARNEY e HESTERLY, 2011).

Brito e Cândido (2013) argumentam que um adequado processo de gestão da inovação tecnológica e a criação de uma cultura inovadora nas pequenas e médias empresas fazem com que sejam aumentadas a sua sobrevivência e o seu desenvolvimento.

\section{ATIVIDADES DE INOVAÇÃO}

As atividades de inovação são todas as etapas científicas, tecnológicas, organizacionais, financeiras e comerciais que conduzem à implementação de inovações. Algumas dessas atividades podem ser inovadoras, enquanto outras não são novas, mas necessárias para a implementação das inovações (MANUAL DE OSLO, 2005).

Conforme o Manual de Oslo (2005), durante um determinado período, as atividades de inovação em uma empresa podem ser definidas em três tipos: (i) Bem-sucedida, por resultar na implementação de uma inovação (embora não necessariamente bem-sucedida comercialmente); (ii) Em progresso, pelo fato de ainda não ter resultado na implementação de uma inovação; (iii) Abandonada, antes da implementação da inovação.

Gibson e Skarzynsky (2008) afirmam que as organizações que desejam incorporar a inovação ao cotidiano da empresa devem preocupar-se em implementar práticas de gestão que foquem na atividade inovativa em todas as suas dimensões.
A capacidade de inovação das organizações depende de uma série complexa de fatores, que vão além da capacidade tecnológica, sendo necessário adequar a competência organizacional e relacional. As competências devem estar presentes nas empresas inovadoras, pois elas envolvem conhecimentos necessários que conduzem à inovação.

Avanitis e Hollenstein (1998) realizaram uma análise no setor produtivo com o objetivo de investigar padrões específicos nas atividades de inovação e fontes externas de conhecimento, concluindo que os comportamentos econômicos podem coexistir e a relação entre indústrias específicas e modos de inovação não é direta.

O comportamento inovador das organizações pode ser analisado através de uma visão do que acontece internamente. Por meio de um estudo empírico com 152 empresas inovadoras, confirmou-se a existência de relações entre os atributos internos e 0 processo inovativo, onde o objetivo não foi explicar os resultados obtidos com as inovações, mas a forma como são gerenciadas as atividades inovadoras (GALENDE e FUENTE, 2003).

Bezerra (2010) explica que as atividades inovativas estão interligadas ao processo inovativo de forma sistemática e integrada, sendo que tais atividades conduzem ao desenvolvimento de novos processos, mecanismos de seleção e procedimentos voltados à criação de novos produtos.

\section{CENÁRIO}

O setor moveleiro no Brasil tem grande representatividade na economia pelo fato do número de empresas, volume de negócios e empregos gerados. Existem milhares de empresas espalhadas por todo o país, sendo que muitas se concentram nos principais polos moveleiros.

A indústria moveleira do Brasil faturou, em 2014, R\$ 44,45 bilhões, sendo a indústria moveleira gaúcha responsável por $R \$ 7,38$ bilhões desse montante. Destaca-se, entre os polos moveleiros, o Polo de Bento Gonçalves, no RS, pois concentra o maior número de empresas, maior número de mão de obra e maior produção (MOVERGS/IEMI, 2015).

No ano de 2014, havia 19.700 empresas que atuavam no setor moveleiro nacional. Essas 
empresas eram responsáveis por 321.395 postos de trabalho. A indústria moveleira do Brasil faturou, em exportações, US\$ 689,5 milhões, sendo a indústria gaúcha responsável por US\$216,8 milhões desse total em 2014 (MOVERGS/IEMI, 2015).

O Vale do Paranhana caracteriza-se por ser uma região predominantemente voltada ao setor coureiro-calçadista, compreendendo diversos fabricantes desde calçados a artigos de couro. Por outro lado, a indústria moveleira também tem grande impacto na economia desta região pelo fato de que o número de empresas inseridas no setor moveleiro do Vale do Paranhana surgiu de forma espontânea num arranjo produtivo local.

Quando empresas de um determinado setor se juntam em um arranjo produtivo local, existe a possibilidade de haver uma importante contribuição para o desenvolvimento de uma região em razão dos benefícios sociais gerados através do surgimento de um conjunto de serviços e fornecedores locais. Pode-se afirmar que uma grande parcela dos arranjos produtivos compõe-se por micro e pequenas empresas, reforçando sua posição competitiva ao privilegiarem relacionamentos de cooperação (ALBINO e SOUZA, 2008).

O Instituto Brasileiro de Geografia e Estatística (IBGE) divulgou, no ano de 2013, os resultados da Pesquisa de Inovação (Pintec) relativos ao período de 2009 a 2011 (IBGE, 2013). A taxa de inovação corresponde ao quociente entre o número de empresas que declararam ter implementado alguma inovação e o número total de empresas no setor pesquisado. Na indústria brasileira como um todo, constatou-se que a taxa de inovação ficou em 35,56\%, a taxa de inovação de produto registrou $17,26 \%$ e a taxa de inovação de processo registrou 31,67\%. Na indústria do Rio Grande do Sul, o mesmo relatório apresentou 42,24\%, 23,81\% e $36,74 \%$ respectivamente para taxa de inovação, taxa de inovação de produto e taxa de inovação de processo.

De acordo com o Plano Estratégico de Desenvolvimento Regional 2011-2020 (COREDEPES, 2010), são sugeridos alguns projetos que podem impulsionar as taxas de inovação da indústria do Vale do Paranhana. O Projeto 19 trata da implantação de duas incubadoras tecnológicas, pois a indústria necessita de proteção e de incentivos ao desenvolvimento, 0 que pode ser proporcionado pela incubação e auxílio tecnológico. No Projeto 20, sugere-se o fortalecimento do Polo de Inovação Tecnológica a fim de que sejam aportados recursos anuais destinados a financiar produtos e processos inovadores. O Projeto 21 visa a oferecer prêmio para a empresa industrial que apresentar o caso de um produto ou um processo com características inovadoras na região. No Projeto 22, propõese 0 reconhecimento das atividades inovadoras, pois elas geram novos negócios e ampliam a renda. Por fim, no Projeto 23, é proposto $\mathrm{o}$ incentivo a produtos e processos inovadores.

\section{METODOLOGIA}

Com o intuito de que se obtivessem as informações necessárias, permitindo um melhor diagnóstico com relação à inovação e às atividades de inovação das empresas, decidiu-se adaptar o Diagnóstico de Inovação, resultado do Projeto de Extensão Produtiva e Inovação - Projeto Extensão (AGÊNCIA GAÚCHA DE DESENVOLVIMENTO E PROMOÇÃO DO INVESTIMENTO, 2015).

O Diagnóstico de Inovação, destina-se a verificar se as empresas investem em inovação, conhecem ou não as atividades inovativas, os métodos de gestão da inovação e os mecanismos públicos para a obtenção de subsídios à inovação.

Ao adaptar-se o Diagnóstico de Inovação, buscou-se uma maior extração de informações das empresas, possibilitando o aprofundamento do diagnóstico do setor moveleiro do Vale do Paranhana. O gestor da empresa, ao responder sim nas questões do Diagnóstico de Inovação, foi perguntado sobre qual, quais, como, quem, quanto e onde em determinadas questões. Para a obtenção das informações, o pesquisador deslocou-se a cada uma das empresas que faz parte da pesquisa, aplicando o Diagnóstico de Inovação diretamente com os gestores e registrando as respostas de forma escrita.

\section{COLETA DE DADOS}

O Diagnóstico de Inovação foi aplicado em dezoito micro e pequenas empresas que atuam no setor moveleiro do Vale do Paranhana que participam ou já participaram do Projeto de Extensão Produtiva e Inovação, 
divididas entre as cidades de Parobé, Taquara, Igrejinha e Três Coroas/RS.

O diagnóstico é composto por trinta questões e dividido em seis seções, tendo sido respondido pelos gestores das empresas. As seções referem-se à sensibilização, à estrutura de gestão, à geração de ideias, ao desenvolvimento, à difusão e à captação de recursos.

Ao final do Diagnóstico de Inovação, decidiuse aprofundar, ainda mais, os fatores que dificultam a busca pela inovação e pela implementação das atividades inovativas, acrescentando-se a seguinte pergunta: $\mathrm{Na}$ sua opinião, quais os principais fatores que dificultam o processo de inovação?

\section{ANÁLISE E SÍNTESE DOS RESULTADOS}

Através da aplicação do Diagnóstico de Inovação, averiguou-se que, dentre as dezoito empresas que participaram desta pesquisa, apenas sete inovaram, evidenciando um diagnóstico bastante preocupante em virtude da importância da inovação atualmente. Entre as empresas inovadoras, duas aprimoraram algum produto e cinco implementaram inovações de processo.

Em relação à pergunta que foi adicionada ao final do diagnóstico, foram obtidas as seguintes respostas: (i) Falta de recursos: 46,42\%; (ii) Falta de mão de obra qualificada: 28,57\%; (iii) Risco de investimento em novos equipamentos e não obtenção de retorno: 7,14\%; (iiii) Falta de incentivos do governo: $10,71 \%$ e (iiiii) Falta de conhecimento do gestor: $7,14 \%$.

Com relação às barreiras à inovação, verificou-se que a indústria moveleira do Vale do Paranhana encontra dificuldades na obtenção de financiamentos e, sendo assim, não dispõe de recursos para investimento, principalmente em maquinário. Outro fator relevante, identificado, trata do risco de investimento em inovação sem que haja demanda necessária para o seu retorno.

Analisando-se os resultados obtidos em comparação à literatura, observa-se o que já havia sido citado por Cavalcanti (2007) em relação às principais barreiras ao investimento em pesquisa, desenvolvimento e inovação nas pequenas e médias empresas, que podem ser agrupadas em quatro áreas: (i) Falta de recursos financeiros; (ii) Falta de conhecimento; (iii) Falta de capital humano e (iiii) Falta de governança. Apenas a falta de governança não foi apontada pelos gestores como fator de bloqueio às inovações.

Utilizando-se a metodologia do IBGE, calculou-se as taxas de inovação na indústria moveleira do Vale do Paranhana, levando-se em conta o número de empresas que implementaram alguma inovação pelo número total de empresas que participaram da pesquisa. Identificou-se que a taxa de inovação é de $38,88 \%$, a taxa de inovação de produto é $11,11 \%$ e a taxa de inovação de processo é $27,77 \%$.

Comparando-se os resultados nacionais, obtidos pela Pintec, com os da aplicação do Diagnóstico de Inovação, observa-se que a taxa de inovação da indústria moveleira do Vale do Paranhana é superior à taxa de inovação nacional. Por outro lado, as taxas de inovação de produto e processo são inferiores aos percentuais nacionais apurados de 2009 a 2011. Constatou-se que as taxas de inovação no setor moveleiro do vale do Paranhana são inferiores às taxas na indústria do Rio Grande do Sul.

Analisando-se as seções do Diagnóstico de Inovação, na primeira seção encontram-se as questões relativas à sensibilização, em que se destaca o fato de a grande maioria dos gestores perceber o impacto da inovação nas outras empresas e buscar novos conhecimentos em eventos e em artigos e revistas especializadas no assunto. 
Tabela 5: Número de respostas do Diagnóstico de Inovação - Sensibilização

\begin{tabular}{|c|c|c|c|}
\hline & Sensibilização & Sim & Não \\
\hline 1 & $\begin{array}{l}\text { A empresa participou de pelo menos um evento (congresso, encontro, palestra, etc.) sobre o tema } \\
\text { inovação nos últimos } 12 \text { meses? }\end{array}$ & 11 & 7 \\
\hline 2 & $\begin{array}{l}\text { A empresa percebe o impacto da inovação nas outras empresas, ou seja, melhoria de desempenho de } \\
\text { empresas que introduziram inovações no mercado? }\end{array}$ & 15 & 3 \\
\hline 3 & A empresa implementou, nos últimos 12 meses, algum processo/produto novo? & 7 & 11 \\
\hline 4 & As ações estratégicas da empresa são norteadas pela busca de inovações? & & 18 \\
\hline 5 & A empresa busca conhecimentos sobre tecnologia através de artigos e revistas especializadas? & 11 & 7 \\
\hline
\end{tabular}

Fonte: Adaptado de AGDI/GMAP (2014)

$\mathrm{Na}$ seção dois, observam-se as questões sobre estrutura de gestão. Tais questões apuram se a empresa possui algum responsável pelas ações ou projetos de inovação, bem como se os processos e mecanismos estão realmente estruturados. Apenas três empresas possuíam um responsável pelas ações e projetos de inovação. Nas demais questões desta seção, todas as respostas foram não.

Os resultados obtidos nesta seção são podem ser considerados negativo pelo fato de, na grande maioria das empresas, não existir um responsável pelas inovações e de não haver uma estrutura correta que conduza à inovação.

Tabela 6: Número de respostas do Diagnóstico de Inovação - Estrutura de Gestão

\begin{tabular}{|c|c|c|c|}
\hline & Estrutura de gestão & Sim & Não \\
\hline 6 & A empresa conhece os métodos de gestão de inovação? & & 18 \\
\hline 7 & Existe um responsável pela condução das ações/projetos de inovação na empresa? & 3 & 15 \\
\hline 8 & $\begin{array}{l}\text { Existem processos estruturados para condução da inovação (geração de ideias, seleção de ideias, } \\
\text { desenvolvimento de produtos, etc.)? }\end{array}$ & & 18 \\
\hline 9 & $\begin{array}{l}\text { Existem mecanismos de gerenciamento de ações bem sucedidas (boas práticas) em relação aos projetos } \\
\text { de inovação? }\end{array}$ & & 18 \\
\hline 10 & $\begin{array}{l}\text { Existem mecanismos de gerenciamento de dificuldades superadas (lições aprendidas) em relação aos } \\
\text { projetos de inovação? }\end{array}$ & & 18 \\
\hline
\end{tabular}

Fonte: Adaptado de AGDI/GMAP (2014)

A geração de ideias é o tema da terceira seção, onde se observa que menos da metade das empresas interage com fornecedores ou clientes a fim de identificar ideias ou oportunidades para a inovação e que apenas duas buscaram parcerias com universidades ou institutos externos com a finalidade de gerar ideias ou novos produtos.

Tabela 7: Número de respostas do Diagnóstico de Inovação - Geração de Ideias

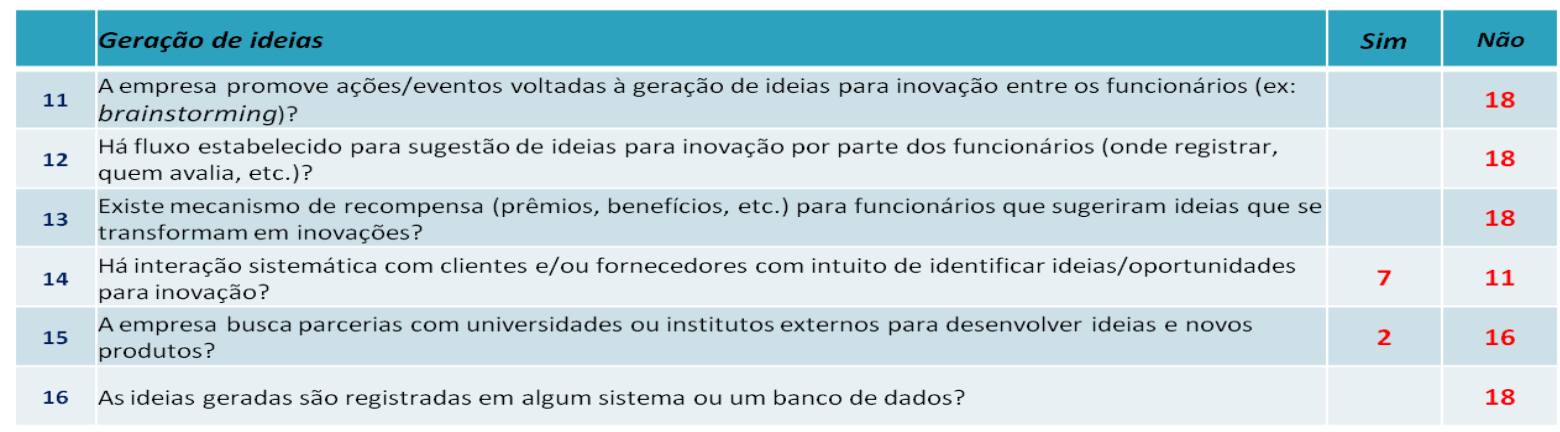


Fonte: Adaptado de AGDI/GMAP (2014)

$\mathrm{Na}$ quarta seção, encontram-se as questões relacionadas a desenvolvimento, onde se questiona quanto a um responsável por pesquisa e desenvolvimento, se existem recursos alocados para inovação e se há

possibilidade para desenvolvimento de novas ideias. Esta seção foi a que obteve o pior resultado entre todas elas, pois todos os gestores responderam não para todas as questões.

Tabela 8: Número de respostas do Diagnóstico de Inovação - Desenvolvimento

\begin{tabular}{|l|l|c|}
\hline & Desenvolvimento & Sim \\
\hline 17 & Existem critérios formalizados para o julgamento das ideias (independente da fonte da ideia)? & 18 \\
\hline 18 & $\begin{array}{l}\text { Há possibilidade de desenvolvimento para ideias que sejam diferentes do portfólio de produtos da } \\
\text { empresa? }\end{array}$ \\
\hline 19 & $\begin{array}{l}\text { A empresa investe no desenvolvimento de ideias mais radicais, com maiores riscos associados (risco } \\
\text { tecnológico, risco de mercado, etc.)? }\end{array}$ \\
\hline 20 & Existe um fluxo estabelecido para o processo de desenvolvimento de produtos (PDP)? & 18 \\
\hline 21 & A empressa possui departamento (ou pessoa responsável) de Pesquisa \& Desenvolvimento? & 18 \\
\hline 22 & Existe verba alocada para o desenvolvimento de inovações? \\
\hline 23 & $\begin{array}{l}\text { Há disponibilidade de recursos na empresa para desenvolver as inovações financeiros, estrutura, } \\
\text { pessoas, etc.)? }\end{array}$ \\
\hline
\end{tabular}

Fonte: Adaptado de AGDI/GMAP (2014)

A penúltima seção trata de difusão, em que se pergunta sobre a implementação de inovações em processo em um curto espaço de tempo, sobre a preocupação com a proteção intelectual e se a empresa mensura as inovações implantadas no seu faturamento. Os resultados obtidos nesta seção são bastante apreensivos, pois nenhuma empresa se preocupa com o depósito de patentes. $\mathrm{Na}$ maioria das empresas, não foi possível implementar alguma inovação de processo em menos de três meses e apenas uma empresa conseguiu visualizar a representatividade das inovações no seu faturamento.

Tabela 9: Número de respostas do Diagnóstico de Inovação - Difusão

\begin{tabular}{|l|l|c|c|}
\hline & Difusão & Sim & Não \\
\hline 24 & $\begin{array}{l}\text { As sugestões de inovações de processo são implementadas em curto espaço de tempo (menos de } 3 \\
\text { meses)? }\end{array}$ & \begin{tabular}{l}
15 \\
\hline 25
\end{tabular} & Há preocupação com a proteção intelectual (ex: patentes) das inovações desenvolvidas? \\
\hline 26 & A empresa mensura a representatividade das inovações desenvolvidas no seu faturamento? & 18 \\
\hline
\end{tabular}

Fonte: Adaptado de AGDI/GMAP (2014)

Captação de recursos é o tema da última seção, em que se visualizam questões sobre a obtenção de fomento e subsídio à inovação, se a empresa possui competências necessárias para a elaboração de projetos para a captação de recursos, se já captou recursos via políticas públicas e se monitora sistematicamente oportunidades para a captação de recursos disponibilizados pelo governo. 
Tabela 10: Número de respostas do Diagnóstico de Inovação - Captação de Recursos

\begin{tabular}{|c|c|c|c|}
\hline & Captação de Recursos & $\operatorname{Sim}$ & Não \\
\hline 27 & A empresa conhece os mecanismos públicos de fomento e subsídio à inovação (FINEP, MCT, BRDE, etc.)? & 13 & 5 \\
\hline 29 & A empresa possui as competências necessárias para elaboração de projetos de captação de recursos? & & 18 \\
\hline
\end{tabular}

Fonte: Adaptado de AGDI/GMAP (2014)

As empresas conhecem os mecanismos públicos de fomento e subsídio à inovação, no entanto apenas uma empresa captou recursos para investimento em inovação. De forma geral, as empresas possuem conhecimentos necessários para a elaboração de projetos para a captação de recursos e, no entanto, não acompanham sistematicamente as oportunidades para a obtenção de recursos disponibilizados pelo governo.

Na questão 1 do Diagnóstico de Inovação, os gestores citaram FIMMA e Congresso em Gramado sobre liderança e inovação Formando Novos Líderes. Melhorias em processo, aquisição de maquinário e produtos aprimorados foram citados na questão 2 do diagnóstico. Para a questão 3 foram obtidas as seguintes respostas: melhoria em processo e produto aprimorado. Com relação à questão 5, obtiveram-se respostas como PROMOB, Casa Cláudia, AAI, Top Eventos, Sob Medida, Revista da Madeira, Minha Casa, Casa e Cia, Casa e Cor e Top Casas. Na questão 14, os gestores apontaram que há interação com fornecedores, clientes e arquitetos. Para a questão 15 foi citado apenas FACCAT PEIEX. Na questão 27, os gestores citaram como fontes de subsídio à inovação BNDES, FINEP e BRDE. Por fim, na questão 28, apenas um gestor declarou ter tentado obter subsídios para investimento em inovação por meio do BNDES.

\section{CONCLUSÕES}

Este estudo apresentou os resultados de uma pesquisa exploratória que teve por objetivo o diagnóstico da indústria moveleira do Vale do Paranhana no que concerne à inovação. A metodologia utilizada foi a adaptação e aplicação do Diagnóstico de Inovação, que faz parte do Projeto de Extensão Produtiva e Inovação, elaborado pelo Estado do Rio Grande do Sul.

Através dos resultados obtidos, foi possível constatar que a indústria moveleira do Vale do Paranhana tem uma taxa de inovação superior à nacional, mas inferior à da indústria gaúcha. Verificou-se, também, que as suas taxas de inovação de produto e processo são inferiores às médias gaúcha e nacional. Estes resultados são preocupantes, principalmente, em função da taxa de inovação de produto na indústria moveleira do Vale do Paranhana, que é de $11,11 \%$, resultado de duas empresas inovadoras em produto dentre as dezoito onde foi aplicado o diagnóstico.

As inovações implementadas foram novas apenas para as empresas, configurando o menor grau de inovação. Os gestores apontaram diversos fatores que prejudicam as atividades de inovação e a inovação, destacando-se a falta de recursos, a falta de mão de obra qualificada e a falta de conhecimento do gestor.

Diante dos resultados da pesquisa, algumas sugestões podem ser feitas a fim de que se consiga reduzir ou eliminar os fatores que prejudicam ou inibem a inovação $e$ as atividades inovativas. Com relação à falta de recursos, propõe-se aos governos estadual e federal maior disponibilidade de linhas de crédito voltadas à indústria moveleira do Vale do Paranhana, a qual depende desses recursos, principalmente, para o investimento em equipamentos.

A falta de mão de obra qualificada realmente é um fator que causa impacto em qualquer tipo de indústria, não sendo diferente na indústria moveleira. Em função disso, sugerese aumentar as vagas para o ensino técnico no Vale do Paranhana, bem como a 
constituição de uma parceria entre os cursos técnicos e as empresas moveleiras a fim de que se diminua a demanda por esse tipo de profissional.

É de extrema importância que a indústria moveleira busque a parceria pública ou privada com 0 intuito de que receba consultorias, bem como participe de projetos tais como o Projeto de Extensão Produtiva e Inovação, uma vez que, por vezes, o recebimento de consultorias ou a participação em projetos geram um baixo custo para a empresa e, em alguns casos, não resultam em gasto.

Foram identificados diversos fatores que prejudicam a inovação e as atividades de inovação, em que se destacam os organizacionais, pois as empresas não

\section{A. REFERÊNCIAS}

[2]. AGÊNCIA GAÚCHA DE DESENVOLVIMENTO E PROMOÇÃO DO INVESTIMENTO. Projeto Extensão Produtiva e Inovação. Disponível em: $<$ http://www.agdi.rs.gov.br/?model=conteudo\&men u=968> Acesso em: 09 fev. 2015.

[3]. ALBINO, A.A.; SOUZA, S.D.C. Aplicação do modelo Diamante de Porter e análise dos determinantes da competitividade para 0 APL moveleiro de UBÁ. Anais. XV Simpósio de Engenharia de Produção, Bauru, SP, 2008.

[4]. BARBIERI, J. C. Organizações Inovadoras: estudos e casos brasileiros. São Paulo: FGV, 2003.

[5]. BARNEY, J. B.; HESTERLY, W. S. Administração estratégica e vantagem competitiva. 3. ed. São Paulo: Pearson Prentice Hall, 2011.

[6]. BEZERRA, C. M. Inovações tecnológicas e a complexidade do sistema econômico. São Paulo: Cultura Acadêmica, 2010.

[7]. BRITO, K.N; CÂNDIDO, G.A. Difusão da inovação tecnológica como mecanismo de contribuição para formação de diferenciais competitivos em pequenas e médias empresas. Revista Eletrônica de Administração, v.9, n.2, 2013.

[8]. CARVALHO, Marly Monteiro de. Inovação: estratégias e comunidades de conhecimento. São Paulo: Atlas, 2009.

[9]. CAVALCANTI, M.C.B. Relatório dos capitais intangíveis inteligência empresarial (UFRJ). conhecem os métodos de gestão da inovação e a maioria não possui processos que conduzem à inovação corretamente estruturados.

Esses fatores poderiam ser reduzidos ou eliminados através da contratação de um profissional que possua qualificação para implementar os métodos de gestão da inovação, além de estruturar os processos que conduzem à inovação, como um Engenheiro de Produção, por exemplo. A participação em projetos do governo como o Projeto de Extensão Produtiva e Inovação e a contratação de consultorias, como as que são fornecidas pelo Serviço Brasileiro de Apoio às Micro e Pequenas Empresas - SEBRAE, também são de extrema importância para que a taxa de inovação da indústria moveleira do Vale do Paranhana seja alavancada.

In: Revista de Inteligência Empresarial. Rio de Janeiro. v.1, n. 31, p. 11-15, 2007.

[10]. DE NEGRI, J. A.; SALERNO, M. S.; CASTRO, A. B. Inovações, padrões tecnológicos e desempenhos das firmas industriais Brasileiras. In: DE NEGRI, J. A.; SALERNO, M. S. Inovações, padrões tecnológicos e desempenho das indústrias Brasileiras. Brasília: IPEA, 2005.

[11]. GALENDE, J.; FUENTE, J. M. Internal Factors determing a firm's inovative behaviour. Research Policy, 32, 715-736, 2003.

[12]. GIBSON, R.; SKARZYNSKY, P. Inovação: prioridade ํo 1. Rio de Janeiro: Elsevier, 2008.

[13]. INSTITUTO BRASILEIRO DE GEOGRAFIA E ESTATÍSTICA (IBGE). Pesquisa de Inovação Tecnológica 2011 (PINTEC). Rio de Janeiro, 2013. Disponível em: <http://www.pintec.ibge.gov.br/downloads/pintec20 11\%20publicacao\%20completa.pdf>. Acesso em: 17 set. 2015.

[14]. MANÃS, A.V. Gestão de tecnologia e inovação. São Paulo: Érica, 2001.

[15]. MANUAL DE OSLO. Diretrizes para coleta e interpretação de dados sobre inovação. 3. ed. Produção: ARTI e FINEP. Trad.: Flávia Gouveia, 2005.

[16]. MOTTA, P.R. Transformação organizacional: a teoria e a prática de inovar. Rio de Janeiro: Qualitymark, 1999.

[17]. MOVERGS (ASSOCIAÇÃO DAS INDÚSTRIAS DE MÓVEIS DO ESTADO DO RIO 
GRANDE DO SUL). Dados do setor moveleiro. Disponível em: <http://www.movergs.com.br/numeros-setor >. Acesso em: 09 fev. 2015.

[18]. PLANO ESTRATÉGICO DE DESENVOLVIMENTO REGIONAL 2011-2020. Orgnizador Paulo Roberto de Aguiar von Mengden - Taquara: COREDEPES, 2010.

[19]. PORTER, M. E. Criando as vantagens competitivas de amanhã. In: GIBSON, R. (Ed.).
Repensando o futuro. São Paulo: Makron Books, 1998.

[20]. ROBBINS, S.P. Administração: mudanças e perspectivas. Tradução: Cid K. Moreira. São Paulo: Saraiva, 2001.

[21]. TERRA, J.C. 10 Dimensões da Gestão da Inovação - Uma abordagem para a transformação organizacional. Rio de Janeiro: Elsevier, 2012. 


\section{Capítulo 13}

\section{INFLUENCIA DAS ESTRATÉGIAS DE MANUTENCÃO NA DISPONIBILIDADE FISICA DE EQUIPAMENTOS DE MOAGEM DE UMA MINERADORA}

\section{Flávio Campos Pinheiro \\ Marcus Vinícius de Abreu Soeiro \\ Renato Ramos Coelho}

RESUMO: Este trabalho objetivou analisar estratégias de manutenção utilizadas em uma mineradora e sua influência na disponibilidade física dos equipamentos de moagem. Para isto, analisou-se, no período entre janeiro e julho de 2016: política de mannutenção; práticas adotadas para a manutenção da área de moagem da usina de beneficiamento, tempo médio entre falhas (MTBF), tempo médio para reparo (MTTR) e disponibilidade física dos equipamentos de moagem. O MTBF variou entre 23:03:05 e 37:49:36 horas, com média e desvio padrão (DP) de 28:35:26 \pm 06:46:55 horas. O MTTR excluiu o tempo necessário para manutenções planejadas e preventivas, sua média e DP foram de 01:17:03 \pm 01:02:01 horas. A disponibilidade física variou entre $88,15 \%$ e $95,41 \%$, ficando abaixo da meta estipulada pela mineradora em apenas dois meses. A análise, pelo teste de spearman, da correlação existente entre a disponibilidade física e a produção indicou um valor de 0,857, com uma significância de $p<0,05$. Desta forma, verificou-se que em $73,44 \%$ das vezes que a manutenção disponibiliza os equipamentos de moagem, a meta de produção foi atingida. Assim, conclui-se que as estratégias de manutenção adotadas foram bem-sucedidas para a disponibilização dos equipamentos, embora haja necessidade de se analisar os eventos em que a meta de produção não foi atingida por ação de fatores não relacionados diretamente à manutenção. 


\section{INTRODUÇÃO}

A conservação de instrumentos e ferramentas é uma prática observada desde os primórdios da civilização. No entanto, somente a partir do surgimento dos primeiros relógios mecânicos no século $X V I$, que apareceu a figura do técnico em montagem e manutenção. Este processo se intensificou com o advento da Revolução Industrial, em que o uso das máquinas ampliou a necessidade de manutenção. No início do século XX a introdução da produção em série levou à criação de equipes de reparos, um órgão subordinado à operação, cujo objetivo básico era exercer a manutenção das máquinas.

Durante a II Guerra Mundial, a administração industrial passou a se preocupar não só em sanar rapidamente as falhas e perda de produtividade, mas a evitar e prevenir que elas ocorressem. Com isto, as equipes de manutenção passaram a ser tão importantes quanto as de operação. O efeito disto foi uma grande mudança no conceito e na consciência gerencial acerca dos custos e da necessidade de inovações das estratégias e procedimentos de manutenção (TAVARES, 2005).

Esta mudança conceitual fez com que a manutenção, antes vista como um mal necessário, passasse a ser abordada como função estratégica, com objetivo claro de garantir a disponibilidade e confiabilidade dos equipamentos preservando a segurança e integridade das plantas e instalações (MARTINS; LAUGENI, 2006). Assim, a estratégia de manutenção, que é influenciada por fatores internos e externos, se concretiza por políticas adequadas aos diversos cenários dentro de uma Empresa. Este fato indica a importância da gestão participativa no processo de manutenção, uma vez que cabe aos responsáveis por sua execução a indicação dos pontos de gargalo para os gestores (GOMES et al, 2016).

Por isto, a política de manutenção deve ser dimensionada à cada caso e realidade de Empresa. A política corretiva, que é trabalhar até quebrar, é muito usada nos casos em que o conserto é fácil, ou quando a falha não é previsível. A política preventiva é usada quando o custo da falha não planejada é alto e quando a falha não é totalmente aleatória. $A$ política preditiva é usada quando a manutenção é dispendiosa, seja devido ao seu custo direto ou à interrupção da produção durante a manutenção. A maior parte das empresas adota um sistema misto de políticas de manutenção, envolvendo mais de uma das aqui descritas (SLACK et al, 2007).

Diante deste contexto, o objetivo deste trabalho foi analisar as estratégias de manutenção adotadas em uma Empresa de Mineração, identificando a influência dessas na disponibilidade física dos seus equipamentos.

\section{POLÍTICA DE MANUTENÇÃO DA MINERADORA}

Todas as Empresas, em especial as que possuem processo produtivo em escala industrial, definem suas estratégias e prioridades competitivas baseadas em fatores relacionados ao seu sistema produtivo, tais como flexibilidade, produtividade e qualidade (FACCIO et al, 2014). Este pressuposto é válido para diversas políticas de diferentes áreas, inclusive para a política de manutenção da Mineradora analisada.

Trata-se de uma multinacional situada no Estado de Minas Gerais. Sua política de manutenção, em consonância com o proposto por Gomes et al (2016) representa o compromisso gerencial, envolvendo os elementos humano, técnico e econômico. Ela desenvolve-se a partir da proposição de princípios e seleção das estratégias de manutenção de acordo com os resultados objetivados pela Mineradora, especialmente no atendimento do programa de produção, o custo planejado e a qualidade requerida.

De forma a cumprir esta política, a manutenção é responsável pelo estado satisfatório dos equipamentos e instalações, contribuindo para o aumento da produtividade e qualidade dos produtos, desenvolvendo melhorias de desempenho e auxiliando na otimização dos processos (FACCIO et al, 2014; VAZ, 2004; MONCHY, 1989). Para isto, cabe às áreas de manutenção da Mineradora buscar maior eficácia na aplicação de recursos, aprimorar continuamente os seus processos, através da capacitação dos seus recursos humanos, da motivação do pessoal e da adoção de ferramentas adequadas para a tomada de decisão.

A Mineradora busca com as áreas da manutenção, portanto, uma maior eficiência de toda a planta produtiva. Pinto; Xavier (2006) relatam que, além do que está previsto nas Políticas de Manutenção da Mineradora, a 
área responsável deve contribuir para um programa de produção, otimizando os recursos necessários, em busca de maximizar a disponibilidade dos equipamentos atuando com qualidade, segurança e respeito ao meio ambiente.

A complexidade dos equipamentos de mineração e a diversidade dos ativos físicos fazem da manutenção uma função igualmente complexa, composta pelos métodos e funções gerenciais que devem estar voltados para o máximo desempenho, produtividade e qualidade. Assim, os tipos de manutenção a serem adotados são definidos a partir dos tipos de intervenções nos equipamentos (PINTO; XAVIER, 2006).

A Política da Mineradora estudada classifica estes processos em cinco tipos: manutenção corretiva, que se subdivide em planejada e não planejada; manutenção preventiva; manutenção preditiva; manutenção de melhoria; manutenção autônoma. Esta classificação condiz com o pressuposto de Slack et al (2007) de que a maior parte das empresas adota uma combinação de diversos tipos de manutenção, pois cada equipamento e instalação possuem diferentes características.

A manutenção corretiva ocorre quando não se prevê ações predeterminadas para evitar a falha ou perda de desempenho. Diversos autores como Pinto; Xavier (2006), Heizer; Render (2001) mencionam que a política corretiva é a busca de correção de falhas aleatórias nos equipamentos, podendo ser planejada ou não planejada. Na Mineradora analisada a manutenção corretiva é prioritariamente não planejada devido a não se prever ações predeterminadas para impedir a falha dos equipamentos.

A manutenção preventiva da Mineradora é destinada à redução da probabilidade de falha, podendo ser periódica (sistemática) ou aperiódica (sensitiva ou por condição). Assim, ela se enquadra ao que Slack et al (2007), Martins; Laugeni (2006) mencionam com o objetivo de reduzir ou evitar a falha de um componente em intervalos planejados. O planejamento da manutenção preventiva é realizado com base no tempo do ciclo de vida dos componentes de cada máquina e equipamento, sendo assim sistemática, ou com base em inspeções rotineiras da condição ou desempenho do equipamento, sendo assim aperiódica. Esta prática é condizente com o que é proposto por Pinto; Xavier (2006).

A manutenção preditiva é adotada para otimizar a troca de peças ou a reforma de componentes, através da extensão dos intervalos de manutenção. Trata-se de um conjunto de técnicas de inspeção de equipamentos que possibilita a identificação de sintomas e defeitos, bem como estimar o tempo durante o qual é possível a operação do equipamento antes da avaria, ou seja, após determinado a falha providencia-se em um momento adequado uma manutenção preventiva para mantê-lo com desempenho e condições ideais de produção (VAZ, 2004). Com isto, determina-se a condição necessária para a execução da manutenção preventiva.

Outro tipo de manutenção adotada pela Mineradora é a de melhoria, esta representa o progresso de natureza gradativa e contínua que deve ser aplicada aos equipamentos da empresa, para prolongamento de sua vida útil e redução do tempo de manutenção. Baseiase na investigação das causas fundamentais das falhas, e atua evitando a sua reincidência. Este tipo de melhoria, também chamada de Engenharia de Manutenção nada mais é que a adoção de atitudes proativas de manutenção, ou seja, a procura das causas básicas das falhas para desenvolver melhorias, permitindo maior facilidade nas manutenções dos equipamentos (PINTO; XAVIER, 2006).

A Mineradora também adota outro método de manutenção, do qual fazem parte tanto o sistema de gerenciamento da manutenção quanto a gerencia de operação. Esta é a manutenção autônoma que envolve o pessoal da operação em atividades de inspeção, check-list e realização de tarefas simples de manutenção, visando a antever danos ao equipamento. A esta estratégia de manutenção, Slack et al (2007) deram o nome de Manutenção Produtiva Total (TPM). Este modelo promove a integração da operação nas atividades de manutenção, de forma que quem opera é também responsável por manter o equipamento, de forma autônoma, ou seja, por iniciativa própria.

Por fim, a política de manutenção adotada pela Mineradora estabelece mecanismos de avaliação constante da performance da manutenção. Estes mecanismos envolvem análise de tempo médio entre falhas (MTBF), tempo médio para reparo (MTTR), desempenho e disponibilidade física dos 
equipamentos, de forma a se verificar a efetividade da aplicação dos recursos humanos e materiais neste setor. Este acompanhamento é de responsabilidade da equipe do Planejamento, Programação e Controle da Manutenção (PCM) e condiz com o que é preconizado por Vaz (2004).

Assim, a política de manutenção da Mineradora está voltada para os resultados estabelecidos por ela. As áreas de manutenção devem sempre buscar o máximo de desempenho e ampliação da vida útil dos equipamentos, contribuindo para o programa de produção qualidade dos produtos e atendendo aos custos planejados, bem como garantindo a segurança dos operadores e à proteção contra danos ao meio ambiente.

\section{MANUTENÇÃO DE MOAGEM}

A área de moagem da Mineradora analisada localiza-se em uma usina de beneficiamento responsável pela redução granulométrica do minério de ferro. É um circuito composto por 3 linhas de alimentação, sendo 2 moinhos de bola em cada linha (Figura 1).

Figura 1 - Representação esquemática da área de moagem

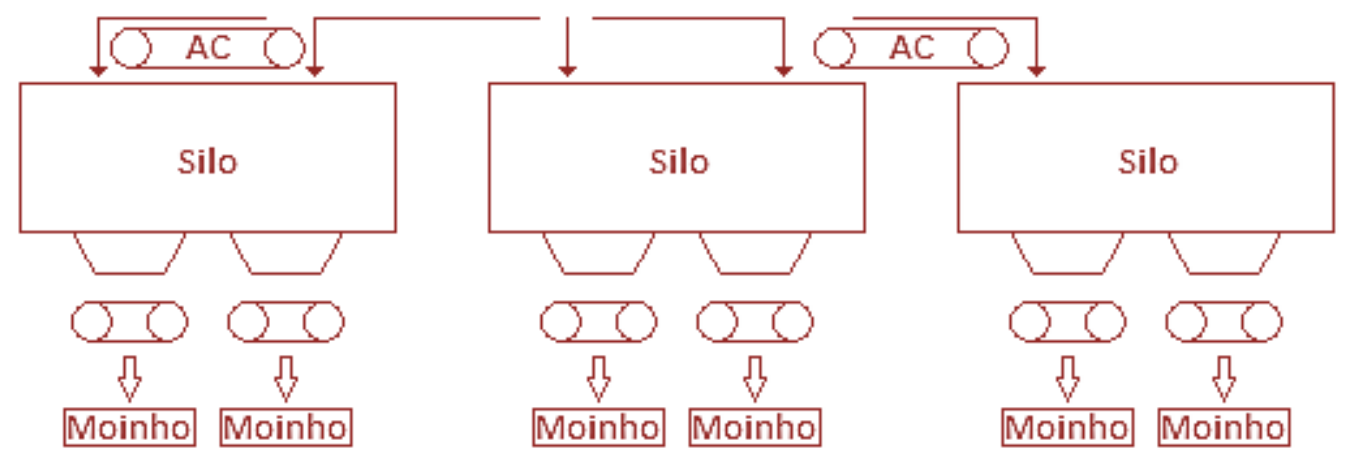

O processo da moagem se dá pela alimentação primária dos três silos. Em seguida os alimentadores de correia (AC) levam o minério de ferro para o chute que alimenta os moinhos, estes realizam a moagem do minério, reduzindo sua granulometria. Em seguida, o material moído é bombeado para o processo de beneficiamento seguinte. Desta forma, uma falha nos $A C$, silos, moinhos ou bombas irá implicar diretamente na produtividade.

Assim, o acompanhamento do desempenho da manutenção da moagem se dá através do MTBF, MTTR e, principalmente, a disponibilidade física dos equipamentos do setor.

\section{RESULTADO E DISCUSSÃO}

A Tabela 1 apresenta os dados consolidados do MTBF, MTTR e disponibilidade física dos equipamentos de moagem entre os meses de janeiro e julho de 2016.

Observa-se na Tabela 1 que o MTBF não tem um valor constante. Enquanto no mês de janeiro 2016 ele foi de 23:03:05 horas, no mês de maio o tempo foi de 37:49:36 horas, sendo este o melhor resultado mensal no período analisado. O tempo médio entre falhas foi de 28:35:26 \pm 06:46:55 horas. Este grande desvio padrão indica que a moagem ainda tem um comportamento heterogêneo de MTBF, o que indica a necessidade de se estratificar os meses com melhor desempenho para saber quais os fatores existentes nestes meses que produziram esse resultado. 
Tabela 1 - MTBF, MTTR e disponibilidade física dos equipamentos de moagem de janeiro a julho de 2016

\begin{tabular}{|c|c|c|c|c|c|c|c|c|}
\hline & Jan & Fev & Mar & Abr & Mai & Jun & Jul & Ano \\
\hline MTBF (horas) & $\begin{array}{c}23: 03: 0 \\
5\end{array}$ & $\begin{array}{c}29: 01: 3 \\
7\end{array}$ & $\begin{array}{c}33: 39: 1 \\
2\end{array}$ & $\begin{array}{c}33: 15: 4 \\
0\end{array}$ & $\begin{array}{c}37: 49: 3 \\
6\end{array}$ & $\begin{array}{c}22: 27: 2 \\
9\end{array}$ & $\begin{array}{c}29: 51: 2 \\
3\end{array}$ & \\
\hline MTTR (horas) & $\begin{array}{c}00: 51: 5 \\
4\end{array}$ & $\begin{array}{c}00: 28: 0 \\
6\end{array}$ & $\begin{array}{c}00: 27: 3 \\
0\end{array}$ & $\begin{array}{c}01: 00: 0 \\
7\end{array}$ & $\begin{array}{c}02: 38: 3 \\
1\end{array}$ & $\begin{array}{c}02: 53: 2 \\
3\end{array}$ & $\begin{array}{c}00: 39: 5 \\
0\end{array}$ & \\
\hline $\begin{array}{c}\text { Disponibilidade } \\
\text { física realizada (\%) }\end{array}$ & 93,38 & 95,06 & 95,41 & 93,89 & 88,61 & 88,15 & 92,83 & 91,51 \\
\hline $\begin{array}{c}\text { Meta de } \\
\text { disponibilidade } \\
\text { física (\%) }\end{array}$ & 91,26 & 91,26 & 91,26 & 91,26 & 91,26 & 93,00 & 91,26 & 92,46 \\
\hline $\begin{array}{c}\text { Produção realizada } \\
\text { (toneladas) }\end{array}$ & 977.828 & 1.021 .4 & 1.111 .8 & 1.009 .6 & 884.364 & 945.972 & 875.018 & 6.826 .1 \\
\hline $\begin{array}{c}\text { Produção } \\
\text { programada } \\
\text { (toneladas) }\end{array}$ & 1.018 .7 & 950.051 & 1.053 .1 & 1.001 .0 & 1.007 .1 & 1.000 .0 & 986.000 & 7.016 .1 \\
\hline & 42 & & 86 & 00 & 48 & 00 & & 27 \\
\hline
\end{tabular}

O MTTR representa o somatório do tempo de reparo dos equipamentos a cada falha, implicando diretamente no tempo total de equipamento parado. Nos dados apresentados na Tabela 1, exclui-se o tempo necessário para manutenções corretivas planejadas e preventivas, pois elas são programadas. Nota se que o MTTR da moagem ficou em 01:17:03 \pm 01:02:01 horas, sendo a pior performance no mês de junho. Existem diversas hipóteses para explicar o MTTR, uma delas pode ser a ocorrência de falhas catastróficas nos equipamentos, que demandaram muito tempo para serem sanadas. Outra hipótese que não pode ser descartada é a crise financeira vigente que implicou na diminuição do quadro de funcionários da manutenção.

Como a disponibilidade física dos equipamentos depende do MTBF e do MTTR, esta passa a ser o principal objetivo da manutenção. Assim, não adianta a área da moagem aumentar o tempo entre as falhas se o tempo para o seu reparo se mantiver com um grande quantitativo de horas. Isto ocorre porque a disponibilidade física é o percentual do tempo em que o equipamento ou instalação fica disponível para operação em relação a um determinado intervalo de tempo. Por isto ela é inversamente proporcional ao MTBF e afetada diretamente pelo MTTR (PINTO; XAVIER, 2006).

$\mathrm{Na}$ Tabela 1, observa-se que a disponibilidade física não é estável. O mês de junho ficou com $88,15 \%$, a pior marca do período analisado, $4,88 \%$ abaixo da meta estipulada de $92,46 \%$. O mês de março, por sua vez, apresentou uma disponibilidade de $95,41 \%$ a melhor marca do período analisado, 3,09\% acima da meta estipulada para o ano de 2016. Esta variação confirma a relação entre disponibilidade e MTBF, uma vez que as falhas são inesperadas. Porém outro fator que pode afetar diretamente esta disponibilidade é o MTTR, pois, se as falhas demandarem muito tempo para serem sanadas ou eliminadas, a disponibilidade do equipamento fica muito comprometida.

No entanto, nem todos os fatores relacionados a disponibilidade do equipamento são de responsabilidade direta da manutenção. A qualidade de matérias prima, a utilização física dos equipamentos em relação à sua capacidade instalada, especialidade técnica e o turno de trabalho também afetam a eficiência da produção (BARRIENTO et al, 2016).

A área da moagem, como todas as áreas da Mineradora, possui metas a serem cumpridas. Para toda a área de manutenção do complexo de beneficiamento de minério de ferro as metas variam em função da produção estabelecida para o mês. Assim, a chave para o sucesso da manutenção é a entrega dos equipamentos em condição do uso para o alcance das metas estipuladas, o que ratifica a importância da política de estratégia de 
manutenção adotada pela Mineradora analisada.

De forma a verificar o grau de influência das estratégias de manutenção na disponibilidade física dos equipamentos de moagem, aplicouse o Teste de Correlação de Spearman entre os dados de disponibilidade física realizada e a produção realizada. A opção por este teste deveu-se ao quantitativo de dados de apenas sete meses (SPSS, 2015).

Obteve-se um valor de Spearman de 0,857, com uma significância de $p<0,05$, o que refletiu em um $r^{2}$ de 0,73 . Desta forma, verifica-se que em $73,44 \%$ das vezes que a manutenção disponibilizar os equipamentos de moagem, a meta de produção será atingida. As outras ocasiões em que a meta de produção não for atingida, deve se a ação de fatores que não estão relacionados diretamente com a manutenção (BARRIENTO et al, 2016).

Da mesma forma, outros fatores relacionados ao custo indireto e a eficiência do processo produtivo podem não ser de fácil identificação. Para que estes fatores sejam percebidos e recebam a devida tratativa, Gomes et al (2016) sugerem o uso de ferramentas que tornem mais confiável o indicador disponibilidade física. As ferramentas sugeridas por estes autores envolvem instrumentos de qualidade, como brainstorming, diagrama de Pareto e o $5 \mathrm{~W} 1 \mathrm{H}$.

\section{CONSIDERAÇÕES FINAIS}

A finalidade deste artigo foi analisar a política de manutenção adotada por uma Mineradora e a sua influência sobre a disponibilidade

\section{REFERÊNCIAS}

[1]. BARRIENTO, V.F. KOMNINAKIS, D. ACHCAR, J.A. Manutenção de equipamentos em uma indústria alimentícia: um estudo de caso para identificar origens de impacto no desempenho. Anais do XXIII SIMPEP, p. 1-13, 2016.

[2]. FACCIO, M., PERSONA, A., SGARBOSSA, $F$. and ZANIN, G. Industrial maintenance policy development: A quantitative framework. International Journal of Production Economics, n. 147, p. 85-93, 2014.

[3]. GOMES, V.G. POLICARPO, R.V.S. GOMES, V.G. Consolidação da confiabilidade do física dos equipamentos de moagem. Observou-se que a política adotada está de acordo com o que os principais autores mencionam sobre manutenção. O estabelecimento de metas para a equipe de manutenção, e a execução das manutenções preestabelecidas pela Mineradora, que incluem as corretivas, preventivas, preditivas, de melhoria e autônomas demonstrou-se ser eficaz, uma vez que houve uma correlação positiva forte entre a disponibilidade do equipamento de moagem e a produção em toneladas.

Por outro lado, ainda se observa que em cerca de $25 \%$ das vezes que ocorre indisponibilidade dos equipamentos de moagem, não há vínculo direto com a área de manutenção. Assim, sugere-se a aplicação de ferramentas de gestão para a identificação dos gargalos do sistema produtivo não vinculados à manutenção, uma vez que a análise do MTBF, MTTR, e da disponibilidade física dos equipamentos da moagem, entre janeiro de 2016 e julho de 2016 indicaram que a manutenção tem cumprido seu papel dentro da estrutura organizacional da Mineradora avaliada.

É possível concluir então que para se obter valores constantes nos indicadores de performance da manutenção, ou seja, obterse uma confiabilidade constante nos equipamentos e uma disponibilidade estável destes, deve-se buscar a eliminação da ocorrência de falhas inesperadas através da adoção e seguimento das políticas de manutenção estabelecidas, bem como a análise de possíveis gargalos produtivos que não estejam vinculados a ações da área de manutenção.

indicador de disponibilidade utilizado no processo de planejamento e controle de manutenção. Anais do XXIII SIMPEP, p. 1-14, 2016.

[4]. HEIZER, J. RENDER, B. Administração de operações: bens e serviços. 5.ed. Rio de Janeiro: LTC, 2001.

[5]. MARTINS, P.G. LAUGENI F.P. Administração da Produção. 2.ed. São Paulo: Saraiva, 2006.

[6]. MONCHY, F. A função manutenção: formação para a gerência da manutenção industrial. São Paulo: DURBAN / EDBRAS, 1989. 
[7]. PINTO, A.K.; XAVIER, J.A.N. Manutenção: função estratégica. 2.ed. Rio de Janeiro: Qualitymark, 2006.

[8]. SLACK, N.; CHAMBERS, S.; JOHNSTON, R. Administração da produção. 2.ed. São Paulo: Atlas, 2007.

[9]. SPSS, 2015. SPSS 25.0 Tutorial. IBM. USA.
[10]. TAVARES, L.A. A Evolução da Manutenção. Revista Nova Manutenção y Qualidade, n.54, 2005.

[11]. VAZ, J. C. Gestão da manutenção. In: CONTADOR, J. C. (Cord.). Gestão de operações. 2. ed. São Paulo: Edgard Blücher, 2004. 


\section{Bapítulo 14}

\section{ANÁLISE DA EFICÁCIA DE UM PROGRAMA DE GESTÃO DE FADIGA}

\section{Renato Ramos Coelho \\ Marcus Vinícius de Abreu Soeiro \\ Diego Fernandes Silva}

Resumo: Fadiga é a redução do desemprenho físico e mental, podendo estar associada à maior probabilidade de ocorrência de acidentes no trabalho. 0 programa de gestão de fadiga (PGF) surge, portanto, como possibilidade de gerenciamento dos fatores aassociados a ela. No entanto, ainda há dúvidas sobre a eficácia de programas desta natureza. Assim, este trabalho visou analisar comparativamente os dados do PGF obtidos em 2015 e 2016 em uma mesma empresa, de forma a verificar a eficácia destes. Esta verificação se deu pela análise de dados qualitativos e quantitativos presentes nos PGF dos anos analisados. Os resultados indicaram a ausência de acidentes, melhora do índice de massa corporal (IMC), da alimentação, do nível de atividade física e das queixas de ruídos internos nos veículos, advogando a favor da eficácia do PGF de 2015. Por outro lado, a piora do escore de sonolência diurna e o não aprendizado dos conteúdos de sono, combate ao estresse e ergonomia ao volante indicam pontos fracos do PGF. Fatores externos como o aumento do tempo de deslocamento para o trabalho e do estresse parental indicaram a importância da análise de fatores externos a empresa para a gestão da fadiga. 


\section{INTRODUÇÃO}

Fadiga é uma redução reversível do desempenho físico e mental das pessoas, podendo gerar sonolência, monotonia, comprometendo a capacidade de trabalhar e ocasionando maior possibilidade de erros e acidentes, principalmente quando associada à condução de veículos (BORGHINI et al, 2014) e operação de equipamentos (SÁNCHEZ et al, 2009).

Devido a esta maior possibilidade de erros, várias empresas têm adotado Programas de Gestão de Fadiga (PGF) direcionados aos trabalhadores que realizam atividades com requisitos críticos (RAC) como condução de veículos e operação de máquinas.

O objetivo do PGF é a avaliação e gestão dos mecanismos causadores de fadiga, bem como o treinamento dos operadores sujeitos a eles, de forma a se conscientizarem dos fatores desencadeantes e sobre como evitalos. Com isto, visa-se a prevenção do acidente de trabalho ao mesmo tempo que se potencializa a produtividade (WILBERG et al, 2015).

No entanto, a fadiga é multifatorial e a análise dos seus condicionantes envolve vários parâmetros de saúde. Assim, o conceito Total Work Health (TWH) proposto pelo National Institute for Occupational Safety and Health (NIOSH), que analisa inúmeras possibilidades de saúde no local de trabalho (SORENSEN et $\mathrm{al}$, 2013), atende às necessidades da elaboração de um PGF. O uso do TWH possibilita o controle dos fatores associados à fadiga, tais como estresse físico, psíquico e cognitivo (WISNER, 1994), de organização do trabalho e de riscos ambientais, relacionados ao indivíduo (sono, meio de transporte, capacidade de relacionar-se, questões socioculturais e ambiente domiciliar), e à empresa (tarefa e atividade, turnos/rodízios e mecanismo de gestão), permitindo a análise tanto de fatores relacionados à fadiga, quanto o controle de outros contribuintes ao erro e acidentes (SORENSEN et al, 2013).

Por outro lado, apesar de todas as recomendações vigentes no PGF, ainda não há dúvida sobre sua eficácia para a prevenção de acidentes, bem como se, entre um ano e outro, as recomendações feitas foram ou não adotadas. Desta forma, o objetivo deste trabalho é analisar comparativamente os dados do PGF obtidos em dois anos subsequentes (2015 e 2016) em uma mesma Empresa, de forma a verificar se as recomendações e treinamentos dados foram realmente absorvidos pelos trabalhadores. Esta verificação se deu através da análise das respostas qualitativas dadas à ficha de avaliação, do relato de acidentes ocasionados por fadiga e através da análise estatística dos dados quantitativos obtidos.

\section{METODOLOGIA}

A coleta de dados envolveu a análise de documentos de Saúde e Segurança do Trabalho (SST) da Empresa alvo de 2015 e 2016: 1. Programa de Controle Médico de Saúde Ocupacional - PCMSO (BRASIL, 1978a); 2. Programa de Prevenção de Riscos Ambientais - PPRA (BRASIL, 1978b); 3. Programa de Gerenciamento de Risco - PGR (BRASIL, 1978c); 4. Análise Ergonômica do Trabalho - AET, BRASIL, 1978d); 5. PGF.

Para a realização deste último, tanto em 2015 quanto 2016, foi utilizada uma amostra de 8 profissionais que responderam a um questionário próprio que continha: 1. Identificação, Idade, Peso, Altura, Gênero, Estado civil e filhos; 2. Formação e treinamentos; 3. Forma e tempo de deslocamento para o trabalho; 4. Cargo, tarefa, atividade, experiência, turnos, presença de pausas e rodízios; 5. Satisfação, stress e conflitos no trabalho e/ou em casa; 6. Riscos ambientais associados ao trabalho e equipamentos de proteção individual (EPI); 8. Alimentação, uso de estimulantes, medicamentos, álcool e fumo; 9. Tempo e interrupções de sono; 10. Fatores adicionais de fadiga; 9. Questionário de Chalder; 10. Escala de Sonolência de Epworth; 11. Escala de Necessidade de Descanso (ENEDE); 12. Questionário SF-36.

O Questionário Chalder é composto por 11 itens contendo questões que envolvem sintomas de fadiga física e mental. Sua resposta é bimodal, com as duas primeiras colunas valendo zero e as duas últimas valendo um ponto. Uma soma das notas superior a quatro indica fadiga no avaliado (CHO et al, 2007).

A Escala de Epworth avalia a sonolência diurna. Compõe-se por oito questões de situações cotidianas com resposta variando de zero (nenhuma probabilidade de cochilar) a três (alta chance de cochilar) pontos. Somatório de pontos inferior a sete indica sonolência diurna inexistente ou dentro da 
normalidade, entre sete e oito pontos indica sonolência diurna moderada e acima de nove pontos indica grave sonolência diurna (BERTOLAZl et al, 2009).

A ENEDE indica a necessidade de descanso. Ela é composta de 11 questões com resposta bimodal, com as duas primeiras opções valendo zero e as duas últimas valendo um ponto. O somatório dos pontos é convertido, via regra de três, em uma escala de zero a 100. Notas superiores a 54 indicam necessidade de descanso imediato (MORIGUCHI, 2009).

O SF-36 é um instrumento para a avaliação da qualidade de vida composto por 36 itens divididos em oito domínios: 1. Capacidade funcional; 2. Aspectos físicos; 3. Dor; 4. Estado geral da saúde; 5. Vitalidade; 6. Aspectos sociais; 7. Aspectos emocionais; 8. Saúde mental. O escore final varia de zero (pior estado geral) a 100 (melhor estado geral). Escores maiores que 60 pontos são satisfatórios (CICCONELLI et al, 1999). Em consonância com o proposto por Moriguchi (2009) foram utilizados os domínios capacidade funcional, aspectos físicos e vitalidade para o PGF cuja eficácia está sendo avaliada.

Os dados qualitativos foram comparados através de técnicas descritivas. Os escores obtidos nos testes aplicados em 2015 e 2016 foram analisados pelo teste de Wilcoxon, devido ao quantitativo de oito avaliados, com significância de $p<0,05$ (SPSS, 2015).

\section{RESULTADOS E DISCUSSÃO}

Os dados qualitativos observados na documentação de SST dos PGF da empresa pesquisada de 2015 e 2016 indicaram que, no PCMSO (Quadro 1), houve a exclusão do Risco Físico, em função de nova medição de ruídos realizada ao longo do ano de 2016 (BRASIL, 1978e) e a inclusão de atividades em laboratório no Risco Ergonômico. Nenhuma destas alterações resultou em impacto sobre a possibilidade de fadiga em Condutores de Veículos, uma vez que elas não agiram sobre os mecanismos causadores desta (BORGHINI et al, 2014).

Quadro 1: Dados do PCMSO em 2015 e 2016

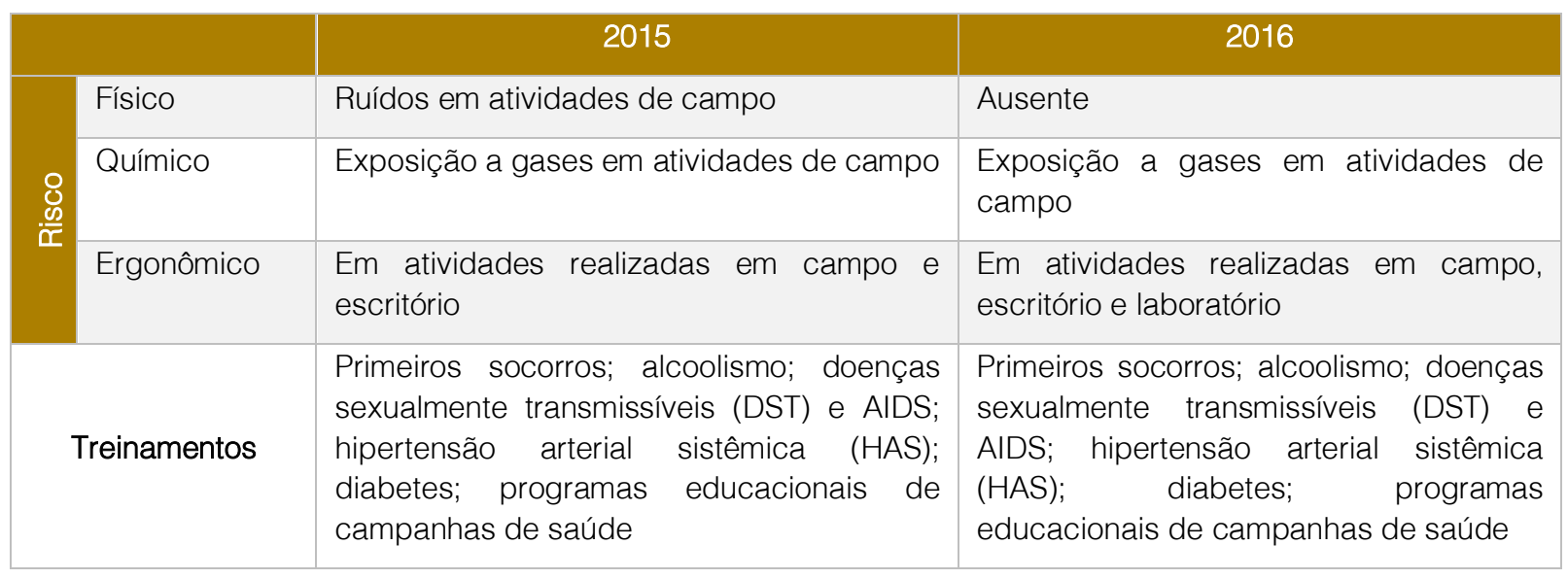


Quadro 2: Dados do PPRA em 2015 e 2016

\begin{tabular}{|c|c|c|c|}
\hline & Coletivas & $\begin{array}{c}2015 \\
\text { Designar um funcionário responsável pela } \\
\text { CIPAMIN }\end{array}$ & $\begin{array}{c}2016 \\
\text { Designar um funcionário responsável pela } \\
\text { CIPA }\end{array}$ \\
\hline $\begin{array}{l}\frac{0}{0} \\
\frac{0}{0} \\
\frac{0}{0} \\
\sum\end{array}$ & Individuais & $\begin{array}{l}\text { EPI: Capacete; óculos; máscara PFF2; } \\
\text { protetor auricular; luva de vaqueta; capa de } \\
\text { chuva; perneira; máscara de apicultor; } \\
\text { botina de segurança; colete reflexivo; } \\
\text { macacão de espeleologia; bloqueador } \\
\text { solar; repelente; apito; joelheira; ecohead }\end{array}$ & $\begin{array}{l}\text { Somente em atividades de campo } \\
\text { EPI: Capacete; óculos; máscara PFF2; } \\
\text { protetor auricular; luva de vaqueta; capa de } \\
\text { chuva; perneira; máscara de apicultor; } \\
\text { botina de segurança; colete reflexivo; } \\
\text { macacão de espeleologia; joelheira; } \\
\text { ecohead } \\
\text { Acessórios de segurança: bloqueador solar; } \\
\text { repelente; apito. }\end{array}$ \\
\hline & co Ergonômico & $\begin{array}{l}\text { Pode causar danos à saúde como: lesões } \\
\text { musculoesqueléticas; dores lombares. } \\
\text { Prevenção: mudança contínua de posturas; } \\
\text { treinamento ergonômico; ginástica laboral; } \\
\text { alongamentos }\end{array}$ & $\begin{array}{l}\text { Pode causar danos à saúde como: lesões } \\
\text { musculoesqueléticas; dores lombares. } \\
\text { Prevenção: mudança contínua de posturas; } \\
\text { treinamento ergonômico; ginástica laboral; } \\
\text { alongamentos }\end{array}$ \\
\hline
\end{tabular}

O PPRA (Quadro 2) apresentou alteração em Medidas Coletivas quanto ao tipo de Comissão Interna de Prevenção de Acidente (CIPA) a ser adotada, em 2015 foi a de Mineração (CIPAMIN), regulamentada pela NR 22 (BRASIL, 1978c) e em 2016 adotou-se a CIPA regulamentada pela NR 5 (BRASIL, 1978f). As medidas individuais incluíram o momento de uso do EPI (apenas em atividades de campo) e a nomenclatura Acessórios de Segurança para os produtos que não se encaixam na definição de EPI. Nenhuma destas alterações impacta a possibilidade de fadiga em Condutores RAC (BORGHINI et al, 2014).

O PGR (Quadro 3) que em 2015 era apenas um, passou para onze em 2016. Isto aconteceu devido a uma demanda da contratante da empresa avaliada. No entanto não houve alteração nas ações de SST entre o PGR de 2015 e os de 2016, uma vez que os cenários mineiros não alteraram (BRASIL, 1978c). Também não houve impacto sobre a probabilidade de fadiga (BORGHINI et al, 2014).

\section{Quadro 3: Dados do PGR em 2015 e 2016}

\begin{tabular}{|c|c|c|}
\hline & 2015 & 2016 \\
\hline $\begin{array}{l}\text { Objeto do } \\
\text { contrato }\end{array}$ & $\begin{array}{l}\text { Serviços em espeleologia englobando, mas } \\
\text { não se limitando a organização em análise de } \\
\text { dados espeleológicos; elaboração e } \\
\text { interpretação de análises de relevância } \\
\text { espeleológicas; consultoria na elaboração de } \\
\text { projetos com foco em hidrogeologia; } \\
\text { elaboração de relatórios de caracterização } \\
\text { geológica/hidrogeológica; } \\
\text { identificação e descrição de amostras; } \\
\text { realização de a } \\
\text { geológico/hidrogeológico; marcação e } \\
\text { levantamento topográfico em cavidades; } \\
\text { confecção de mapas e análises } \\
\text { espaciais/conversão e vetorização de dados } \\
\text { e suporte em tecnologias associadas }\end{array}$ & $\begin{array}{l}\text { Serviços em espeleologia englobando, mas não } \\
\text { se limitando a organização em análise de dados } \\
\text { espeleológicos; elaboração e interpretação de } \\
\text { análises de relevância espeleológicas; consultoria } \\
\text { na elaboração de projetos com foco em } \\
\text { hidrogeologia; elaboração de relatórios de } \\
\text { caracterização geológica/hidrogeológica; coleta e } \\
\text { identificação e descrição de amostras; realização } \\
\text { de mapeamento geológico/hidrogeológico; } \\
\text { marcação e levantamento topográfico em } \\
\text { cavidades; confecção de mapas e análises } \\
\text { espaciais/conversão e vetorização de dados e } \\
\text { suporte em tecnologias associadas }\end{array}$ \\
\hline RAC & RAC2 & ПAС \\
\hline $\begin{array}{l}\text { Controle do } \\
\text { Risco de } \\
\text { Acidente }\end{array}$ & $\begin{array}{l}\text { Procedimentos operacionais de saúde e } \\
\text { segurança; análise preliminar da tarefa e } \\
\text { procedimentos específicos da gerência } \\
\text { gestora do contrato inerente à execução das } \\
\text { atividades. }\end{array}$ & $\begin{array}{l}\text { Procedimentos operacionais de saúde e } \\
\text { segurança; análise preliminar da tarefa e } \\
\text { procedimentos específicos da gerência gestora } \\
\text { do contrato inerente à execução das atividades. }\end{array}$ \\
\hline
\end{tabular}


A AET (Quadro 4) de 2016 apresentou, em relação a de 2015, aumento do número de profissionais efetivos e autônomos, presença de conflitos, piora na satisfação e maior quantidade de profissionais estressados. Todos estes fatores podem atuar negativamente sobre a fadiga, por terem efeito sobre os aspectos físico, psíquico e cognitivo do Ser Humano (WISNER, 1994). No entanto, a ausência de quadros de dor entre os profissionais da empresa é um fator que previne a fadiga (BORGHINI et al, 2014).

Perpassadas as questões relativas à SST da empresa, tem-se os fatores passíveis de serem influenciados por fatores humanos. Os oito condutores da empresa avaliada permaneceram os mesmos entre 2015 e 2016, o que permitiu a comparação entre eles. Os dados referentes a estes condutores, bem como a análise estatistica pelo Teste de Wilcoxon entre os valores obtidos para idade, peso, altura, índice de massa corporal (IMC), tempo de sono e de deslocamento para o trabalho, e escores do Chalder, Epworth, ENEDE e SF-36 em 2015 e 2016 encontramse descritos na Tabela 1. Os dados qualitativos relativos a gênero, estado civil, filhos, interrupção de sono, prática de atividade física, meio de transporte para o trabalho, relato de doenças e de uso de medicamentos, conflitos e estresse, alimentação, álcool, fumo, café e outros estimulantes, satisfação com o trabalho e formação profissional nos anos de 2015 e 2016 encontram-se descritos no Quadro 5.

Quadro 4: Dados da AET em 2015 e 2016

\begin{tabular}{|c|c|c|c|}
\hline & 2015 & 2016 \\
\hline \multicolumn{2}{|c|}{ Jornada de trabalho } & 44 horas/semanais, sem horas extras & 44 horas/semanais, sem horas extras \\
\hline \multicolumn{2}{|c|}{$\begin{array}{l}\text { Quantitativo de } \\
\text { profissionais }\end{array}$} & 20 homens e 2 mulheres & $\begin{array}{l}20 \text { homens e } 5 \text { mulheres, sendo } 5 \\
\text { autônomos }\end{array}$ \\
\hline \multicolumn{2}{|c|}{$\begin{array}{l}\text { Relação com chefias e } \\
\text { colegas }\end{array}$} & Sem conflitos para todos & $\begin{array}{lcc}\text { Conflitos, } \quad \text { quando } & \text { existentes, } & \text { são } \\
\text { associados ao trabalho e resolutivos } & \end{array}$ \\
\hline \multicolumn{2}{|c|}{$\begin{array}{l}\text { Satisfação } \\
\text { trabalho }\end{array}$} & Plena para todos & $\begin{array}{l}10 \% \text { dos profissionais relatam não estar } \\
\text { plenamente satisfeitos }\end{array}$ \\
\hline \multicolumn{2}{|c|}{ Relação com o trabalho } & Trabalho interessante para todos & Trabalho interessante para todos \\
\hline \multicolumn{2}{|c|}{ Estresse no trabalho } & $6 \%$ dos colaboradores relatam estresse & $\begin{array}{l}5 \text { profissionais relatam estresse físico e } \\
2 \text {, cognitivo }\end{array}$ \\
\hline \multicolumn{2}{|l|}{ Dor } & $11 \%$ relatam dor, maioria nos joelhos & Sem relato \\
\hline \multicolumn{2}{|c|}{ Absenteísmo } & Sem registro no ano de 2014 & Sem registro no ano de 2015 \\
\hline \multirow{7}{*}{ 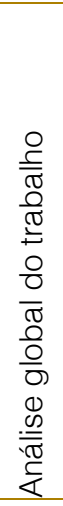 } & $\begin{array}{l}\text { Ambiente } \\
\text { variável }\end{array}$ & Atividades a céu aberto e matas & Atividades a céu aberto e matas \\
\hline & $\begin{array}{l}\text { Sistema } \\
\text { produção }\end{array}$ & Por demanda, sem metas & Por demanda, sem metas \\
\hline & $\begin{array}{l}\text { Ritmo de } \\
\text { trabalho }\end{array}$ & $\begin{array}{l}\text { Sem rotatividade, sem monotonia e sem } \\
\text { métodologia previamente estabelecida }\end{array}$ & $\begin{array}{l}\text { Sem rotatividade, sem monotonia e sem } \\
\text { métodologia previamente estabelecida }\end{array}$ \\
\hline & Ciclo de trabalho & $\begin{array}{l}\text { Fixo apenas em } \quad \text { atividades } \\
\text { administrativas }\end{array}$ & $\begin{array}{l}\text { Fixo apenas em } \quad \text { atividades } \\
\text { administrativas }\end{array}$ \\
\hline & $\begin{array}{l}\text { Pausas e micro- } \\
\text { pausas }\end{array}$ & Livres & Livres \\
\hline & $\begin{array}{l}\text { Período de } \\
\text { almoço }\end{array}$ & Fixo entre 12:30 e 13:30 & Fixo entre 12:30 e 13:30 \\
\hline & Recreação & Não há & Não há \\
\hline \multirow[b]{2}{*}{ 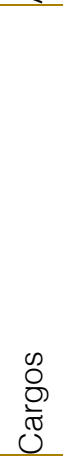 } & $\begin{array}{l}\text { Auxiliar } \\
\text { Campo } \\
\text { Técnico } \\
\text { Ambiental }\end{array}$ & $\begin{array}{l}\text { Ciclo de trabalho: maior parte do tempo } \\
\text { conduzindo condução de veículo ou } \\
\text { caminhando, sem repetitividade. } \\
\text { Riscos ergonômicos: longas caminhadas } \\
\text { com o peso da mochila nas costas e } \\
\text { manuseio de facões. }\end{array}$ & $\begin{array}{l}\text { Ciclo de trabalho: maior parte do tempo } \\
\text { conduzindo condução de veículo ou } \\
\text { caminhando, sem repetitividade. } \\
\text { Riscos ergonômicos: longas caminhadas } \\
\text { com o peso da mochila nas costas e } \\
\text { manuseio de facões. }\end{array}$ \\
\hline & $\begin{array}{l}\text { Analista } \\
\text { ambiental e } \\
\text { Diretoria } \\
\text { (Técnica } \\
\text { Administrativa) }\end{array}$ & $\begin{array}{l}\text { Ciclo: Varia entre escritório e campo } \\
\text { Escritório: atividades em computador e } \\
\text { postura assentada, repetitividade e } \\
\text { monotonia. } \\
\text { Campo: risco ergonômico da caminhada } \\
\text { com mochilas, sem repetitividade }\end{array}$ & $\begin{array}{l}\text { Ciclo: Varia entre escritório e campo } \\
\text { Escritório: atividades em computador e } \\
\text { postura assentada, repetitividade e } \\
\text { monotonia. } \\
\text { Campo: risco ergonômico da caminhada } \\
\text { com mochilas, sem repetitividade }\end{array}$ \\
\hline
\end{tabular}


A diferença entre as médias das idades era esperada, uma vez que um ano se passou. A diminuição do peso médio refletiu nos valores do IMC, uma vez que não houve diferença entre as médias de altura. Esta diminuição de peso e IMC, benéfica para a prevenção da fadiga, pode ser devida ao treinamento realizado com os gestores no Programa de 2015, que sugeriu o incentivo a melhora da qualidade dos lanches servidos aos trabalhadores na empresa, bem como a inclusão do nutricionista no plano de saúde corporativo. Também se credita este fato a maior consciência dos profissionais quanto a qualidade de sua própria alimentação, conforme se observa na diferença das respostas sobre este item no Quadro 4.

Tabela 1: Dados dos condutores em 2015 e 2016

\begin{tabular}{|c|c|c|c|}
\hline & & 2015 & 2016 \\
\hline & Idade (anos) & $29,86 \pm 5,70$ & $30,86 \pm 5,70^{*}$ \\
\hline & Peso (kg) & $80,00 \pm 24,81$ & $72,43 \pm 14,51^{*}$ \\
\hline & Altura $(\mathrm{cm})$ & $174,04 \pm 0,04$ & $174,04 \pm 0,04$ \\
\hline & $\mathrm{IMC}\left(\mathrm{kg} / \mathrm{cm}^{2}\right)$ & $25,43 \pm 6,43$ & $23,87 \pm 4,93^{*}$ \\
\hline & Tempo de sono (horas) & $6,93 \pm 1,37$ & $6,86 \pm 1,07$ \\
\hline Temp & deslocamento para o trabalho (minutos) & $40,71 \pm 36,56$ & $52,86 \pm 38,93^{\star}$ \\
\hline & Chalder & $2,43 \pm 3,82$ & $1,43 \pm 2,57$ \\
\hline & Epworth & $4,43 \pm 2,44$ & $6,29 \pm 2,29^{*}$ \\
\hline & ENEDE & $19,48 \pm 21,27$ & $24,68 \pm 15,49^{*}$ \\
\hline \multirow{3}{*}{ SF-36 } & Capacidade Funcional & $91,43 \pm 10,69$ & $87,14 \pm 11,85$ \\
\hline & Aspectos Físicos & $60,71 \pm 42,96$ & $71,43 \pm 41,90$ \\
\hline & Vitalidade & $61,43 \pm 7,48$ & $71,43 \pm 11,90$ \\
\hline
\end{tabular}

* Diferença significativa $(p<0,05)$ avaliada pelo Teste de Wilcoxon

O tempo de sono não se alterou, permanecendo abaixo do desejável para a maioria dos trabalhadores. Também não houve diferença no relato de interrupções do sono, que ocorre para dois condutores. A soma destes dois dados pode implicar em fadiga crônica (McARDLE et al, 2011). O nível de atividade física melhorou em 2016, mas continua abaixo do necessário para que o sujeito não seja considerado como sedentário (BRASIL, 2014). Baixos níveis de atividade física também estão relacionados à fadiga crônica (McARDLE et al, 2011).

\section{Quadro 5: Dados Qualitativos dos Questionários de 2015 e 2016}

\begin{tabular}{|c|c|c|}
\hline & 2015 & 2016 \\
\hline Gênero & Masculino: 7 & Masculino: 7 \\
\hline Estado civil & 4 casados; 2 solteiros; 2 divorciados & 4 casados; 2 solteiros; 2 divorciados \\
\hline Filhos & $\begin{array}{l}2 \text { condutores com uma criança de menos } \\
\text { de } 5 \text { anos cada }\end{array}$ & $\begin{array}{l}2 \text { condutores com uma criança de } \\
\text { menos de } 5 \text { anos cada }\end{array}$ \\
\hline ão de sono & 2 com interrupção rotineira do sono & 2 com interrupção rotineira do sono \\
\hline Atividade física & $\begin{array}{l}4 \text { não praticam nenhuma; } 4 \text { praticam } \\
\text { menos que } 3 \times / \text { semana }\end{array}$ & $\begin{array}{l}4 \text { não praticam nenhuma; } 4 \text { praticam } \\
\text { menos que } 3 \times / \text { semana }\end{array}$ \\
\hline Meio de $\mathrm{t}$ & 4 público; 3 carro; 1 caminha & 4 público; 4 carro; 2 carro/caminhada \\
\hline Doen & Sem re & Sem relato \\
\hline Medicamentos & Sem relato & Sem relato \\
\hline Conflitos & 3 relatam no trabalho & $\begin{array}{l}2 \text { relatam em casa; } 2 \text { relatam em casa e } \\
\text { trabalho }\end{array}$ \\
\hline Estresse & 3 físic & 4 físico; 3 físico e mental \\
\hline Alimentação & $\begin{array}{l}2 \text { relatam saudável e cinco vezes ao dia; } \\
\text { demais relatam qualidade ruim e esparsa }\end{array}$ & $\begin{array}{l}\text { Todos mais que } 4 \text { vezes ao dia; } 2 \\
\text { relatam baixa qualidade }\end{array}$ \\
\hline Álcool & 6 bebem socialmente & 6 bebem socialmente \\
\hline Fumo & s; 1 regular & 2 eventuais; 1 regular \\
\hline Café e estimulantes & 3 regularmente, 1 eventualmente & 4 regularmente, 2 eventualmente \\
\hline $\begin{array}{l}\text { Satisfação } \\
\text { trabalho }\end{array}$ & 1 insatisfeito com o salário & 1 insatisfeito \\
\hline Formação profissional & $\begin{array}{l}5 \text { terceiro grau completo; } 2 \text { técnicos; } 1 \\
\text { segundo grau completo }\end{array}$ & $\begin{array}{l}5 \text { terceiro grau completo; } 2 \text { técnicos; } 1 \\
\text { segundo grau completo }\end{array}$ \\
\hline $\begin{array}{l}\text { Fatores adicionais de } \\
\text { fadiga }\end{array}$ & $\begin{array}{l}2 \text { excesso de ruído; } 2 \text { dificuldades do } \\
\text { trajeto de trabalho; } 1 \text { tarefas domésticas; } 1 \\
\text { dupla jornada }\end{array}$ & $\begin{array}{l}3 \text { falta de perspectiva profissional; } 2 \\
\text { dificuldades do trajeto de trabalho }\end{array}$ \\
\hline
\end{tabular}


O tempo de deslocamento para o trabalho aumentou após um ano, mesmo com nenhum profissional pesquisado tendo se mudado e um deles adotando o transporte particular. Isto reflete piora do transporte da cidade em que se localiza a empresa pesquisada, embora a queixa deste item entre os profissionais não tenha se alterado. Esta dificuldade de locomoção pode causar um aumento na fadiga relacionada ao estresse físico (WISNER, 1994).

Entre as respostas dos questionários aplicados, observou-se que houve diferença, para pior no Epworth e no ENEDE. Isso significa que os condutores da empresa avaliada estão apresentando mais sonolência diurna (BERTOLAZl et al, 2009) e mais necessidade de descanso (MORIGUCHI, 2009). Estes resultados podem ser devido à maior quantidade de estresse e de conflitos relatados (WISNER, 1994), a insatisfação com o trabalho não se alterou, não repercutindo nos piores escores relacionados à fadiga.

Não há relato de doenças, uso de medicamentos e nem de uso abusivo de álcool, fumo, café e estimulantes tanto em 2015 quanto em 2016. Também não houve alterações na formação profissional, estado civil ou estrutura familiar dos condutores. Desta forma, parece que estes fatores não estão relacionados à piora dos escores relacionados à fadiga. Por outro lado, os conflitos em casa aumentaram em 2016. Em 2015 a dupla jornada e os afazeres domésticos foram relatadas como fator causador de fadiga por dois condutores, em 2016 ninguém se queixou disto. A falta de perspectiva profissional dentro da empresa objeto deste estudo foi queixa de três condutores em 2016.

Não houve alteração quanto aos veículos utilizados pelos condutores entre o ano de 2015 e 2016, sendo estes camionetes pick up ano 2015 em boas condições de uso com cabine dupla; quatro portas laterais; capacidade para cinco passageiros; air bags para motorista e passageiro; ar condicionado; direção hidráulica; regulagem de bancos e direção; vidros, travas e retrovisores elétricos; alarme; sistema de som AM/FM com reprodutor de $C D$ e comando no volante; motor diesel com potência de 180 CV; transmissão manual de cinco velocidades; tração 4x4 com caixa de redução e diferencial autoblocante traseiro; freios a disco com ABS nas quatro rodas; tanque de combustível de 75 litros; cinto de segurança de três pontos para quatro passageiros e abdominal para um; Santo Antônio dentro do habitáculo, conforme normatização da contratante.

Assim, observa-se que qualquer ocorrência interna ao veículo que possa promover a fadiga deve se a fatores humanos. Dentro destas possibilidades de ocorrência, ressaltase a conversa e o som ambiente, uma vez que ambos podem induzir a sonolência se estiverem ausentes (WILBERG et al, 2015). Por outro lado, o excesso de ruído pode gerar fadiga mental crônica (GANIME et al, 2010), principalmente se superar os $85 \mathrm{~dB}$ de ruído contínuo por um período superior a oito horas (BRASIL, 1978e). Observou-se que o comportamento dos condutores quanto ao ruído dentro do veículo, que era motivo de queixa de dois condutores em 2015 não apareceu em 2016, indicando que o treinamento aplicado aos condutores em 2015 surtiu efeito. O resultado positivo do treinamento para a minoração do ruído foi condizente com o observado por Machado et al (2014).

Embora o Santo Antônio dentro do habitáculo seja uma exigência da contratante, ele representa um risco de acidente, uma vez que ele fica muito próximo à cabeça de condutor e passageiros, de forma que o mais seguro seria a sua supressão.

A empresa avaliada sempre seguiu orientação proveniente de sua contratante de promover pausas programas durante a condução de veículos, de 15 minutos a cada $200 \mathrm{~km}$ ou duas horas de condução, o que está de acordo com a pausas de atividade recomendadas pela NR 17 (BRASIL, 1978d). Por outro lado, os Programas de 2015 e 2016 ressaltaram a importância de estas pausas ocorrerem em circunstâncias favoráveis. Que incluem local com sombra e com acesso a bebidas não alcoólicas e comidas leves para que haja a possibilidade de um breve descanso. O Programa de 2015 não apresentou meios para a escolha do local. O de 2016 sugeriu o uso de aplicativos de smartphone de mapas e navegação para a escolha destes locais, o que foi considerado pelos condutores como uma boa sugestão.

De forma a promover uma melhor ergonomia para o condutor, os Programas de Gestão de Fadiga de 2015 estabeleceu um 
procedimento padrão para a regulagem do banco do motorista. Esta posição deve permitir a movimentação do condutor para acessar os instrumentos do carro sem que ocorram movimentos extremos dos membros (VIEIRA; KUMAR, 2004). A distância do painel deve permitir visualizar o painel e o trajeto com a menor necessidade de movimentos oculares o possível, uma vez que este movimento gera fadiga (AHLSTROMA; FRIEDMAN-BERGB, 2006). Esta distância também deve impedir a flexão excessiva dos joelhos, uma vez que isto diminui a quantidade de sangue circulante nos membros inferiores, favorecendo isquemias e o surgimento de varizes (VIEIRA; KUMAR, 2004). O encosto do banco deve ser regulado de forma a manter a curvatura normal da lordose lombar, mesmo que para isto seja necessário improvisar um rolo lombar na altura da cintura (McKENZIE, 1997). O treinamento realizado em 2016 indicou que estas orientações dadas em 2015 não foram absorvidas e nem seguidas pelos condutores da empresa avaliada.

\section{CONSIDERAÇÕES FINAIS}

Considerando-se que não houve registro de acidentes e nem de situações de risco na Empresa alvo durante o período em que este estudo foi realizado, acredita-se que o PGF cumpriu o papel a que se propôs. Além deste dado de ausência de acidentes, a melhora do

\section{REFERÊNCIAS}

[1]. AHLSTROMA, U. FRIEDMAN-BERGB, F.J. Using eye movement activity as a correlate of cognitive workload. International Journal Industrial Ergonomics, v. 36, p. 623 - 636, 2006.

[2]. BERTOLAZI A.N. FAGONDES, S.C. HOFF, L.S. PEDRO, V.D. BARRETO, S.S.M. JOHNS, M.W. Validação da escala de sonolência de Epworth em português para uso no Brasil. Jornal Brasileiro de Pneumologia, v. 35, n. 9, p. 877-83, 2009.

[3]. BORGHINI, G. ASTOLFI, L. VECCHIATO, G. MATTIA, D. BABILONI, F. Measuring neurophysiological signals in aircraft pilots and car drivers for the assessment of mental workload, fatigue and drowsiness. Neuroscience and Biobehavioral Reviews, v. 44, p. 58-75, 2014.

[4]. BRASIL. NR-7: Programa de Controle Médico de Saúde Ocupacional. Brasília: Ministério do Trabalho, 1978a.

[5]. BRASIL. NR-9: Programa de Prevenção de Riscos Ambientais. Brasília: Ministério do Trabalho, 1978b.
IMC, da alimentação, e do nível de atividade física associados à diminuição das queixas relativas à ruídos nos veículos indicaram que parte do conteúdo ministrados no treinamento de 2015 foram absorvidos por gestores e condutores. Por outro lado, a piora dos dados de sonolência diurna e a falta de absorção dos conteúdos relativos a sono, combate ao estresse e ergonomia ao volante indicam que há necessidade de se rever a metodologia de ensino do treinamento para estes itens. O aumento do tempo de deslocamento para o trabalho, do estresse, no local de trabalho e parental, e a falta de perspectiva profissional surgiram como novos desafios para o gerenciamento da fadiga. No PGF de 2017 espera-se verificar o efeito do uso de aplicativos de smartphones para a escolha dos melhores locais para o descanso a ser realizado a cada $200 \mathrm{~km}$ ou duas horas de direção sobre os dados de fadiga dos condutores da empresa avaliada.

A continuidade deste estudo envolve a análise do PGF de um maior número de empresa, de forma a verificar até que ponto características intrínsecas e de organização influenciam nos mecanismos causadores e de gestão de fadiga. Complementarmente, pode se verificar o uso de outros instrumentos de avaliação da fadiga e se fatores correlatos a ela, bem como de outras metodologias pedagógicas para que ocorra uma maior absorção dos conteúdos ministrados nos treinamentos.

[6]. BRASIL. NR-22: Segurança e Saúde Ocupacional na Mineração. Brasília: Ministério do Trabalho, 1978c.

[7]. BRASIL. NR-17: Ergonomia. Brasília: Ministério do Trabalho, 1978d.

[8]. BRASIL. NR-15: Atividades e Operações Insalubres. Brasília: Ministério do Trabalho, 1978 e.

[9]. BRASIL. NR-5: Comissão Interna de Prevenção de Acidentes. Brasília: Ministério do Trabalho, $1978 f$.

[10]. BRASIL. Pesquisa Nacional de Saúde 2013. Brasília: Instituto Brasileiro de Geografia e Estatística, 2014.

[11]. CHO, A.J. COSTA, E. MENEZES, P.R. CHALDER, T. BHUGRA, D. WESSELY, S. Crosscultural validation of the Chalder fatique questionaire in brazilian primary care. Journal of Psychosomatic Research, v. 62, n. 3, p. 301-4, 2007.

[12]. CICONELLI, R.M. FERRAZ, M.B. SANTOS, W. MEINÃO, I. QUARESMA, M.R. Tradução para a 
língua portuguesa e validação do questionário genérico de avaliação de qualidade de vida SF-36 (Brasil SF-36). Revista Brasileira de Reumatologia, v. 39, n. 3, p. 143-150, 1999.

[13]. GANIME, J.F. O ruído como um dos riscos ocupacionais: uma revisão de literatura. Revista Electrônica Cuatrimestral de Enfermeria, n. 19, p. 1 - 15, 2010.

[14]. MACHADO, A.C.M. MACHADO, L.G. FONSECA, T.C. COELHO, R.R. Níveis de ruído em uma unidade de terapia intensiva: avaliação sob a ótica da ergonomia. Anais do XXI SIMPEP, p. 1-10, 2014.

[15]. McARDLE W.D. KATCH, F.I. KATCH, V.L. Fisiologia do Exercício: energia nutrição e desempenho humano. 7. ed. Rio de Janeiro: Guanabara Koogan S.A., 2011.

[16]. McKENZIE, R. A. The Lumbar Spine: mechanical diagnosis and therapy. New Zealand: Spine Publications, 1997, 164p.

[17]. MORIGUCHI, C. S. Adaptação Cultural e Avaliação dos Parâmetros Psicométricos da Versão brasileira da Need for Recovery Scale. $61 \mathrm{f}$. Dissertação (Mestrado) - Programa de Mestrado em Fisioterapia do Centro de Ciências Biológicas e da Saúde da Universidade Federal de São Carlos. 2009.
[18]. SÁNCHEZ, A.S. FERNÁNDEZ, P.R. LASHERAS, F.S. COS JUEZ, F.J. NIETO, G. Prediction of work-related accidents according to working conditions using support vector machines. Applied Mathematics Computation, v. 218, p. 353952, 2011.

[19]. SORENSEN, G. McLELLAN, D. DENNERLEIN, J.T. ALLEN, J.D. BODEN, L.I. OKECHUKWU, C.A. STODDARD, A. WAGNER, G.R. Integration of health protection and health promotion: rationale, indicators, and metrics. Journal Occupational Environment Medicine, v. 55, p. S12-8, 2013

[20]. SPSS, 2015. SPSS 25.0 Tutorial. IBM. USA.

[21]. VIEIRA, E. R. KUMAR, S. Working postures: A literature review. Journal of Occupational Rehabilitation, v. 14, n. 2, p. $143-$ 159, 2004

[22]. WILBERG, H. NILSSON, E. LINDÉN, P. SVANBERG, B. POOM, L. Physiological responses related to moderate mental load during car driving in field conditions. Biological Psychology, v. 108, p. 115-25, 2015.

[23]. WISNER, A. A Inteligência no Trabalho. Brasília: FUNDACENTRO, 1994. 


\section{Gapítulo 15}

\section{UM APLICATIVO GRATUITO DE \\ ENGENHARIA \\ ECONOMICA \\ DESENVOLVIDA \\ EM \\ MELHORAR \\ O PROCESSO \\ $D E$ \\ $\mathrm{C}++$ \\ PARA \\ APRENDIZAGEM À DISTÂNCIA}

\section{Ricardo Alexandre Deckmann Zanardini}

Alessandra de Paula

Cristiane Adriana Ripka

Kellen Coelho dos Santos

Luiz Antônio Forte

Resumo: O presente trabalho foi desenvolvido numa instituição de ensino superior do Brasil e foi motivado pela dificuldade que muitos estudantes de cursos de gestão de produção industrial enfrentam no estudo da disciplina de ciência da computação onde o principal objetivo é aprender a programação de computadores. Optamos por trabalhar em conjunto com a disciplina de engenharia econômica para motivar e ajudar na compreensão dos conceitos relacionados com a linguagem $\mathrm{C}++$ assim como promover melhorias nas etapas de programação. Cada equipe de 4 a 5 estudantes desenvolveu um aplicativo que tinha as principais ferramentas de engenharia econômica e, para fins sociais, estes estudantes compartilharam livremente estes aplicativos postando o endereço de acesso nas suas redes sociais. Foi observado que houve $44,83 \%$ de melhoria no desempenho dos estudantes nas avaliações do curso após a sua participação no projeto. Também foi possível observar a boa aceitação dos usuários a respeito das aplicativos desenvolvidas e compartilhadas gratuitamente. 


\section{INTRODUÇÃO}

A programação de computadores corresponde a uma sequência de etapas que direcionam o processamento de um fluxo de operações que possui uma utilidade. Esta é uma atividade que envolve arte, engenharia e ciência (SEBESTA,2012). Para criar um programa de computador é necessário seguir regras semânticas e sintáticas. Através da programação é possível especificar qual informação processar, como fazer isso, e quais resultados serão exibidos. Atualmente há várias linguagens de programação que permitem a transformação destas etapas em linguagem de máquina que será executada pelo computador. Entre as várias linguagens, $\mathrm{C}++$ é a linguagem universal de programação (SCHILDT,2003)

A utilização da linguagem $\mathrm{C}++$ é interessante devido ao seu desempenho eficaz. Entretanto muitos estudantes têm problemas com o aprendizado de logica e de linguagem de programação. Frequentemente a metodologia e exemplos utilizados para ensinar uma linguagem de programação não são capazes inicialmente de mostrar a sua importância

Como estamos numa busca constante por melhorias no processo de ensino e aprendizado, precisamos pensar sobre novas metodologias que possam melhorar o processo de aprendizado. Freire (2002) afirma que é importante reforçar a curiosidade e a capacidade crítica dos estudantes para atingir sua educação integral. Behar (2009) acreditava que há necessidade de haver interações entre os estudantes e os professores acerca do conteúdo a ser abordado. Também é importante que haja significado para os tópicos abordados nas aulas (Schell \& Javicki, 2013). Existe preocupação de que as práticas reflexivas resultem em um melhor ensino e melhores resultados educacionais (Jaeger, 2013). O uso da tecnologia motiva os alunos a interagir mais, e Murphy, Walker e Webb (2013) dão uma visão sobre como isso é possível. É claro que se o desempenho dos estudantes não for bom quanto o esperado, é necessário fazer alguns arranjos para mudanças no contexto

Para promover melhorias no processo de ensino e aprendizado, uma vez que a dificuldade no entendimento da disciplina for detectada, desenvolvemos um projeto integrando as disciplinas de ciência da computação e engenharia econômica, ambas na modalidade de ensino á distância. Neste projeto, estudantes poderiam programar diferentes métodos abordados na disciplina de engenharia econômica destinados a resolver problemas reais. Com relação a este trabalho, o principal objetivo foi promover melhorias no processo de aprendizagem dos estudantes do curso de Gestão da Produção Industrial em relação a disciplina de ciência da computação. Também foi parte deste trabalho proporcionar aos familiares, amigos e pessoas em geral acesso à possibilidade de obter resultados relacionados à Engenharia Econômica, como recuperação de capital, retorno de investimentos, cálculo de viabilidade de projetos, entre outros.

\section{A IMPORTÂNCIA DO C++ E DA ENGENHARIA ECONÔMICA}

$\mathrm{C}++$ é uma linguagem compilada. Para que um programa seja executado, é preciso um texto que será processado por um compilador e gerará um programa executável (Stroustrup, 2013). Este texto possui uma estrutura lógica que envolve um raciocínio frequentemente sequencial. Basicamente, os dados são relatados, processados através de operações binárias, aritmética, estruturas de repetição e, posteriormente, os resultados obtidos são apresentados. Atualmente, existem várias linguagens de programação, como $\mathrm{C}, \mathrm{C}++$, Java, Python, PHP e outras.

$\mathrm{C}++$ é uma linguagem ponderosa e amplamente utilizada. Em cursos presenciais já existe uma metodologia muito satisfatória para o ensino de linguagem de programação e não é usual procurar inovações. Entretanto, no aprendizado á distancia nós precisamos promover melhorias devido à expansão desta modalidade de ensino e da necessidade de os alunos aprenderem mais e mais. Devido ao aprendizado ocorrer em uma sala de aula virtual, os atuais recursos de informática oferecem uma ampla variedade de opções que podem e precisam ser exploradas.

Em uma sala de aula, os alunos nem sempre têm esse acesso, mas na educação a distância o estudante está bem inserido no mundo virtual. É possível usar o computador para que esse uso contribua para o processo de aprendizagem e facilite a compreensão de conceitos relacionados aos assuntos estudados (Bittar, 2011). Também é importante relacionar contextos do ensino presencial e a distância ao lidar com 
gerenciamento de conteúdo e sistemas de aprendizagem (Tori, 2010).

Em relação aos assuntos da Ciência da Computação, os alunos são inicialmente apresentados a importância da programação atualmente. Em seguida, o design e a programação são exibidos. A noção de design e programação pode ser detalhada como:

\section{Expressar ideias em código;}

Expressar ideias independentes em códigos independentes;

Representar através de código a relação entre ideias;

\section{Combinação de ideias expressas em código;}

Expressar ideias simples em códigos simples (Stroustrup, 2013).

Após essas apresentações iniciais, os alunos têm acesso aos primeiros contatos com a linguagem $\mathrm{C}++\mathrm{e}$ conceitos relacionados a variáveis, aritmética, constantes e ligações circulares (se, enquanto, para). Também são discutidos indicadores, matrizes e outros tópicos importantes. A lógica de programação é trabalhada em paralelo com a linguagem de programação. No que diz respeito à Engenharia econômica, os principais conceitos para engenheiros são abordados (Newnan, Eschenbach e Lavelle, 2004). Entre os vários tópicos abordados nós podemos destacar: Pagamento único, série uniforme, recuperação de capital, série uniforme de gradiente aritmético, valor presente da série geométrica, composição contínua a taxa nominal, fluxo de caixa uniforme contínuo, depreciação e muito mais.

Todos os assuntos estudados na disciplina de Engenharia Econômica têm relações com problemas reais muito próximos do desempenho dos alunos, tanto na vida empresarial quanto na vida pessoal. Esses temas são muito importantes para ajudar no estudo da viabilidade de projetos, por exemplo. As decisões econômicas diferem da maneira fundamental dos tipos de decisões tipicamente encontradas no projeto de engenharia (Park, 2004). Na Produção Industrial, os conhecimentos relacionados à disciplina de Engenharia econômica são importantes no que diz respeito ao estudo da viabilidade de compra ou troca de equipamentos. Eles também são importantes em outros problemas de tomada de decisão, como a melhor escolha para angariar fundos ou o prazo ideal para a troca de equipamentos. Os problemas encontrados na disciplina de engenharia econômica e, consequentemente, em várias situações reais podem ser resolvidos por meio de fórmulas específicas. O uso de calculadoras ou planilhas é muito útil. Mas para isso, você precisa de conhecimento relacionado aos assuntos da disciplina. Portanto, o desenvolvimento de um aplicativo gratuito e autoexplicativo permite que qualquer pessoa resolva esses problemas.

\section{A PRÁTICA PEDAGÓGICA}

Os alunos que frequentam o curso de Gestão de Produção Industrial na aprendizagem à distância têm acesso aos conteúdos disponíveis no sistema de gerenciamento de aprendizagem. As classes virtuais contem vídeos elaborados pelos professores das disciplinas, livros, textos, exemplos e exercícios resolvidos. Todos os alunos têm acesso a centros de apoio de sala de aula, um total que corresponde a mais de 430 lugares distribuídos em várias cidades do Brasil. Em cada centro, há instrutores que podem ajudar esses alunos. Os alunos também recebem suporte via internet. No sistema de gerenciamento de aprendizagem, existe um canal para que os alunos entrem em contato com os instrutores. As diretrizes são feitas por escrito, por voz ou vídeo. Também é incentivada a formação de grupos de estudo e a participação nos fóruns. Além do suporte presencial e do sistema de gerenciamento de ambiente, os alunos também recebem suporte por e-mail, batepapo e telefone.

O desenvolvimento do trabalho foi feito em duas etapas. $\mathrm{Na}$ primeira etapa 1032 estudantes matriculados no curso tiveram acesso ao material via internet, assistiram ás aulas, fizeram as atividades, e realizaram as avaliações sem relação com a disciplina de engenharia econômica que foi oferecida no mesmo período. No segundo estágio os estudantes participaram do projeto interdisciplinar. Neste estágio, em paralelo com as aulas regulares, participaram no desenvolvimento da aplicativo usando o conhecimento previamente adquirido assim como os novos conhecimentos.

As diretrizes para o desenvolvimento da aplicativo foram: Cobrir todo o conteúdo da disciplina de engenharia econômica, possuir 
uma interface simples e intuitiva, oferecer uma breve descrição dos conceitos de cada função da aplicativo e informar como a entrada de dados deveria ser feita, apresentar os resultados de uma forma simples com explicações conceituais apropriadas

Os aplicativos desenvolvidas pelos estudantes foram feitos em blocos. Cada bloco estava destinado a uma função especifica da aplicativo. Um dos blocos refere-se ao cálculo do valor presente líquido (NPV) e os respectivos pagamentos

A estrutura básica deste bloco pode ser vista abaixo:

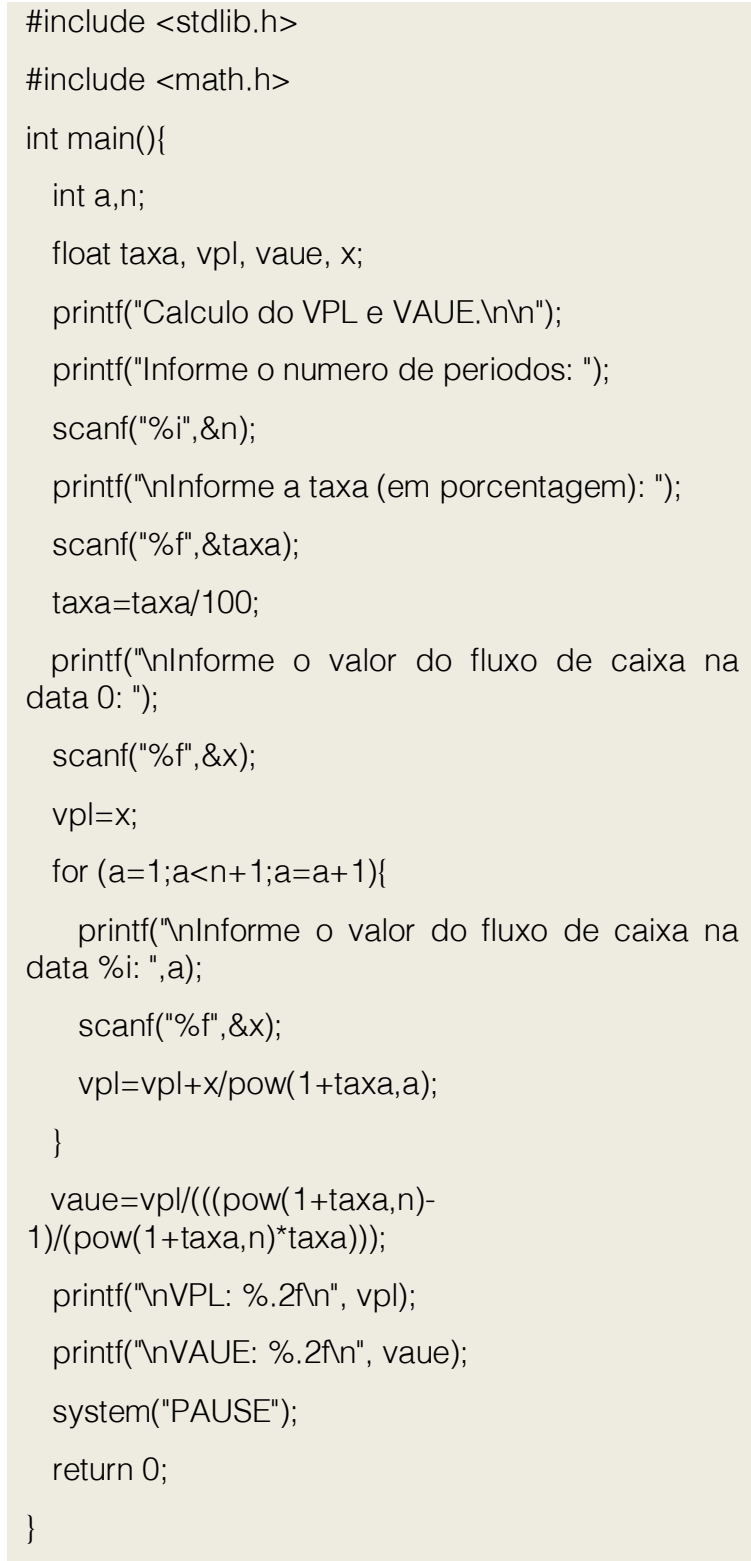

É importante notar que este aplicativo foi destinado para pessoas que não necessariamente tenham conhecimento técnico relacionado a engenharia econômica, mas que necessitam obter informações uteis em relação a problemas econômicos

Para a análise dos resultados, o desenvolvimento do projeto foi observado e analisado para verificar a influência desta prática pedagógica na melhor compreensão e aplicativo das disciplinas da Ciência da Computação. Além de avaliar o aplicativo produzido em termos de operação, interface de usuário e lógica de programação, as atividades e avaliações usuais do curso foram realizadas.

Para comparar o desempenho dos alunos na fase em que a aplicativo foi desenvolvida com o desempenho dos alunos durante as aulas tradicionais foi considerada a média obtida pelos alunos nas duas fases do projeto. Observou-se que inicialmente o desempenho dos alunos foi menor do que o esperado. A média obtida na primeira avaliação foi igual a 58. Com participação no projeto, a média dos alunos aumentou para 84, o que corresponde a um aumento de $44,83 \%$. Na pesquisa de avaliação realizada com os alunos, ficou evidente que a prática contribuiu para melhorar a compreensão dos temas estudados.

Além da melhoria do desempenho acadêmico, houve um aumento da participação dos estudantes em grupos de estudo, e uma postura mais ativa sobre o gosto pelo estudo de Engenharia econômica.

\section{CONCLUSÕES}

No ensino a distância, um dos grandes objetivos é fazer com que os alunos sintam que pertencem ao sistema de gerenciamento do ambiente educacional e que os tópicos abordados, bem como a forma como esses assuntos são oferecidos, estão próximos da sua realidade. Também é importante encorajar os alunos a buscar constantemente conhecimentos e aplicações práticas em outras áreas e em situações cotidianas. Muitas vezes, os exemplos apresentados em uma disciplina diferem da realidade dos alunos. Isso não é ruim, mas quando as aplicações estão mais próximas do contexto em que os alunos estão inseridos tem-se um melhor resultado. 
No caso da disciplina Ciência da Computação, foi identificado que inicialmente os alunos não estavam realmente envolvidos com os tópicos abordados A compreensão de conceitos relacionados a variáveis, estruturas de repetição e, sobretudo, a importância da aquisição de conhecimento relacionado à programação de computadores não foi efetiva. Criar os aplicativos e disponibilizar esses aplicativos ao público foi importante na percepção dos estudantes de que a programação de computadores pode ser útil, não só para seu próprio benefício, mas também pode ajudar os outros a resolver seus problemas.

Depois de analisar os comentários postados pelos usuários dos aplicativos produzidos, foi

\section{REFERÊNCIAS}

[1]. BEHAR, PA (2009). Modelos pedagógicos em educação a distância. Porto Alegre: Artmed

[2]. BITTAR, M (2011). A abordagem instrumental para o estudo da integração da tecnologia na prática pedagógica do professor de matemática. Educar em Revista, $1,157-171$

[3]. FREIRE, P (2002) Pedagogia da autonomia: saberes necessários à prática educativa. São Paulo: Paz e Terra

[4]. JAEGER, EL (2013) Teacher reflection: Supports, barriers, and results. Issues in Teacher Education, 22(1), 89-104

[5]. MURPHY, D, WALKER, R, WEBB, G (EDS.). (2013). Online learning and teaching with technology: case studies, experience and practice. Routledge

[6]. NEWNAN, DG, ESCHENBACH, TG, LAVELLE, JP (2004). Engineering economic analysis. (9th ed.). Oxford university Press, New York possível identificar a satisfação e gratidão desses usuários. Quanto aos alunos, a melhora no desempenho em relação ao assunto da ciência da computação foi bastante significativa. As notas obtidas nas avaliações aumentaram 44,83\%.

Analisando as publicações dos alunos e as respostas dadas no questionário periódico de avaliação institucional, também foi identificado um aumento na satisfação com a forma como o projeto foi desenvolvido. Claro, quando se trata de programação de computadores, há muito a ser estudado. No assunto da Ciência da Computação, os tópicos abordados correspondem a uma pequena parte de um grande universo de conhecimentos e possibilidades.

[7]. PARK, CS (2004) Fundamentals of engineering economics. Pearson, New Jersey

[8]. SCHELL, GP, JANICKI, TJ (2013) Online course pedagogy and the constructivist learning model. Journal of the Southern Association for Information Systems, 1(1), 26-36

[9]. SCHILDT, $\mathrm{H}$ (2003) C++: The complete reference. (4th ed.). McGraw-Hill, New York

[10]. SEBESTA, RW (2012) Concepts of programming languages. (10th ed.). Pearson, New Jersey

[11]. STROUSTRUP, B (2013) The C++ programming language. (4th ed.). AddisonWesley, New Jersey

[12]. TORI, R (2010) Educação sem distância: as tecnologias interativas na redução de distâncias em ensino e aprendizagem. São Paulo: Senac. 


\section{Gapítulo 16}

\section{MAPEAMENTO DE FLUXO DE VALOR: UM ESTUDO DE CASO EM UMA EMPRESA DE FERRAMENTARIA}

\section{Glauco Medeiros Borges \\ Fernanda Kempner-Moreira \\ Edson Manfioletti Gomes \\ Felipe Vicentin Moises}

Resumo: O mapeamento de fluxo de valor é uma das ferramentas da produção enxuta que permite analisar os processos e identificar melhorias a serem implantadas, de forma a agregar valor às organizações. Este artigo tem como objetivo analisar o processo de fabricação de uma indústria de produção de matriz para extrusão de alumínio localizada no sul de Santa Catarina, por meio do mapeamento do fluxo de valor, identificando as contribuições da ferramenta ao processo industrial. Trata-se de um estudo de caso, fundamentado em pesquisa bibliográfica. O mapeamento de fluxo de valor futuro indicou que pequenas mudanças e um investimento relativamente baixo solucionariam os problemas identificados, como redução do lead time de produção, diminuição da ociosidade dos operadores e redução dos custos com terceirização e transportes. Outros valores podem ser agregados, como novas oportunidades de negócio, o que elevaria a competitividade sustentável.

Palavras-chave: Produção Enxuta. Mapeamento de Fluxo de Valor. Eficiência Produtiva. 


\section{INTRODUÇÃO}

O aumento da competitividade industrial tem obrigado as organizações a buscarem meios de garantir a efetividade de seus processos como forma de manter-se no mercado de maneira sustentável. Produtos e processos são constantemente revisitados para verificar possibilidades de melhoria como meio de alavancar a qualidade, reduzir custos, assimilar novas tecnologias e inovar.

Os processos produtivos têm especial impacto neste desafio, e o sistema de produção lean tem contribuído para melhorar processos e alavancar a competitividade por meio de reestruturações e diferenciações. Como filosofia de produção, introduz práticas e ferramentas que levam as organizações a produzir mais com menos, identificando pontos de melhoria e inovação incremental. Uma das ferramentas utilizadas é o Mapeamento do Fluxo de Valor (VSM), que permite identificar desperdícios e melhorar o processo por meio dos fluxos que agregam valor (ROTHER, SHOOK, 2003).

O Mapeamento do Fluxo de Valor permite que as organizações analisem seus processos e identifiquem melhorias a serem implantadas, sempre com intuito de aumentar a produtividade e atender aos clientes de maneira mais efetiva e personalizada. Essas contribuições do VSM são relevantes especialmente no contexto de competitividade que se impõe para as indústrias de modo geral. Sendo assim, questiona-se: quais contribuições $\mathrm{O}$ Mapeamento do Fluxo de Valor pode agregar a uma organização industrial?

Como forma de responder a esta questão de pesquisa este artigo tem como objetivo analisar o processo de fabricação de uma indústria de produção de matriz para extrusão de alumínio localizada no sul de Santa Catarina por meio do mapeamento do fluxo de valor, identificando as contribuições da ferramenta ao processo industrial. Este estudo justifica-se pelas contribuições geradas para a organização, que poderá apropriar-se delas para alavancar seus negócios e gerar maior produtividade e efetividade.

O artigo é apresentado com a seguinte estrutura: (1) Introdução, onde são apresentados a contextualização, a pergunta e o objetivo do artigo e a justificativa para sua construção; (2) Fundamentação Teórica, resgatando os conceitos pertinentes ao
Mapeamento do Fluxo de Valor; (3) Metodologia da Pesquisa, onde se apresenta os procedimentos metodológicos utilizados no estudo; (4) Caracterização da Empresa objeto de estudo; (5) Apresentação dos Dados com o Mapeamento do Fluxo de Valor Atual; (6) Análises e Discussões, apresentando o Mapeamento do Fluxo de Valor Futuro e as sugestões de melhoria; (7) Considerações Finais.

\section{FUNDAMENTAÇÃO TEÓRICA}

O Sistema Toyota de Produção (STP) foi desenvolvido com objetivo de garantir que a produção atenda os clientes no menor tempo possível, com a maior qualidade percebida e com o menor custo possível (OHNO, 1988). O STP deu origem à filosofia Lean de produção, ou produção enxuta, cujos conceitos e técnicas têm sido incorporados pelas indústrias para redução de desperdícios no fluxo de valor, melhoria da produtividade e aumento do valor criado para os clientes (SRIPARAVASTU, GUPTA, 1991 apud GAMBI, 2011), acreditando-se que estes elementos incrementam a competitividade sustentável.

Womack e Jones (2004) elevam a produção enxuta para o conceito de pensamento enxuto, sustentando que deve ser incorporado por toda a empresa, não somente pelo setor produtivo. Essa ampliação de escopo deve-se ao fato de que a produção enxuta é um modelo estratégico e integrado de gestão que auxilia a organização a alcançar seus objetivos ao elevar o desempenho da qualidade e da produtividade (GODINHO FILHO, FERNANDES, 2004), por meio de cinco princípios básicos (WOMACK, JONES, 2004):

(a) Especificar Valor: definir o que gera valor sob a perspectiva do cliente;

(b) Identificar o Fluxo de Valor: identificar todas as ações necessárias e eliminar os desperdícios no processo produtivo;

(c) Fluxo Contínuo: criar um fluxo contínuo sem interrupções ou esperas;

(d) Produção Puxada: produzir de acordo com a demanda do cliente final;

(e) Busca da Perfeição: aplicar a melhoria contínua em produtos e processos.

Trata-se de uma forma de especificar valor, alinhando os processos organizacionais na melhor sequência, de forma que sejam 
realizados em fluxo (sem interrupção) e de forma cada vez mais eficaz (WOMACK, JONES, 2004). A essência é aproximar-se dos clientes, de forma a oferecer-lhes o que realmente desejam, respeitando-se o conceito de realizar mais com menos. Significa "localizar e eliminar os desperdícios, sendo eles tudo o que não agrega valor ao cliente" (SALGADO et al, 2009, p. 347). No setor produtivo esse pensamento enxuto assume 0 nome de produção lean (ou produção enxuta).

Uma das ferramentas base para garantir o fluxo produtivo neste tipo de produção é o Kanban, um mecanismo de gerenciamento visual de ordens de produção, de estoque e movimentação ao longo do fluxo produtivo, por meio de cartões físicos ou virtuais (COSTA, 2012). Voltado para a rapidez do processo, o Kanban não faz controle de qualidade, devendo ser simples para o propósito de ajustar o processo produtivo (MARÇOLA, TONETTO, ANDRADE, 2009).

A produção lean tem entre suas práticas gerenciais o Just in Time (JIT), o Sistema de Qualidade Total (TQM) e o Mapeamento de Fluxo de Valor (VSM) (GAMBI, 2011). Esta última possibilita à organização enxergar e entender os fluxos do processo produtivo, seja de material ou informação, criando um fluxo de valor necessário para o processo produtivo (ROTHER, SHOOK, 2003).

O mapeamento do fluxo de valor permite reavaliações constantes do processo atual, o que garante dinamismo e melhorias no estado futuro, ou seja, um mapa futuro com o estado ideal do sistema de produção (CHEN, LI, SHADY, 2010). Não é um simples mapeamento do processo, pois se preocupa em planejar e atender as demandas dos clientes, resultando em ações que garantam a efetividade do processo (WILSON, 2010).

Esse mapeamento inicia-se pela definição da família de produtos, seguida pela observação no chão de fábrica de todo o fluxo de valor (atividades que agregam e não agregam valor), que gera o mapa do estado atual. Ao desenhar 0 estado atual e identificar oportunidades de melhoria, um novo desenho com o estado futuro deve ser elaborado (GAMBI, 2011).

Para Milard (2001 apud SALGADO et al, 2009) o mapeamento de fluxo de valor deve seguir o seguinte esquema: (a) treinar a equipe no mapeamento do fluxo de valor; (b) selecionar o fluxo de valor a ser melhorado; (c) definir os elementos do fluxo de valor; (d) analisar e mapear o estado atual; (e) analisar um mapa futuro; (f) implementar novos processos; (g) melhorar continuamente.

Algumas métricas são utilizadas para a melhoria do desempenho no mapeamento de fluxo de valor. Entre elas está o lead time, que é o tempo entre o pedido e o recebimento do mesmo, ou entre uma ordem e sua execução. Longos prazos de lead time geram desvantagens competitivas para as organizações (OHNO, 1988; TREVILLE, SHAPIRO, HAMERI, 2004).

Outras métricas referem-se ao tempo de processamento, ou seja, o tempo efetivamente gasto desde que se inicia o processo de produção até que ele termine (MOREIRA, 2011) e o takt time, ou ritmo de produção, que reflete o tempo de trabalho disponível pela demanda do cliente, ou seja, o tempo em que deve ser produzido um produto para atender a demanda (LUCRESIA JR., CARDOSO, CHAVES, 2006).

\section{METODOLOGIA DA PESQUISA}

$\mathrm{Na}$ construção deste artigo foi utilizada a pesquisa bibliográfica para o levantamento do referencial teórico sobre o tema. A pesquisa bibliográfica possibilita a análise do conteúdo, esclarecendo conceitos por meio de uma nova perspectiva (MARCONI, LAKATOS, 2003).

Como método de pesquisa foi utilizado o estudo de caso, considerado o mais indicado para a pesquisa de fenômenos contemporâneos dentro de seu contexto real, porque explora fatos por várias perspectivas. "O estudo de caso permite uma investigação para se preservar as características holísticas e significativas dos eventos da vida real, tais como, processos organizacionais e administrativos" (YIN, 2001, p. 21).

Ao pretender observar o contexto, a coleta de dados ocorre no ambiente natural, por meio de múltiplas fontes (TRIVIÑOS, 1987). Durante o mês de abril de 2017 foram realizadas visitas in loco para conhecer e analisar o processo por meio de observação participativa. Também foram realizadas entrevistas com o diretor geral da organização, Sr. Giovani Guarezi, que complementaram as informações coletadas. 
A análise dos dados seguiu o esquema proposto por Gambi (2011), partindo-se das atividades que agregam e não agregam valor para gerar o mapa do estado atual. Ao avaliar o estado atual do processo identificou-se oportunidades de melhoria, que geraram um novo desenho do estado futuro.

\section{CARACTERIZAÇÃO DA EMPRESA}

A Fiosul Ferramentaria é uma empresa de pequeno porte, localizada na cidade de Tubarão - Santa Catarina, especializada em matrizes para extrusão de perfis de alumínio sob encomenda. Iniciou em 2010 prestando serviços de manutenção e correção de matrizes, introduzindo a produção de matrizes sólidas em 2013 e, mais recentemente, também matrizes tubulares. Conta com três colaboradores gerenciados pelo proprietário, Sr. Giovani Guarezi.

Essa ampliação do processo produtivo demandou investimento em maquinário e tecnologia, além do rearranjo do processo produtivo. Atualmente o carro chefe é a produção de matrizes de extrusão sob encomenda, mas ainda presta serviços de manutenção. Como a produção é por encomenda, o processo produtivo precisa estar bem ajustado para garantir matrizes com vida útil elevada e adequados às necessidades dos clientes, entre os quais encontram-se empresas como Alump, Aluxa, Arconi (novo nome da Alcoa), Esaf e Perfisud.

A empresa conta basicamente com três processos de fabricação interna e três processos de fabricação externa (terceirizados). Os equipamentos/etapas utilizados no processo de fabricação interna são: Torno Mecânico, Fresa CNC e Acabamento Manual. Já os equipamentos/etapas utilizados no processo externo são: Têmpera a Vácuo, Retífica Horizontal, Eletroerosão a fio.

\section{APRESENTAÇÃO DOS DADOS}

Os grandes problemas encontrados na empresa foram o lead time longo para cada peça, os altos custos com terceirização, custos e riscos com transportes, ociosidade dos operadores. Considerando que boa parte do serviço é terceirizado e o período de tempo é considerado longo, pois é feito na cidade de Joinville - Santa Catarina, cerca de
300 km de distância da cidade de origem, Tubarão.

Com base nessa necessidade, foi efetuado um Mapeamento de Fluxo de Valor. Neste mapeamento foi descrito todo o processo de produção de um lote de peças desde o pedido até a entrega dos produtos ao cliente. Vale ressaltar que a Fiosul efetua a fabricação de lotes exclusivos para cada cliente, ou seja, são produzidos lotes de peças específicos.

O processo de fabricação das matrizes inicia com o pedido do cliente, o que gera o start na produção. Em seguida, o Planejamento e Controle da Produção (PCP) informa aos departamentos/setores sobre o início do novo lote de peças, detalhando a quantidade e o prazo de entrega solicitados pelo cliente. Concomitantemente, o PCP faz o pedido da matéria-prima para o fornecedor Aços São Paulo, cujo lead time de chegada ao parque fabril da Fiosul é de seis dias. Esse lead time requer que a empresa deixe um estoque mínimo para a segurança do processo produtivo, entretanto esse controle não é efetivo.

Após a chegada da matéria-prima, o primeiro passo é proceder à modelagem da peça no Torno Mecânico. Esse processo possui um tempo de ciclo de 02h30, gerando estoque intermediário, que fica esperando para entrar para ser processado no próximo equipamento (Fresa). O estoque gerado pelo Torno Mecânico é ocasionado pelo tempo de ciclo do próximo equipamento da linha de produção, a Fresa CNC, que requer 04h00 para processamento. Ambos os equipamentos fazem parte do processo interno da empresa.

Após os processos do Torno Mecânico e da Fresa CNC a produção inicia as etapas externas do processo (terceirizadas). As peças são enviadas via transportadora, por meio do modal rodoviário, para a cidade de Joinville - SC, cerca de $300 \mathrm{~km}$ da Fiosul. O lead time de transporte desde a retirada pela transportadora até o retorno das peças é de dois dias. Na empresa prestadora do serviço as peças passam por três processos: Têmpera a Vácuo, Retífica Horizontal, Eletroerosão a fio. O lead time para a execução desses três processos totalizam cinco dias, o que soma um lead time total de sete dias.

Quando as peças retornam ao parque fabril da Fiosul, chegam praticamente prontas, 
devendo passar pelo último processo interno: o Acabamento Manual. Esse processo dura cerca de 03h00, e é realizado minuciosamente por um operador que verifica todos os acabamentos necessários e a qualidade esperada da peça. Por fim a peça acabada é enviada para a expedição para seguir ao destino final, o cliente.

Figura 1 - Fluxograma do Processo Produtivo
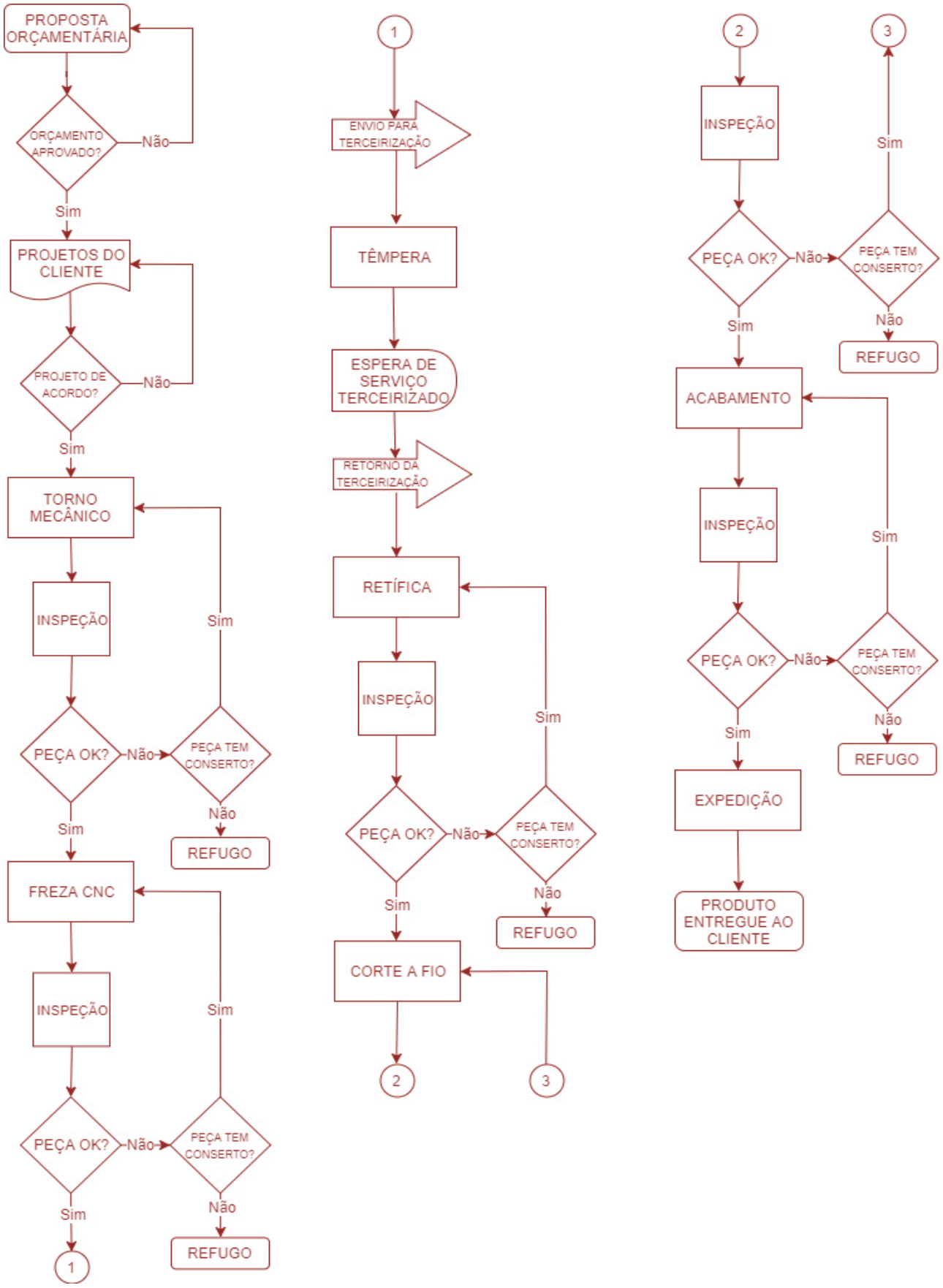

Fonte: os autores (2017).

As peças de refugo não conseguem ser reaproveitadas, sendo sucateadas. Após desenhar o fluxograma do processo produtivo procedeu-se o Mapeamento de Fluxo de
Valor. Seguindo as etapas estabelecidas por Milard (2001 apud SALGADO et al, 2009), a equipe responsável pelo mapeamento foi treinada e, com o fluxo selecionado, definiu-se 
os elementos do fluxo de valor, realizando a análise e o desenho do mapa do estado atual.

\section{ANÁLISES E DISCUSSÕES}

Com base no Mapeamento de Fluxo de Valor Atual, foi realizado um brainstorming entre os envolvidos para encontrar possíveis soluções. O desenho do Mapeamento de Fluxo de Valor Atual é apresentado na figura 2.

Figura 2 - Mapeamento de Fluxo de Valor Atual

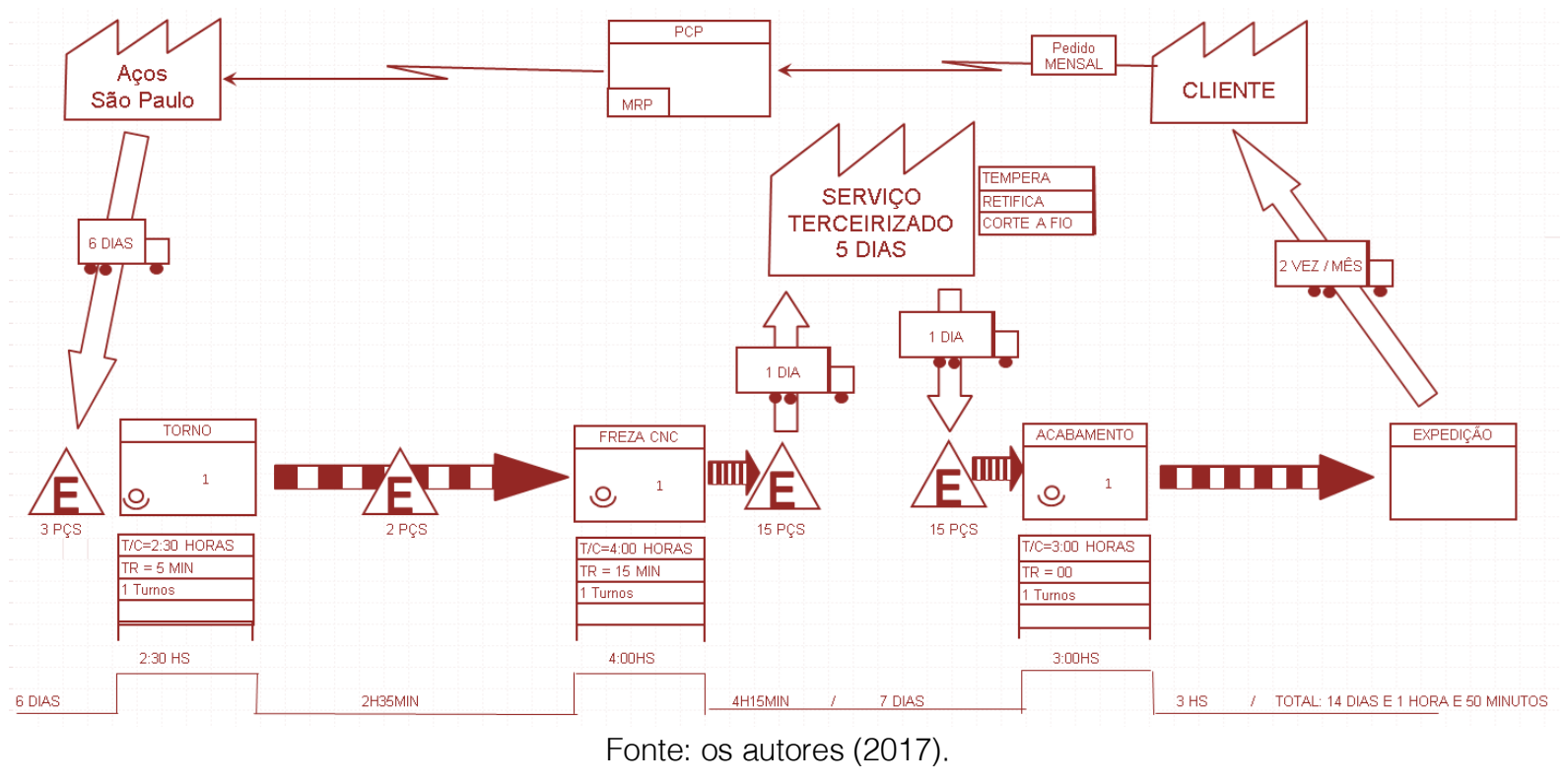

Constatou-se que é essencial para o processo a colocação de cartões Kanban para controle dos fluxos de produção. Esses cartões Kanban devem ser aplicados em cada etapa do processo, transformando um sistema empurrado em um sistema puxado, ordenando os estoques e gerenciando os chamados estoques pulmão, onde deverá haver um controle sobre a quantidade que deve ficar em cada ponto onde antes havia estoques descontrolados.

Sugere-se a aquisição de dois equipamentos para compor a linha, fazendo com que a empresa passe a ter cinco processos internos e apenas um processo externo (a Têmpera a Vácuo), que ainda se manterá terceirizado por se tratar de um trabalho muito específico de tratamento térmico que requer um profissional altamente qualificado para fazê-lo, o que justifica a terceirização como forma de minimizar os riscos envolvidos.

Entretanto, identificou-se uma empresa localizada a $50 \mathrm{~km}$ de distância do parque fabril da Fiosul que também executa 0 processo de Têmpera a Vácuo, com os mesmos índices de qualidade. A mudança de fornecimento deste processo reduzirá o lead time total de terceirização, que atualmente é de sete dias, para aproximadamente 1,5 dias.

Com essas alterações espera-se alcançar as seguintes melhorias no processo: redução de lead time para cada peça na linha de produção, redução de tempo e risco de transporte, redução do tempo e alto custo de serviço prestado por terceiros, aumento da eficiência produtiva da empresa, redução do tempo de ociosidade dos operadores.

No fluxo proposto à empresa, o conceito inicial do processo mantém-se o mesmo. O processo inicia-se como pedido do cliente, que posteriormente passa ao PCP que dá sequência ao restante do processo. Uma das melhorias impostas ao atual fluxo é a colocação de cartões Kanban em cada etapa do processo, forçando o sistema a tornar-se um sistema puxado, contrário ao sistema atual que é empurrado. Com os cartões Kanban os estoques passarão a ser pilhas pulmões. 
Figura 3 - Mapeamento de Fluxo de Valor Futuro

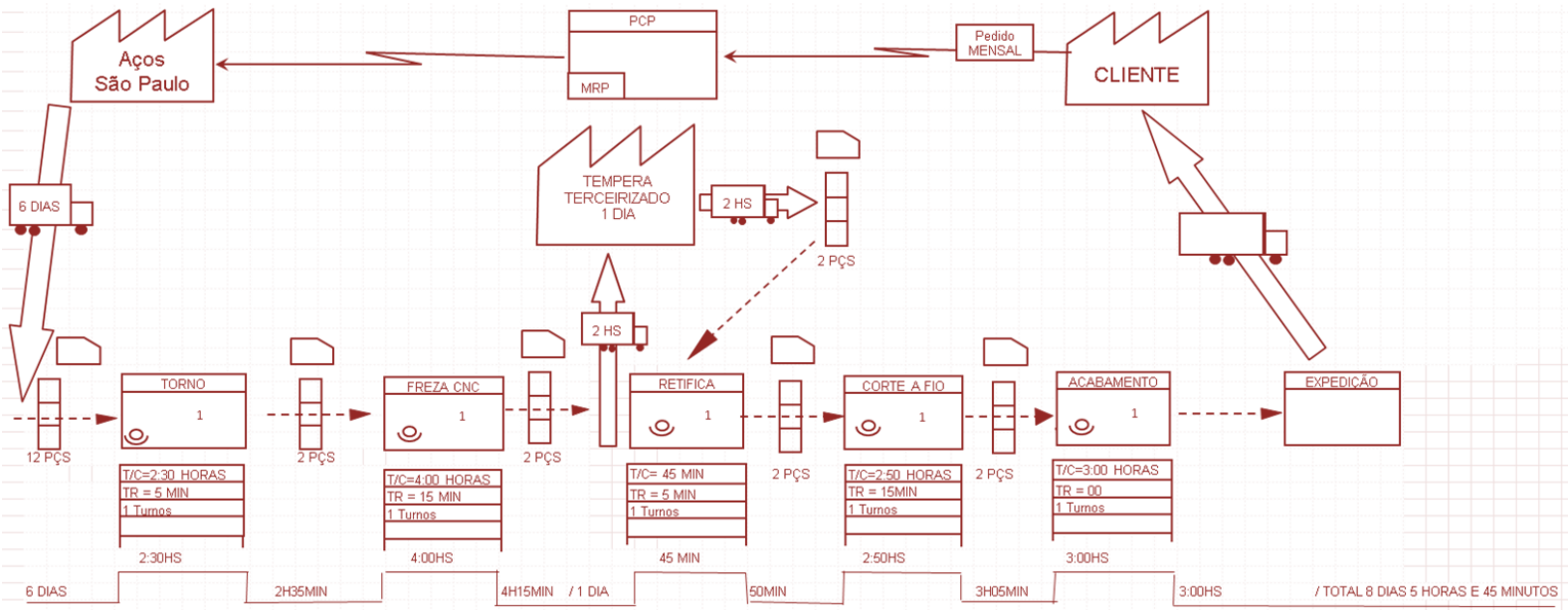

Fonte: os autores (2017).

No sistema proposto, apenas uma etapa do processo permaneceu terceirizada, a Têmpera a Vácuo, com alteração de fornecedor para reduzir o lead time, já que o fornecedor proposto se encontra a $50 \mathrm{~km}$ do parque fabril e mantém o atual padrão de qualidade, reduzindo o tempo total de terceirização que antes era de sete dias para aproximadamente 1,5 dia.

Quadro 1 - Dados do Processo

\begin{tabular}{|c|c|c|}
\hline & Dados do Processo Atual & Dados do Processo Futuro \\
\hline Tempo de trabalho diário & 480 minutos & 480 minutos \\
\hline Número de Operadores & 3 & 3 \\
\hline Lead Time para 1 peça & 14 dias, 1 hora e 50 minutos & 8 dias, 5 horas e 45 minutos \\
\hline Tempo de processamento total & 9 horas e 30 minutos & 13 horas e 05 minutos \\
\hline Número de peças por mês & 30 peças & 30 peças \\
\hline Jornada de trabalho mensal & 22 dias & 1,36 peças/dias \\
\hline Takt Time & 1,36 peças/dia & 0,45 peças/operador \\
\hline Produtividade & 0,45 peças/operador & $74,14 \%$ \\
\hline Eficiência & $53,83 \%$ & \\
\hline
\end{tabular}

Fonte: Os autores (2017).

Apesar do aumento de dois postos de trabalhos, foi detectado que no processo atual há ociosidade em algumas etapas, o que permite um rearranjo e a manutenção do número de colaboradores (3). Com esse novo fluxo a eficiência produtiva aumentará de $53,83 \%$ para $74,14 \%$, o que reflete em ganhos financeiros e competitivos para a organização.

Analisando os gastos mensais da empresa com Eletroerosão a Fio e Retífica Horizontal, constatou-se que, além dos tempos de transporte e processamento externo, o gasto com a terceirização destes processos é elevado. São gastos com a Eletroerosão cerca de $R \$ 9.000,00$ por mês, considerando-se o valor de $R \$ 300,00$ por peça $\times 30$ peças/mês.

O investimento em um equipamento seminovo e em boas condições de uso gira em torno de $\mathrm{R} \$ 125.000,00$, o que representa um payback inferior a 16 meses. Na mesma linha de raciocínio, os gastos mensais com Retífica Horizontal chegam a $\mathrm{R} \$ 3.000,00$ por mês, considerando-se o valor de $\mathrm{R} \$ 100,00$ por 
peça $\times 30$ peças/mês. Um equipamento seminovo e em boas condições de uso requer um investimento em torno de $\mathrm{R} \$ 30.000,00$, representando um payback inferior a 11 meses, o que justifica a aquisição destes equipamentos.

Além da análise do payback outros elementos corroboram para esta decisão, que impacta em outro problema detectado no mapeamento: a ociosidade dos operadores. Conquistas como a redução do lead time e da dependência de terceiros devem ser somadas à possibilidade de abertura de novas oportunidades de negócios ao oferecer estes serviços para outras empresas.

\section{CONSIDERAÇÕES FINAIS}

O Mapeamento de Fluxo de Valor proporciona às organizações uma amplitude de visão muitas vezes não observada no cotidiano dos processos. Ao analisar o processo de maneira mais específica e com olhar crítico é possível analisar pontos importantes e outros que podem ser melhorados, às vezes com poucas mudanças e inovações incrementais.

Este artigo se propôs a analisar o processo de fabricação de uma indústria de produção de matriz para extrusão de alumínio localizada no sul de Santa Catarina por meio do mapeamento do fluxo de valor, identificando as contribuições da ferramenta ao processo industrial. O Mapeamento do Fluxo de Valor Futuro indicou que pequenas mudanças e um

\section{REFERÊNCIAS}

[1]. CHEN, J.C.; LI, Y. SHADY, B.D. From value stream mapping toward a lean/sigma continuous improvement process: an industrial case study. International Journal of Production Research, London, v.48, n.4, p. 1069-1086, 2010.

[2]. COSTA, E. L. J. Gestão em processos produtivos. 1.ed. Curitiba: Intersaberes, 2012.

[3]. GAMBI, L. N. Recomendações para a implantação de conceitos e técnicas de produção enxuta em empresas, fabricantes de produtos sob encomenda, do aglomerado industrial de Sertãozinho. 155 f. Dissertação (Mestrado) - Escola de Engenharia de São Carlos, Universidade de São Paulo, São Carlos, 2011. investimento relativamente baixo em novos equipamentos para incorporar processos atualmente terceirizados proporcionarão mudanças significativas como a redução de lead time para cada peça na linha de produção, redução de tempo e risco de transporte, redução do tempo e custo do serviço prestado por terceiros, aumento da eficiência produtiva da empresa e redução do tempo de ociosidade dos operadores. Ao aumentar a eficiência produtiva à empresa poderá solucionar seus diversos problemas.

Além disso, abre-se a possibilidade de novos negócios com a incorporação de processos produtivos de Eletroerosão a Fio e Retífica Horizontal, pois a empresa poderá oferecer esses serviços para outras organizações. Essas mudanças impactam positivamente a organização por meio de inovação incremental que alavancará e agregará valor aos processos produtivos.

Essas melhorias advindas do Mapeamento do Fluxo de Valor correspondem aos resultados esperados pela produção lean, elevando os níveis de produção, diminuindo os erros, eliminando os desperdícios e as falhas no processo. Entende-se que esse mapeamento deva ser revisto periodicamente, de forma a adaptar o processo produtivo para novas estratégias organizacionais. Também é relevante a adoção do pensamento enxuto, ampliando a filosofia Lean para outros setores da organização como forma de buscar melhoria contínua e manutenção da competitividade sustentável.

[4]. GODINHO FILHO, M.; FERNANDES, F.C.F. Manufatura Enxuta: uma revisão que classifica e analisa os trabalhos apontando perspectivas de pesquisas futuras. Gest. Prod., São Carlos, v. 11, n. 1, p. 1-19, abr. 2004.

[5]. LUCRESIA JR., J.; CARDOSO, A.A.; CHAVES, C.A. Manufatura enxuta aplicada em área de montagem de peças automotivas. XIII Simpósio de Engenharia de Produção - SIMPEP. Bauru, SP, Brasil, 2006.

[6]. MARCONI, M.A.; LAKATOS, E.M. Fundamentos de metodologia científica. 5.ed. São Paulo: Atlas, 2003.

[7]. MARÇOLA, J. A; TONETTO, J. A; ANDRADE, J. H. Relato da implementação de um 
sistema Kanban em uma empresa fabricante de utensílios domésticos de alumínio. XXIX Encontro Nacional de Engenharia de Produção - ENEGEP. Salvador, BA, Brasil, 2009.

[8]. MOREIRA, Daniel Augusto. Administração da produção e operações. 2. ed. São Paulo: Cengage Learning, 2011.

[9]. OHNO, T. Toyota production system: beyond large-scale production. Portland: Productivity, 1988.

[10]. ROTHER, M.; SHOOK, J. Aprendendo a enxergar: mapeando o fluxo de valor para agregar valor e eliminar o desperdício. São Paulo: Lean Institute Brasil, 2003.

[11]. SALGADO, E.G. et al. Análise da aplicação do mapeamento do fluxo de valor na identificação de desperdícios do processo de desenvolvimento de produtos. Gest. Prod., São Carlos, v. 16, n.3, p. 344-356, Set. 2009.
[12]. TREVILLE, S.; SHAPIRO, R.D.; HAMERI, A$P$. From supply chain to demand chain: the role of lead time reduction in improving demand chain performance. Journal of Operations Management, v. 21, n. 6, p. 613-627, jan. 2004.

[13]. TRIVIÑOS, A.N.S. Introdução à pesquisa em ciências sociais: a pesquisa qualitativa em educação. São Paulo: Atlas, 1987.

[14]. WILSON, L. How to Implement Lean Manufacturing. McGraw Hill: United States of America, 2010.

[15]. WOMACK, J.P.; JONES, D.T. A mentalidade enxuta nas empresas: elimine o desperdício e crie riqueza. 4.ed. Rio de Janeiro: Elsevier, 2004.

[16]. YIN, R.K. Estudo de caso: planejamento e métodos. 2.ed. Porto Alegre: Bookman, 2001. 


\section{Capítulo 17}

\section{APLICACÃO COMBINADA DE MAPA DE FLUXO DE VALOR E SIMULAÇ̃O DE EVENTOS DISCRETOS NA MELHORIA DE LINHA PRODUTIVA}

\section{Gabriel Cardinali}

Emerson José de Paiva

Márcio Dimas Ramos

Carlos Henrique Oliveira

\section{Tarcísio Gonçalves de Brito}

Resumo: No atual cenário econômico, é imperativo satisfazer as exigências de qualidade impostas pelos clientes, tanto quanto a produtos, quanto a serviços. Para as organizações, tais exigências podem ser satisfeitas, se essas se atentarem à melhoriia da qualidade de seus processos produtivos. Na busca por essa melhoria, têm-se buscado implementar métodos e ferramentas de comprovada eficácia científica. Dentre estes, destacam-se o Mapa de Fluxo de Valor (VSM), uma das ferramentas da filosofia Lean, e a Simulação de Eventos Discretos (SED). Neste estudo, propõe-se uma abordagem híbrida dessas duas ferramentas, uma complementando a outra. O VSM aplicado, incialmente, na identificação de gargalos, falhas e desperdícios; e, em segundo estágio, na proposição de uma situação futura; e a SED para se obter uma previsão do comportamento futuro do sistema. Os resultados dessa combinação apontam para uma boa adequação da proposta, e um relevante incremento das taxas de produção. 


\section{INTRODUÇÃO}

Atender à qualidade exigida pelos seus clientes, tanto quanto a produtos, quanto a serviços, é fundamental para sustentabilidade das organizações, frente ao mercado consumidor. Mais, manter essa qualidade pode ser um diferencial competitivo em relação à concorrência. A manutenção dessas vantagens competitivas instiga pesquisadores, engenheiros e gestores a buscar e desenvolver novas tecnologias e métodos, implementar ações corretivas e preventivas, investir em treinamento e, por fim, adotar ferramentas de qualidade para um melhor controle dos processos.

Dentre as diversas ferramentas disponíveis atualmente, destacam-se, aqui, o Mapeamento do Fluxo de Valor e a Simulação de Eventos Discretos. O presente trabalho pretende utilizar uma abordagem híbrida dessas duas ferramentas.

O Mapa de Fluxo de Valor, ou VSM (Value Stream Map), é uma das ferramentas disponíveis na chamada "Filosofia Lean", sendo utilizada para o mapeamento do estado atual, com vistas a identificar gargalos, lead time e tempo de processamento real. A partir dela, é possível propor um mapa de fluxo futuro, visando o balanceamento da linha produtiva, eliminando tais gargalos e, consequentemente, reduzindo o lead time.

A Simulação de Eventos Discretos (SED), por sua vez, é uma ferramenta utilizada para se avaliar os processos, novos ou não, sem a necessidade de se intervir imediatamente neste, aqui empregada para se comparar a situação atual com a proposta pelo mapa de fluxo de valor futuro.

O presente estudo teve por pretensão construir os Mapas de Fluxo de Valor, atual e futuro, desenvolvendo-se, em seguida, cenários de simulação computacional que pudessem fornecer uma visão geral de como o processo estava se comportando e como se comportaria, se modificações fossem implementadas. O estudo foi conduzido a partir da coleta de dados e modelagem do processo de produção de uma indústria de pedras ornamentais.

\section{REFERENCIAL TEÓRICO}

\subsection{FILOSOFIA LEAN}

Embora esta filosofia tenha sua origem nas empresas de manufatura, o Lean, atualmente, também tem sido aplicado, de acordo com Olesen et al. (2015), a outros setores como cuidados na saúde, serviços públicos, desenvolvimento de produto, construções, serviços de pós venda e em serviços, foco do presente trabalho.

De acordo com Womack et al. (1990), o ponto crucial da filosofia Lean é a redução de tudo que se faz necessário para a produção, como esforço humano na fábrica, espaço de produção, investimento em ferramentas, engenharia de horas de trabalho, tempo dispendido para desenvolvimento de produto, procurando manter níveis de estoque adequados, reduzir defeitos e custos, otimizar o fluxo produtivo e desenvolver a melhoria contínua. Em complemento, Liker (2003) diz que o objetivo principal do Lean Manufacturing é a produção de bens acabados, com a qualidade exigida pelo cliente e com o mínimo desperdício.

Taj e Berro (2006) caracterizam desperdício como toda atividade realizada para a produção que não agrega valor ao produto acabado. Ohno (1988) classifica desperdício em sete categorias, a saber: a) excesso de produção; b) espera; c) transporte; d) processamento desnecessário; e) estoque em excesso; f) movimentos desnecessários; e g) defeitos.

Tais desperdícios podem ser mitigados ou elimitados, com a aplicação de ferramentas da Filosofia Lean, destacando-se, aqui, o Mapa de Fluxo de Valor.

\subsection{MAPA DE FLUXO DE VALOR (VSM)}

De acordo com Belokar (2012) o propósito do VSM é identificar e destacar, durante o desenvolvimento do VSM presente, fontes de desperdícios na linha produtiva, que serão eliminados na implantação do mapa de estado futuro. O VSM auxilia no desenvolvimento de um fluxo contínuo ou puxado da linha produtiva, de modo a conectar o cliente a cada processo, individualmente, limitando a produção somente quanto ao pedido e ao prazo.

$\mathrm{Na}$ construção do VSM, além de se identificar cada processo, cliente, fornecedor e o fluxo de informação entre eles, é necessário também que se identifiquem certas características exclusivas de cada setor produtivo como tempo de ciclo, tempo de troca ou reparo, quantidade de turnos, quantidade de operadores, além de peças 
estocadas entre os processos e, se possível, se o processo é dedicado (o que possibilita a instalação de um fluxo contínuo) ou não a uma família de produtos. Destas informações, as principais são tempo de ciclo, tempo de troca ou reparo e peças estocadas, utilizadas para determinar o tempo de processamento, porcentagem de agregação de valor do processo e o lead time.

Andrade (2015) determina o tempo de processamento como a soma do tempo de ciclo de todas as operações do processo produtivo, excluindo os tempos que não agregam valor (tempo de troca ou reparo). O cálculo do lead time, de acordo com a teoria do VSM, é a soma do tempo de processamento com os tempos de estoques intermediários. Estes tempos são calculados pela multiplicação do takt time do processo (que é a divisão entre o tempo de trabalho disponível para produção e a demanda desejada) pelo número de peças de cada estoque intermediário.

\subsection{SIMULAÇÃO DE EVENTOS DISCRETOS (SED)}

O desenvolvimento de projetos de simulação deve ser conduzido a partir de modelos de referência para o planejamento das atividades, modelagem dos sistemas em softwares especializados e análise dos resultados a partir de ferramentas ou técnicas estatísticas adequadas.

Neste trabalho, julgando-se tratar de um modelo de referência já bastante difundido, principalmente na área acadêmica, adotou-se o modelo adaptado por Chwif e Medina (2010), o qual divide o processo de simulação em três macrofases, a saber: concepção, responsável pelo planejamento, definição dos objetivos, construção do modelo conceitual e tratamento de dados de entrada; implementação, onde um modelo conceitual gerado na fase anterior, devidamente verificado e validado, é convertido em códigos, resultando num modelo computacional, o qual deverá, em seguida, ser também verificado e validado; por fim, a análise é a macro fase responsável pelas inferências possíveis a partir das respostas produzidas pelo modelo computacional gerado e executado.

De acordo com Chwif e Medina (2010), a simulação é uma ferramenta que facilita a tomada de decisão não somente de analistas, mas também de gerentes e pessoas ligadas diretamente ao desenvolvimento da operação, de maneira a fornecer uma melhor compreensão sobre os processos inerentes ao real, retratando as interações entre os processos, entidades e recursos. Em complemento, Montevechi et al. (2009) afirmam que a simulação importa o sistema real para um ambiente controlado, computacional, possibilitando a análise do seu comportamento, experimentações, confronto de teorias, sem o envolvimento de riscos físicos ou monetários

A simulação pode ser utilizada, além do auxílio na tomada de decisões, na redução de riscos; ajuda no desenvolvimento de estratégias de gerenciamento e na compreensão dos fenômenos associados, demonstrando o fluxo e a interação entre os processos fases e os produtos, de maneira a facilitar a visualização do processo por completo (KELLNER et al., 1999).

Para a modelagem computacional, o software utilizado no desenvolvimento do presente trabalho é o ProModel, um simulador de eventos discretos, com aplicações tanto em indústrias, quanto em logística e serviços. Quando utilizado em áreas industriais ele oferece uma gama de funções, tais como o balanceamento de linhas, projetos de células produtivas, modificações de layouts, implantação de Lean Production, suporte a projetos Six Sigma e apoio ao PCP (Planejamento e Controle da Produção).

\section{MATERIAIS E MÉTODOS}

A partir de um problema real (a redução do lead time do processo de fabricação de bancadas de granito), identificou-se a oportunidade de se apresentar o VSM, como forma de se balancear o processo (em relação a tempos, principalmente), cujo modelo de melhoria oriundo, originou um modelo conceitual, que, por fim, foi convertido em um modelo de simulação computacional.

A empresa em estudo trabalha com pedras ornamentais, mais precisamente mármore, e produz pias - contemplando a instalação do furo de bojo (Figura 1.A), cuba (Figura 1.B) e torneira (Figura 1.C) - e bancadas de acordo com o pedido do cliente. 


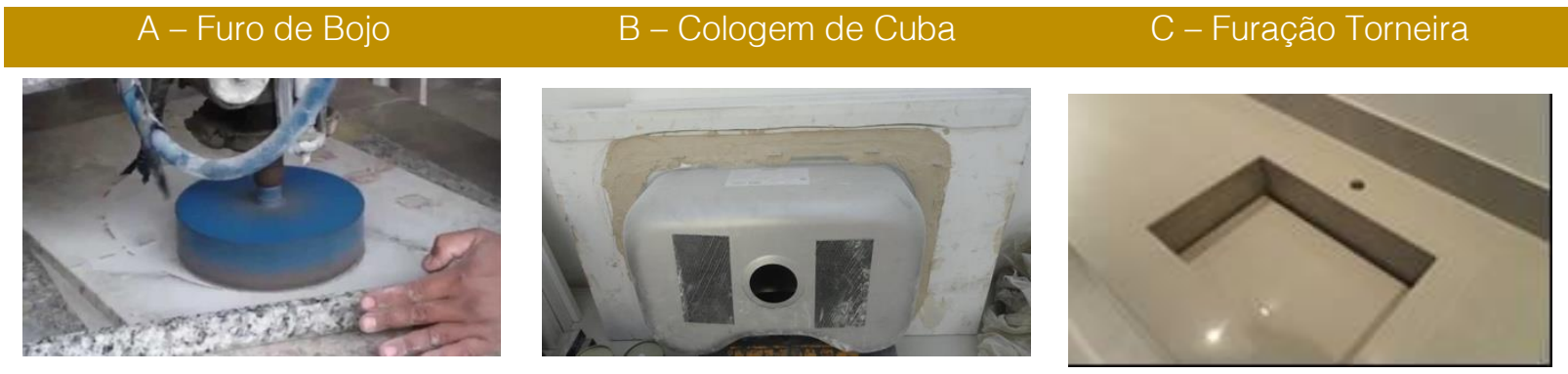

Figura 1 - Serviços de bancada de cozinha

Durante a venda desses produtos, a organização oferece um prazo ao cliente de acordo com as especificações requeridas no produto. Porém, além desse prazo de entrega não estar sendo atendido, os produtos ficam muito tempo em estoque tanto antes de entrar para a produção quanto a cada processo produtivo (corte, colagem e acabamento final), representando uma diferença muito grande entre o tempo de processamento e o tempo de agregação de valor. Isto, consequentemente, encarecia o preço do produto final, além de apresentar diversos desperdícios, como por exemplo, excesso de movimentação e produção, espera, transporte, estoques, o que ocorre devido ao desbalanceamento das atividades produtivas.

Como primeiro passo, a coleta de tempos foi executada, com o intuito de identificar os tempos e movimentos inerentes ao processo. Para isso, dividiram-se as medições em cada setor produtivo. Nestes, coletaram-se os tempos de acordo com cada etapa produtiva. Além dos tempos de processamento e preparação entre cada etapa, os dados de quantidade de peças em estoque, os estoques intermediários, e as peças em processamento também foram levantados. Avaliaram-se, ainda, a quantidade de operadores em cada posto produtivo, o lead time, fluxo de informação e transporte, a fim de se construir o VSM presente.

\subsection{MAPA DE FLUXO DE VALOR (VSM) ATUAL}

O Mapa de Fluxo de Valor Atual gerado (APÊNDICE A) contemplou todos os processos produtivos, seguindo a lógica de produção observada. Além da lógica produtiva, o mapa também demonstrou como se dava a comunicação entre os postos produtivos e os demais setores, distinguindo não somente o tipo de informação entre cliente e o setor produtivo, como também, o setor produtivo e o setor responsável pelo planejamento da produção.

O transporte da matéria prima entre os processamentos, realizado de maneira empurrada, o tipo de recebimento de matéria prima e envio de produto acabado, também puderam ser observados no mapa, identificados pelas setas cinzas, listradas e contínuas.

Os tempos de ciclo de cada posto de trabalho representa o tempo gasto por metro, para se preparar o produto acabado. Portanto, o tempo de processamento, o lead time e a agregação de valor, representado no VSM, é o tempo gasto para se produzir uma bancada (pois inclui o processo de furo de bojo e colagem da cuba) referente a um metro linear. $\mathrm{Na}$ descrição dos tempos de cada atividade produtiva, onde é classificado o setor como dedicado ou não, representa um posto do qual pode ou não ser incluído em uma célula produtiva de mesma família de produto.

O VSM atual apresenta tempo de processamento total de 7.740 min por produto acabado, 66,19 min de lead time e 0,72\% de agregação de valor, constatando-se, com isso, uma grande oportunidade de melhoria.

A partir da construção VSM presente, a situação atual foi transformada em um modelo computacional, com a tradução dos dados coletados nos elementos básicos do modelo. A Figura 2 apresenta o modelo de simulação computacional resultante. 
Figura 2 - Simulação Atual

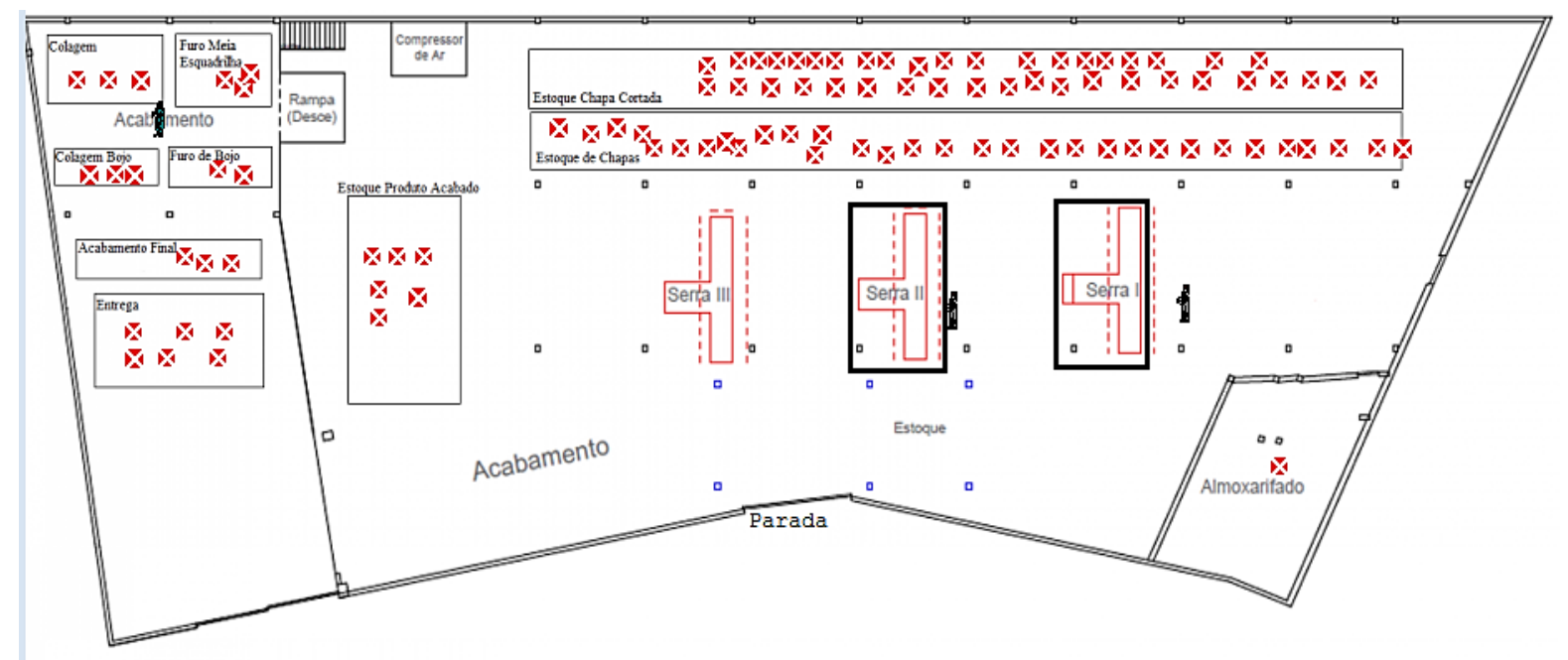

\subsubsection{RESULTADOS DA SIMULAÇÃO DO VSM ATUAL}

A Tabela 1 apresenta os resultados para produtos acabados, da simulação do cenário atual, durante o tempo de processamento estabelecido ( 6 horas de trabalho mais 1 de aquecimento), que representa o tempo disponível de trabalho no local em estudo. Com esse tempo de produção e as configurações de acordo com os dados coletados, observa-se somente um produto acabado com o tempo de processamento no sistema de 401,47 minutos.

Tabela 1 - Produtos Acabados

\begin{tabular}{|c|c|c|c|}
\hline \multicolumn{1}{|c|}{ Nome } & Total de Saídas & $\begin{array}{c}\text { Tempo médio no } \\
\text { Sistema (Min) }\end{array}$ & $\begin{array}{c}\text { Tempo médio em } \\
\text { operação }\end{array}$ \\
\hline Chapa & 0,00 & 0,00 & 0,00 \\
\hline Peça Cortada & 0,00 & 0,00 & 0,00 \\
\hline Peça Esquadrilha & 0,00 & 0,00 & 0,00 \\
\hline Bancada & 1,00 & 413,09 & 401,47 \\
\hline Bojo & 0,00 & 0,00 & 0,00 \\
\hline Bancada Furada & 0,00 & 0,00 & 0,00 \\
\hline Pia & 0,00 & 0,00 & 0,00 \\
\hline
\end{tabular}

A Figura 3 apresenta o nível de ocupação dos operadores de três importantes recursos da linha produtiva: a Serra1, a Serra2 e o Acabamento. 
Figura 3 - Percentual de tempo em atividade pelos operadores

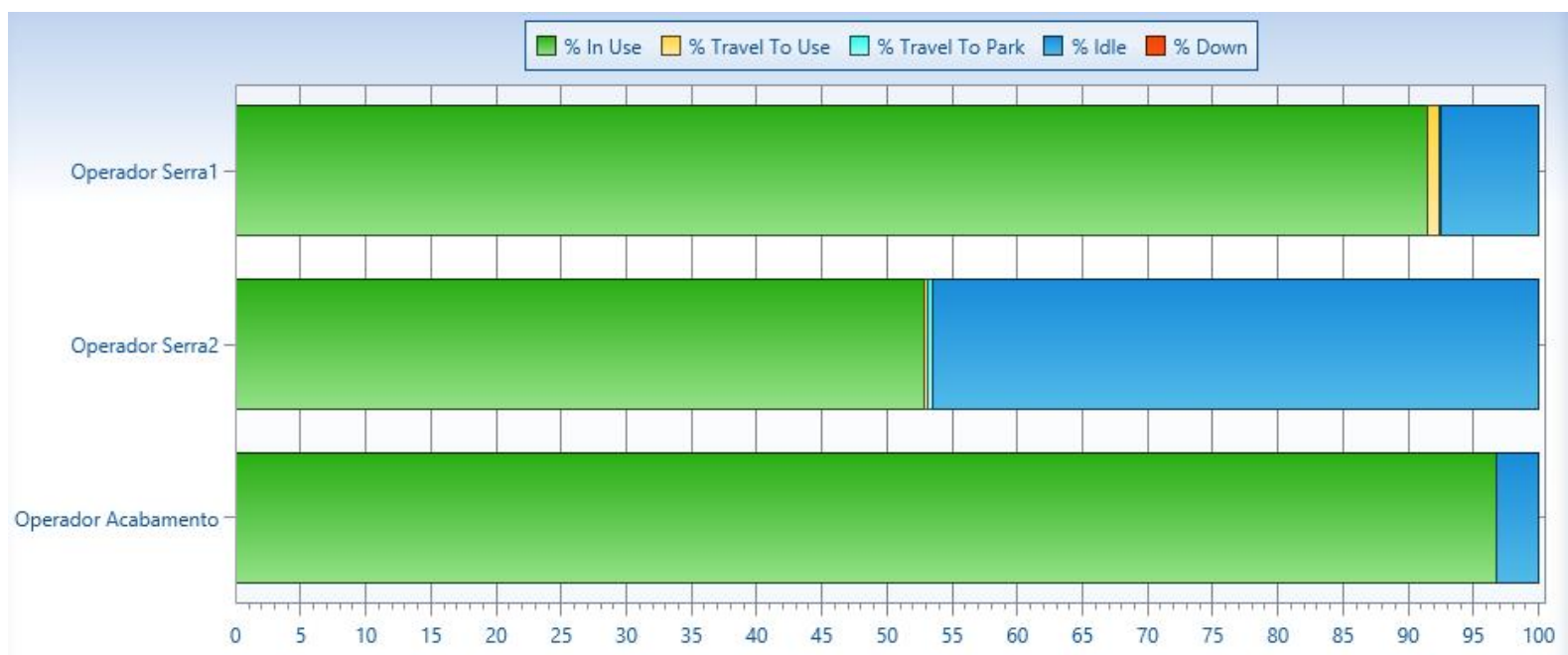

Na legenda pode-se ler: \% de Ocupação; \% em Deslocamento; \% Deslocamentos

Extras; \% em Ociosidade; \% de Paradas Não Programadas.

Percebe-se que o Operador Serra2 permanece em atividade durante $53 \%$ do tempo, enquanto que o Operador Serra1, 92\% do tempo. Já o Operador Acabamento, permaneceu em atividade durante, praticamente, $100 \%$ do tempo.

A Figura 4 apresenta os estados dos recursos de produção.

Figura 4 - Estado das entidades

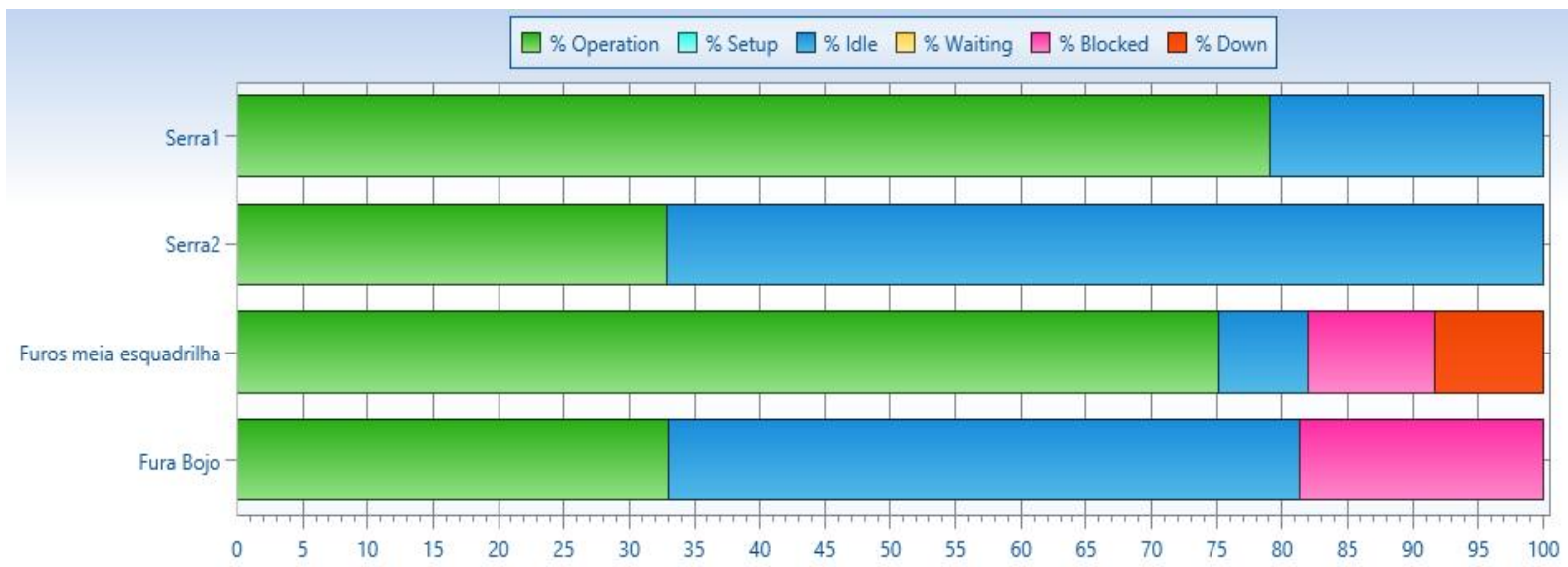

Na legenda pode-se ler: \% em Operação; \% em Setup; \% Ocioso; \% em Espera; \% Bloqueado; \% em Paradas Não Programadas.

Assim como o Operador Serra2 (Figura 3), a Serra2 também fica muito tempo ociosa, $67 \%$ do tempo - uma vez que ela necessita do Operador Serra2 para estar em operação. Além da Serra2, outro recurso com ociosidade significante é o local onde se fura o bojo, $66 \%$ do tempo. Como forma de se reduzir a ociosidade desses recursos, aumentando-se, consequentemente, o tempo de agregação de valor ao cliente, propõe-se modificar o layout, de forma a unificar esses processos.

Observa-se, no entanto, certa ociosidade em todos os recursos produtivos observados.

\subsection{MAPA DE FLUXO DE VALOR FUTURO}


O VSM futuro (APÊNDICE B) representa os novos aspectos produtivos como lógica de processamento entre os processos produtivos, fluxo de informação, intervalo de recebimento de matéria prima e de entrega, além de novos tempos de ciclo e reparo, devidamente especificados para a construção de um VSM futuro.

$\mathrm{Na}$ construção do VSM futuro optouse por usar a lógica de transporte e produção FIFO (Firts In First Out - primeiro que entra é o primeiro que sai) para evitar estoque desnecessários entre processos, implementação de uma célula produtiva que contemple os processos dedicados a uma só família de produtos, e outras melhorias, porém a serem comprovadas pela simulação.

Com esse novo modelo produtivo, pode-se observar que o tempo de processamento diminuiu para, em média, uma pia acabada a cada uma hora de produção (de $506 \mathrm{~cm}$ de perímetro - média de 16 pias e bancadas analisadas), podendo ser menor quando se tratando de bancadas, por eliminar as etapas de furo e colagem de bojo.

Com a adoção dessas melhorias, obteve-se uma agregação de valor de $17,08 \%$, além de reduzir o tempo de processamento de 7.740 minutos para 360 minutos e o lead time de 66,19 minutos para 61,5 minutos.

O desenvolvimento da situação futura (Figura 5), alinhada ao VSM Futuro resultou, principalmente, na redução do tempo de processamento, reestruturação do layout, realocação de operadores, cálculo de takt time, remoção dos estoques intermediários, alocação de um estoque pulmão, identificação de onde puxar e programar a produção e apontar algumas melhorias futuras.

Figura 5 - Simulação da situação futura (sugestão de melhoria)

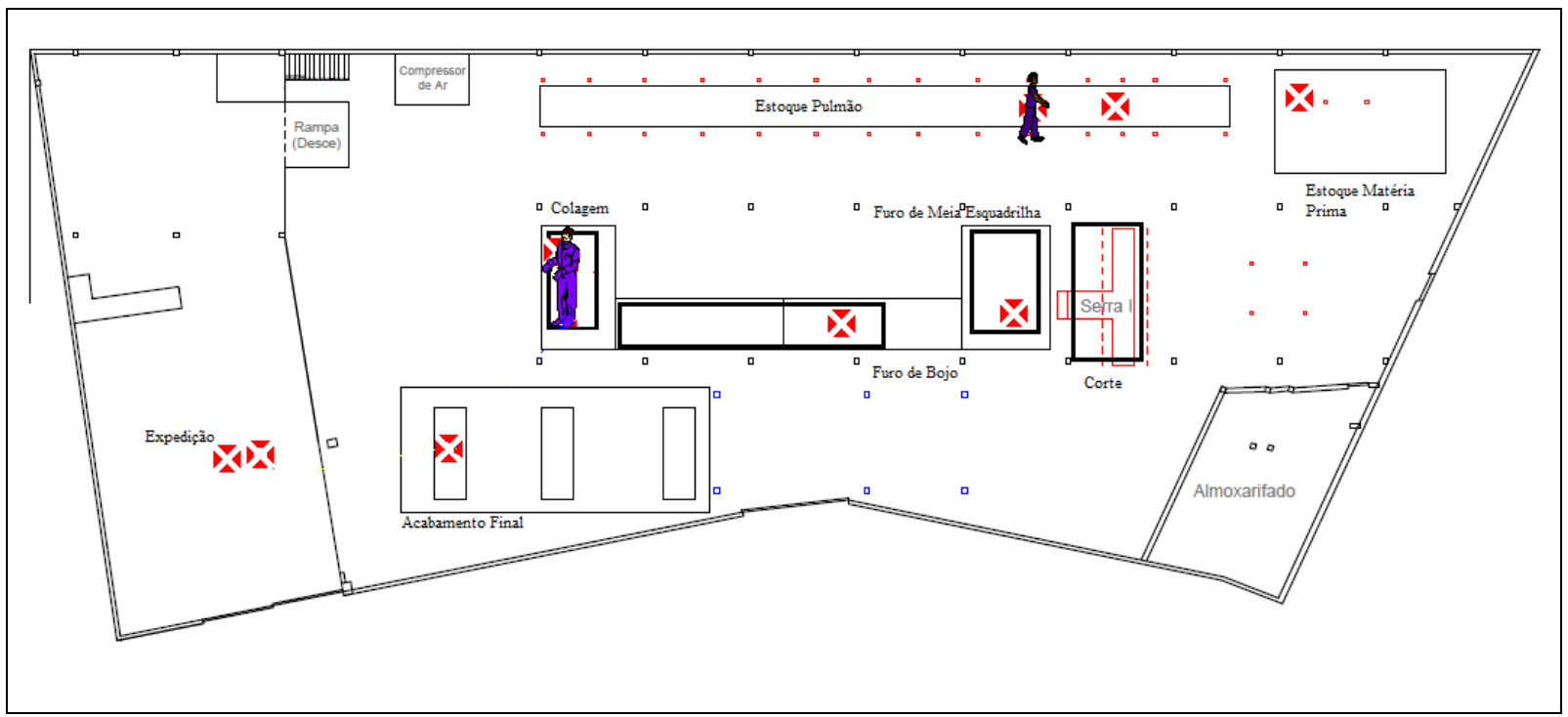

Além dessas melhorias, identificou-se que a situação atual não executava uma lógica ordenada para o transporte dos produtos entre os postos produtivos, o que contribuía para a existência de estoques entre processos e, para erradicar esses estoques, adotou-se FIFO.

Para a reestruturação do layout, criouse uma célula produtiva que contempla os setores dedicados a uma só família de produtos (corte de meia esquadrilha, furo de bojo e colagem), além da redução do número de serras de corte de três para uma, devido ao seu baixo tempo de processamento, reduzindo-se a quantidade de operadores em alguns setores como o setor de corte $e$ acabamento final (demonstrado no VSM futuro), ainda se mantendo os setores de acabamento final e expedição.

Além dessas modificações, mantevese o estoque de matéria prima, adotando-se um intervalo definido de recebimento e criando-se um estoque pulmão à frente do setor de corte, devido ao seu baixo tempo de processamento, direcionado à célula de produção. 


\subsubsection{RESULTADOS DA SIMULAÇÃO DO VSM ATUAL}

A simulação do estado futuro (proposto) foi, também, realizada durante 6 horas, porém, as quantidades de produtos acabados aumentaram para 6 (2 Bancadas e 4 Pias) em relação ao cenário atual, resultando numa melhoria de $600 \%$, produzindo, não somente pia ou bancada em um dia de trabalho, mas sim, ambos os produtos. Tal resultado pode ser constatado a partir dos dados da Tabela 2.

Tabela 2 - Produtos Acabados

\begin{tabular}{|c|c|c|c|}
\hline Nome & Total de Saídas & $\begin{array}{c}\text { Tempo médio no } \\
\text { Sistema (Min) }\end{array}$ & $\begin{array}{c}\text { Tempo médio em } \\
\text { operação }\end{array}$ \\
\hline Chapas & 0,00 & 0,00 & 0,00 \\
\hline Chapas Cortadas & 0,00 & 0,00 & 0,00 \\
\hline Chapa Bancada & 0,00 & 0,00 & 0,00 \\
\hline Chapa Esquadrilha & 0,00 & 0,00 & 571,47 \\
\hline Chapa Esqu Bancada & 0,00 & 0,00 & 0,00 \\
\hline Chapa Pia & 0,00 & 0,00 & 0,00 \\
\hline Bancada & 2,00 & 212,00 & 49,00 \\
\hline Pia & 4,00 & 194,5 & 62,00 \\
\hline
\end{tabular}

Em relação aos estados dos recursos, observa-se um aumento significativo no percentual de utilização, além da redução do tempo de ociosidade, resultando numa agregação de valor ao cliente, notavelmente maior, fruto de um balanceamento das operações produtivas, conforme se constata pela Figura 6.

Figura 6 - Estados dos Recursos

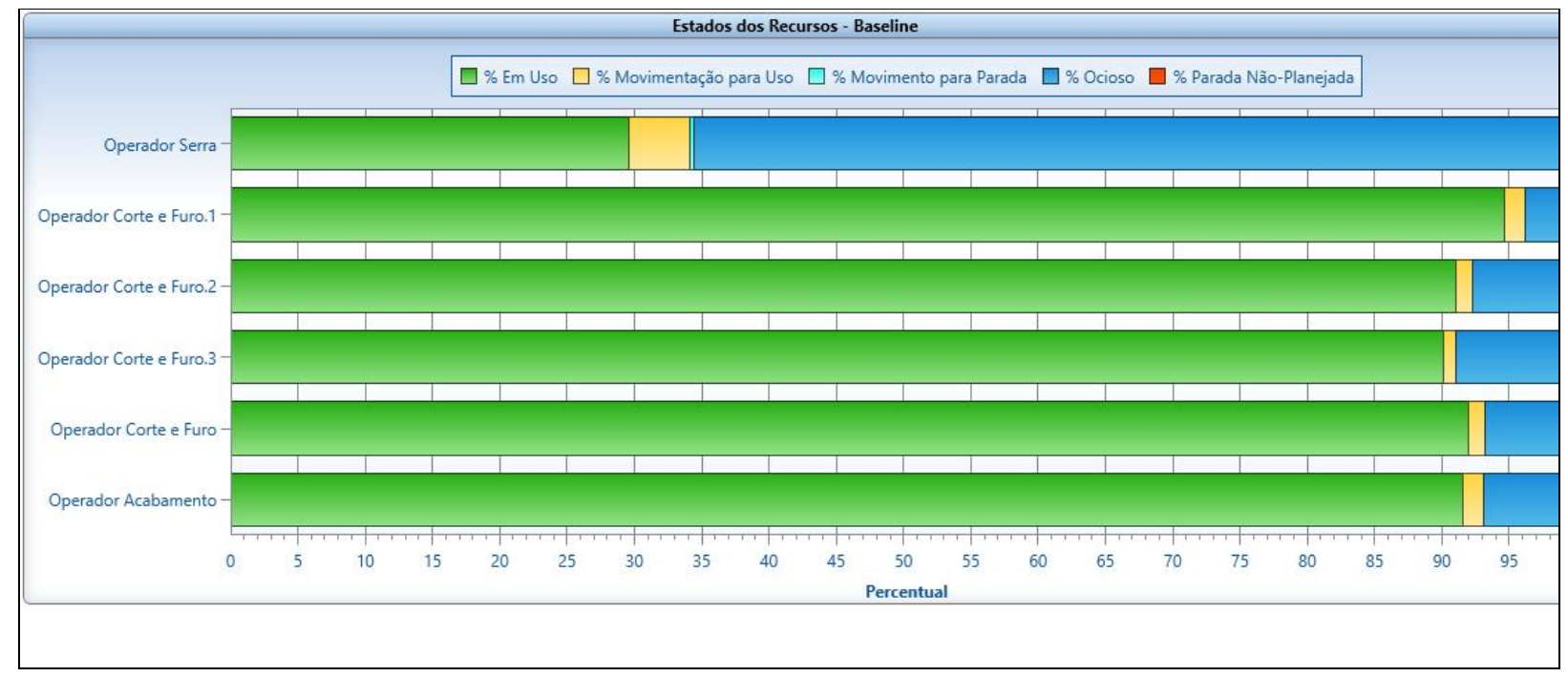




\section{CONSIDERAÇÕES FINAIS}

A combinação das ferramentas VSM e SED, proposta como forma de se buscar melhorias no processo produtivo de uma marmoraria, se mostrou bastante eficaz. O VSM auxiliou na obtenção de uma visão geral processo produtivo, detalhando tempos de processamento, estoques intermediários, fluxos de informação e transporte. A SED, por sua vez, permitiu experimentarem-se novos modelos, de modo que os resultados pudessem ser observados, sem que, com isso, se interferissem nos processos reais.

Comparando-se os resultados dos cenários das simulações desenvolvidas para os VSM atual e futuro, identificou-se um aumento de agregação de valor ao cliente de $16,36 \%$, incremento do número de produtos acabados por dia, passando de um (cenário atual) para seis (cenário futuro), além de redução do tempo de processamento, de lead time (de 7.740 minutos para 61,5 minutos), de estoque entre processos e da ociosidade dos operadores, resultando no balanceamento das atividades produtivas, maior fluidez

\section{REFERÊNCIAS}

[1]. ANDRADE, P. F., PEREIRA, V. G., DEL CONTE, E. G. Value stream mapping and lean simulation: a case study in automotive company. The International Journal of Advanced Manufacturing Technology, Londres. 2015.

[2]. BELOKAR, R., KUMAR V, KHARB, S. $S$. An application of value stream mapping in automotive industry: a case study. International Journal of Innovative Technology and Exploring Engineering. Vol 1. 2012.

[3]. CHWIF, L., MEDINA, A. C. Modelagem E Simulação De Eventos Discretos: Teoria E Aplica

[4]. KELLNER, M. I., MADACHY, R. J., RAFFO, David M. Software Process Simulation Modeling: Why? What? How? The Journal of Systems and Software, v. 46, p. 91 -105. 1999.

[5]. LIKER, J. K. O modelo Toyota: 14 Principios de Gestão do maior fabricante do mundo.Nova York, NY: McGraw Hill, 2003.

[6]. MONTEVECHI, J. A. B., COSTA, R. F. S., LEAL, F., PINHO, A. F., JESUS, J. T. Economic evaluation of the increase in produtiva e eliminação dos estoques intermediários.

Ressalta-se, entretanto, que resolução do problema da ociosidade dos operadores passa, também, pela realocação de, ao menos, um operador, para realizar outras funções no cenário futuro proposto.

Pelos resultados obtidos pela análise do VSM Futuro e da simulação do novo layout produtivo, propõe-se que esse possa ser implementado na linha produtiva, objeto de estudo, uma vez que, pelas simulações realizadas, melhorias podem ser alcançadas a partir desse novo layout.

\section{AGRADECIMENTOS}

Os autores gostariam de expressar sua gratidão à CNPq, Capes, FAPEMIG, DPPG/UNIFEI e ao Grupo de Estudos em Qualidade e Produtividade - GEQProd, pelo seu apoio na realização deste trabalho.

production capacity of a high technology products manufacturing cell using discrete event simulation.Proceedings of the Winter Simulation Conference, Austin, USA, 2009

[7]. OHNO, T., Sistema Toyota de Produção: Além da produção em larga escala.Portland, Oregon: Productivity press, 1988.

[8]. OLESEN, P., POWELL, D., HVOLBY, H., FRASER, K. USING LEAN PRINCIPLES TO DRIVE OPERATIONAL IMPROVEMENTS IN INTERMODAL CONTAINER FACILITIES:A conceptual framework. Journal of facilities Management, vol. 13, p. 266-281. 2015

[9]. TAJ, S., BERRO, L. Application of constrained management and lean manufacturing in developing best practices for productivity improvement in an auto-assembly plant", International Journal of Productivity and Performance Management, Vol. 55,p. 332-345. 2006.

[10]. WOMACK, J.P., JONES, D.T. and ROOS, D., A Máquina que mudou o mundo: A história da produção enxuta. Nova York, NY: Rawson Associates, 10 ed, p. 322, 1990. 
ANEXO A - VSM ATUAL

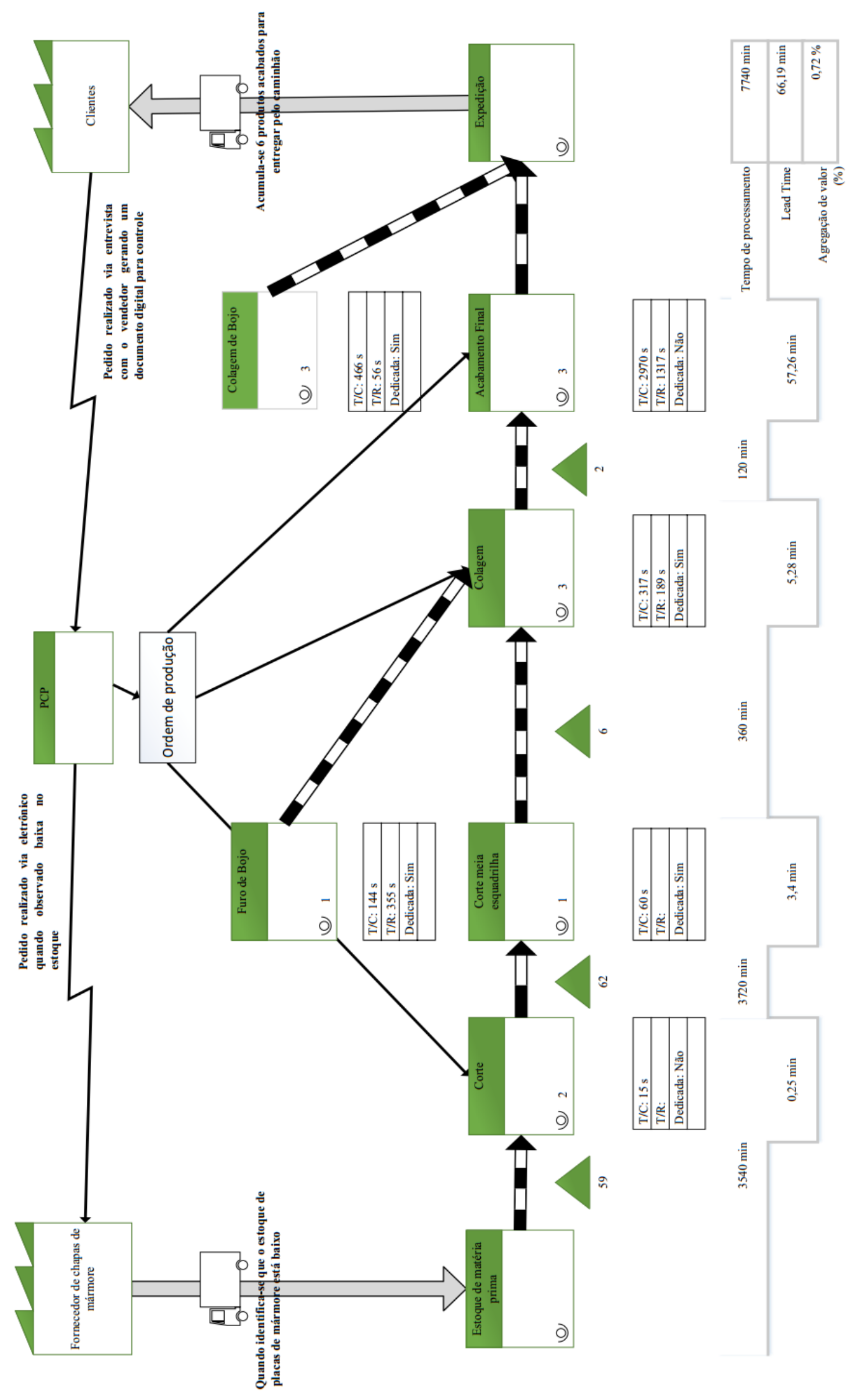


ANEXO A - VSM FUTURO

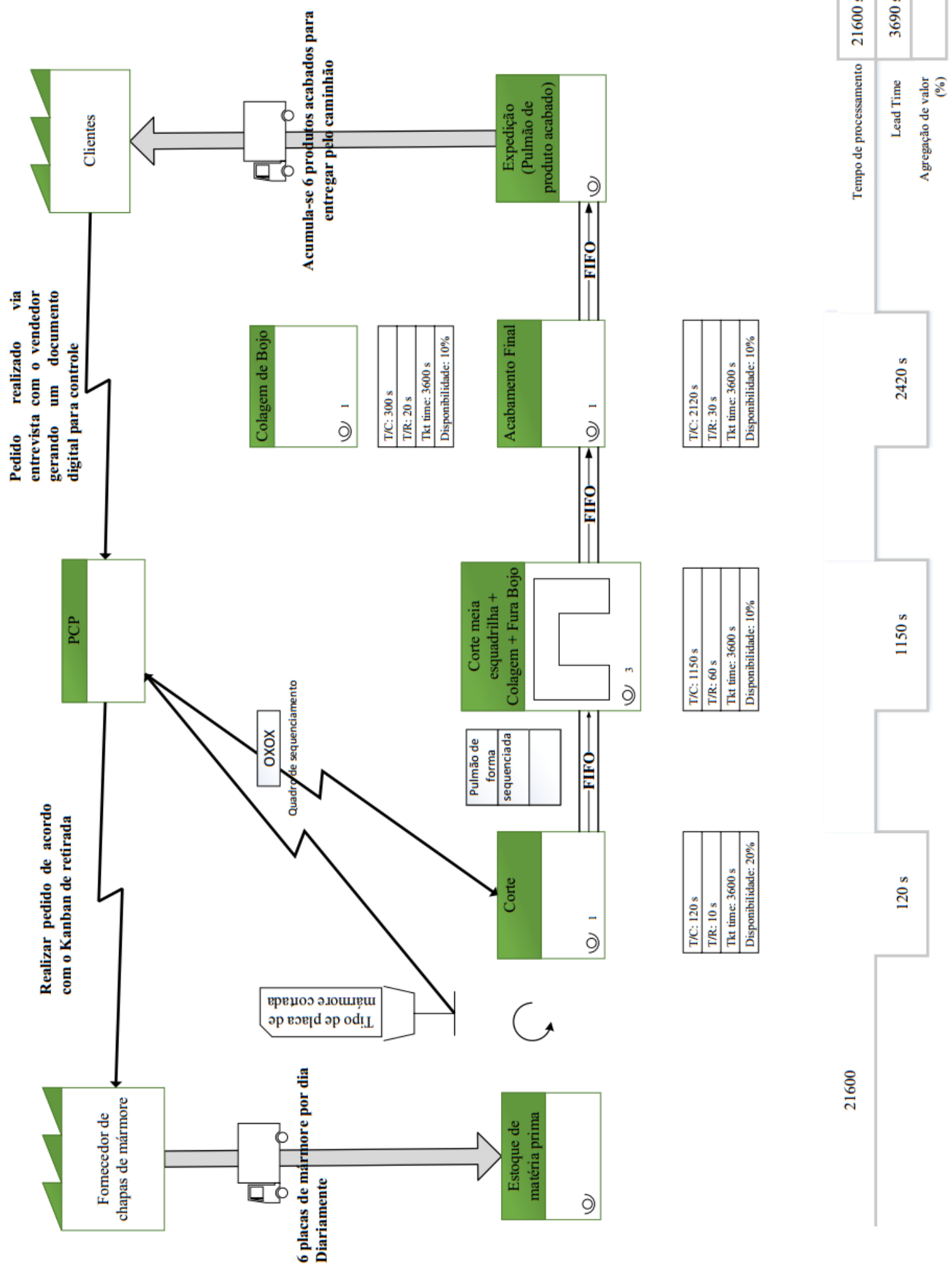




\section{Gapítulo 18}

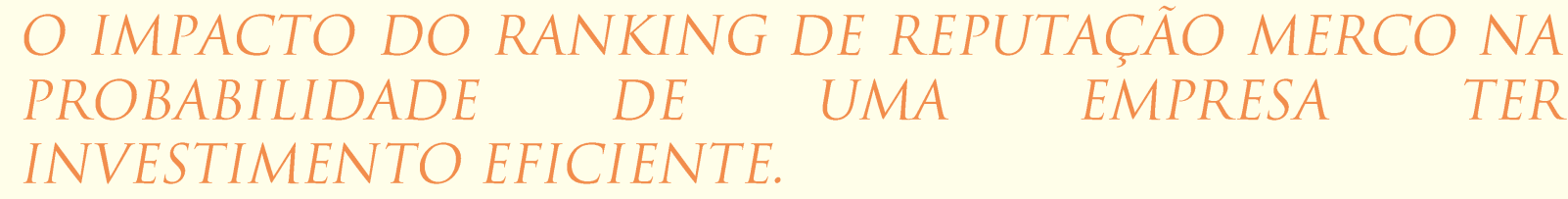

\section{Mirian Wawrzyniak Chimirri}

Resumo: Este Trabalho Tem Por Objetivo Determinar O Impacto Que A Reputação Exerce Nas Decisões De Investimento Das Empresas Espanholas Através De Dados Longitudinais De 180 Firmas Entre 2000 E 2015. A Mensuração Para Reputação Corporativa É Feita Através Da Classificação No Ranking De Reputação Merco, Que Divulga Anualmente Uma Lista Com As Cem Empresas Espanholas Mais Bem Reputadas Naquele Ano. Os Dados Financeiros E De Estrutura De Propriedade São Obtidos Através Do Sistema Sabi. O Modelo Proposto Tem Como Variável Dependente O Nível De Investimento Da Firma, Que É Construído Através Do Resíduo Da Regressão Entre Investimentos E Crescimento Das Vendas. As Variáveis Explicativas, Além Da Reputação, São Financeiras, De Estrutura De Propriedade E De Restrição Financeira.Uma Regressão Logística Ordinal É Utilizada Para Determinar Como A Reputação Afeta Na Probabilidade Da Empresa Ser Classificada Por Apresentar Underinvestment, Investimento Eficiente Ou Overinvestment. Os Resultados Mostram Que A Classificação No Ranking De Reputação Não É Significante Em Determinar As Chances De A Empresa Ter Investimentos Eficientes, Acima Ou Abaixo Do Ideal.

Palavras-chave: Decisões De Investimento; Reputação Corporativa; Investimento Ótimo 


\section{INTRODUÇÃO}

No mundo corporativo ter uma boa reputação ganha cada vez mais espaço, a divulgação de rankings como a da revista Fortune nos Estados Unidos ou o Merco na Espanha são eventos muito aguardados por gestores e investidores. De fato, um estudo feito em outubro de 2015 pela 10 Sustainability em parceria com o Babson College concluiu que uma boa reputação é responsável por pelo menos $11 \%$ do valor de uma empresa (ROCHLIN et al. 2015).

De fato, na literatura recente, diversos autores encontraram relação positiva entre reputação e faturamento. Borda et al. (2016) acreditam que uma reputação favorável melhora a produtividade e a lucratividade da firma e para Fernando et al. (2015) existe relação positiva entre alta reputação e maior spread.

Mas ainda são poucos e recentes os estudos que se dedicam a mensurar o impacto que a reputação exerce nas decisões de investimento da firma. Liberman (2016) indica que mutuários pagam por ter uma boa reputação, pois isso thes permite acessar o mercado de crédito formal e atua como uma garantia do empréstimo. De forma semelhante, Anginer et al. (2015) afirmam que empresas com melhor reputação têm mais facilidade em obter crédito e conseguem melhores taxas. Por isso é esperado que empresas mais bem reputadas, ao conseguir crédito com maior facilidade e com melhores taxas invistam de maneira eficiente. Jian e Lee (2001) conseguiram comprovar esta hipótese, mas utilizando a reputação do CEO da empresa. Seus resultados mostram que CEO's mais bem reputados conseguem selecionar melhor os projetos que serão bons para a empresa e que o mercado é mais favorável a estas empresas, oferecendo melhores condições de financiamento.

É importante verificar os fatores que afetam as decisões de investimento das empresas, pois de acordo com De Long e Summers (1991) existe uma forte relação entre investimento e crescimento econômico, principalmente quando este investimento é feito em máquinas e equipamentos. Entretanto Easterly (2004) alerta para a necessidade de fazer investimentos de maneira eficiente. $O$ crescimento do valor da empresa e consequente crescimento econômico do país não são alcançados simplesmente pela acumulação de capital. Não adianta investir em maquinário se não forem capacitados os trabalhadores para operá-lo nem aumentar a produção se não há demanda para isto. Portanto, é fundamental que as empresas invistam de forma eficiente, ou seja, aproveitem todos os projetos que irão maximizar o seu valor.

Nesse contexto, este estudo tem por objetivo verificar como a reputação impacta nas decisões de investimento das firmas espanholas entre 2000 e 2015. Deseja-se mensurar como a reputação impacta nas chances de uma empresa fazer investimentos abaixo ou acima do ideal, ou de maneira eficiente.

Os dados utilizados provêm de duas fontes de dados, uma delas é o ranking de reputação Merco, divulgado anualmente com as 100 empresas espanholas mais bem reputadas, e a outra é o sistema Sabi, da qual são utilizados dados financeiros e de estrutura de propriedade. A base final é um painel com 180 empresas que já estiveram presentes no ranking Merco em algum ano, durante 16 anos.

A classificação das empresas entre os três níveis de investimento: underinvestment, investimento eficiente ou overinvestment, tem inspiração no trabalho de Biddle et al. (2009), que considera que para ser eficiente a empresa deve ter seu investimento presente igual ao crescimento das vendas do período anterior. Portanto, a classificação é feita com base no resíduo da regressão que tem como variável dependente o investimento, e variável explicativa, o crescimento das vendas.

O modelo tem então como variável dependente o nível ou a taxa de investimento, e como variáveis dependentes uma mensuração de reputação, feita através da classificação no ranking Merco, algumas variáveis de controle financeiras, variáveis de estrutura de propriedade que indicam práticas de governança corporativa, e um índice de restrição financeira.

Para verificar como a reputação interfere nas chances da empresa estar em determinado nível de investimento é utilizado o modelo de regressão logística ordinal com um estimador robusto de heterocedasticidade. Os resultados apontam para a não significância da reputação nas chances de a empresa ter investimentos eficientes, acima ou abaixo do ideal.

Este estudo está organizado em cinco seções, sendo esta introdução a primeira. Em 
seguida é feita uma breve revisão da literatura. Na seção seguinte, são mostrados os resultados encontrados e por fim as conclusões

\section{FUNDAMENTAÇÃO TEÓRICA}

O tema reputação corporativa ganhou destaque na década de 1990, principalmente em virtude do trabalho de Charles Fombrum em seu livro "Reputation: Realizing value from the corporate image" em 1996, e do lançamento da revista "Corporate Reputation Rewiew" em 1997.

No artigo "The Reputacional Lanscape", Fombrum e Van Riel (1997) destacam seis visões distintas envolvendo a reputação corporativa, os autores concordam que apesar de várias visões distintas, é possível definir:

"A reputação corporativa é a representação coletiva das ações passadas da firma e dos resultados que descrevem a habilidade de firma em fornecer resultados bons para as partes interessadas. Ela mede a relação de uma empresa tanto internamente, com seus funcionários, quanto externamente com seus stakeholders, nos ambientes competitivo e institucional."

(FOMBRUM; VAN RIEL, 1997, p.10)

De modo semelhante, Argenti e Forman (2002) entendem a reputação corporativa como a soma das percepções dos clientes, investidores, empregados e comunidade em geral. As imagens que eles têm da empresa devem estar alinhadas com a identidade corporativa e pode ser influenciada por propaganda, mas é criada principalmente através das experiências de cada um com os produtos, funcionários e serviços da organização. Já para Dowling (2000) a reputação deve ser baseada em valores humanos, como honestidade e responsabilidade. Diferente da identidade corporativa, que é apenas o conjunto de símbolos, marcas e nomes utilizados para a comunicação entre empresa e clientes, a reputação representa a confiança dos indivíduos em relação à empresa.

Os autores McGuire, Schneeweis e Branch (1990) se propuseram a responder duas perguntas cruciais envolvendo o tema reputação. Se um bom desempenho financeiro melhora a percepção do público sobre a empresa e se ter uma boa reputação afeta o desempenho financeiro da firma. Os autores perceberam que a resposta para ambas as perguntas é positiva, pois a relação entre reputação e desempenho financeiro é uma via de mão dupla. Baseados neste resultado, Roberts e Dowling (2002) mensuraram o impacto de uma boa reputação no desempenho financeiro (ROA) através de modelos autorregressivos. Eles perceberam que a reputação atual depende do desempenho e da reputação do período anterior e que a performance financeira do futuro vai depender da reputação do período corrente. Portanto, um bom desempenho financeiro unido a uma boa reputação leva à manutenção do bom desempenho ao longo dos anos.

Muitos autores buscaram os motivos que fazem com que uma empresa com alta reputação tenha um melhor desempenho financeiro. Srivastava et al. (1997) por exemplo, acreditam que a reputação corporativa melhora a imagem da empresa para os investidores, fazendo com que eles aceitem investir nela enfrentando um risco maior ou obtendo um retorno menor. Através de um estudo com 205 empresas listadas pela revista Fortune, eles verificaram que em empresas com alta reputação o índice de disponibilidade de risco aceito pelo investidor é maior, e que o resultado necessário para a manutenção do status de mercado é menor. Assim, ao melhorar sua reputação, a empresa tende a aumentar seu valor de mercado, mesmo que não tenha alterado seus resultados financeiros.

Em um estudo mais recente Anginer et al. (2015) buscaram a relação entre reputação e custo do financiamento da dívida. Utilizando o ranking das mais admiradas companhias publicado pela revista Fortune, os autores encontraram uma relação inversa entre o score no ranking e o custo da dívida. Além disso, esta relação é maior quando as informações sobre a firma são menos difundidas, nas firmas menores e em firmas com maior risco de default. Eles acreditam que isso ocorra, pois, a reputação ajuda a explicar as distorções de crédito, capturando a informação não observada sobre a possibilidade da empresa não honrar seu compromisso com a dívida. Portanto, empresas com melhor reputação têm mais facilidade em obter crédito e conseguem melhores taxas, pois a reputação age como uma proxy para a garantia de que a dívida será paga. 
Cao et al.(2014) encontraram evidências de que ter uma alta reputação também diminui o custo do capital próprio. Eles analisaram quase dez mil grandes companhias estadunidenses durante 25 anos e, controlando por diversas outras variáveis determinantes para o custo do capital próprio, encontraram um impacto positivo e significante da reputação sobre o Ke. Esse efeito se mostrou maior em empresas com maior grau de assimetria de informação, fazendo com que os autores concluíssem que a reputação age como um determinante do custo de capital próprio da empresa por reduzir a assimetria de informação e, com isso, promover uma diluição mais eficiente do risco.

Assim, percebe-se que existe um consenso na literatura de que uma boa reputação corporativa colabora para a saúde financeira da firma, principalmente na presença de falhas de mercado, como a assimetria de informação. Seja por atrair mais investidores ou por fazer com que os clientes confiem mais nos produtos e serviços oferecidos, manter uma boa reputação ao longo dos anos é fundamental para a manutenção do sucesso financeiro da empresa. Entretanto, cabe lembrar que é preciso tomar cuidado ao estimar modelos econométricos envolvendo reputação, pois ela pode ser tanto determinante do sucesso financeiro, quanto, por ele determinada (MCGUIRE et al., 1990).

\section{BANCO DE DADOS E MÉTODOS DE PESQUISA}

Para a realização deste estudo foram utilizados dados financeiros e de reputação de 180 empresas espanholas entre os anos 2000 e 2015 em um painel balanceado. As variáveis financeiras e de estrutura de propriedade foram obtidas no sistema SABI (Sistema de Análise de Balanços Ibéricos) e o indicador de reputação provém do Merco (Monitor Empresarial de Reputação Corporativa), que tem por objetivo avaliar a reputação corporativa de empresas espanholas desde 2000. Através da avaliação de questionários respondidos por gestores, especialistas, consumidores e funcionários, 0 merco divulga anualmente um ranking com as 100 empresas mais bem reputadas da Espanha.

Portanto, o banco de dados final foi formado com base no ranking anual Merco. Todas as empresas (180), excetuando-se os intermediários financeiros, que estiveram presentes nos ranking Merco em pelo menos um ano tiveram seus dados financeiros e de estrutura de propriedade procurados no sistema Sabi. Assim, para as empresas que não têm uma pontuação divulgada no ranking Merco em algum ano esta observação não pode ser considerada como "missing", pois isso significa que a empresa não conseguiu estar entre as 100 primeiras naquele anoe isso deve ser levado em consideração na criação da variável que mensura reputação.

\subsection{MODELO PROPOSTO E CONSTRUÇÃO DE VARIÁVEIS}

O modelo proposto tem por objetivo verificar a hipótese de que uma empresa com melhor reputação obtém mais sucesso nas suas decisões de investimentos. Para isso, a escolha das variáveis foi baseada no modelo proposto por Biddle, Hilary e Verdi (2009) que avalia como a qualidade dos relatórios financeiros melhora a eficiência do investimento. Eles consideram que essa qualidade nos relatórios financeiros diminui a assimetria de informação e, portanto, melhora as escolhas dos gestores em projetos de investimento que realmente vão acrescentar valor à firma.

No presente estudo, a variável colocada no modelo para captar o benefício que informações mais simétricas têm no processo decisório de investimentos da firma é a reputação, ao invés dos índices para qualidade das informações financeiras utilizadas pelos autores Biddle et al. (2009). Outra diferença é a inclusão de uma variável de restrição financeira, que pode impactar negativamente no investimento ótimo por dificultar a obtenção de recursos.

O modelo proposto tem como variável dependente o nível de investimento da empresa, que pode ser de investimento eficiente, abaixo do ideal ou acima do ideal. A variável Y é explicada pela classificação no ranking e outras variáveis de controle, distribuídas em: variáveis de desempenho financeiro, indicadores de boas práticas de governança corporativa e índice de restrição financeira, conforme mostra a equação (1).

$$
\begin{aligned}
Y_{i t}=\alpha+\beta_{1} \text { Reput }_{i t}+\beta_{2} \text { Fin }_{i t} \\
+\beta_{3} \text { Gov }_{i t}+\beta_{4} \text { Restr }_{i t} \\
+\varepsilon
\end{aligned}
$$


Em que $Y_{i t}$ é o nível do investimento, Reput ${ }_{i t}$ é a variável que mensura reputação, Fin $_{i t}$ é um conjunto de variáveis financeiras, Gov representa algumas variáveis de estrutura de propriedade, importantes para uma melhor governança corporativa, e consequente diminuição dos custos de agência. E Restr ${ }_{i t}$ representa a restrição financeira encontrada por algumas empresas.

A construção da variável dependente é inspirada no trabalho de Biddle et al. (2009) que estimam um modelo de investimento para cada firma como função de suas oportunidades de crescimento, conforme equação abaixo:

$$
\begin{aligned}
\text { Investimento }_{i t} & =\beta_{0} \\
& +\beta_{1} \text { CrescVendas }_{i, t-1} \\
& +\varepsilon_{i t}
\end{aligned}
$$

O erro do modelo pode ser considerado como a distância que a empresa está do seu investimento ideal. Assim, as empresas com resíduo mais próximo de zero foram consideradas como eficientes, as com resíduo muito distante de zero positivamente, como overinvestment e as com resíduo muito distante de zero negativamente, como underinvestment, conforme mostra o quadro 1.

\begin{tabular}{|c|c|}
\hline Variável & Definição \\
\hline INV_OTIMO & $\begin{array}{l}\text { Assume valor } 1 \text { se empresa faz investimentos de maneira eficiente e } 0 \\
\text { em caso contrário. }\end{array}$ \\
\hline OVER_INV & $\begin{array}{c}\text { Assume valor } 1 \text { se empresa faz investimentos acima do valor eficiente } \\
\text { eficiente e } 0 \text { em caso contrário. }\end{array}$ \\
\hline UNDER_INV & $\begin{array}{l}\text { Assume valor } 1 \text { se empresa faz investimentos aabaixo do valor eficiente } \\
\text { eficiente e } 0 \text { em caso contrário. }\end{array}$ \\
\hline
\end{tabular}

Quadro 1: Descrição das Variáveis Dependentes

As variáveis explicativas utilizadas no modelo estão descritas no quadro 2, elas foram inspiradas na literatura acerca do tema, principalmente no trabalho de Biddle et al. (2009). 
Quadro 2: Descrição das Variáveis explicativas

\begin{tabular}{|c|c|}
\hline Variável & Definição \\
\hline REPUTACAO & $\begin{array}{l}\text { Variável discreta que assume valores entre } 1 \text { e } 10 \text { de acordo com a classificação no ranking } \\
\text { Merco ou } 0 \text { caso não tenha feito parte do ranking no ano. }\end{array}$ \\
\hline FC_K & Fluxo de caixa corrente em razão do Estoque de Capital Passado \\
\hline VENDAS_K & Total das vendas em razão do Estoque de Capital Passado \\
\hline CRESC_VENDAS & Taxa de crescimento das vendas \\
\hline DIVIDA_K & Total do passivo em razão do Estoque de Capital Passado \\
\hline $\mathrm{ROE}$ & Lucro líquido em razão do Patrimônio Líquido \\
\hline $\mathrm{ROA}$ & Lucro líquido em razão do total do ativo \\
\hline EBITDA_JUROS & Taxa de cobertura de juros mensurada pelo Ebitda em razão do pagamento de juros \\
\hline In_AT & Tamanho da empresa mensurado pelo logaritmo natural do Ativo Total \\
\hline FOLGA_FIN & $\begin{array}{c}\text { Folga financeira medida pela razão entre ativos correntes e passivo circulante sobre a razão } \\
\text { entre dívida e ativo total. }\end{array}$ \\
\hline ACION_MAJ & $\begin{array}{l}\text { Variável dummy que assume valor um se a empresa possui um acionista com mais de } 50 \% \text { das } \\
\text { ações e zero em caso contrário. }\end{array}$ \\
\hline TIPO_ACION & $\begin{array}{l}\text { Variável dummy que assume valor um se o maior acionista é um indivíduo ou tem natureza } \\
\text { familiar e zero em caso contrário. }\end{array}$ \\
\hline ACION_GESTOR & $\begin{array}{l}\text { Variável dummy que assume valor um se o maior acionista também é gestor da empresa e zero } \\
\text { em caso contrário. }\end{array}$ \\
\hline KZ_REST & $\begin{array}{l}\text { Variável dummy que assume valor um se a empresa é classificada como restrita } \\
\text { financeiramente pelo índice } \mathrm{KZ} \text { e zero em caso contrário. }\end{array}$ \\
\hline
\end{tabular}

\subsection{MODELO DE REGRESSÃO ORDINAL}

Como a variável dependente apresenta três alternativas que possuem uma ordem natural, o modelo ordinal deve ser utilizado. Este modelo é uma generalização dos modelos binomiais e seu objetivo é descrever a probabilidade de ocorrência de cada um dos eventos descritos pela variável dependente em função de parâmetros, de modo que as probabilidades somem no máximo um para todas as alternativas.

O modelo ordinal é uma extensão do modelo binomial e pode ser utilizado quando a variável dependente apresenta um pequeno número de possibilidades que apresentam uma ordem naturalmente (CAMERON e TRIVEDI, 2010), neste caso são três: underinvestment, investimento eficiente ou overinvestment.

Dado o modelo de regressão: $y_{i}^{*}=x_{i}^{\prime} \beta+\varepsilon_{i}$ e definindo as possibilidades da variável dependente como $j=1,2$ ou 3 para underinvestment, investimento eficiente ou overinvestment, respectivamente, tem-se que a probabilidade de ocorrência do evento j é dada por:

$$
\begin{gathered}
\operatorname{Pr}\left(y_{i}=j\right)=P_{r}\left(\alpha_{j-1}<y_{i}^{*} \leq \alpha_{j}\right) \\
\operatorname{Pr}\left(y_{i}=j\right)=P_{r}\left(\alpha_{j-1}<x_{i}^{\prime} \beta+\varepsilon_{i}\right. \\
\left.\leq \alpha_{j}\right) \\
\operatorname{Pr}\left(y_{i}=j\right)=P_{r}\left(\alpha_{j-1}-x_{i}^{\prime} \beta<\varepsilon_{i}\right. \\
\left.\leq \alpha_{j}-x_{i}^{\prime} \beta\right)
\end{gathered}
$$

Ou seja, a probabilidade de ocorrência do evento j é a probabilidade de que $y_{i}^{*}$ esteja entre dois limites: $\alpha_{j-1}$ e $\alpha_{j}$ (CAMERON e TRIVEDI, 2010).

\section{RESULTADOS}

$\mathrm{Na}$ tabela 1 estão presentes os resultados encontrados através da regressão logística ordinal, que mensura as chances de uma empresa ser classificada como underinvestment, investimento eficiente ou 
overinvestment, nesta ordem. A estimação foi feita usando o estimador de heterocedasticidade robusto para controlar as diferenças entre as empresas.

Os números exibidos ao lado das variáveis são os coeficientes da regressão e os símbolos *, ** $e^{* \star \star}$ representam a significância estatística de cada variável a $10 \%, 5 \%$ e $1 \%$, respectivamente. Abaixo dos coeficientes, entre parênteses, estão os erros padrão de cada estimativa.

Tabela 1: Regressão logística ordinal

\begin{tabular}{|c|c|c|}
\hline \multirow[t]{2}{*}{ REPUTACAO } & 0,007 & \\
\hline & $(0,023)$ & \\
\hline \multirow[t]{2}{*}{ FC_K } & $-0,795$ & * \\
\hline & $(0,428)$ & \\
\hline \multirow{2}{*}{ VENDAS_K } & 0,010 & \\
\hline & $(0,020)$ & \\
\hline \multirow[t]{2}{*}{ DIVIDA_K } & $-0,163$ & ** \\
\hline & $(0,078)$ & \\
\hline \multirow{2}{*}{ ROE } & 0,232 & \\
\hline & $(0,261)$ & \\
\hline \multirow{2}{*}{$\mathrm{ROA}$} & 3,180 & $\star *$ \\
\hline & $(1,494)$ & \\
\hline \multirow[t]{2}{*}{ EBITDA_JUROS } & 0,000 & \\
\hline & $(0,00)$ & \\
\hline \multirow{2}{*}{ In_AT } & 0,012 & \\
\hline & $(0,042)$ & \\
\hline \multirow[t]{2}{*}{ FOLGA_FIN } & $-0,015$ & * \\
\hline & $(0,080)$ & \\
\hline \multirow{2}{*}{ ACION_MAJ } & 0,127 & \\
\hline & $(0,124)$ & \\
\hline \multirow[t]{2}{*}{ TIPO_ACION } & 0,199 & \\
\hline & $(0,283)$ & \\
\hline \multirow[t]{2}{*}{ ACION_GESTOR } & $-0,252$ & \\
\hline & $(0,295)$ & \\
\hline \multirow[t]{2}{*}{ KZ_REST } & 0,39 & $\star \star *$ \\
\hline & $(0,169)$ & \\
\hline \multirow[t]{2}{*}{ Cut1 } & $-0,19$ & \\
\hline & $(0,619)$ & \\
\hline \multirow[t]{2}{*}{ Cut2 } & 0,511 & \\
\hline & $(0,618)$ & \\
\hline Efeito fixo da firma & Não & \\
\hline № Observações & 1137 & \\
\hline Teste de Wald & 38,41 & *** \\
\hline
\end{tabular}


Os resultados encontrados mostram que a reputação apresenta coeficiente positivo, porém muito pequeno, para a chance de estar em um nível de investimento mais alto. Além disso, este coeficiente não é significativo.

As variáveis significativas do modelo são o fluxo de caixa em razão do estoque de capital passado, a dívida sobre o estoque de capital passado e a folga financeira, que apresentam relação negativa ao fato de estar em um nível maior de investimento; e o retorno sobre os ativos e o índice de restrição financeira, que apresentam relação positiva.

O teste de Wald é utilizado para assegurar a significância das variáveis no modelo. Neste caso, a hipótese nula não é rejeitada e, portanto, os parâmetros são significativos para o modelo.

Em suma, percebe-se com do modelo de regressão logística ordinal que a reputação não exerce impacto significativo na probabilidade de a empresa mudar de um nível de investimento para outro. Contudo, é preciso considerar que são utilizadas apenas empresas que já estiveram no ranking alguma

\section{REFERÊNCIAS}

[1]. ANGINER, D. et al. Firm Reputation and the Cost of Debt Capital. 2016.

[2]. ARGENTI, P. A.; FORMAN, J. The power of corporate communication: Crafting the voice and image of your business. McGraw Hill Professional, 2002.

[3]. BIDDLE, G. C.; HILARY, G.. Accounting quality and firm-level capital investment. The Accounting Review, 2006. v. 81, n. 5, p. 963-982.

[4]. BIDDLE, G. C.; HILARY, G.; VERDI, R. S. How does financial reporting quality relate to investment efficiency? Journal of accounting and economics, 2009. v. 48, n. 2, p. 112-131.

[5]. BORDA, A. et al. Looking for a service opening: Building reputation by leveraging international activities and host country context. Journal of World Business, 2016.

[6]. CAMERON, A. C.; TRIVEDI, P. K. Microeconometrics using stata. College Station, TX: Stata press, 2009.

[7]. CAO, Y. et al. Company reputation and the cost of equity capital. Review of Accounting Studies, 2015 v. 20, n. 1, p. $42-81$. vez, ou seja, todas já foram consideradas por um, ou mais anos, como empresas bem reputadas.

\section{CONSIDERAÇÕES FINAIS}

Os resultados preliminares mostram que a reputação não exerce impacto significativo nas chances de a empresa ter investimentos eficientes, acima ou abaixo do ideal. Contudo, é preciso considerar que todas as empresas presentes na amostra já estiveram entre as 100 empresas espanholas mais reputadas em um ou mais anos. Portanto, este resultado mostra apenas que estar em melhor colocação no ranking não exerce impacto significativo na probabilidade de investir de maneira eficiente ou não.

Com isso, cabe destacar que é interessante que em estudos futuros esta análise seja refeita considerando dados de empresas que nunca estiveram entre as 100 melhores no ranking Merco e construir uma nova mensuração para reputação para verificar se estes resultados são mantidos ou não.

[8]. DE LONG, J. B.; SUMMERS, L. H. Equipment investment and economic growth. The Quarterly Journal of Economics, 1991. v. 106, n. 2, p. 445-502.

[9]. DOWLING, G. Creating Corporate Reputations: Identity, Image and Performance: Identity, Image and Performance. OUP Oxford, 2000.

[10]. EASTERLY, W. R. Globalization, inequality and development: the big picture. Institute for Monetary and Economic Studies, Bank of Japan, 2004.

[11]. FERNANDO, C. S. et al. Prestige without purpose? Reputation, differentiation, and pricing in US equity underwriting. Journal of Corporate Finance, 2015. v. 32, p. 41-63.

[12]. FOMBRUN, Charles. Reputation. John Wiley \& Sons, Ltd, 1996.

[13]. FOMBRUN, C.; VAN RIEL, C. The reputational landscape. Corporate reputation review, 1997. p. 1-16.

[14]. JIAN, M. LEE, K. W. Does CEO reputation matter for capital investments?. Journal of Corporate Finance, 2011. v. 17, n. 4, p. 929-946. 
[15]. LIBERMAN, A. The value of a good credit reputation: Evidence from credit card renegotiations. Journal of Financial Economics, 2016 v. 120 , n. 3, p. 644-660.

[16]. MCGUIRE, J. B.; SCHNEEWEIS, T.; BRANCH, B. Perceptions of firm quality: A cause or result of firm performance. Journal of management, 1990. v. 16, n. 1, p. 167-180.

[17]. ROBERTS, P. W.; DOWLING, G. R. Corporate reputation and sustained superior financial performance. Strategic management journal, 2002 v. 23, n. 12, p. 1077-1093.

[18]. ROCHLIN, S. et al. Defining the Competitive and Financial Advantages of Corporate Responsibility and Sustainability. Project ROI, 2015.

[19]. SRITVASTAVA, R. K. et al. How Do Reputations Affect Corporate Performance? The Value of Corporate Reputation: Evidence from the Equity Mara kets. Corporate Reputation Review, 1997. v. 1, n. 1, p. 61-68. 


\section{Bapítulo 19}

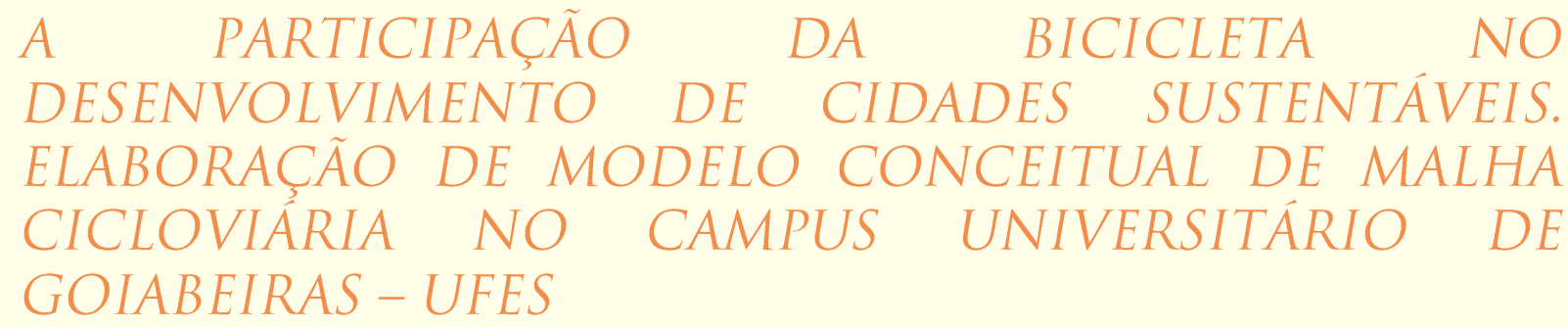

\section{Miguel Macedo de Carvalho Filho}

Antônio Luiz Caus

Marta Monteiro da Costa Cruz.

Resumo: Buscando maior adesão da bicicleta como meio de transporte e reduzir os conflitos existentes entre pedestres $\mathrm{x}$ ciclistas $\mathrm{x}$ automóveis no interior do campus universitário de Goiabeiras - Ufes, em Vitória - ES, este trabalho elaborou um modelo conceitual de malha cicloviária para o campus em questão. Através de métodos qualitativos e quantitativos, comparou-se Vitória a outras cidades modelos em mobilidade por bicicleta, como Paris e Amsterdam e baseado em dados da pró reitoria de planejamento da universidade, estimou-se o público em potencial para adesão desse meio de deslocamento. Em campo, foram levantados os caminhos existentes no interior da Ufes e elaborado um diagnóstico sobre a estrutura física de cada um deles, bem como definidos os pontos de origem (os acessos ao campus) e polos geradores de demanda (centros de ensino e de serviços) da universidade. A escolha do melhor traçado de malha cicloviária foi obtido respeitando as árvores protegidas ambientalmente do campus, bem como as possibilidades de intervenção e expansão da infraestrutura física da Ufes, visando aproveitar ao máximo os caminhos já existentes. o mapa de traçados cicloviários e os demais estudos realizados neste artigo foram entregues a prefeitura universitária como sugestão na elaboração do plano diretor físico do campus. 


\section{INTRODUÇÃO}

Em 3 de janeiro de 2012 foram instituídas no Brasil as diretrizes da Política Nacional de Mobilidade Urbana, fundamentadas em alguns princípios e objetivos, tais como:

-Desenvolvimento sustentável das cidades, nas dimensões socioeconômicas e ambientais (Art 5ํㅡㄹ parágrafo II);

-Prioridade nos modos de transporte não motorizados sobre os motorizados [...] (Art 6으, parágrafo II);

-Promover o desenvolvimento sustentável com a mitigação dos custos ambientais [...] (Art 7ํㅡ, parágrafo IV);

Atualmente, o automóvel é visto como um rápido meio de ir e vir e que pode ser utilizado, mesmo que parcialmente, em todos os deslocamentos rotineiros de uma sociedade. De acordo com dados do Departamento Nacional de Trânsito (DENATRAN, 2017) a frota de automóveis no Brasil já é de 51.896 milhões, sendo 910.911 mil apenas no Espírito Santo, o que equivale a 4,26 pessoas/carro.

Apesar de todo o conforto, o uso exagerado do carro traz custos sociais como os congestionamentos cada vez maiores, doenças causadas devido ao excesso de poluição e sedentarismo, impactos ambientais provenientes da emissão de gases estufa, entre outros.

Segundo Blondel, Mispelon e Ferguson (2011), os automóveis chegam a emitir $271 \mathrm{~g}$ de Co2/km.passageiro, configurando-se como grandes vilões ambientais e causadores de problemas respiratórios em cidades como São Paulo, onde apesar de transportarem apenas 30\% da população são responsáveis por $72,6 \%$ das emissões de gases do efeito estufa, de acordo com inventário do Instituto de Energia e Meio Ambiente (IEMA, 2017).

Além disso, segundo o Diagnóstico Nacional do Esporte (2015), 45,9\% dos brasileiros não praticam atividade física regularmente, com o sedentarismo estando por trás de $13,2 \%$ das mortes anuais no Brasil.

A bicicleta surge, sob o ponto de vista de sua utilização como meio de transporte rotineiro, como uma alternativa sustentável aos problemas supracitados, podendo em diversos casos substituir os deslocamentos feitos por veículos de passeio e transporte coletivo. Além de não emitir poluentes conforme é utilizada, ela proporciona uma maior aderência à prática constante de atividade física pelas pessoas, principalmente se inseridas em atividades do dia-a-dia, como ir pedalando ao trabalho/estudo, e não em momentos de lazer (HILLSDON; THOROGOOD, 1996).

Enxerga-se na cidade de Vitória, Espírito Santo, um enorme potencial para o desenvolvimento de uma mobilidade mais sustentável e ativa. Por comparação, no que tange sua área geográfica, a capital capixaba possui $98,194 \mathrm{~km}^{2}$ de extensão (IBGE, 2017), sendo menor que outras cidades consideradas referências na mobilidade por bicicleta, a exemplo de Amsterdã que possui 219,3km² (Central Agency for Statistics, CBS, 2015) e Paris $105,4 \mathrm{~km}^{2}$ (Institute Nationale de la statique et des études économiques, INSEE, 2014).

Com relação a sua topografia, a cidade é de maioria plana, possuindo uma região menos populosa em áreas alto relevo, já que este tipo de topografia encontra-se em grande parte concentrada no Parque da Fonte Grande, como pode ser visto na Figura 1. 
Figura 1 - Mapa topográfico da cidade de Vitória, ES

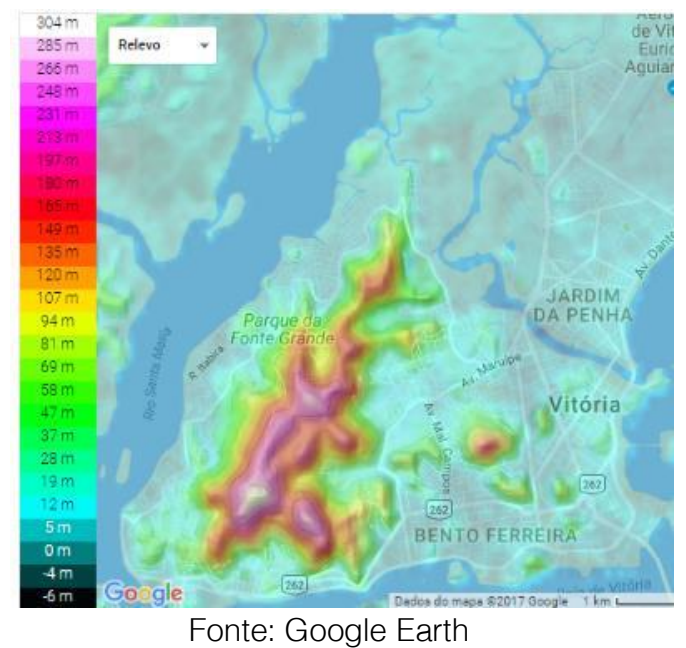

Já a topografia na região do Campus Universitário da Universidade Federal do
Espírito Santo (Ufes) é em sua maioria plana, como mostra a Figura 2:

Figura 2: Mapa topográfico da Universidade Federal do Espírito Santo e do seu entorno

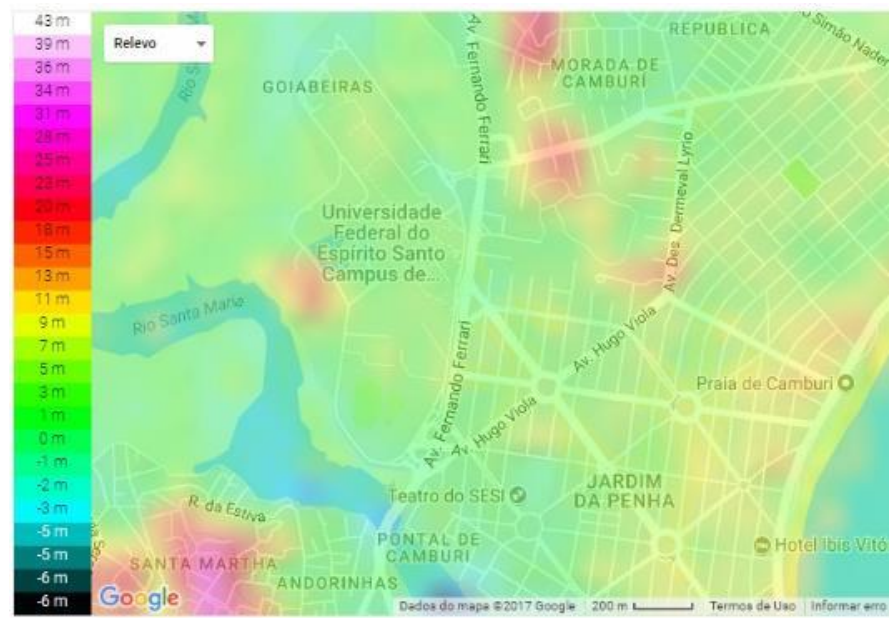

Fonte: Google Earth

Estima-se que a distância média ideal para uma pessoa pedalar é de 7,5km (Coleção Bicicleta Brasil - programa brasileiro de mobilidade por bicicleta, 2007). Adotou-se, nesta análise, um raio de $5 \mathrm{~km}$ em torno do Campus Universitário (foi adotado um raio de $5 \mathrm{~km}$ ao invés dos $7,5 \mathrm{~km}$ recomendadados para compensar as curvas e trechos não lineares que os ciclistas realizam. Sendo assim, $5 \mathrm{~km}$ de raio em linha reta representam uma distância maior a ser percorrida). Cruzando esse raio com os dados fornecidos da quantidade de docentes e discentes da universidade em questão, fornecidos pela Pró Reitoria de Planejamento (2017), constatou-se o público em potencial para adesão do uso da bicicleta em $38 \%$ da comunidade que frequenta o local. Além disso, diversas rotas cicloviárias chegam ao Campus oferecendo um caminho mais seguro para aqueles que optam pela bicicleta como meio de transporte. A Figura 3 apresenta em vermelho as ciclovias e em verde as ciclorrotas nos bairros próximos a UFES. 
Figura 3: Mapa cicloviário da cidade de Vitória, ES.

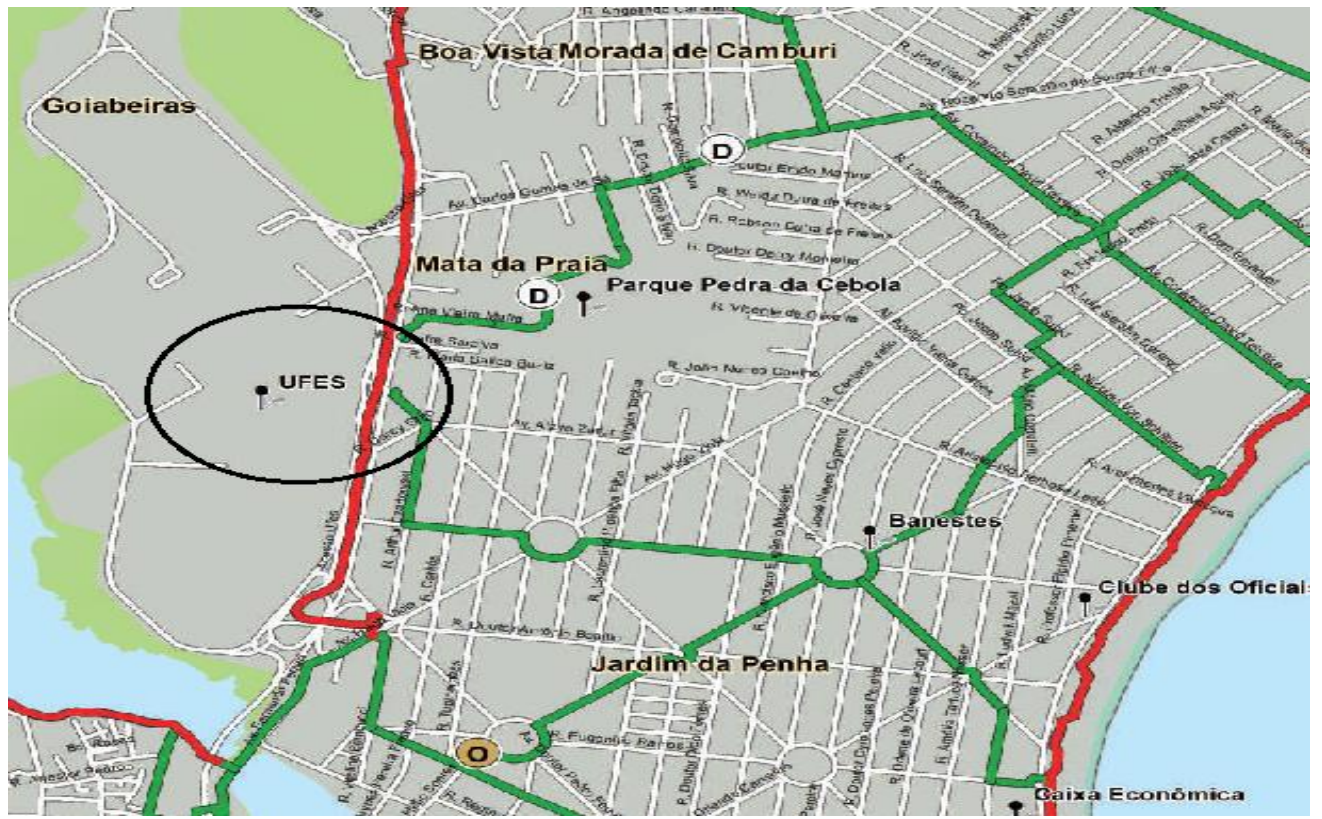

Fonte: Secretaria do Estado de Transportes e Obras Públicas

Baseado nos benefícios que o uso da bicicleta pode proporcionar ao seu usuário e à sociedade em que está inserida, ao meio ambiente e ao tráfego urbano, bem como nas diretrizes de Política Nacional de Mobilidade Urbana e no potencial que a cidade de Vitória e a Ufes possuem em desenvolver este modelo de mobilidade ativa, este estudo busca apresentar o processo de elaboração de um modelo conceitual de malha cicloviária para o Campus Universitário de Goiabeiras, da Ufes, localizado em Vitória (ES) partindo da ideia de facilitar a vida dos ciclistas já existentes que frequentam o local, estimulando que esses continuem a usar a bicicleta como meio de locomoção, bem como ajude a atrair novos adeptos desse modo de deslocamento. O plano proposto também busca por um fim aos conflitos de tráfego existentes entre pedestre $x$ ciclista $x$ automóvel, permitindo que a região onde 0 Campus está inserido se torne mais harmônica, ativa, sustentável e saudável.

Este artigo está subdividido em cinco capítulos. No capítulo 2 será apresentada a fundamentação teórica para o desenvolvimento do modelo. O capítulo 3 apresentará as metodologias utilizadas. Em seguida, o capítulo 4 mostrará os resultados obtidos e o capítulo 5 as considerações finais.

\section{FUNDAMENTAÇÃO TEÓRICA}

Muitas pessoas entendem como ciclovia todo e qualquer caminho feito para o tráfego da bicicleta, mas essa definição não está correta.

As definições de vias específicas para a circulação da bicicleta (Caderno de referência para elaboração de plano de mobilidade por bicicleta nas cidades, 2007) são basicamente três:

Ciclorrota: Todo e qualquer caminho, não precisando possuir qualquer tipo de sinalização indicativa, em que a bicicleta pode trafegar. Não possui segregação física nem faixa pintada.

Ciclovia: Espaço destinado à circulação exclusiva de bicicletas, segregado fisicamente da via onde está contida, devendo possuir sistema de drenagem próprio. Deve possuir largura mínima de 2,20m. Na figura abaixo é apresentada o modelo de uma ciclovia bidirecional segregada fisicamente da via dos automóveis e da calçada de pedestres: 


\section{Figura 4: Representação de uma ciclovia.}

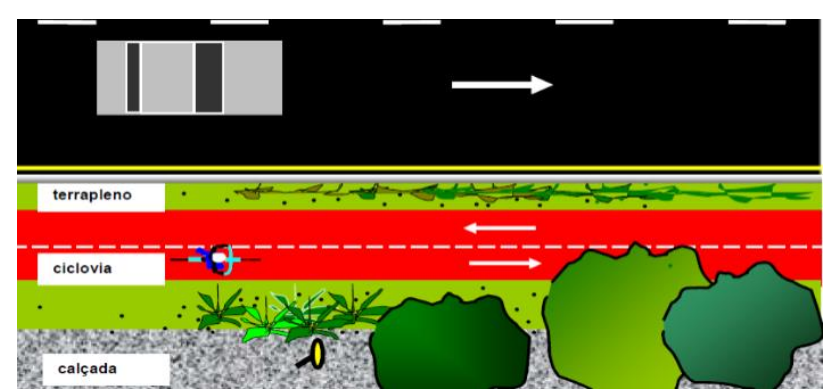

Fonte: GEIPOT, 2001

Ciclofaixa: Espaço destinado à circulação exclusiva de bicicletas, estando no mesmo nível e sem separação física da via onde está contida (possuindo no máximo tachões descontínuos para segregá-la), com seus limites demarcados através de uma faixa pintada ao chão. Utiliza do mesmo sistema de drenagem do local onde está inserido. Deve possuir largura mínima de 2,20m, quando bidirecional. Como pode ser observado na Figura 5, a ciclofaixa não possui segregação física contínua da via de automóveis.

Figura 5: Representação da ciclofaixa em via de automóveis.

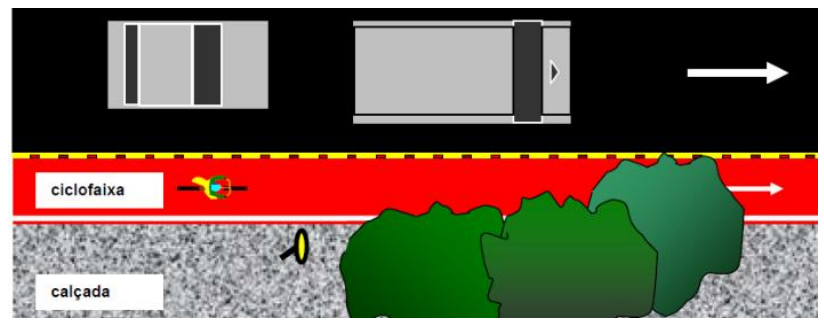

Fonte: GEIPOT, 2001

Há tambem duas definições importantes referentes aos locais de estacionamento das bicicletas: o paraciclo e o bicicletário. A diferença básica entre eles é que no primeiro existe apenas um suporte fixo para a bicicleta ser presa, já o segundo, além de possuir o suporte fixo, deve estar em um local fechado com controle de entrada e saída de pessoas, segurança e cobertura.

De uma maneira geral, motoristas e pedestres acreditam que o lugar do ciclista não é nem na rua compartilhando a via com o carro, nem na calçada com as pessoas. Porém, é isso que afirma o código de trânsito brasileiro (CTB, 1998).

No Art. 58 do CTB, nas vias urbanas e nas rurais de pista dupla, a circulação de bicicletas deverá ocorrer, quando não houver ciclovia, ciclofaixa, ou acostamento, ou quando não for possível a utilização destes, nos bordos da pista de rolamento, no mesmo sentido de circulação regulamentado para a via, com preferência sobre os veículos automotores. Já no Art. 29, parágrafo 2ํㅡㄹ devem ser respeitadas as normas de circulação e conduta estabelecidas neste artigo, em ordem decrescente, os veículos de maior porte serão sempre responsáveis pela segurança dos menores, os motorizados pelos não motorizados e, juntos, pela incolumidade dos pedestres.

Diante das tipologias de vias cicláveis e do CTB, entende-se que a bicicleta pode trafegar por qualquer caminho existente, mas é desejável sempre que possível um caminho exclusivo para ela, como uma ciclovia ou ciclofaixa. 


\section{METODOLOGIA}

Com base nas definições apresentadas, para a elaboração do modelo conceitual cicloviário no Campus da Ufes, o tipo de via para bicicleta será definido da seguinte forma:

- Ciclofaixa em via de tráfego veicular, sempre que houver espaço para a sua inserção, respeitando os $2,20 \mathrm{~m}$ mínimos para a bicicleta e os $2,7 \mathrm{~m}$ para cada faixa de automóvel que houver.

- Ciclofaixa em calçada, sempre que houver espaço para a sua interseção, respeitando os 2,20m mínimos para a bicicleta. Deve ser respeitado também o mínimo recomendado pela ABNT NBR 9050:2004 de 1,50m para pedestres.

- Ciclovia, sempre que as dimensões da via ou calçada não comportarem uma ciclofaixa, sempre que não houver a possibilidade de ampliação da calçada ou que a ampliação for mais custosa que uma ciclovia.

- Ciclorrota sinalizada compartilhada com calçada, apenas para calçadas que liguem trechos internos dentro de um mesmo polo de origem, para ligarem uma ciclofaixa ou ciclovia a um bicicletário ou em calçadas existentes que não são comumente utilizadas por pedestres.

Para o desenvolvimento do modelo conceitual de malha cicloviária, foram seguidos dois passos (letras a e b) entre os recomendados pelo Caderno de Referência para elaboração do Plano de Mobilidade por Bicicleta nas cidades, do Ministério das Cidades e outros três passos (letras c, d, e) recomendados por Gabriel (2016):

a) Definição da área de atuação do projeto. (A área, como citado anteriormente, é - Campus Universitário de Goiabeiras, da Universidade Federal do Espírito Santo).

b) Obtenção de mapas e plantas identificadoras da área em estudo;

c) Análise das origens e destinos;

d) Análise das vias e de seus pontos críticos;

e) Escolha do traçado;

A partir de um mapa 3D fornecido pela Pro Design Ufes, foram indicados nele os centros de ensino e principais serviços oferecidos, os quais foram agrupados em 11 polos geradores de demanda, sendo os centros de ensino indicados por letras e os serviços por números:

Figura 5: Mapa 3D do Campus Universitário da UFES, com seus principais pontos de origem e destino destacados.

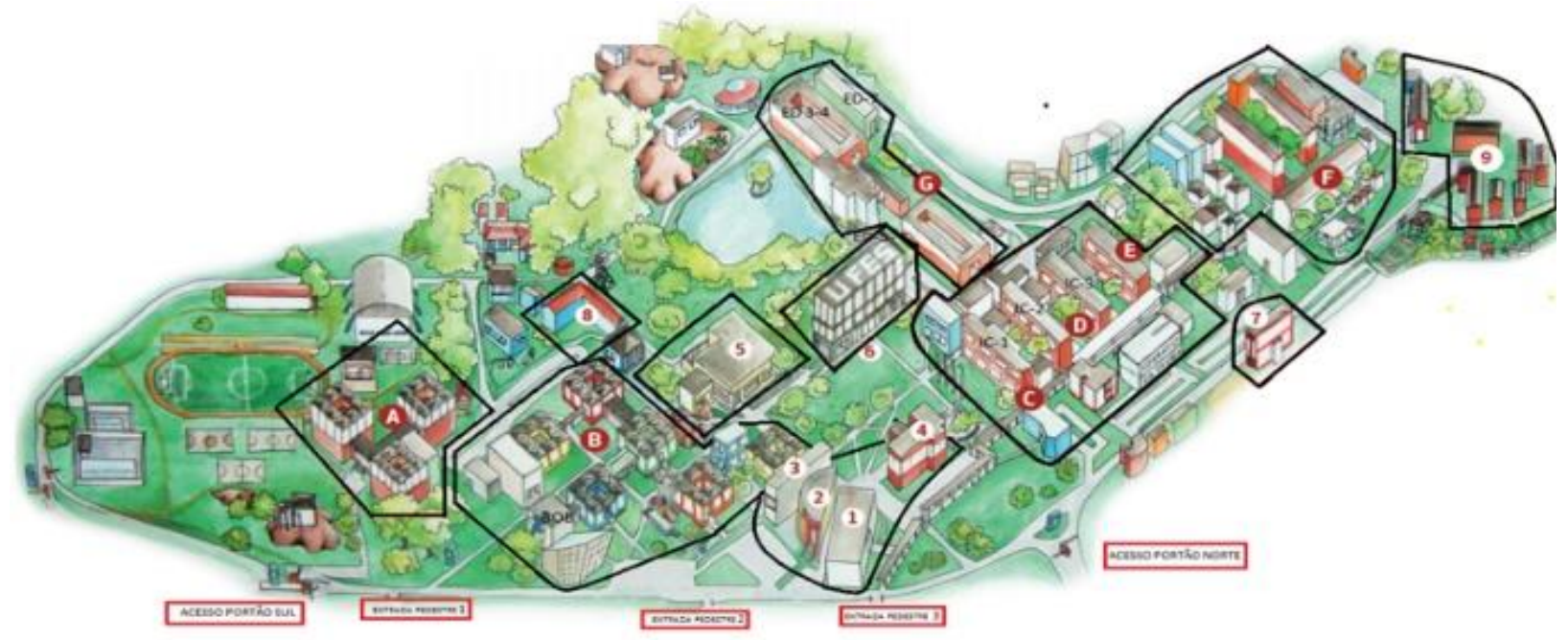

Fonte: Pro Design Ufes. Nota: Mapa modificado pelo autor 


\section{1 polo: (A) CEFD - Centro de Educação Física e Desportos;}

\section{2o polo: (B) CAR - Centro de artes; \\ 3o polo: (C) CCE - Centro de ciências exatas, (D) $\mathrm{CCHN}$ - Centro de ciências humanas e naturais, (E) CE - Centro de educação; \\ 4ำ polo: (F) CT - Centro tecnológico \\ 5o polo: (G) CCJE - Centro de ciências jurídicas e econômicas}

6o polo: (1) Pró-reitoria de extensão e próreitoria de graduação; (2) Teatro universitário; (3) Cine Metrópolis; (4) Reitoria e pró-reitoria de pesquisa e pós graduação;

\section{7o polo: (5) Restaurante Universitário; \\ 8o polo: (6) Biblioteca Central; \\ 9o polo: (7) Centro de línguas; \\ 10ำ polo: (8) Creche; \\ 11o polo: (9) Prefeitura universitária;}

Foram levantadas também todas as possíveis entradas para ciclistas no Campus de Goiabeiras, sendo selecionadas cinco entradas, nas quais duas são usualmente utilizadas por automóveis e três por pedestres. Tais entradas representam os pontos de origem, que são:

1a origem: Acesso portão sul;

$2^{\underline{a}}$ origem: Entrada pedestres 1;

3를 origem: Entrada pedestres 2;

4ํㅡㄹ origem: Entrada pedestres 3;

\section{5a origem: Acesso portão norte;}

O planejamento de um sistema cicloviário deve aproveitar as infraestruturas já existentes fazendo a conexão das rotas para dar maior rapidez ao ciclista (BASTOS, 2009). Para que este sistema tenha real uso por parte da população, é necessário que a construção deste se viabilize nos mesmos trajetos que os usuários da bicicleta já trafegam, pois normalmente é a rota origem/destino mais rápida para eles (BASTOS, 2009).

Buscando identificar todos os caminhos existentes na área interna da Ufes, foi-se a campo acompanhando as rotas existentes, as quais foram inseridas na figura 6 .

Figura 6: Mapa de caminhos da Ufes.

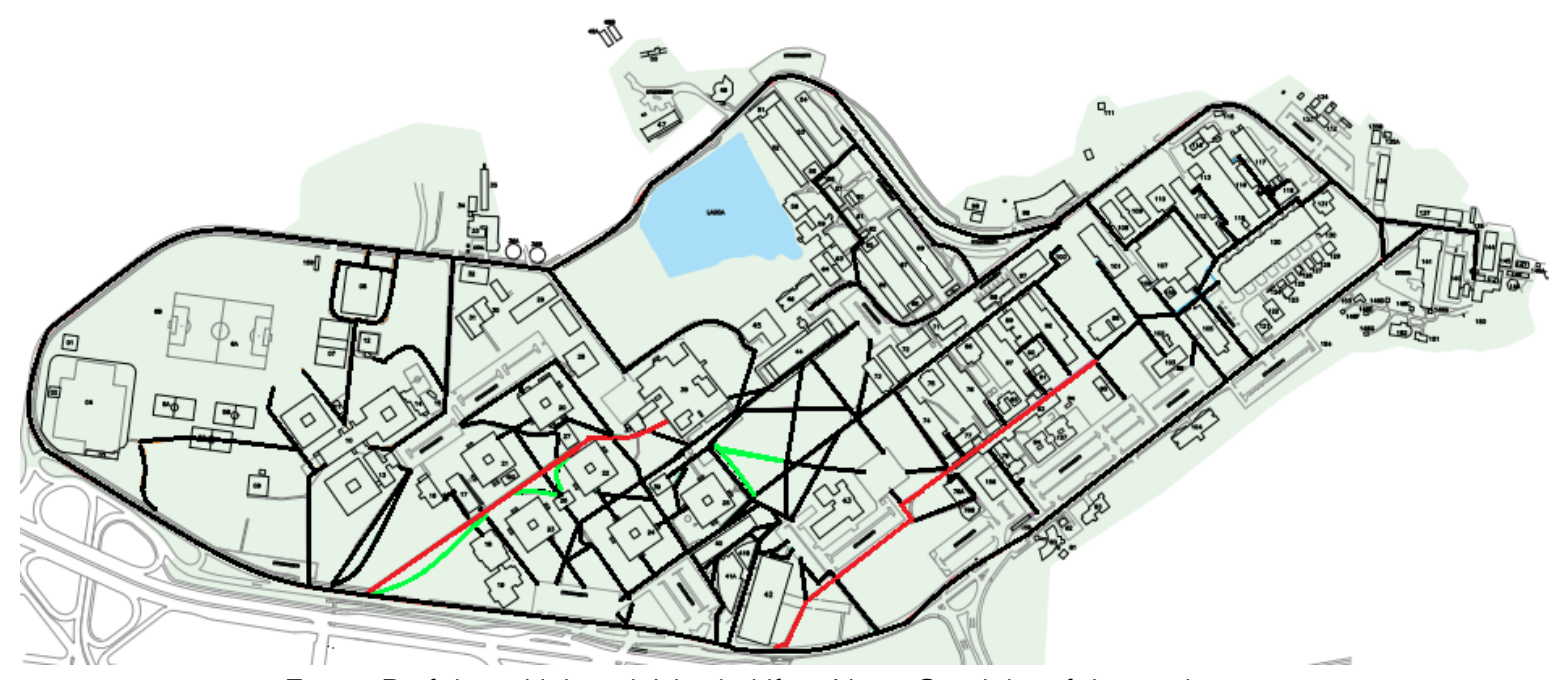

Fonte: Prefeitura Universitária da Ufes. Nota: Caminhos feitos pelo autor

Na cor preta, constam os caminhos usuais da universidade, sejam eles para carros ou pedestres, dotados de estrutura física adequada, como calçamento/pavimento. $\mathrm{Na}$ cor verde, temos as rotas sem estrutura física adequada onde se formaram caminhos de terra batida em meio a áreas abertas, sendo usualmente utilizados como "corta caminho" para pedestres ou utilizados por ciclistas para trafegarem em local separado daqueles que andam a pé. $\mathrm{Na}$ cor vermelha são as principais passarelas da universidade, consideradas rotas críticas, visto que possuem uma circulação intensa de pessoas, bicicletas e moto, além de servirem como a principal ligação entre as duas mais movimentadas entradas de pedestres da Ufes e seus maiores centros de ensino. 
Para a escolha dos caminhos, foram utilizados os seguintes critérios:

- Criação de um anel cicloviário externo, com vias radiais dirigindo-se ao interior do Campus, objetivando, quando possível, tirar o alto fluxo de bicicleta do interior do Campus e deixando-o na parte mais externa, apenas fazendo vias finais que as leve para o interior do Campus, no destino final;

- Quando possível, utilizar as estruturas oficiais de pedestres ou automóveis já existentes. Como a utilização da bicicleta não exerce grande esforço sobre a pavimentação, ela não necessita de uma infraestrutura maior do que a já utilizada (FERREIRA, 2007), sendo assim a opção por ciclofaixa uma alternativa mais barata;

- Trechos que tenham calçadas que raramente são utilizadas por pedestres ou que liguem apenas prédios isolados a outra rota principal, tendo elas baixo fluxo de pedestres, ciclorrota;

- Para trechos críticos, trechos que não possibilitariam a inserção de ciclofaixa com largura mínima ou a largura mínima para pedestres, trechos onde não há a possibilidade de ampliação da calçada, utilização de ciclovia;

- As vias cicláveis devem passar obrigatoriamente em parte dos paraciclos já existentes de cada polo gerador de demanda, visto que em tais locais são onde as bicicletas são estacionadas e, portanto, trata-se do destino final dos ciclistas.

\section{RESULTADOS E DISCUSSÕES}

Para se chegar ao melhor traçado cicloviário, foi feito levantamento das larguras dos caminhos da Ufes, de sua localização específica, da estimativa de custos para aterro, terraplenagem e ampliação da calçada. Alguns traçados foram descartados por passarem em locais onde existem árvores nativas que não podem ser removidas, ou ser uma região que sofre constantes alagamentos, devido ao Campus Universitário ter sido construído sobre um mangue. A Figura 7 indica a escolha final dos traçados:

Figura 7: Mapa conceitual de traçados cicloviários no Campus Universitário.

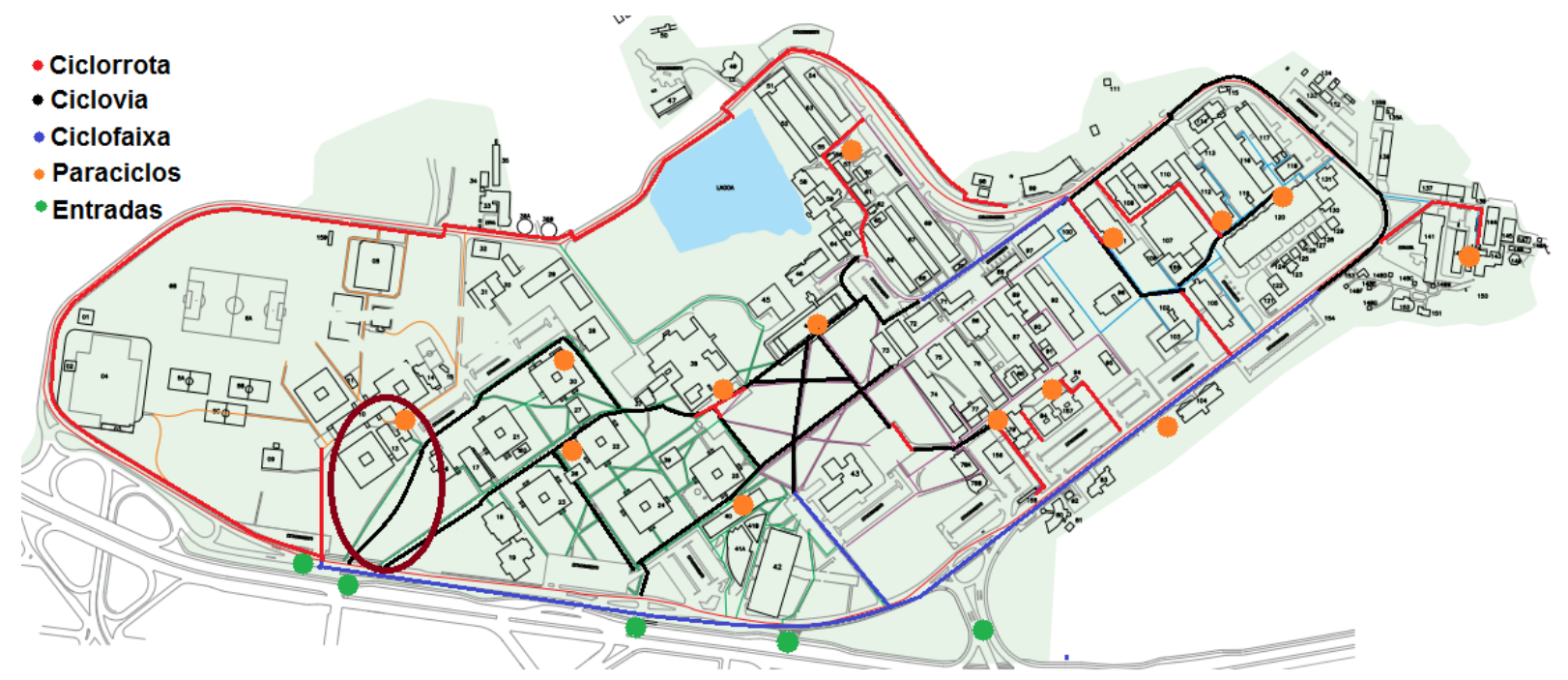

Fonte: Prefeitura Universitária da Ufes. Nota: Mapa modificado pelo autor

- Região 7, 9 integradas ao Anel cicloviário: Foram utilizadas ciclorrotas em calçada, ciclofaixa na via de automóvel e ciclovia.

A ciclorrota foi inserida em uma calçada de 2,5 metros que não é muito utilizada por pedestres visto que está longe das entradas e após todos os polos de destino. A ciclofaixa foi utilizada na parte da via que possui entre 9 e 10 metros de largura, onde sua inserção obedece as regras do Departamento Nacional de Infraestrutura de Transportes (DNIT) de largura mínima. A ciclovia foi utilizada apenas onde a ciclofaixa não obedeceria à largura 
mínima para automóveis, sendo assim escolhido um traçado onde a ciclovia passaria na calçada do trecho.

Por fim, o anel foi pensado como uma alternativa de caminho ao trecho crítico que ligava a entrada aos destinos C, D, E e F. Desta forma, os ciclistas iriam das entradas rodeando o Campus e acessando uma das vias radiais para chegar ao destino final, sem precisar acessar as passarelas saturadas de pedestres, tendo uma rota exclusiva para trafegar, com distância semelhante e podendo desenvolver uma velocidade maior já que o seu caminho não contará com alta circulação de pessoas a pé.

- Região A, B, 1, 2, 3, 4, 5, 6, 8: Optou-se pelo uso de ciclovias para extinguir o conflito entre pedestres $x$ ciclistas, aproveitando caminhos "não oficiais" já existentes devido ao seu já atual uso corriqueiro pelos próprios ciclistas existentes.

Essa região é a mais movimentada do Campus já que além de compreender um dos centros de ensino, compreende também o restaurante universitário, a biblioteca central e - local de serviços administrativos da universidade. Outro fator que motivou a escolha da ciclovia nesta região foi o fato de possuir árvores nativas bem próximas das calçadas, sendo consideradas de proteção ambiental e proibidas de serem cortadas ou removidas e colocadas em outro local, fazendo com que a ampliação da via de pedestre para uma posterior inserção de ciclofaixa ou compartilhamento de via fosse impossível. Desta maneira, a ciclovia tendo seu próprio caminho segregado, pode contornar as árvores, tendo uma liberdade maior de traçado.

- Região F, 9: Ciclovias radiais e ciclorrotas compartilhadas em passarela de pedestres.

Foram utilizadas ciclorrotas radiais ligando o interior desse ponto de destino a trechos do anel cicloviário. Em algumas partes, foi escolhido ciclovia, pois a passarela possui $1,2 \mathrm{~m}$, valor limite mínimo do exigido pela
ABNT para garantir a acessibilidade da via. Logo, optou-se pela criação de uma ciclovia paralela aos caminhos já existentes.

- Região G: Ciclorrotas compartilhadas com calçada de pedestres.

Para a região $G$, a opção foi a mais simples e barata, as ciclorrotas, visto que os caminhos de pedestres no local possuem calçadas de cerca de 4 metros de largura e tráfego de pedestres não saturados já que é apenas para deslocamento da própria região (a região G não é um caminho intermediário para pessoas que se deslocam para outros destinos, por exemplo. Ou seja, só circula nele quem realmente está indo ou voltando dele). Vale ressaltar que, para ciclorrotas, apesar de não ser obrigatório, são recomendadas sinalizações dizendo que no local é permitido o tráfego de bicicletas e que os pedestres possuem preferência.

\section{CONSIDERAÇÕES FINAIS}

Baseado nas diretrizes da Política Nacional de Mobilidade Urbana, o trabalho se propôs a elaborar um estudo conceitual de traçados cicloviários para o Campus Universitário de Goiabeiras, a ser entregue a Prefeitura Universitária, para que este seja utilizado na elaboração do próximo plano diretor físico da universidade, com previsão para o ano de 2020.

As pessoas andam mais de bicicleta quando se sentem mais seguras para realizar tal atividade e a maioria delas se sente mais segura quando as vias cicláveis são separadas das vias dos automóveis (Monsere et al. 2014).

Assim sendo, este trabalho conclui o primeiro passo necessário para que a Ufes se torne um local mais "amigo" dos ciclistas, criando um ambiente favorável para que mais pessoas possam optar por utilizar a bicicleta como meio de transporte, auxiliando assim no desenvolvimento de uma cidade mais humana e sustentável. 


\section{REFERÊNCIAS}

[1]. ASSOCIAÇÃO BRASILEIRA DE NORMAS TÉCNICAS. NBR 9050, Acessibilidade a edificações, mobiliário, espaços e equipamentos urbanos. Rio de Janeiro: ABNT, 2004.

[2]. BASTOS, Virginia MAGANO. Proposta de um sistema de transporte cicloviário inclusivo na cidade do Rio Grande - RS. 2009

[3]. BLONDEL, Benoît; MISPELON, Chloé; FERGUSON, Julian. Quantifying CO2 savings of cycling. Brussels: European Cyclists Federation ASBL, 2011.

[4]. BRASIL. Lei n. 12.587, de 3 de janeiro de 2012. Institui a Política Nacional de Mobilidade Urbana. Disponível em: <http://www.planalto.gov.br/ccivil_03/_ato20112014/2012/lei//12587.htm>. Acesso em: 25 de março de 2017.

[5]. BRASIL. Lei no 9.503, de 23 de setembro de 1997. Institui o Código de Trânsito Brasileiro. Disponível em <https://www.planalto.gov.br/>. Acesso em: 25 de março de 2017.

[6]. CENTRAAL BUREAU VOOR DE STATISTIEK - CBS - Population Register Data, 2015. Disponível em < https://www.cbs.nl/engb/background/2016/01/population-register-databasis-for-the-netherlands-population-statistics>. Acesso em: 01 de junho de 2017.

[7]. DEPARTAMENTO NACIONAL DE TRÂNSITO - DENATRAN - Frota de veículos 2017, de 26 de abril de 2017. Disponível em <http://www. denatran. gov. br/estatistica/610-frota2017 > . Acesso em: 20 de maio de 2017.

[8]. FERREIRA, Clarisse Rocha (2007). Análise de Parâmetros que afetam a Avaliação Subjetiva de Pavimentos Cicloviários: Um estudo de caso em Ciclovias do Distrito Federal. 2007

[9]. GABRIEL, Paulo Victor. Mobilidade urbana sustentável para o município de Criciúma: a implantação de uma infraestrutura cicloviária. 2016
[10]. EMPRESA BRASILEIRA DE PLANEJAMENTO DE TRANSPORTES - GEIPOT. Manual de planejamento cicloviário. 3 ed. Brasília, 2001.

[11]. GOOGLE. Google Earth, 2017. Disponível em <www.google.com/intl/pt-PT/earth/>. Acesso em: 14 de abril de 2017

[12]. HILLSDON, Melvyn; THOROGOOD, Margaret. A systematic review of physical activity promotion strategies. London, 1996.

[13]. INSTITUT NATIONAL DE LA STATISTIQUE ET DES ÉTUDES ÉCONOMIQUES - INSEE, Exploitations principales en géographie, de 01 de janeiro de 2014. Disponível em < www.insee. $\mathrm{fr} / \mathrm{fr} / \mathrm{statistiques} / 1405599$ ?geo=DEP75>. Acesso em: 01 de junho de 2017.

[14]. INSTITUTO BRASILEIRO DE GEOGRAFIA E ESTATÍSTICA - IBGE - Área territorial oficial, de 29 de junho de 2017. Disponível em <http://www.ibge.gov.br/home/geociencias/areaterr itorial/principal.shtm>. Acesso em: 02 de julho de 2017.

[15]. INSTITUTO DE ENERGIA E MEIO AMBIENTE - IEMA - Inventário de emissões atmosféricas do transporte rodoviário de passageiros no município de São Paulo, de 2017. Disponível em <https://www.emissões.energiaeambiente.org.br>. Acesso em: 22 de maio de 2017.

[16]. MONSERE, C. et al. Lessons from the Green Lanes: Evaluating Protected Bike Lanes in the U.S. NITC-RR-583. Portland, OR: Transportation Research and Education Center (TREC), 2014.

[17]. PROGRAMA BRASILEIRO DE MOBILIDADE POR BICICLETA - BICICLETA BRASIL. Caderno de referência para elaboração de: Plano de mobilidade por bicicleta nas cidades. Brasília: Secretaria Nacional de Transporte e da Mobilidade Urbana, 2007. 


\title{
Gapítulo 20
}

\section{ANÁLISE DE ATRIBUTOS DA EMBALAGEM DE PEQUI QUE INFLUENCIAM A PREFERENCIA DE COMPRA DOS CONSUMIDORES DA CIDADE DE TANGARÁ DA SERRA - MT USANDO ANÁLISE CONJUNTA}

\author{
Jéssica Ramos de Oliveira \\ Eduardo José Oenning Soares \\ Rodolfo Benedito da Silva \\ Alexandre Gonçalves Porto \\ Rodrigo Carniel Sefstron
}

Resumo: O marketing tem dentre seus objetivos o intuito de compreender as variáveis que afetam o comportamento do consumidor, sendo este influenciado por diversos atributos que compõem o produto, incluindo a embalagem. Este trabalho tem como objetivo identificar e quantificar os atributos da embalagem de pequi em conserva que influenciam a preferência dos consumidores. Foram analisados quatro atributos: imagem do produto no rótulo, cor, informações sobre o produto e preço. Foram elaboradas 9 imagens contendo as combinações de atributos e níveis gerados pelo planejamento fatorial fracionado. As imagens foram avaliadas por 150 consumidores da cidade de Tangará da Serra - MT, através de questionário aplicado em vias públicas próximas a supermercados. Para analisar e quantificar o impacto que cada atributo da embalagem desempenha na preferência dos consumidores foi aplicada a técnica de Análise Conjunta. Assim foi possível verificar que o atributo com maior importância relativa foi a imagem, com $36 \%$ da preferência dos consumidores, em seguida a informação apresentou $27 \%$ de importância relativa, cor $24 \%$ e preço com menor impacto, apresentando 13\% da preferência dos consumidores. Através dos resultados foi possível notar o poder que a imagem pode gerar ao ser inserida em rótulos de produtos alimentares, sendo capaz de despertar sensações e desejos nos consumidores. Observou-se também o impacto que informações adicionais podem gerar, nota-se que estas devem ser completas e claras para despertar interesse nos consumidores. Os resultados obtidos são importantes para o desenvolvimento de embalagens para pequi em conserva que atraiam os consumidores, agregando valor ao produto e contribuindo para a industrialização e comercialização desse produto. 


\section{INTRODUÇÃO}

O Cerrado é o segundo maior bioma brasileiro, ocupando em torno de $24 \%$ do território do país (OLIVEIRA; SCARIOT, 2010) com ampla diversidade de plantas, gerando um enorme potencial extrativista e econômico. Um dos símbolos do cerrado brasileiro é o pequizeiro, do gênero Caryocar, sendo seu fruto conhecido como pequi ou piqui, fortemente apreciado na Região CentroOeste, Norte e parte do Nordeste do país e muito utilizado na culinária local (OLIVEIRA et al., 2008).

O pequi é comercializado predominantemente in natura, ou seja, é comercializado geralmente em feiras com a ausência de processamento industrial. Portanto há pouca visibilidade comercial dos produtos industrializados e minimamente processados nos mercados, como por exemplo, o pequi embalado a vácuo, pequi em conserva, polpa de pequi, creme de pequi, óleo de pequi e farofa de pequi.

A embalagem pode contribuir positivamente com a visibilidade comercial e com o consumo do pequi processado, ressaltando características e informações atrativas segundo as necessidades e desejos dos consumidores, de forma a atrair a atenção e influenciar a decisão de compra dos consumidores.

A decisão de compra do consumidor pode ser influenciada por diversos fatores, como exemplo os fatores extrínsecos, no qual mantém uma comunicação entre o produto e o consumidor por meio de imagens gráficas e informações no rótulo.

Desta maneira pesquisar e avaliar a estrutura de preferência do consumidor no que diz respeito a embalagem pode gerar benefícios para o marketing industrial. Tendo em vista as diversas qualidades nutricionais, a baixa comercialização e o desconhecimento por conta do mercado consumidor, o estudo da embalagem do pequi em conserva torna-se muito importante, pois pode contribuir com o marketing, a fim de elaborar estratégias que atraiam a atenção e desperte o interesse dos consumidores, promovendo e incentivando o consumo por produtos regionais.

Diante do exposto, o estudo tem como objetivo analisar o impacto que características e informações em embalagens de pequi em conserva podem apresentar na decisão de compra, aplicando a técnica de Análise Conjunta.

\section{FUNDAMENTAÇÃO TEÓRICA}

\subsection{CARACTERIZAÇÃO COMERCIALIZAÇÃO DO PEQUI}

Pequi é um fruto típico do Cerrado rico em nutrientes e no ponto de vista funcional, contém propriedades sensoriais diferenciadas e agradáveis, como cor, aroma e sabor (BEZERRA et al., 2015). A casca do fruto representa de $70 \%$ a $80 \%$ do peso úmido (DUBOC et al., 2013), possui uma grande potencialidade para consumo humano, tendo em vista o elevado teor proteínas, fibras, lipídios e hidratos de carbono, contudo ele é muito descartado (AMORIM et al., 2016).

Já o óleo do pequi é muito utilizado na alimentação e em produtos cosméticos, pois é rico em ácidos graxos. É muito aplicado na medicina popular por conter efeito cicatrizante e anti-inflamatório, utilizado em casos de doença respiratória, dores musculares e úlceras gástricas (BEZERRA et al., 2015).

A amêndoa do pequi possui um conteúdo rico em nutrientes, composto por fibras, vitamina E, minerais e especialmente por proteínas brutas. Por conta disto a amêndoa é utilizada na fabricação de farofas, doces, pães, barra de cereais, também pode ser utilizada como um aperitivo salgado e torrado. A amêndoa do pequi produz um óleo nobre muito utilizado em indústrias de cosméticos (DUBOC et al., 2013).

O fruto do pequizeiro apresenta diversos benefícios à saúde, podendo ser utilizado como matéria-prima dos mais variados produtos. O marketing industrial pode se aproveitar destas aplicações e benefícios a fim de incentivar a utilização e o consumo de frutos regionais.

\subsection{COMPORTAMENTO DO CONSUMIDOR}

Analisar o cliente pode contribuir com o melhoramento de produtos e serviços, no desenvolvimento de estratégias de marketing e na segmentação do mercado. Neste sentido, faz-se essencial conhecer quais fatores influenciam o comportamento de compra do consumidor. Kotler e Armstrong (2000) os dividiu em: fatores culturais, fatores sociais, fatores pessoais e fatores psicológicos. 
Entender o consumidor e como ocorre o processo de consumo pode acarretar em diversos benefícios: pode auxiliar os gerentes na tomada de decisão; disponibilizar de informações e conhecimento aos pesquisadores de marketing sobre os consumidores; dar apoio aos legisladores ao criar leis referentes à compra e venda, como também contribuir com os consumidores médios em decisões de compra (MOWEN; MINOR, 2004).

A embalagem é o meio pelo qual as empresas alimentícias podem convencer os consumidores a comprar determinado produto, deste modo, todos os atributos da embalagem devem ser elaborados de forma adequada e combinada para atrair a atenção do consumidor no momento da compra (ARES, 2010). Portanto, o conceito de embalagem e seus atributos devem ser estudados e definidos corretamente, para que possa despertar reações desejadas no comportamento do consumidor.

\subsection{CONCEITOS DE EMBALAGEM}

As embalagens podem ser classificadas em níveis de materiais. Segundo a Agência Nacional de Vigilância Sanitária, (ANVISA, 2002) divide-se em: embalagem primária, aquela que fica em contato direto com o produto alimentício; embalagem secundária, é a embalagem designada a conter a embalagem primária; embalagem terciária, é a embalagem que agrupa em seu conteúdo uma ou mais embalagens secundárias.

A embalagem é uma ferramenta para atrair a atenção dos consumidores, dispondo de informações, formatos e cores que podem contribuir no processo decisório de compra. A resposta gerada pelos rótulos e embalagens é influenciada pelo formato como a informação é apresentada (MIKLAVEC et al., 2015).

\subsection{CARACTERÍSTICAS DA EMBALAGEM QUE INFLUENCIAM NA DECISÃO DE COMPRA DO CONSUMIDOR}

A embalagem é um meio para influenciar a decisão de compra dos consumidores, portanto é preciso identificar corretamente atributos como, imagem, cor, preço, formato e informações, a fim de gerar as expectativas adequadas com relação ao produto.
A cor da embalagem desempenha um papel extremamente importante na escolha de produtos alimentícios, podendo transmitir uma variedade de informações, como o sabor e aroma, contribuir com a diferenciação do produto e consequentemente influenciar $\mathrm{o}$ comportamento dos consumidores (MARSHALL et al., 2006; VELASCO et al., 2014)

As informações contidas nos rótulos são uma importante fonte de conhecimento sobre o produto e o que se espera do mesmo, possuem maior relevância na área da alimentação saudável, no qual há esforços direcionados ao projeto e design da embalagem com intuito de melhorar a escolha saudável (BIALKOVA; HANS, 2011).

O preço é um atributo do produto que apresenta uma forte influência sobre a decisão de compra dos consumidores. Romano et al. (2015) estudou a percepção dos consumidores brasileiros de suco de romã, identificando os atributos relevantes nas embalagens que interferem na intenção de compra.

\section{MATERIAL E MÉTODOS}

\subsection{PARTICIPANTES}

O estudo aplicou questionário como um instrumento de coleta de dados. O questionário foi aplicado para 150 consumidores, caracterizados por pessoas adultas selecionados de forma aleatória em vias públicas próximas a supermercados da cidade de Tangará da Serra - MT. O número de observações foi definido por amostragem de população finita, conforme Hair Jr. (2005) e Malhotra (2012), segundo número populacional e suas estratificações. $\bigcirc$ questionário foi dividido em duas partes, a primeira constava com perguntas de caráter sócio demográfico, a fim de traçar o perfil dos consumidores. A segunda parte foi constituída de imagens das embalagens de pequi em conserva contendo as variáveis que podem contribuir com a escolha do consumidor.

\subsection{ATRIBUTOS E NIVEEIS}

Ao escolher um produto os consumidores são atraídos por elementos visuais contidos no rótulo, tais como cor, tamanho e elementos gráficos, que podem comunicar informações (ARES et al., 2011). Desta forma, os atributos 
analisados na pesquisa foram imagem, cor, informação e preço.

Os rótulos geralmente contém imagens e informações verbais constituindo o primeiro contato com o consumidor (FISZMAN et al., 2015), portanto eles desempenham um papel importante na captura da atenção dos consumidores, pois podem implicar a ideia do sabor do produto, anuncia-lo, e contribuir na decisão de compra. Sendo assim, foi analisado a influência da imagem na embalagem de pequi em conserva, em três níveis diferentes: com imagem do fruto, com imagem de um prato típico que utiliza o fruto e com a imagem do fruto integral com a casca.

Velasco et al. (2014) ressalta que os consumidores podem associar cor e sabor em decorrência da repetida exposição em mercados, ou pela cor do ingrediente primário do produto. Portanto, foi analisado a influência da coloração da embalagem na decisão de compra utilizando três níveis: a cor amarela, pois representa a coloração do fruto, ingrediente principal do produto; a cor verde, pois representa um produto de origem vegetal; e a cor preta, que de acordo com Fernández (2000) representa o máximo de sofisticação, indicando ser um produto luxuoso.

As informações nas embalagens são essenciais para comunicar os consumidores sobre a marca, o produto e seus benefícios. Atualmente há uma mudança nos hábitos alimentares, indicando maior busca por alimentos funcionais (MIKLAVEC et al., 2015), portanto a presença de informações nutricionais pode aumentar a percepção dos consumidores, neste sentido ocorreu a análise da presença de informação nutricional na embalagem, abordando o conteúdo de antioxidantes, pois conforme Rocha et al. (2015) o pequizeiro é rico em extratos antioxidantes como carotenoides e compostos fenólicos. Foi analisada a informação nutricional em três níveis: contendo informação sobre antioxidante: "contém antioxidantes", com informação de antioxidantes e benefícios a saúde: "contém antioxidantes", "combate o envelhecimento" e "previne doenças cardíacas" e sem nenhuma informação nutricional.

Conforme Romano et al. (2015) o preço é considerado uma propriedade não sensorial do produto, representando uma grande influência no processo de decisão de compra. No estudo foi analisada a interferência do preço na intenção de compra do pequi em conserva, sendo representado em dois níveis. Através da observação de valores reais do preço do pequi em conserva em supermercados da cidade de Tangará da Serra - MT foi obtida a média de $R \$ 15,00$, para o estabelecimento dos níveis foi considerado uma variação de 10\% resultando em $R \$ 16,50$ e $R \$ 13,50$ que foram utilizados na pesquisa.

Na Tabela 1 estão relacionados os níveis dos atributos das embalagens.

Tabela 1- Combinações entre atributos e níveis

\begin{tabular}{|c|l|}
\hline \multirow{2}{*}{ Atributos } & \multicolumn{1}{|c}{ Niveis } \\
\hline \multirow{2}{*}{ Imagem } & Pequi \\
\cline { 2 - 2 } & Pequi com casca \\
\cline { 2 - 2 } & Prato típico \\
\hline \multirow{2}{*}{ Cor } & Amarelo \\
\cline { 2 - 2 } & Verde \\
\hline \multirow{2}{*}{ Informações } & Preto \\
\hline \multirow{2}{*}{ Preço } & Antioxidantes \\
\cline { 2 - 2 } & Antioxidantes + Benefícios à saúde \\
\cline { 2 - 2 } & Sem informações \\
\hline & $\mathrm{R} \$ 16,50$ \\
\cline { 2 - 2 } & $\mathrm{R} \$ 13,50$ \\
\hline
\end{tabular}


A pesquisa utilizou quatro atributos, contendo níveis, estes resultaram em uma combinação fatorial de $18\left(3^{3} \times 2^{1}\right)$ estímulos. Contudo, por conta do número de estímulos ser muito grande foi realizado um planejamento fatorial fracionado a fim de reduzir o número de estímulos e tornar o questionário menos cansativo para os respondentes. Desta forma, o planejamento fatorial fracionado resultou em 9 estímulos, sendo apresentado na Tabela 2.

Tabela 2 - Tratamentos resultantes do planejamento fatorial fracionado

\begin{tabular}{|c|c|c|c|c|}
\hline Estímulos & Imagem no rótulo & Cor do rótulo & Informações no rótulo & Preço \\
\hline 1 & Pequi & Preto & Antioxidantes + Benefícios ${ }^{*}$ & $R \$ 13,50$ \\
\hline 2 & Prato típico & Preto & Sem informações & $R \$ 13,50$ \\
\hline 3 & Prato típico & Verde & Contém antioxidantes & $R \$ 13,50$ \\
\hline 4 & Pequi com casca & Amarelo & Sem informações & $R \$ 13,50$ \\
\hline 5 & Pequi & Amarelo & Contém antioxidantes & $R \$ 13,50$ \\
\hline 6 & Pequi & Verde & Sem informações & $R \$ 16,50$ \\
\hline 7 & Prato pronto & Amarelo & Antioxidantes + Benefícios* & $R \$ 16,50$ \\
\hline 8 & Pequi com casca & Preto & Contém antioxidantes & $\mathrm{R} \$ 16,50$ \\
\hline 9 & Pequi com casca & Verde & Antioxidantes + Benefícios* & $R \$ 13,50$ \\
\hline
\end{tabular}

\subsection{CRIAÇÃO DAS IMAGENS}

A partir dos estímulos resultantes do planejamento fatorial fracionado, foram criadas as imagens contendo uma combinação de atributos, com o intuito de demonstrar aos respondentes as variáveis que serão analisadas. A criação das imagens das embalagens foi realizada com o auxílio do software Inkscape 0.91 (Inkscape Team, 2016). A Figura 1 ilustra alguns rótulos criados para demonstração aos respondentes da pesquisa.

Figura 1 - Exemplos do rótulos das embalagens.

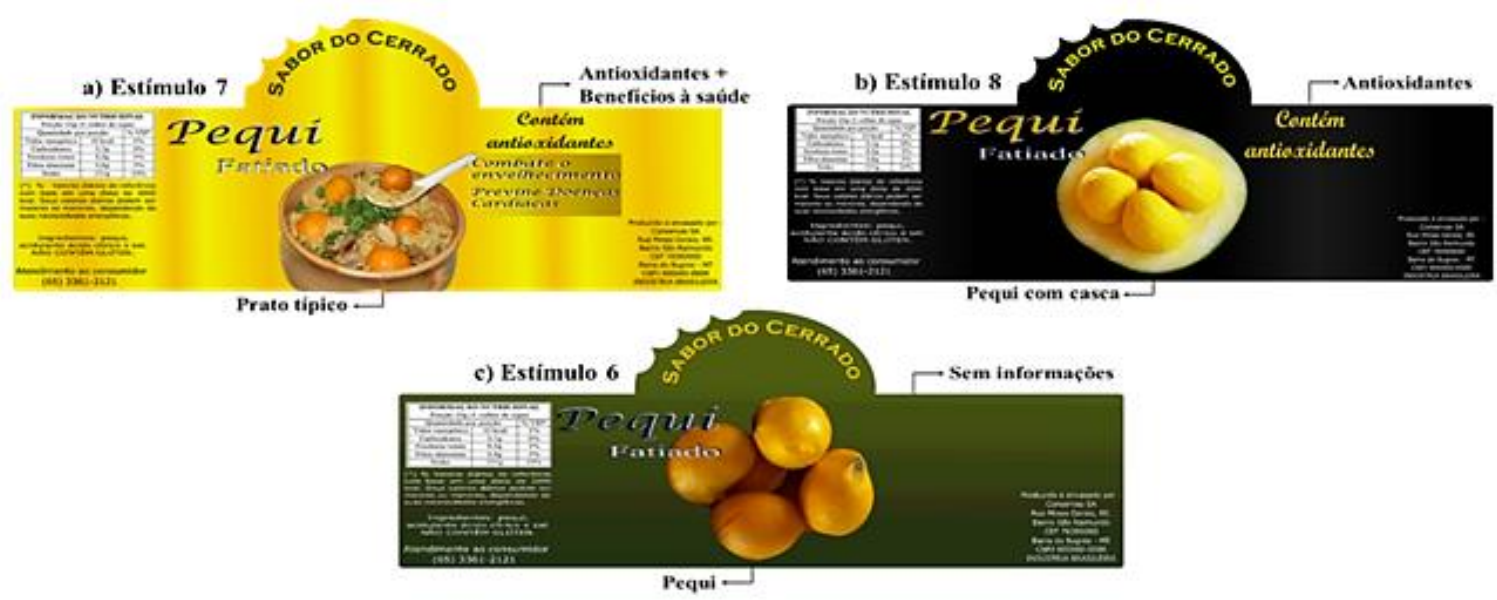

A Figura 1a representa o estímulo 7, o qual apresenta o rótulo de cor amarela, com a imagem de um prato típico e contendo informações de benefícios à saúde e a presença de antioxidantes no alimento. A Figura $1 \mathrm{~b}$ ilustra 0 estímulo 8,0 qual 
apresenta o rótulo de cor preta, com a imagem de um pequi com casca e a presença de informação apenas sobre antioxidantes. Já a Figura 1c) apresenta o estímulo 6, o qual ilustra o rótulo de cor verde, com a imagem de um fruto de pequi e ausente de informações extras.

\subsection{COLETA DE DADOS}

A pesquisa foi submetida ao Comitê de Ética em Pesquisa (CEP) da Universidade do Estado de Mato Grosso por meio do Certificado de Apresentação para Apreciação Ética (CAAE) ำ 44452715.4.0000.5166, o qual permitiu iniciar a pesquisa (parecer $\mathrm{n}$ ․: 1.065.606).

A coleta de dados foi realizada em seis dias distribuídos entre os dias treze e vinte de julho na cidade de Tangará da Serra - MT. As entrevistas foram realizadas em dias úteis em horário comercial.

O questionário foi composto por perguntas de caráter sócio demográfico, desta forma foi possível definir o perfil dos consumidores. Posteriormente era apresentado aos entrevistados imagens com os estímulos da embalagem geradas por meio das combinações dos atributos, os participantes definiram notas em uma escala hedônica de nove pontos (1 = não preferido; $9=$ fortemente preferido). Podendo assim identificar quais são as expectativas e preferências dos consumidores de pequi em conserva.

\subsection{ANÁLISE DE DADOS}

Primeiramente, os resultados sócios demográficos obtidos na coleta de dados foram analisados e formado o perfil dos entrevistados.

Foi aplicada a técnica de Análise Conjunta, a fim de identificar a importância relativa dos atributos selecionados, tornando possível caracterizar as preferências dos consumidores. Todos os dados foram analisados utilizando o software XLSTAT (Addinsoft, 2016).

\section{RESULTADOS E DISCUSSÃO}

Através da aplicação de questionários, foi possível traçar o perfil sócio demográfico dos consumidores de pequi da cidade de Tangará da Serra - MT. Foi utilizada a técnica Análise Conjunta a fim de obter a importância relativa de cada atributo estudado na pesquisa. A Tabela 3 ilustra as características dos participantes.

Tabela 3 - Características sócio demográficas dos participantes

\begin{tabular}{|c|c|c|}
\hline Atributos & Classe & $\%$ \\
\hline \multirow{2}{*}{ Gênero } & Feminino & 53,3 \\
\hline & Masculino & 46,6 \\
\hline \multirow{2}{*}{ Naturalidade } & Mato Grosso & 53,3 \\
\hline & Outros & 46,6 \\
\hline \multirow{5}{*}{ Idade } & $18-24$ & 26 \\
\hline & $25-34$ & 25,3 \\
\hline & $35-44$ & 16 \\
\hline & $45-54$ & 18 \\
\hline & 55 acima & 14,6 \\
\hline \multirow{4}{*}{ Escolaridade } & Ensino fundamental & 28,6 \\
\hline & Ensino médio & 42,6 \\
\hline & Graduação & 23,3 \\
\hline & Pós-Graduação & 5,3 \\
\hline
\end{tabular}


Tabela 3 - Características sócio demográficas dos participantes (continuação)

\begin{tabular}{|c|c|c|}
\hline \multirow{4}{*}{ Atributos } & \multicolumn{2}{|c|}{ Classe } \\
\hline \multirow{4}{*}{ Estado civil } & Solteiro & 36 \\
\cline { 2 - 3 } & Casado & 40 \\
\cline { 2 - 3 } & Relacionamento estável & 13,3 \\
\cline { 2 - 3 } & Divorciado & 8 \\
\hline \multirow{4}{*}{ Renda familiar } & Viúvo & 2,6 \\
\cline { 2 - 3 } & 1 salário & 22,6 \\
\cline { 2 - 3 } & $2-4$ salários & 60,6 \\
\cline { 2 - 3 } & $4-6$ salários & 8,6 \\
\cline { 2 - 3 } & $6-8$ salários & 4,6 \\
\hline \multirow{3}{*}{ Frequência de compra } & Acima de 8 salários & 3,3 \\
\cline { 2 - 3 } & Diariamente & 1,3 \\
\cline { 2 - 3 } & Semanalmente & 1,3 \\
\cline { 2 - 3 } & Quinzenalmente & 3,3 \\
\cline { 2 - 3 } & Mensalmente & 30 \\
\hline & Anualmente & 64 \\
\hline
\end{tabular}

Por meio dos resultados do questionário foi possível traçar o perfil sócio demográfico dos consumidores de pequi. Como ilustra a Tabela 3 a participação de mulheres na pesquisa foi ligeiramente maior. O mesmo se observa quanto a naturalidade, na qual a porcentagem de matogrossenses foi pouco maior do que a porcentagem de participantes de outros estados.

Quanto a idade houve predominância na faixa etária de 18 a 24 anos, representados por $26 \%$ dos participantes e na faixa de 24 a 34 anos, representados por $25,3 \%$, sendo assim na pesquisa houve maior concentração de participantes com idades de 18 a 34 anos.

Com relação ao nível de instrução pode-se observar que houve predominância de participantes que possuem o nível médio de escolaridade, correspondendo a $42,6 \%$ dos participantes.
A pesquisa revelou uma concentração maior de participantes casados (40\%) e solteiros $(36 \%)$, sendo que os demais se declararam em relacionamento estável ou viúvos. Quanto a renda familiar a maioria declarou obter entre 2 a 4 salários.

Quanto a frequência de consumo de pequi pode-se observar que a maioria dos participantes declararam consumir anualmente o produto, demonstrando a necessidade de maiores investimentos em marketing industrial a fim de tornar o produto mais consumido entre os consumidores.

Os resultados obtidos na aplicação de questionário foram analisados pela técnica de Análise Conjunta por meio do software XLSTAT (Addinsoft, 2016). Estes dados estão ilustrados na Tabela 4. 
Tabela 4 - Resultado da Análise Conjunta sobre a intenção de compra de pequi em conserva

\begin{tabular}{|c|c|c|c|}
\hline Atributo & IR \% & Níveis & Utilid. Parcial \\
\hline \multirow{3}{*}{ Imagem } & $36^{c}$ & Pequi com casca & $0,187^{b}$ \\
\hline & & Pequi & $-0,746^{a}$ \\
\hline & & Prato típico & $0,559^{c}$ \\
\hline \multirow{3}{*}{ Cor } & $24^{b}$ & Amarelo & $0,179^{b}$ \\
\hline & & Preto & $-0,077^{a b}$ \\
\hline & & Verde & $-0,102^{a}$ \\
\hline \multirow{3}{*}{ Informações } & $27^{b}$ & Antioxidantes & $-0,224^{a}$ \\
\hline & & Antioxidantes + Benefícios & $0,633^{b}$ \\
\hline & & Sem informações & $-0,409^{a}$ \\
\hline \multirow{2}{*}{ Preço } & $13^{a}$ & $\mathrm{R} \$ 13,50$ & $-0,041^{a}$ \\
\hline & & $R \$ 16,50$ & $0,041^{a}$ \\
\hline
\end{tabular}

Utilidades parciais para o mesmo atributo e importâncias relativas entre os atributos com letras diferentes são significantemente diferentes ( $p \leq 0.05)$, de acordo com o teste de Kruskal-Wallis para comparações múltiplas. Sinais negativos nas utilidades parciais significam impacto negativo na preferência de consumo.

Os resultados demonstraram que o atributo com maior importância relativa foi a imagem na embalagem, representado por $36 \%$, seguido do atributo informações contendo 27 \% de importância relativa. O atributo cor apresentou 24\% de importância relativa, seguido do preço com $13 \%$.

A Figura 2 ilustra os resultados da função utilidade de cada atributo, com o intuito de proporcionar melhor visualização da dimensão da influência de cada fator sobre a intenção de compra dos consumidores.

Figura 2- Resultados das utilidades parciais utilizando a técnica análise conjunta.
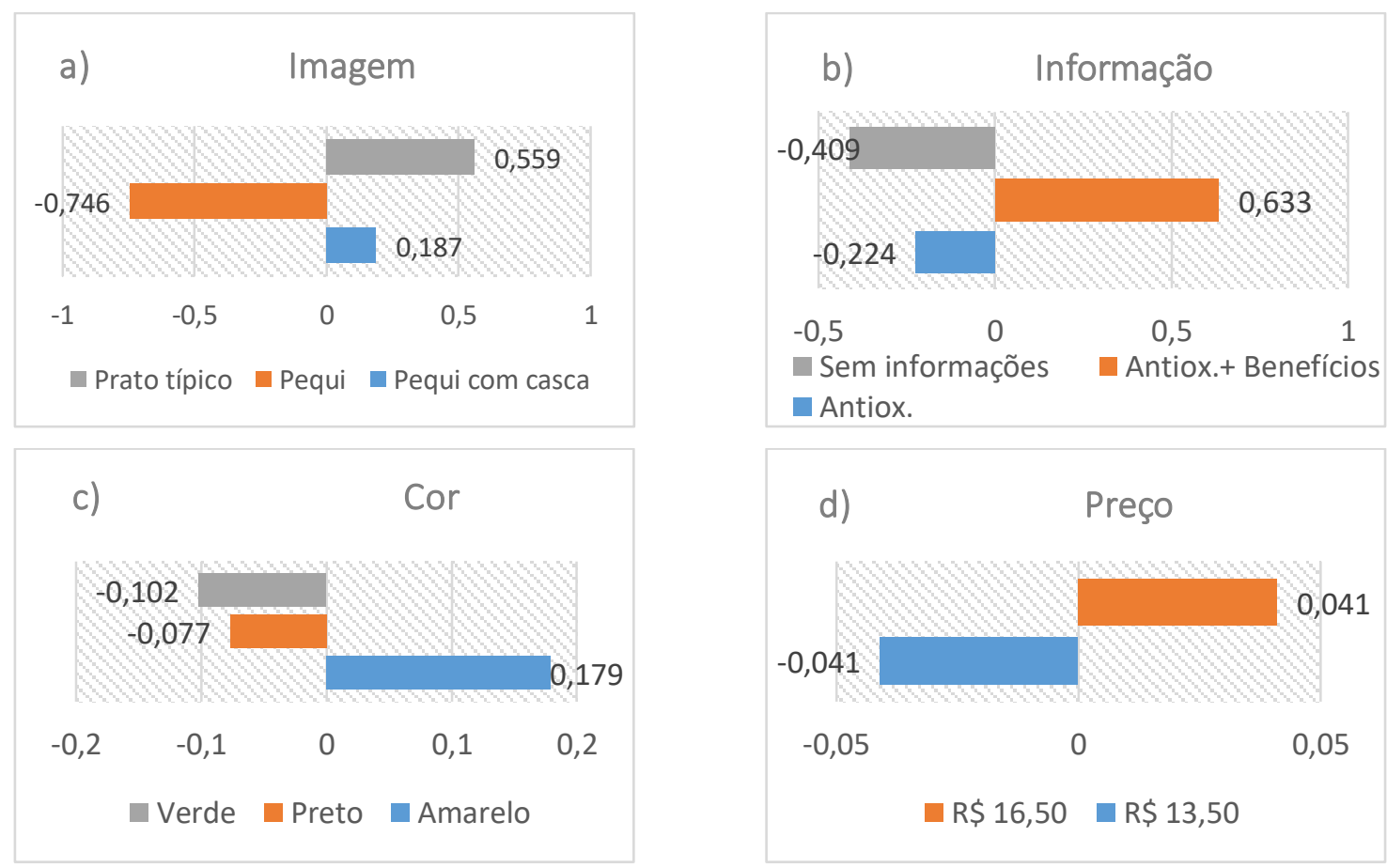

a $\mathrm{R} \$ 16,50 \quad \mathrm{R} \$ 13,50$ 
Ao analisar os resultados da utilidade parcial dos atributos pode-se notar que o atributo imagem (Figura 2a) houve uma variação na aceitação dos consumidores, isto é comprovado pela diferença estatística entre os níveis estudados, visto as letras associadas aos valores de utilidades parciais representadas na Tabela 4, ou seja, cada nível exerce uma influência diferente no participante.

Os resultados obtidos demonstram a importância das imagens em rótulos de alimentos e sua capacidade de atender às sensações e desejos dos consumidores. O estudo de Fizsman (2015) sobre influência da imagem na embalagem aplicado a suplementos alimentares obteve resultados semelhantes, em que foi notado maior interesse pelo rótulo que continha imagem de uma fita métrica, pois isso gera associação com a circunferência da cintura, uma preocupação de diversas pessoas que se relaciona com a perda de peso.

A respeito do atributo informações, os níveis "Antioxidantes" e "Sem informações" não apresentaram diferenças significativas conforme pode ser observado na Tabela 4. Assim, pode-se considerar que a percepção do consumidor foi igual para ambos os níveis. Estes apresentaram valores negativos, evidenciando a rejeição por rótulos que continham apenas informação sobre antioxidante e pela ausência de informações nos rótulos (Figura $2 b$ ). Entende-se que conter uma informação incompleta na embalagem é tão negativo quanto não ter informação alguma, sendo necessário utilizar informações completas, concisas e de fácil entendimento pelo público, caso contrário é preferível que não contenha nenhuma informação adicional.

Já as informações de "Antioxidantes + Benefícios a saúde" apresentou melhor aceitação pelos participantes, expresso pelo valor de 0,633 de utilidade parcial (Figura 2b). Sendo assim nota-se que somente a informação sobre antioxidante não exerce influência nos participantes. Entretanto, ao uni-la a informações de benefícios à saúde gera maior interesse nos consumidores.

O resultado obtido indica maior preocupação dos participantes quanto ao consumo de alimentos funcionais e suas melhorias à saúde, confirmando o estudo realizado por Ares et al. (2008), em que investigou a influência da informação nutricional no rótulo de diversos produtos. A pesquisa apontou que as alegações de benefícios para a saúde podem influenciar na aceitação de alimentos funcionais de acordo com o conhecimento nutricional do público alvo. Os resultados do presente estudo demonstram a importância de adicionar informações complementares no rótulo do pequi em conserva como forma de atrair consumidores, contribuir com $\mathrm{O}$ conhecimento nutricional do público e tornar o fruto conhecido quanto à seus benefícios a saúde.

Para o atributo cor (Figura 2c), com $24 \%$ de importância relativa, os resultados apontam intenção de compra maior por produtos com rótulos na cor amarela com valor de 0,179 de utilidade parcial. Este resultado pode indicar que os participantes relacionavam a coloração do fruto com a coloração do rótulo, obtendo assim maior preferência. Esta associação da cor da embalagem com a coloração do ingrediente primário do produto também foi percebida na pesquisa de Ares e Deliza (2010) que estudaram a influência do formato e da cor de sobremesas lácteas nas expectativas dos consumidores, demonstrando que os consumidores associavam a cor da embalagem com o sabor esperado da sobremesa, mais especificamente a associação da cor preta da embalagem com o sabor de chocolate.

Os resultados encontrados na pesquisa são contrários aos obtidos pelo estudo de Carneiro et al. (2005) sobre os efeitos da rotulagem na intenção do consumidor de comprar óleo de soja, no qual todos os consumidores foram afetados pelo atributo preço, visto que o nível de preço baixo obteve maior importância relativa, atingindo maior intenção de compra dos consumidores. Os resultados apresentam-se opostos também aos encontrados por Romano et al. (2015) em seu estudo sobre a percepção dos consumidores brasileiros quanto a embalagem não-tradicional e inovadora de um suco de fruta, em que o atributo preço foi mais relevante sobre a intenção de compra do consumidor, dado o nível preço baixo que demonstrou impacto positivo para todos os participantes da pesquisa. Estes resultados indicam que aspectos extrínsecos, como o preço, exercem papel importante no processo de escolha de um produto.

Conforme o resultado apresentado pode-se afirmar que os atributos imagem, informações adicionais e cor influenciam a preferência de compra dos consumidores. Sendo assim, é 
possível desenvolver estratégias de marketing para o layout de embalagens que atraiam a atenção dos consumidores para os produtos regionais, tornando-os mais conhecidos, incentivando assim o consumo e a comercialização de produtos regionais, agregando valor a produtos minimamente processados.

\section{CONSIDERAÇÕES FINAIS}

Através da técnica de Análise Conjunta foi possível identificar o gosto esperado por meio da importância relativa de cada atributo. Os consumidores tiveram a preferência de consumo afetada pelo atributo imagem, com importância relativa de 36\%, sugerindo que a imagem é o primeiro contato com os consumidores, sendo assim, o atributo que requer maior atenção na elaboração da embalagem.

O atributo informações exerceu um impacto significativo na preferência dos consumidores,

\section{REFERÊNCIAS}

[1]. AMORIM, D. J. et al. Characterization of Pequi (Caryocar brasiliense): Shells and Evaluation of Their Potential for the Adsorption of Pbll lons in Aqueous Systems. Journal of the Brazilian Chemical Society, v. 27, N. 3, p. 616-23, 2016.

[2]. ANVISA, Agência Nacional de Vigilância Sanitária. Resolução RDC nº 259. Disponível em <http://portal.anvisa.gov.br/wps/wcm/connect/36bf 398047457db389d8dd3fbc4c6735/RDC_2

59.pdf?MOD=AJPERES $>$. Acesso em: 22 mar. 2017.

[3]. ARES, G. et al. Food labels: Do consumers perceive what semiotics want to convey? Food Quality and Preference, v. 22, p. 689-98, 2011.

[4]. ARES, G. et al. Relationship between involvement and functional milk desserts intention to purchase: Influence on attitude towards packaging characteristics. Appetite, v. 55, p. 298-304, 2010.

[5]. ARES, G., DELIZA, R. Identifying important package features of milk desserts using free listing and word association. Food Quality and Preference, v. 21, p. 621-8, 2010.

[6]. BEZERRA, N.K.M.S.; BARROS, T.L.; COELHO, N.P.M.F. Ação do óleo de pequi (Caryocar brasiliense) no processo cicatricial de lesões cutâneas em ratos. Revista Brasileira Plantas Medicinais, v.17, N.4, p.875-80, 2015.

[7]. BIALKOVA, S.; HANS, C. M. An efficient methodology for assessing attention to and effect of correspondendo a $27 \%$ da importância relativa, onde os consumidores demonstraram maior preferência pelas informações sobre antioxidantes acompanhada de informações sobre os benefícios a saúde, confirmando a mudança no estilo de vida atualmente, no qual as pessoas têm demonstrado maior preocupação com a saúde, buscando por produtos funcionais.

A cor obteve $24 \%$ de importância relativa, no qual a cor amarela exerceu maior impacto na preferência dos consumidores $\mathrm{O}$ preço desempenhou menor impacto na preferência, com apenas 13\% de importância relativa. Sendo que os valores estudados não demonstraram diferenças estatísticas

Assim sendo, verifica-se que os resultados obtidos pela pesquisa foram satisfatórios, demonstrando as preferências dos consumidores de Tangará da Serra quanto à aspectos da embalagem do pequi em conserva

nutrition information displayed front-of-pack. Food Quality and Preference, v. 22, p. 592-601, 2011.

[8]. CARNEIRO, J. D. S. et al. Labelling effects on consumer intention to purchase for soybean oil. Food Quality and Preference, v. 16, p. 275-82, 2005.

[9]. DUBOC, E. et al. Análise da viabilidade econômico-financeira de um sistema agrissilvipastoril com pequi (Caryocar spp.). Estudo de caso: Sítio Recanto Água Limpa, MT. Dourados, MS: Embrapa Agropecuária Oeste, 2013.

[10]. FERNÁNDEZ, J. L. G. Comunicación no verbal: Periodismo y médios audiovisuales. Madrid: Universitas, 2000.

[11]. FISZMAN, S.; CARRILLO, E.; VARELA, P. Consumer perception of carriers of a satiating compound: Influence of front-of-package images and weight loss-related information. Food Research International, v. 78, p. 88-95, 2015

[12]. HAIR Jr., J. F. et al. Análise multivariada de dados. 5.ed. Porto Alegre: Bookman, 2005.

[13]. Inkscape Team (2016). Draw Freely: Free and Open Source Software licensed under the GNU General Public License.

[14]. KOTLER, P., ARMStRONG, G. Introdução ao Marketing. 4.ed. Rio de Janeiro: JC, 2000.

[15]. KOTLER, P.; KELLER, K, L. Administração de Marketing.12.ed. São Paulo: Pearson 2006. 
[16]. MALHOTRA, N.K. Pesquisa de Marketing: Uma orientação aplicada. 3.ed. Porto Alegre: Bookman, 2001.

[17]. MARSHALL, D.; STUART, M.; BELL, R. Examining the relationship between product package colour and product selection in preschoolers. Food Quality and Preference, v. 17, p. 615-21, 2006.

[18]. MIKLAVEC, $K$. et al. The influence of health claims and nutritional composition on consumers' yoghurt preferences. Food Quality and Preference, v. 43, p. 26-33, 2015.

[19]. MOWEN, J. C., MINOR, M. S. Comportamento do consumidor. 1.ed. São Paulo: Pearson, 2004.

[20]. OLIVEIRA, M. E. B. et al. Aspectos agronômicos e de qualidade do pequi. Fortaleza: Embrapa Agroindústria Tropical, 2008.
[21]. OLIVEIRA, W. L., SCARIOT, A. Boas práticas de manejo para o extrativismo sustentável do pequi. Brasília: Embrapa Recursos Genéticos e Biotecnologia, 2010.

[22]. ROCHA, L.B. et al. Gallic acid as the major antioxidant in pequi (Caryocar brasiliense Camb.) fruit peel. Revista Brasileira de Plantas Medicinais, v.17, n.4, p.592-598, 2015.

[23]. ROMANO, K. R.; ROSENTHAL, A.; DELIZA, R. How do Brazilian consumers perceive a non-traditional and innovative fruit juice? An approach looking at the packaging. Food Research International, v. 74, p. 123-30, 2015.

[24]. VELASCO, C. et al. The context of colourflavour associations in crisps packaging: A crosscultural study comparing Chinese, Colombian, and British consumers. Food Quality and Preference, v. 38, p. 49-57, 2014. 


\section{Capítulo 21}

\section{INTEGRACÃO DA METODOLOGIA DMAIC PARA O AUMENTO DAS CONFORMIDADES ADQUIRIDAS NA FABRICACÁO DOS SIDECARS EM UMA EMPRESA DO SETOR AUTOMOTIVO}

\section{Juan Pablo Silva Moreira}

Saulo Fonseca Soares

Janser Queiroz Oliveira

Resumo: O mercado tem estimulado uma competitividade que cresce ano após ano, impulsionando as organizações na busca por uma redução de custos para se manterem atuantes no mercado. Objetivo é deste trabalho, portanto, desenvolver um estudo quanto aos benefícios obtidos com aplicação metodologia DMAIC em uma empresa do setor automotivo, que para fins de confidencialidade do mesmo, designar-se-á, como Empresa Beta, analisando a contribuição que este instrumento oferece para a redução das falhas e para o aumento da produtividade do empreendimento, além disso, evidenciar o auxílio desta metodologia no processo de tomada de decisão dos problemas enfrentados na linha de produção do empreendimento. Por isso, a fim de tornar a concretização visível aos colaboradores da empresa, nessa análise foi utilizado formulários de maneira descritiva e qualitativa, pois essas formas pesquisa permitem maior interação com o cotidiano da linha de produção organizacional. Através desta pesquisa, foi possível evidenciar que a solução deste problema garantiu uma melhora significa nos sidecars fabricados pela Empresa Beta, além disso, pode-se perceber que este instrumento se mostra um grande aliado para garantir a melhoria continua no empreendimento, visto que possibilita uma redução considerável nos custos, além de não haver restrições quanto às áreas ou setores em que a metodologia pode ser aplicada. 


\section{INTRODUÇÃO}

O mercado tem estimulado uma competitividade que cresce ano após ano, impulsionando as organizações na busca por uma redução de custos para se manterem atuantes no mercado. De acordo com Conte e Durski (2002) as mudanças impostas pela globalização têm se mostrando importantes para a criação de uma nova relação existente entre o trabalho, a gestão, a aprendizagem e a capacidade dos colaboradores atuarem e colaborarem para o crescimento das companhias. Nesta nova etapa do mercado, se torna necessário que as empresas adotem uma visão mais abrangente quantos aos aprimoramentos que ocorrem na produção, e com isso elevem o controle de qualidade para competir em um patamar de igualdade para com os seus concorrentes.

Com processo de inovações tecnológicas, tornou-se muito importante que os empreendimentos desenvolvam periodicamente melhorias para que seus produtos não entrem em decadência. Para Tidd et al. (2008) a era da tecnologia consiste em formular novas de planejar, organizar e coordenar os parâmetros julgados essenciais para desenvolver instrumentos mais rentáveis e, como isso obter um aumento da lucratividade almejada pelos gestores.

O Seis Sigma foi desenvolvido nos anos de 80 com a finalidade de reduzir a variabilidade dos processos, fazendo com que os produtos fabricados se destaquem perante a concorrência (CORONADO e ANTONY, 2002). Uma das principais características do Seis Sigma é a metodologia DMAIC (Define Definir, Measure - Medir, Analyse - Analisar, Improve - Melhorar, Control - Controlar), que auxilia na utilização de diretrizes estatísticas (PANDE, NEUMAN e CAVANAGH, 2000).

Por isso, objetivo deste trabalho é desenvolver um estudo quanto aos benefícios obtidos com aplicação metodologia DMAIC em uma empresa fabricante de sidecars, que para fins de confidencialidade do mesmo, designar-seá, na presente pesquisa como Empresa Beta, analisando a contribuição que este instrumento oferece para a redução do tempo de setup e para o aumento da produtividade do empreendimento, além disso, evidenciar o auxílio desta metodologia no processo de tomada de decisão dos problemas enfrentados na linha de produção do empreendimento.
Deste modo, com a finalidade de analisar o tema abordado com uma maior exatidão, desenvolveu-se um estudo sistemático dos conteúdos disponíveis em métodos, técnicas e procedimentos de caráter cientifico. Assim, quanto aos objetivos, esta pesquisa foi caracterizada como descritiva, pois de acordo com Gil (2002) a pesquisa descritiva fornece "a descrição das características de determinada população ou fenômeno, ou, então, o estabelecimento de relação entre as variáveis".

A fim de que se analisar melhor a qualidade dos triciclos desenvolvidos pela Empresa Ômega, os autores deste trabalho fazem uso de uma abordagem quantitativa. Essa abordagem possibilita uma relação direta entre o mundo real e o ambiente pesquisado, já que permite analisar, questionar e interpretar determinado fato com o auxílio de determinados dados numéricos e estatísticos. Para Fonseca (2002) a pesquisa quantitativa recorre à linguagem matemática para descrever as causas de um fenômeno ou as relações existentes entre determinadas variáveis.

\section{GESTÃO DA QUALIDADE}

A Gestão da Qualidade pode ser definida como um conjunto de atividades operacionais ou de gerenciamento que uma organização desenvolve para assegurar que seus produtos estão sendo criados em conformidade com os padrões de qualidade previamente estipulados pelos gestores organizacionais (MONTGOMERY, 1996). De acordo com Paladini (2004) a Gestão da Qualidade tem o objetivo de propor técnicas que melhorem o resultado das organizações e, auxiliem desta forma, na redução de defeitos existentes na linha de produção.

Hraqdesky (1997) salienta que a finalidade da Gestão da Qualidade pode ser visualizada como tornar os processos produtivos mais eficientes e voltados à melhoria contínua do produto. A melhoria continua pode ser visualizada com uma filosofia que tem como princípio a produção com qualidade, reduzindo o tempo e padronizando os processos necessários para se agregar valor a um produto (MOURA, 1994).

A Gestão da Qualidade tem a finalidade de passar indicadores de confiabilidade e satisfação para as organizações e para os consumidores (MOREIRA et al., 2015). A 
figura abaixo demonstra as ações

no cenário atual:

correlacionadas com a Gestão da Qualidade

Figura 1 - Atividades relacionadas com a Gestão da Qualidade

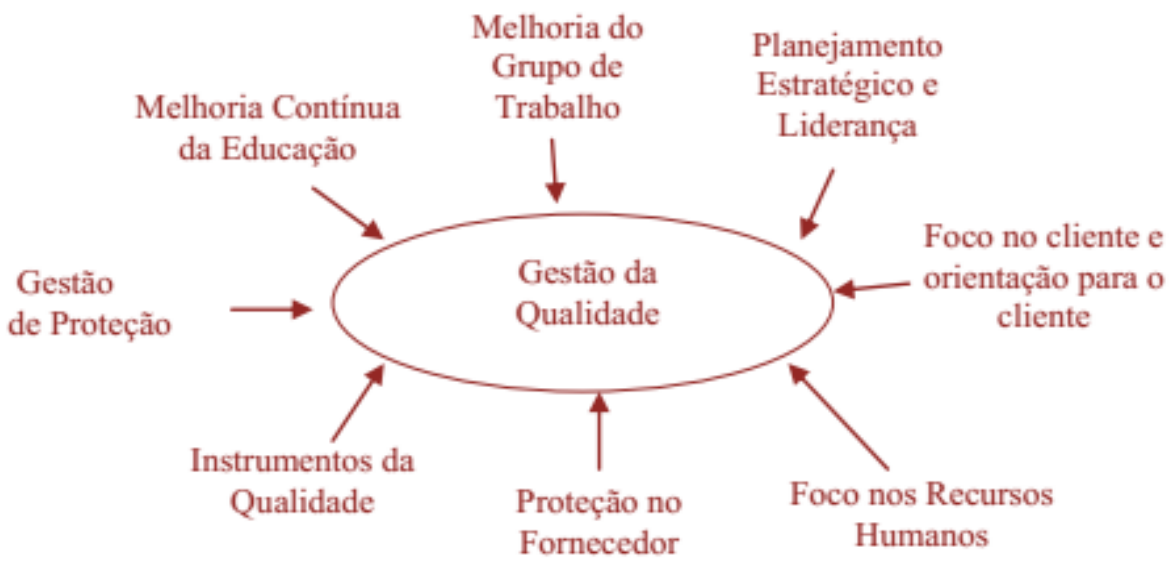

Fonte: Adaptado de Mahdiraji, Arabzadeh e Ghaffari (2012)

A Gestão da Qualidade está focada no princípio da melhoria contínua, e para se alcançar tal realização, é necessário que se haja a integração de ações intermediárias na relação existente entre o capital intelectual (Recursos Humanos), o Fornecedor, o Trabalho em Equipe com o Planejamento Estratégico e Liderança, pois através deste estilo de gestão é possível obter uma melhoria na gestão que será compreendida pelos clientes dos produtos desenvolvidos pelo empreendimento (MOREIRA et al., 2015).

\subsection{LEAN SEIS SIGMA}

Para Werkema (2010, p. 18) o Lean Seis Sigma trata-se:

(...) de uma ferramenta estratégia gerencial disciplinada e altamente quantitativa, que tem como objetivo a maximização da lucratividade e da performance de uma empresa, através da melhoria de processo e produtos e da satisfação dos clientes.

O termo Sigma é de origem grega que significa desvio padrão, podendo ser representa pela $(\square)$ e pode ser visualizada uma medida de dispersão que tem a função de analisar os fatores que estão correlacionados com a produtividade da organização. O programa Seis Sigma não foi desenvolvido para ser uma proposta revolucionária, mas para auxiliar na elaboração de diretrizes que auxiliem na melhoria contínua, garantindo que as necessidades dos clientes sejam traduzidas para os requisitos do projeto (FOLARON, 2003).

Os projetos Seis Sigma nem sempre obtém o resultado esperado pela organização e o índice de projetos que fracassam por custarem mais do que o estimado ou que excedem o tempo de execução previsto, é realmente alto (ANBARI e KWAK, 2004). Nesse sentido, convém destacar que existem fatores que precisam ser considerados durante a implementação e uso do Seis Sigma para que este programa tenha maior chance de atingir seus objetivos. Dentre eles, pode-se destacar:

- o entendimento da alta administração sobre o Seis Sigma, uma vez que o comprometimento dela é essencial para que o apoio adequado seja fornecido ao programa (ARIENTE et al., 2005);

- o comprometimento dos indivíduos envolvidos no projeto e a presença de competências entre os utilizadores, tais como: conhecimento de ferramentas da qualidade e métodos estatísticos inerentes ao programa Seis Sigma; capacidade de mensurar custos e ganhos; e a comunicação durante a execução do projeto (RODRIGUES e WERNER, 2008);

- a presença de iniciativas prévias de qualidade também é um fator crítico de sucesso para a implantação do programa (TRAD e MAXIMIANO, 2009). 


\subsection{METODOLOGIA DMAIC}

De acordo Pande (2001), os modelos habituais de melhorias aplicados aos métodos ao longo dos tempos têm sido embasados nas diretrizes der W. Edwards Deming, também nomeadas como PDCA (Plan, Do, Check e Action).

Dentro do contexto do Seis Sigma, a metodologia permite conduzir os projetos de melhoria durante suas cinco etapas: Define Definir, Measure - Medir, Analyse - Analisar, Improve - Melhorar, Control - Controlar. Esse método promove a utilização de uma ideologia científica que demonstra um conjunto de sequências que estão racionalmente relacionadas com investigação e pela elucidação de uma falha.

O DMAIC tem destaque nas etapas de planejamento, ao permitir a elaborar ação de uma análise profunda e precisa antes da implantação das melhorias, gerando resultados efetivos. Por esse motivo, durante as fases de Melhoria e Controle, a aplicação dos conceitos do Seis Sigma aliados às ferramentas Lean tem se tornado bastante proveitoso para a utilização efetiva das ações planejadas (HARRY \& SCHROEDER, 2000). Os mesmos autores afirmam ainda que a aplicação da metodologia Seis Sigma pode ser dividida em cinco fases (DMAIC), descritas da seguinte forma:

- Define: tem a finalidade de identificar as necessidades dos clientes, associando-as aos objetivos estratégicos da empresa, para que identificar as oportunidades de melhorar os processos produtivos da organização.

- Measure: obtido o levantamento dos dados atuais do processo, identificando os problemas mais relevantes e analisado 0 sistema de medição;

- Analyse: a partir do uso de ferramentas para identificação da causa raiz do problema definido, evitando identificar consequências no lugar de causas.

\section{ANÁLISE DOS RESULTADOS}

Com base nos dados coletados foi realizada a proposta de análise qualitativa com base nas premissas da metodologia DMAIC. A primeira atividade desenvolvida para a implantação desta proposta foi à realização de uma reunião com todos os colaboradores do
- Improve: analisado as possíveis alternativas, com a elaboração de um plano de ação, avaliando a implementação das mudanças no processo;

- Control: garantiu que o objetivo da meta seja mantido em longo prazo, padronizando as alterações realizadas, monitorando as variáveis críticas do processo para manter a capacidade estabelecida das melhorias futuras (HARRY \& SCHROEDER, 2000).

Para ARIENTE et al., (2005) é fundamental que haja o envolvimento de todos no processo de implantação do Seis Sigmas, como o respaldo da alta administração. Isso irá proporcionar uma taxa de sucesso na operacionalização dos processos.

\section{METODOLOGIA}

Para iniciar o processo de implantação da metodologia DMAIC, foi realizado um estudo teórico quanto a utilização deste instrumento como impulsionador para o processo de melhoria contínua dos sidecars fabricados pela Empresa Beta. Em seguida, para dar maior eficiência à pesquisa desenvolveram-se dois formulários, compostos por questões abertas e fechadas, aplicados a todos os doze (12) colaboradores da organização. Os dados posteriores deste estudo foram adquiridos através de consulta a sites, artigos de caráter técnico-científicos, livros, monografias, teses e dissertações.

As questões contidas nos formulários tratavam de evidenciar informações sobre a organização estratégica do empreendimento, a produção dos equipamentos, a missão, a visão e os objetivos da empresa. Além disso, os formulários serviram também para identificar os possíveis fatores que influenciam no gargalo do processo produtivo, bem como, avaliar a opinião dos envolvidos no processo de melhoria e também monitorar os resultados obtidos em todo o processo de fabricação dos sidecars fabricados pela empresa em análise.

empreendimento, para que eles pudessem fornecer suas opiniões quanto à importância de uma filosofia de melhoria contínua que auxilia a corrigir os erros no processo produtivo da empresa. Vasconcelos (2009) evidencia que a eficiência em uma melhoria operacional só ocorre quando todos os colaboradores compreendem os motivos ou 
os "porquês" de se implantar esta melhoria e como esta melhoria será benéfica para o andamento da empresa.

Desta forma, com base nos pontos de vistas adquiridos pelos colaboradores, tornou-se possível desenvolver o planejamento para se implantar uma metodologia de análise que estivesse em conformidade com a missão, a visão e os valores organizacionais registrados pela Empresa Beta.
Para melhor evidenciar o desenvolvimento de qualquer atividade no contexto organizacional, é importante demonstrar todos os procedimentos, torna-se necessário a compreensão e a sequência lógica das atividades que o compõem (GRIMALDI \& MANCUSO, 1994). Por esse motivo, a fim de realizar uma melhor análise desta metodologia, foi elaborado um mapeamento de processos que tem a finalidade de descrever as atividades essenciais para implantação da filosofia (Figura 2).

Figura 2 - Fluxograma da metodoloia DMAIC

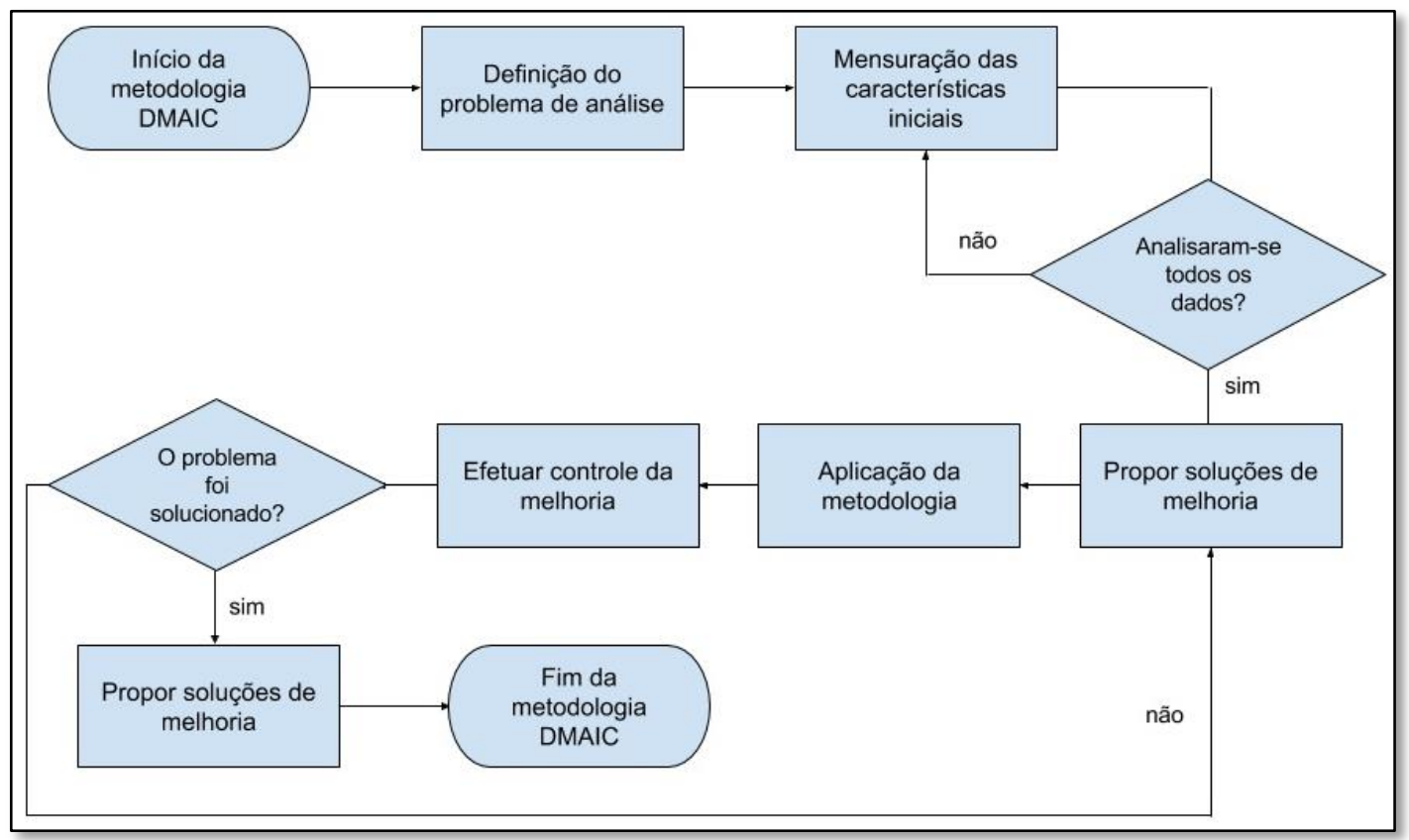

O início da metodologia ocorre com a definição do problema ou do gargalo que será analisado. Na sequência são realizadas as mensurações das características iniciais do problema. Nesta etapa são realizadas todos os levantamento de dados que poderão de alguma forma auxiliar na visualização do gargalo que será evidenciado.

Posteriormente, são realizadas as análises para verificar a causa-raiz do problema, bem como as consequências deste problema no processo produtivo do empreendimento. Além disso, são identificadas as causas que contribuem para a má qualidade do produto final que será comercializado com o cliente. Caso seja necessário identificar novas características para serem mesuradas, é realizada uma nova atividade para identificar outros fatores que podem contribuir para solucionar o problema.

$\mathrm{Na}$ etapa seguinte, é realizada através da metodologia Brainstorming, uma análise para identificar as possíveis melhorias que serão utilizadas para solucionar o problema em evidência. Em seguida, é realizado o processo de implantação e controle da metodologia DMAIC de acordo com as diretrizes analisadas no conteúdo bibliográfico. Caso as soluções implantadas não obtiverem êxito, são propostas novas de solução com a finalidade de solucionar o gargalo existente no processo produtivo do empreendimento.

Desta forma, o primeiro passado executado nesta pesquisa foi definição das possíveis causas, esta atividade possibilita uma 
garantia maior de que o problema não se estenda para outras etapas do processo produtivo. Esta análise FMEA foi adquirida através de um levantamento realizado com a colaboração dos funcionários e gestores (quadro 1). A Análise de Modos e Efeitos de Falhas, ou FMEA (Failure Mode and Effects Analysis) é uma metodologia analítica que permite "identificar e documentar de forma sistemática falhas em potencial, de maneira a eliminá-las ou reduzir suas ocorrências por meio de um processo de aplicação estruturado" (ROMEIRO FILHO et. al, 2010).

Todos os fatores observados foram inseridos em um quadro (tabela 1) que os classifica de acordo com a sua Severidade (S), Ocorrência (O), Detecção (D) e o Número Prioridade de Risco (NPR) - obtido através da equação NPR $=\mathrm{S} \times \mathrm{O} \times \mathrm{D}$.

Tabela 1 - Análise FMEA do processo de fabricação dos sidecars

\begin{tabular}{|c|c|c|c|c|c|}
\hline Risco (S) & S & 0 & $\mathrm{D}$ & (NPR) & $\begin{array}{l}\text { Prioridade (Grau) } \\
\text { de Risco }\end{array}$ \\
\hline 1. Incoerência nas especificações dos clientes & 5 & 4 & 1 & 20 & BAIXO RISCO \\
\hline 2. Incidência de trincas longitudinais & 9 & 4 & 2 & 72 & $\begin{array}{l}\text { RISCO } \\
\text { MODERADO }\end{array}$ \\
\hline $\begin{array}{l}\text { 3. Incidência de porosidades/impurezas na } \\
\text { solda do chassi }\end{array}$ & 8 & 4 & 2 & 96 & $\begin{array}{l}\text { RISCO } \\
\text { MODERADO }\end{array}$ \\
\hline 4. Quebra da Carenagem & 9 & 6 & 6 & 324 & ALTO RISCO \\
\hline 5. Desgaste da Solda & 10 & 4 & 4 & 240 & ALTO RISCO \\
\hline 6. Parte elétrica instalada incorretamente & 9 & 7 & 6 & 378 & ALTO RISCO \\
\hline 7. Quebra do chassi na motocicleta & 7 & 2 & 1 & 14 & BAIXO RISCO \\
\hline 8. Falta de Matéria Prima & 4 & 4 & 1 & 16 & BAIXO RISCO \\
\hline
\end{tabular}

Na sequência foi utilizada a ferramenta $5 \mathrm{~W} 2 \mathrm{H}$, através dessa atividade inicial são levantadas e registradas as informações básicas para analisar problema em questão os motivos que levam a falha nos componentes elétricos ser um fator que influencia de maneira negativa na qualidade dos sidecars oferecidos pelo empreendimento (tabela 2). 
Tabela 2 - Definição do problema através da ferramenta 5W2H no proceso de fabricação dos sidecars

\begin{tabular}{|c|c|c|}
\hline \multicolumn{3}{|c|}{ Definição do Problema } \\
\hline WHAT? & Qual o problema? & $\begin{array}{l}\text { Mal funcionamento dos componentes elétricos } \\
\text { do sidecar }\end{array}$ \\
\hline WHY? & Porque é um problema? & Causa de mal funcionamento do sidecar \\
\hline WHO? & Quem detectou? & Colaborador da linha montagem \\
\hline WHERE? & Onde foi detectado? & $\begin{array}{c}\text { No processo de montagem dos componentes } \\
\text { elétricos }\end{array}$ \\
\hline WHEN? & Quando foi detectado? & No primeiro semestre de 2017 \\
\hline HOW? & Como foi detectado? & Ao realizar o teste funcional \\
\hline HOW MUCH? & $\begin{array}{l}\text { Quanto é o prejuízo } \\
\text { financeiro causado pelo } \\
\text { problema? }\end{array}$ & $\begin{array}{l}\text { Fabricação de peças de reposição e } \\
\text { retrabalho: aproximadamente } \mathrm{R} \$ 500,00 \text { por } \\
\text { sidecar }\end{array}$ \\
\hline
\end{tabular}

Através desta etapa de visualização, pode-se evidenciar que esta falha pode causar o atraso e desgaste em outras peças do sidecar, além disso, por ser um processo que não pode ser reutilizado, é necessário fazer o descarte em caso de eventuais problemas, acarretando uma perda maior de lucratividade.
Por esse motivo, com a finalidade de diagnosticar os fatores que levaram a não detecção do problema durante o processo produtivo, foi utilizado à ferramenta da qualidade Diagrama de Ishikawa (figura 2).

Figura 3 - Diagrama de Ishikawa obtido no processo de Mal funcionamento dos componentes elétricos do sidecar

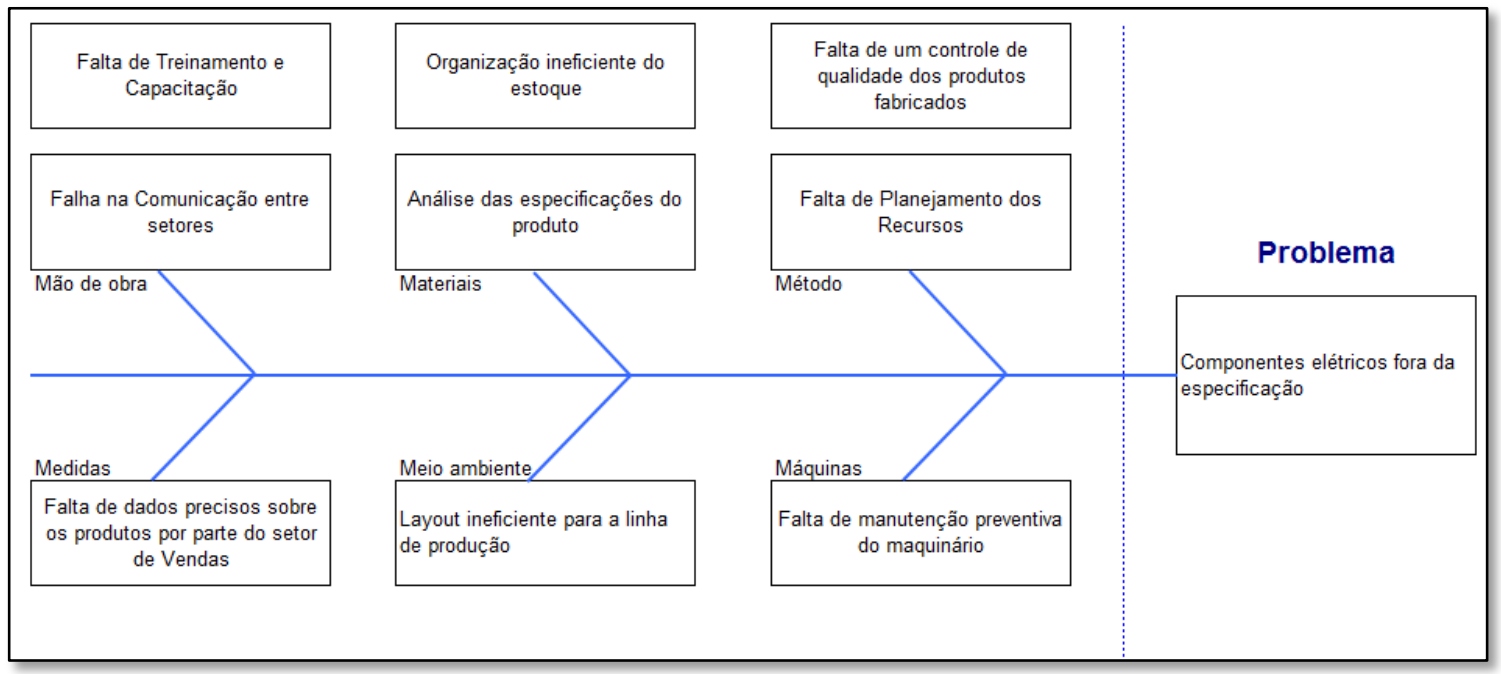


Com a verificação das causas em potencial, foi possível evidenciar que a falha no descarte dos componentes elétricos que estão fora das especificações de qualidade está diretamente ligada à má qualidade dos produtos, já que quando não é feito o descarte de forma correta dos equipamentos irregulares, é possível que um colaborador faça a montagem do processo com peças defeituosas, prejudicando a estrutura dos sidecars fabricados pela Empresa Beta.
Por esse motivo, torna-se necessário a realização de um plano de ação corretiva para evidenciar e solucionar as causas raízes responsáveis pela não detecção do problema. Esse plano de ação se mostrou útil, pois tinha a finalidade de levar à extinção dos problemas ocorridos no processo produtivo. A tabela 3demonstra, de maneira simplificada, o plano de ação para a contenção da falha observada na linha de produção.

Tabela 3 - Implantação de ações corretivas

\begin{tabular}{|c|c|c|c|}
\hline Causa Raiz & \multicolumn{2}{|c|}{ Plano de Ação Corretiva } & $\begin{array}{c}\text { Data de início da } \\
\text { Implantação }\end{array}$ \\
\hline $\begin{array}{c}\text { Peças de má } \\
\text { qualidade ou fora das } \\
\text { especificações não } \\
\text { foram descartadas de } \\
\text { maneira correta }\end{array}$ & $\begin{array}{c}\text { Criar processo que auxilie no } \\
\text { descarte correto dos produtos, } \\
\text { além de elaborar Instruções de } \\
\text { Trabalho (IR) que auxiliem neste } \\
\text { procedimento }\end{array}$ & $\begin{array}{c}\text { Colaboradores } \\
\text { e Gestores }\end{array}$ & $\begin{array}{c}\text { No mês de março } \\
\text { de } 2017\end{array}$ \\
& $\begin{array}{c} \\
\end{array}$ & & \\
\hline
\end{tabular}

Para garantir que esta falha não ocorresse na linha de produção, foi elaborado um cronograma de produção que informasse o número de cada componente fabricado, bem como o local armazenado, assim se torna possível que os colaboradores visualizem através deste cronograma quais os componentes fabricados estão de acordo com as especificações e quais que devem ser descartados. Além disso, foi criado um equipamento que permitisse realizar o teste dos componentes antes de inseri-los nos sidecar, elevando desta forma o índice de qualidade nos produtos vendidos pelo empreendimento.

Estas melhorias possibilitaram um aumento na qualidade dos produtos, já que se torna possível que os colaboradores observem e efetuem os testes de quais peças apresentam as especificações exigidas pelos clientes.
Após ter se concluído todos os procedimentos referentes ao processo de implantação da metodologia DMAIC, passando-se algumas semanas do processo em andamento, foi realizada uma comparação entre o antes e o depois da implantação desta metodologia, em que pode-se evidenciar a incidência de uma redução satisfatória das falhas no processos de fabricação dos sidecars, as informações obtidas foram evidenciadas no gráfico, representadas como figura 3 . A média de 10 falhas semanais (representado de azul) foi substituída por uma média de aproximadamente 4 falhas (representado de laranja), ou seja, houve uma redução de 50\% das falhas existentes no setor, acarretando um aumento na produtividade e uma melhoria significativa nos sidecars entregues aos clientes. 
Figura 4 - Gráfico Comparativo das Falhas

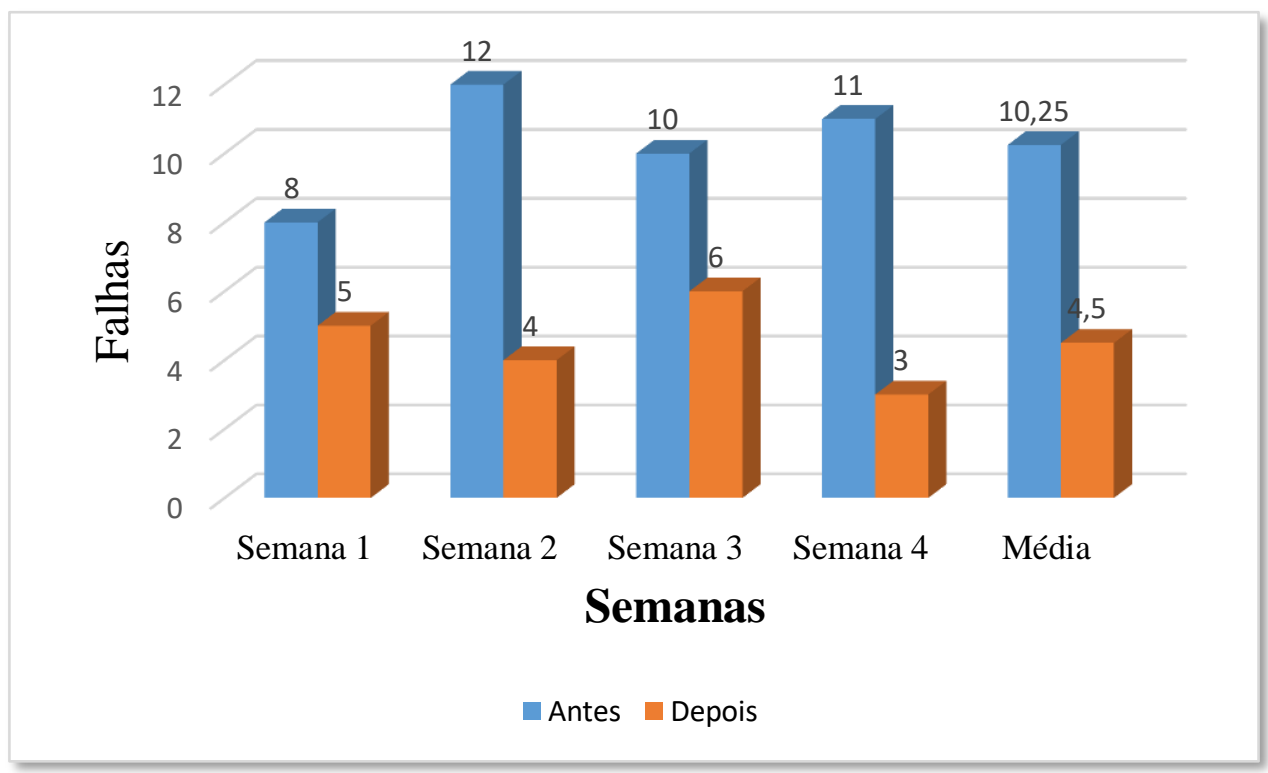

Deste modo, foi possível perceber que após a implantação da melhoria os colaboradores terão um respaldo maior sobre quais atitudes tomar caso ocorresse algum problema. Esse fator fez com que se elevasse a motivação dos funcionários, já que com a experiência adquirida, seria possível que eles fizessem as escolhas que auxiliassem no aumento da qualidade dos sidecars oferecidos pela organização.

\section{CONSIDERAÇÕES FINAIS}

Tendo em vista a busca constante dos empreendimentos por soluções eficientes e definitivas para as dificuldades encontradas no cotidiano do ambiente industrial, a metodologia Define, Measure, Analyse, Improve, Control (DMAIC) tem se tornado um instrumento de grande utilidade para o mercado, uma vez que permite a solução e a extinção de gargalos ao mesmo passo que evita a expansão de problemas que se originam da sua não prevenção (WERKEMA., 2010). Com a finalidade de demonstrar a eficiência desta metodologia realizou-se um estudo de caso, em que foi explanado as oito etapas do DMAIC no problema de "Componentes elétricos fora de especificação". Durante sua aplicação foi possível evidenciar as informações essenciais para a verificação dos fatores que levam a incidência deste gargalo, tornando possível a sua resolução definitiva.

Desta forma, foi possível evidenciar que a solução deste problema garantiu uma melhora significa nos sidecars fabricados pela Empresa Beta, além disso, pode-se perceber que este instrumento se mostra um grande aliado para garantir a melhoria continua no empreendimento, visto que possibilita uma redução considerável nos custos, além de não haver restrições quanto às áreas ou setores em que a metodologia pode ser aplicada. 


\section{REFERÊNCIAS}

[1]. ANBARI, F. T.; KWAK, Y.H. Success Factors in Managing Six Sigma Projects. Project Management Institute Research Conference. London, UK, Julio, 2004.

[2]. ARIENTE, M.; CASADEI, M. A. GIULIANI, A. C.; SPERS, E. E. Processo de mudança organizacional: estudo de caso do Seis Sigma. 2005.

[3]. FOLARON, J. The Evolution of Six Sigma. Six Sigma Forum Magazine, v.2, n.4, 2003, p.35-45.

[4]. FONSECA, J. J. S. Metodologia da pesquisa científica. Fortaleza: UEC, 2002. Apostila.

[5]. GIL, Antonio Carlos. Como elaborar projetos de pesquisa. 4. Ed. São Paulo: Atlas, 2008.

[6]. HARRY, M. \& SCHROEDER, R. Six Sigma: the breakthrough management strategy revolutionizing the world's top corporations. Currency: New York, 2000.

[7]. HRAQDESKY. J. Aperfeiçoamento da qualidade e produtividade. São Paulo: Makron Books, 1997.

[8]. MAHDIRAJI, H.A., ARABZADEH M. \& GHAFFARI, R. Supply chain quality management. Growing Science Ltda., p. 2463-2472, 2012.

[9]. MONTEGOMERY, D.C. Introduction to statistical quality control. $3^{\mathrm{a}}$ ed. Nova York: Wiley, 1996.

[10]. MOREIRA, J. P. S et al. Implantação das Metodologias MASP e 5S no almoxarifado de uma indústria de sidecar. In: Encontro Nacional de Engenharia de Produção, Fortaleza/CE. 2015.

[11]. MOURA, E. As Sete Ferramentas Gerenciais da Qualidade: Implementando a melhoria contínua com maior eficácia. São Paulo: Makron Books, 1994.

[12]. PALADINI, E. P. Gestão da qualidade: teoria e pratica. 2. ed. São Paulo: Atlas, 2004.

[13]. PANDE, S. Estratégia Seis Sigma: como a GE, a Motorola e outras grandes empresas estão aguçando seu desempenho. Rio de Janeiro: Qualitymark, 2001.

[14]. RODRIGUES, J.; WERNER, L. Descrevendo o Programa Seis Sigma : Uma Revisão da Literatura. XXVIII Encontro Nacional de Engenharia de Produção.A integração de cadeias produtivas com a abordagem da manufatura sustentável. Rio de Janeiro, RJ, Brasil, outubro de 2008.

[15]. ROMEIRO FILHO, E. et al. Projeto do produto. Rio de Janeiro: Elsevier, 2010.

[16]. SHONBERGER, R. Japanese Manufacturing Techniques: Nine Hidden Lessons in Simplicity. New York: Free Press, 1982.

[17]. TRAD, S.; MAXIMIANO, A.C.A. Seis Sigma: Fatores críticos de sucesso para sua implantação. RAC, Curitiba, v. 13, n. 4, art. 7, Out./Dez. 2009 p.647-662.

[18]. WERKEMA, C. Lean Seis Sigma Introdução as Ferramentas Lean Manufacturing. Rio de Janeiro: Werkema, 2010. 


\section{Bapítulo 22}

\section{A POLITICA NACIONAL DE RESÍDUOS SÓLIDOS E O GERENCIAMENTO DE RESIDUOS DA CONSTRUCÃO CIVIL}

\section{Monalyza Teles Teixeira}

Adilson Silva de Almeida Júnior

Priscylla Jordânia Pereira de Mesquita

Resumo: O gerenciamento de resíduos sólidos tem sido um tema frequentemente debatido devido a publicação da lei 12.305 que institui a política nacional de resíduos sólidos e obriga os estados e municípios a criarem e executarem o plano de gerenciamento de resíduos. Neste contexto a construção civil se destaca devido a alta geração de resíduos e seu potencial de reciclagem. Dentro dessa perspectiva, este trabalho tem como objetivo analisar os desafios oportunidades em um canteiro de obras frente a geração de resíduos. Para tanto, foi realizada uma pesquisa documental e observacional para levantamento de dados e análise da situação real do canteiro de obras. Com base nos resultados, verificou-se que a obra não possui um plano de gerenciamento de resíduos, mas devido a organização encontrada no canteiro de obras, a empresa tem interesse em gerir corretamente seus resíduos apesar da existência de impasses que devem ser resolvidos. Verificou-se também que na obra, nem todas as suas fases são tão significativas na geração de resíduos e que algumas se destacam. Analisando os tipos de resíduos frequentemente gerados nas etapas da obra, pode-se sugerir algumas oportunidades de utilização, tanto dentro do canteiro de obras, quanto fora dele. A partir do estudo feito na pesquisa conclui-se que é de suma importância a criação, execução e acompanhamento do plano de gerenciamento de resíduos. 


\section{INTRODUÇÃO}

Desde os primórdios, o ser humano tem buscado por seu conforto e comodidade, inicialmente vivendo como nômades. À medida que viu-se a necessidade da prática da agricultura e pecuária, o homem começou a alojar-se fixamente e foi aí que iniciaram primeiros impactos à natureza, o que inicialmente, por não se manterem em um só lugar tornava-se irrelevante (FARIAS, 2014).

Um dos trabalhos mais importantes e significativos para desenvolvimento urbano hoje tem sido a construção civil, porém tem sido também o maior consumidor de recursos naturais, causador de maiores impactos ambientais e gerador de grande quantidade de resíduos (GUEDES, 2014).

A construção civil é uma das indústrias que mais utiliza recursos naturais e é, também, a maior geradora de resíduos, sendo que a tecnologia construtiva adotada no Brasil favorece 0 desperdício de materiais (MARIANO, 2008).

Por esse motivo, há muito tempo se vê a grande preocupação com as consequências que o crescimento urbano têm trazido ao meio ambiente, fazendo com que em 1983 a Comissão Mundial sobre Meio Ambiente e Desenvolvimento da ONU começasse a pensar em Desenvolvimento Sustentável, que tem como âmago o uso planejado dos recursos naturais, consciente de que tais recursos são finitos no meio ambiente (MENDES, 2007).

Quando se trata de sustentabilidade na construção civil, muito se fala em controle, reutilização e reciclagem de resíduos, por estarem diretamente ligados um ao outro, visto que, se numa obra, tem-se o cuidado em administrar bem os resíduos utilizando-os novamente podendo, com isso diminuir $\mathrm{O}$ consumo de recursos naturais, tem-se uma obra buscando o desenvolvimento sustentável (BRASIL, 2016).

Foi buscando melhorar e administrar bem essa gestão de resíduos, que em 2002 foi aprovada a resolução de no307 pelo CONAMA - Conselho Nacional do Meio Ambiente, exigindo do poder público Planos Integrados de Gerenciamento dos Resíduos da Construção Civil, visando reduzir significativamente esses impactos causados pelos resíduos e pelo extravagante uso dos recursos ambientais (BRASIL, 2010).
Mais tarde, em 2010, foi publicada a Lei Federal 12.305 que institui a Política Nacional do Resíduos Sólidos - PNRS, que visa inicialmente, não logo a gestão dos resíduos e sim a prevenção, a tentativa inicial de evitar ao máximo a geração dos tais resíduos, depois reaproveitá-los, os que não puderem ser reaproveitados, reciclados e por fim o que não puder ser de forma alguma reutilizado, nem modificado pra o uso, ser destinado a um local que seja menos impactante ao meio ambiente (MACHADO, 2012).

O que segue em falta são sistemas ou programas que visam a não geração dos resíduos, uma vez que os Planos de Gestão estão voltados à destinação, reciclagem ou reutilização dos resíduos já gerados e não à formas de prevenção para que o resíduos diminuam ou nem sejam gerados (MATTOSINHO; PIONÓRIO, 2009).

A falta de tais sistemas que previnam a geração dos resíduos persiste por ser algo que está ligado direto ou indiretamente á todas as fases da obra, desde a criação do projeto, planejamento da obra, qualidade do material a ser utilizado, chegando a refletir na produção e execução propriamente dita da obra (CARVALHO; SOUZA; LIBRELOTTO, 2014).

Com base nesse estudo, na definição e planejamento dessas atividades, esta pesquisa tem como objetivo proporcionar um melhor compreensão acerca dos desafios enfrentados pelos gerentes das obras e das oportunidades de gestão dos resíduos através da prática do plano, mostrando a preocupação acerca da execução para que seja evitada ou ao menos reduzida a geração de resíduos sólidos, o que também poderá mostrar aos engenheiros possíveis reduções dos custos operacionais no setor da construção civil.

\subsection{METODOLOGIA}

O presente estudo foi realizado em um canteiro de obras da construção de condomínio de prédios residenciais na cidade de Teresina. O procedimento de coleta de dados envolveu o levantamento de documentos da empresa tais como projeto, cronograma e indicadores de sustentabilidade. Dentre os documentos analisados, deu-se enfoque ao Plano de Qualidade da Obra, ao cronograma de planejamento e aos dados referentes à 
implantação do manejo adequado dos resíduos.

O tipo de estudo aqui evidenciado se configura como transversal por descrever os indivíduos de uma população a partir das características em comum que possuem, das ações que realizam num determinado ambiente, neste caso o canteiro de obras da construção civil com seu respectivo gerente de obra (THIOLLENT, 2013). Utilizou-se nessa pesquisa a abordagem qualitativa devido a busca por uma profunda compreensão do contexto e utilização de mais de uma fonte de dados. O presente estudo possui natureza aplicada, com o objetivo de contribuir para fins práticos, partindo de estudos teóricos e com a motivação de produzir conhecimento para a aplicação dos resultados, a classifcação da pesquisa quanto à natureza é aplicada.

\section{FUNDAMENTAÇÃO TEÓRICA}

\subsection{GERAÇÃO E GESTÃO DE RESÍDUOS NA CONSTRUÇÃO CIVIL}

O capitalismo atual tem contribuído significativamente para a geração de maior quantidade de resíduos mundialmente, ficando em primeiro lugar os países mais desenvolvidos e que tem o poder aquisitivo elevado. O Brasil, apesar de não ser desenvolvido e de possuir renda bem menor, fica entre os maiores produtores de lixo do mundo (GODECKE, 2013).

No Brasil a quantidade lixo aumenta a cada ano, contabilizando um aumento de 60 mil toneladas/dia entre 2007 e 2013, tendo crescido 1,3\% de 2011 para 2012 e tendo um aumento mais significativo do que a taxa de crescimento populacional (CHAMON et al., 2013). De 2013 a 2014 essa quantidade de resíduos cresceu em 3,2\% e nesse intervalo de tempo, 7 milhões de toneladas de lixo não foram coletadas, o que significa dizer que tiveram um destino impróprio (BRASIL, 2014).

Estudos comprovam que, por haver o entendimento do que a geração de resíduos pode trazer para o futuro, quanto maior o grau de instrução da população, mais preocupação se tem com o meio ambiente e com a quantidade de lixo gerada. Porém com o aumento do poder aquisitivo, a geração de resíduos aumenta proporcionalmente. (KEMERICH et al., 2013).
A exemplo disso, a construção civil é um setor que vem se destacando no cenário brasileiro e impulsionando o mercado econômico. Em contrapartida é responsável por grandes impactos ambientais, já que os resíduos produzidos dessa atividade são constituídos de material inerte, causando grandes transtornos à população por não ter a gestão adequada (AMADEI, et. al., 2011).

A gestão dos resíduos sólidos da construção civil apresenta-se precária no cenário mundial e brasileiro, em consequência disso, inúmeros impactos ambientais são ocasionados pela falta de investimentos e políticas públicas voltadas para a disposição correta desse tipo de resíduo, que é produzido de forma grandiosa em todas as regiões brasileiras. Dessa forma, por apresentar metade do lixo produzido em todo território nacional, os resíduos sólidos da construção civil devem ser geridos por leis e políticas que obriguem o poder executivo das cidades buscarem maneiras de disposição adequada para os mesmos (MESQUITA, 2012).

A situação do gerenciamento dos resíduos sólidos de construção civil, de forma geral, é preocupante e necessita de muitos progressos. Considerada parte do saneamento básico, a gestão dos resíduos não tem sido tratada pelo poder público com a importância que merece. Com isso, comprometem-se os recursos naturais (solo e os recursos hídricos), reforçando a necessidade de integração das ações desses setores na melhoria da qualidade de vida da população brasileira e na segurança e sustentabilidade dos processos industriais (SILVA; FERNANDES, 2012).

Atualmente, apesar da dificuldade enfrentada pelas empresas construtoras neste quesito de gerenciamento do resíduo, muitas têm se esforçado devido à grande concorrência do ramo, onde quem trabalha com menor custo é quem leva a obra, e para trabalhar com menos custo, deve-se seguir um Plano de gerenciamento de resíduos, de preferência voltado para a reciclagem ou reaproveitamento do material (DIAS, 2007).

Neste contexto, verifica-se que, compartilhada a gestão de riscos no caso dos resíduos sólidos, todos têm parcela de responsabilidade sobre produção e destinação. Ressalta-se que o conceito de possibilidade nociva, ou seja, de risco surge através de um "processo de modernização complexo e acelerado" que prima por 
desenvolvimento e crescimento econômicos acentuados, desconsiderando a higidez ambiental onde todos participam sem excluir nenhum agente social.

\subsection{PLANOS DE GESTÃO DOS RESÍDUOS DE CONSTRUÇÃO CIVIL}

Acredita-se que um bom planejamento de execução da obra poderia diminuir significativamente 0 retrabalho $e \quad 0$ desperdício de materiais, onde é necessário demolir pra refazer, e consequentemente mais resíduos serão gerados aumentando o custo de transporte e o local de destinação dessas sobras. (DIAS, 2007).

Sendo assim, todas as obras em execução devem ter além das licenças ambientais, um Plano de Gerenciamento de Resíduos, contendo todos os tipos de resíduos gerados pela obra, a composição dele e o local ou forma de destinação que será dada aquele entulho (BRASIL, 2010). Porém, com a globalização e o crescimento populacional principalmente nas capitais, os locais adequados e tratados para essa finalidade estão cada vez mais escassos, e acabam exigindo um preparo maior e uma abordagem técnica bem mais precisa para que o local atenda aos requisitos exigidos por normas (CALIJURI, 2002).

Portanto, a despeito de clamar por uma aplicabilidade imediata, surte poucos efeitos em sua realidade, pois normatizar e engendrar um mínimo ético ambiental em uma sociedade alheia às causas ambientais ou, se não alheia, consciente deste pensamento ambiental em interstícios. Não obstante, sendo a Lei 12.305/10 e o CONAMA 448/2012 um mecanismo que busca remediar a lacuna de um superego ecológico, não se pode desconsiderá-la sob pena de cair em uma crítica teimosa e sem fim. Existem pontos positivos que, embora ainda não tenham sido aplicados de forma eficiente devem ser manifestados (MILARÉ, 2011).

Todo canteiro de obras afim de implantar um Plano de Gestão de Resíduos de Construção Civil, deve inicialmente fazer um cronograma dividido em quatro etapas, sendo a primeira a reunião inaugural fazendo a apresentação e conscientização da necessidade do plano e demonstrar as vantagens da implantação do mesmo. A segunda etapa implica no planejamento onde será realizado o levantamento da situação atual do canteiro de obras no que se refere aos resíduos, a área do canteiro quantidade de funcionários, entre outras informações relevantes e preparada toda a proposta do plano. Feito isso entra-se na terceira e quarta etapa, que implica na implantação onde será colocado em prática todo o planejamento e monitoramento onde deverão ser feitas avaliações e verificações do andamento do plano através de formulários e check-lists, atentando-se da necessidade ou não de providências para que $\mathrm{o}$ andamento esteja sempre em melhoria (SÃO PAULO, 2005).

$\mathrm{Na}$ resolução do CONAMA 307, podemos encontrar as cinco etapas que devem compor um Plano de Gerenciamento de Resíduos em um canteiro de obras bem como demonstra o que deve ser feito em cada uma delas. É o que mostra o Art. 9o da resolução exposto à seguir:

"Art. 9o Os Planos de Gerenciamento de Resíduos da Construção Civil deverão contemplar as seguintes etapas: (nova redação dada pela Resolução 448/12) (Resolução CONAMA 307 - Art. 9)

I. I - caracterização: nesta etapa o gerador deverá identificar e quantificar os resíduos;

II. II - triagem: deverá ser realizada, preferencialmente, pelo gerador na origem, ou ser realizada nas áreas de destinação licenciadas para essa finalidade, respeitadas as classes de resíduos estabelecidas no art. 3ำ desta Resolução;

III. III - acondicionamento: o gerador deve garantir o confinamento dos resíduos após a geração até a etapa de transporte, assegurando em todos os casos em que seja possível, as condições de reutilização e de reciclagem;

IV. IV - transporte: deverá ser realizado em conformidade com as etapas anteriores e de acordo com as normas técnicas vigentes para $\mathrm{O}$ transporte de resíduos;

V. V - destinação: deverá ser prevista de acordo com o estabelecido nesta Resolução." 


\section{RESULTADOS E DISCUSSÕES}

De acordo com a resolução 307 da legislação do CONAMA, que tem como principal função minimizar e eliminar os grandes impactos no meio ambiente oriundos de resíduos da construção civil, obriga todos os municípios do país a terem um Plano de Gerenciamento dos Resíduos da Construção Civil (BRASIL, 2012).

Em visita na obra estudada, foi verificado que o canteiro de obras não dispõe de um Plano de Gerenciamento dos Resíduos com os parâmetros exigidos pelo CONAMA, nem mesmo um procedimento a ser seguido visando todos esses cuidados.

Foi verificado também que a destinação dos resíduos, apesar dos cuidados e da disposição possivelmente adequada dos resíduos no canteiro, não é feita como esperado pelas normas talvez, por não possuir um parâmetro a seguir ou mesmo um procedimento.

Não é dado devido destino correto a cada tipo de resíduo, porém tem-se o cuidado de não dispor o resíduo em locais ilegais, pelo menos nesta fase da obra onde o terreno por contar com uma área bem extensa, ainda comporta com certa folga o armazenamento dos resíduos.

O que a obra faz para dispensar parte dos resíduos armazenados é usar de doações para algumas empresas que se utilizam desse tipo de material, como por exemplo a madeira para panificadoras. Por esse motivo, as baias existentes no canteiro estão sempre com a lotação ao extremo (Imagem 01), devido as empresas que recebem as doações não necessitarem na mesma velocidade em que o resíduos é gerado

\section{Imagem 01 - Resíduos separados por baias (vista de dentro das baias)}

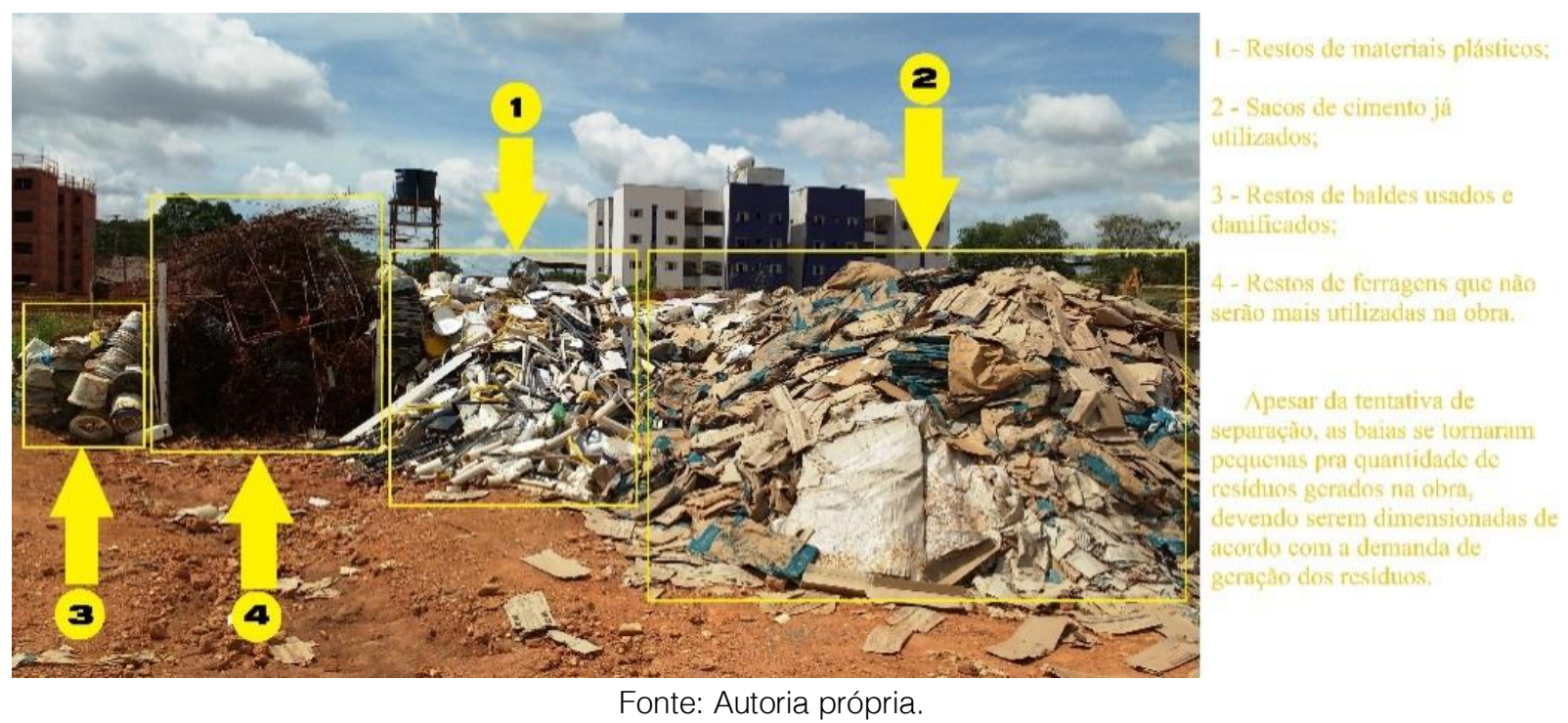

Foi feito o registro dos armazenamentos de entulhos produzidos no canteiro da obra estudado. É o que se pode ver na Imagem 02 a seguir: 


\section{Imagem 02 - Disposição de resíduos no canteiro de obras}

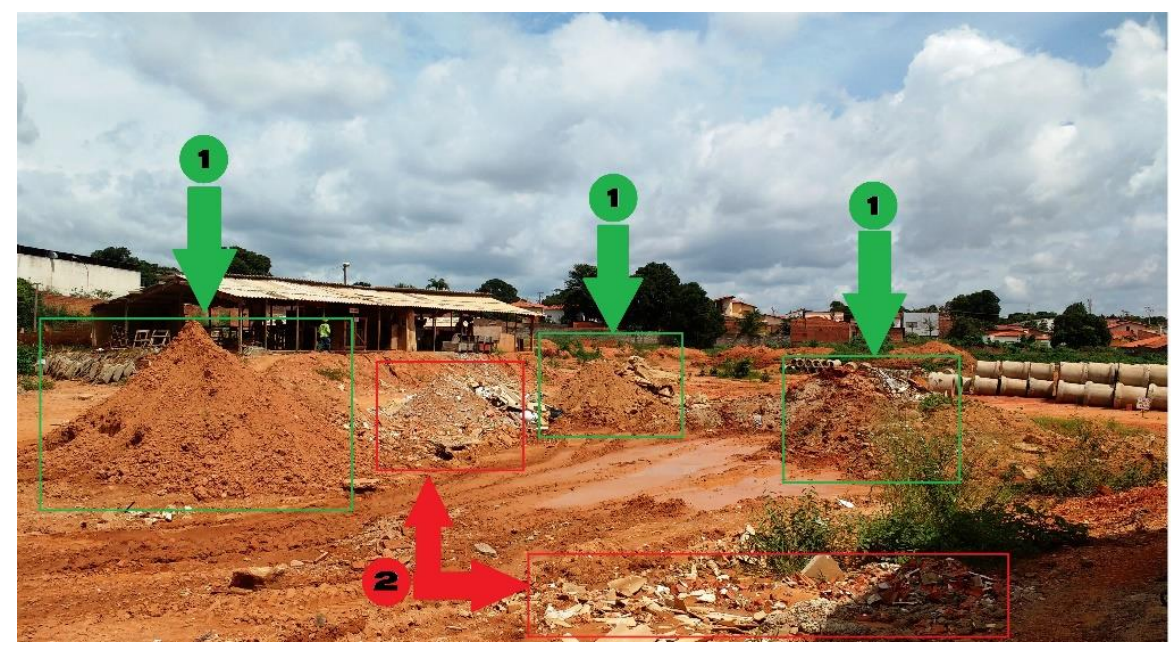

1 - Entulhos

caracterizados com solos, separados, e podem ser reutilizados para aterros ou reaterros na própria obra;

2 - Restos de louças, pedaços de gesso, solos e restos de blocos

cerâmicos. Entulhos misturados e já sem possibilidade de separação, podendo ocorrer de não servir mais para reutilização.

Fonte: Autoria própria.

Outro fator positivo neste sentido é que a empresa é certificada na norma de qualidade ISO 9001, que é uma norma que visa padronização das formas de execução dos serviços através de procedimentos e, apesar que de forma sucinta, se preocupa com a geração de resíduos e consumo de água e energia, exigindo o acompanhamento disto através de Indicadores Mensais de Sustentabilidade (Ver Imagem 03).

Imagem 03 - Indicadores Mensais de Sustentabilidade

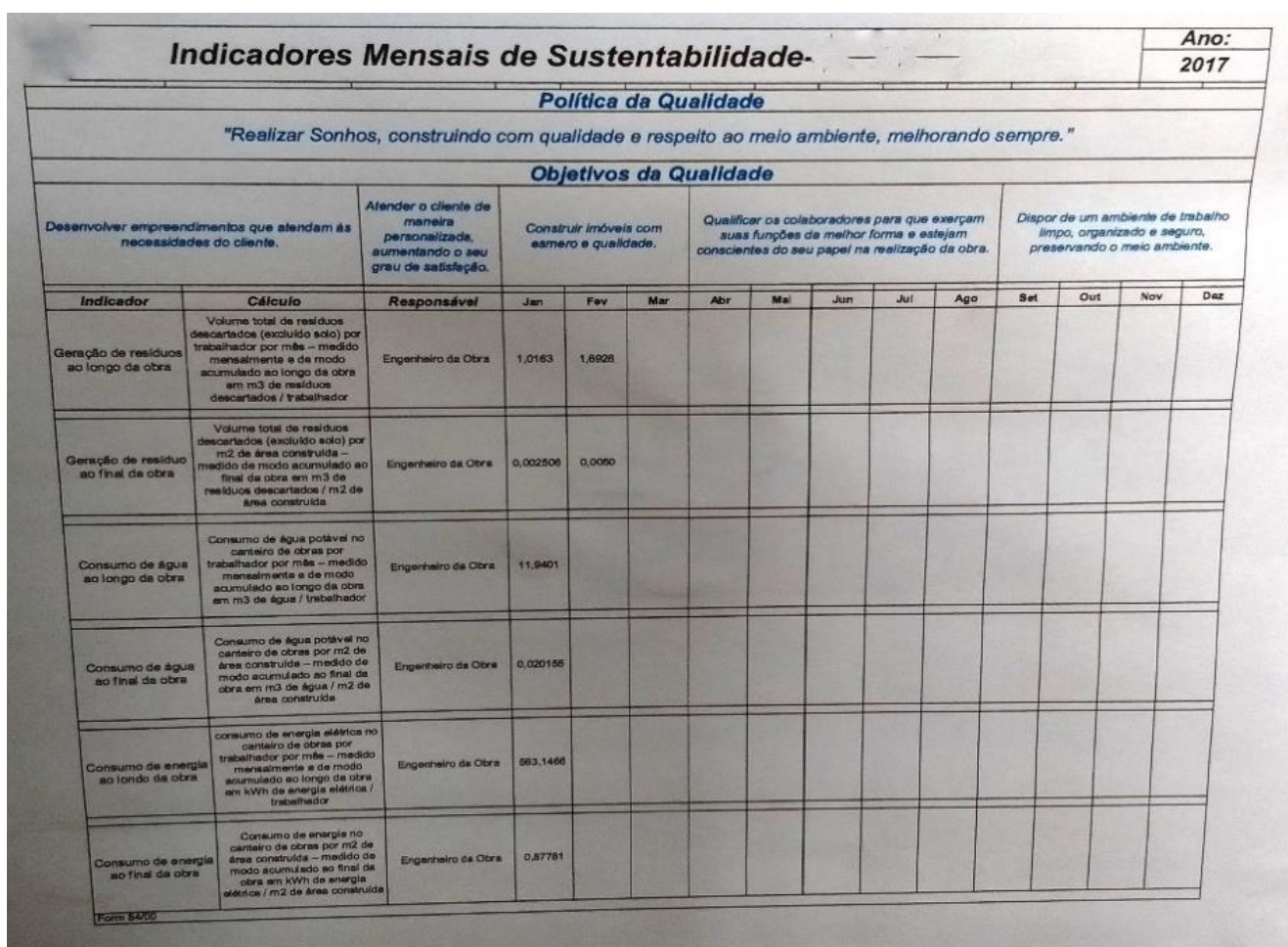

Fonte: Autoria própria. 
Analisando o Indicadores Mensais de Sustentabilidade, verificou-se que são feitas as seguintes medições referente a geração de resíduos:

Geração de resíduos ao longo da obra que é calculada da seguinte forma: Volume total de resíduos descartados (excluído solo) por trabalhador por mês - medido mensalmente e de modo acumulado ao longo da obra em m3 de resíduos descartados/trabalhador;

Geração de resíduo ao final da obra que é calculada da seguinte forma: Volume total de resíduos descartados (excluído solo) por m2 de área construída - medido de modo acumulado ao final da obra em $\mathrm{m} 3$ de resíduos descartados / m2 de área construída;

Com os valores explanados no formulário (Imagem 05), foi possível gerar um gráfico dos valores de Geração de resíduos para melhor visualização dos resultados até a data em que foi feita a visita na obra, que ainda se encontra em andamento, e perceber a diferença dessas variáveis comparando o início da obra até o momento atual.

Gráfico 01 - Valores dos indicadores mensais acumulados de sustentabilidade de Geração de Resíduos (Kg)

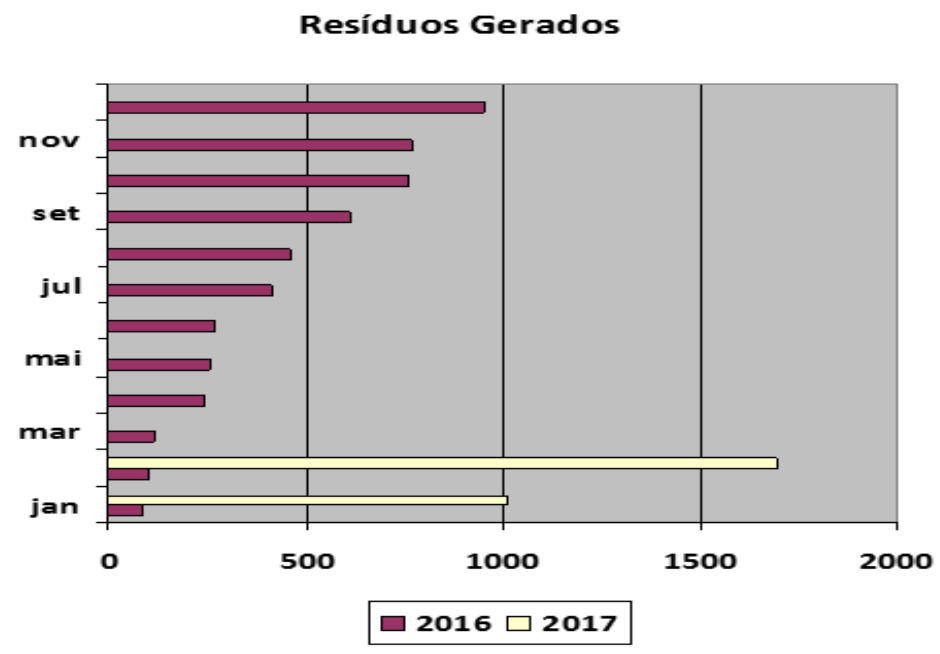

Fonte: Autoria própria.

Analisando o Gráfico 01 que contempla os anos de 2016 até 2017 onde a obra continua em andamento, pôde-se observar que os valores tiveram uma alta mais significativa do mês de abril de 2016, tendo sido produzido um valor de $244 \mathrm{~kg}, 126,6 \mathrm{~kg}$ de resíduos a mais, comparado a quantidade produzida em março que foi $117,4 \mathrm{~kg}$, significando um aumento de $107,79 \%$, mais que o dobro do mês anterior.
Em segundo lugar ficou o mês de fevereiro de 2017, tendo sido produzido um valor de 1692,6 kg, 676,3 kg de resíduos a mais, comparado a quantidade produzida em janeiro que foi $1016,3 \mathrm{~kg}$, significando um aumento de $66,55 \%$. Os outros meses variam entre $0,84 \%$ a $55,10 \%$. 
Gráfico 02 - Quantidades de resíduos gerados por mês na obra

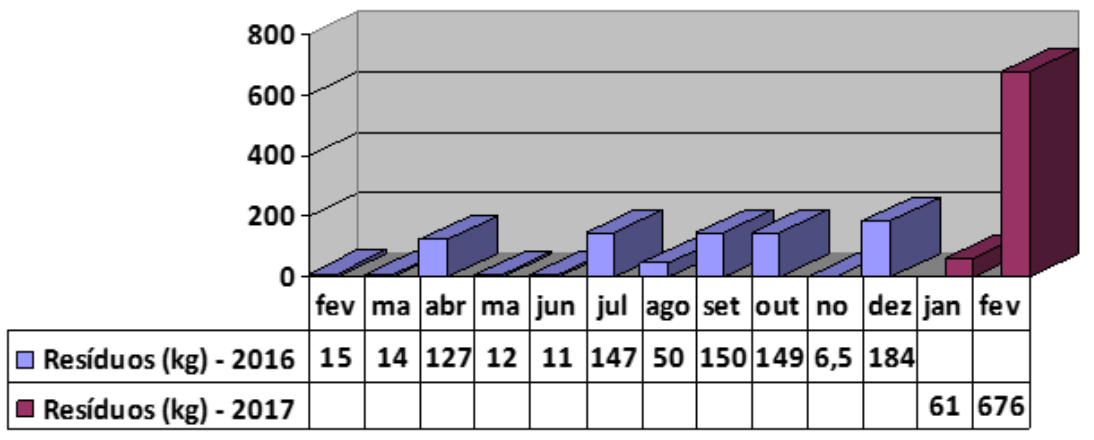

$\square$ Resíduos (kg) - 2016 ๑ Resíduos (kg) - 2017

Fonte: Autoria própria.

Como isso podemos concluir facilmente que em fevereiro, onde foi produzido mais resíduos, foi na etapa em que a obra se encontrava com mais serviços em execução, porém analisando o andamento da obra percebeu-se que os serviços que geram mais resíduos são os de alvenaria/lajes, revestimentos cerâmicos, instalações elétricas e hidrossanitárias e gesso em placa.

Diante de todo o exposto, nota-se a grande dificuldade enfrentada na obra em manter práticas relacionadas à gestão de resíduos sem um plano de gestão pra ser seguido. As dificuldades que os gestores de obra enfrentam, geralmente se repetem de forma semelhante na grande maioria das obras.

$\mathrm{Na}$ obra em questão pode-se dizer que um dos maiores desafios encontrados diante desta pesquisa, além do investimento necessário no próprio canteiro de materiais para que sejam construídas baias em tamanho suficiente ou até mesmo para melhor organização dos resíduos e dos próprios materiais que ainda serão utilizados na obra, tem-se também a falta de locais licenciados para destinação dos materiais que a obra não consegue doar.

Outro desafio que pode ser citado e que pode facilmente ser resolvido é a falta de um Plano de Gestão de Resíduos da própria obra, de onde o engenheiro da obra poderia seguir os parâmetros e se organizar de acordo com as necessidades da obra preparando o canteiro pra receber e armazenar os resíduos adequadamente durante o tempo em canteiro até que fossem destinados ao local final.
Visto que um dos grandes desafios é justamente o de destinação dos resíduos por falta de locais adequados e até mesmo licenciados para o tal, sugere-se que sejam analisadas as várias oportunidades de utilização desses resíduos tanto dentro do próprio canteiro como também fora dele

\section{CONSIDERAÇÕES FINAIS}

A pesquisa abordou um assunto de extrema importância na construção civil devido a grande necessidade de identificar locais de destinação, considerado um dos maiores desafios enfrentados pela gerência das obras. Para evitar que a quantidade a ser destinada a esses locais seja elevada, aproveita-se de oportunidades que incluem reciclagem ou reaproveitamento dos resíduos gerados em obra.

Baseado nos resultados obtidos no decorrer da pesquisa, verificou-se que a obra instrumento deste estudo, não possui um Plano de Gerenciamento de Resíduos. Observou-se também, pela organização encontrada no canteiro de obras, que a empresa tem grande interesse em gerir corretamente seus resíduos e está à disposição para que ocorra a implementação de ferramentas que forneçam o direcionamento de como proceder aos assuntos relacionados à gestão de resíduos, comprovando que a existência desse Plano de Gestão de Resíduos é de suprema importância numa obra, para que exista parâmetros e procedimentos a serem seguidos. 


\section{REFERÊNCIAS}

[1]. AMADEI, D. I. B. Questão dos resíduos de construção civil: Um breve estado da arte. Revista NUPEM, v.3, n.5, ago./dez. Campo Mourão, 2011.

[2]. BRASIL, Associação Brasileira de Empresas de Limpeza Pública e Resíduos Especiais -ABRELPE. Manual para Implantação de Sistema de Gestão de Resíduos de Construção Civil em Consórcios públicos. Disponível em:< http://www.mma.gov. br/component/k2/item/10333consorcios >. Acesso em: 25 de fevereiro de 2016.

[3]. BRASIL, Associação Brasileira de Empresas de Limpeza Pública e Resíduos Especiais -ABRELPE. Lei no 12.305/2010. Política Nacional dos Resíduos Sólidos- PNRS. 2010.

[4]. BRASIL, Associação Brasileira de Empresas de Limpeza Pública e Resíduos Especiais - ABRELPE. Panorama de Resíduos Sólidos no Brasil - 2014.

[5]. BRASIL, Associação Brasileira de Empresas de Limpeza Pública e Resíduos Especiais -ABRELPE. Lei no 12.305/2010. Política Nacional dos Resíduos Sólidos- PNRS. 2010.

[6]. CALIJURI, M. L.; MELO, A. L. O.; LORENTZ, J. Ferreira. Identificação de áreas para implantação de aterros sanitários com uso de análise estratégica de decisão. Informática Pública, v. 4, n. 2, p. 231-250, 2002.

[7]. CARVALHO, H. A.; SOUZA, J. C.; librelotto, I. I. Benefícios da gestdião de projetos e planejamento em relação ao impacto ambiental causado por desperdício em obras. Alagoas, 2014.

[8]. CHAMON, R. C.; CARDOSO, R.; BARROS, C. F. I Congresso Fluminense de Engenharia, Tecnologia e Meio Ambiente-UFF.

[9]. DIAS, E. C. M. Gerenciamento de resíduos na construção civil. São Paulo, 2007.

[10]. FARIAS, I. P. Proposta de modelo de gestão de resíduos da construção civil para a zona leste da cidade de Teresina-PI. 2014.

[11]. GODECKE, M. V.; NAIME, R. H.; FIGUEIREDO, J. A. S. O consumismo e a geração de resíduos sólidos urbanos no Brasil. Revista Eletrônica em Gestão, Educação e Tecnologia Ambiental, v. 8, n. 8, p. 1700-1712, 2013.
[12]. GUEDES, G. S. Gestão de Resíduos na Construção Civil. Revista Terceiro Setor \& GestãoUnG, v. 8, n. 1, p. 21-28, 2014.

[13]. KEMERICH, P. D. et al. Gestão dos resíduos sólidos urbanos: a visão da população na cidade de Frederico Westphalen. Revista Eletrônica em Gestão, Educação e Tecnologia Ambiental, v. 10, n. 10, p. 2059-2068, 2013.

[14]. MACHADO, P. A. L. Princípios da política nacional de resíduos sólidos. Revista do Tribunal Regional Federal da 1a Região, 2012.

[15]. MARIANO, L. S.; COSTA, M. R. M. M; BRAGA, M. C. B. Gerenciamento de resíduos da construção civil com reaproveitamento estrutural: estudo de caso de uma obra com $4.000 \mathrm{~m}^{2} .2008$.

[16]. MATTOSINHO, C.; PIONÓRIO, P. Aplicação da produção mais limpa na construção civil: uma proposta de minimização de resíduos na fonte. São Paulo. 2009.

[17]. MENDES,M.C. sustentável. t. Disponível em: $<$ http://educar.sc.usp.br. biologia/textos/m_a_txt2. html. 2007.

[18]. MESQUITA, A. S. G. Análise da geração de resíduos sólidos da construção civil em Teresina, Piauí. Holos, Ano 28, Vol. 2. Piauí, 2012.

[19]. MILARÉ, E. Direito do ambiente: a gestão ambiental em foco: doutrina, jurisprudência, glossário. 7. ed. São Paulo: Revista dos Tribunais, 2011.

[20]. SÃO PAULO, Sindicato da Indústria da Construção Civil do Estado de São Paulo SindusCon-SP. Gestão Ambiental de Resíduos da Construção Civil - A experiência do SindusCon-SP 2005.

[21]. SILVA,V. A; FERNANDES, A. L. T. Cenário do gerenciamento dos resíduos da Construção e demolição (RCD) em Uberaba-MG. Sociedade \& Natureza, v. 24, n. 2, mai/ago. Uberlândia, 2012.

[22]. THIOLLENT, M. J. M. Aspectos qualitativos da metodologia de pesquisa com objetivos de descrição, avaliação e reconstrução. Cadernos de Pesquisa, 2013. 
Alutary 


\section{ADILSON SILVA DE ALMEIDA JÚNIOR}

Graduando do $9^{\circ}$ período de Engenharia de Produção da Universidade Santo Agostinho, Técnico em Eletromecânica pelo SENAI com cursos de aperfeiçoamento nas áreas de Engenharia de Materiais, Logística Reversa, Engenharia Sustentável, Balanced Scorecard, dentre outros. Habilidades com diversas ferramentas, dentre elas, Bizagi Modeler, SketchUP, Prezi e Excel. Possui artigos publicados nos Anais do SIMPEP 2017 e ENEGEP 2017. Bolsista do PIBIC pela UNIFSA.

\section{ADRIEL AUGUSTO DOS SANTOS SILVA}

Graduando em Engenharia Civil pelo Centro Universitário de Patos de Minas - UNIPAM (2014 - atual).

\section{ALESSANDRA DE PAULA}

Doutora em Engenharia de Produção (UFSC), Mestre em Engenharia de Produção e Sistemas ( PUC PR), Especialista em Formação de Docentes e Orientadores Acadêmicos, Especialista em Planejamento e Gestão Estratégica, Especialista em Engenharia de Produção, graduada em Administração. Coordenadora e professora titular do Centro Universitário Internacional UNINTER, com experiência na área de Inteligência Organizacional, Administração da Qualidade, Estratégias Competitivas e Modelos de Gestão e Inovação. Atua desde 2005 na Educação Presencial e na Educação a Distância. Atualmente integra o grupo de Pesquisa: Práticas de ensino e gestão organizacional. Autora de duas obras e Referee de congressos como Enegep e Simpep.

\section{ALEXANDRE GONÇALVES PORTO}

Engenheiro Agrícola pela Universidade Federal de Pelotas (1999), mestre em Engenharia e Ciência de Alimentos pela Fundação Universidade Federal do Rio Grande (2001) e doutor em Ciência e Tecnologia de Sementes pela Universidade Federal de Pelotas (2004). Atualmente é Professor Adjunto da Universidade do Estado de Mato Grosso (UNEMAT). Foi Pró-Reitor de Extensão e Cultura e atualmente é Pró-Reitor de Gestão e Finanças da UNEMAT. Tem experiência na área de Processamento e Tecnologia de Produtos Agroindustriais, atuando principalmente na área de pós-colheita de produtos agropecuários.

\section{ANA CAROLINE DZULINSKI}

Doutoranda (2016) em Engenharia de Produção pela Universidade Tecnológica Federal do Paraná (Ponta Grossa, Paraná), do grupo de pesquisa de Desenvolvimento de Produtos e Processos de Manufatura; Formação obtida na Universidade Tecnológica Federal do Paraná (UTFPR), Campus Ponta Grossa (PR): Mestrado em Engenharia de Produção (2014 - 2016): Grupo de pesquisa de Desenvolvimento de Produtos e Processos de Manufatura; PósGraduada em Gestão Industrial - Produção e Manutenção (2012) Graduada em Engenharia de Produção em Controle e Automação (2007 - 2011) Graduada em Tecnologia em Fabricação Mecânica (2012 - 2017). Experiência Profissional: Trabalhou na Indústria de 2011 (Agosto) a 2013 (Outubro) na área de desenvolvimento de novos produtos e processos de manufatura do segmento metal mecânico e ferramentas. 
Mestranda em Política Públicas e Gestão da Educação Superior da Universidade Federal do Ceará, Técnica em Assuntos Educacionais da UFC.

\section{ANDRÉ FELIPE SIMÕES}

Possui graduação em Engenharia Metalúrgica pela Pontifícia Universidade Católica do Rio de Janeiro (1994), mestrado em Engenharia Metalúrgica - Pontifícia Universidade Católica do Rio de Janeiro (1998), doutorado em Planejamento Energético pela Universidade Federal do Rio de Janeiro (2003) e pós-doutorado em Planejamento de Sistemas Energéticos pela Universidade Estadual de Campinas - Unicamp (2006). Obteve a Livre-Docência, pela USP, em setembro de 2013, com tese defendida na área de "Mudanças Climáticas e a Agenda Brasileira de Infraestrutura Energética". É Professor Doutor Associado em regime de Dedicação Integral à Docência e à Pesquisa (RDIDP) do Curso de Bacharelado em Gestão Ambiental da Escola de Artes, Ciências e Humanidades da Universidade de São Paulo (EACH/USP). Entre 2011 e 2013, foi Coordenador do referido curso de graduação da EACH/USP e membro titular da Comissão de Graduação da EACH. Atua também como Prof. Dr. do Programa de Pós-Graduação em Energia - IEE/USP (professor credenciado) e do Programa de Pós-Graduação em Sustentabilidade da EACH/USP (professor credenciado) . Entre 2006 e 2011, foi professor doutor credenciado no Programa de Planejamento de Sistemas Energéticos - CPG/FEM/Unicamp. Por conta de atuação em 29 projetos de pesquisa/consultoria de fomento nacional e/ou internacional, possui experiência na área de Planejamento Energético e Ambiental. Macro temas dos projetos já desenvolvidos: Mudanças Climáticas Globais, Mercado Internacional de Créditos de Carbono, Matriz Energética, Energias Renováveis, Eficiência Energética, Gases de Efeito Estufa, Alternativas de Mitigação, Alternativas de Adaptação, Desenvolvimento Sustentável no Brasil e no Mundo, Universalização do Acesso à Energia Elétrica, Petróleo, Gás Natural, Transportes (no contexto de conexões com os temas energia e mudanças climáticas) e Engenharia Ambiental. Eventualmente, atua como Assessor Científico da Fundação de Amparo à Pesquisa do Estado de São Paulo (FAPESP). Integrante do Fórum Brasileiro de Mudanças Climáticas (FBMC) e do Painel Brasileiro de Mudanças Climáticas (PBMC). Revisor do 50 Relatório de Avaliação do IPCC. Revisor parecerista dos periódicos "Climate and Development", "Regional Environmental Change" e "Journal of Environmental Management". Em abril de 2015, conquistou o Prêmio Vale-Capes de Ciência e Sustentabilidade.

\section{ANDRÉ PEREIRA MARQUES}

Mestre (2004) em Engenharia Elétrica pela Escola de Engenharia Elétrica, Mecânica e de Computação (EMC) da Universidade Federal de Goiás (UFG) e graduado (1984) em Engenharia Elétrica na EMC/UFG. Gerencia e atua no Departamento de Engenharia e Controle da Manutenção da CELG Distribuição S.A. e é professor do Instituto Federal de Educação, Ciência e Tecnologia de Goiás.

\section{ANGELA CAROLINA LAURINDO DE MENDONÇA}

Graduada em Engenharia de Produção pelo Centro Universitário CESMAC, onde durante a graduação foi bolsista no Programa de Bolsas de Iniciação Científica (PIBIC), e participou de projetos de extensão. 


\section{ANTÔNIO LUIZ CAUS}

Possui graduação em Engenharia Civil pela Universidade Federal do Espírito Santo (Ufes) 1975 - e mestrado em Engenharia de Produção pela Universidade Federal da Paraíba (UFPb) - 1977 - campus Campina Grande (atual UFCG). Atualmente é gerente da área de desenvolvimento urbano e técnico em planejamento do Instituto de Apoio à Pesquisa e ao Desenvolvimento Jones dos Santos Neves (IJSN), professor do departamento de Engenharia de Produção da Universidade Federal do Espírito Santo, atuando principalmente nos seguintes temas: engenharia civil, sistema de transporte urbano, transporte ferroviário, modernização e projetos.

\section{BRUNO COSSE PEDROSO}

Graduando do curso de Engenharia Elétrica da Escola de Engenharia Elétrica, Mecânica e de Computação (EMC) da Universidade Federal de Goiás (UFG). Bolsista do Programa Jovens Talentos para a Ciência - CAPES (2014-2015); Participante do Fórum CREA-GO Jovem (2014-2016), Coordenador Titular Estadual do Fórum; Membro do Núcleo de Robótica Pequi Mecânico (2015-2016); Diretor Acadêmico do Centro Acadêmico da Engenharia Elétrica UFG (2015/2016); Presidente do Centro Acadêmico da Engenharia Elétrica UFG (2016/2017); Estagiário no Departamento de Engenharia e Controle da Manutenção da CELG D (2016).

\section{CACILDA DE JESUS RIBEIRO}

Doutora (2002) e pós-doutora (2004) em Engenharia Elétrica pela Escola de Engenharia de São Carlos (EESC) da Universidade de São Paulo (USP). Engenheira Eletricista graduada (1994) na Unifeb, e Especialista em Engenharia de Segurança do Trabalho (2008) pela UFG. Atua como professora associada na Escola de Engenharia Elétrica, Mecânica de Computação da Universidade Federal de Goiás

\section{CARLOS HENRIQUE OLIVEIRA}

Possui graduação em Engenharia Mecânica com ênfase em Produção, especialização em Qualidade e Produtividade e mestre em Engenharia de Produção pela Universidade Federal de Itajubá. Atualmente é professor assistente na Universidade Federal de Itajubá-campus avançado de Itabira e atua nas áreas de Estatística, Engenharia da Qualidade, Seis Sigma e Lean Manufacturing (Manufatura Enxuta).

\section{CRISTIANE ADRIANA RIPKA}

Mestranda em Administração e Direção de Empresas (UDE), Especialista em Formação de Docentes e de Tutores, Especialista em Gestão do Conhecimento, graduada em Administração de Empresas. Experiência na área de Educação, com ênfase em Administração Educacional, atuando principalmente nos seguintes temas: educação a distância, simuladores, práticas pedagógicas, processos e manutenção. 


\section{DIEGO FERNANDES SILVA}

Engenheiro de Produção pela Universidade de Franca (2012), MBA em Engenharia e Inovação no Centro Universitário Uniseb (2015). Mestrando em Administração das Organizações na FEA-RP (USP). Pós-graduando em Educação a Distância: Planejamento, Implantação e Gestão no Centro Universitário Claretiano. Professor e Auxiliar de Coordenação do curso de Engenharia de Produção no Centro Universitário Claretiano. Estudante no grupo de pesquisa do Núcleo de Pesquisas em Inovação, Gestão Empreendedora e Competitividade da Universidade de São Paulo (INGTEC).

\section{EDGAR MANUEL CARREÑO FRANCO}

Possui graduação em Ingenieria Electrica da Universidad Nacional de Colombia (1999), Mestrado em Ingenieria Electrica da Universidad Tecnológica de Pereira, Colombia (2003) e Doutorado em Engenharia Elétrica na UNESP-FEIS, Brasil (2008). Atualmente é Docente em Engenharia Elétrica do CECE- UNIOESTE na cidade de Foz de Iguaçu-PR e Coordenador do Programa de Pos-Graduação em Engenharia Elétrica e Computação - PGEEC. Tem experiência na área de Engenharia Elétrica, com ênfase em planejamento de sistemas de Transmissão e Distribuição da Energia Elétrica, atuando principalmente nos seguintes temas: Previsão demanda, Planejamento de sistemas de transmissão e distribuição, Otimização matemática.

\section{EDSON MANFIOLETTI GOMES}

Graduando do curso de Engenharia de Produção da Faculdade Capivari - FUCAP.

\section{EDUARDO JOSÉ OENNING SOARES}

Engenheiro de Produção Agroindustrial formado pela Universidade do Estado de Mato Grosso (UNEMAT). Mestre e Doutor em Engenharia de Produção pela Universidade Federal de Pernambuco (UFPE). Foi professor na graduação e pós-graduação na Faculdade Boa Viagem em Recife, e da Universidade de Cuiabá (UNIC) de Tangará da Serra no curso de Engenharia de Produção. Atualmente é professor Adjunto da UNEMAT no curso de Engenharia de Produção Agroindustrial. Realiza pesquisas na área de Gestão da Produção, Gestão da Qualidade, Desenvolvimento de Produtos e Marketing Industrial.

\section{EMERSON JOSÉ DE PAIVA}

Possui graduação em Matemática, mestrado em Engenharia de Produção, e doutorado em Engenharia Mecânica, na área de Projeto e Fabricação. Atualmente, é professor de Otimização e Simulação da Universidade Federal de Itajubá, Campus Itabira e é vice-líder do Grupo de Estudos em Qualidade e Produtividade - GEQProd, da Unifei, Campus de Itabira.

\section{EUCLIDIA SELÊNIA PEREIRA TEIXEIRA}

Mestranda do Mestrado Profissional em Políticas Públicas e Gestão da Educação Superior pela Universidade Federal do Ceará(UFC), especialista em Unidade de Terapia Intensiva pela Universidade Estadual do Ceará (UECE) e graduada em Enfermagem pela Universidade Federal do Ceará (UFC). Enfermeira do Hospital Universitário Walter Cantídio (HUWC/UFC) e do Hospital São José de Doenças Infecciosas da Secretaria Estadual de Saúde do Ceará (HSJ/SESA-CE). 


\section{FABIANO BARBIERI}

Formado em Engenharia de Produção pelas Faculdades Integradas de Taquara - FACCAT, no ano de 2015, atualmente mora na cidade de Sydney, Austrália, onde atua como Gerente Assistente na empresa Glaziers.Com Projects e cursa Diploma em Gerenciamento de Projetos na Australian Pacific College.

\section{FÁBIO DE OLIVEIRA NEVES}

Possui graduação em Biotecnologia Bacharelado pela Universidade Federal de Alfenas (2012) e mestrado em ECOLOGIA E TECNOLOGIA AMBIENTAL pela Universidade Federal de Alfenas (2015), atualmente está no doutorado em ciências ambientais pela UNESP/SOROCABA. Experiencia em sistema de gestão ambiental e organizacional, tecnologias ambientais princípios em sustentabilidade além de estatística básica e aplicada

\section{FELIPE AUGUSTO DA SILVA}

Graduando em Engenharia Civil pelo Centro Universitário de Patos de Minas - UNIPAM (2015 - atual).

\section{FELIPE VICENTIN MOISES}

Graduando do curso de Engenharia de Produção da Faculdade Capivari - FUCAP.

\section{FERNANDA KEMPNER-MOREIRA}

Doutoranda do Programa de Pós Graduação em Engenharia e Gestão do Conhecimento (EGC/UFSC). Mestre em Administração pelo Programa de Pós Graduação em Administração da Universidade Federal de Santa Catarina (2011). Especialista em Marketing e Gestão de Pessoas (2002) e Gestão Financeira e Contábil (2008). Graduada em Administração pela Faculdade Estadual de Ciências e Letras de Paranavaí (2001). Membro do Grupo de Pesquisa ENGIN/UFSC (Núcleo de Engenharia da Integração e Governança do Conhecimento para a Inovação). Professora da Faculdade Capivari nas disciplinas Administração da Produção, Sistemas de Produção e Gestão de Pessoas.

\section{FLADHIMYR CASTELLO}

Mestre em Engenharia Elétrica pela Pontifícia Universidade Católica do Rio Grande do Sul (PUCRS). Certificado Project Management Professional (PMP) pelo Project Management Institute (PMI) desde 2005 e Certified Scrum Master pela Scrum Alliance desde 2009. Experiência de mais de 10 anos em gestão de projetos, programas e portfólio. Professor universitário de graduação e pós-graduação em diversas instituições. Professor do MBA em Gestão de Projetos para Engenharia e Arquiteturas do IPOG. Fladhimyr é Trainer Training em Programação Neurolinguística, atua como coach promovendo o desenvolvimento profissional das equipes. 


\section{FLÁVIO CAMPOS PINHEIRO}

Engenharia de Produção pela Claretiano (2017), Matemática Bacharelado pela Funcesi ( 2005), MBA (pós graduação) com foco em pessoas, projetos e finanças pela Funcesi. 35 anos de experiência como Supervisor de Manutenção Preventiva na área de mineração trabalhando na Vale. Professor na área de manutenção do curso técnico do SENAI e, atualmente, da escola FIDE MG na cidade de Itabira.

\section{GABRIEL CARDINALI}

Graduado em Engenharia de Produção pela Universidade Federal de Itajubá - UNIFEI, campus de Itabira, MG, desenvolveu diversas pesquisas na área de qualidade, Simulação de Eventos Discretos, melhoria contínua e Lean Manufacturing. Atualmente trabalha no setor de melhoria contínua da Coca-Cola Andina de Ribeirão Preto.

\section{GLAUCO MEDEIROS BORGES}

Graduando do curso de Engenharia de Produção na Faculdade Capivari - FUCAP. Possui experiência com projetos de engenharia aplicada nas áreas de redução de custos, melhoria contínua, lean manufacturing, implantação de ferramentas da qualidade, mapeamento de fluxo de valor, projetos de melhoria em linha de produção e equipamentos. É autor de vários artigos científicos nas áreas, com publicações em congressos nacionais e internacionais. Tem como áreas de interesse o estudo do uso da inteligência organizacional como ferramenta de melhoria contínua dentro das organizações. Atualmente é coordenador regional do CREAJr-SC: Regional Tubarão.

\section{JAIRO MARLON CORREA}

Possui graduação em Licenciatura Em Matemática pela Universidade Estadual do Oeste do Paraná (2004), Pós-Graduação Latu Senso em Educação Matemática pela Universidade Estadual do Oeste do Paraná (2006), Pós-Graduação Strictu Senso em Métodos Numéricos em Engenharia pela Universidade Federal do Paraná (Mestrado em 2007 e Doutorado em 2015). Atualmente é docente do Magistério Superior na UTFPR (Medianeira-Pr). Tem experiência na área de Previsões de Séries Temporais (Redes Neurais Artificiais, Modelos SARIMAX, Modelos GARCH, incluindo Decomposição Wavelet)

\section{JANSER QUEIROZ OLIVEIRA}

Possui graduação em Engenharia de Produção pelo Centro Universitário do Triângulo - Unitri (2009). Especialização em Gerenciamento de Projetos pela Faculdade Católica de Anápolis (2013). Atualmente é professor do Centro Universitário de Patos de Minas - UNIPAM. Possuindo experiência nas áreas de Gerenciamento da Cadeia de Suprimentos, Gestão da Qualidade e Gestão por Processos.

\section{JÉSSICA RAMOS DE OLIVEIRA}

Possui graduação em Engenharia de Produção Agroindustrial pela Universidade do Estado de Mato Grosso - UNEMAT (2017). Mestranda em Ambiente e Sistema de Produção Agrícola pela Universidade do Estado de Mato Grosso - UNEMAT, atuando em qualidade da água para consumo humano e uso agrícola. 


\section{JHONATHAN FERNANDES TORRES DE SOUZA}

Mestrando pelo programa de Sustentabilidade pela Universidade de São Paulo (atual). Graduado em Gestão Ambiental pela Universidade de São Paulo (2014). Tem experiência na área de Ciências Ambientais, com ênfase em emissões de GEE, energia e mudanças climáticas. Trabalhou 2 anos e meio em projeto de parceria CETESB-BID sobre análise econômica de cenários de baixo carbono para a indústria do Estado de São Paulo.

\section{JOSÉ ANTÔNIO MARTINS COURY}

Engenheiro Mecânico, graduado na Universidade Federal de Uberlândia, em julho/1985. Conselheiro da Câmara Especializada de Engenharia Mecânica e Metalurgia do CREA-GO. Experiência Profissional de 32 anos, na empresa Celg Distribuição S/A: Usina Hidrelétrica de Cachoeira Dourada, 10 anos, como responsável pelos serviços de manutenção mecânica nas unidades geradoras e demais equipamentos; Oficina do Setor de Diagnósticos e Reparos de Equipamentos, como responsável pelos serviços de manutenção mecânica dos equipamentos Sistema Celg (transformadores de força, transformadores de potencial, transformadores de corrente, entre outros).

\section{JOSÉ CARLOS DE TOLEDO}

Possui graduação em Engenharia de Produção pela Universidade de São Paulo (1979), mestrado em Engenharia de Produção pela COPPE - Universidade Federal do Rio de Janeiro (1985), doutorado em Engenharia (Engenharia de Produção) pela Universidade de São Paulo (1993) e especialização em TQM pela AOTS/JUSE, Japão (1990). Atualmente é professor titular do Departamento de Enga. de Produção e do PPGEP da UFSCar. Tem experiência na área de Engenharia de Produção, com ênfase em Gestão da Qualidade e Gestão do Desenvolvimento de Produto, atuando principalmente nos seguintes temas: sistemas de gestão da qualidade, gestão do processo de desenvolvimento de produto, controle e melhoria de processos, gestão da qualidade na agroindústria, sistemas de gestão da qualidade para unidades de produção rural, ferramentas para melhoria contínua da qualidade, gestão da qualidade e acreditação em serviços de saúde

\section{JUAN PABLO SILVA MOREIRA}

Graduando em Engenharia de Produção pelo Centro Universitário de Patos de Minas UNIPAM (2014 - atual). Possui experiência em pesquisas científicas nas áreas de Engenharia da Qualidade, Gestão por Processos, Gestão do Desempenho e Gestão Ambiental com ênfase em Certificações Ambientais e Gerenciamento de Resíduos Sólidos.

\section{KELLEN COELHO DOS SANTOS}

Possui graduação em COMEX pela Faculdade Educacional de Araucária (2010), especialização em Gestão Ambiental e Desenvolvimento Sustentavel pelo Centro Universitário Internacional Uninter (2013) e especialização em Formação de Docentes e de Tutores: Orientadores Acadêmicos em EAD pelo Centro Universitário Internacional Uninter (2016). Atualmente é tutora do Centro Universitário Internacional Uninter. Tem experiência na área de Administração. 


\section{LARISSA CARNAÚBA DE OLIVEIRA}

Graduada em Engenharia de Produção pelo Centro Universitário CESMAC, cursou Engenharia Química na Universidade Federal de Alagoas ( UFAL), onde foi monitora de química orgânica. Tem experiência como Engenheira júnior no grupo Ultra descartáveis. Atualmente é Gerente de projetos e cursa MBA em Gestão Empresarial na FGV.

\section{LARYSSA RAMOS DE HOLANDA}

Mestra em Engenharia de Produção pela Universidade Federal de Pernambuco (UFPE), onde foi bolsista CAPES, e graduada em Economia pela Universidade Federal de Alagoas (UFAL) onde foi bolsista MEC através do Programa de Educação Tutorial (PET-ECONOMIA), pesquisadora do Núcleo de Estudos Regionais (NER-ECO) e monitora. Tem experiência como instrutora do SEBRAE, professora titular nas faculdades CESMAC, FIC/UNIFAL, e FAN/FGV, e coordenadora do Curso de Engenharia de Produção e do curso técnico em Logística na FIC/UNIFAL. Atualmente é professora Tempo Integral do CESMAC, onde leciona, orienta atividades de pesquisa e extensão, e compõe o colegiado e NDE do curso de Engenharia de Produção.

\section{LEONARDO DA CUNHA BRITO}

Graduado (1998) pela Universidade Federal de Goiás, Mestre (2001) e Doutor (2003) pela Universidade de Brasília, Brasil. Desde 2004, trabalha na Escola de Engenharia Elétrica, Mecânica e de Computação (EMC) da Universidade Federal de Goiás (UFG), Brasil, onde atualmente é Professor Associado. Suas áreas de interesse incluem métodos de modelagem, simulação e otimização, além de inteligência computacional aplicada a problemas de Engenharia.

\section{LEVI LOPES TEIXEIRA}

Licenciado em Matemática pela Faculdade de Filosofia, Ciências e letras de Mandaguari. Tem especialização (Lato Sensu) em Metodologias de Ensino pela Pontifícia Universidade Católica do Paraná (PUC-PR), Mestrado e Doutorado em Métodos Numéricos pela Universidade Federal do Paraná (UFPR). Trabalhou, na função de professor, por quinze anos no Centro de Ensino Superior de Foz do Iguaçu, atuando nas disciplinas de Lógica, Cálculo, Estatística e Matemática Financeira. Atualmente é Professor Adjunto no Departamento de Engenharia de Produção da Universidade Tecnológica Federal do Paraná - Medianeira, atuando na disciplina de Pesquisa Operacional.

\section{LUIZ ANTONIO FORTE}

Possui graduação em Engenharia Ambiental e Sanitária pela Universidade Tuiuti do Paraná (2010). Pós-graduação em engenharia de segurança do trabalho pela Universidade Tecnológica Federal do Paraná (2012). Tem experiência na área de Engenharia Sanitária, com ênfase em Controle da Poluição.

\section{MÁRCIO DIMAS RAMOS}

Doutor em Engenharia Mecânica (UNIFEI/2015); Mestre em Engenharia Mecânica (UNIFEI/1997); Graduado em Engenharia Mecânica (UNIFEI/1994) e Bacharel em Matemática Aplicada à Informática (FEPI/1990). Atualmente, Professor Adjunto da Universidade Federal de Itajubá - Campus Itabira, área Metrologia. Atua em aproveitamento de Energia. 


\section{MARCUS VINÍCIUS DE ABREU SOEIRO}

Engenheiro mecânico pela UFMG (2003), Mestre em Processo de Fabricação pela PUC/MG (2010). MBA em Gerenciamento de Manutenção pela Faculdade Pitágoras (2006). Experiência como supervisor de manutenção, coordenador de projetos e estudos em melhoria performance, destacando-se no melhor redesenho da estrutura da manutenção, planejamento operacional e investimento em modernização tecnológica. Vivência em gerenciamento de plantas industriais e na aplicação de modernas técnicas de gestão visando a racionalização de processos produtivos e otimização da produtividade. Possuo 10 anos de experiências como docente, atualmente ministro aulas para engenharia de produção, civil e mecânica.

\section{MARGARIDA MARIA DE SOUZA}

Mestranda em Política Públicas e Gestão da Educação Superior da Universidade Federal do Ceará e Secretaria Executiva da UFC.

\section{MARIA ALEXSANDRA PIRES CAVALCANTE}

Formada em Gestão de Hospitais Universitários pela Universidade Federal do Ceará - UFC; especialista em Auditoria pela Universidade Federal do Ceará - UFC; Mestranda em Políticas públicas e Gestão da educação superior - POLEDUC - UFC; Professora Universitária da Faculdade Ateneu. Trabalhou como diretora de Execução orçamentária e Financeira na Maternidade Escola Assis Chateaubriand entre 2009-2012.

\section{MARIA ELEONOR LITAIFF}

Graduada em Tecnologia em Fabricação Mecânica pela Universidade Tecnológica Federal do Paraná, campus Ponta Grossa. (2017)

\section{MARIA LIDUINA FREITAS PINTO}

Mestranda do Curso Profissional em Políticas Públicas e Gestão da Educação Superior, da UFC, Especialista em Enfermagem Obstétrica e Graduada em Enfermagem pela UECE. Chefe do Setor de Apoio e Dlagnóstico Terapêutico da Maternidade Escola Assis Chateaubriand da UFC.

\section{MARTA MONTEIRO DA COSTA CRUZ}

Possui graduação em Engenharia Civil pela Universidade do Estado do Rio de Janeiro (1991), mestrado em Engenharia de Transportes pela Universidade Federal do Rio de Janeiro (1993) e doutorado em Engenharia de Transportes pela Universidade Federal do Rio de Janeiro (1997). Atualmente é professora titular da Universidade Federal do Espírito Santo, professora do curso de engenharia de produção e professora permanente do Programa de PósGraduação em Engenharia Civil, área de concentração em transportes. Tem experiência na área de Engenharia de Transportes, com ênfase em transporte de carga, atuando principalmente nos seguintes temas: simulação, transporte ferroviário, logística, portos e análise de envoltória de dados. 


\section{MAXWEEL VERAS RODRIGUES}

Doutor em Engenharia de Produção pela Universidade Federal de Santa Catarina e Professor da Universidade Federal do Ceará.

\section{MIGUEL MACEDO DE CARVALHO FILHO}

Tecnico em eletrotécnica formado pelo Ifes - Vitória e graduando em Engenharia Civil pela Ufes, tendo realizado um ano de graduação sanduíche na Université de Lorraine, em Metz França. Medalhista de prata na OBMEP e de bronza na OCM. Fundador da marca de camisa EuEscolhiPedalar; Fundador da startup iDeliver; Já trabalhou como professor voluntário em projeto social preparatório para prova de seleção do Ifes para alunos de $8^{\underline{a}}$ série da rede pública da cidade de Vila Velha - ES.

\section{MIRIAN BATISTA DE OLIVEIRA BORTOLUZZI}

Possui graduação em Engenharia de Produção Agroindustrial pela Universidade do Estado de Mato Grosso (UNEMAT) e Mestrado em Engenharia de Produção pela Universidade Federal de Pernambuco (UFPE) - na linha de Pesquisa Operacional.

\section{MIRIAN WAWRZYNIAK CHIMIRRI}

Graduada em ciências econômicas pela FEA-RP / USP, atualmente é aluna de mestrado do programa de engenharia de produção da EESC-USP na linha de pesquisa de Economia, Finanças Corporativas e Econometria.

\section{MONALYZA TELES TEIXEIRA}

Graduanda do 9o período de Engenharia de Produção na UNIFSA (Universidade Santo Agostinho), Representante Estadual da Engenharia de Produção no Piauí pela Abepro Jovem, Técnica em Eletromecânica pelo SENAI, possui cursos nas áreas de logística reversa, engenharia de materiais, finanças pessoais e Balanced Scorecard. Participou como congressista e autora de artigo no 27 POMS (Production Operation Management Society), 2016 em Orlando, FL. Atualmente é bolsista do PIBIC com o projeto sobre a política nacional de resíduos sólidos e o gerenciamento de resíduos da construção civil.

\section{ORLANDO POCI JUNIOR}

Professor do Instituto Brasileiro de Engenharia de Custos, mestre em engenharia civil pela universidade federal fluminense e especialista em gerenciamento de projetos certificado pelo Project Management Institute (PMI). Gerenciou projetos de gestão pela qualidade com certificação ISO 9001, implantação sistema de gestão ERP e coordenou o planejamento e controle de empreendimentos de construção civil.

\section{OSCAR REGIS JUNIOR}

Doutor em Engenharia e Ciência dos Materiais pela UFPR (2006 - 2011). Possui mestrado em Engenharia e Ciência dos Materiais pela UEPG (2000-2004). Possui especialização em Engenharia de Segurança do Trabalho pela UNISUL (1993-1994). Possui especialização em Administração Industrial- pela FERJ (1992-1993). Graduado em Engenharia Mecânica pela 
UDESC/FEJ (1986-1991). Atualmente é professor EBTT na UTFPR - Campus Ponta Grossa. Tem experiência na área de Engenharia Mecânica, atuando principalmente nos seguintes temas: Segurança do trabalho, Manutenção Industrial, Sistema de Gestão, Corrosão e Aspersão Térmica.

\section{PAULO ROBERTO DE AGUIAR VON MENGDEN}

Bacharel em Ciências Econômicas pela Universidade Federal do Rio Grande do Sul UFRGS- CORECON - 4a R - № 3208, Mestre em Gestão Tecnológica: Qualidade Ambiental, pela Universidade FEEVALE. Economista da Prefeitura Municipal de Porto Alegre, aposentado, Ex-consultor da Organização Panamericana da Saúde - OPS e Secretário Executivo do Conselho Regional de Desenvolvimento do Paranhana Encosta da Serra. Professor do Curso de Engenharia de Produção das Faculdades Integradas de Taquara FACCAT.

\section{PRISCYLLA JORDANIA PEREIRA DE MESQUITA}

Doutoranda e Mestre em Ciência dos Materiais pela Universidade Federal do Piauí, especialista em Biocombustíveis e Novas Tecnologias Renováveis e em Docência do Ensino Superior, licenciada em Química pelo Instituto Federal de Educação, Ciência e Tecnologia do Piauí. Atualmente é docente na Universidade Federal do Piauí, Universidade, CEUPI e Coordenadora do curso de Engenharia Clvil na Faculdade Maurício de Nassau.

\section{RENATO RAMOS COELHO}

Fisioterapeuta pela UFMG (2000), Especialista em Fisioterapia Esportiva e Traumatoortopedia pela UFMG (2001), Mestre em Motricidade Humana pela UCB/RJ (2006) e Doutor em Engenharia Civil pela COPPE/UFRJ (2015). Acadêmico de Engenharia de Produção do Claretiano - Centro Universitário. Diretor Técnico da Nomus Consultoria e Treinamento em Saúde e Segurança do Trabalho. Fisioterapeuta da Fundação de Assistência Médica e de Urgência de Contagem - MG. Professor do Curso de Especialização em Engenharia de Segurança do Trabalho do UNIBH.

\section{RICARDO ALEXANDRE DECKMANN ZANARDINI}

Mestre em Métodos Numéricos em Engenharia pela Universidade Federal do Paraná (UFPR) e licenciado e bacharel em Matemática pela Universidade Tuiuti do Paraná (UTP). Iniciou sua carreira de docente em 1995. Atuou em diversas instituições de ensino, exercendo variadas atividades: professor de graduação e de pós-graduação, coordenador de curso, organizador de eventos e membro de conselho editorial. Publica artigos científicos, elabora material didático, participa de congressos e orienta trabalhos de conclusão de curso. É autor do livro "Um breve olhar sobre a história da matemática" e juntamente com o professor Marcos Antônio Barbosa, é autor do livro "Iniciação à pesquisa operacional no ambiente de gestão".

\section{RITA DE CÁSSIA LOPES MORO}

Doutoranda em Sustentabilidade pela EACH/USP; Mestra em ciências pelo programa de Têxtil e Moda pela EACH/USP; Especialização em Engenharia de Segurança do Trabalho pela Universidade Paulista; Graduação em Engenharia Têxtil pela Universidade Estadual de Maringá. Integrante do Grupo de Pesquisa Moda na Cadeia Têxtil. Tem experiência no setor privado, tendo atuado em empresas têxteis e de auditoria como Toyota Máquinas Têxteis Brasil Ltda, Omi do Brasil S.A. e Bureau Veritas. 


\section{RODOLFO BENEDITO DA SILVA}

Possui graduação em Engenharia de Produção Agroindustrial pela Universidade do Estado de Mato Grosso - UNEMAT (2010), mestrado em Engenharia de Produção pela Universidade Federal do Rio Grande do Sul - UFRGS (2014), onde atualmente também é doutorando em Engenharia de Produção. Tem experiências na área de Engenharia de Produção, com ênfase em Planejamento e Controle da Produção (PCP), Logística, Pesquisa Operacional e métodos quantitativos aplicados à Gestão da Produção.

\section{RODRIGO CARNIEL SEFSTRON}

Graduando em Engenharia de Produção Agroindustrial da Universidade do Estado de Mato Grosso (UNEMAT), Campus de Barra do Bugres/MT. Foi Diretor Presidente da Empresa Júnior do curso, Criativa Consultoria, no período de janeiro a dezembro de 2016.

\section{SAMUEL BELLIDO RODRIGUES}

Possui graduação em Licenciatura Matemática pela Universidade Estadual do Oeste do Paraná (2004), mestrado em Métodos Numéricos em Engenharia pela Universidade Federal do Paraná (2007) e doutorado em Métodos Numéricos em Engenharia pela Universidade Federal do Paraná (2015). Atualmente é professor adjunto da Universidade Tecnológica Federal do Paraná. Tem experiência na área de Previsões de Séries Temporais (Support Vector Regression, Redes Neurais, Modelos SARIMA, Modelos GARCH, incluindo Decomposição Wavelet).

\section{SAULO FONSECA SOARES}

Graduando em Engenharia de Produção pelo Centro Universitário de Patos de Minas UNIPAM (2014 - atual). Possui experiência em pesquisas científicas nas áreas de Engenharia da Qualidade, Gestão por Processos.

\section{SUELI MARIA DE ARAÚJO CAVALCANTE}

Doutora em Educação pela Universidade Federal do Ceará (UFC), mestra em Engenharia de Sistemas e Computação pela Universidade Federal do Rio de Janeiro (UFRJ) e graduada em Administração de Empresas, pela UECE e Computação, pela UFC. Professora Associada do Departamento de Administração e do Mestrado Profissional em Políticas Públicas e Gestão da Educação Superior, da UFC. Prestou assessoria como Diretora de Controle da Pró-reitoria de Administração.

\section{TARCÍSIO GONÇALVES DE BRITO}

Possui graduação em Engenharia Mecânica, especialização em Engenharia Ambiental, mestrado em Engenharia Mecânica e doutorado em Engenharia de Produção pela Universidade Federal de Itajubá (2015). Tem experiência nas áreas de Engenharia Mecânica e Produção, atuando nos seguintes temas: Processos de Manufatura, Desenho Técnico I e II, Elementos de Máquinas, Dinâmica de Máquinas, Controle de Qualidade. Atua na área de Projeto e Análise de Experimentos. Atualmente professor adjunto A da Universidade Federal de Itajubá, Brasil. 


\section{TASIA HICKMANN}

Possui graduação em Tecnologia em Manutenção Eletromecânica pela Universidade Tecnológica Federal do Paraná (UTFPR), graduação em Licenciatura em Matemática pela Universidade Estadual do Oeste do Paraná (UNIOESTE), mestrado em Matemática (Área de concentração: Álgebra) pela Universidade Estadual de Maringá (UEM) e doutorado em Métodos Numéricos em Engenharia (Área de concentração: Programação Matemática) pela Universidade Federal do Paraná (UFPR). Atualmente é docente do Magistério Superior na UTFPR - Câmpus Medianeira. Áreas de interesse: Análise Numérica; Modelagem Computacional; Cálculo Fracionário; Modelagem de Séries Temporais.

\section{THAÍS HELENA CAVALCANTE LIMA}

Mestranda em Política Públicas e Gestão da Educação Superior da Universidade Federal do Ceará, Advogada e Técnica Administrativa da UFC.

\section{VIVIANE VIANA SOFISTE DE ABREU}

Engenheira de produção formada pelo Centro de Tecnologia da Indústria Química e Têxtil SENAI/CETIQT - RJ. Possui experiência profissional em gestão de projetos e trabalhos científicos sobre apoio multicritério à decisão, gestão de riscos, gestão ambiental e gestão de tempo publicados em simpósios e congressos de abrangências nacionais e internacionais. Seus interesses de pesquisa estão orientados para a área de gestão de projetos, tomada de decisão e modelagem de sistemas do ponto de vista do apoio multicritério à decisão em cenários complexos. 
Agência Brasileira do ISBN ISBN 978-85-93729-50-8

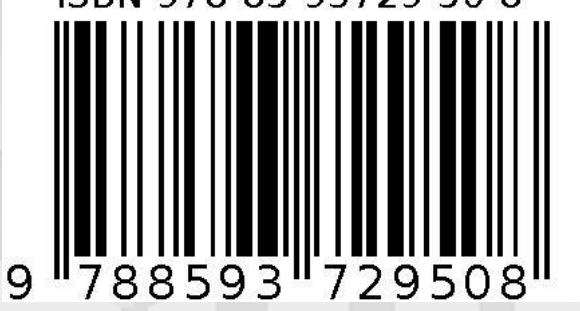

